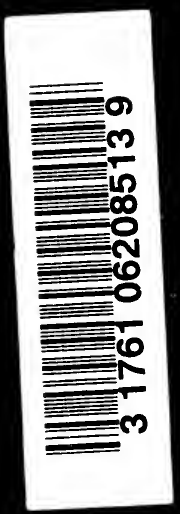




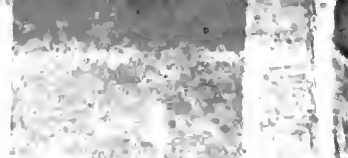




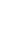


Digitized by the Internet Archive in 2007 with funding from Microsoft Corporation 


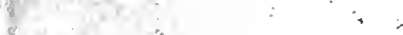



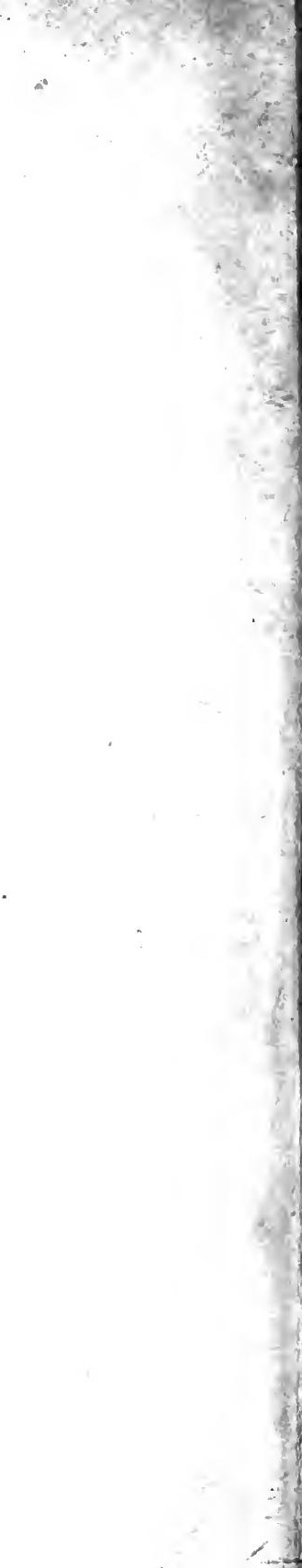



\section{TWENTIETH CENTURY TEXT-BOOKS}

EDITED BY

A. F. Nightingale, Ph. D., Ll.D.

FORMERLY SUPERINTENDENT OF HIGH SCHOOLS, CHICAGO 



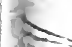




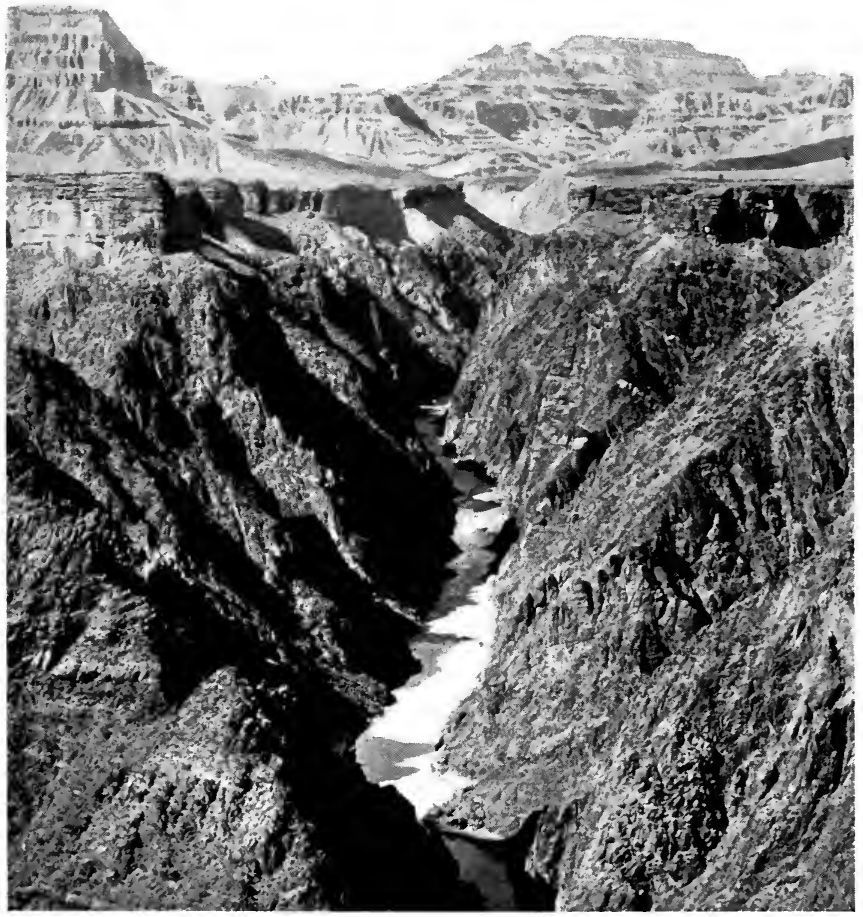

The Grand Canyon of the Colorado River.

The cliffs and terraces above are carved from strata, hard and soft. The depths of the gorge are in granite. See page 71. 


\title{
AN INTRODUCTION TO \\ PHYSICAL GEOGRAPHY
}

\author{
BY \\ GROVE KARL GILBERT \\ GEOLOGIST, UNITED STATES GEOLOGICAL SURVEY \\ AUTHOR OF \\ GEOLOGY OF HENRY MOUNTAINS, I.AKE BONNEVILLE, ETC. \\ AND \\ ALBERT PERRY BRIGHAM \\ PROFESSOR OF GEOLOGY IN COLGATE UNIVERSITY \\ AUTHOR OF TEXT-BOOK OF GEOLOGY
}

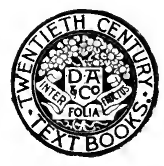

NEW YORK

D. APPLETON AND COMPANY

19.02 


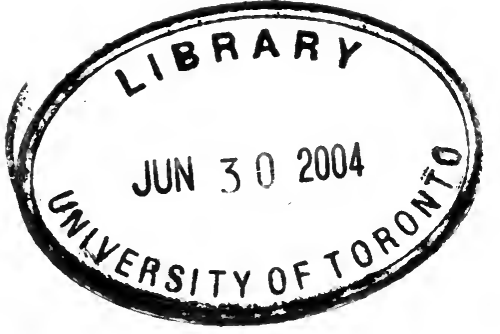

Copyright, 1902

BY D. APPLETON AND COMPANY

Published June, 1902 


\section{PREFA CE}

THE authors have striven to adapt this book to the earlier stages of the high-school course $e_{2, \ldots \rightarrow c}$. this end the statements are simple, technical terms are sparingly used, and when employed they are promptly defined. Thus approached, Physical Geography may well serve to introduce young students to the spirit and method of science. The aim of the volume as thus set forth will explain the omission of a few of the more difficult conceptions of land physiography which appear in some school texts.

The treatment, so far as possible, is concrete. Wherever practicable, each subject is opened with a type case, in the description of which the terminology is called forth and the principles begin to appear. Other examples follow, with a systematic statement of principles, and the principles are further illustrated by application. This is believed to be in the line of good teaching, and is a method to which our subject lends itself with special effectiveness.

While the principles of Physical Geography belong to the earth as a whole, and type cases are cited from all regions, the greater emphasis is put on our continent. A separate chapter on North America would pass our limit of space, but when the entire text has been read, all the greater features of the continent will have received attention.

The average judgment of teachers has been sought in apportioning the space to the several greater departments of the subject. Nearly one-half is given to the lands. The relation of organisms to the earth is introduced wherever appropriate, and the two closing chapters add further illustrations, and treat the principles in a systematic way. 


\section{vi AN INTRODUCTION TO PHYSICAL GEOGRAPHY}

The order of topics has been adopted after deliberate consideration. The study of the lands is brought in early, in the belief that here is the sure appeal to the students' interest and previous knowledge. Alike for their familiarity, variety, and dynamic interest, the stream and its valley come first. This order is also conveniently adjusted to the school year; field excursions, associated with the study of lands, can begin in the autumn, and map study and other laboratory exercises can be carried on during the winter, as may be desired. The atmosphere will be reached during the cold season, which, however, is as favorable as any other for practical exercises in this subject. The ocean is put late, because it is remote from most schools, and has not been seen by the majority of young students. It is plain that shore-lines should follow both land and sea, and that the formal treatment of life should be at the end.

The illustrations are closely correlated with the text, and their titles are accompanied by supplementary explanations. Many cross-references are given, especially where one figure shows features described in different chapters.

'The teachers' pamphlet which accompanies this volume contains suggestions for teaching the several chapters, with bibliography, lists of practical exercises, and further elucidation of certain points in the text.

Our acknowledgments are due to Dr. C. Hart Merriam, Chief of the United States Biological Survey, who has read parts of the manuscript and made useful suggestions; to Dr. Francis R. Lane, Director of High Schools, Washington, D. C., who has read the proofs and criticized them from the pedagogical point of view; to Mr. D. C. Ridgley of the West Division High School, Chicago, whose critical opinion as to plan and method has been specially valuable; to the United States Geological Survey and other bureaus of the Government, and to many individuals, who have given cordial assistance in illustrating the volume. Personal acknowledgment of this help is elsewhere given.

The Authors. 


\section{CONTENTS}

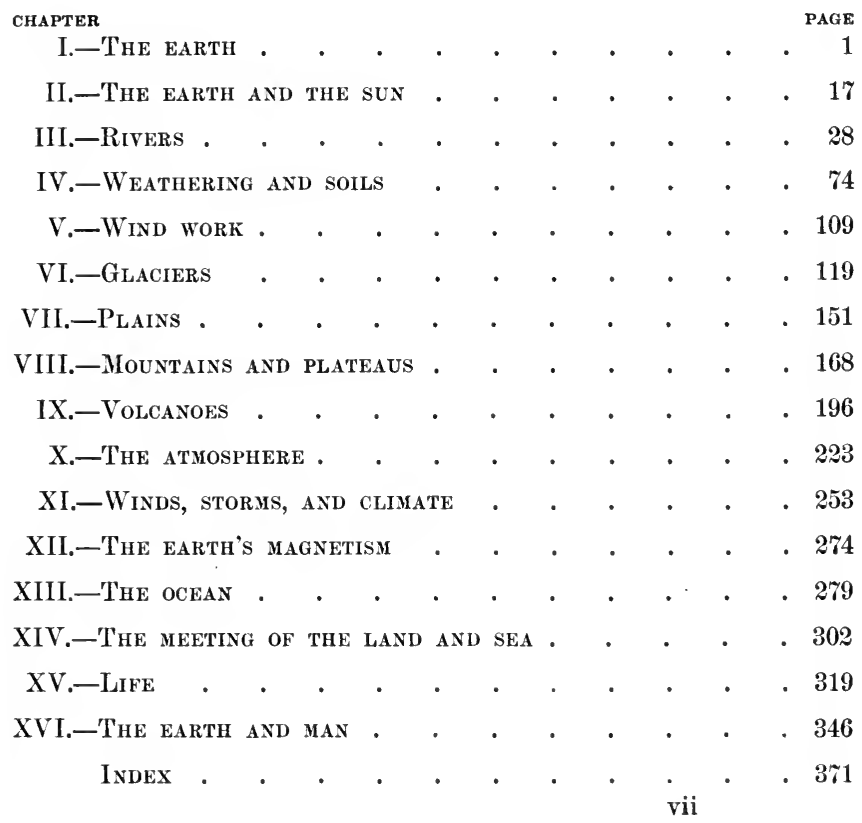




\section{LIST OF ILLUSTRATIONS}

FIGURE

SUBJECT

PAGE

Grand Canyon of the Colorado River

Frontispiece

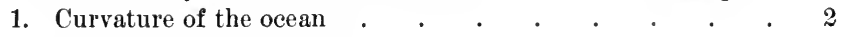

2. Section showing soil, waste, and bed-rock . . . . 4

3. Stratified rocks. . . . . . . . . . 5

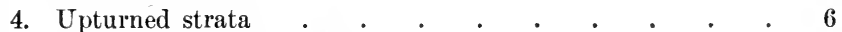

5. Ideal section of part of the earth's crust . . . . . 7

6. Water and land hemispheres . . . . . . . 8

7. The brook is a carrier . . . . . . . . . . 9

8. Uplifted sea-margin . . . . . . . . . 10

9. Map expressing relief by shading . . . . . . 14

10. Map expressing relief by hachures_. . . . . . 15

11. Map expressing relief by contours . . . . facing 16

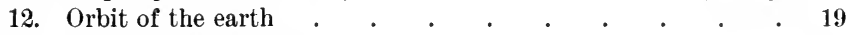

13. Attitude of the earth . . . . . . . . $\quad$. 20

14. Relation of the earth to the sun's rays June 21 . . . 21

15. Relation of the earth to the sun's rays December $22 \quad$. $\quad 23$

16. Illumination of the earth in twelve positions . . . . 24

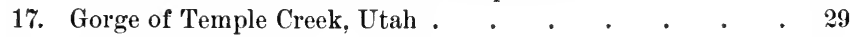

18. Canyon of the Yellowstone River . . . . . . 30

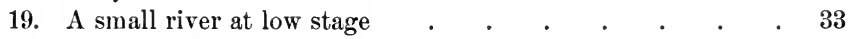

20. Ice-jam . . . . . . . . . . . . 34

21. Cascade due to joints and bedding . $\quad . \quad$. $\quad . \quad$. $\quad . \quad 37$

22. Boulder in bed of Colorado River . . . . . . . $\quad$. 38

23. Waterfall near Gadsden, Ala. . . . . . . . $\quad$. 39

24. Niagara Falls . . . . . . . . . . 40

25. Section through Niagara Falls . . . . . . . 41

26. Alluvial cone . . . . . . . . . . . . . 43

27. Profiles across a valley . . . . . . . . . . . $\quad$. 44

28. Flood-plain of James River, Va. . . . . . $\quad$. 45

29. Scene on the Mississippi during a flood . . . . . $\quad$. 46

30. Scene on the flood-plain of the Mississippi . . . . $\quad$. 47 
FIGURE

SUBJECT

PAGE

31. Meanders of Trout Creek, Wyo.

32. Map: junction of Mississippi and Arkansas rivers. . $\quad 49$

33. A meandering brook . . . . . . . . . 50

34. Map of Caney Fork, Tenn. . . . . . . . . $\quad$. 51

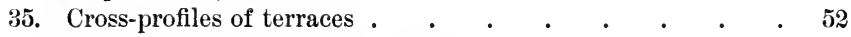

36. Terraces of Uncompahgre Valley . . . . . . . 53

37. Delta of Chelan River . . . . . . . . . $\quad . \quad 54$

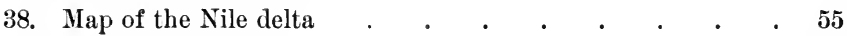

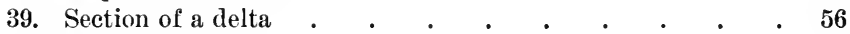

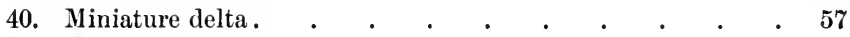

41. Map: part of West Virginia . . . . . . . $\quad$. $\quad$ facing 59

42. Map: head of Seneca Lake, N. Y. . . . . . facing 61

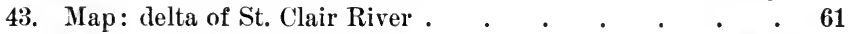

44. Map: part of Westmoreland County, Va. . . facing 62

45. Delaware Water-Gap . . . . . . . . . $\quad 63$

46. Map: trellised drainage in Pennsylvania . . . . 64

47. Nap: coastal region, New Jersey to North Carolina . $\quad 65$

48. Cross-profiles of a divide . . . . . . . . . . 66

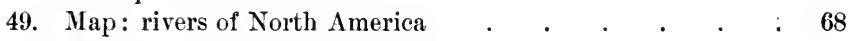

50. Cross-profile of the Grand Canyon of the Colorado River $\quad 71$

51. Canyon of Snake River . . . . . . . . . 72

52. Watkins Glen . . . . . . . . . . . 75

53. Granite . . . . . . . . . . . . . 77

54. Weathered sandstone . . . . . . . . . . 78

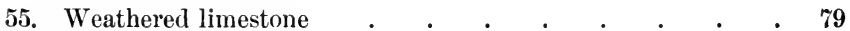

56. A pebbly rock carved by rain . . . . . . $\quad$. 80

5\%. Weathered wall of Trinity College . . . . . . . 82

58. Ant-hill . . . . . . . . . . . . . . $\quad . \quad 83$

59. Shale broken by down-hill "creep" . . . . . 84

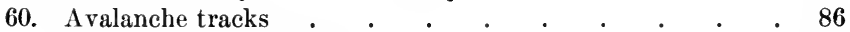

61. Granite crags, Black Hills $\quad . \quad$. $\quad . \quad$. $\quad . \quad$. $\quad .88$

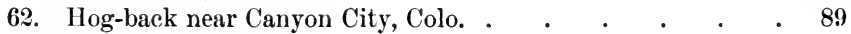

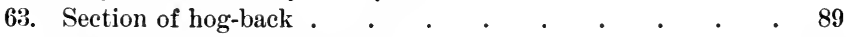

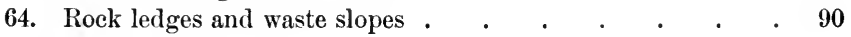

65. Mesa-butte . . . . . . . . . . . . . 91

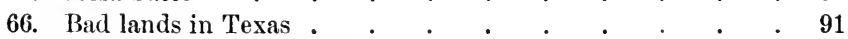

67. Bad lands in South Dakota . . . . . . . . 92

68. Rounded summits, Appalachian Mountains . . . . 92

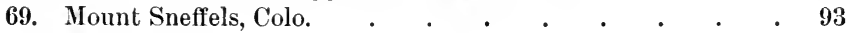

70. Quartz vein . . . . . . . . . . 97

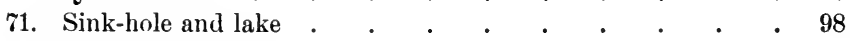

72. Stalactites. $. \quad . \quad . \quad . \quad . \quad . \quad . \quad . \quad . \quad .99$ 
73. Cleopatra Spring and terrace.

74. Old Faithful geyser ․ . . . . . . . 102

75. Ideal section of an artesian well basin . . . . . 104

76. Artesian well at Woonsocket, S. Dak. . . . . . 104

77. Shore of Lake Michigan . • • • . . . . . 106

78. Landslide scenery in Colorado . . . . . . . . 107

79. Cascades of the Columbia River . . . . . . 108

80. Profile of a dune .

81. Diagram; progress of a dune. . . . . . . . 110

82. A patch of grass on a field of loose sand . . . . . 111

83. Dunes in a canyon of Columbia River . . . . . 112

84. Last house in Biggs, Ore. . . . . . . . 113

85. Dune on coast of North Carolina . . . . . . . 114

86. Planting grass to stop drifting of sand . . . . . . 115

87. Sand-wear about boulder . . . . . . . . 116

88. Rock sculptured by wind-driven sand . . . . . . 117

89. Map of Gorner Glacier . . . . . . facing 121

90. Gorner Glacier . . . . . . . . . . 121

91. Crevasse . . . . . . . . . . . 122

92. New-made moraine . . . . . . . . . . 123

93. Glacier of the Cascade range . . . . . . . . . 125

94. Section of Muir Glacier . . . . . . . . . . . 126

95. Muir Glacier . . . . . . . . . . . 127

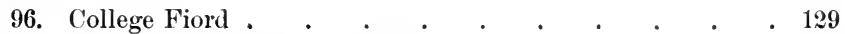

97. Iceberg in the North Atlantic . . . . . . . 130

98. An erratic . . . . . . . . . . . 133

99. Bank of till . . . . . . . . . . . . 134

100. Shore of Lake Ontario at Pillar Point . . . . . 135

101. Kames . . . . . . . . . . . 136

102. An esker. . . . . . . . . . . . . . 136

103. A drumlin . . . . . . . . . . . . $13 \%$

104. Mountain spur rounded by a glacier . . . . . 138

105. Tuolumne Monument . . . . . . . . . . . $\quad$. 139

106. Gibbs Canyon . . . . . . . . . . 140

107. Cross-profile of Gibbs Canyon . . . . . . . 140

108. Pot-holes . . . . . . . . . . . 141

109. Shapes of valley and mountainside; Sierra Nevada . . 142

110. Glacial rock basin . . . . . . . . . 143

111. Map: United States in the Glacial period . . . . 145

112. Glacial lake in the Ontario basin . . . . . . 147

113. Shore of ancient lake . . . . . . . . . . 148

114. Atlantic coastal plain . . . . . . . . . 152 


\section{xii AN INTRODUCTION TO PHYSICAL GEOGRAPHY}

FIGURE

SUBJECT

PAGE

115. Plain of glacial lake

116. Shores of Lake Bonneville . . . . . . . . 158

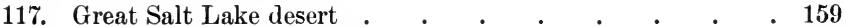

118. The Great Plains, Colorado . . . . . . . . . 163

119. The Great Plains, Kansas . . . . . . . . 164

120. A tundra . . . . . . . . . . . . 166

121. Timber-line on South Lookout Peak . . . . 169

122. Summit of Pikes Peak . . . . . . . . . 170

123. Map: the Rocky Mountains in Colorado . . . . 171

124. Estes Park . . . . . . . . . . 172

125. Section of the Rocky Mountains . . . . . . 174

126. Bird's-eye view of plateaus in southern Utah _ . . 174

127. Section of House range . . . . . . . . . . . . 176

128. Front of House range . . . . . . . . . 177

129. Map: Basin ranges and the Sierra Nevada . . . . 178

130. View in the Adirondack Mountains . . . . . 180

131. Section across Appalachian ridges . . . . . . . 181

132. A bed of bituminous coal . . . . . . . . . 183

133. Plateaus and valleys about Chattanonga . . . . $\quad .184$

134. The Matterhorn . . . . . . . . . 186

135. Placer mining in North Carolina . . . . . . 188

136. Vegetation in the Rocky Nountains . . . . . 190

137. Furka Pass . . . . . . . . . . 194

138. Map: Mount Vesuvius and vicinity . . . . . 197

139. Summit of Mount Vesuvius . . . . . . . . . . . 199

140. Monte Silvestri . . . . . . . . . 202

141. Profile of Hawaii . $\quad . \quad$. $\quad . \quad$. $\quad . \quad$. . . 204

142. The great crater, Kilauea . . . . . . . 204

143. A congealed lava cascade . . . . . . . . . 205

144. Mount Shasta . . . . . . . . . . 206

145. Mount Hood . . . . . . . . . . . . 208

146. A small extinct volcano . . . . . . . . . 210

147. A volcanic crater, holding a lake . . . . . . 211

148. Ideal sections of a wasting volcanic cone . . . . . 212

149. A volcanic neck . . . . . . . . . . . 213

150. Palisades of the Hudson . . . . . . . . . . . 214

151. Obsidian cliff . . . . . . . . . . . . 215

152. Crater Lake . . . . . . . . . . . . . . . 216

153. Mount Mazama . . . . . . . . . . . 217

154. Charleston after the earthquake . . . . . . 221

155. Bends in railway track, made by an earthquake . . . 222

156. Density of the atmosphere . . . . . . . . 226 
165. Slanting and vertical sunbeams . . . . . . 241

166. Daily curve of temperature . . . . . . . 242

167. Relation of sun's rays to earth zones . . . . . . 243

168. Yearly curves of temperature. . . . . . . . 244

169. Temperature map of the United States, Jan. 7, 1886, facing 247

170. Isotherms and heat equator for January . . . . . 248

171. Isotherms and heat equator for July . . . . . . $\quad 249$

172. Isotherms and heat equator for the year . . . . 251

173. The mercurial barometer . . . . . . . 255

174. Weather map of the United States, Jan. 7, 1886 . facing 256

175. Weather map of the United States, Jan. 8, 1886 . facing 256

176. Weather map of the United States, Jan. 9, 1886 . facing 256

177. The anemometer . . . . . . . . . 257

178. A cyclonic storm . . . . . . . facing 258

179. Paths of cyclonic storms . . . . . . . . 260

180. Winds of the Atlantic Ocean . . . . . . . 261

181. Winds of the Indian Ocean in January and February . . 263

182. Winds of the Indian Ocean in July and August . . . 263

183. A waterspout . . . . . . . . . . . 265

184. The general circulation of the atmosphere $\quad$. $\quad$ - $\quad$. 267

185. Irrigation of a vineyard . . . . . . . . 271

186. A magnetic needle . . . . . . . . . . 274

187. The compass card . . . . . . . . . 275

188. Magnetic meridians. . . . . . . facing $2 \% 6$

189. Isogonics for the United States . . . . . . . 276

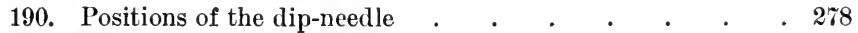

191. Map: the western part of the Atlantic basin . . . 280

192. Profile of the continental sheli . . . . . . 282

193. A coral . . . . . . . . . . . 283

194. A coral-reef . . . . . . . . . . . 284

195. Barrier reef and lagoon . . . . . . . . . . 285

196. An atoll . . . . . . . . . . . . . 285

197. Surf . . . . . . . . . . . . . . . . 289

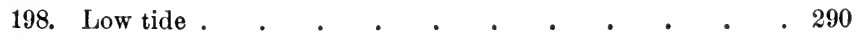


FIGURE

SUBJECT

PAGE

241. A tea-plantation

349

242. Bow, arrow, and quiver . . . . . . . . . 350

243. A cotton-field . . . . . . . . . . . 351

244. A stone ax . . . . . . . . . . . . . 352

245. A spear-head . . . . . . . . . . 353

246. Brush shelters. . . . . . . . . . . 354

247. A tepee . . . . . . . . . . . 354

248. Oil-wells in California . . . . . . . . . 355

249. A $\log$ cabin . . . . . . . . . . . . . 356

250. Mountain road in the Alps . . . . . . . 357

251. Pikes Peak railway. . . . . . . . . . 357

252. A dug-out . . . . . . . . . . . . 358

253. The modern steamship .

254. La Santa Maria . . . . . . . . . . . 359

255. Rock-carvings by Indians . . . . . . . 360

256. Picture-writing by ancient Egyptians . . . . . 360

257. A Samoyed sled . . . . . . . . . . . 361

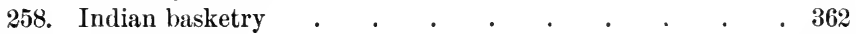

259. Indian pottery. . . . . . . . . . 363

260. A caravan . . . . . . . . . . . 364

261. The mission of San Luis Rey . . . . . . . . 367

262. The pass of the Mohawk . . . . . . . . 368

263. New York harbor . . . . . . . . . . . 369 


\section{ACKNOWLEDGMENT OF IILLUSTRATIONS}

THE following list indicates the sources of illustrations, or, in some instances, the sources of materiaIs from which illustrations were compiled. In a few cases the authors did not succeed in learning to whom acknowledgment was due. Numbers refer to the Figures.

Agassiz's Three Cruises of the Blake, 205.

Bartholomew and Herbertson's Physical Atlas, 161, 162, 170, 171, 172, 180, 181, 182.

Berghaus's Physical Atlas, 188.

Bureau of American Ethnology, 255.

Canadian Geological Survey, 211.

Dana's Coral Islands, 193.

Harrington's Abont the Weather, 173, 177, 179, 184.

Jordan and Heath's Animal Forms, 238.

Jordan and Kellogg's Animal Life, 238.

Kent's Great Barrier Reef of Australia, 194.

Maryland Geological Survey, 131.

New York Central Railroad, 262.

New York State Museum, 9.

Nordenskiold's Voyage of the Vega, 257.

Ober's Storied West Indies, 146.

Pennsylvania Geological Survey, 45, 99.

Swiss Topographical Map, 89.

United States Coast and Geodetic Survey, 10, 189, 191, 200.

United States Department of Agriculture: Biological Survey, 82, 96, 109, 19ז, 198, $220,221,224,226,231,236$; Bureau of Forestry, 219; Bureau of Plant Industry, 86, 240, 245; Bureau of Soils, 242 ; Weather Bureau, 157, 158, 159, 160, 169, 1\%4; 175.

United States Geological Survey, Frontispiece, 5, 7, 11, 18, 19, 21, 28, 29, 30, 33, 34, $40,41,42,44,51,52,55,59,64,66,68,70,75,79,83,84,95,100,101,102,104,108,111,113$, $115,117,120,128,132,133,141,142,144,147,149,151,154,155,185,206,207.208,212,213,223$, 239. See also Cross, Darton, Gulliver, Holmes, Johnson, Russell, Walcott, and Willis.

United States Hydrographic Office, 201.

United States Lake Survey, 43.

United States Life-Saving Service, 218.

United States National Museum, 242, 244, 245, 256, 259.

United States Surveys : Hayden, 234; Powell, 17, 126, 246, 247, 258; Wheeler, 22, 87.

H. C. Baker, 4 ; H. L. Baldwin, 29,30 ; G. H. Barton, 103 ; W. Bell, 22,87 ; N. W. Carkhuff, Frontispiece, 64 ; T. C. Chamberlin, 111 ; J. H. Chapin, 110 ; J. H. Clarke, 20 ; F. V. Coville, 224 ; Whitman Cross, 36, 69, 78, 121, 222 ; E. S. Curtis, 92 ; N. H. Darton, 61, 67, 73 ; J. S. Diller, 144 ; C. E. Dutton, 149 ; John Erbach, 28 ; A. W. Greely, 202 ; F. P. Gulliver, 3, 58, 118 ; E. K. Hallet, 183 ; E. H. Harriman, 252 ; Angelo Heilprin, 260 ; H. W. Henshaw, 56, 143 ; J. G. Hiestand, 251 ; R. T. Hill, 66, 147 ; J. K. Hillers, 17, 18, 246, 247, 258 ; J. A. Holmes, 85, 114, 135, 233 ; W. H. Holmes, $26,116,244,245$; Hook, 122 ; J. P. Iddings, 151 ; W. H. Jackson, 124, 234; W. D. Johnson, 65, 71, 119 ; Clifford Jones, 154; Arthur Keith, 19, 68; Ledrù, 140; C. H. Merriam, 96, 109, 220, 226, 231 ; E. W. Nelson, 221 ; H. C. Oberholser, 82 ; W. H. Osgood, 197 ; T. S. Palmer, 236 ; E. A. Preble, 198 ; W. H. Rau, 150, 241, 253, 254, 263 ; J. H. Renshawe, 123 ; Root, 76 ; I. C. Russell, 23, 62, 77, 88, 98, 105, 106, 214, 235, 243, 249 ; Taunt, 57 ; Ernest E. Thompson, 227, 228, 229, 230 ; H. W. Turner, 108 ; A. C. Vroman, 261 ; C. D. Walcott, 31, 54, 97, 215 ; Leo Wehrli, 134, 254 ; T. C. Weston, 211 ; Bailey Willis, $37,60,93,136$.

The relief maps represented in Figs. 9, 111, 127, 133, 208, were modeled by Edwin E. Howell. 


\section{AN INTRODUCTION \\ TO PHYSICAL GEOGRAPHY}

\section{CHAPTER I}

\section{THE EARTH}

1. Form of the earth.-On September 6, 1522, a little company of weather-beaten and weary sailors brought their vessel to rest in a Spanish port. 'Three years before, Magellan had led them forth, with a fleet of five ships, to find the Spice Islands by a western route. 'Through romantic adventure and heroic endurance the commander brought his expedition around the Horn and across the Pacific to the Philippine Islands, where he was slain. Eighteen men fought their way about the Cape of Good Hope and saw their homes again. No one before them had sailed around the world. They showed by experiment that the earth could be circumnavigated. We sometimes say that they proved it to be round. This is not strictly true. It might have had the shape of an egg, or have been in some other way very different from a sphere. The voyage did prove, however, that our earth lies free in space and is bounded by curved surfaces.

Columbus and other modern men were not the first to infer that the earth is round. Some ancient philosophers felt quite sure of it, for they noted that different groups of stars were seen from places far north or south, and on a flat earth this would not be so. But full proof came with all the freslmess of first discovery to modern peoples, who 
found even more complete evidence than is afforded by a voyage around the world. The sailor approaching port sees land from the mast before he sees it from the deck,

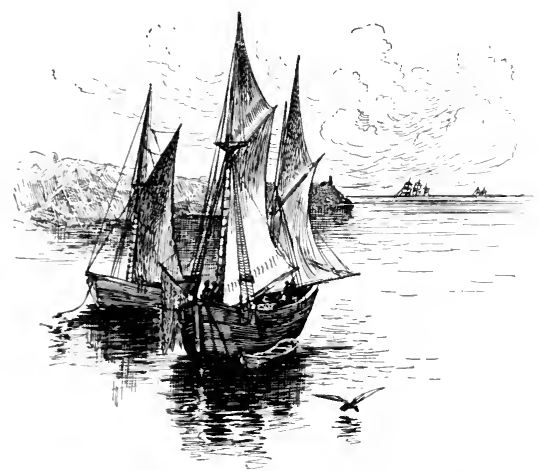

Fig. 1.-The curvature of the ocean. The water partly conceals the distant ships. and he discerns the spires and roofs before the foundations come to view. The outgoing ship is soon "hull down" on the horizon, and at length the masthead disappears. The surface of a lake four miles wide is curved enough to conceal the lower five feet of an object seen across its surface. The earth casts a curved shadow on the moon when it comes between it and the sun.

Thus we know that the earth is nearly round. It is flattened about 13 miles at each pole, and there are other small irregnlarities; so that if it were halved along any plane, the cut surface would not be a perfect circle. The earth is not a perfectly rigid body, but may change its shape from age to age, like a rubber ball compressed in slight degree, now at one point and now at another. It has been the work of the last two centuries to find these small departures from the pattern of a sphere.

2. Latitude and longitude.-It is an important work of every great nation to sound and chart the seas. If the sea is to be a highway, its shoals and channels, harbors and islands must be known in ways that all can understand. Even the wastes of mid-ocean must be so mapped that the mariner can tell where he is and whither he is going. When a new shoal is found by any sailor, it should be made known 
to every shipmaster sailing in those waters. It would be described exactly and in the shortest terms by referring it to imaginary lines of latitude and longitude. Physical geographers deal most with actual things seen on the earth, but, like students of political or commercial geography, they fall back upon this ingenious plan for indicating, in maps and in written speech, the exact positions of geographic features.

We start with the poles, as marking the line about which the earth turns. The circle midway between the poles, dividing the surface into halves, we agree to call the equator. We then imagine circles parallel to this, a degree apart and growing smaller in size, all the way to either pole. We call these parallels of north or south latitude, and number each way from equator to pole. By their aid any point on the earth can be described as to its distance from the middle or equatorial line, and the distance can be plotted on a globe. When this method is used, distances are indicated in degrees, minutes, and seconds. A degree of latitude covers about 69 miles. It is a trifle longer near the poles than near the equator, because there the curve of the surface is less.

We also imagine a system of lines cutting the parallels at right angles and meeting in the poles. Each is a halfcircumference of the earth, and we think of them as one degree apart around the earth. We call them meridians, because it is noon at the same time at all points of any one of them. A degree of longitude covers about 69 miles at the equator, but diminishes to zero at either pole. It is purely a matter of choice where we begin to reckon, but it is common the world over to call the meridian passing through the Greenwich Observatory, near London, zero, and number west or east to $180^{\circ}$. Thus all points in North America are in west longitude and in north latitude. The position of the Capitol at Washington is $38^{\circ} 53^{\prime} 23^{\prime \prime} .2 \mathrm{~N}$. lat., $77^{\circ} 00^{\prime} 33^{\prime \prime} .5 \mathrm{~W}$. long. 
This scheme of lines is particularly useful in mapping and navigating the sea, and in making large surveys on the land, as for government or State boundaries. It enables us to indicate the relations of two distant points more exactly than by referring them to neighboring rivers, lakes, or mountains, though the latter way is often more instructive.

3. The earth without and within.-No one knows much about the inside of our globe. Yet most of its bulk and weight are far within the surface, and geography, which looks at the earth as a whole, must take notice of it. The interior is believed to be very hot. It is known that for every 50 feet of descent into a deep mine there is a gain of about one degree in temperature; and the lavas of volcanoes, flowing up from sources miles below the surface, are as hot as molten iron or copper.

It is also known that the earth is about twice as heavy as the same bulk of the common surface rocks would be. This may mean that the inside is made largely of iron and other metals. Or it may mean that the materials are like those of the surface, but are so packed and condensed under pressure as to weigh much more for the same bulk.

'The outer part of the earth, like the outside of a loaf of bread, is called the Crust. We know that the crust is cold

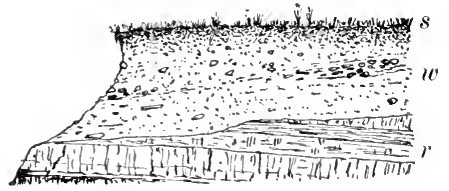

F1G, 2.-Ideal cutting, or "section," showing soil $(s)$, the mantle of waste $(w)$, and bed-rock $(r)$. and rigid, and that the interior is hot. It was formerly believed that the whole interior is molten, but that view is now questioned. We use the word without implying a theory as to the state of the interior, or even that there is some level of abrupt passage from the rind to the core of the earth. Crust is a convenient word for that outer part with which geography has most to do. In it are useful minerals. Its decay forms soil. Over it are the waters 
and the atmosphere. On or near its surface are the hosts of living things. It is the chief subject of our study.

4. The rocks of the earth's crust.-Nearly everywhere there is a blanket of soil and stony waste. On the very

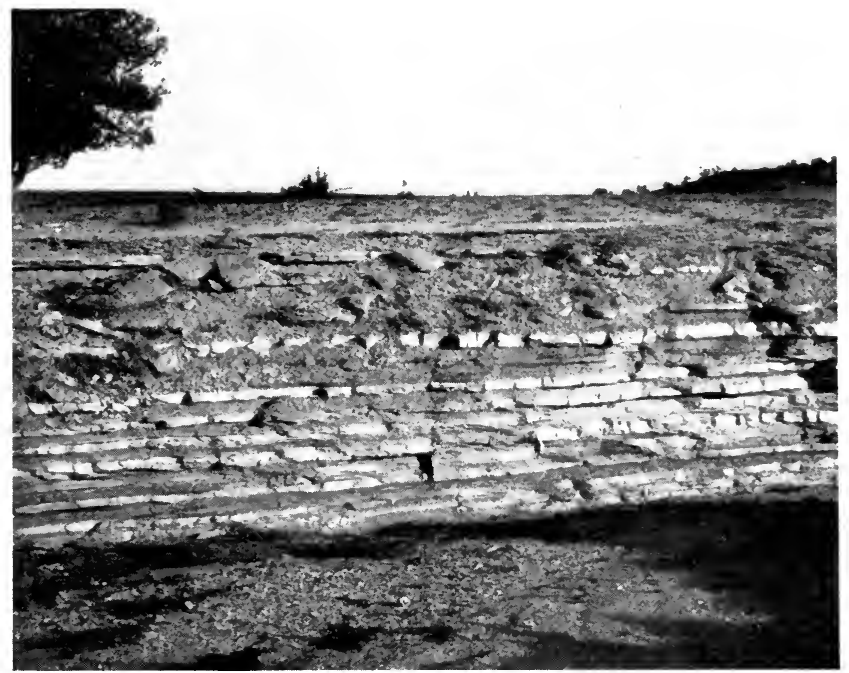

Fic. 3.-Stratified rocks seen in the bank of a creek. Layers of limestone are separated by layers of soft shale.

surface is commonly a true soil, in which plants will grow. Below is clay, or sand, or loam, or gravel. Under this loose layer, and rising out of it in mountains and ledges, is the hard "bed-rock," which continues to great depths, or until we come to the unknown conditions of the earth's interior.

We must now take these thick rocks and divide them into two great sorts. This is not a complete division, for the geologist would find many kinds, but the student of physical geography will find it most useful to know the two classes.

In large parts of the continents the rocks are in layers 
and horizontal. The student will remember quarries in which the layers, each a few inches or a foot or two thick, lie tier on tier. Some are harder and some are softer, and they may be of many colors, but they are either sandstones,

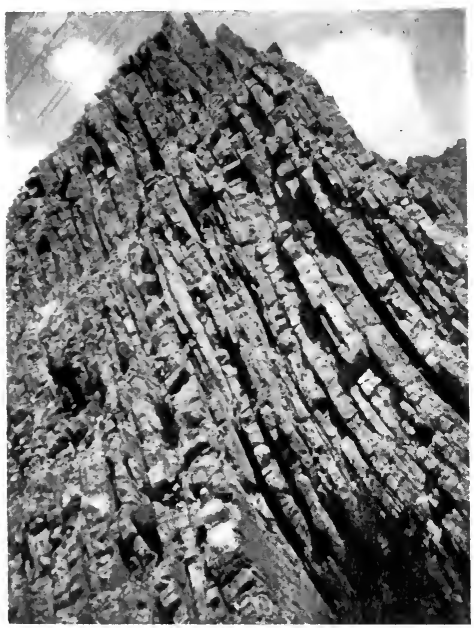

FIG. 4.-Limestone strata which have been upturned in a mountain. shales, or limestones (sections 64-66). They were originally formed as layers of mud or sand in lakes or seas, and have since been hardened into rock. In other places the same rocks are found in the same sort of layers, but the layers are tipped to various slopes, or even stand on edge. Rocks in layers are called Stratified rocks.

In other regions the surface rocks are not in layers, and are neither sandstone, shale, nor limestone, and are crystalline. They have come to be what they are in ways too difficult and various to be explained here. Many of them have cooled from a melted or muchheated state; and they are called Igneous or Crystalline rocks. Granite (section 6\%) may be taken as the most familiar illustration of the class. They are more likely to appear at the surface in mountain regions, but they exist everywhere at some distance underground. If we were to dig or bore deep enough in the layered or stratified rock, we should always find the other kind at the bottom. The igneous rocks, therefore, make up the larger part of the crust, but over them in vast regions the beds of stratified rock lie as a cover. 
If we could pierce the crust under the sea we should find first the soft muds, then perhaps hard muds or stratified rocks, and still below the hard foundation of older rocks.

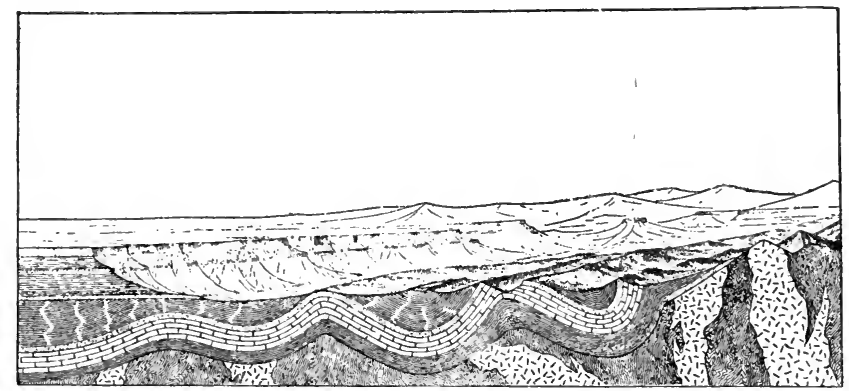

Fig. 5.-Ideal section of part of the earth's crust, with landscape above. Granite and other crystalline rocks appear with irregnlar outlines at the bottom of the section; over them are stratified rocks, partly bent and partly flat. The forms of the landscape are related to the arrangement of the rocks.

5. Land and water.-The student already knows the relative areas of water and land, and knows also much of the continents and their arrangement. It is almost certain that there is open sea, save for ice, about the north pole, and land sheeted with ice about the south pole. The great lands are wide at the north, where they almost encircle the world. The great seas are continuous toward the south, and reach northward in the several oceans. We may regard the seas as one spherical sheet of water, interrupted by lands large and small. The great lands narrow, or are invaded by extensions of the sea, near the equatorial belt, so that the cutting of slender necks at Suez and in Central America completes a water passage around the globe. Low coral islands and high volcanic islands are numerous in the seas, and there is no point on the globe which is more than a few hundred miles from some land. We can also make an instructive division of the earth into 
a land hemisphere, having its center in western Europe, and a water hemisphere with its center near New Zealand.

These facts will help us toward imagining the earth's surface as a whole, but it is much more important to know how the sea and land affect each other. The mud which stains the waters of the brook after a heavy shower will go to the river and then to the sea, and in its bottom, some of it hundreds of miles from shore, will come to rest. Thus the material of the land is constantly cast into the sea. The sun beats on the surface of the sea and lifts its waters as invisible vapor. This is blown over the land, condensed to rain or snow, and falls, creating all rivers, watering the fields, and making life on land possible. So far as we can see, a living world without the ocean is impossible. In the chapters on the land and the ocean we shall learn of many

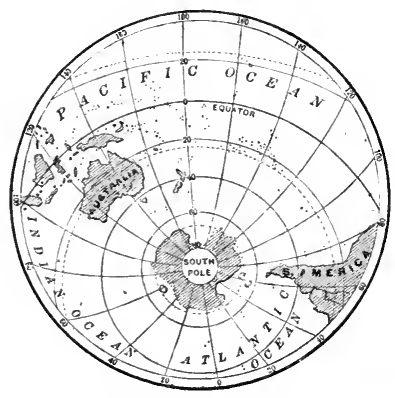

Water hemisphere.

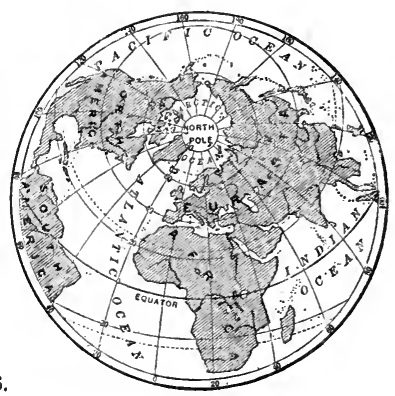

Land hemisphere.

other links that bind the two, and make our planet one world indeed. There is no part of it so distant that it does not help to make us what we are.

If we study the brook more closely we find that every time a flood courses through it its channel is changed. Here an overhanging bank is washed away, making a tree fall; there a shelving shore is built higher by a deposit of mud or sand. Here a gravelly bar grows longer or shorter; there a swimming-pool is made deeper or shallower. 
Through such changes we come to know that the brook is a carrier not only of fine mud, but of sand and gravel, catching them as they fall from bank or cliff, and driving and rolling them onward to the river and the sea.

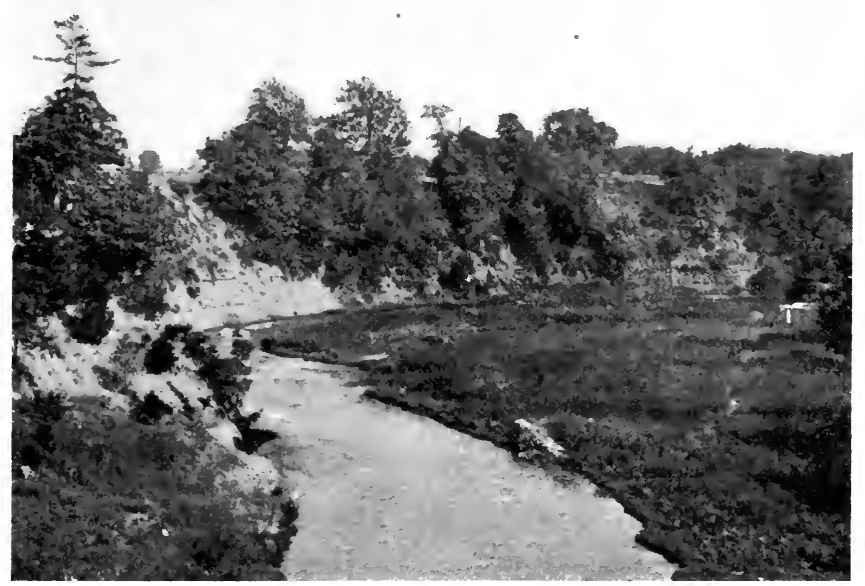

Fig. 7.-The brook is a carrier. As the rock of the high bank crumbles, fragments fall into the water and are swept away. The brook is also a digger. In time of flood its strong current, thrown against the bank at the bend, tears out stones and earth.

6. The outflow of lava in volcanoes. - Not less strange and wonderful to us is the flow of lava, pouring out of the earth like molten iron from a furnace, hardening as it cools, and pouring and hardening again and again, till a hill or mountain is built up; or the bursting of other lava into ash-like fragments which rain on the surrounding lands till fields and meadows, and even forests and cities, are buried and destroyed. The volcano tells not only of great heat below the outer layers of the crust, but of forces so 
enormous that the crust itself is rent in giving passage to the pent-up liquid.

\%. Rivers of ice, or glaciers.-Among the peaks of lofty mountains are other streams made of ice, not more marvelous, perhaps, than streams of water, but exciting our wonder because far away and unfamiliar. Glaciers are fed by the wintry snows of the cold heights, and creep downward until melted by the warmer air of the lowlands. They also are carriers, plucking pebbles and boulders and fine earth from their channels, and dropping them in the valleys below. Many centuries ago, before the records of history began, immense glaciers, or ice-sheets, overspread much of Canada and encroached on the United States from the north. The period of this ice invasion is called the Ice Age, or the Glacial Epoch, and the geography of many lands then underwent important changes.

8. Up and down movements of the land.-Many students will find near their homes stratified rocks which contain shells that grew in the sea. They were enclosed in muds of the sea-bottom, the muds were hardened into the rocks we see, and rocks and shells are now perhaps hundreds of

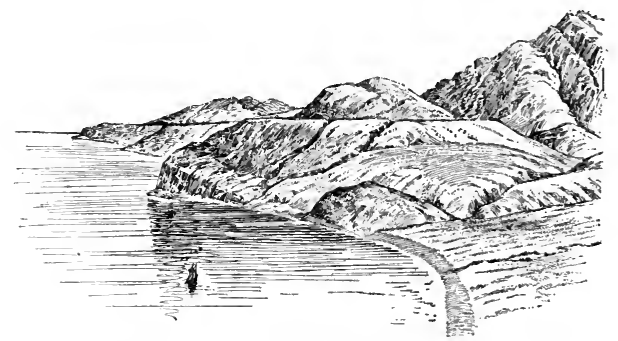

Fig. 8.-An uplifted sea-margin. The beating of waves washes away rock and earth at the shore, especially on bold capes, making cliffs and shelves. When the land is lifted higher the same"thing is done along the new shore-line.

feet above the water. This means that old sea-bottoms have come up out of the water and now form land. Can we find any lands which are now experiencing such uplift, or which 
have thus risen in recent times? On the south shore of Maine geologists have found old sea-beaches more than 200 feet above the sea. These tell that that region has risen up out of the ocean late in the making of our continent. Similar old sea-margins, cut against the slopes of the landare found on the borders of Alaska and Scotland and Norway. Villages and landing-places have seen the sea flow away from them since men began to record modern history. In other places sinking has been going on. Such movements go on very slowly-so slowly that they can not be felt or seen. Only the result can be measured after a period of time.

9. Continuous change.-It is important to obtain a clear understanding of the fact that the face of the earth is always changing. The mud and sand of the flooded brook were washed by rain from field and hillside, and their removal changed the form of the surface. When their journey ends and they again come to rest under the sea, they change the form of the sea-bottom. The work of each storm may be so small that we can hardly detect it; but time is long, and all the storms of thousands of centuries can even remove hills, or hollow out valleys, or make shoals where once the ocean was deep. A glacier creeps along so slowly that we must make careful measurement to be sure that it moves at all, but by grinding away for ages it makes great changes in the form of its bed and builds high hills of stony waste at its end. The work of the volcano is more conspicuous, because it heaps up a hill or blasts out a hollow by a single effort. Where the land is rising, bays are becoming gradually shoal and narrow, capes are extending and islands are broadening, straits are giving place to isthmuses, and the whole coast is gaining new ontlines.

We must understand, too, that such changes have been in progress for an immense period in the past. By means of them the forms of land and sea, the plains and valleys, hills and mountains, have been made and remade, until 
every feature is the result of change. There was a time when men thought of the earth as unchanging, but the geographer no longer speaks of the "everlasting hills." $\mathrm{He}$ believes each shape of the surface to have been produced through some series of changes, and in seeking to learn the history of its origin finds never-failing interest. A growing world is a living world, and to study geography well is to look upon the noblest of panoramas.

10. The atmosphere.-Here is land and there is sea, but over all is the air, invisible, but keenly felt, forming a blanket covering the continents and the oceans. It is indeed a blanket, for without its protection heat would fly off into space and the surface of the earth would be always frozen. It is never long still, and in its ebb and flow, its creep and rush over the earth, it is the great carrier of clouds and of heat. It is in some way breathed by all living ereatures, even by the lowest plants and by animals in the deepest seas, and thus in many ways is necessary to life. We shall come to its study in later chapters, and find it one of the most important themes in increasing our knowledge of the earth.

11. Living things.-The early settlers found New England and the Appalachian region covered with dense forests. Through the Mississippi valley grew the grasses and flowers of the prairies and the endless woods of the region toward the Gulf. In the western plains and valleys are grasses for pasturage, and wide tracts of bushes and herbs. In the western mountains trees and meadows and gardens of Alpine flowers predominate over rocks and snows. And so, the world over, the carpet of vegetation colors every picture. Insects and birds fill the lower air, beasts tread the ground, and worms and burrowing creatures occupy the soil. All lakes of fresh water teem with fish, and the ocean has infinitely more life than all the lands together. We do not, of course, forget that land life is much of it of a higher sort; but we find the best teach- 
ing of geography in seeing how the land and sea, and the sea of air above them, have helped to make all living creatures what they are. An oyster can not live upon the land nor an oak in the sea. A palm would die in Greenland, and a reindeer would pine in a southern home. Each has come to its estate through the long history of its ancestors, living in conditions of moisture or dryness, heat or cold, and influenced by them.

12. Geography.--If we wish to know the other planets in our solar system, or the arrangement of the fixed stars, we study astronomy. If we would learn the laws and uses of electricity, we turn to physics. If we desire knowledge of the ancient history of our earth, of the growth of its lands and of the animals and plants of long ago, we study geology. Should our object be to understand animals or plants in a thorough way, zoology or botany would be our theme. But our purpose is to know the earth as a whole. Land and sea, air and rock, beast and tree combine to form it; and we give some study to each, not to know all about any one, but to see how each controls the rest, and how all work together. This is the seience of geography. And because we deal with the natural earth and not with its political provinces, we call our subject Physical Geography.

The earth belongs to the sun and revolves around it. Thus we must touch upon astronomy. The winds and storms and tides and flowing waters show the working of forces, and so we look to physies for help. Some animals have become used to cold climates, others are fitted to endure heat. Some plants, like the dandelion, are widely scattered, because the seeds have become fitted for travel by the winds. Some live on high mountains, some in swamps, and others in deserts. The zoologist and botanist will tell us about these, and with their help we shall see the earth as the home of life. To form true notions of our whole planet, because men live upon it and because they 
have been much influenced by their surroundings-this is the purpose of geography.

13. Maps.-These are a convenient means of bringing the earth under our eye and of describing it to others. They are miniature representations of the whole earth, or of a part of it. In a small-scale map one inch might repre-

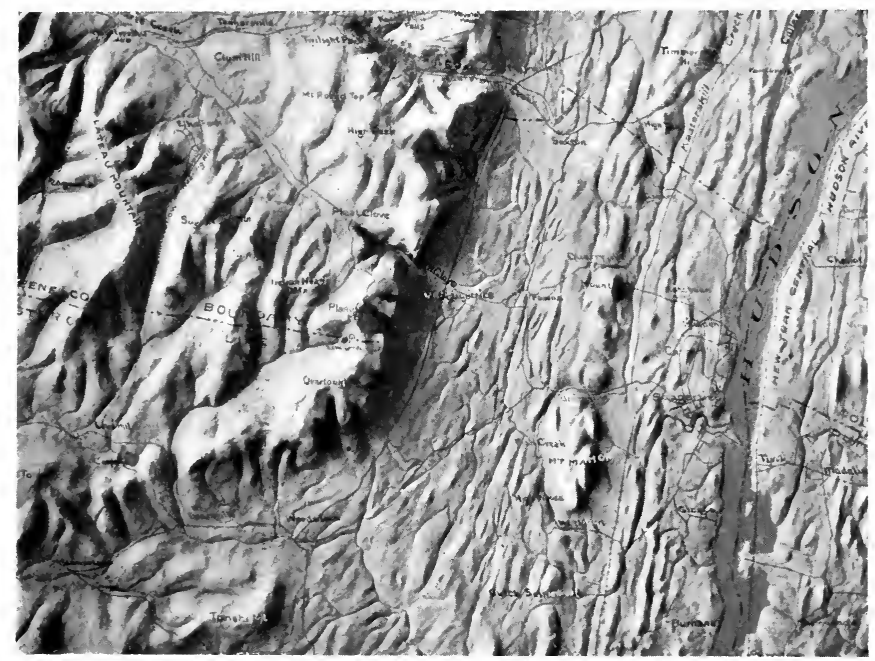

Fia. 9.-Map expressing relief by shading. From a model of the district a photograph was made, and this was copied by the "half-tone" process. Scale, one inch equals five miles. The map shows parts of the Hudson Valley and the Catskill Mountains, or Platean. See pages 60 and 100.

sent hundreds of miles, as in a common page map of North America. But on the atlas sheets published by the United States Geological Survey one inch commonly represents one mile. In such a map many natural and artificial features ean be included. The map scale for a closely populated city would be much greater than this. Upon consulting a map the seale should be at once sought.

Various devices are used to show not merely the ground- 
plan or arrangement, but reliefs or elevations as well. This may be done by shading (Fig. 9), or by short lines called Hachures (Fig. 10), or by eurved lines known as Contours (Fig. 11). Hachures are short lines pointing in the direction of the slope of the ground. They are made heavier where the slope is steeper. A contour is everywhere at

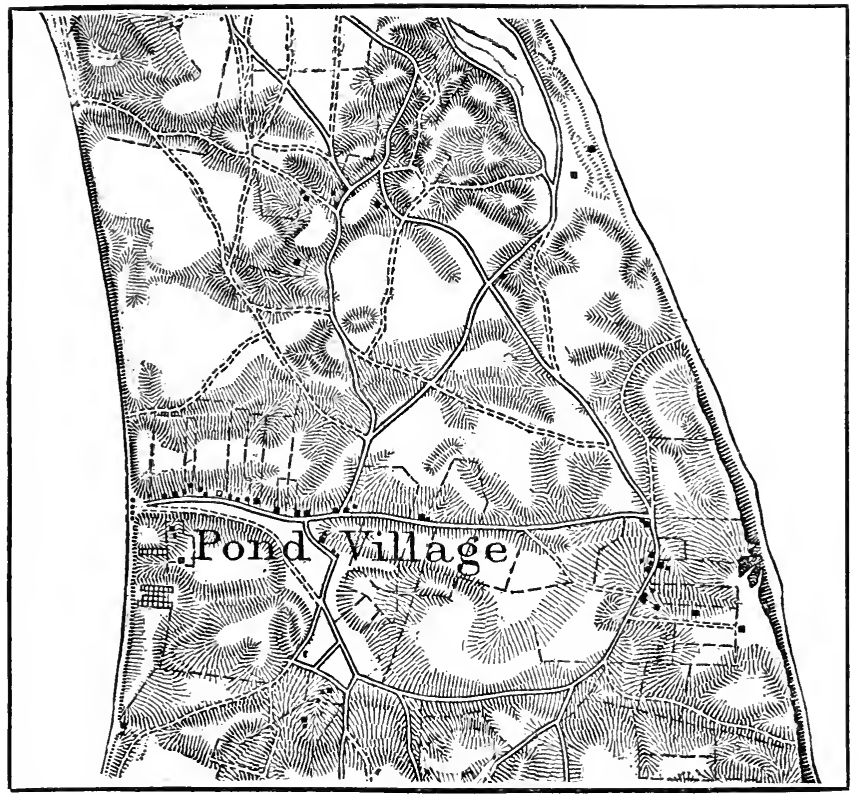

Fig. 10.-Map expressing relief by hachures. Shows part of Cape Cod, Mass. Scale, one inch equals two-thirds of a mile.

right angles to the direction of slope. It represents the course one might take if he walked horizontally across sloping ground, choosing his way so as to go neither up nor down. The outline of a lake is a contour about the valley in which the lake lies. If water shonld be added to the lake until it is ten feet deeper the new lake outline 
would be a contour at a level ten feet higher. The contours of a map represent level lines about the sides of valleys and hills, each at a height differing by a regular interval from that of the contour next below it. In Fig. 11 the contour interval is ten feet, in Fig. 42, twenty feet. If the contours are crowded, the slope is steep. If they are far apart, the ground is nearly level.

Models are relief maps, and are thus more true to nature, if well made, than flat maps. Many models are deceptive and harmful because the heights and slopes are so exaggerated as to teach untruth; but there are also many truthful models, especially of small regions, in which the scale for heights is the same as the scale for distances. A globe is the most general map, and it may be smooth, or wrought in relief. Pictures are of use in geography. They show smaller areas, but in greater detail. Specimens are in some ways best, for they are actual parts or products of the earth. We illuminate maps, models, pictures, and specimens by records of travel, and, best of all, travel ourselves, and thus make geography interesting and real. 


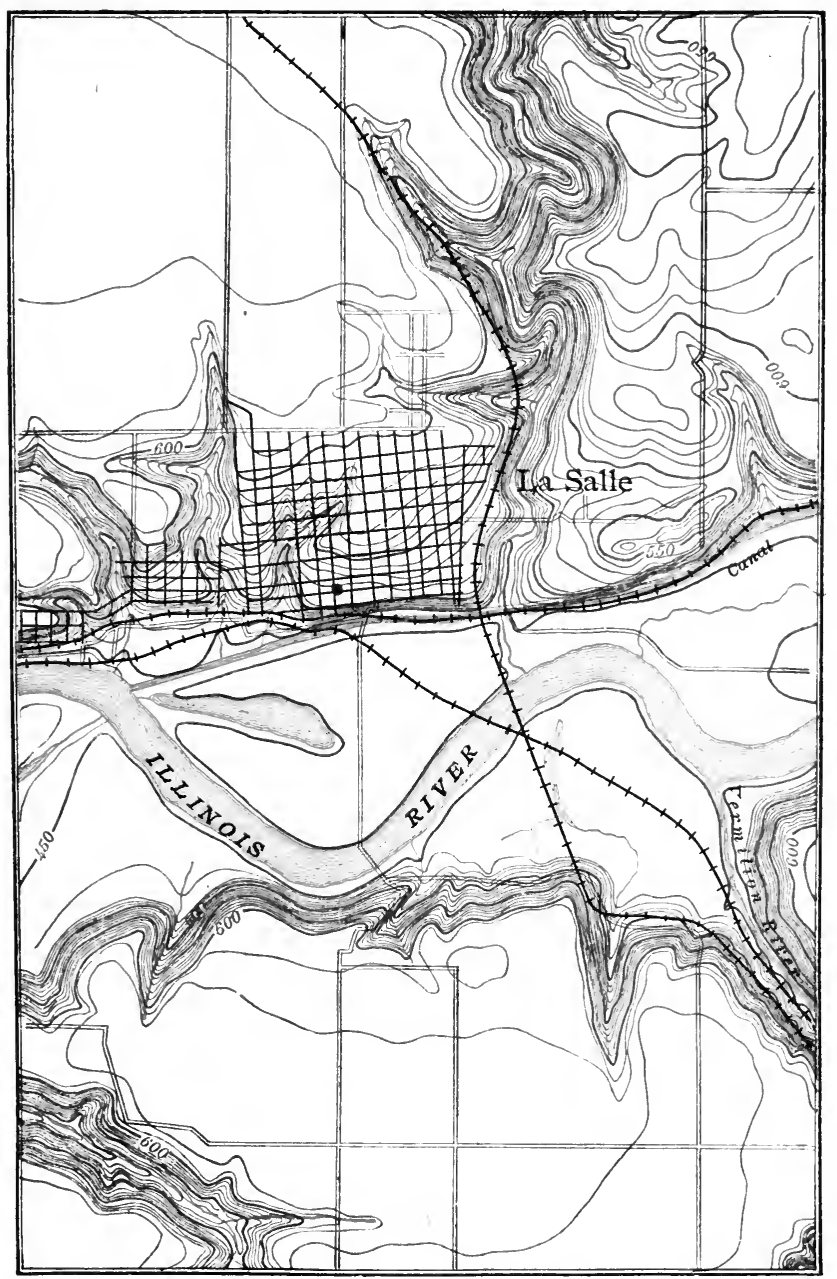

Fir. 11.-Map expressing relief by contours. Contours are in brown, water features in blue. Contour interval, ten feet. Figures show the heights of contonrs above sea-level. Contours at $450,500,550,600$, and 650 feet above sea-level are distinguished by heavier lines. Scale, one inch to the mile. The area represented is in the State of Illinois. See pages 15 and 67. 


\section{CHAPTER II \\ THE EARTH AND THE SUN}

14. The sun.-The earth may be said to belong to the sun. To no other heavenly body are we related in any such close way. We travel around it, we can not get away from it, and without it there could be no life on the earth. We can not comprehend what astronomers tell us of its size. It means little to say that its diameter is nearly a million miles. But it helps our imagination more to say that it is nearly four times as far through the sun as it is from here to the moon. Large as our planet seems to us when we travel to distant lands, it is a mere speck in comparison with the sun. If the setting sun, seen through a hazy atmosphere, seems to us as big as a cart-wheel, we must use our reason to try to appreciate its real size. We can better understand that it is very hot. Its outer gases, rising and sinking in mountains and gulfs of flame, but faintly inform us as to the inconceivable heat of the seething fluids within. One might freeze within a half-mile of the greatest conflagration kindled by man; but we often screen ourselves from the sun's rays at a distance of almost a hundred million miles.

15. The earth is one of the planets.-A family of globes belongs to the sun, making up the solar system. Here belong Mercury and Venus, nearer the sun than we are, and Mars, Jupiter, Saturn, Uranus, and Neptune, whose paths are outside of ours. Satellites like our moon, and many small bodies called asteroids, are in the sun's family, but the study of these belongs chiefly to astronomy. Our aver- 
age distance from the sun is nearly 93,000,000 miles. The distance changes somewhat in different parts of the year, and in different periods of time. We shall understand our own planet better if we remember that all the others likewise have a turning motion, like a top, and all follow paths around the central sun.

16. The sun warms and lights the earth.-It is hardly too much to say that the warming of the earth by the sun is more important than all other facts of geography taken together. Without this supply of heat the oceans would become ice, and all lands would be frost-bound, save where volcanoes are at work. There could be no life on the earth, no clouds, rain, or snow. Without rivers or glaciers, without variation of temperature, and without life, no changes could come over the forms of the land. Here would be a dark world also. With no sum, no reflected light from the moon, and no clouds, perpetual night would be relieved only by the faint light of the fixed stars. Even on a warm earth no life of high order could exist without light. So dependent are we on the sun that we might almost say that our whole study of Physical Geography is a search for the consequences that flow from our relation to the sun.

1\%. The earth turns around at a uniform rate.-The time for a complete turn we call a day, and for convenience we divide it into twenty-four parts and call them hours. The turning is always about one line, as with a top, and we imagine such a line passing through the center of the earth and call it the Axis. The points where this line reaches the surface we call the north and the south poles. The spinning motion of the earth is commonly known as its Rotation. A top always runs down. The earth turns with but slight loss of speed from age to age. The rubbing or friction of the top against the floor and against the atmosphere brings it to rest. The earth (of which the air is only a part) requires no mechanical support, and swings free in relatively empty space. The friction is almost 
nothing, and it goes on with the impulse given to it at its beginning.

18. The turning earth swings around the sun.-The time for a complete swing we call a year. While the earth is making one swing, each part of it is turned toward the sun about 365 times; hence we say that a year is made up of so many days. From earliest ages men have thus marked the greater and lesser divisions of time. The natural day and natural year could be appreciated and used long before the earth's movements were known as their cause. It is common to call this motion of the earth its Revolution. The path which the earth thus takes each year is

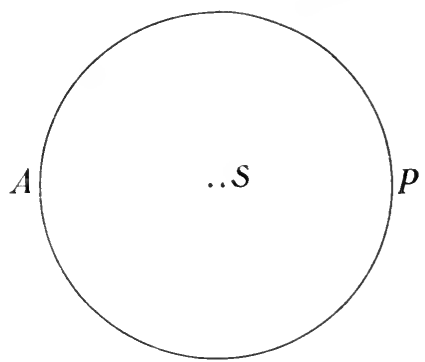

Fig. 12.-The elliptic orbit of the earth and its two foci. The center is midway between the foci. The sun being at $S$, the swinging earth is $91,500,000$ miles distant at $P$ (perihelion) and $94,500,000$ miles distant at $A$ (aphelion). known as its Orbit. It is almost a circle, but is in fact an ellipse (see Fig. 12). The sun is at one focus of the elliptic orbit, about 1,500,000 miles from the center. It results from this that we are about 3,000,000 miles nearer the sun on January 2 than we are six months from that time. The imaginary plane in which the earth's yearly path lies is the plane of its orbit, and is also called the Plane of the Ecliptic. To understand this statement it is well to think of the plane as a perfeetly flat surface of great extent, and of the orbit as a curve marked upon it. If a boat sails around an island, the water-surface represents the plane in which it travels. When the book is so held that this page is flat, the surface of the paper is the plane of the ellipse in Fig. 12.

On the equator a man is carried through about 25,000 miles a day by reason of the earth's rotation. Around the sun he travels nearly 600,000,000 miles in a year. He does 
not feel either motion because all his surroundings, including the atmosphere, go with him. We have a similar unconsciousness when we forget the motion of a swift, smoothly running train until we look through the window.

19. The axis of the earth is not perpendicular to the plane of its orbit.-If it were, the equator would lie in the plane of the orbit, or, in other words, the plane of the equator

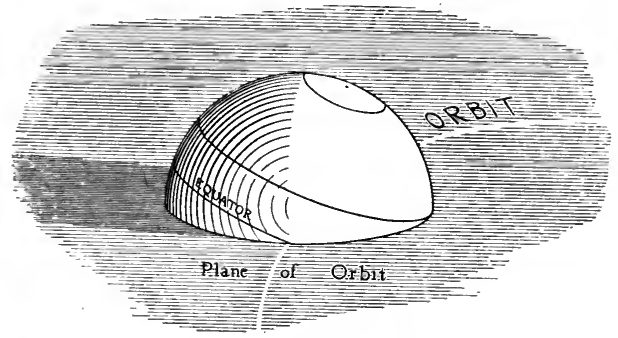

Fig. 13.-Diagram to show the attitude of the earth with reference to the plane of its orbit.

would coincide with the plane of the orbit. But in fact the axis is inclined $23 \frac{1}{2}^{\circ}$ from the perpendicular position, so that the equator lies half above and half below the orbital plane (see Fig. 13). Inclining thus, the axis of the earth points toward the pole-star at the north. Although the earth swings in its orbit between positions nearly $200,000,000$ miles apart, the star is so enormously remote that it ever seems in range with the axis.

20. The turning of the earth causes day and night.-We have seen what are the motions of the earth, and its position in these motions. These are especially matters of astronomy, but we are now to see what are the geographic consequences. The first and simplest is named here. A distant light can shine on but half of a sphere at one time. If the spherical earth were stationary in reference to the sun's light, day would be perpetual on one side and night on the other. We may add that the heat would make life 
impossible on the one side, cold would prevent life on the other, and only a narrow zone might be habitable. The rotation of the earth brings different parts in succession into the light and heat, and the regularity of the rotation gives us a uniform succession of days and nights.

21. The tipping of the axis and the yearly revolution of the earth cause the days and nights to become longer and shorter.-This will be best understood by studying the earth in several positions in its yearly path. Let us first take the point at which the north pole and the northern hemisphere in general are turned toward the sun (Fig. 14), the point occupied by the earth about June 21. As the axis leans over to the extent of $23 \frac{1}{2}^{\circ}$, the sun's rays reach to $a, 23 \frac{1}{2}^{\circ}$ beyond the north pole. Because the sum shines across the pole so far, we place there what we call the arctic circle, and all points within it have constant day for a short

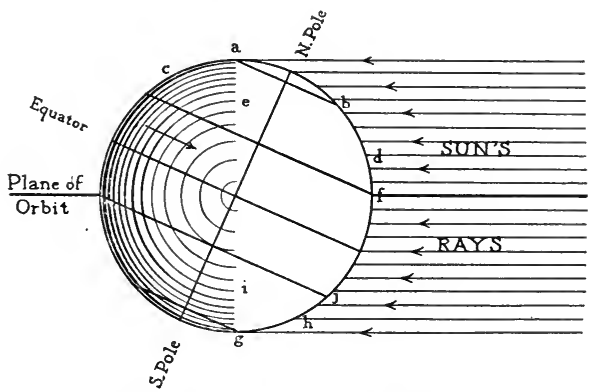

Fig. 14.-Relation of the earth to the sun's rays on June 21. The arrow near the equator points in the direction of rotation.

time, while the earth is in that part of its yearly journey. (Fig. 14 should be constantly consulted.) If one stands at $a$ at twelve o'clock of our night he will then see the "miclnight sun" on the horizon as he looks toward the pole. In twelve hours he will be at $b$, and will see the sun in the south, $47^{\circ}$ above the horizon, or more than half-way to the zenith, the point directly above him. 
Let us next consider $c$, some point in the north temperate latitudes. One who has that position at midnight will be at $d$ twelve hours later. He will have passed out of the shadow and into the light at $e$, less than half-way from $c$ to $d$, and his day will therefore be longer than his night. It is for this reason that our longest days and shortest nights are in the latter part of June. Sunrise occurs at $e$, and it is noon at $d$. At noon the sun appears in the south, but almost up to the zenith. Standing at $e$, and looking in the direction of the sun's rays, we see that the rising sun will appear much to the north of east.

Let us now change to a position in which the sun is exactly overhead at noon. We find it at $f, 23 \frac{1}{2}^{\circ}$ north of the equator. Here we draw the line which we call the tropic of Cancer. North of it the midday sun always appears in the south, but less and less so as we approach the line. At the equator it is plain that the sun shines half around the earth, and day and night are each twelve hours long. We can understand from our figure that the day about June 21 varies from twelve hours at the equator to twenty-four at the arctic circle.

If we turn to the southern hemisphere we find the opposite conditions prevailing. At $g$ on the antarctic circle the sun is seen in the north, on the horizon, once in 24 hours. Within the circle night reigns for the time. In the south temperate zone $i$ marks sunrise and $h$, noon. The sun shines less than half-way around the earth, hence the days are short and the nights are long. The sun is in the north, and is low in the sky, even at noon.

The student should remember that the account above given is wholly true only for a short time about June 21 . He should also take a globe, or any ball marked like Fig. 14 or Fig. 16, and a lamp, and observe for himself. The descriptions of the text-book can not supply clear ideas unless careful study is also given.

In six months the earth will have moved to the opposite 
point in its orbit (December 22 in Fig. 16). Its position in reference to the sun's rays is now shown in Fig. 15. The north pole and northern hemisphere are turned away from the sun. The time is about December 22. It is night within

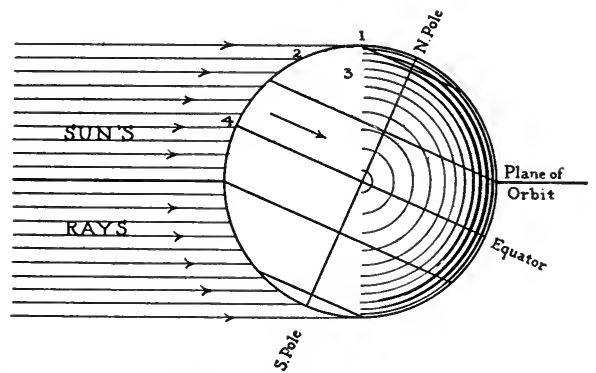

Fig. 15.-Relation of the earth to the sun's rays on December 22.

the arctic circle, and an observer on the circle, 1 , will see the sun on the southern horizon for a few moments in each twenty-four hours. In the temperate zone less than half the circuit of the earth is lighted at one time by the sun ; hence the days are short and the nights are long. An observer at 2 sees the sun at noon low in the south, and when he comes around to sunset, 8 , it appears to go down much to the south of west. At the equator the sun at noon, looking from 4 , is still in the south, but day and night are equal in length. The noon sun is seen in the south as far south as the tropic of Capricorn, but there it appears overhead, and south of that line it is in the north. We now find long days in the south temperate zone, and constant day, for a short time, within the antarctic circle, for the sun now shines $23 \frac{1}{2}^{\circ}$ past the south pole.

If we could, about December 22 , pass swiftly from the north to the south pole, we should begin our journey in a land of continuing night, passing to days varying from a few moments at the arctic circle to twelve hours at the equator, and thence to continuing day about the south pole. 
In December and June, therefore, the conditions of day and night are exactly opposite in the northern and southern hemispheres. The polar circles mark the limits to which the sun shines alternately across the poles, and the tropics mark the north and south bounds of the equatorial belt in which the sun may be seen directly overhead.

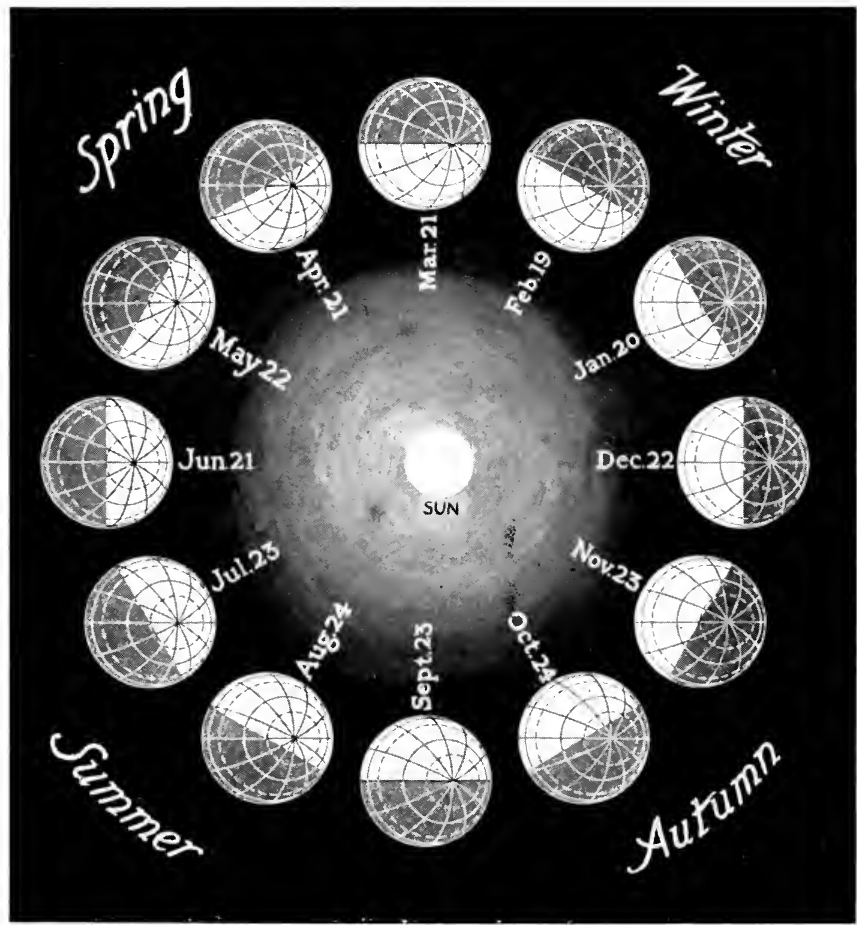

F'ig. 16.-Ifumination of the earth in twelve positions, corresponding to montlis. The north pole is turned toward ns.

The student should consult again Fig. 16 . We are now looking along a line vertical to the plane of the earth's orbit. We see the position of our globe on Jume 21 and 
December 22, as above described. Three months away, or one-fourth the distance about the orbit, in either direction, we see the earth as it is March 21 or September 23. Just half of the whole earth is lighted at once as before, but the light always shines to both poles, and not beyond. Thus, whether one stood at the arctic circle or in the temperate zone, or at the tropic of Cancer, or on the equator, day and night would each last twelve hours. Hence these positions in the earth's path are the equinoxes, or points of equal nights and days. These four positions of the earth should be well understood, and then we can appreciate the fact that the days grow longer and the nights shorter in the northern hemisphere from December until June, and the reverse changes go on from June until December.

22. The changes of the seasons also are due to the inclination of the axis and the earth's revolution about the sun.When the days are long and the sun rides high in the sky, more heat falls on the surface than when the days are short. The air is warm, the soil is warm, the clouds send down rain rather than snow, plants thrive, migratory birds fly north, and we call the time summer. It is then winter in the southern hemisphere. Six months from that time the days are short, the sun rides low, less heat is received, the air is cool, the clouds drop snow, and we call the time winter. The intermediate conditions of spring and autumn fall in the times of more equal days and nights.

23. Zones of climate.-When the sun is low in the sky, its slanting rays give us less heat than when it is high. This is illustrated by the cooling of the afternoon as the sun descends, and it has much to do with the great zones of climate. In the arctic and antarctic regions the sun's rays always come slanting to the surface, and warm it little. Near the equator they are always high, and warm the surface much. Between the two they change from high in summer to low in winter, and warm the land and sea moderately. Hence we speak of temperate zones. If the axis 
did not tip, days and nights would always be equal on all parts of the earth. The noonday sun would then be always at the zenith at the equator, always on the horizon at the poles, and always at a moderate elevation in the middle regions of north and south. The familiar change of seasons would not exist, and the extremes of heat and cold between the equator and the poles would be greater than now. We shall see, however, as we go on, how the climate of a region depends on many things besides its latitude.

24. Time.-We have seen that the rotation of the earth gives a short natural measure which we call a day. And the succession of the seasons, with the passage of the sun between positions high and low, gives the longer measure which we call the year.

It is plain that when noon has come at a given point, say at Washington, it is afternoon for all places east, and before noon in all places west. In other words, each place has its local time. Noon reaches Washington forty-three minutes earlier than Chicago, and more than three hours earlier than San Francisco. For each fifteen degrees of longitude there is a difference of one hour in local time. If time were kept only by stationary clocks, these differences would cause no practical inconvenience, and in fact they received little attention so long as journeys were rare and slow; but with the general carrying of watches and with great increase of travel they became a source of much annoyance and difficulty. Each railway company set all its clocks and watches to correspond to local time at some one station and there was a difference between local time and "railroad time" at every other station. To escape such confusion the system of Standard Time was adopted. Under that system the country is divided into north and south belts fifteen degrees broad, and all parts of each belt use the time which is local for places on the central meridian of the belt. The times in two adjacent belts differ by just 
one hour. In the following list of standard time districts the degrees mark west longitude:

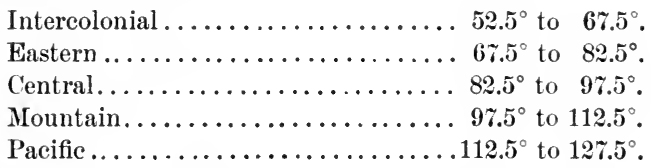

25. Summary.-The earth is one of a family of planets, each pursuing a nearly circular path about the sun. Being very small as compared with its distance from the sun, it receives but the smallest fractions of the sun's light and heat, but these are all-important to the earth, and make its life possible. The rotation of the earth causes day and night. The inclination of the axis, combined with the annual revolution, causes the changes in the length of day and night, and the succession of the seasons. These changes alternate between the northern and southern hemispheres. Our measures for duration, or the passage of time, are found in the periods required for the two great movements of the earth. 


\section{CHAPTER III}

\section{RIVERS}

26. Terms.-We begin our study of rivers by looking at a narrow valley. We often call such a valley a Gorge, referring to its depth, or throat-like form; or a Ravine, a word which means a narrow passage worn by swift waters. A Gully is a small ravine, like a deep ditch; Canyon is commonly used of great gorges in the western United States; while Gulch is a name often given to gorges in western mining regions. Glen, Dale, and Dell are somewhat poetic words for small valleys secluded among hills.

27. A gorge.-Let us choose any gorge, large or small, which we know best, and enter it. No two will be alike, yet some of the same things will be seen in all. It may be $50,100,300$, or 500 feet deep. If we are among the western mountains and plateaus there will be some greater gorges, even to a mile in depth. The gorge may have vertical walls on either hand. If so, we shall nearly always find the solid rocks exposed, and these rocks often consist of layers or beds. The beds vary in thickness from an inch or two to several feet, and often some are harder than others. In this case they will stand in relief, while the soft beds are crumbling away. If the rocks are not much decayed, they often show even faces of considerable size, standing up like a wall of masonry in which each block has been smoothly dressed. Such faces are caused by straight cracks or partings in the rocks called joints, and when the rocks lie in horizontal beds, the joints are 28 
about vertical. They make it possible for gorges to have perpendicular cliffs (see Fig. 17).

Two sets of joints commonly eut each other nearly at a right angle, hence it is that niches and buttresses in great variety often develop along the sides of a gorge.

But the walls are not usually vertical from bottom to top. We may often climb over a slope of waste that has fallen from above. Such a slope of waste is called a Talus, because in form it resembles the ankle. It may consist of fine, sliding fragments not yielding secure footing; or we may find a rough but solid path over large blocks of rock. Whether the talus be steep or not, and whether it be of fine or coarse material, will depend on the nature of the rocks in which the gorge is

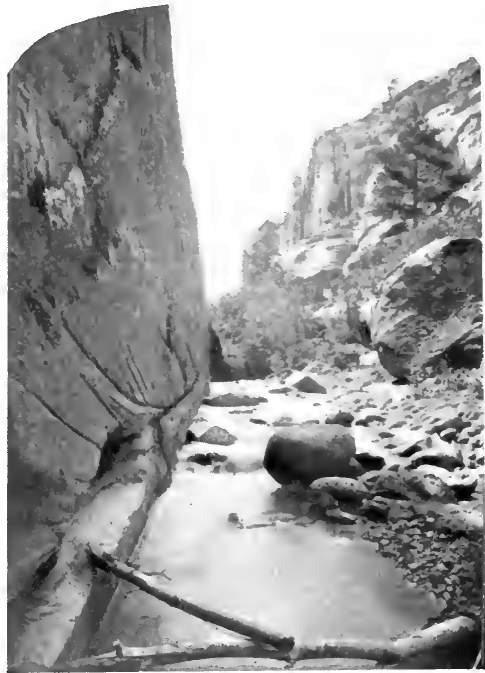

Fig. 1\%.-Gorge of Temple Creek, Utah. The cliff at left is a joint plane; other joints divide the distant cliff into vertical slabs. The ereek is now small and doing little work, but in flood time it has rolled even the great boulder at the right.

cut. Rising from the top of the talus is often a vertical cliff, at the foot of which one may pick his way for a long distance without finding a path to the top.

Most gorges have more or less sloping sides. This is partly due to the talus, as already described. It is also cansed by the crumbling of the npper walls, as blocks of rock are wedged off by frosts or pushed down by the growing roots of trees, which in such places thrust them- 


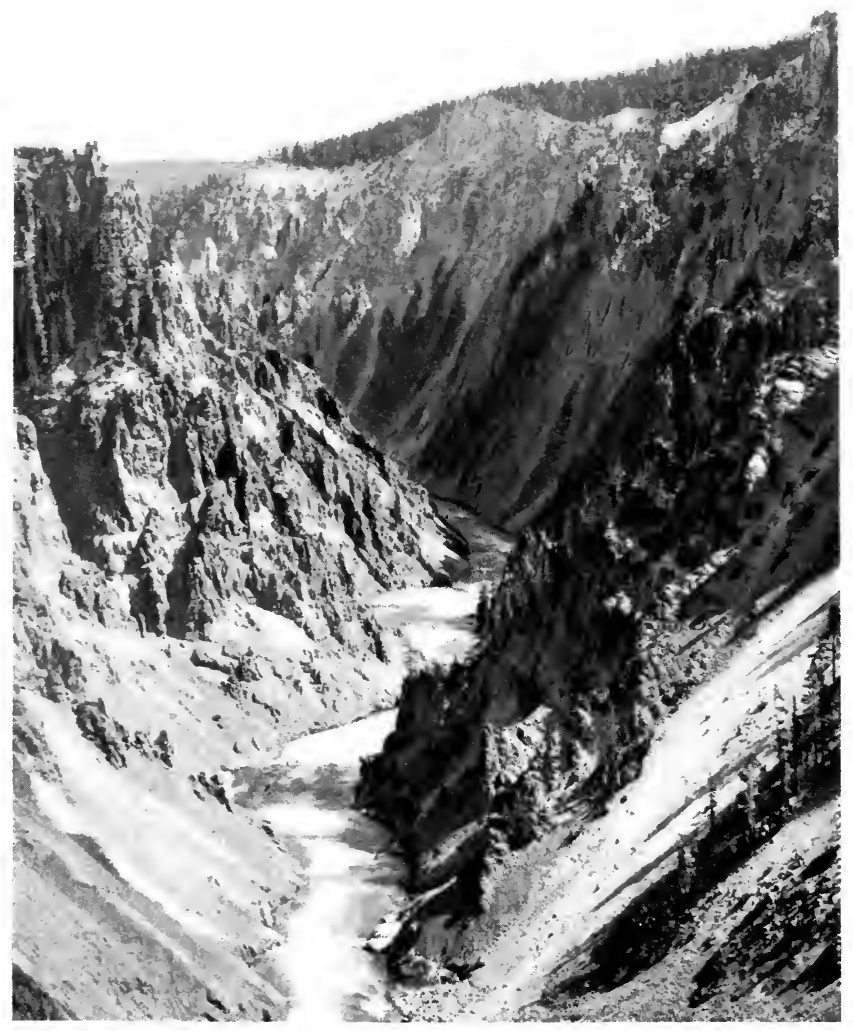

Fig. 18. - Canyon of the Yellowstone, a V-gorge, showing crags and talus slopes. 
selves into cracks and apply great pressure. A gorge with evenly sloping sides is often called V-shaped, and the $\mathrm{V}$ is narrow or broad, according to the amount of wasting which has taken place.

A gorge may have in general the $V$ form, but show some irregularities. If a hard layer of rock ten feet thick lies between softer beds it will stand out and form a small cliff on the slope. Thus we may have short slopes alternating with low cliffs on the sides of the gorge. The cliffs mark the hard beds, and the slopes are formed of waste veneering the edges of the soft beds (Fig. 64 and frontispiece).

If the gorge is excavated in softer material, such as clay or sand, we may find very smooth and symmetrical slopes perfectly illustrating the $V$ form. Such slopes show inclinations of $30^{\circ}$ to $40^{\circ}$ with the horizon.

A multitude of small gorges can receive no notice here, but are of local interest and of value to students of geography. As examples of great gorges in the East we may name the Kanawha, the Hudson in the Highlands, the Deerfield, and the Saguenay. Here may be mentioned also the short gorges or "water gaps" of the Delaware at Stroudsburg, the Susquehanna at Harrisburg, and the Potomac at Harpers Ferry. All these are flaring and of considerable age. The Niagara, the Mississippi at Minneapolis, Ausable Chasm, and Watkins Glen are examples of younger, steepwalled gorges. The Yellowstone, the Royal Gorge of the Arkansas, the Black Canyon of the Gunnison, and the Grand Canyon of the Colorado, are examples of the profound river gorges of the western United States.

28. The stream.-Along the bottom of every gorge is a stream channel. In it may flow a great river or a brook or only a temporary torrent. The stream is there because the slopes of the land gride the water that way, and the stream may thus be said to exist on account of the channel. But in an equally important way the gorge exists because of 
the stream, for the stream is in fact the maker of the gorge and is still at work on it, deepening and enlarging. Let us look at the stream. We shall often find it a roaring torrent in April and May, and only a rivulet making its way among the stones in August or September. In many ravines the bed is dry during the summer months, except after a heavy shower or long rain. Then the water quiekly gathers from the fields and rolls yellow and muddy where just before a dry path led up over the pebbles of the stream bed. 'This suggests that during the breaking up of the spring, and after the heavy rains of summer and autumn, the stream does most of its carrying work.

Let us examine the bed of the stream. We shall often find a floor of rock. If the stream shows such a floor, we may know that it is effectively carrying away the waste which is supplied up-stream by the breaking up of rocks. The flood current is so swift and strong in volume that little rocky rubbish ean rest in its path. This also means that the rocks of the stream bed are exposed to wear whenever the eurrent is strong. They are filed down by the sand and pebbles that sweep aeross them. Their surfaces are dissolved and the fine matter is borne away. Flakes and blocks of the rock loosen by frost in winter, and are hurried off by the floods of spring. Thus the gorge is growing deeper by the wearing of its floor.

But on either hand will often lie banks of waste at the foot of the cliffs. These will be more or less attacked, according to the power of the stream. And at some points of less slope the bed of the stream will be covered with shingle, or coarse, rough waste. And in some still pools, sand and mud will gather, until the down-stream rim of the little basin is eut away. Thus the bed will be protected at some points and subjeet to wear at others. Depressions are gradually filled, jutting ledges are worn away, and the bed of the stream gains a smooth grade.

If we find the floor of the stream covered with waste, 


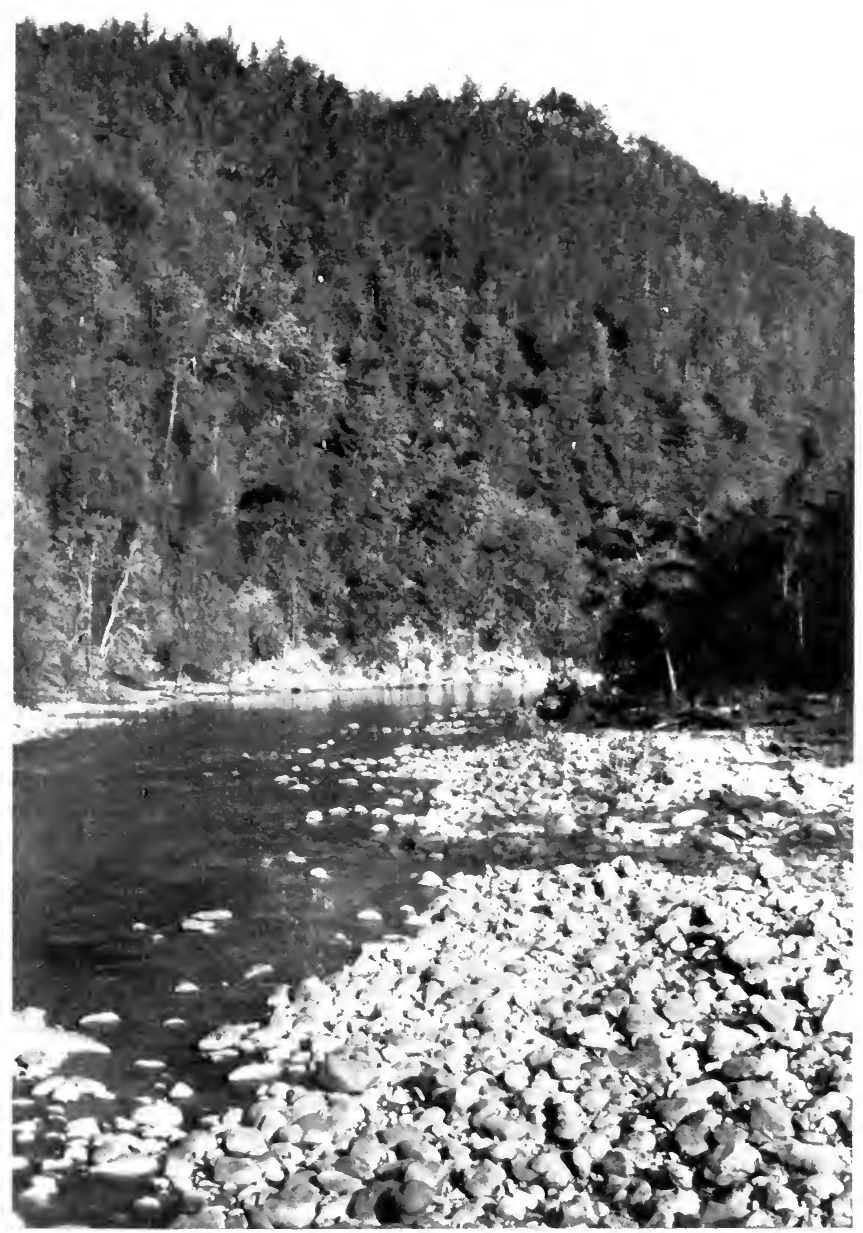

Fig. 19.-A small river at low stage. The water is clear. The shore at the bend shows bed-rock, but the river bottom near by is covered by loose blocks (boul. ders) which have been rounded by rolling. 


\section{AN INTRODUCTION TO PHYSICAL GEOGRAPHY}

this means that the crumbled rocky matter is supplied faster than the stream can carry it away. Thus a river or brook may be overloaded-that is, so charged with land waste that instead of filing the rocky channel, it casts down a protecting blanket of mud and stones upon it. This, however, does not happen so often in gorges as along the bottoms of open valleys where the flow is less swift.

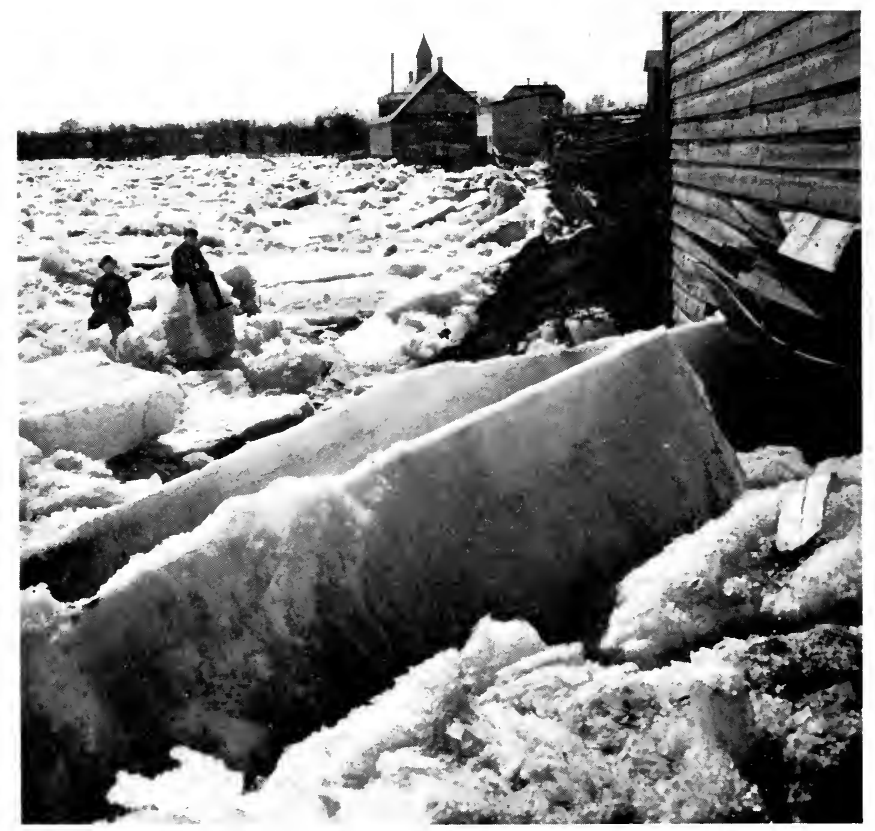

H'IG. 2U.-Ice-jam, Red River, Manitoba.

The student should see that some of the stones in the stream bed are angular, and some have the corners reduced, or are well worn and rounded. These differences depend on the varying distance along which the current has pushed and rubbed the fragments. All the finer 
rock floor thus made has been easily swept down the stream and is resting in the banks, or has been carried out and spread over the floor of the sea.

These are the ways in which a stream works on the bed of its channel : by-

1. Filing with sand and pebbles.

2. The dissolving of rock by the water.

3. Ice-push of blocks of rock in the spring.

4. 'The heaving of blocks by water freezing in cracks.

And also, as a carrier, it removes the rock chips its tools have loosened. Little by little, year by year, century by century, it works away, grinding and sawing its bed and making the gorge deeper.

The widening of the gorge or valley, due partly to the stream and partly to weathering, will be described in later sections.

29. Sources of the water--Having studied the gorge and the work of the water flowing in it, let us inquire for the sources of the water. It all comes at first from the sea, or in less degree from lakes and rivers, by evaporation, by the formation of clouds and the fall of rain. On all land surfaces the water tends to gather, to flow along the lines of greatest slope, to form rills at first and then larger streams. As soon as a stream of any size has formed on a sloping surface, gorge-making begins. But rainwater does not all flow directly into surface streams. Much of it soaks into the soil and often deep into the rocks, and comes out in the form of springs. The journey underground may cover a few rods or many miles. Great caverns may be made by solution and by wear of the waters, and springs of great volume, even to thousands of gallons per minute, may boil up at the surface and set in motion a large surface stream at once.

In regions of cold winters much water lies on the surface as snow until the coming of spring, and then melts quickly, and thus floods are larger and more valley-making 
is accomplished than would be possible if the water fell as rain and ran freely away after each storm.

As we have just seen, only a part of the falling rain runs directly away. If the soils and rocks are porous, or the surface is flat, or the air very dry, less runs away than if the rocks are hard, the surfaces steep, and the air moist. Hence it is that the percentage of "run-off" to the entire amount of rain varies from one-third or two-fifths in New England to one-quarter in the Mississippi valley, and much less in the dry regions of the world.

30. River basins. - The amount of water forming a given stream also depends on the size of the Basin. The basin of a river includes all the land surface which inclines toward it, and whose surplus waters enter the ocean or trunk stream. by it. A river, then, in the true sense includes all its branches however small, and a river system is a tree-like group of streams reaching down to the ocean by one trunk.

31. Divides. - The boundary between the basins of two adjoining streams or stream systems is called a Divide, because the water falling as rain is there divided, part of it going to one stream and part to the other. A divide is the higher land forming the watershed or water-parting between two river basins. It may follow the crest of a ridge, high or low, or it may traverse a plain so level that its course is uncertain or even variable. The very flat region at the head of the Illinois and Chicago rivers, now crossed by the Drainage Canal, illustrates the flexible meaning of the word divide. The streams that enter Lake Ontario from New York are not separated from the Susquehanna and Alleghany by a ridge, but there is an interlocking system of head-waters, in which the local divides are sometimes hill ridges, and sometimes flat and swampy areas in valleys. It is stated that small steamers may, in high water, pass between the Mississippi and the Red River of the North. In high mountain regions where the divide is usually a sharp edge, it is rarely straight for any distance, but 


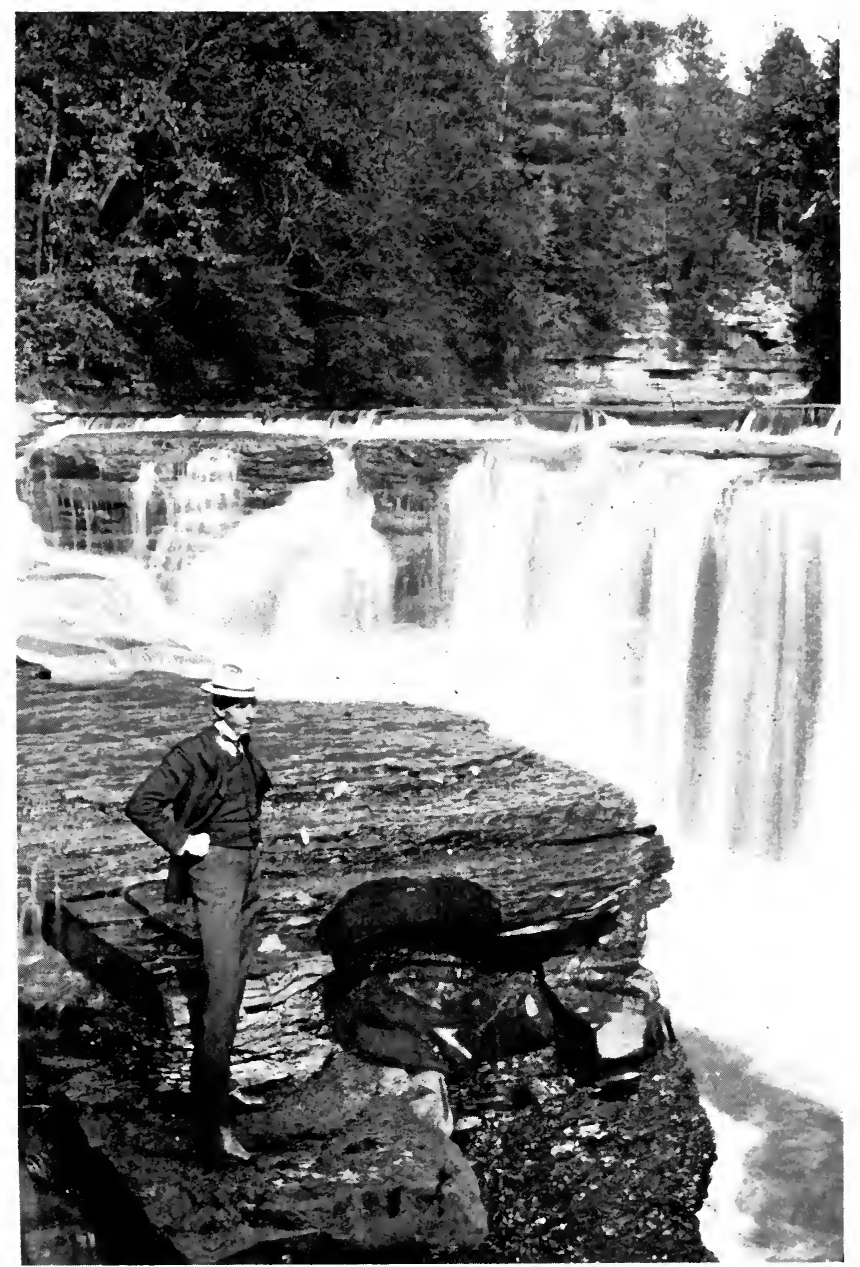

Fig. 21.-Cascade, due to joints and bedding planes. Fall Creek, near Ithaca, N. Y. In the foreground is a pot-hole whose walls have been partly broken away. 
full of sharp curves and zigzags. As there are divides separating river systems, so there are subordinate divides between different branches of the same system.

32. Waterfalls and rapids.-These are common in gorges. A series of falls with alternating rapids will often be found. Water pouring over sin-

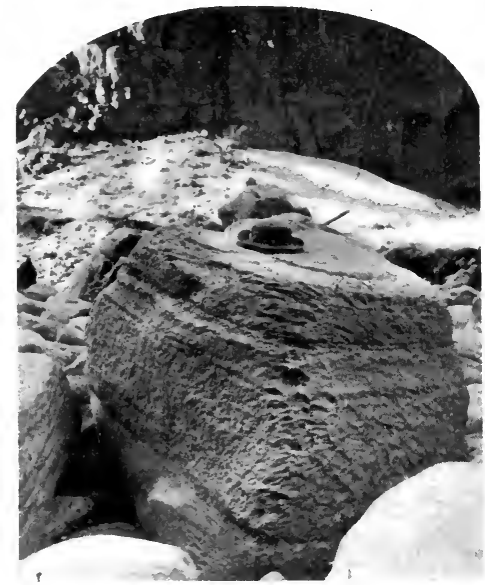

Fig. 22.-A limestone boulder in the bed of the Colorado at a rapid. During floods sand is swept over it (from right to left), grinding and carving it. gle beds or steps of the rock forms low falls. Strong rapids occur in the Grand Canyon of the Colorado, opposite the mouths of tributaries. These side-streams have brought great boulders down their steep torrent beds, and heaped them in the main channel as barriers over which the trunk river plunges.

Falls of considerable height are formed in various ways. If welldeveloped joints cross the track of the stream, the blocks wear away up-stream to a given joint, which maintains a wall over which the water descends. With several joint planes and the planes of bedding, a stairway is often made over which the water cascades to the bottom. If softer beds of rock are capped by a hard layer, the decay of the soft beds and the blows given them by the falling water cut them back and leave the hard sheet projecting over them, thus giving the waters a single plunge to the bottom. This is the way in which Niagara is formed. There the rocks are nearly horizontal. The falls are about 160 feet in height. Sixty feet or more of the upper rocks are hard, 


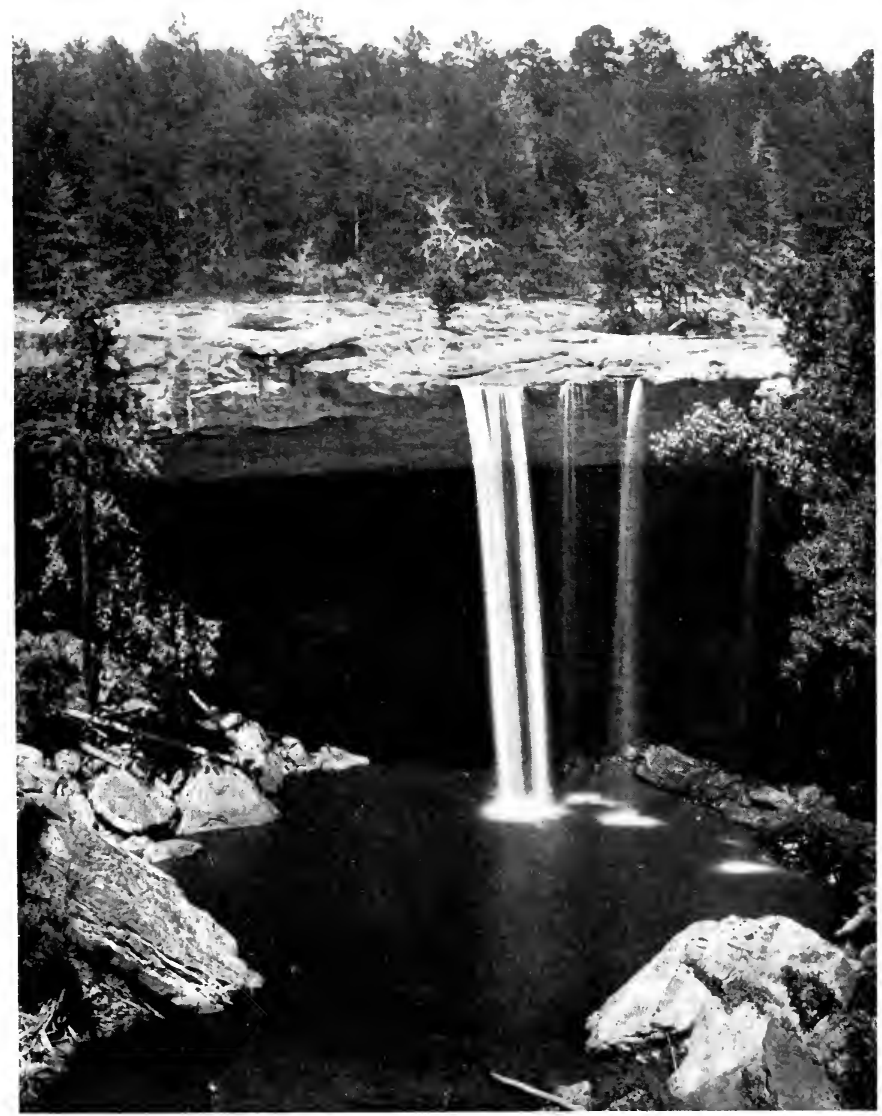

Fir. 23.-A waterfall neur Gadsden, Ala. A strong layer of sandstone projects like a cornice because the soft shale beneath has been eaten away. The fullen blocks are angular because not rolled by the stream. The deep hollow under the fall contains a pool of still water. The stream is now small. In flood it spreads over the bare rock to the edge of the forest, and plunges with great force to the bottom of the pool, 


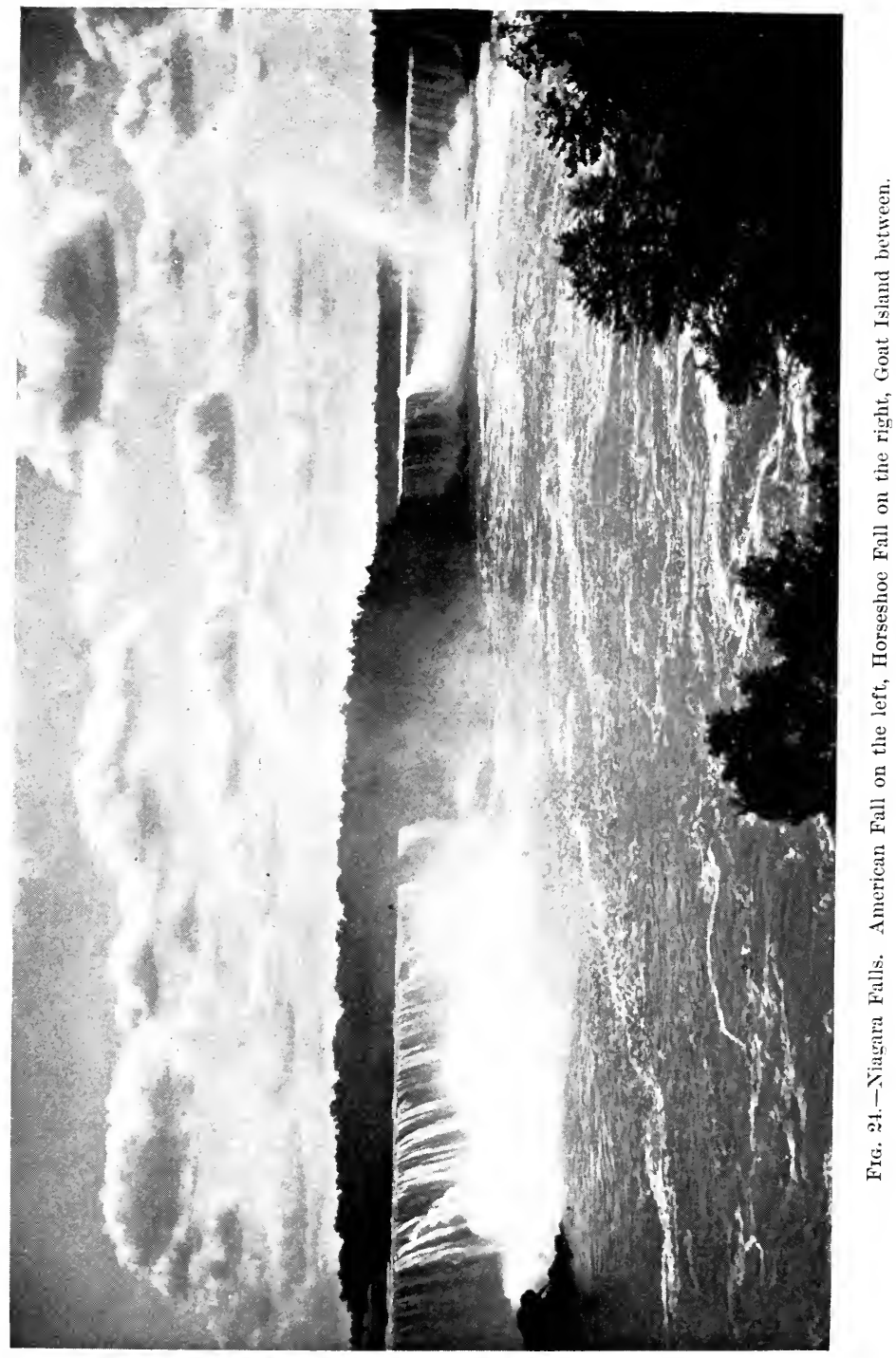


thick beds of limestone. For the most part, the rocks below these are shales or hardened muds. These wear back, as shown in the diagram (Fig. 25). As the foundation is removed, great blocks of the hard, capping rock fall down. Thus the form of the falls changes, and they are receding-that is, the gorge is growing longer at the south end, as the falls slowly move up the river toward Buffalo. The rate of recession is four to five feet per year. In such a fall the water strikes the bottom with great force, and tears or wears the rock. Hence a pool is formed.

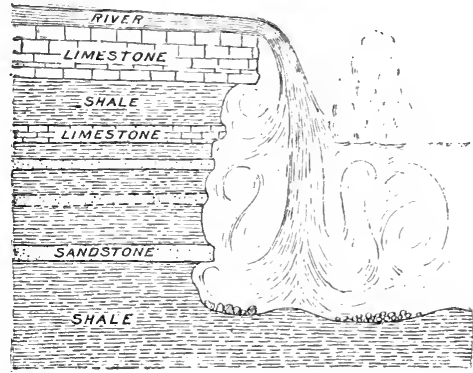

FIG. 25,-Diagram showing the appearance of rocks and stream if a deep cutting (section) were made at Niagara Falls. Upper limestone abont 60 feet thick. Water below the fall, 200 feet deep. Boulders, tumbled about by the water, help to wear the shale.

At the base of the Horseshoe Fall the water is about 200 feet deep. At the base of some small falls in Watkins Glen, fine, well-like pools, six to ten feet deep, with vertical rock walls, are seen. These smaller pits in stream beds are known as pot-holes, and may be found in the rocky floor of almost any swift stream. They vary in diameter from a few inches to several feet, and, if large, may be 20 feet deep or more. They are drilled down by pebbles or larger stones whirled by the dashing and rushing waters (Figs. 21 and 108).

Over the sides of ravines small waterfalls are often found. This means that the main stream has sunk its channel more rapidly and deeply than the side-stream. Where the Columbia River has opened a gorge through the Cascade range the valleys of two creeks end high on the wall, and their leaping waters break into spray like the Bridal Veil Fall of the Yosemite. The Latourelle is 260 feet high and the Multnomah 600. 
While waterfalls are most numerous along small streams and in the lesser gorges, we see in the case of Niagara that great streams may fall. The Mississippi at Minneapolis forms the Falls of St. Anthony. Here also the capping rock is limestone, but thinner than at Niagara. Shoshone Fall in Idaho is similar in origin, but in this case the hard bed over which the Snake River plunges is a horizontal sheet of cooled lava.

33. Man's use of waterfalls. - Where a stream descends quickly, it is possible to divert it from its bed, carry it a short distance in a canal or flume, and use it to turn the wheels of shops and factories; and the sites of waterfalls are especially favorable for such utilization. The primitive grist-mill and sawmill are followed by larger undertakings, and towns and cities grow where nature offers power to help man's work. It was about mill-wheels that Lowell and Lawrence, Fall River and Holyoke grew in New England, Rochester in New York, and Minneapolis in Minnesota. The power of Trenton Falls is used in Utica; a thread of Niagara's great volume turns wheels of neighboring shops and lights the streets of Buffalo, and the swift streams of the Southern Appalachians are harnessed to do the work of man. On the border of the campus of Cornell University a waterfall in a deep gorge has been put to use by the building of a unique structure, a hydraulic laboratory, in which all the problems arising from the use of water for power may be subjected to experiment and exact study. Thus the force of the earth is linked to the thought and enterprise of man.

34. Alluvial fans or cones.-Where a gorge passes into an open valley one often finds a gathering of land waste having the form of a fan, with the apex pointing up the side valley. From the apex toward the border, the slope may be gentle or quite sharp. If the grade in the side gorge is steep, the swift waters will bring out coarse, bouldery waste and drop it suddenly, making a steep fan. If the 
grade is less, finer material will eome down and be carried farther out on the floor of the trunk valley, giving a wide fan of small slope. The stream flows sometimes along one radius of the fan and sometimes on another, thus building up all parts in suceession. Such a body of waste forms a more or less perfect segment of a low cone; hence the term Alluvial Cone is often used. In a mountain land

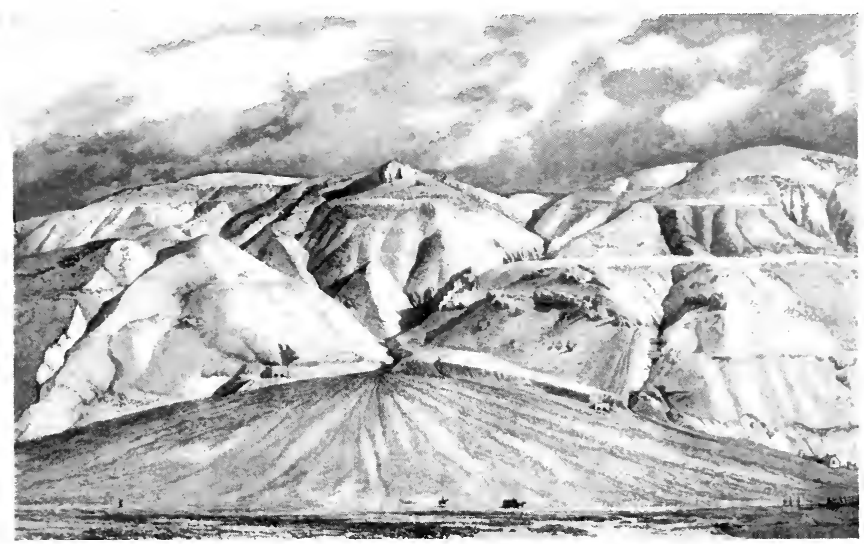

Fıg. 26:-An allnvial cone. Near Great Salt Lake, Utah.

like Switzerland such cones are eommon and large, and a thrifty people, desiring every possible acre of land for tillage, confine the lawless torrent in a single channel of masonry. Thus they "rectify" the stream, clear away the boulders, and gather good harvests from what seems forbidding ground.

35. Development of a valley.-Let us now reeall the fact that of the gorges of $\mathrm{V}$-shape some are more open than others. The upper slopes of sueh gorges are often well rounded. As time goes on, much rock weathers away on the sides of the valley, and steadily slips down toward the stream and is carried away. Thus by degrees the gorge be- 
comes an open valley. It is profitable to picture to ourselves such growth of a wide valley out of a narrow, steepwalled gorge. And it is well in our walks and travels to

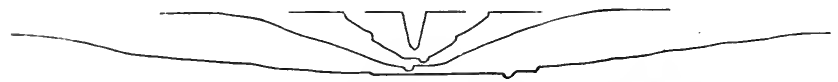

Fig. 27.-Profiles across a valley at different stages of development.

wateh for valleys which are neither very narrow nor very wide, but are in middle stages of growth.

36. Open valleys. - As the valley broadens, the slopes of the valley sides become gentle. Here and there may be steep bluffs of small extent, but the general inclination is quite moderate. In field excursions cross profiles of narrow and wide valleys should often be drawn. On the sides of open valleys rocky ledges may oceur, showing that a perfect grade has not been reached. But with time enough, such ledges will crumble and a perfect slope of soil or coarser waste will appear.

The river in such a valley commonly flows on a floor of waste which it has laid down. Here and there it may cross rocky ledges, giving rise to rapids such as are more commonly seen in gorges. Above each rapid is a stretch of nearly still water, giving us an alternating series of rapids and "reaches." Hence the "portages" so common in canoeing trips, and which form a feature in primitive carriage of goods by water. Many of these portages, as at Little Falls and Cohoes on the Mohawk, were early superseded by canals. Even if there are no ledges of rock, there are still alternations of rapid and reach; but these are low-water features only. At high stage the forward slope of the water surface is nearly even, but there are differences in the current, causing bars of waste to form here and there; and at each of these bars a rapid appears when the flood has passed. It is instructive to study a familiar creek when its banks are full, and see how little trace remains of wellknown deeps and shoals. 
A large river may be many feet deep, and is often a halfmile or more in width. A few great rivers like the Amazon show a width of many miles at their seaward ends. The stream is bordered by banks varying from a few feet to twenty or more in height. These banks are the edges of nearly flat grounds which stretch away to the base of the valley slopes. These are known as-

3\%. Flood-plains.-Commonly the water is confined between the banks, but in the spring, or after great rains, the stream passes its banks and floods the strips of flat ground

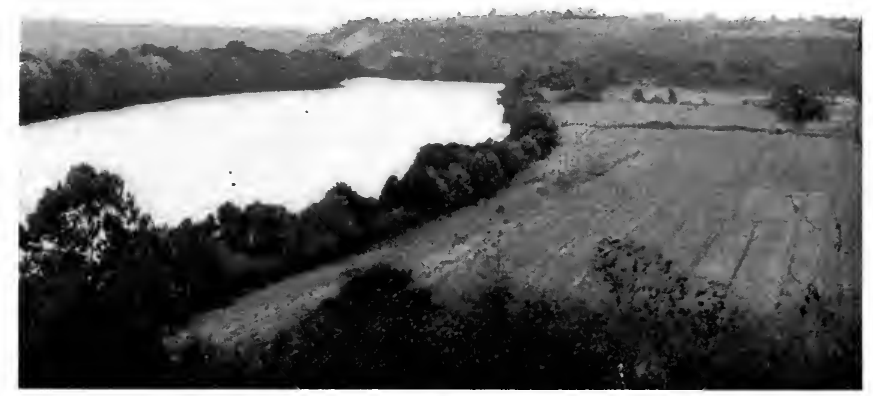

Fig. 28.-Flood-plain of the James River, Va.

on either hand. At such times the river is charged with mud, and a layer of this fine material is spread over the flooded grounds. Thus when the water retires, it leaves them a little higher than before. The deposit consists of fine waste, largely derived from soils of the uplands. It thus constantly adds to the fertility of the lowlands, which 
bear rank forests, and when these are cleared yield perennial harvests. They are easily tilled, and are usually the lands first occupied in a new country. Their smooth surfaces offer natural grades for the primitive wagon and stage,

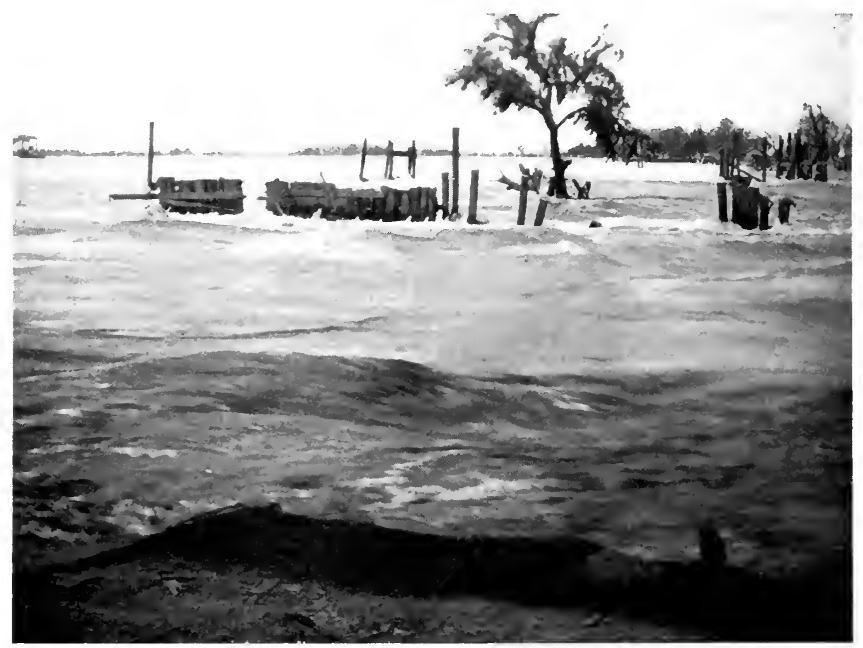

FIG. 29.-Scene on the Mississippi during a great flood. Overflowing a levee, the water tears out a section of it and spreads over the plain.

as for the railway of later days. If the stream is navigable, the products of the valley may be easily and cheaply exchanged for needed articles from distant regions. A large share of the population of most countries is found on the flood-plains of rivers. These strips of low ground, therefore, have great interest to the geographer. The student should examine the atlas sheets of the United States Geological Survey for these forms. The Missouri River in Missouri will be found to have flood-plains varying from $1 \frac{1}{2}$ to 8 miles in width. The flood-plains of the Illinois River are more than a mile wide at Lasalle (see map, Fig. 11) and Ottawa and are three miles wide at Chillicothe. That 
of the Mississippi is 6 miles wide, near Clinton, Iowa, and much wider than this in its lower course. The middle Rhine exhibits one of the most carefully tilled and thickly settled flood-plains of Europe, while Egypt as a habitable and productive land consists chiefly of the flood and delta plains of the Nile.

Along a large river the flood-plain is higher next the stream, because there the waste first lodges in times of overflow, and the plain slopes gently thence to the valley sides. Such a strip of higher ground, from its resemblance to a dike thrown up to restrain floods, is called a "natural levee." It often happens that the outer parts of the plain are flooded while long strips of natural levee appear between the back water and the main channel, and therefore the farmers of a great flood-plain build their houses close to the river.

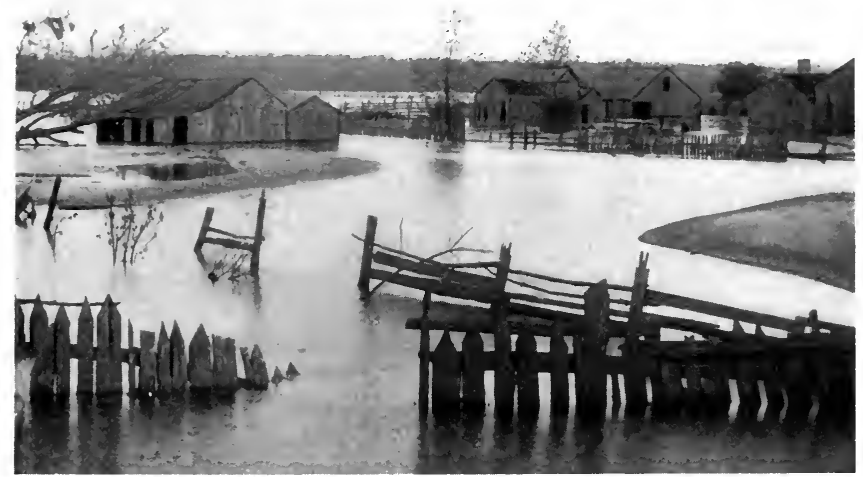

Fig. 30.-Scene on the flood-plain of the Mississippi after a break in the levee.

38. Floods.-Since so many people live on flood-plains and the most important industries of town and country are 
often centered there, floods become most destructive, and to deal with them is a problem of greatest importance. The Genesee, usually a little river, is sometimes two miles wide on its flood-grounds in Livingston County, and oceupies, once or twice in a generation, streets and stores in Rochester. The Ohio River, fed by swift streams, rises 50 feet above its normal surface at Cincinnati. The Mississippi, enlarged by the melting snows of the Appalachians and the Rocky Mountains, is subject to enormous floods. The great flood of 1897 covered 13,000 square miles, and destroyed $\$ 15,000,000$ worth of property. This flood was carefully studied, and the officiai report upon it, issued by the United States Weather Bureau, forms a large volume. The Weather Bureau is able in some measure to predict such floods, to the saving of much life and property.

We should not forget, however, that floods are beneficent, since river plains are made and kept fertile by them. The annual flood of the Nile, rising 25 feet at Cairo, enriching

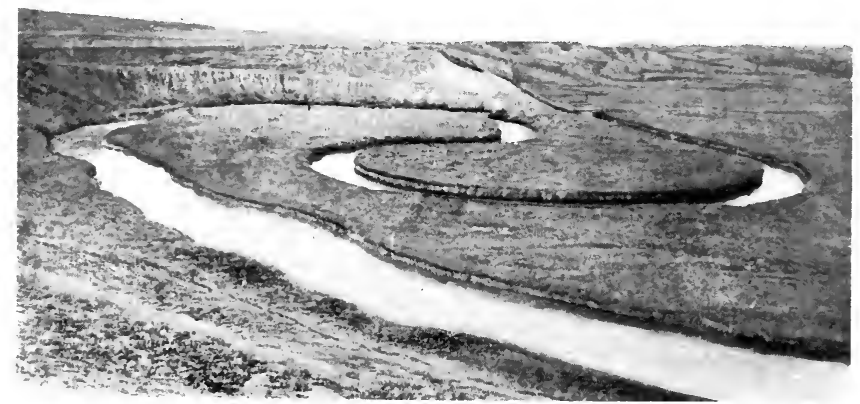

FIG. 31.-Meanders of 'Trout Creek, Yellowstone Park.

and watering the land and supporting millions of people, is a conspicuous illustration. The evils of floods are to be largely eseaped by prediction, by the making of levees, by 
protecting river-banks against wear, and by avoiding the lowest levels in the making of homes. We should not forget to observe that a river which passes through great lakes, as the St. Lawrence, has its flow equalized, and its lower course is thus free from floods.

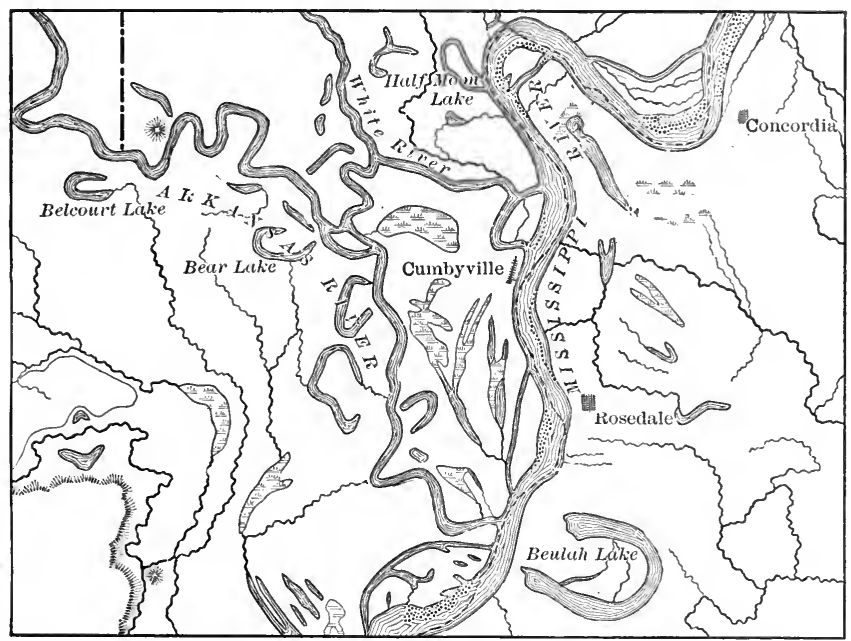

FIG. 32.-Junction of the Mississippi and Arkansas rivers ; showing meanders, oxbow lakes, and river swamps. The swing of the meander is in proportion to the size of the river. Scale, 1 ineh $=\tau$ miles.

39. Meanders. - Many rivers, as they traverse their floodplains, swing to right and left in strong curves. Thus the distance from Cairo, Ill., to the Gulf of Mexico is about 500 miles, but by the river one travels over 1,000 miles. The breadth of these swings of the Mississippi is from 3 to 6 miles. On the outside of the curves there is deep water and a steep bank, at which landings are possible for steamboats. On the inner side is a sloping beach passing beneath shallow water. The river cuts away the outer shore and adds to the other, and thus widens the belt of curves or Meanders, as they are called, from a winding river 


\section{(1)} $12 x+y^{2}$

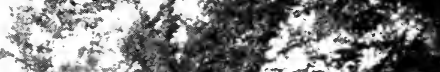
Hor 20 and

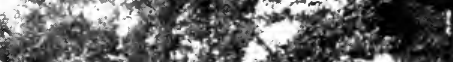

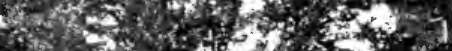

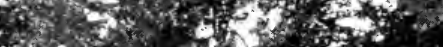

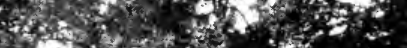

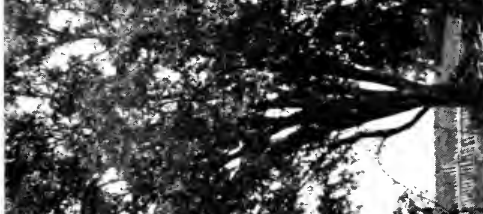

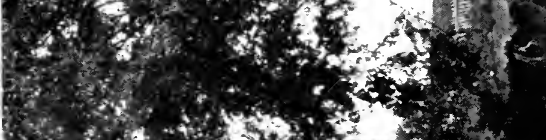

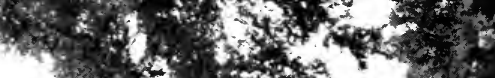

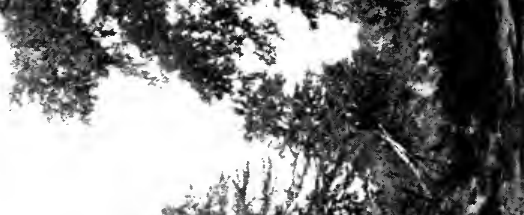

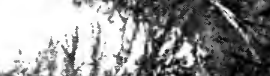

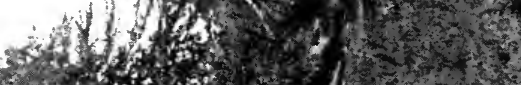

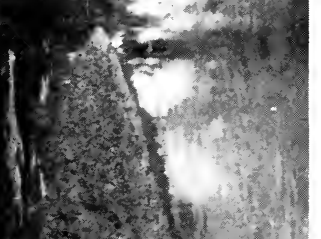

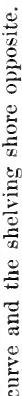

$\cong$

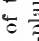

莺兽

ซ

$\stackrel{0}{ \pm 0}$

ฮ

光芯

空 क

월

प्ष

政

$\stackrel{8}{\circ}$

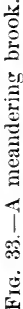

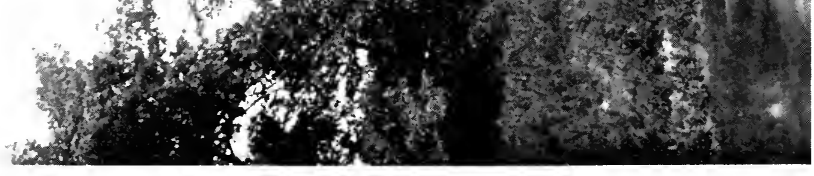

6. $6 x+2$

(x)

x m n

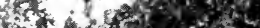


of Asia Minor. Little by little, however, the tongue of land that reaches into a great bend is narrowed at its base, by the growth of other bends, until at last the neck is cut away, and the river track is shortened. By such a "cut-off" of one of the great Mississippi meanders, the river may be shortened at a given point by 15 or 20 miles. The curving channel thus abandoned by the current is soon partitioned from the river by the growth of a barrier of waste, and becomes an "ox-bow" lake (Fig. 32).

The Mississippi has been taken as an example, and there is advantage in its study because its importance has caused the making of elaborate maps, but the meandering habit is not limited to great rivers. It is as perfectly seen in rivers of moderate size, and in brooks, as along the Mississippi or Lower Arkansas. The width of the swing will depend on the size of the stream. It may be a few rods for a brook and miles for a great river.

40. Meanders sunk in a plateau.-Fig. 34 shows how the Caney Fork has sunk its channel into the plateau country in eastern Tennessee

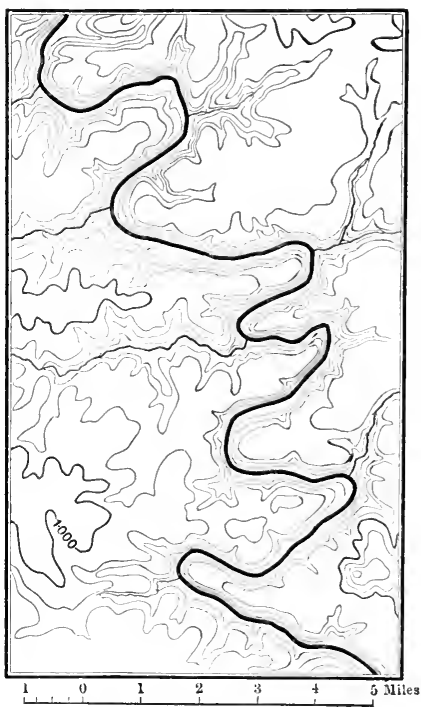

Contour Interval 100 feet

Fig. 34.-Nap showing bends of Caney Fork. The river has made a gorge 300 to 400 feet deep, but keeps the bends it gained as a meandering stream on the plain above. on its way to the Cumberland. Gaining its sinuous eourse on a once smooth surface, it has kept it, as it wears its channel down toward the sea-level. The east branch of the Susquehamna River in northern Pennsylvania and the Osage River in Missouri show the same conditions. 
A good description of the unstable course of the Mississippi is found in Mark Twain's Life on the Mississippi. The author describes the feelings of a man who wakes to find that the river has changed its course in the night and transferred his plantation from Louisiana to Mississippi, and vivid emphasis is put upon the difficulties of the "cub" pilot in learning the river.

We have yet to notice a most important result of these river swings. Their development not only varies the route of the water, but carries it sooner or later to all parts of the valley floor. Coming to the edge of the flood-plain, the river cuts a slice out of the valley slope, now on this side and now on that, and thus meandering has much to do with making narrow valleys grow wide. The student will not need to search long to find lagoon lakes, abandoned chan-
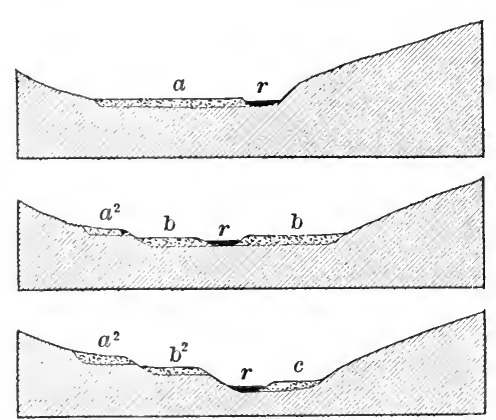

Fig. 35.-Cross-profiles of a valley at three stages of development, to show how river terraces are made. $r$, river. $a, b, c$, successive flood-plains. $a^{2}, b^{2}$, remnants of first and second flood-plains, remaining as terraces. nels, and curved bluffs, cut by the swinging. stream from the sides of a valley.

\section{River terraces.-} We have seen that in each flood the river spreads a film of mud over its flood-plain and raises its surface. At the same time it is often sinking its bed. Hence a time will come when flood-waters will not rise on the flood-plain. They will, instead, cut into its edges and trim much of it away, and out of this waste and that brought from up-stream will form a new flood-ground. The remnants of the higher, forsaken plain are known as River or Alluvial Terraces. Several sets of them, at successive levels, are seen in the valley of the Connecticut and 


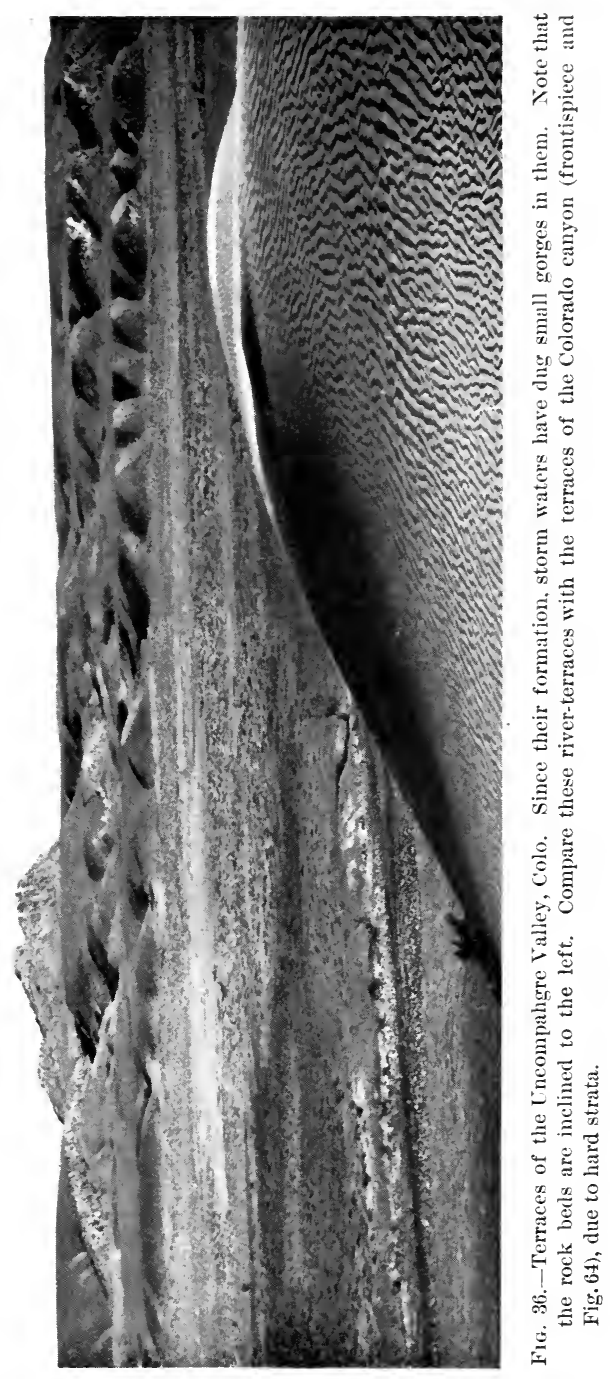




\section{AN INTRODUCTION TO PIIYSICAL GEOGRAPHY}

along other rivers. They are not often important in size, but may afford good sites for single homes or parts of towns.

42. Deltas. - Gathering its tribute of land-waste from the Appalachian and Rocky Mountains, and from the plateaus

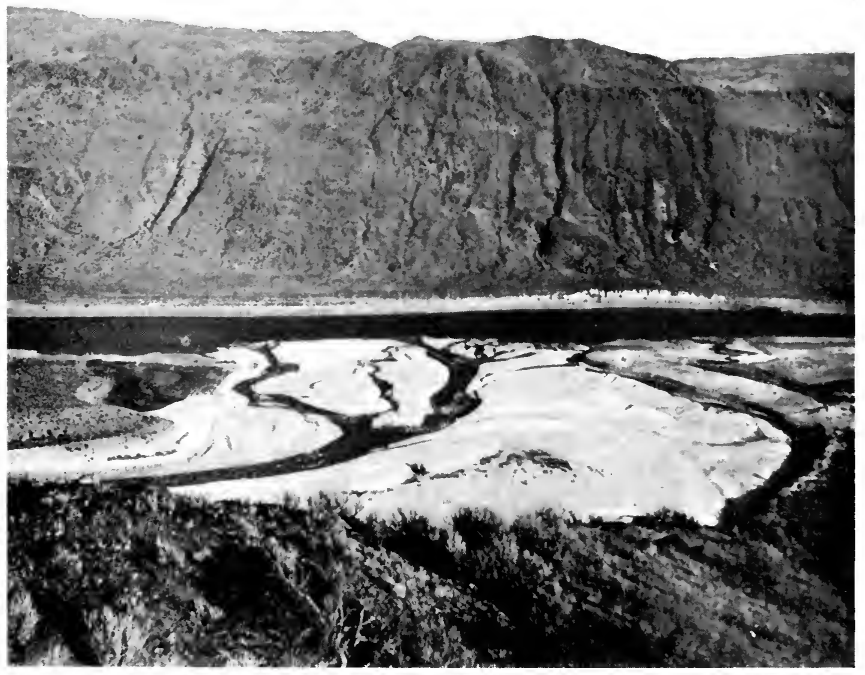

FIG. 37.-Delta formed by Chelan River where it enters the Columbia. Note the distributaries. The white area was overrun by a recent flood which deposited much gravel and buried all vegetation.

and prairies that lie between, the Mississippi River lays down its burden on the plain of the lower valley and at the borders of the Gulf of Mexico. Even its finest mud sinks 
to the bottom as the flowing river unites with the standing water of the sea, and a shoal is thus built up, to become at

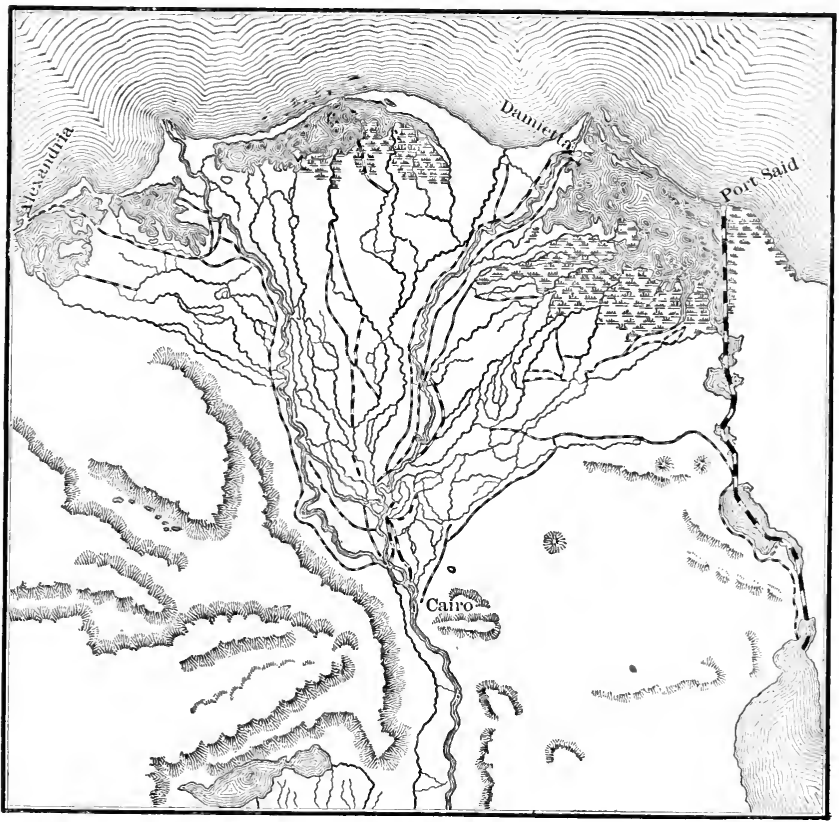

Fig. 38.-Delta of the Nile. Note the fan-shape, with the apex at Cairo. The distributaries are many. Capes are built into the sea at the main months. There are many railways, because the fertile soil supports a large population.

last a part of the land. So the river-plain is built higher and is also extended southward. The growing plain is called a Delta. The river, building its channel above the adjoining land, breaks through its banks at various points and discharges part of its water by down-stream branches. These are locally called Bayous, but are more widely known as Distributaries, a name which distinguishes them from upstream branches or tributaries. Not only the land, but the sea-bottom, for a long way out, belongs properly to the 
delta, its materials having come down the river. More than 1,000 feet of such deposits are disclosed by an artesian well boring at New Orleans. Two great problems are always presented by the Mississippi delta: 'To protect the lands from flood, wherefore levees are made at great expense ; and to keep an open channel for navigation, wherefore jetties, or artificial banks, have been built along one of the "passes" at the river-mouth, to confine and quicken the flow, and thus scour and deepen the channel.

Other deltas must be more briefly described. The Yukon has one of the great deltas of the world, giving off its first distributary 100 miles from the coast. Its delta is a Tundra, or plain that is always frozen below, though clothed in summer with grass and flowers (see page 155). The delta of the Colorado, though large, is not so evident on a map, because it is filling the head of the Gulf of California rather than building an extension in the open sea. The Nile, the Po, the Tiber, and the Rhone deltas are notable examples, and interesting facts about them should be sought in encyclopedias and other books of reference. The Ganges, Brahmaputra, and Hoang-Ho are enormous deltas of the Asiatic sea-border.

43. Deltas on lake borders.-It must not be thought that all deltas contain hundreds or thousands of square

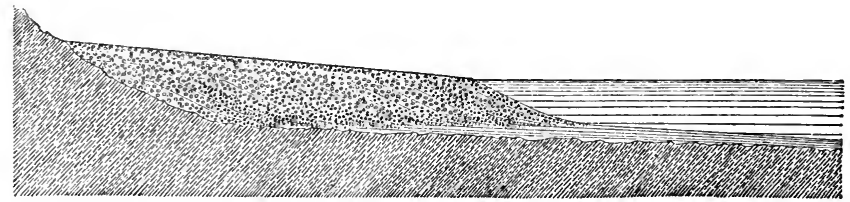

Fig. 39. -Section of a delta made of gravel and sand.

miles or are built on the borders of the ocean. Many are seen on the shores of lakes, and when a swift upland stream is there suddenly checked the delta will contain sand, gravel, and boulders, and thus be different from the ma- 
rine delta. Its form will be different also, and instead of the delta surface passing smoothly down to the bottom of the water, it will have an abrupt slope in front. When the stream, pushing for a little way through the shallow water,

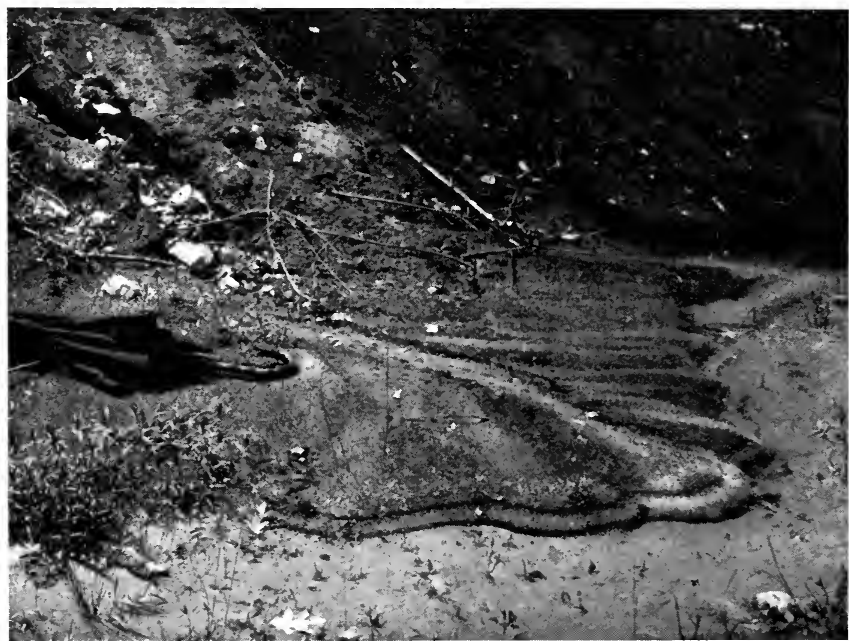

Fig. 40.-Miniature delta. During a rain a pool was formed at the foot of a steep slope of earth. A rill dug a miniature gorge in the slope and washed the waste to the pool, where it built a delta. Before the pool dried away the wind made wavelets, which carved a shore terrace about the edge of the delta.

reaches the brink, its load will settle and slide down the incline, much as teams and wagons make a "fill" in carrying a road grade across a gorge. The interior structure, if we should slice the delta through, would appear as in Fig. 39. The stream will swing from one line to another, building up the delta on different parts of its front, and shaping that front into a series of lobes. All of these features can be seen in miniature after a wayside pool, receiving a wet-weather torrent, has dried away (Fig. 40).

44. Young, mature, and old valleys.-These are important terms in physical geography, and we are now prepared 
to understand them. They are useful because they express the great fact that the forms of the land are changing, or having a development which can be traced, somewhat as we follow the growth of a plant or the history of a town. They are used, as we shall see, not only of valleys, but of other land forms, as plateaus or mountains.

A young valley is narrow, has steep sides, and carries a vigorous stream flowing on an uneven floor. The gorges already named are illustrations. A mature valley is deep, but open also, having flaring sides, and gentle, roundcd upper slopes. The valley of Seneca Lake is mature, but Watkins Glen, entering it, is young. The one was a river valley growing deeper and wider long before the Ice Age, while the other has been made since the glaciers disappeared. All the great valleys of New York and Pennsylvania are mature. The Shenandoah of Virginia and the Connecticut Valley in Massachusetts illustrate a similar degree of growth.

The Hudson Valley from Glens Falls to Newburg is 12 to 20 miles wide and is fully mature. Through the Highlands it is narrow and steep-walled, and we call it young. Here the case is different, however, for one part of the valley is perhaps as old in time as the other. The open part is cut in the soft rocks, which crumble readily away. The Highland gorge is cut in hard rocks, and the river's task, being slowly done, is less advanced. The gorge of the Mohawk at Little Falls, N. Y., is both younger in time and is cut in harder rocks, while the wide parts of the valley, as at Utica or Amsterdam, are in soft rocks and are older. But this can not be fully explained here. The development of a valley depends thus on the time for wear and the hardness or resistance of the rocks.

We have already seen how a narrow valley grows wide and a steep-walled valley becomes open. The floor of the valley is widened by the swing of the river in gentle curves or strong meanders, while the slopes are reduced by all the 


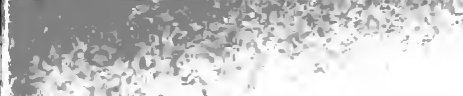$$
\therefore-a x^{2} x^{2}=0
$$

,

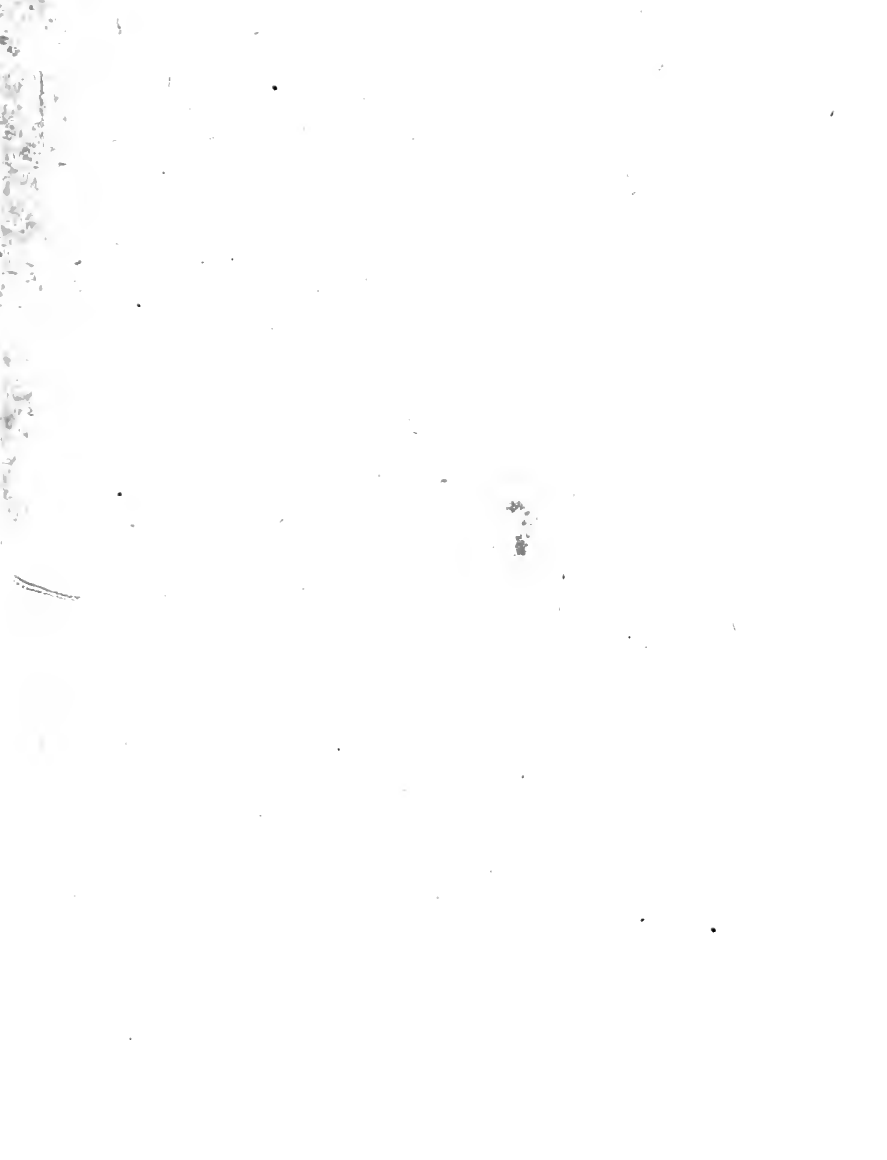




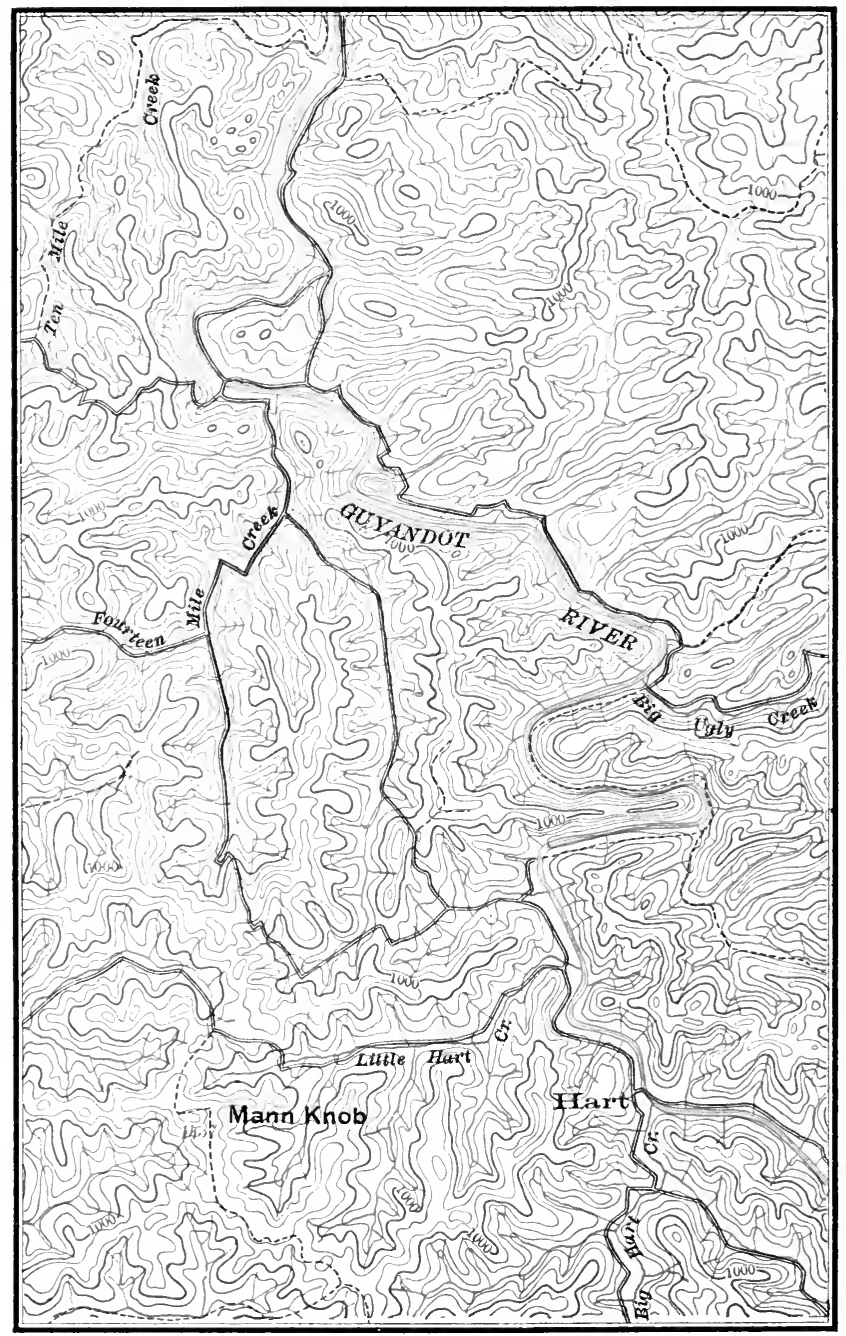

Frg. 41.-Map of part of West Virginia. Scale, 1 inch $=2$ miles. Contour interval, 100 feet. The streams have full possession of the land ; their gorges penetrate all parts of the plateau. Roads find better grades along the valleys than on the uneven divides. See Sec. 45. 
processes of decay or weathering, as described in the next chapter. At the same time rapids and falls disappear and the river comes to flow on a graded floor.

As the slopes fade out, the valleys become wide, the divides low, and the rivers sluggish, and the whole land surface passes into old age. The student should try to imagine the evolution of a valley from early youth through the various stages of maturity to old age.

45. The general work of a river system.-Let us picture to ourselves an elevated plain near the sea, and a branching river system formed upon it. Where the river descends steeply to the sea it will plow a gorge. This gorge will extend backward, up-stream, branching where the river branches, and its divisions will in time ramify throughout the river basin. While they are growing at the headwaters, the lower gorge will be changed to an open valley, and this broadening also will extend gradually up-stream. At first there will be remnants of plain between the gorges, but these will grow narrow as the gorges grow broad, and will finally be replaced by crested hills, which will then soften and sink with the flattening of valley slopes. All these changes will proceed from the trunk stream toward the confines of the basin and at last reach the outer divides separating the basin from other basins. Thus the whole plain will be at first furrowed and made rough, and the ridges between furrows will be afterward reduced so as to lessen the roughness. In a very long time the entire basin will be again made a plain, but the final plain will be much lower than the original, being but little above the level of the sea.

The great fact is, that the level of the land is slowly reduced and the waste is carried off to the sea-bottom. The uplands of New England, or Virginia, are now of moderate height. They were probably once much higher. The Highlands of Scotland are subdued lands. They may have towered like the Alps or Andes. Follow the river 
from the mountains to the sea. See the waste in talus and fan, terrace, flood-plain, and delta. But much of it has gone beyond the shore-line, and spreads far out to sea. We shall come to it again in our study of the ocean.

46. Imperfect development of drainage.-If the farmer has a swampy field, he opens a channel or a network of ditches and draws the surplus water away. He may even cut across a rim of higher ground if the cost be not too great. If human life were longer and he could afford to wait, nature would drain the swamp or pond for him. Some stream would head into it and carry away the waters. So, wherever we see water standing on the land in lake or swamp, we must understand that the drainage is still imperfect, that the river system has not yet developed its branches in a mature way and taken possession.

47. Lakes.-These are illustrations of imperfect drainage, and if many are present they stamp a region as having a young surface. Lake basins are depressions which detain the waters from passing directly to the sea. They are made in many ways which can not be fully described in an elementary book. The greater number are due to the glacial invasion and will be explained in a later chapter. Some, like Great Salt Lake and the Dead Sea, are due to bendings or unequal movements of the earth's crust. Small lakes sometimes occupy old volcanic craters (Fig. 147). Others lie in sink holes (Fig. 71), in regions of great caverns and the caving in of the surface rocks. Such lakes are common in Kentucky. We have seen how cut-offs in river valleys form ox-bow lakes. When we study the shores of the sea, we shall observe the making of lakes by shutting off the waters of deep bays. Alluvial cones at the mouths of some Swiss gorges are built across the main valleys, crowd the streams to the other side, and dam the waters coming from above. Landslips and lava floods blockade valleys into which they descend and make small lakes behind them. 


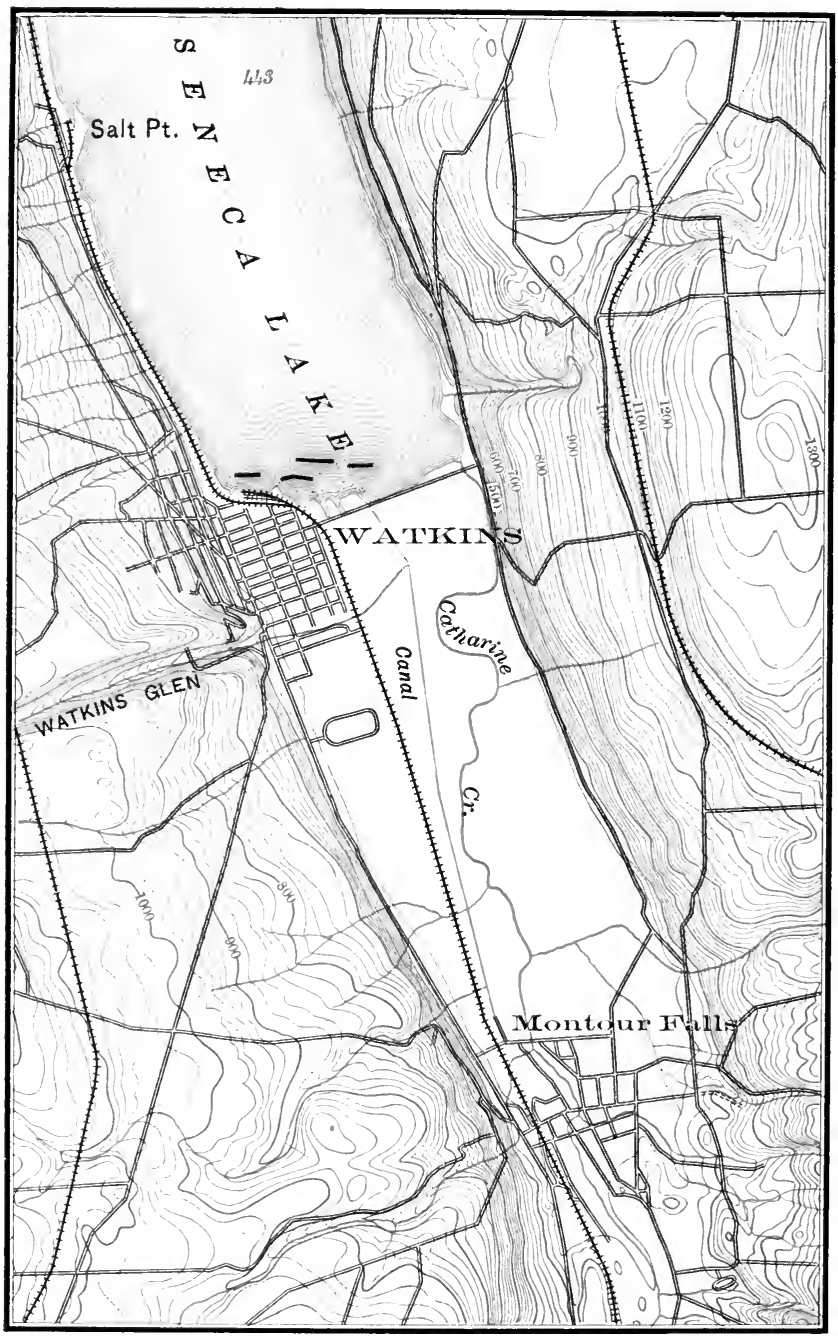

Frg. 42.-Head of Seneca Lake, New York. Scale, $1 \mathrm{inch}=1$ mile. Contour interval, 20 feet. Catharine and Watkins Creeks are bringing waste to fill the lake, and have already built the alluvial plain from Montour Falls to Watkins. 
48. Disappearance of lakes.-But we are here most concerned to see how lakes disappear as drainage becomes mature. If the rapids of the St. Lawrence and the rocks of the Thousand Islands should be cut away, Lake Ontario would be partly drained, but only in part, because about 400 feet of its depth are below sea-level. But when Niagara has finished its work the bed of Lake Erie will be dry, for its lowest point is more than 100 feet above the surface of Lake Ontario. This would take a long time, but the process is already complete with many small lakes, which once existed, but whose bottoms are now meadows.

This brings us to the second important way in which lakes disappear. Streams bring down their load and build deltas at the edge and spread the mud over the entire bottom. Water-loving plants grow about the edges and help to fill the shallow places. Small shell-making creatures abound in some lakes, and their crumbling remains form a white deposit of calcium carbonate or shell marl. Trees and leaves add their part, and at length the basin is full and the water is displaced. The sawing of outlet channels and the filling of basins are responsible for the disappearance of many lakes, and all stages of the process can be found by the observing student in the northern United States.

The vlies, or flat meadows of the Adirondack region in New York, represent filled lakes. Ithaca, N. Y., lies upon a broad delta formed at the head of Cayuga Lake, of waste brought in by several streams. Watkins occupies

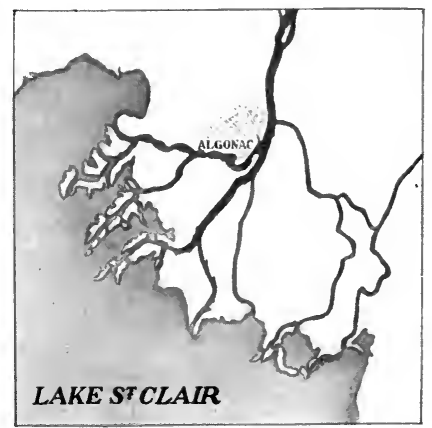

Fig. 43.--Delta of the St. Clair River. Scale, 1 inch $=11$ miles.

a similar delta at the head of Seneca Lake (Fig. 42). A delta is rapidly encroaching on Lake St. Clair (Fig. 43) 
The south end of Lake Lucerne in Switzerland is diminishing by the growth of a delta on which Flüelen and Altdorf stand. A similar shortening occurs where the Rhine enters Lake Constance and the Rhone, Lake Geneva.

49. Swamps. - All marsh lands are marks of imperfect drainage, and they often are due to the nearly completed filling of lakes. Others occur on flood-plains and deltas, and are due to wanderings and irregular deposits of streams. Swamps are often caused by checking of waterflow through the growth of trees and shrubs, and they disappear when forests are cut away. Swamps caused by the dams which beavers construct (Fig. 234) have a similar history.

50. Imperfect drainage on new lands.-Much of the flat ground along our Atlantic coast was formerly a part of the sea-bottom, and has been turned into land by the gentle rising of the continent. The streams have not had time to cover the surface with their head-waters. Hence the rain falling on the smooth areas between the streams evaporates, or drains off slowly underground. The same is true of the plains drained by the Maumee and the Red River of the North, except that these formed the beds of lakes and became land by the draining off of the waters. Compare the fully drained land of Fig. 41 with the scattered streams and smooth interstream surfaces of Fig. 44.

51. Arrangement of streams depending on the form of the rocks.-In northwestern Pennsylvania the rivers branch more and more as one goes toward the head-waters, just as boughs and twigs branch from the main limbs of a tree. The rocks there lie in nearly horizontal beds, and do not influence the ground plan of the streams. But in central Pennsylvania, where the beds are tilted and the country is traversed by alternating belts of strong and weak rocks, the arrangement of streams is different. Valleys have been opened in the belts of weak rocks, leaving the strong rocks prominent as mountain ridges. A few large trunk streams, like the Susquehanna and Lehigh Rivers, cross or cut through 


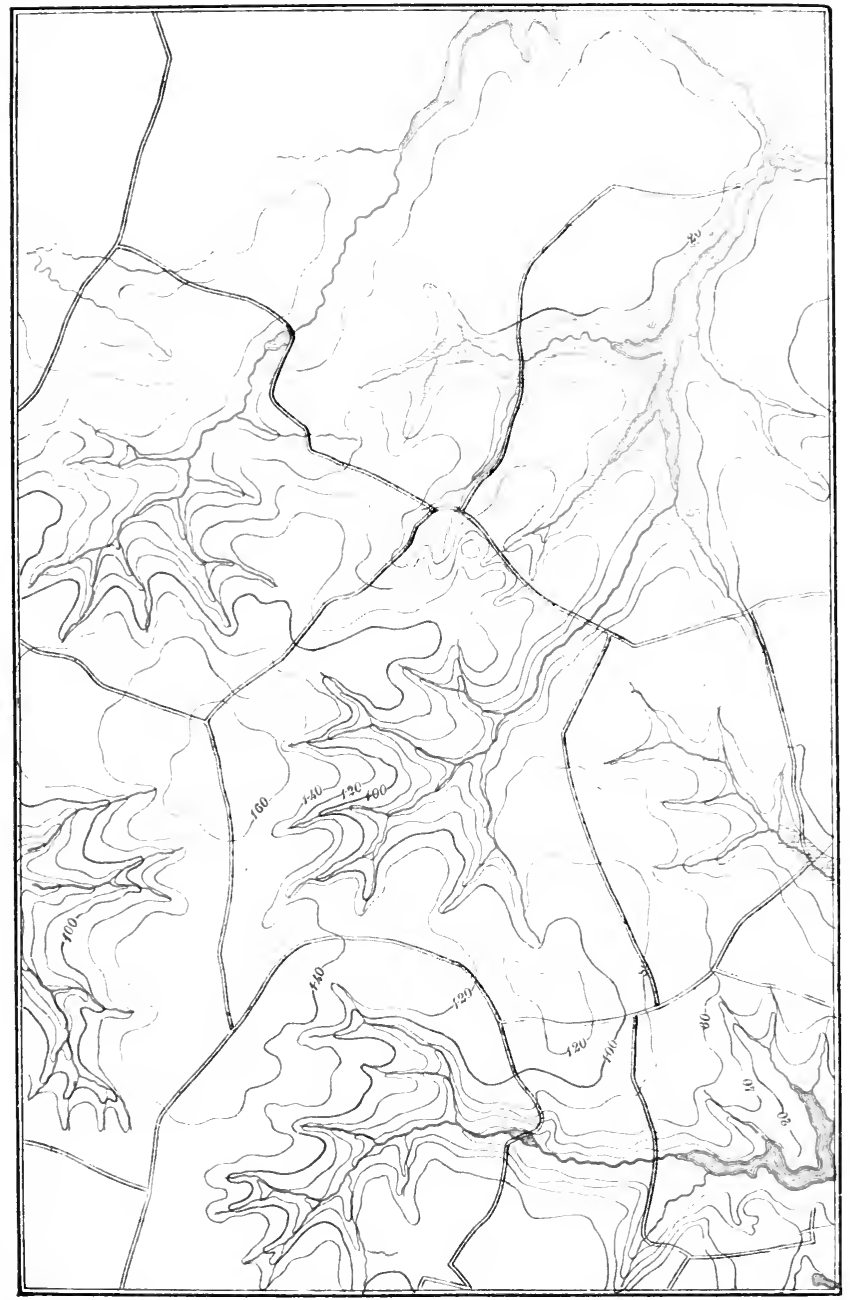

Frg. 44.-Part of Virginia, bordering the Potomac River. Scale, 1 inch $=1$ mile. Contour interval, 20 feet. Streams are developing their valleys by eating backward into the land, but tracts of the original plain remain. Roads find easy grades on the divides. See Sec. 50. 
the ridges without swerving, but most streams run parallel to them, following the belts of weak rock. It is common for a small stream flowing along a valley between two ridges to turn and pass by a "water-gap" through one of them. If a sketch map of the drainage be traced, to avoid

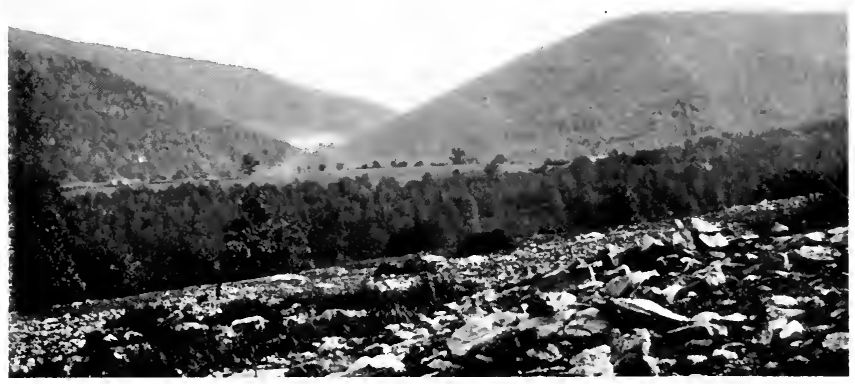

FiG. 45.-Delaware Water-Gap, a gorge through a mountain ridge, where the Delaware River passes from one open valley to another.

the confusion of other natural or political features of a map, the streams will form a network of rude right angles, and hence such drainage is often called Rectangular or Trellised, from its close resemblance to a grape-vine trained in that manner. The student should contrast the treepattern and trellis-pattern of drainage as seen in Figs. 46 and $4 \%$.

52. Drainage modified by rising and sinking of the lands. - It is well known that lands are sometimes higher and sometimes lower in relation to sea-level. Thus the geologists of New Jersey have found stumps of trees submerged in sea-water. Corduroy roads made in early days have also been covered, and the salt water comes farther into the mouths of streams than in former years. They have therefore concluded that the coast is slowly sinking; the rate 


\section{AN INTRODUCTION TO PHYSICAL GEOGRAPHY}

is about two feet in 100 years. There is another proof that the Atlantic coastal region has gone down. If the student will look at the map of Chesapeake Bay (Fig. 4\%) he will see that its ground-plan comprises a trunk with numerous branches. It is like a river system, except that trunk and branches are comparatively stout. If we imagine a stream system carving valleys at the sea-border, and then picture the sea-border as sinking so that the salt waters flow into the main valley and its tributaries, we shall get such a plan as Chesapeake Bay shows. This is the real history of the region, When the land stood higher the Susquehanna River flowed to the edge

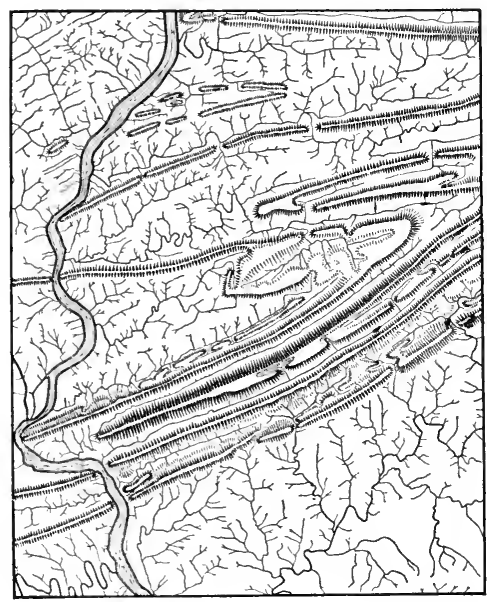

눈

FIg. 46.-Trellised drainage in central Pennsylvania. The conrse of the Susquehanna is independent of mountain ridges; other streams conform to them. Southeast of the ridges the rocks are less varied and the stream pattern is tree-like. of the ocean, and the Potomac and James were its branches. When the sinking of the land admitted the waters of the ocean the rivers all became tributary to Chesapeake Bay. Delaware Bay and Albemarle and Pamlico Sounds have the same origin. Geographers often speak of the "drowning" of river valleys by subsidence.

If, on the other hand, the land were to rise out of the sea, the edge of the sea-bed would be added to the land, and the rivers would flow out across the new land to the receding sea-border. As the land came up, the rivers would have to descend more to reach the sea. By reason of this greater 
descent they would flow faster, and begin to cut narrow channels again, where they had perhaps wandered over their deltas and swamp lands.

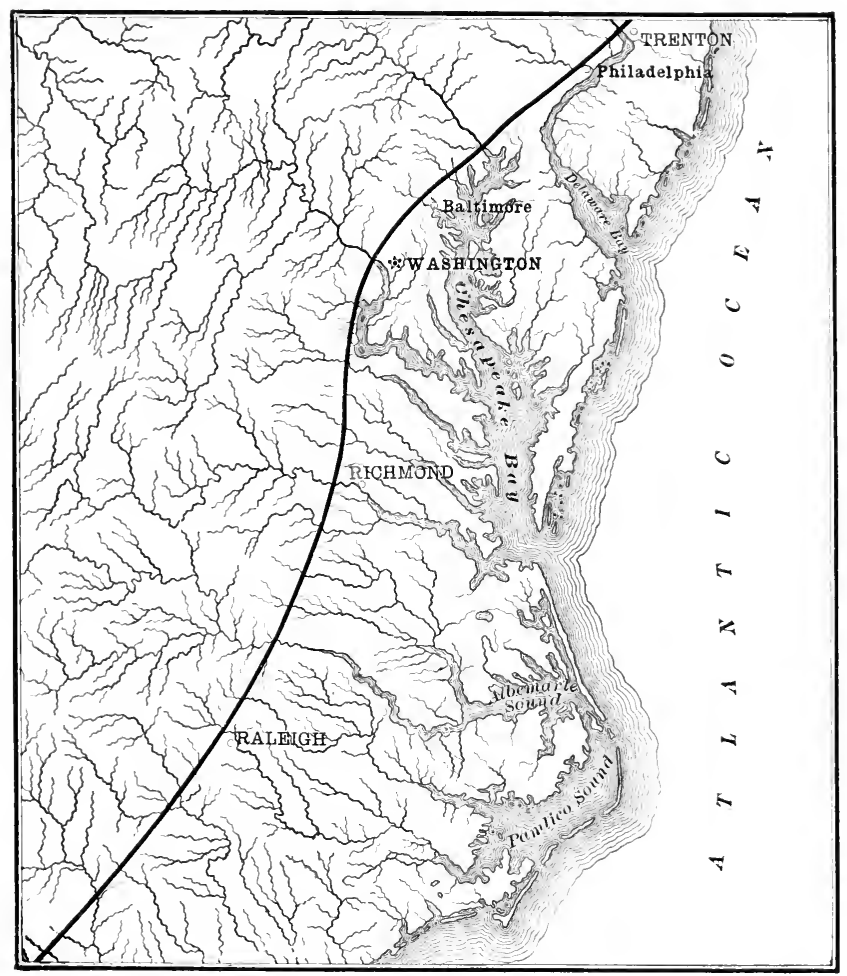

Fia. 47.-Coastal region from New Jersey to North Carolina. Scale, 1 incli $=110$ miles. The heavy line represents the Fall Line (Sec. 59). The bays are drowned valleys (Sec. 52). Along the belt of the Appalachian Mountains the stream patteru is trellised (See. 51), elsewhere tree-like.

53. Shifting of divides.-One of the more simple cases can best be explained by the diagram, Fig. 48. Let $A B C$ represent the profile of a region whose water-parting is at $B$, and which has a short steep slope $A B$, and a long gen- 
tle slope $B C$. It is clear that the streams coursing down $A B$ will be more swift and destructive than those flowing from $B$ to $C$. The land waste will be largely carried to $A$,

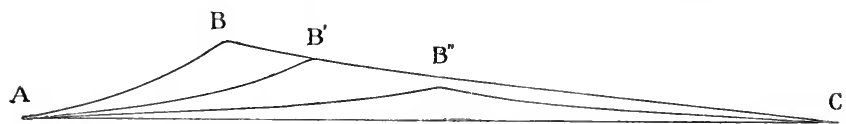

Frc. 48.-Cross-profile of a divide, showing changes in height and position.

and the divide will move to $B^{\prime}$ and then to $B^{\prime \prime}$. It will not stop until the slopes on its two sides are the same, but its shifting will be slow toward the last.

From near the east front of the Catskill Plateau Schoharie Creek flows northwest, then north, then east by the Mohawk to tide-water in the Hudson at Troy. Its broad, flat, upper valley is seen in the north part of the map on page 14 . But the east-flowing streams on the Catskill front reach tide-level in the Hudson in a few miles. They are therefore swift and vigorous, and they are cutting back great gorges and robbing territory from the Schoharie. In the same way the southern branches of the Mohawk are conquering land from the Susquehanna basin in central New York.

54. River systems.-The rest of this chapter will be given to a short review of the more important rivers of North America. Bringing from his school-work in geography a good knowledge of their directions, relative strength, and the extent of their basins, the student should now comprehend more fully their character. The divides should be traced and their character observed with all the helps obtainable, and careful study should be given to the drainage basin in which one lives.

55. The Mississippi system.-This single system well studied will give a nearly complete introduction to physical geography. Here we have the drainage of the central United States from the Appalachian to the Rocky Mountains. A relatively narrow belt on the north is tributary 
to the Great Lakes, and a similar small strip on the south drains to the Gulf by other streams. The source of the river is 1,680 feet above the sea, and it is fed by many lakes. These are of glacial origin, and all the upper part of the basin lies within the area modified by the great ice sheet. The upper river flows in a valley between rocky but often well-separated bluffs. At Minneapolis it enters a short gorge, where the old valley for a few miles was shut off by a mass of glacial waste, and the river forced to carve a new valley in the rocks. At some points on the borders of Iowa the valley is narrow, as if the same thing had happened there. The bluffs of the lower river, from the mouth of the Ohio, are cut in soft material, and give sites to such cities as Memphis, Natchez, and Vicksburg. The flood-plain is from 5 to 80 miles wide. Its broader and lower part is properly part of the delta, for a deep bay once reached up from the Gulf to the point where the Ohio now comes in, and this bay has gradually been filled by the waste the river has brought.

The Missouri is so much larger than the upper Mississippi that it might well be considered as the trunk stream. Here we find the torrent head-waters in the Rocky Mountains in Montana and Wyoming, followed by a long and comparatively sluggish course across the Great Plains, where the waters are heavy with waste, and can sink their valley but little below the general surface. The Platte River in Nebraska is noted for its great width and shallowness. The next great tributary is the Arkansas. This river has its torrential course in central Colorado, an open valley south from Leadville between mountain ranges, a deep transverse passage eastward by the Royal Gorge, and then resembles the Missouri in its long passage across the plains. In eastern Arkansas its flood-plains and cut-off lakes are like those of the lower Mississippi (Fig. 32). The Red River can only be named, and we pass to the eastern affluents. The Illinois River has cut a shallow valley 


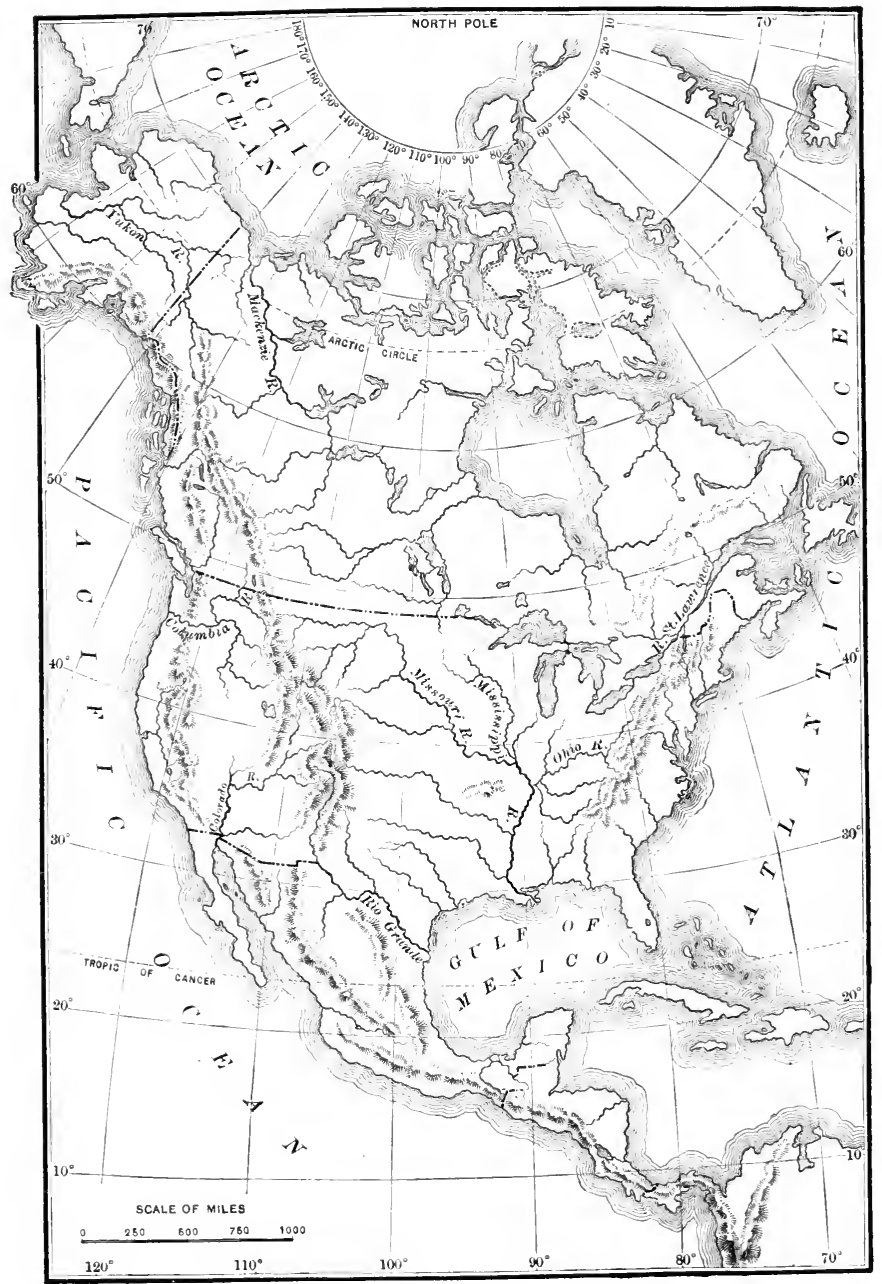

Fig. 49.-The rivers of North America. 
across the prairies and is interesting as having once carried much of the outflow from the Great Lakes region. The channel thus made, more than a mile broad, is seen in Fig. 11 as a valley between high bluffs, containing the modern flood-plain. The Ohio brings the waters from western Pennsylvania, from southwestern New York within eight miles of Lake Erie, from far-away Virginia through the Kanawha, and from western North Carolina by the curiously winding channel of the Tennessee.

The Mississippi is a continental river, with its myriad torrents in the mountains of east and west, its leisurely stretches across broad plateaus and plains on either hand, to the trunk channel, down which the ceaseless stream of water and land-waste pours into the Gulf.

56. St. Lawrence system.-It is useful to regard all of the Great Lakes as expansions of the St. Lawrence River. A great river system drained eastward over this region before the lakes were in existence. Portions of its valleys were deepened by the ice, and other portions were blockaded by rock-waste, and so the lakes came into being. In this view, the St. Louis River of Minnesota, the Sault St. Marie, the St. Clair, Detroit, and Niagara, and each great lake, are but different parts of the one great river. The river descends but 21 feet from the Superior to the Huron level, thence 8 feet to the Erie level, and 326 feet by Niagara River and Falls to Ontario. The gentle reaches and rapids below the Thousand Islands bring the river to tidelevel at Montreal. Thence the St. Lawrence valley is occupied by an inlet of the sea.

This is commercially the most important inland water system of the world. Here are the ports of Duluth, Milwankee, Chicago, Detroit, Cleveland, Buffalo, Montreal, and Quebec. The greater of these ports vie with New York, Liverpool, and Hamburg in the tonnage of their shipping. Over this route pass the iron ore of Minnesota, and the wheat and corn of the prairies and the plains. Such a 
body of waters penetrating the heart of North America may be compared, in its influence on the development of commerce and the shaping of history, to the English Channel and the North and Baltic Seas.

5\%. Drainage of New England.-The Penobscot and Kennebec, the Merrimac, Connecticut and Housatonic, all traverse the worn mountain and plateau region of northern and central New England, and reach the sea at the heads of narrow bays, which bear witness, like those of the St. Lawrence and Chesapeake, to the former elevation of the land and its later sinking. All of these rivers are actively deepening their upper courses, and many of them show fine terraces and flood-plains. The Connecticut has an open valley, carved out of soft rocks, from northern Massachusetts to Middletown, Conn.

58. Rivers of New York.-Though not a lofty upland, New York is remarkable for the wide dispersion of its waters, which flow to the Gulfs of St. Lawrence and Mexico, and to Chesapeake and Delaware Bays. Its chief internal river, the Hudson, is tidal for 150 miles, and has had much to do in determining the lines followed by early settlement and by later travel and commerce.

59. Rivers of the Southern Atlantic slope.-These rise in the Alleghany Plateau, as the Susquehanna and the Potomac, or in the Appalachian Mountain belt, as the Lehigh and Schuylkill. Still farther south the rivers rise in the mountains, traverse the low, worn Piedmont Plain, cross the "Fall Line," and run along tidal courses between flat grounds to the sea. The Fall Line is the boundary between an inner belt of older, harder rocks of higher surface, and the soft, low-lying rocks of the Atlantic Coastal Plain. The crossing is often marked by rapids, locating the head of navigation, affording water-power, and determining the sites of cities (Fig. 47).

60. The Colorado River.-This great stream drains much of Wyoming, Colorado, New Mexico, and Utah, and nearly 
all of Arizona. Its northern and northeastern branches head among mountains and course through gorges and high valleys. Its trunk first crosses a system of uplifted plateaus, through which it has excavated a series of profound canyons, and then traverses lowlands to the Gulf of California. The descent is great, being 6,000 feet from Green River City, Wyo., to the sea, while the Ohio-Mississippi in flowing from Pittsburg to the Gulf of Mexico, an equal distance, descends but 600 feet. The Grand Canyon, celebrated not only for its scenery, but as the most impressive of all examples of the work of rivers in making gorges, is at one point more than a mile in depth. Its lower part is there narrow and steep-walled, but above it opens widely, being elabo-

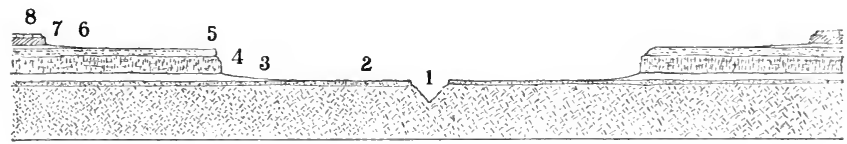

Fig. 50.-Cross-profile of the Grand Canyon of the Colorado River. Base-line represents sea-level. 1, granite; 2,5 , and 7 , sandstone ; 4 and 8 , limestone ; 3 and 6 , shale. Scale, 1 inch $=15,000$ feet. Compare with frontispiece and Fig. 64 . The frontispiece represents the inner gorge (1) and terrace (P), with the middle cliff (5) at left, and the upper cliff $(8)$ in the distance. Fig. 64 shows the upper and middle cliffs.

rately carved in alcoves, buttresses, and turrets (see the frontispiece and Fig. 64). The hard beds make conspicuous cliffs, and the soft beds are obscured by slopes of waste. The secret of the topography is in the dryness of the region and the vigor of the river. The general surface decays slowly, while the stream, fed with mountain rains and snows, and flowing rapidly, cuts into the rocks like a sharp steel saw.

61. Drainage of California. - At the east is a high mountain range, the Sierra Nevada. The Coast Range follows the ocean. Between the two is a long, wide, central valley drained southward by the Sacramento and northward by the San Joaquin. These rivers gather the torrent waters from both ranges of mountains, and come together at the 
head of a narrow bay connected with the Pacific by the Golden Gate. The mountains offer mineral wealth, and the streams have not only washed out the gold dust, but have formed the soil and furnish the water for the rich agriculture of the great valley.

62. Columbia River.-This stream heads on the western slopes of the Rocky Mountains and cuts across or through the Cascade Range by wild defiles. It receives as its chief

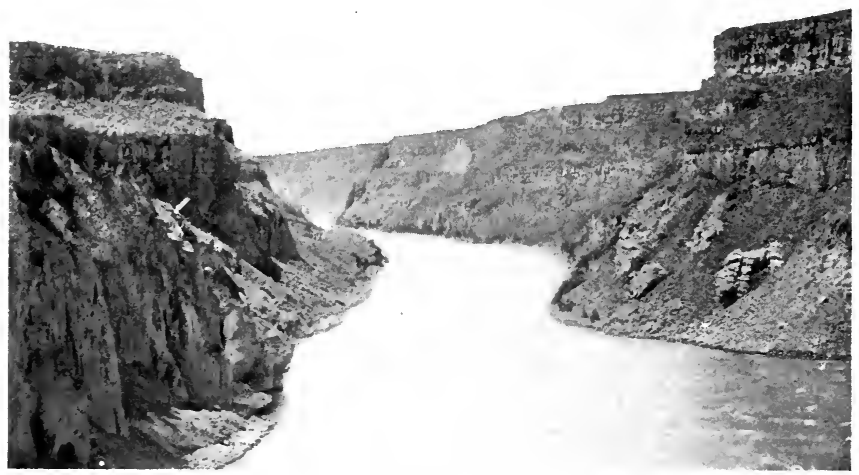

Fig. 51.-Canyon of Snake River, in Idaho.

tributary the Snake River. Over much of the valley of the Snake broad and deep floods of lava were poured in earlier times. Through these the river has carved a deep and very long gorge, which is only second in rank to the Grand Canyon of the Colorado. The Columbia River is affected by the tides to a distance of 140 miles from its mouth.

63. The Yukon.-In passing the Fraser, the Mackenzie, and the rivers of the Hudson Bay region with a bare mention, the student should not forget that they are important streams; but we turn now to the great Alaskan river. The 
Yukon is 2,000 miles long, and has a basin about one-third as large as that of the Mississippi. It is the artery of the great interior plains of Alaska, is navigable for 1,500 miles, and is therefore of great importance as a route of travel and commerce, despite the fact that it is closed by ice for more than half the year. As we have seen, it has built into Bering Sea a great delta. 


\section{CHAPTER IV}

\section{WEATHERING AND SOILS}

Is our study of streams we have seen that flowing water does not act alone in breaking up the rocks and changing the face of the earth. We now seek to understand that many forces work together to cause a wasting of the land surface. As all this work is done upon the rocks, we must study a few kinds of rock in order to see the nature of these changes.

64. Sandstone.-If we crush a piece of common sandstone and examine the fragments with a hand magnifier, we shall find them to be grains of sand similar to those we see in a sand-bank or on the beach. Commonly the grains consist largely of quartz, a mineral resembling glass, but much harder. Other mineral fragments occur, especially feldspar, but quartz is the more abundant. Upon the grains, if the stone is red, may be seen bits or patches of reddish substance. This is an oxid of iron and is the cement which held the grains together. Other substances, like calcium carbonate, may serve as a cement. This means that all sandstones once consisted of loose sand-grains which have been bound together by a cement.

If the student will search in a boulder heap, he will probably find some piece of sandstone which is so soft that it can be cut with a knife, or will even crumble in the hand. Here the cement is losing its hold, and the sand is going back to its old condition. Let us weigh a piece of dry sandstone, then soak it a day in water and weigh it again. We shall find that water has been absorbed, 74 
sometimes as much as one-eighth of the weight of the stone. This means that there is free space among the sand-grains, which water or air may enter. Suppose the stone freezes after absorbing the water. Expansion will take place and the sand-grains will tend to be thrust apart, and after many such wettings and freezings, the stone

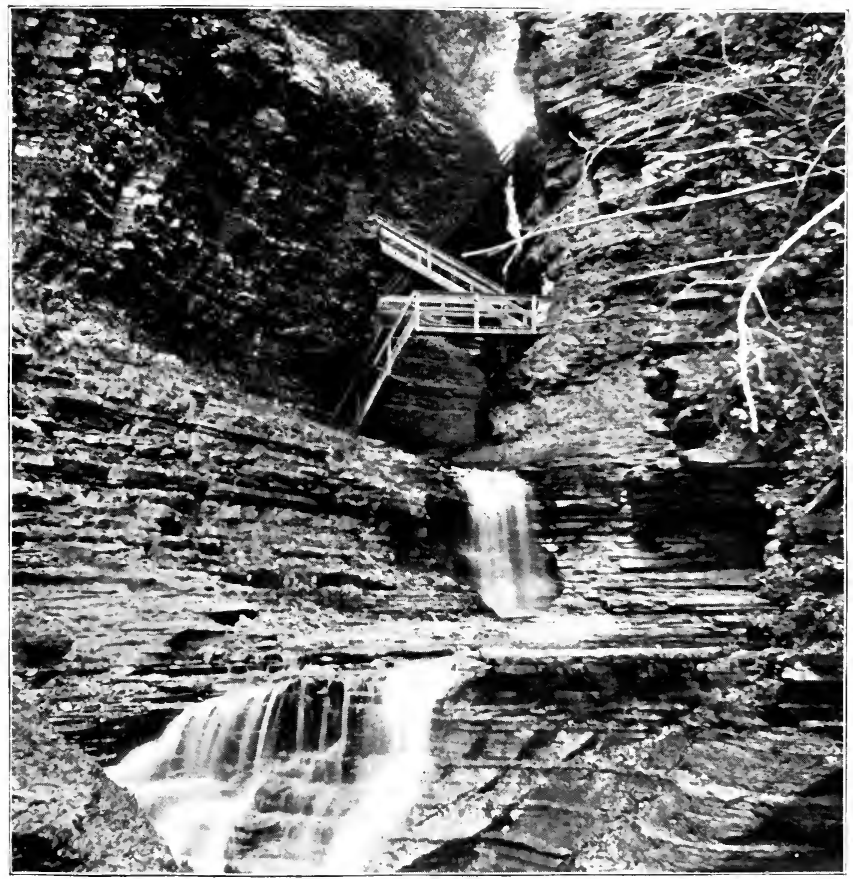

Fik. 52.-Watkins Gleu; a gorge earved from beds of shale.

will erumble. Hence a very porous sandstone is not a good building stone for outside work. A little seareh will discover sandstones, in buildings or other struetures, which show sealing. This is one of the ways in which the stone can be destroyed, but the fact most important to remember 
is that such rock is built out of small, separate grains and may return to its former condition.

65. Shale.-There is a very fine-grained, soft rock, which splits easily into thin leaves along its planes of bedding. In an exposed ledge, thin fragments and slivers of such a rock will have formed a slope of easily sliding waste, and such waste, used for mending roads, may swiftly turn into mud as rain falls on it and vehicles crush it. We call such rock Shale, and, like the sandstone, it consists of small bits of mineral bound together. The differences are: first, that the shale often contains much of the fine, smooth substance (an aluminum silieate) which is known as Clay, and, second, that the other minerals in the shale are more finely pulverized than the grains in a sandstone.

66. Limestone.-A soft mineral, known as calcium carbonate, makes up the bulk of this rock. It may have various colors, due to impurities which it contains, hence we see blue, gray, yellow, and black limestones. A very pure and light gray or white limestone, ealled Chalk, occurs in parts of Texas, Kansas, and Iowa, and especially in England. It is soft and fine-grained. Limestone is used for building, and is often "burnt" for quieklime. The burning changes the calcium carbonate to caleium oxid or lime. When greatly hardened and erystalline, we know it as Marble. Limestone will dissolve more readily in water than most other rocks (see Fig. 55). It was originally made by the deposit of the hard parts of lowly creatures. Such animals unconsciously gather dissolved ealcium carbonate from the waters in which they live, and build it into shells. Thus we see how limestones are brought together, and how they may waste and disappear again.

6\%. Granite.-The three kinds already studied are the chief rocks that are made or accumulated in water. Many rocks are the product of heat, either deep down in the crust of the earth, or acting in the outflow of lava from volcanic openings. Basalt belongs to the latter class. It is 
dark, heavy, and contains much iron. Granite is a common building stone, and samples may be seen by all. It belongs to the first-named class of igneous rocks, those formed far below the surface and brought to light by the removal, through the ages, of the overlying rocks.

The chief minerals in the common granite are three. If the student will look carefully he will see glassy bits of a very hard mineral. This is Quartz. He may also see a pink, greenish, or white mineral. This is Feldspar. There

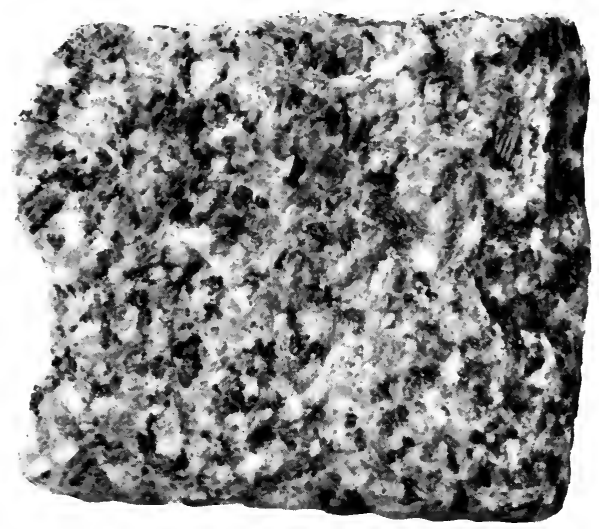

Fig. 53.-Granite.

are also scales, often very small, of the shiny, thin-splitting mineral known as Mica. These three minerals are massed together in finer or coarser fragments, to make up the rock. Anything that will tear these mineral bits apart will cause the rock to break down. One of the three, the feldspar, decays slowly under the weather, and much of it becomes in time a smooth clay. In the city of Washington there are places where the rotted granite could be excavated with a spade.

These are but a few out of many kinds of rocks, but they will serve as examples to show how all rocks are built 
up of mineral particles and may be broken down again. It is to such breaking down that the diversity of the earth's surface, the forms of its hills and mountains, and the existence of its mantle of soil, are largely due.

To a short study of these processes of destruction we now turn. Rocks are broken and worn by river action, as we have seen; and other chapters will show how they yield to the friction of glaciers and the pounding of seawaves. The destructive processes referred to in

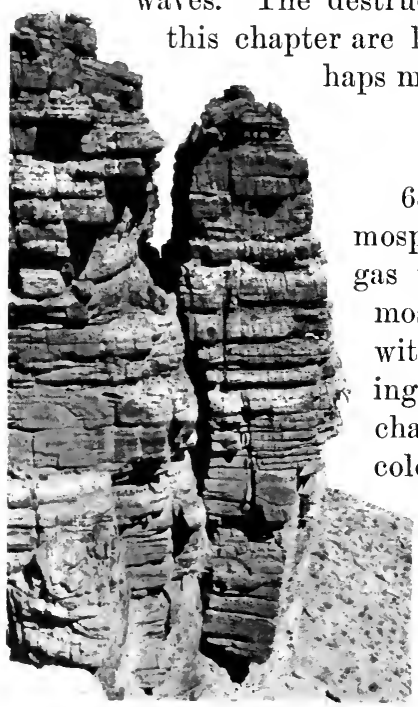

Fig. 54.-Weathered sandstone. The rock is composed of horizontal layers, and is divided by vertical joints. The weathering is most rapid along joints and at the divisions between layers.

\section{Surface Wasting}

68. The atmosphere. - Our atnosphere contains much oxygen, a gas which combines readily with most substances. When it unites with iron it causes rust, and rusting involves softening, and a change to dull brown or reddish color, in place of the former metallic luster. Most rocks contain iron in some form, the rusting of which causes the rocks to show stain and by and by to decay. This is one important case of Weathering, a term which is used to cover the softening and breaking up of rocks which in a number of ways goes on quietly at the surface of the earth. The surface of a stone block or boulder is often thus changed, while the inner parts, if opened to view by the hammer, show the true color and hardness of the rock. A bed of clay or sand is usually weathered to dull hues above, but re- 
mains of a bluish color below. This change is due to the oxygen of the air, which penetrates all parts not filled

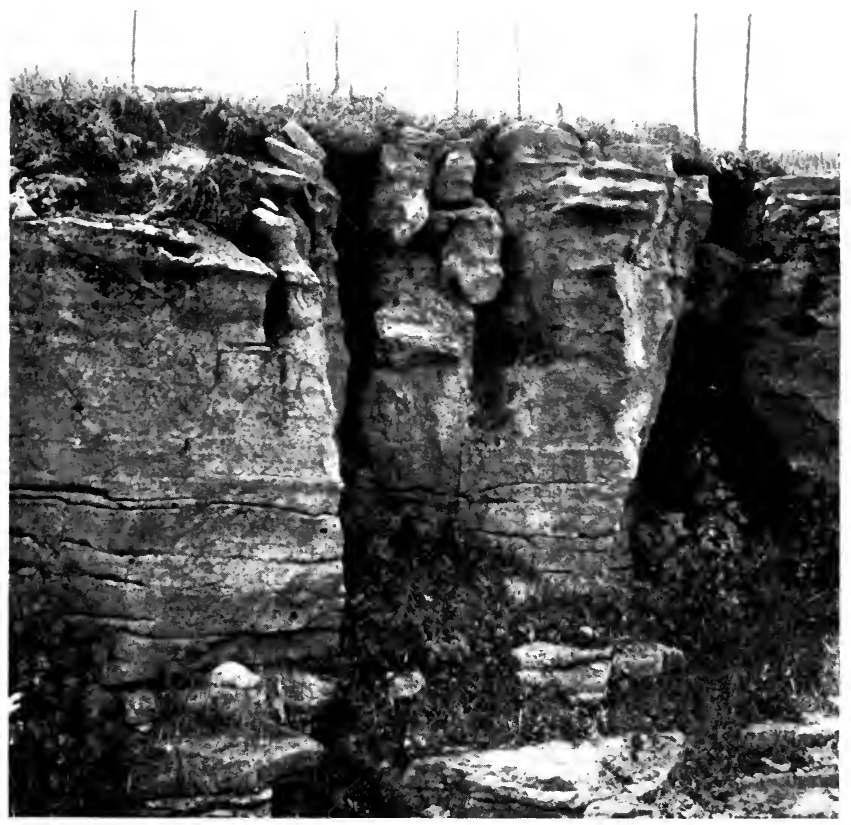

Fig. 55.-Weathered limestone. Wasting is by solution. Water finds readiest access along joints.

by water. Marble tombstones lose their polish after a few years. Rain and air, holding small amounts of carbon dioxid and other gases, dissolve a little of the surface and so remove the luster. Cleopatra's Needle, now standing in Central Park, New York, was preserved for many centuries in Egypt, because the air is there so dry and pure. But some protective wash had at once to be applied to the surface when exposed to the damper air of the Atlantic coast, especially where mingled with the 
gases that flow from the chimneys of a great city (see Fig. 5\%).

69. Rain wash.-Notice a bank of earth just after a heavy shower. The soil crumbles and its grains freely fall

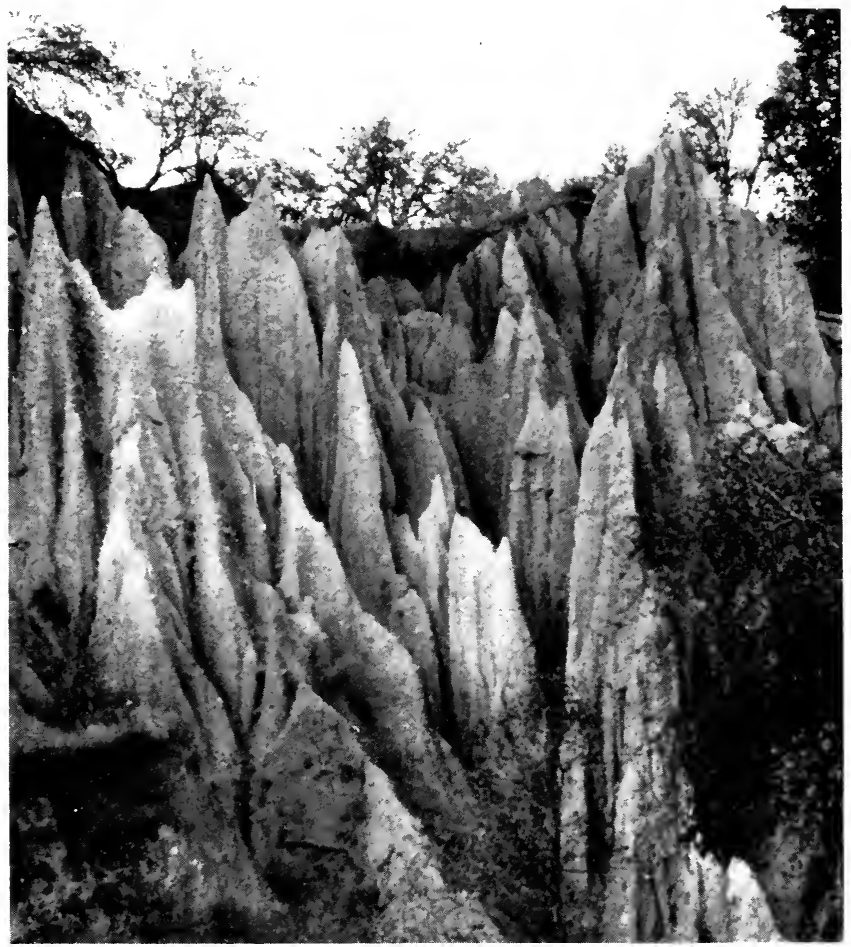

Fig. 56.-A pebbly rock carved by rain ; Russian River, Cal.

apart. There are small furrows or channels down the slope, and rills of water, still running in the channels, are dark with the grains of earth they have been able to pick up. Permanent streams work only on narrow strips of land, but rain soaks and softens the rocks and soil everywhere and 
gives the first start to loosened particles. The rain rills begin the great task of carrying which the creeks and river's continue.

70. Solution.-If a gallon of water from any stream or well were evaporated, a small amount of solid matter would be found. In a tea-kettle much water is evaporated, and still more in a steam-boiler, and the inner surface of each receives a hard coating. This solid matter has been dissolved from the rocks by water. Thus whether we observe that the damp air changes the polished marble to a dull surface, or remark that some water is "hard" and other is " soft," we are noting the effects of solution upon the rocks of the earth's crust.

71. Frost and changes of temperature.-The wasting of Cleopatra's Needle is due not only to the oxygen and other gases of the air, and to solution, but to the freezing and thawing of its moistened surface. Even in summer the heating and swelling under the hot sun of noon, and the cooling and shrinking of night, will make some rocks crack and flake. The student should examine stone buildings, and he will be sure to find cracks and signs of decay of which there was no indication when the buildings were made. Dr. Livingstone records in his notes such cracking of the rocks of Central Africa, where the noon temperature was $137^{\circ} \mathrm{F}$. The upper slopes and top of Pikes Peak are covered with a mantle of sharp-edged granite boulders riven from the bed-rock of the mountain by changes of temperature, together with the freezing of water which soaks into crevices (see Fig. 122).

72. Plants.-All trees which have strong tap-roots stir the earth to a considerable depth, and even grasses often send their slender roots two feet into the ground. When plants die their roots decay, and the process of decomposition produces new substances, some of which are powerful to produce decay in rocks. As trees and herbs grow everywhere, thrusting the earth apart by their roots, and 


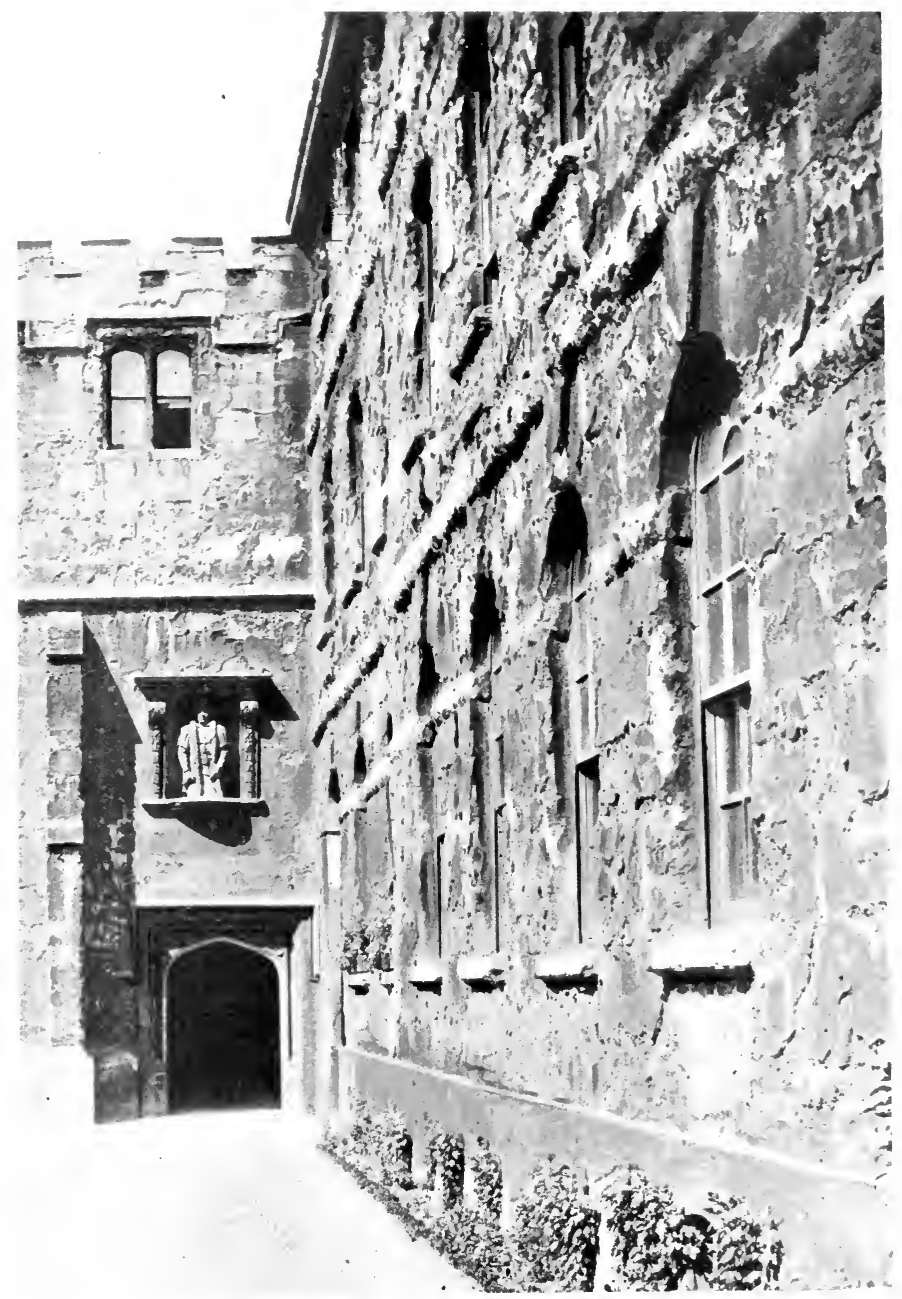

FIG. 5\%,-Weathering of limestone in the wall of an old building; Trinity College, Oxford, England. 
mixing with it in their decay, we can see that the influence of plants is almost universal.

A gorge should be visited and a study should be male of the roots of the trees on its steep slopes and crests. The roots thrust themselves far into the joints and planes of bedding and rend the rocks apart with great power. At the same time mosses mantle many rock surfaces, keeping them moist, and thus helping water to do its work of destruction.

73. Animals.-The prairie-dog is widely found in the western United States. It digs deep burrows, and easts up at the mouth of each one a mound of earth. The "villages" inhabited by these creatures sometimes cover many acres. Thus a large work is done by them in stirring

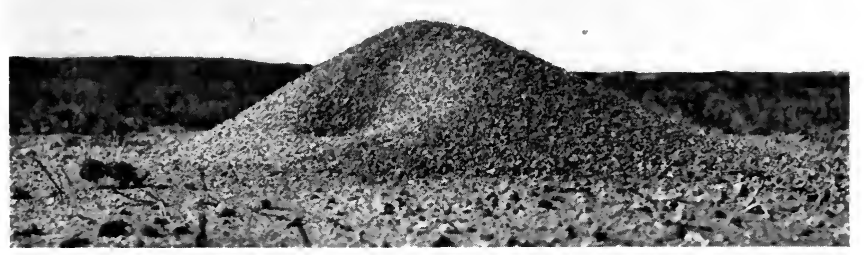

FIG. 58.-Ant-hill; Arkansas Valley, Colo. Height, about one foot.

the earth at its surface and a little below. Of similar effect is the work of woodchucks and the elaborate system of tunnels made by ground-moles. In like manner crawfishes burrow deeply, and it is said that they have even caused breaks in the levees of the Mississippi River. Beavers and muskrats earry on their operations at the borders of streams, and the beavers cut much small timber, flood many acres by their dams, and have been known to excavate canals for floating wood to their ponds (see Fig. 234). The hillocks built by ants are composed of sand-grains brought from 


\section{AN INTRODUCTION TO PHYSICAL GEOGRAPHY}

tunnels underground, and are in some places so numerous as to make a dotted pattern on the hillside.

Near the close of his life Darwin took to his publisher a manuscript of which he spoke in modest terms. It was published, and has become famous, because it shows how

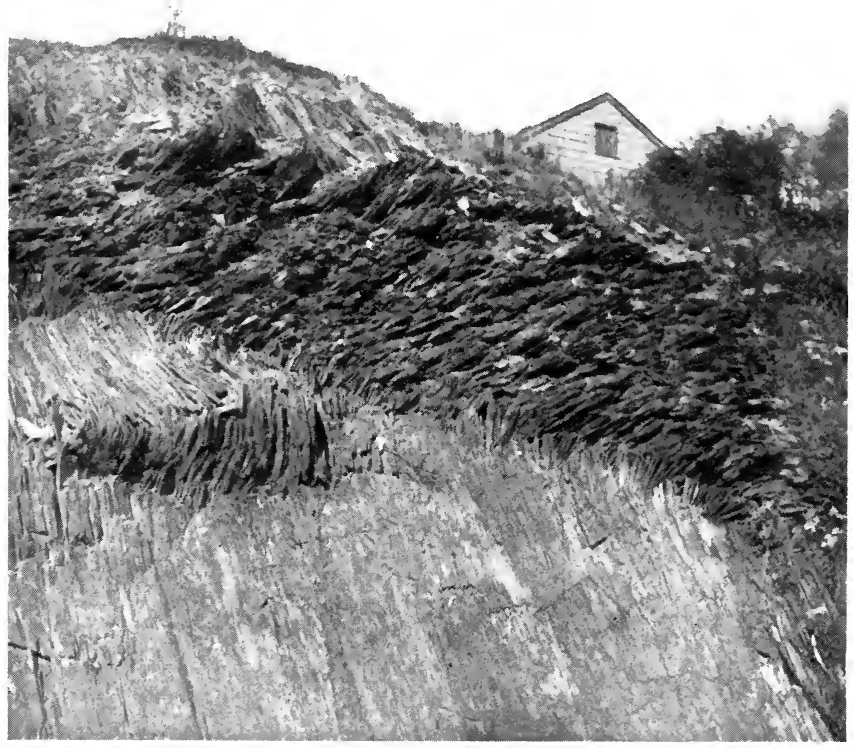

FıG. 59.-Shale broken by down-hill creep ; Columbia, Pa.

large a work the common earthworm does in pulverizing the soil and mingling the substances which compose it. And we must not fail to see in man himself a vigorous modifier of the earth's surface. He causes changes in 
many ways, but the most important is by clearing the forests and turning up the earth with the plow. Thus rains, frosts, winds, and surface streams, all are given a chance to work, and the decay and transfer of the materials of the earth's surface are much hastened.

74. Creep.-When the farmer runs a side-hill plow along a steep slope he turns the soil toward the bottom of the hill, and in so doing he assists in a work on which nature is ever engaged. As the friction between particles is lessened by the entrance of water, and as the soil is slightly moved by cooling and warming, freezing and thawing, its weight pulls steadily in one direction, and this causes a real but imperceptibly slow down-hill movement which we call Creep. On steep mountainsides this of course progresses less slowly than on ordinary sloping fields.

75. Rock falls. - Where rivers, or the sea, are undermining a cliff, or where a cliff has in any way been formed, masses of the upper rocks come to be insecurely supported. Frosts and roots use their thrusting power, joints are opened, and blocks tumble to the bottom. Thus gravitation aids in the destruction of the lands.

76. Avalanches.-Masses of snow losing their poise on high mountain slopes go down with fearful speed and destructive power. They cut such lanes through the forests as may be seen in the Rocky Mountains or the Alps (Fig. 60), and sweep rocks and earth in their course. The Swiss people set rows of strong stakes across the slopes where avalanches are in the habit of starting, and thus check the snows above their farm plots and villages.

7\%. Thickness of land waste.-When a surveyor or contractor estimates the cost of making railway cuttings or canals, he takes into account the thickness of the earthy mantle that covers the rock. The excavation may be partly in waste and partly in rock, according to its depth and the thickness of the waste cover. The latter varies much from point to point. In many valleys the deposits of 


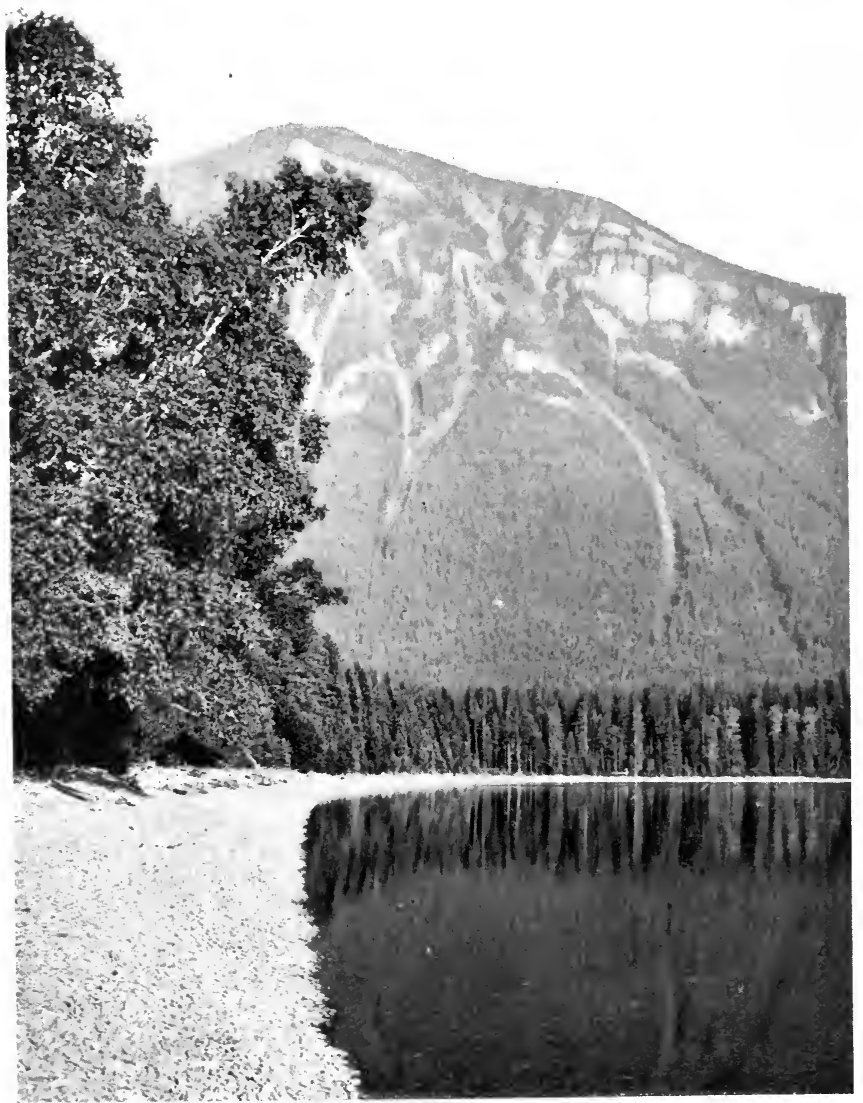

Fig. 60.-Avalanche tracks throngh a forest of fir ; northern Montana. The moun. taiuside was worn smooth and steep by a great glacier, and bears little soil. 
clay, sand, and gravel are several hundred feet deep. But often on the uplands and sometimes in valleys the rock comes to the surface. Thus the earthy cover varies from slight to great depth, but if we dig deep enough the solid rock will be found.

78. Local waste.-If a rock decays in its original place, as through wetting and drying, freezing and thawing, and the agency of roots, the earth and soil may be called local. Some of the materials once forming the surface will have been dissolved and carried away, but the parts not readily dissolved will remain. Hence the rock controls the soil. Such is the case with the soils of Kentucky and Tennessee. Limestones make the rich "Blue Grass region" of Kentucky, and sandstones make the poorer parts of the State.

79. Transported waste.-The soils of the central valley of California have mainly come down from the Sierras by the wash of the rivers. The soils of Lonisiana have been brought from the Rocky Mountains, from the Great Plains, from the prairies, and from the plateaus and mountains of the Appalachian region. They have been transferred by the Mississippi and its branches. The earthy mantle of Connecticut and Rhode Island is in part composed of rock flour and stones brought from Massachusetts and the northern New England States. The Connecticut and other rivers have done some of this work, but much more is due to the great glacier moving south over that region. In the northeastern United States all of the waste mantle is composed in part of local rocks, and in part of rocky matter moved from the north by glacier currents. We thus speak of transported waste, or Drift, a word especially applied to material moved by glaciers.

\section{Land Forms Due to Surface Wasting}

80. Mountains.-The Catskill Mountains of New York, or Greylock, Wachusett, and Monadnock in New England, do not stand forth as mountains because they have been lifted 
above the surrounding country, but because the surrounding lands have wasted away, and their materials have been

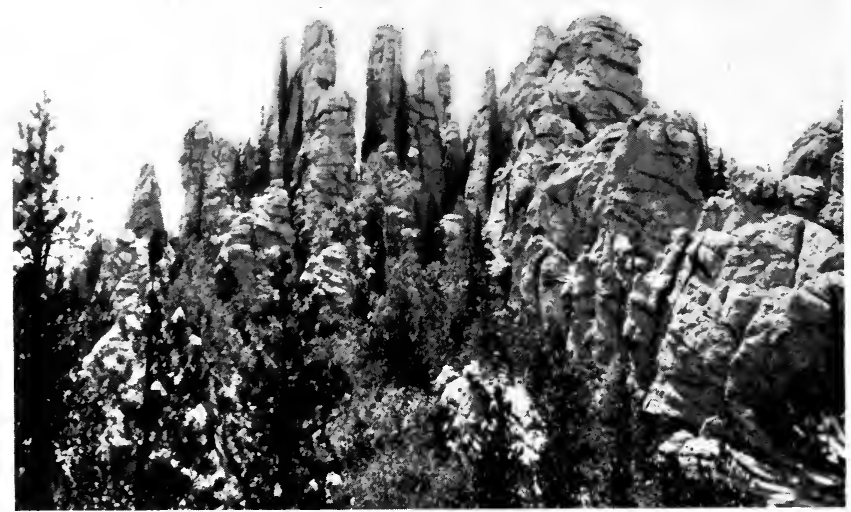

FIG. 61.-Granite crags in the Black Hills of South Dakota.

carried to the sea. In like manner, the mountain ridges of Pennsylvania and Virginia are from one to four thousand feet higher than the valleys that run between them; and this is not because of a difference in uplift, but is due to the wasting of the softer rocks. The country has grown rough in time, as a smoothed surface of a coarse-grained wood does, after years of exposure to the weather.

It is, however, true that many mountain masses are higher than the adjoining lands ever were. The Rocky Mountains, for example, have always been much higher than the Great Plains, though both have suffered uplift (see Chapter VIII). 
81. Rock ledges and waste slopes.-Almost every mountain or steep hill shows us ledges, or sometimes long benches or shelves, of harder rock, which resists the destroying

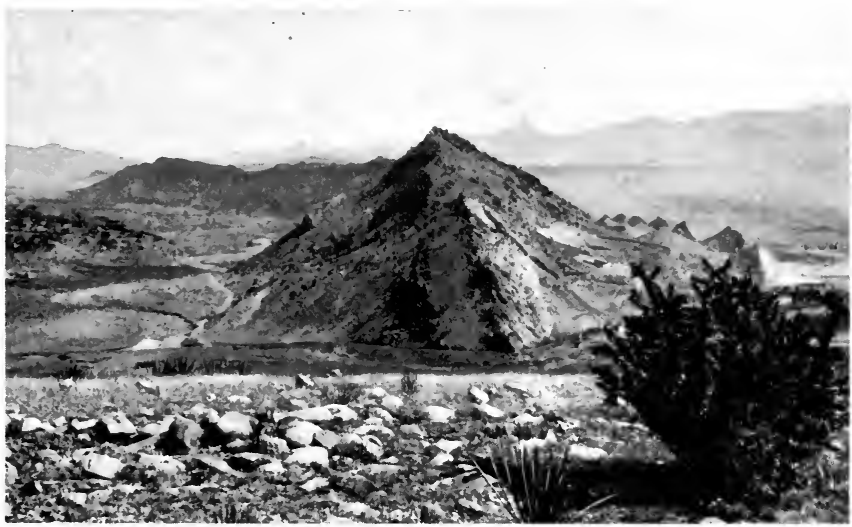

Fig. 62.-_"Hog-back," near Canyon City, Colo. A small mountain ridge, due to the unequal wasting of strong and weak rocks. See Fig. 63 .

forces we have been studying, while between the ledges are smooth slopes of soil or coarser rocky waste (see Fig. 64). In time the ledges will crumble away and the

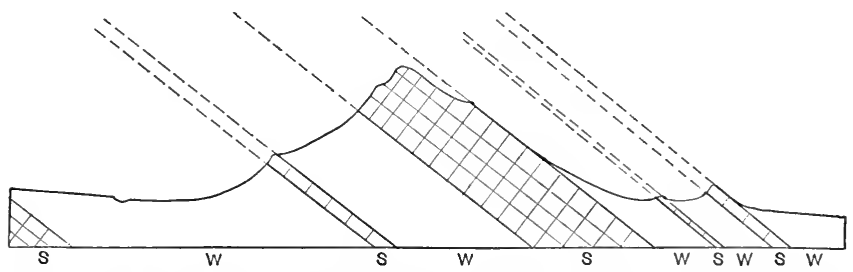

FIG. 63.-Section of the ridges and valleys shown in Fig. 62. $S, S, S$ are strong rocks; $W, W, W$, weak rocks. The rocks were once more extensive, as indicated by the broken lines.

slopes will take full possession. These changes are seen to good advantage in many parts of the far West where the 


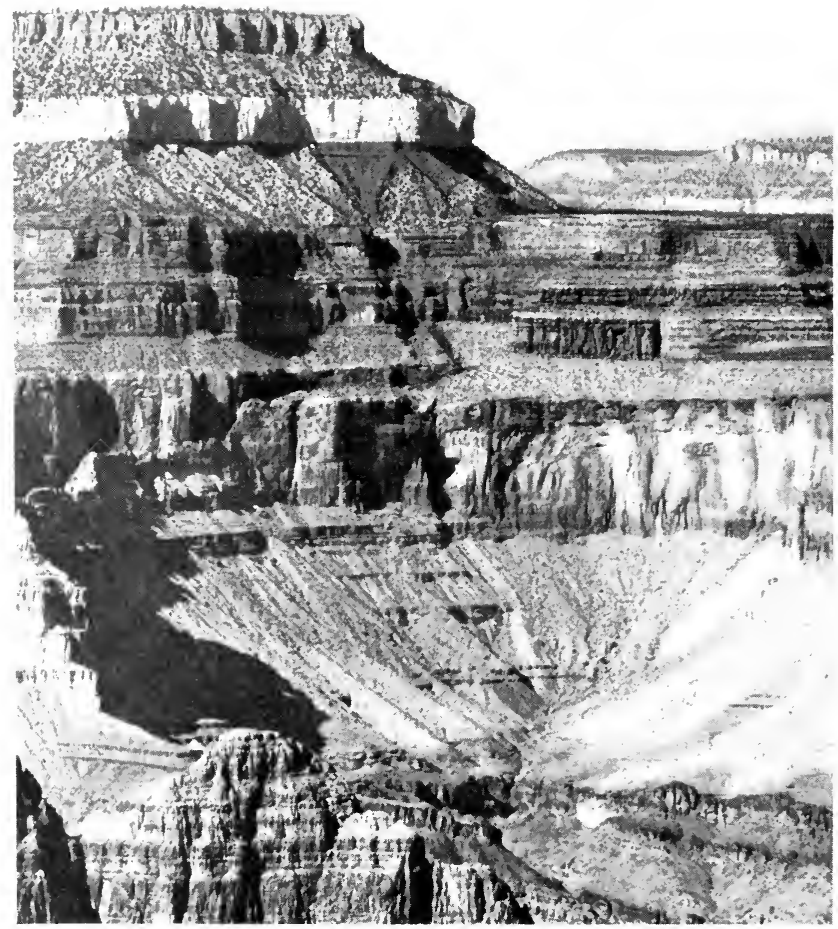

Fia. 64.-Rock ledges (limestone and sandstone) and waste slopes (concealing shale); Grand Canyon of the Colorado River, Arizona. See page 89. 
rocks are horizontal, with harder and softer layers, and there is so little vegetation that the forms of the hillsides

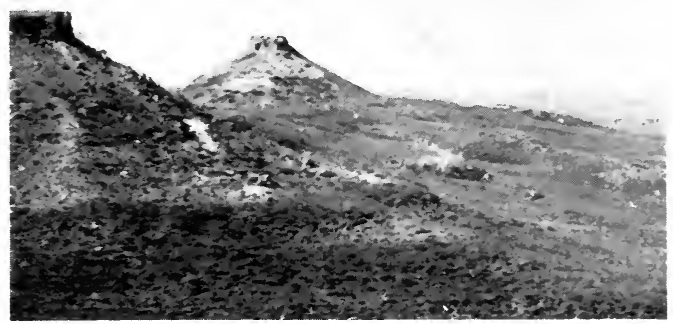

Fig. 65.-A mesa-butte in Oklahoma. At the left is the profile of a mesa at the same level. The butte was once part of the mesa.

are fully exposed to view. Sometimes the upper surface of a horizontal hard bed is bare over a considerable area, while the edge is kept as a cliff by the weathering of soft

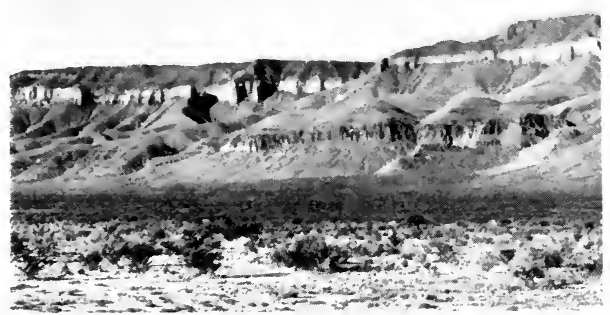

Fig. 66.-Bad lands near the Diablo Mountains, Texas. Each hard stratum is marked by a line of cliffs.

beds below. Such a shelf or table is called a Mesa. If the broadening of valleys divides a mesa so that part of it 


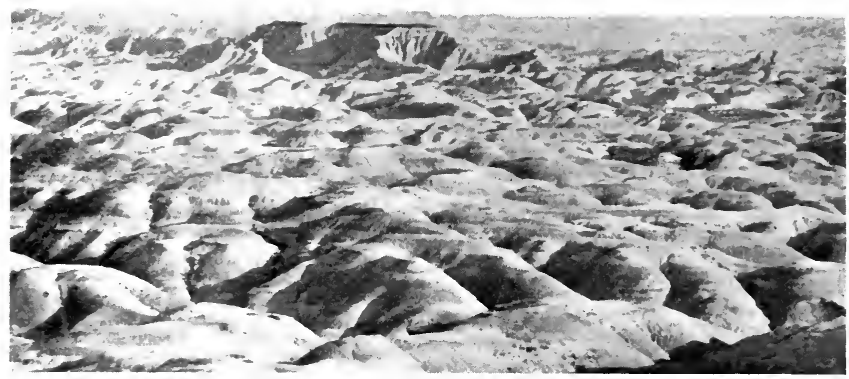

Fig. 67.-Bad lands of South Dakota.

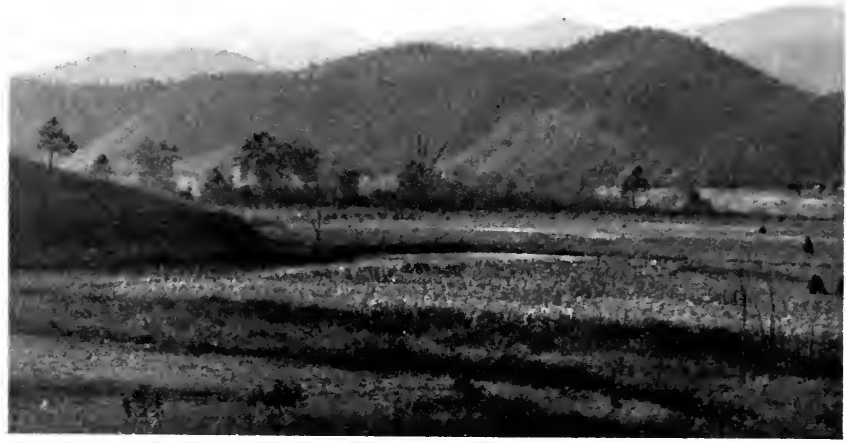

Fig. 68.-Hills and mountains of the Appalachian system, showing rounding of summits. 
stands as a separate hill (Fig. 65), the hill is called, in the same western region, a Butte, or Mesa-Butte.

82. Bad lands.-On slopes where the soil is poor, or for any other reason plants do not grow, decay is slow, and wear by running water comparatively rapid. Ravines ex-

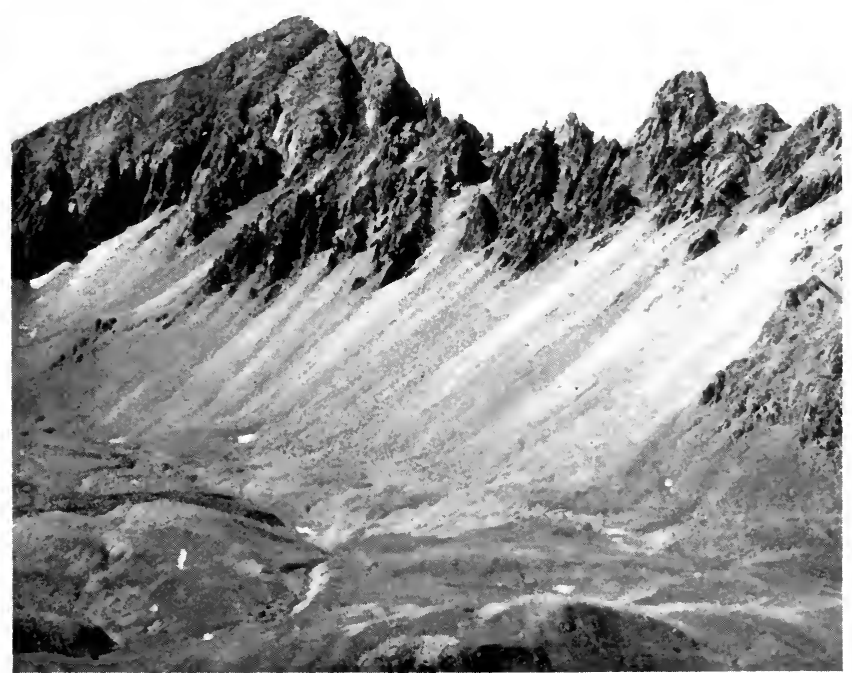

FIG. 69.-Mount Sneffels, Colorado, a sharp-crested mountain.

tend and branch until the whole area is carved into narrow, steep-sided ridges and hills. Such tracts occur most frequently in the drier parts of our Western States, where they are called Bad Lands, because unfit alike for tillage and grazing (see Figs. 66 and $6 \%$ ). 
83. Sharp peaks and rounded summits.-Any good picture of the southeastern ranges of the Appalachian system will show how round and subdued the mountain tops are (Fig. 68). Long ages of weathering have caused this. But the San Juan Mountains of Colorado, the Canadian Rockies, the Alps, and the Pyrenees bristle with sharp ridges and peaks (Figs. 69 and 134). These mountains have existed long enough to have deep narrow valleys and steep slopes made by weathering, streams, and glaciers, but not long enough to have their sharp crests subdued. These are samples of the ways in which wasting controls the shapes of the earth's surface.

\section{SoILs}

84. What soil is.-The student should observe any excavation that penetrates a few feet below the surface. For a few inches, or one or two feet, the material will be dark in color and mixed with living roots and decayed vegetable matter. The latter may be present in small measure, or it may abound, even making the surface matter almost black. This superficial layer is called the Soil. It is the support not only of the natural growth of land plants, but of all cultivated plants. Its origin is therefore interesting, and no other material consideration is so important to our race as its preservation.

85. Origin of soil.-It will be observed that we have carefully aroided using the word soil in writing of the general waste mantle, although it is often loosely so used. The student should distinguish clearly and use it only of the veneer of earthy matter which is specially fitted to support life. Like the waste that lies below it, the soil is derived from the solid rocks, but it alone is enriched by the addition of vegetable matter. The chief foods of growing plants are water and certain substances contained in air, but they need also something contained in rock waste, and the decaying vegetable matter in the soil helps to prepare the waste for their use. 
86. Kinds of soil-_All farmers roughly classify their soils. A clayey soil they call heavy, and are careful not to work it when it is too wet. Otherwise it bakes and is unproductive. A sandy soil they call light. It requires abundant moisture, else the water leaches off and the roots can not nourish the plant. The best soils are mixtures of clayey and sandy waste, and are called loams, which also are said to be light or heavy according to their character. As soils are of many kinds, it is fortunate that the needs of plants are also varied, so that some can thrive where others would perish. Swamp soils are often made available by drainage, and are of great value, especially for truck farming. Lime, potash, and phosphates are among the soil elements that plants use most, although they make but a small portion of the entire soil. Hence they may become exhausted, and the prudent farmer "rotates" his crops and adds fertilizers, to keep up a due supply of these materials.

$8 \%$. The use of soil depends on climate. - Wheat thrives in Manitoba, corn in Illinois, and cotton in Mississippi. The soils are not indeed the same, but the principal difference is in the climate, which makes soils useful for certain crops. In the western part of the Great Plains, and in the valleys farther west, there is so little rain that our food plants do not thrive, but wherever the needed water can be supplied by irrigation good crops can be raised. There is no reason to doubt that the soils of northern Siberia are as rich as those of southern Europe, but the temperature is hostile to agriculture.

88. Soils of the United States.-These depend on the forces which have made them. As we have seen, those of New England are largely transported soils. On Cape Cod and Marthas Vineyard they are sandy. On the uplands of Massachusetts they are clayey, depending thus on the action of the glacier in its moving and melting. This will be better understood after the study of glaciers. Then, too, the student will learn what parts of our country were affected 
by the ice invasion. South of the ice limit, as in Virginia, Kentucky, and other States, the soil is made of the local rocks, and is clayey, sandy, and rich or poor in lime and other elements, according to the nature of the bed-rocks and the character of weathering. Much of the soil of the Gulf region is of alluvial or river-borne material. Around the borders of our Great Lakes are tracts of level land mantled over with lake muds deposited when the waters stood at a higher level. Thus every soil has a history, and its origin is in some way related to the changes by which the lands have come to their present condition. It is of interest to add that the Department of Agriculture has organized a division for the study and mapping of the soils of the United States.

\section{Underground Changes in the Earth's Crust}

89. Water in the rocks. - If a piece of common clay or a handful of soil be dried in an oven it will lose considerable weight, thus showing that a large amount of water was held among the mineral fragments. Samples of dry sand in Colorado have been found to absorb water to the extent of 29 per cent of their rolume. If a boring be made, water will generally be found before great depths are reached. There is often an abundant supply within a few feet of the surface. Quicksand is only a fine sand so filled with water that its grains move with little friction, and it readily engulfs man or beast that seeks to traverse it. All the deeper and solid rocks also contain water. No granite is so hard and compact that it does not hold among its mineral particles a small percentage of water.

This water is nearly stationary in hard rocks which are not crossed by cracks. But where there are fissures it circulates with more or less freedom. Through beds of sand, and particularly in layers of gravel, water will flow readily, though much more slowly than in a surface stream. The fact that water is present and moves in 
rocks, leads to important changes, several of which we shall now study.

90. Hardening of rocks.-Ground-water, coming in contact with the minerals that make up the rocks, is able to take more or less of the substances into solution. Thus it may take up calcium carbonate, iron, and many other minerals; continuing its course through the rocks, it may afterward deposit part of this dissolved matter among the particles and bind them more firmly together, as by a cement. In a large gravel-pit one can usually see projecting layers of gravel, whose pebbles and sand-grains have been thus bound together by an underground deposit of calcium carbonate.

91. Mineral veins. - Water laden with dissolved minerals often flows through a fissure, and deposits part of its burden on the walls, until the fissure is filled with mineral substances different from the adjoining rocks. On breaking the rock, this Vein, as it is called, appears like a narrow or wide ribbon, whose color depends on the mineral deposited. Many veins are of white quartz, and sometimes the quartz contains gold,

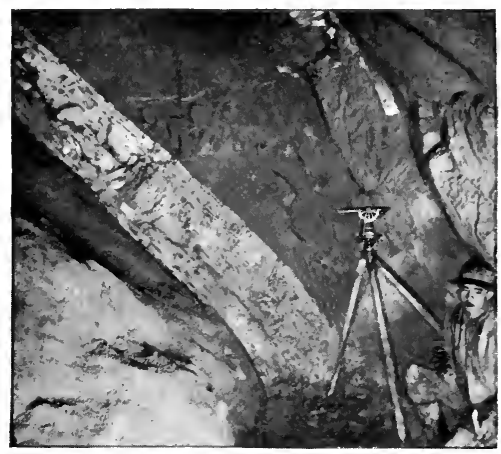

Fig. 70.-A vein of gold-bearing quartz; Nevada City, Cal. in particles often too small to be seen by the unaided eye. Much of the gold of California and Colorado occurs in veins of quartz or some other mineral, and, indeed, veins contain the most important deposits of the precious metals. The metals have been dissolved from the rocks in which their particles were scattered, and brought together by underground waters. 
92. Destruction of rocks by underground waters. - IVe must now look at another side. As already mentioned, the mineral matter contained in underground waters has been obtained by solution from rocks. What the water has gained the rocks have lost, and the effect on the rocks has often been to break them up into grains. In Cornwall, England, the granites are sometimes completely decayed to a depth of several hundred feet. Sandstone boulders and beds of sandstone become heaps and beds of sand in this manner. In other cases the whole substance of a rock is removed, and this brings us to the formation of-

93. Caverns. - The Mammoth Cave in Kentucky consists of a complicated network of passages, having a total length

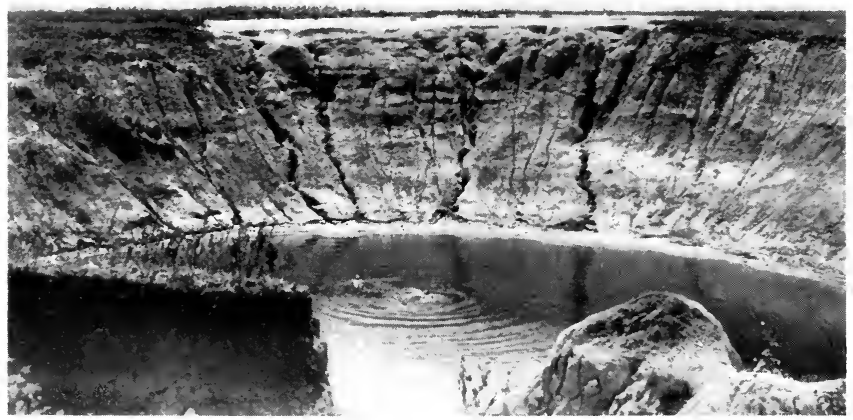

Fig. 71.-Sink hole and lake, Kansas. In this case the rock dissolved beneath was probably salt.

of two hundred miles or more. It has been thoroughly explored and mapped. It is entirely dug ont of limestones. Water, which dissolves limestone more readily than most 
other rocks, filters along the joints and crevices, and gnaws incessantly until great openings result. The calcium carbonate is carried off by underground drainage to some point where the water joins a surface stream, and thence it goes out into the sea. Beds of gypsum and rock salt are dissolved even more rapidly. Fig. 55 shows the mouth of a small cavern made by the enlargement of a joint in limestone.

When a considerable area has been thus undermined, the upper rocks may cave in, thus letting down the surface of the land above. Many small lakes in Kentucky occupy such Sink Holes. A stream may flow for a considerable distance in a tunnel thus made. As the tunnel grows broader, its roof at length falls in, making an open ravine. If a small seetion of the roof remains in place, we have a bridge. Such is the origin

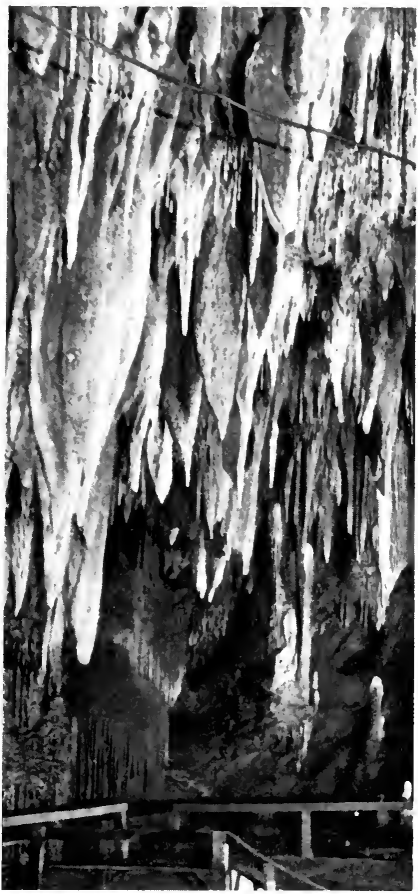

Fig. T2.-Stalactites, Luray Cavern, Virginia. Photograph by C. II. JAMEs; copyrighted.

of the Natural Bridge of Virginia, over which a public highway passes. Another such bridge in the same State is a half mile in extent, and a railway which follows the stream beneath it thus threads a natural tunnel.

94. Stalactites and stalagmites.-The water dripping from the roof of a cavern has soaked through the limestones above and brought out its load of calcium carbonate. Some 
of this is deposited at the point where the water comes out, and a mass like an icicle grows downward. Where the drip is along a crack, the mass will be blade-shaped instead of needle-shaped. As it grows downward it also increases in diameter by the addition of outer layers, like the rings of a tree. Such a formation is a Stalactite. Luray, the most famous and beautiful of the caverns of Virginia, is noted for its stalactites, many of which are large and finely colored by various minerals, mixed in small quantities with the calcium carbonate.

The dripping water strikes the floor of the cavern and there deposits more of its mineral burden, which thus builds a small mound called Stalagmite. Sometimes the stalagmite forms a pavement over a considerable surface.

95. Caverns and living creatures.-Blind fishes and other curiously modified animals are found in eaverns. Such changes have come about by successive generations of these creatures living in the cavern, where the eye, for example, from lack of light, has grown useless, or has disappeared. Many caverns in Europe were the refuge of prehistoric men and animals, whose bones are now found there, and the remains of ancient animals have been found in American caverns also.

96. Springs.-When water has soaked into the earthy mantle or the under rocks, and issues at the surface at a lower level, we call the outflow a Spring. Coming out from a depth to which the warmth of summer does not penetrate, spring water is usually cool, and its temperature does not change from season to season. The size of a spring, like the size of a river, is related to the area from which the water is gathered. An underground river coming to the surface makes a spring of great volume. At Bellefonte, Pa., at several points in Florida, and at the source of the River Jordan, are such springs.

97. Mineral springs.-When the waters, on their way through the rocks, have taken a large amount of min- 
eral in solution, this name is given to them, particularly if the waters have medicinal value, as by the presence of iron, lithium, sulfur, or other substances. Carlsbad and Vichy are well-known springs in Europe, and Saratoga is the most famous of the thousands of mineral spring localities of the United States.

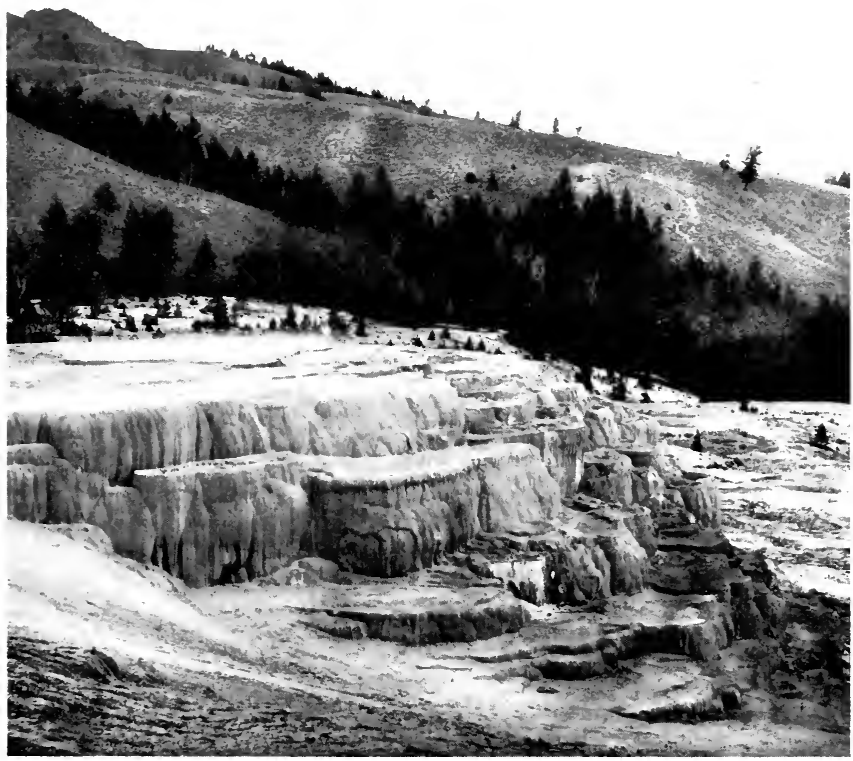

Fig. 73 -Cleopatra Spring and terrace ; Yellowstone National Park, Wyoming.

98. Hot springs. - Those of Arkansas will at once occur to the student. Others are found at Glenwood, Colo., and in the Yellowstone National Park. In such cases the waters have come up through heated rocks, and owe their temperature, either directly or indirectly, to the heat of the earth's interior. Such springs are apt to be charged with 


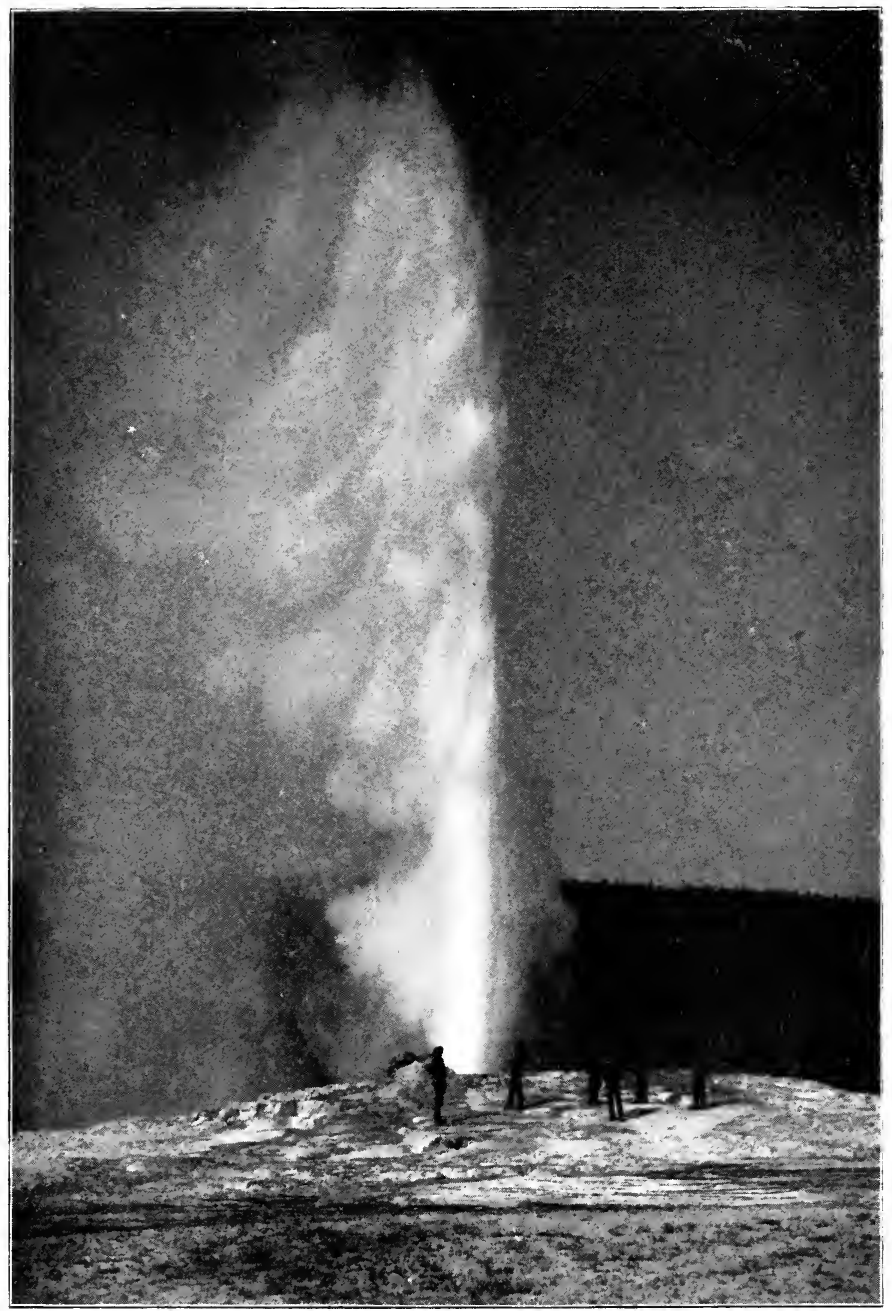

FIg. F4.--Old Faithful Geyser, Yellowstone National Park, Wyoming. 102 
minerals, because hot water dissolves the rocks more readily than cold water. Hence also the waters, losing their heat as they come forth, deposit minerals about the springs. Such abundant deposits form the well-known terraces about some of the springs of the Yellowstone region (Fig. 73).

99. Geysers.-These are periodically eruptive springs found in the Yellowstone Park, in Iceland, and in New Zealand. At intervals of a few minutes, or a few hours, they spout a jet of water into the air, which plays like a fountain for a few moments and subsides. The water is boiling hot, and is mingled with steam. The explanation is found in the fact that the boiling of water may be restrained by pressure. Deep in the geyser throat the water grows gradually hotter, but for a time does not change to steam, on account of the pressure on it of the water above. At last the heat so increases as to overeome the pressure, a great volume of steam is suddenly formed, and its expansion drives a quantity of water into the air (see Fig. 14).

100. Wells.-The mantle of waste is usually filled with water except the uppermost part. This "ground-water," as it is ealled, supplies ordinary springs, and is itself replenished by the part of rain which soaks in. When a boring or digging reaches below the level of permanent ground-water we call the opening a well. Water stands in it up to the ground-water level, and as this is pumped or drawn out the quantity is restored by oozing from the sides.

101. Artesian wells.-These are so named from the province of Artois in France. The principle of these wells is best shown in Fig. 75. The water soaks into a porous bed of rock such as a sandstone. It is kept in this layer by fine-grained beds above and below, through which water does not readily pass. If now the beds all incline a little in one direction there is a constant pressure on the lower waters of the porous bed. If a boring pierce the 


\section{AN INTRODUCTION TO PHYSICAL GEOGRAPHY}

cover rocks, the waters will flow out, and sometimes spout to a considerable height. It is the same principle of

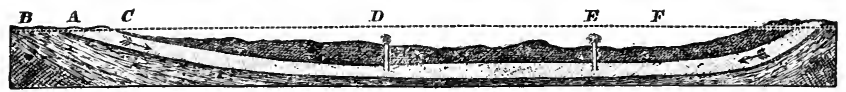

Frg. 75.-Ideal section of a valley, showing the principle of artesian wells. $A$, a porous rock ; $B, C$, impervious rocks ; $F$, height of the water-level in $A ; D, E$, artesian wells, made where the ground is lower than $F$.

hydraulic pressure that is used in making a fountain. This general arrangement of porous and compact beds is fortunately found in many

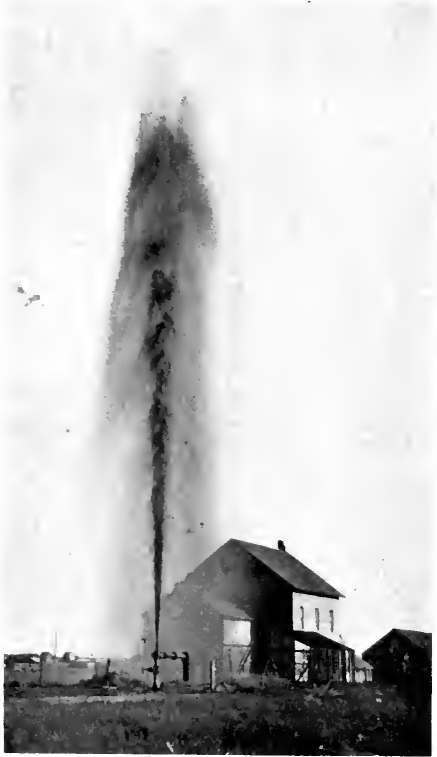

FIG. 76.-Artesian well at Woonsocket, S. Dak. When photographed the jet was 9 r feet high. regions. Hence along the Atlantic coast, as in southern New Jersey, such wells are common, also in northern Illinois about Chicago, and in many parts of the Great Plains from the Dakotas to Texas.

\section{Water supply.-} Here we count springs, wells of all kinds, rivers, and lakes, large and small. Large cities obtain their supplies from rivers and lakes, scattered houses from springs and wells. Unfortunately, not all water is wholesome, and much that is used is dangerous to health and life. As the rain soaks down to join the ground-water it may carry with it any filth that lies on or near the surface, and thus make springs and wells unfit to use. This is 
especially true in a village or thickly settled neighborhood, but even the sewage of a single house may reach a well sunk in the yard. Every one should learn enough about the movements of ground-water to arouse caution in the use of wells, and every one should understand that water which is perfectly transparent and pleasant to the taste may at the same time be filled with the germs of typhoid fever and other diseases. River supply is dangerous if the up-stream region is thickly settled. Lake supplies are safe if due care be taken of the inflowing streams. Deep wells, such as the artesian, are likely to be safe. Increasing attention is given, as it should be, to this important subject, by cities and towns and by the State and National Governments.

\section{LANDSLIDES}

103. Slides in railway cuts.-In the spring one may often see reports of blockades on railway lines because masses of earth have slid upon the track. The underground waters have lessened the coherence of the earth, and the steep slopes can no longer be maintained. Loose waste, as seen in talus slopes or heaps of sand, will rarely have a surface inclination of so much as $35^{\circ}$ with a level plain. If this is exceeded in artificial slopes of earth, slips are sure to take place.

104. Hillside slips.-Small slips may often be found by the observant eye on the slopes of steep hills. Freezing and heaving of the material, followed by thorough soaking, cause it to fall away. On a larger scale slips take place where rivers undercut the valley sides, making an orersteep slope. In the early days such a slide on the borders of the Genesee valley in western New York carried down 17 acres of land, and the hummocky surface caused by the lodging of the material is still to be seen along the valley bottom.

105. Seashore slips.-In a similar way the waves of the sea undercut the shore lands, forming cliffs. A great slide 


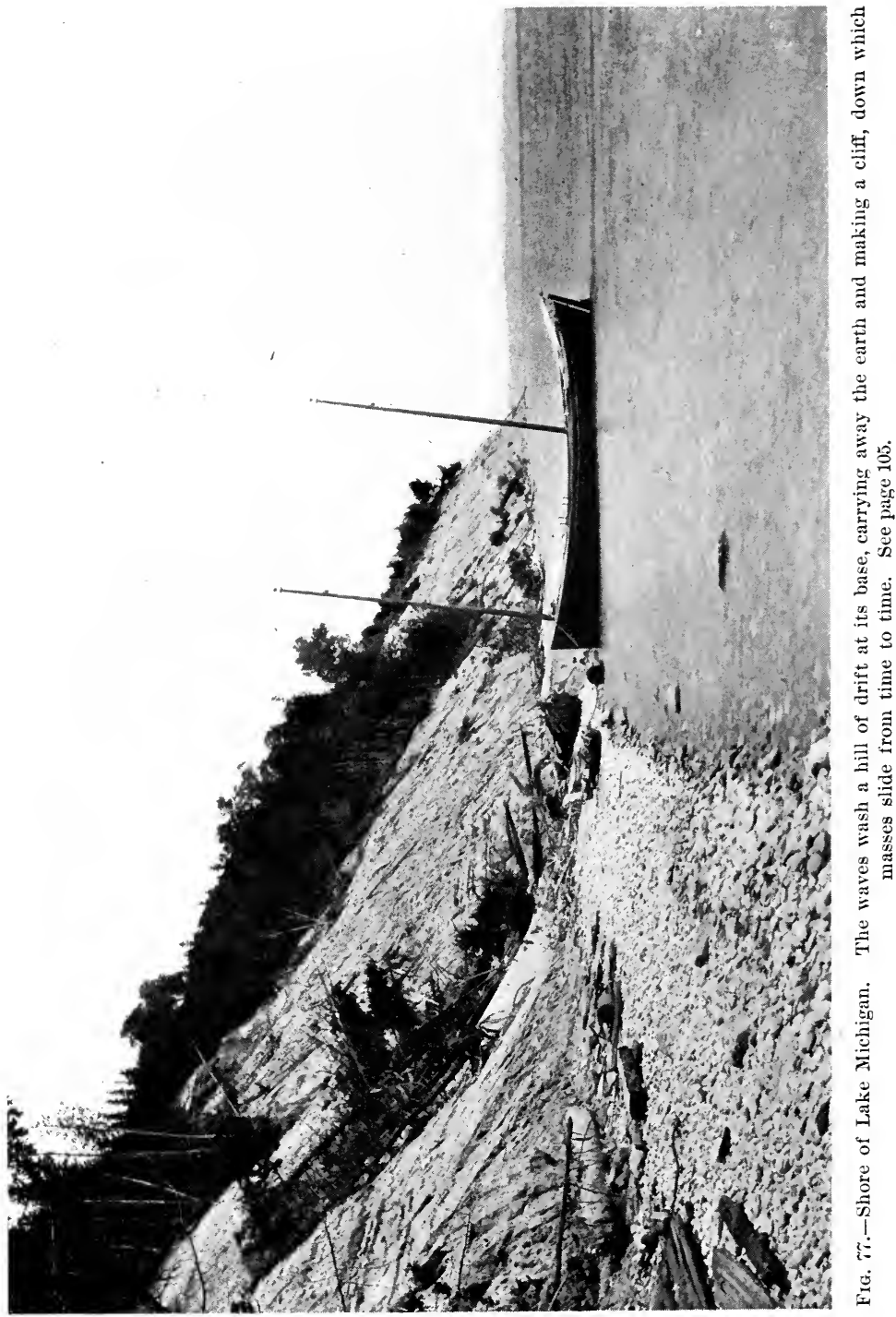


of 12 acres in extent once occurred in this manner on the south shore of England.

106. Landslides in mountain regions.-Here the valleys are deep, the slopes are steep, the destructive forces are active, and everything favors the sliding of vast masses of earth and rock. In 1806 the upper rocks over a large area of the south slope of the Rossberg in Switzerland slid sud-

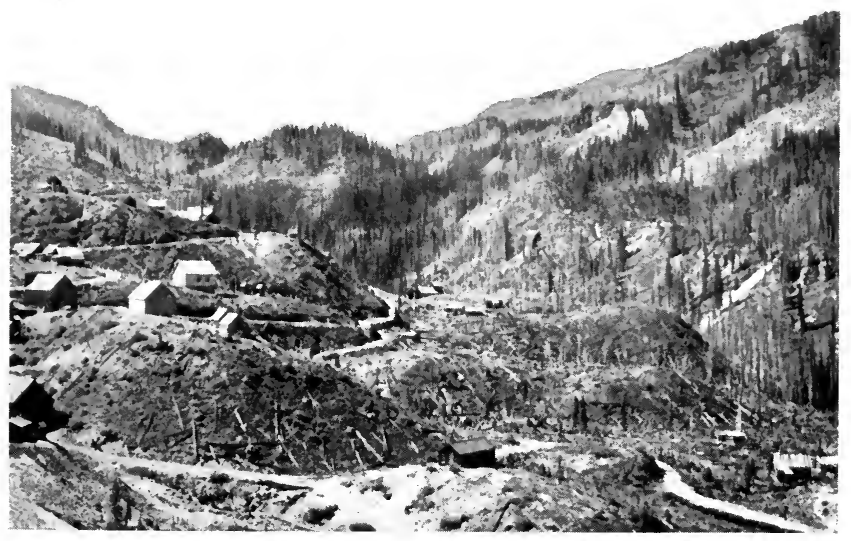

Fig. 78.-Landslide scenery in southern Colorado. The mounds in the valley and on the slopes are masses of earth and rock which have slid from above.

denly into the valley, overwhelming the village of Goldau and causing the death of several hundred of the inhabitants. The earth and rocks, including masses as large as houses, still strew the valley for a distance of two or three miles. The present village is built upon the slide, and a railway cut has been made through it. 


\section{AN INTRODUCTION TO PHYSICAL GEOGRAPHY}

A still larger mass broke from the Cascade Mountains a few centuries ago and slid about two miles to the Columbia River, making a dam and causing the "Cascades." A

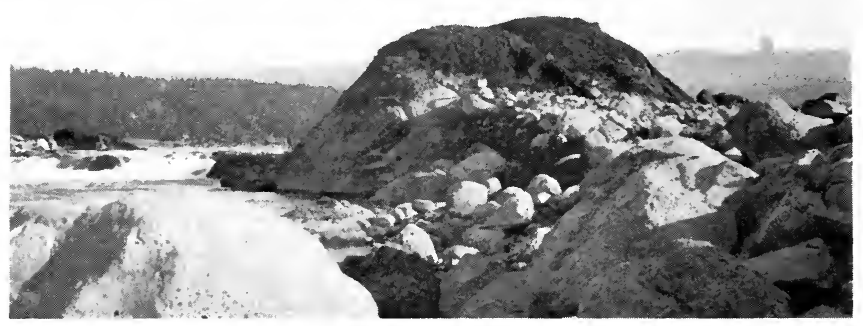

Fig. 79.-The Cascades of the Columbia River. The central hill is a huge boulder. All the boulders of the view, together with the wooded hill at the left, are parts of landslides.

short canal has been made, with locks, that steamers may pass, but above the dam they find deep, quiet water for thirty miles. In this deep water stand stumps of trees which grew before the slide and were killed by the flooding. 


\section{CHAP'TER V}

\section{W I N W O R K}

10\%. Importance of winds. - We are studying the forces which modify the crust of the earth and change the forms of the land; hence the physiographic effects of winds are those which now claim our attention. In the chapters on the atmosphere we shall consider the origin and kinds of winds, and their effects on climate as carriers of heat and moisture. The work of the ocean depends largely on the winds as wave-makers. The chapter on animals and plants will show how winds affect the grouping of many living things.

108. Common examples of wind work.-Dust rises in clouds from traveled roads, to settle upon trees, lawns, and fields. It gathers in the gutters of house-roofs and on roofs of towers which are surrounded with battlements. Seeds brought by winds or birds are lodged with the dust, and thus grasses, shrubs, and even small trees flourish in such high places.

109. How dust is carried.-When very minute particles of earth are mingled with water we call them mud; when they are dry and powdery, dust. The wind, which is only air in motion, picks them up just as moving water does, and carries them till the motion stops; then they settle slowly down. 'The wind does not blow hard in the woods, nor under thick bushes, nor even inside the leafy mesh of a meadow. It can pick up dust only from bare places, such as roads, freshly plowed fields, and barren deserts. And when dust settles from the air, part of it gathers 
among trees and other plants where it is safe from the wind. So the air is a carrier of dust, just as water is a carrier of mud. It takes something from the ground where the ground is bare, and gives something to it where it is clothed with vegetation.

110. How sand is carried.-Sand grains are so much heavier than particles of dust that they can not float in the

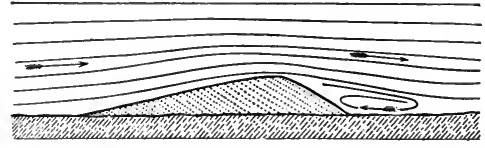

Fig. 80.--Profile of a dune, from back to front, showing its relation to the wind. The flowlines of the air are drawn above, with the eddy in front of the dune.

air. When a strong wind drives them they go rolling and bounding along, and are rarely raised more than a few feet. Drifting sand often gathers in wave-like heaps or hills called Dunes, and these hills are not stationary but travel in a curious way. As the wind blows across one of them its current is turned upward so as to shoot over its crest, leaving a quiet spot, or eddy, beyond (Fig. 80). While it is

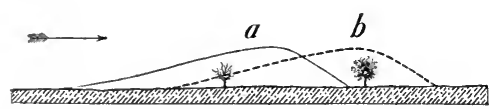

Fig. 81.-Diagram of the progress of a dune, from $a$ to $b$. The arrow flies with the wind. A live tree standing before the dune when it is at $a$ will be buried by the advanee to $b$. Another tree, previonsly killed and still eovered by the dune, will be brought to light when it has reached $b$. rising, sand grains are dragged along with it, but a little beyond the crest they fall into the eddy and come to rest on the lee slope. Thus the wind always robs one side of the dune and gives to the other, and the position of the dunes is changed (Fig. 81). As the dune progresses, a tree or even a house may be gradually buried, and afterward reappear on the opposite side.

111. Places where sand drifts.-Forests, thickets, and meadows protect sand as well as dust. So dunes flourish only on barren lands. Deserts are their chief haunts, but they find starting-points along coasts, where waves have washed up beach sands; along rivers, where sandy bars are 
dried in summer; and in a few places where the mantle of waste is so pure a sand that plants get but feeble hold on the land.

\section{Flying Dust and Drifting Sands in Dry Regions}

112. The western United States.-The plateau regions west of Missouri and Iowa are nearly everywhere subject to great dust storms. The climate is dry, the covering of

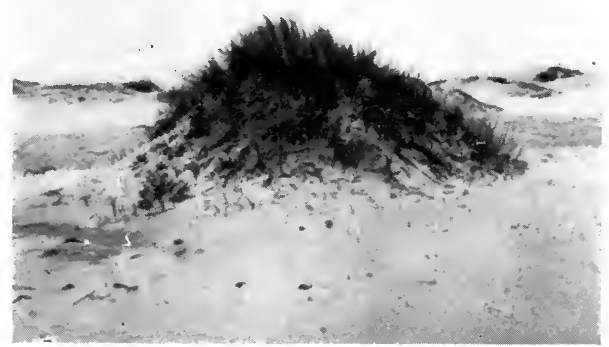

Fig. 82.-A patch of grass on a field of loose sand. Drifting sand-grains lodge among the grass, and a hillock is built.

vegetation scanty, and winds sweep freely for hundreds of miles. The surface earth is picked up and carried in blinding storms. Thirty-eight such storms were reported during the years 1894 and 1895 , and these take no account of the drifting by every considerable breeze. Great storms are apt to occur on the plains two or three times a year, and in parts of California they are more frequent than this. They last from an hour to several days, and hundreds of tons of dust are often borne in a single cubic mile of air. The sun is obscured in some severe storms, and the sand penetrates houses and covers carpets and floors.

Traveling dunes are common in all the western part of 


\section{AN INTRODUC'TION TO PHYSICAL GEOGRAPHY}

the Great Plains, in the region of the Great Basin, and in New Mexico, Arizona, and southern California.

113. Northern Africa.-The Sahara is not so completely a sandy desert as is often supposed. Less than one-third of the Algerian Sahara is said to be covered with drifting sand. Rocky areas are not uncommon, and salt marshes, with numerous fertile oases. But, as a whole, the climate is dry, and the winds sweep the sand over wide areas. On the east the Nile Valley receives its contribution by the winds, so that the sands of the desert mingle with the sediment of the Nile floods.

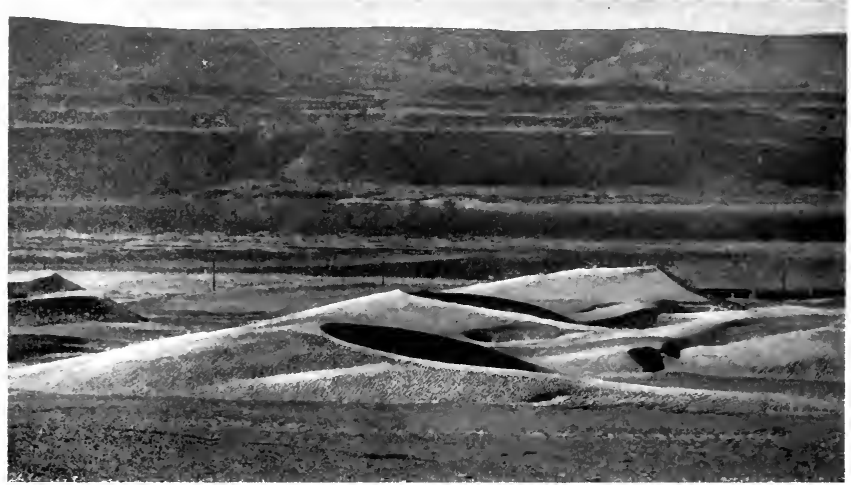

Fig. 83.--Dmes in the canyon of Columbia River. The wind blows, and the dunes migrate, from left to right.

114. Asia. - With little interruption the sandy and halfdesert tract extends from northern Africa far across Asia. Oriental explorers and travelers offer many vivid accounts of the desert storms. One of these, lasting a whole day, was encountered by Dean Stanley on the borders of the Red Sea. "Imagine all distant objects entirely lost to view - the sheets of sand fleeting along the surface of the desert like streams of water; the whole air filled, though invisibly, with a tempest of sand driving in your face like sleet." 
Then follows an account of the difficulties of the caravan, the Bedouins covering their heads with their shawls, and the camels patiently facing the blast.

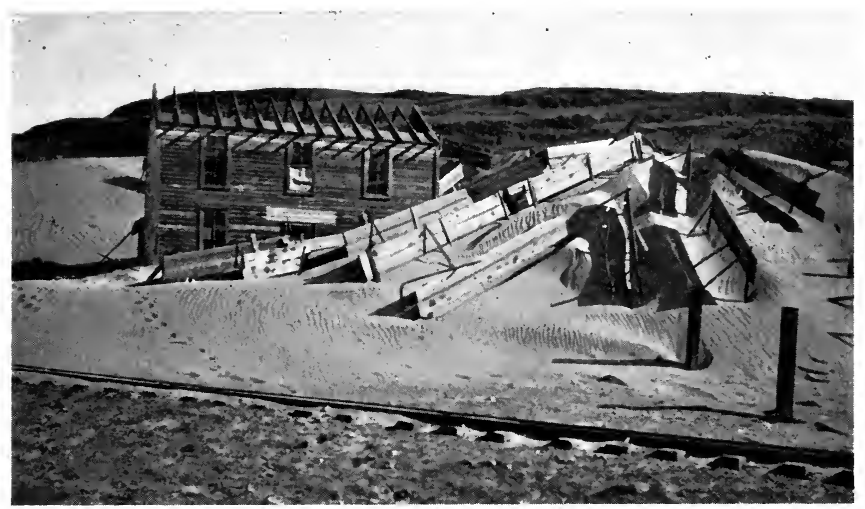

Fig. 84.-The last house in Biggs, Ore., a village overwhelmed by dunes. Attempts to hold the sand back by fences were unsuccessful.

In central China vast areas are covered, sometimes to depths of hundreds, or even thousands of feet, by a yellowish earth which is believed to have been swept to its place mainly by winds. It is called Loess, and is remarkably fine and uniform in character. Streams and even vehicles cut deep gorges into it, and it is so dry that in the bluffs houses or dugouts are excavated in which many Chinese farmers live.

Drifting Sands on the Shores of Lakes axd the Sea

115. The Great Lakes, - From the car window at Michigan City one may look upon the inner slope of a great, bare dune, built by the winds out of the sand on the shore of Lake Michigan. Approaching Chicago by one of the railways from the east one continues to see the sands in a belt of hills scantily clad with trees. Along the eastern shore of the lake are mary dunes, some having a height of 


\section{AN INTRODUCTION TO PHYSICAL GEOGRAPHY}

200 feet; and belts of great dunes are found on the borders of Lake Superior.

116. Dunes of the Atlantic coast.-Let us take Cape Cod as a striking example. Thoreau, the naturalist, who many years ago traversed the length of the cape on foot, has published a diary giving interesting references to the mov-

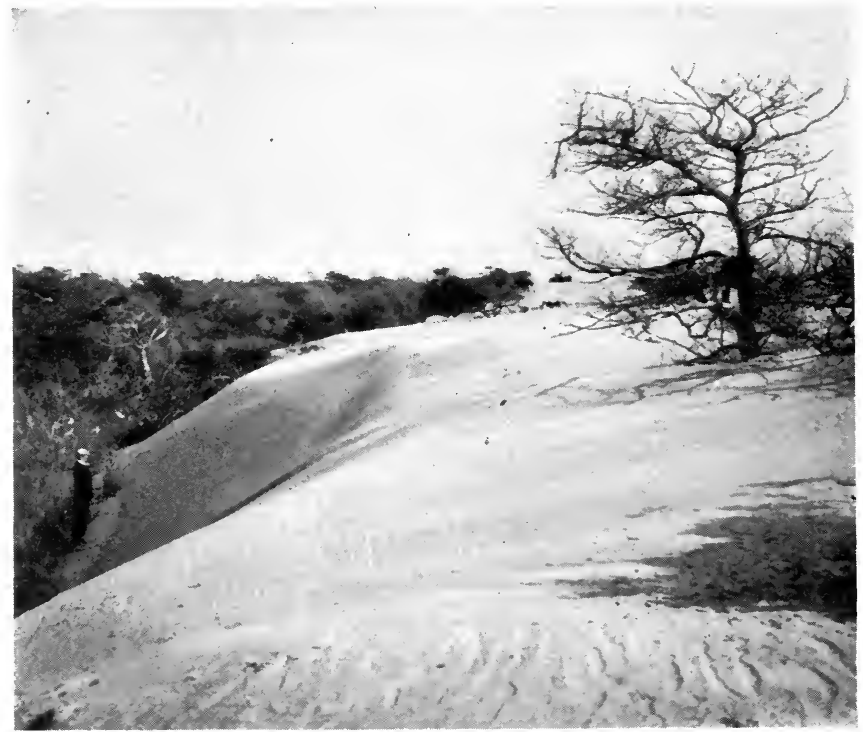

Fig. 85. - Landward side of a dune on the coast of North Carolina. The dune is traveling from right to left, and has killed a tree by burying its lower part.

ing sands. The surface earth of the cape is a loose glacial formation, with much sand and gravel. For long ages the sea has been cutting into these deposits on the east, and sorting out the sand to make beaches. The winds blow freely over the sea and play with the sands at their will. The materials and the worker are thus always at hand, and the result is a long succession of shifting sand-hills.

We may now associate with Cape Cod other parts of 
our Atlantic coast, as the south shores of Nantucket, Marthas Vineyard and Long Island, and the Massachusetts coast north of Cape Ann. Along the south Atlantic coast the beds attacked by wave and wind and forming shore dunes are not glacial, like many in New England, but they are unhardened rocks whose materials are readily broken up and moved from their place.

11\%. Western Europe.-On the coast of Gascony the belt of sand-hills is so continuous that at only two points in a distance of a hundred miles can the streams find their way out into the sea. The dunes on the coast of Holland cover a belt of land sometimes five miles wide. The hills are usually 50 to 60 feet high, butsometimes rise to more than 200 feet. Dunes have been formed on the shores of Norfolk and Cornwall, England, and on some shores of Scotland and Ireland.

\section{Dunes} the Mediterranean. - Many travelers have described the belt of sand-hills along the borders of the ancient Philistia. Ancient cities have been cov-

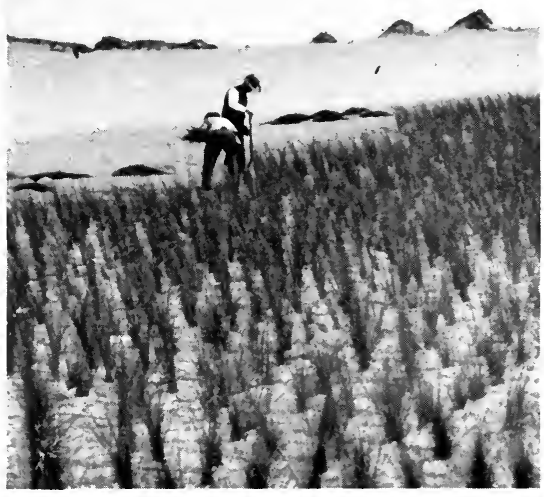

Fig. 86.-Planting grass to stop the drifting of sand, near Provincetown, Cape Cod, Mass.

ered, and fields and orchards are often invaded at the present time. The strip of coastal land affected is from 


\section{AN INTRODUCTION TO PHYSICAL GEOGRAPHY}

one to four miles wide. " "It is a pitiful sight," says Geikie, "to notice olive and fig trees half-buried, their owners striving hard, season after season, to shovel away the sand from their trunks, till they stand, in some cases, almost in pits, which would close over them if the efforts to save them were intermitted even for a short time."

119. How encroaching sands are held in check.-Various methods are used. The French bring about the formation of a shore ridge of sand to a height over which the sands will not blow. This is accomplished by artificial barricades, rising in height from time to time, for a period of years. The principle is similar to that used in making fences to stop the drifting snows at a certain line. Another method is to plant grass or trees on the dunes. Common olean-

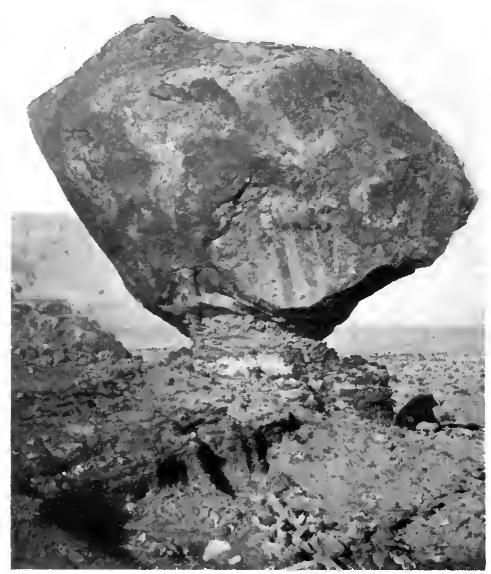

Fig. 8\%.-A boulder resting on a bank of shale which is swept by drifting sand, protects one spot while the ground all about is worn away; northwestern Arizona. ders are used for this purpose in Bermuda. The Department of Agriculture gives attention to this problem; a report on Sand-binding Grasses is found in its yearbook for 1898. Fig. 86 is from this report. Such grasses as are found to thrive naturally on the sand-hills in some localities are set by the hand of man in other regions. This work has been done near San Francisco, along the shore of

Lake Michigan, and near Provincetown, Mass. The danger in the last case is that the sands will blow across the narrow 
neck (Fig. 86) and fill up the harbor. Grasses have thus been used to defend the coasts of France, Holland, and Denmark. Where no precaution is taken, a dune has been known to migrate as much as $\% 0$ feet in one year.

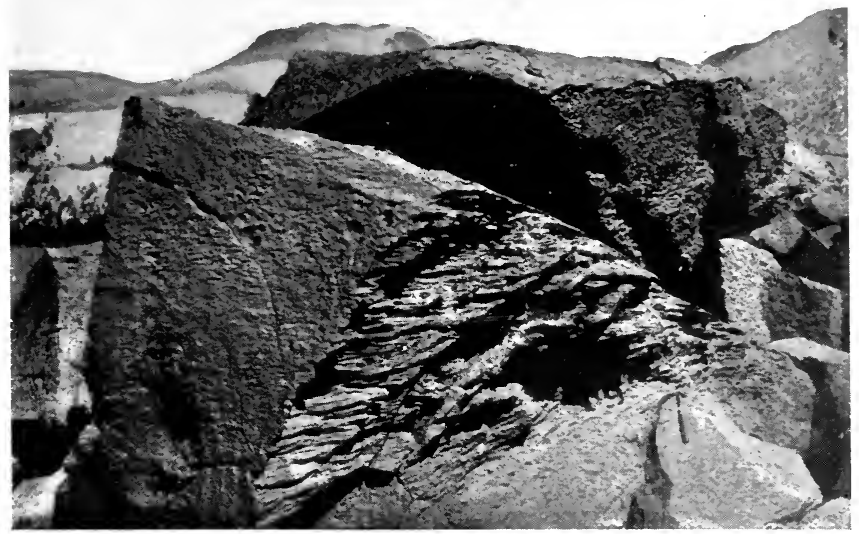

Fig. 88.-Blocks of igneous rock scnlptured by wind-driven sand; Mono Valley, Cal. The sand comes from the right.

120. The sand blast.- Sand driven by powerful currents of air is used in the arts for many purposes. Patterns are cut on glass, and heavy plate glass is readily pierced by such means. The blast is used for bringing out the grain of wood, for giving a granular surface to iron and steel, for carving inscriptions on stone, for lithographic drawing, for cleansing the inner face of tanks from foreign deposits, and for refacing grindstones and emery-wheels.

Sand blown by natural winds does similar work, and this natural sand blast suggested its use by man. Wherever the wind habitually drives sand upon boulders or ledges, wearing will result. Many sand-carved boulders have been found in the Androscoggin Valley, near the 


\section{AN INTRODUCTION TO PHYSICAL GEOGRAPHY}

White Mountains. But it is only in dry regions that such work is important, and many examples of it have been found in the western United States and the Sahara. The student should not, however, suppose that this work is to be compared in importance with that of weathering or streams or glaciers. 


\section{CHAPTER VI}

\section{GLACIERS}

\section{Mountain Glaciers}

121. The Gorner Glacier.-Monte Rosa is one of the highest peaks of the Alps. West of it are Lyskamm, Breithorn, and the Matterhorn. All these mountains rise to about 15,000 feet above the sea, and are the highest points of a lofty ridge which marks the boundary of Switzerland and Italy. North of this ridge a deep valley runs from east to west, and in this valley is the Gorner Glacier. For the places noted in this section the student should constantly refer to the map (Fig. 89). The glacier fills the valley to a depth of many hundred feet, and flows from east to west. It is known at its lower or northwest end as the Boden Glacier. At its eastern end, covering the high slopes north of Monte Rosa, are great fields of snow. This snow, accumulating from year to year and from century to century, packs together, pushes down the mountain slopes, and within a short distance becomes solid ice, which, at the rate of a foot or more per day, flows westward down the valley. The whole length of snow-field and the glacier proper is nine miles. The upper edge of the snow-field is nearly 15,000 feet, and the lower end of the glacier is about 6,000 feet, above the sea.

The glacier is not entirely formed from the snows at its eastern end. Other snows gather on the north slopes of the ridge already described. These form several smaller glaciers which join the Gorner Glacier on the south and 
swell its size. These, beginning at the east, are : the Monte Rosa, Grenz, Twin, Schwarze, Breithorn, Little Matterhorn, and Theodul Glaciers. From the ice and snows rise craggy ridges and peaks, which all together form one of the most splendid views to be found in any land.

Along the trunk glacier the student will see upon the map a number of brown lines. These usually lead up to a rocky ridge which separates two tributary glaciers. As the glaciers crowd the mountainside they pluck away blocks of rock. Other waste rolls down the steep slope and lodges on the edge of the stream of ice. Such a line of waste on the side of a glacier is a Lateral Moraine. When two glaciers unite, the left lateral moraine of the one and the right lateral moraine of the other join together, and a ridge or tract of waste stretches far down the trunk glacier. Such are the brown lines on the Gorner Glacier; they are called Medial Moraines.

Where the glacier is finally overcome by the melting of its ice at the lower end, in the warmer valley region, more waste is found. The stones carried on the surface as medial moraines, and the stones and finer waste carried along in the bottom of the glacier, are lodged in confused heaps where the glacier ends, and make up the Terminal Moraine.

Let the student refer again to the map. He will observe streams which come to an abrupt end. They are formed by the surface-melting of the glacier, and plunge into wells which penetrate the glacier to great depths, or into equally deep cracks, or "crevasses," which may cross the glacier for considerable distances. Where the ice passes over a step or sharp descent of its rocky floor, it is strained, and many crevasses are formed. Cracking and melting combined will often make a glacier surface so rough that it can not be traversed. Several surface pools are also shown. It will be readily understood that the deep fissures, wells, pools, and surface streams vary much from time to time. 


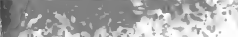

Wh $\rightarrow-7 y_{i}^{-1}-\cdots$

s is

3
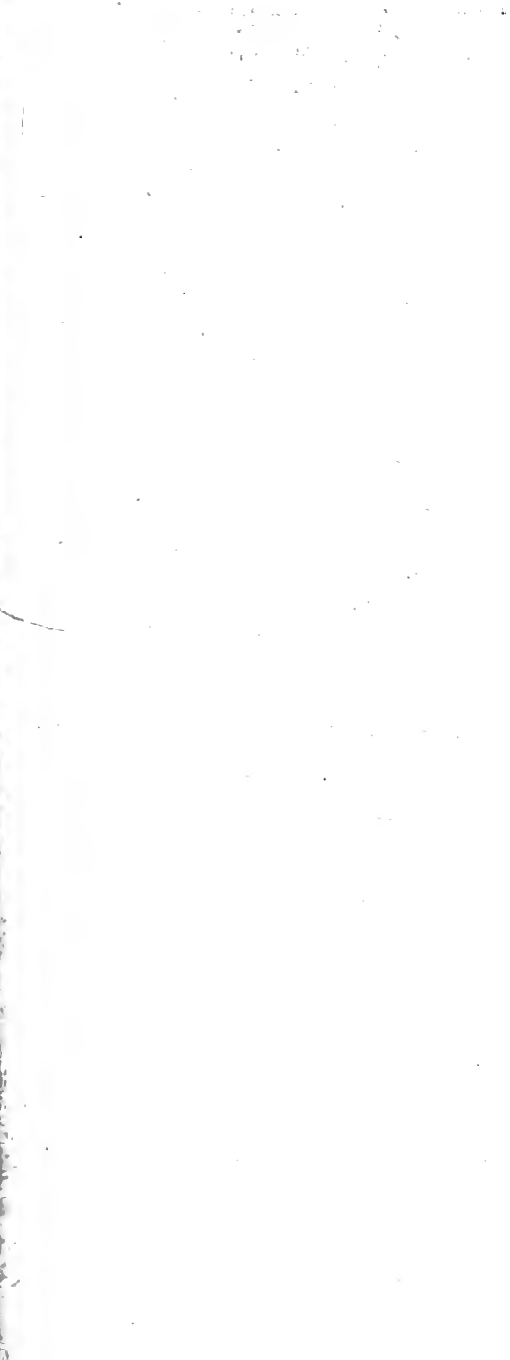


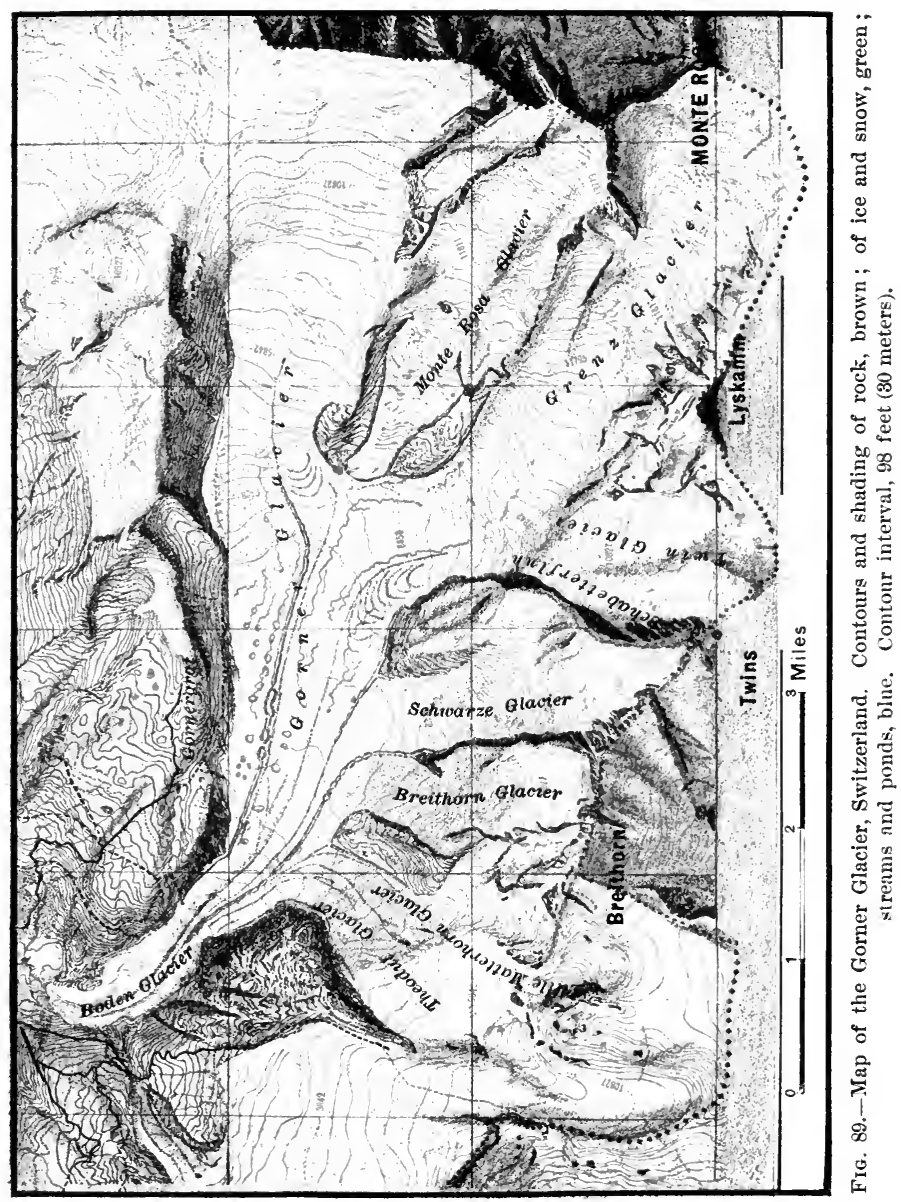




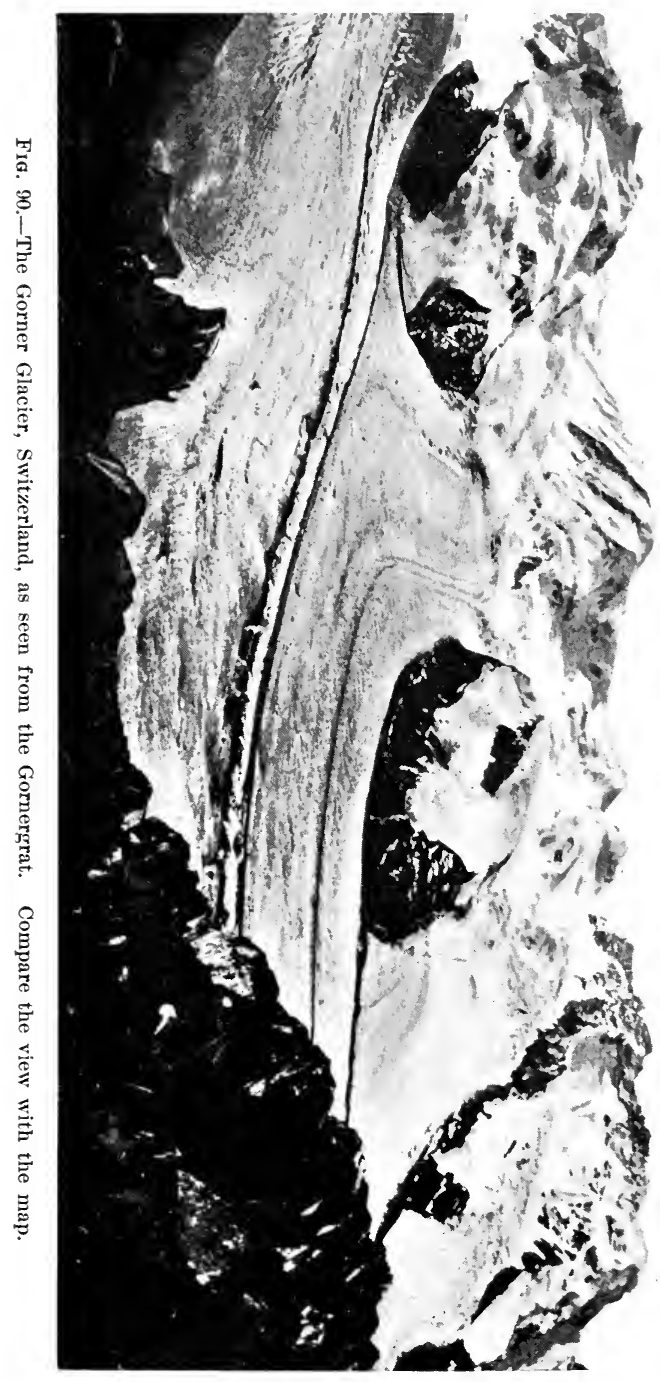

3
0
0
0
0
0
0
0

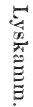

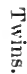

Ð્ّ 


\section{AN INTRODUCTION TO PIIYSICAL GEOGRAPHY}

Melting goes on also within and at the bottom of the ice. All these waters gather into a subglacial stream, which is often a considerable river, and flows into the open air at the lower end of the glacier. This stream under

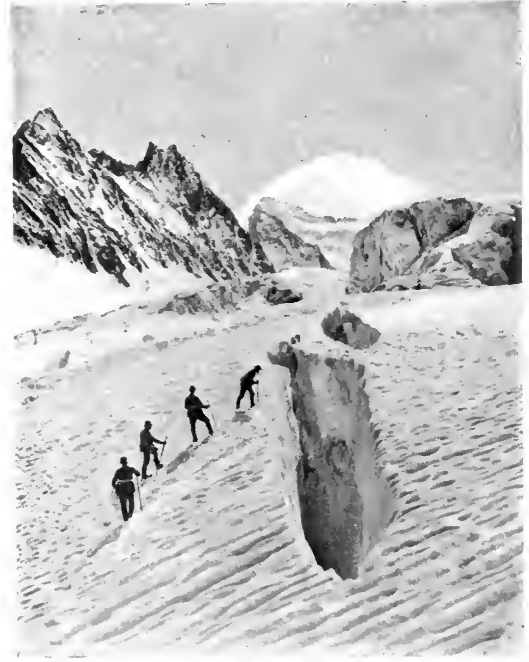

FIG. 91.-A crevasse. See page 120 . the glacier wears the rocks like any other stream. It also receives much rockflour made by the heavy grinding of the ice, and has a milkywhite appearance, which it retains for many miles in the open valley. The Swiss call such water "glacier milk." When firm rocks are ground up the powder is usually white, but the powder from weathering is yellowed by iron oxid.

The lower end of the glacier sometimes for a term of years pushes farther and farther down the valley; and it has thus destroyed cottages which were built too near its foot. The cause of such fluctuations is not well understood, but we can see that any change of climate which brought more snow, or less heat for melting, would make the glacier deeper, and cause the ice to push into the valley with more vigor.

We have thus studied the Gorner Glacier with care, not because it is the largest even of the Swiss ice-streams, but because it shows the characters of a glacier in an instructive way, and because the features described belong more or less to all glaciers. For a more complete knowledge, refer- 


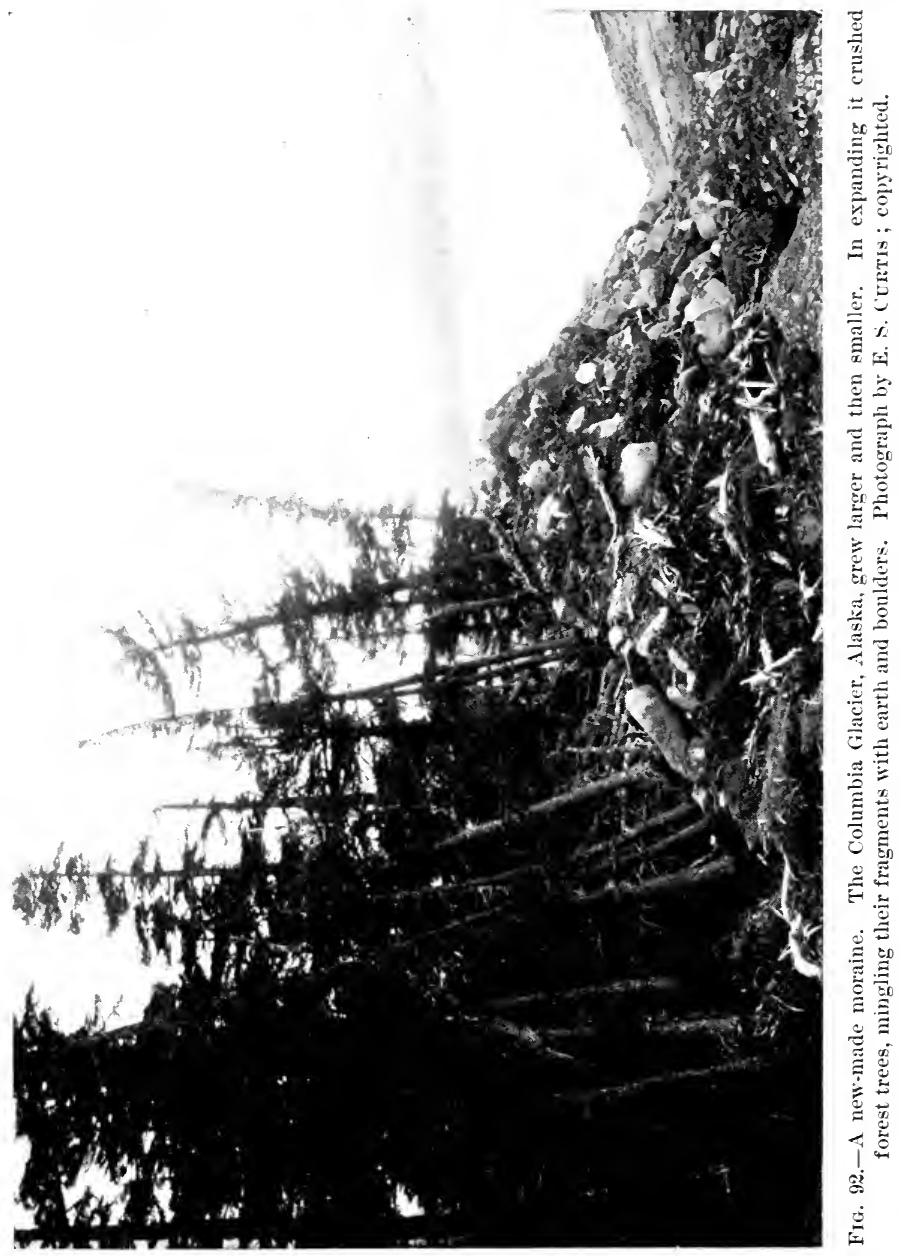




\section{AN INTRODUCTION TO PHYSICAL GEOGRAPHY}

ence should be made to Tyndall's Forms of Water, his Glaciers of the Alps, to text-books of geology, and to works on the Ice Age. We are now prepared to refer to other glaciers, and to see how important they are, or have been, upon the land surfaces of the earth.

122. Other Alpine glaciers.-Switzerland alone, not including the Austrian Alps, has several hundred glaciers. Of these, 138 are more than 5 miles long. The Aletsch, 15 miles long, is the greatest. 'The Lower Aar, 10 miles long, was made famous by the studies of Louis Agassiz. The Rhone Glacier, source of the Rhone River, has a wonderful fall, or cascade, 1,600 feet high, shown in Fig. 254. At the brink the ice is rent by innumerable crevasses, but at the foot it is welded again into a compact, smooth body.

123. Mountain glaciers of other lands.-In Europe these are found in the Pyrenees and Caucasus, and in Norway. In the last country they often descend from the uplands and enter the sea at the head of the sunken valleys, or fiords, which abound on that coast. In Switzerland no glacier reaches a point less than 3,000 feet above sea-level. In Norway, as in Spitzbergen, Greenland, and other northern lands, the lowlands are not warm enough to prevent the descent of the ice-streams to the sea.

In the Himalayas much longer and larger glaciers occur than are found in Europe, though less is known and written about them. Many glaciers occupy the high valleys and slopes of the Andes in South America and of the mountains of New Zealand. In Patagonia they descend to the sea.

124. Mountain glaciers of North America.-In the United States these are all of moderate size and lie in the high mountains of the West. Not long ago a small glacier was found in the Rocky Mountains west of Denver in Colorado, and named the Arapahoe. It is of interest as a remnant of the greater glaciers that once filled the high valleys of that State. Other and larger glaciers occur in the high ranges 


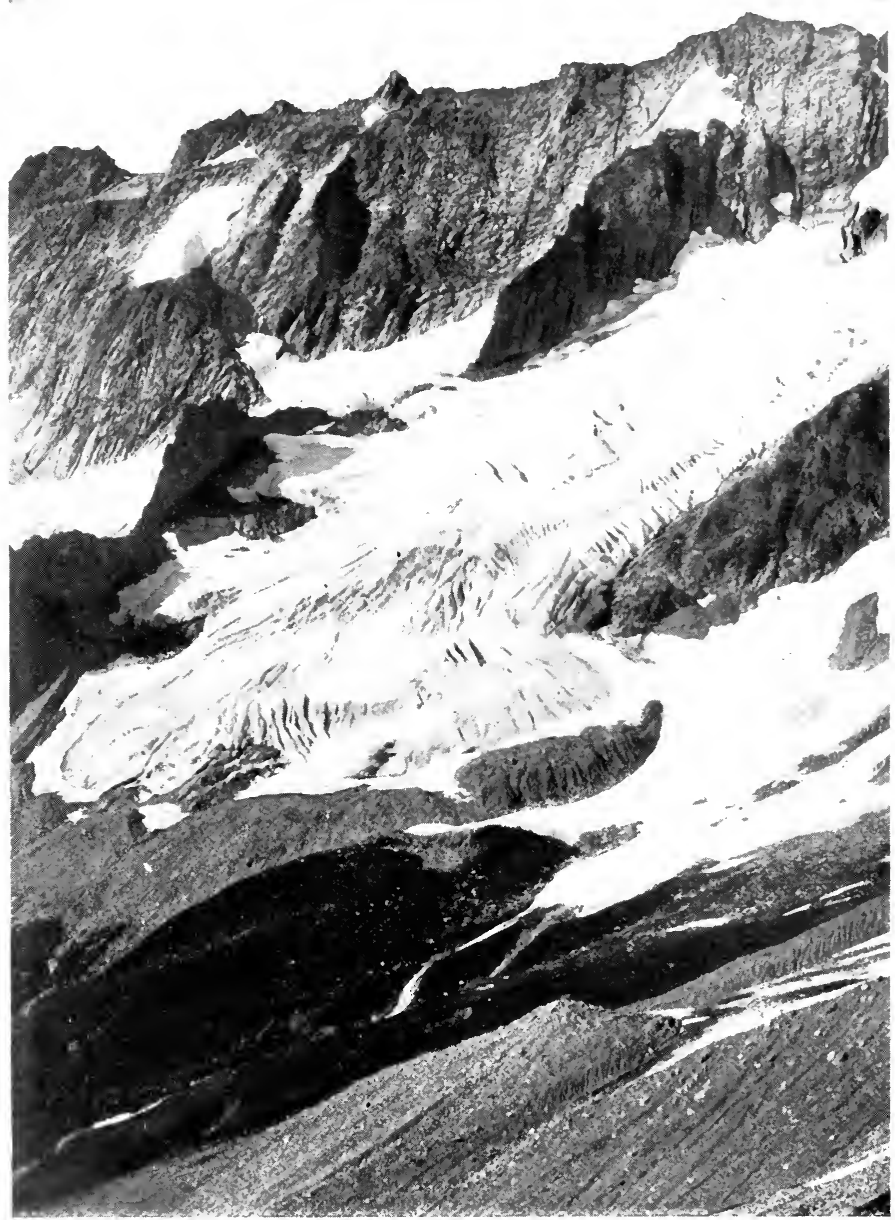

FIG. 93.-A glacier of the Cascade range in northern Washington. Though it is Angust, the higher parts are covered by snow and there are banks of snow farther down. The lower end is surrounded by a curving terminal moraine. It is one of a scries, each occupying an alcove which it has helped to make, and separated from its neighbors by narrow crests. The terminal moraine of another glacier occupies the foreground. 
of northern Montana and Washington (see Fig. 93). A few are scattered among the peaks of the Sierra Nevada, and five lie on the upper slopes of Mount Shasta. Several rivers which flow into the Columbia and into Puget Sound have their sources in the glaciers of Mount Rainier, Mount Hood, Mount Baker, Mount Jefferson, and Mount St. Helens. They are distinguished from other rivers of the region by the milkiness of their waters.

As we follow the Cordilleran system of mountains into Canada, we meet with larger glaciers, some of which descend into the lower valleys. Those of the Selkirk Mountains, along the line of the Canadian Pacific Railway, are best known. Going northward to Alaska, we find the icestreams still larger, and, like those of Norway and Patagonia, they often flow down to the sea.

One of the greater of these ice-streams is the Muir Glacier (Fig. 95). It is also one of the more accessible, and is visited annually by steamers carrying parties of tourists. It lies near the head of Glacier Bay, from whose waters its cliffs of gleaming white rise to a height of 200 feet. Its thickness is 900 feet, so that much lies below the water surface (Fig. 94). From the cliffs, masses crack off

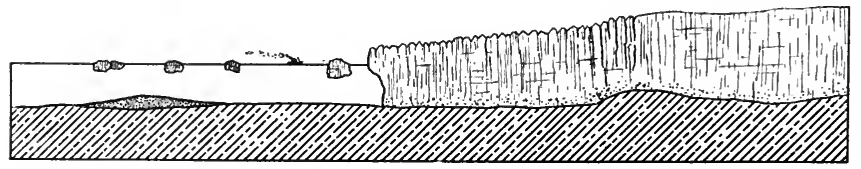

Frg. 94.-Section of end of Muir Glacier and part of Glacier Bay, showing icebergs. Scale, 1 inch $=3,500$ feet.

at intervals and float down the waters of the bay as small icebergs. On either hand are mountains several thousand feet in height, and one rocky mass protrudes through the surface of the ice-stream to a height of 1,500 feet. At least nine ice-streams, flowing from interior valleys, come together in a broader valley or basin to form the trunk 


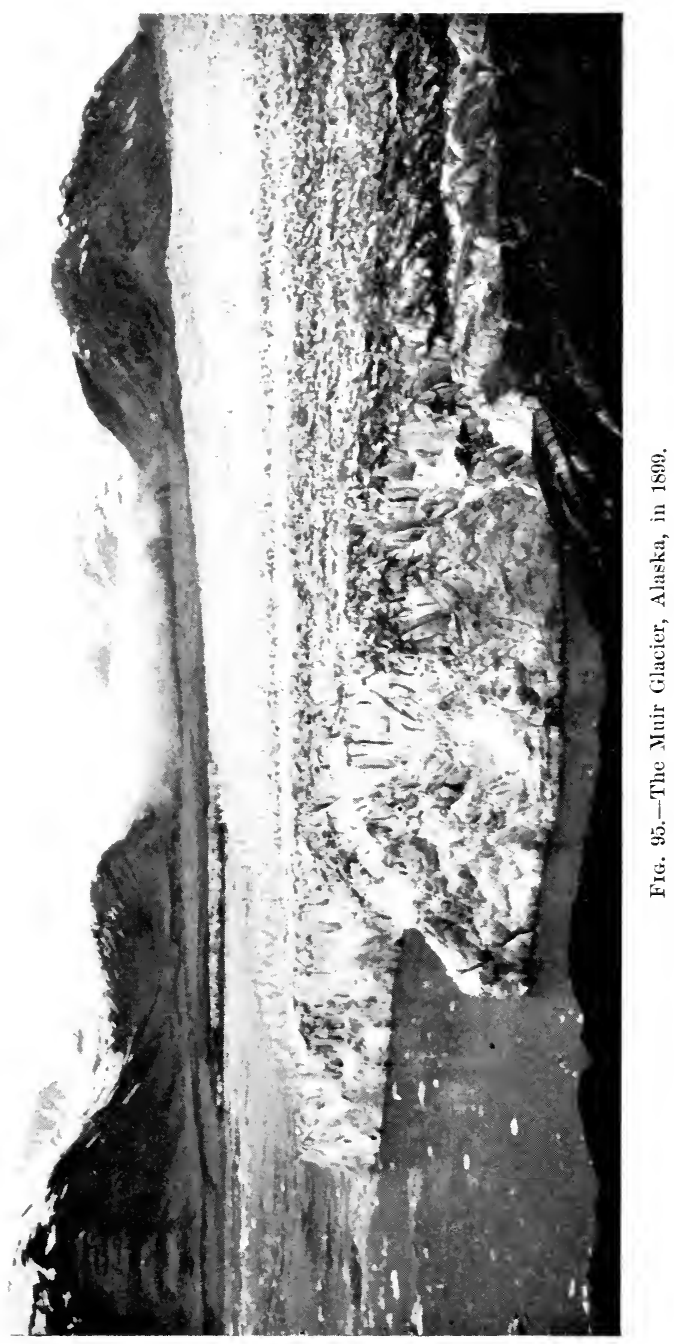




\section{AN INTRODUCTION TO PHYSICAL GEOGRAPHY}

glacier. This glacier was first visited in 1794, by Vancouver, who found it much larger than it is now. It was joined with glaciers from other sides of the bay, and for 40 miles the sea was displaced by a solid mass of ice.

On the southern slopes, and in the deep valleys of the range culminating in Mount St. Elias, are several large glaciers. These unite on the narrow plain that separates the mountains from the sea, and form a glacier 30 miles wide and extending 70 miles along the base of the range. At some points the sea is reached, and at others a narrow strip of land lies between the glacier and the shore. Thus we have mountain glaciers at the sources, but a Piedmont (foot of the mountain) glacier below. This lower ice-field is called the Malaspina Glacier. Its inner part, toward the mountains, is clear, but the outer border, for a width of several miles, is covered with rocks and earth brought in the ice and exposed as the ice melts. On parts of the overlying earth thick forests are growing.

\section{Continental Glaciers}

These are more often called Ice Sheets, because they spread widely over the land, concealing its hills and valleys. The ice sheets which now exist are instructive, because they prove the possibility of such gatherings of ice in former times, and because they throw light on the behavior and appearance of the ancient continental glaciers.

125. Greenland ice-sheet.-The larger part of this great northern land is covered with a sheet of moving ice. The ice-fields are about 1,300 miles long from north to south, and from 300 to 600 miles wide. Much of the border of the island is free from ice, especially toward the south, and along this narrow rim of land are the humble villages of the people, who live by fishing and the hunting of seals and walruses. In the interior the surface of the ice-cap, as it is often called, is several thousand feet above sea-level, and is an even plain. Thence it slopes gently 


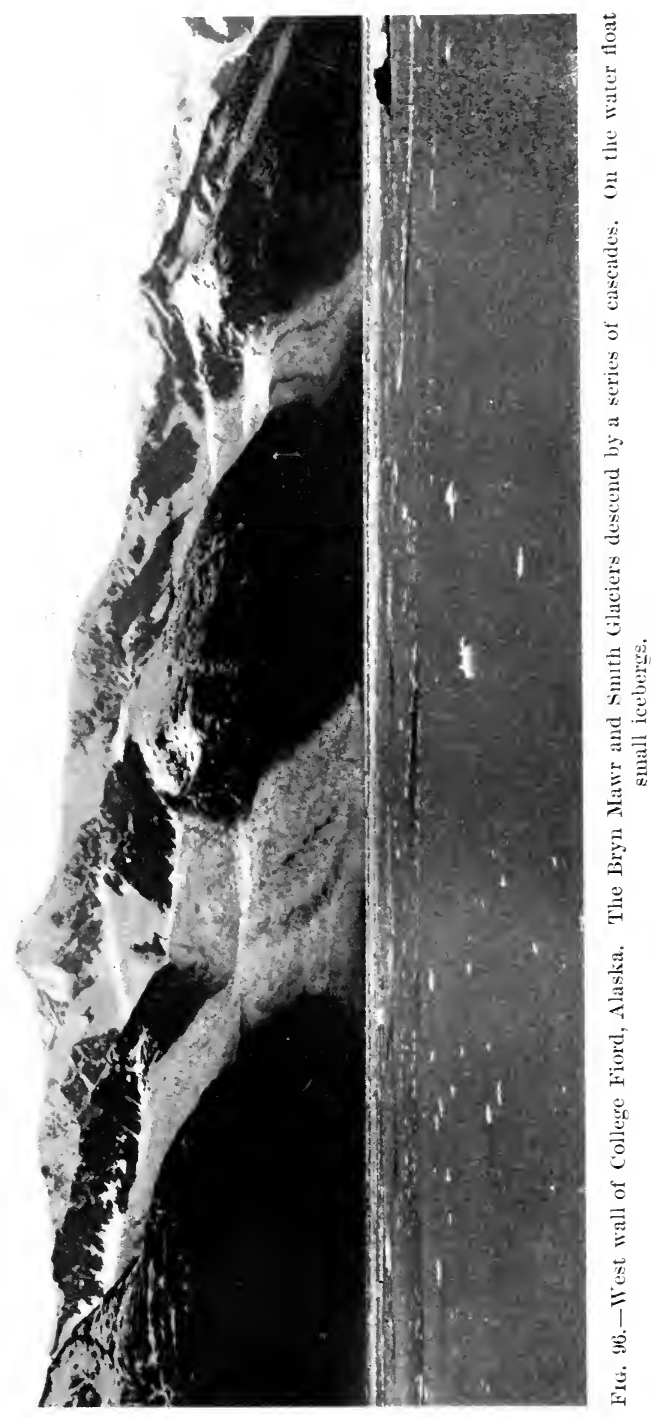




\section{AN INTRODUC'TION TO PHYSICAL GEOGRAPHY}

down toward the edge of the land, where it pours out through valleys and stretches of lower ground to the seaborder. Some of the ice-streams which thus drain off the great central mass are very broad; the Humboldt Glacier enters the sea with a width of about 50 miles. We thus see that whatever may be the shape of the land in the interior of Greenland, all is shrouded from view by this perpetual mantle of frozen water. Nansen crossed the ice of lower Greenland, from sea to sea, in 1888. In recent years Peary has extensively traversed the ice-fields of northern Greenland and determined the limits of the island toward the pole.

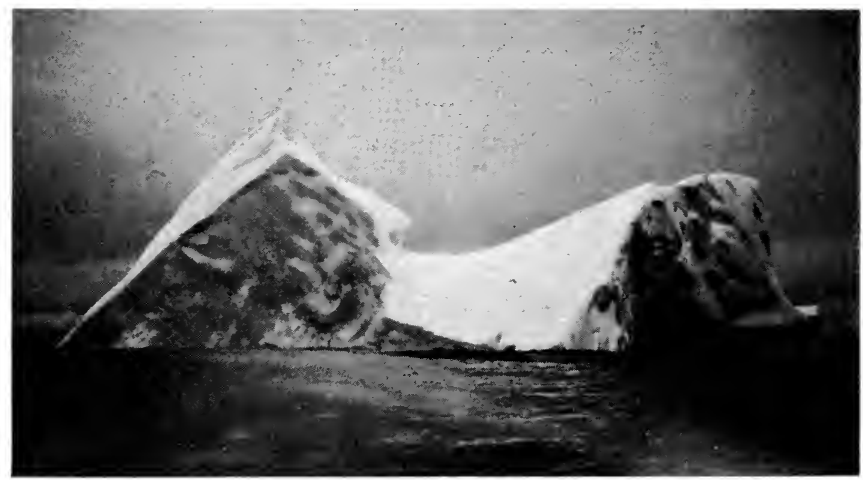

Fig. 97.-An iceberg in the North Atlantic.

126. Icebergs. - When a Greenland glacier, several hundred feet thick, enters water which is deep enough to buoy it up, great masses separate from the frontal part and float away. These are carried southward by ocean currents, often as far as the temperate latitudes, where their fleets put in jeopardy the summer navigation of the North Atlantic. The danger comes at this season, because until the late spring the northern waters are locked in ice which has formed over their surfaces during the winter, and the frag- 
ments of the glacier can get no release. The thinner ice formed by the freezing of sea water, and afterward drifting with wind and current, is called floe-ice. Even this travels far down into the open sea. The Polaris party of about twenty persons, who found themselves adrift on a floe in October, 18\%2, were picked up in April, 1873, having drifted for a distance of 2,000 miles.

12\%. Antarctic ice-fields.-A sheet of ice much larger than that of Greenland is believed to occupy lands surrounding the south pole. The interior has never been explored. Some navigators have coasted for long distances in the south seas along the precipitous edge of this icesheet, whose cliffs rise from 100 to 200 feet above the water. Expeditions are now setting forth from England, Scotland, Sweden, and Germany, for the purpose of adding to our knowledge of this region, which is the largest unexplored area yet remaining on the earth's surface.

128. Conditions necessary for the formation of glaciers.The Rocky Mountains are as high and cold as those of the Pacific States, but their glaciers are comparatively few and small. The difference is due to the abundant moisture and heavy snows of the Pacific belt and the greater dryness of the mountains far from the sea. There is a similar contrast between interior Alaska and its southern border. There are no glaciers upon the mainland of northeastern North America, while Greenland is nearly covered with ice. Greenland is no colder, but has more abundant snows. The Alps lift their great ridges and peaks into high altitudes, and thus stop and cool the clond moisture from the hot Mediterranean until it falls as snow. A cold climate and abundant snowfall are thus essential to the making of glaciers.

129. The glacier's work. - We have seen that a glacier tears away rocky material and carries it to considerable distances. We shall offer no explanation of the motion of a substance so brittle as ice. This is a difficult question, 
and for discussions of it the student is referred to textbooks of geology. But no one doubts that glaciers move, dig into the crust of the earth, and carry stones and finer waste a distance of a few or even of hundreds of miles. A moving, heavy body like a glacier grinds powerfully upon its rocky floor, until its base becomes shod with stones. These stones held by the glacier are like tools, and they both tear up boulders of the bed-rock and grind rocky flour from its surfaces. In mountain valleys the slopes rise steeply above the glaciers, and much material falls on the surface. The rocks carried on and in the glacier or pushed at its base lodge where the final melting takes place, forming moraines. The subglacial stream carries out large amounts of the finer waste. We shall later see how glaciers mold the land surface into various forms.

130. Summary. - A glacier is a mass of moving ice, in a valley, or widely spreading over the land. It can be formed only in regions of considerable cold and large snowfall. At the present time glaciers in low latitudes are found only at considerable heights, while those of the polar regions often descend to the sea. They accomplish many changes upon the earth's surface by wearing the rocks, by stirring and changing the soils, and by depositing their loads in hills and sheets of land waste. Some of these changes we shall now study more fully.

\section{The Glactal Period}

\section{Evidences of a continental glacier in the United} States and Canada.-The land waste and the land surfaces of the northern United States often resemble those found in a region of present glaciers. This is so widely true as to show that great glaciers once covered the face of the country. We are now to study some of the proofs of these earlier glaciers.

132. The drift.-If we examine a field in Maine or New York, or northern Indiana, or Iowa, we shall find the stones, 
the soils, and the subsoils often consisting of different material from the underlying bed-rock. Pebbles and cobblestones, small boulders and great ones, even to hundreds of tons in weight, are scattered over the surface or buried in the finer waste. Bedrock like these loose stones may be found 10 , 20,50 , or even some hundreds of miles away. In a given place all the boulders have come in about the same direction from the parent ledges. In New England the stones have traveled southeast or south. In New York the direction is south or southwest, and in Iowa south. These are "erratic" or strayed boulders, once moved by a glacier, as the Ma-

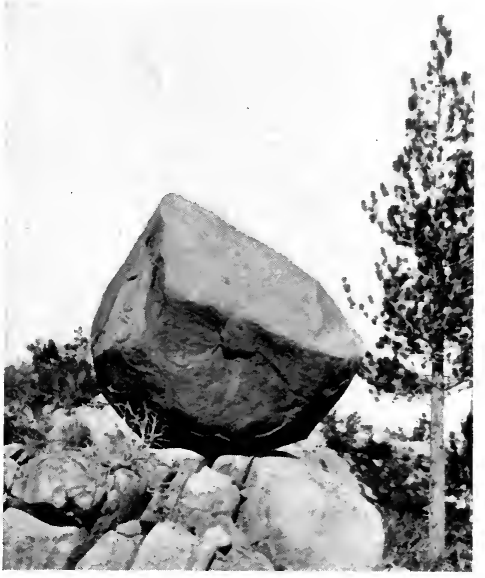

Fig. 98.-An "erratic"; a boulder of granite, about twenty feet across, earried from the Sierra Nevada to Mono Valley by an ancient glacier. laspina Glacier is now carrying stones from Mount St. Elias to the sea-border. Many of the stones, however, are like the rocks below, and these have been carried only a short distance.

It was formerly thought that these stones were brought over the lands by a great flood. But no explanation could be given of the origin of such a flood, and the fact was quite overlooked that the boulders commonly lie in finer, clayey waste, in which coarse and fine are mixed without order. If the mass had been deposited by water, it would have been sorted into coarser and finer layers, as is always the case with such deposits. Such a formation of clay and stones packed in without sorting or order, known as Till or 


\section{AN INTRODUCTION TO PHYSICAL GEOGRAPHY}

Boulder Clay, is one of the best proofs that the region where it is found has been covered by a glacier. The ice moves slowly and heavily over the country, plows and grinds the bed-rocks, and mixes rock waste of various sizes and from various sources.

There is another element in the Drift. A glacier is always melting; and the water that pours from top to bottom of the ice, or flows under the ice and ont from its front, carries clay, sand, and pebbles, which are laid down in beds or strata. Thus we have the stratified, or, as it is often called, the "washed" drift.

133. Glacial scratches.Many of the boulders and pebbles of the till are found to be Glaciated, or marked with parallel scratches. Often they look as if engraved with a sharp needle. Sometimes the scratches are deep and rough. A FiG. 99.-A bank of till; Bangor, Pa. marked polish is seen on some stones. If we dig through the subsoil to the bed-rock, we shall often find the latter scratched in the same way (see Fig. 100), or even deeply grooved and carved into flutings and moldings. The glacier, shod with stones at its base, drags these over the bed-rock, and thus both the moving frag- 
ments and the floor over which they move are polished and graven.

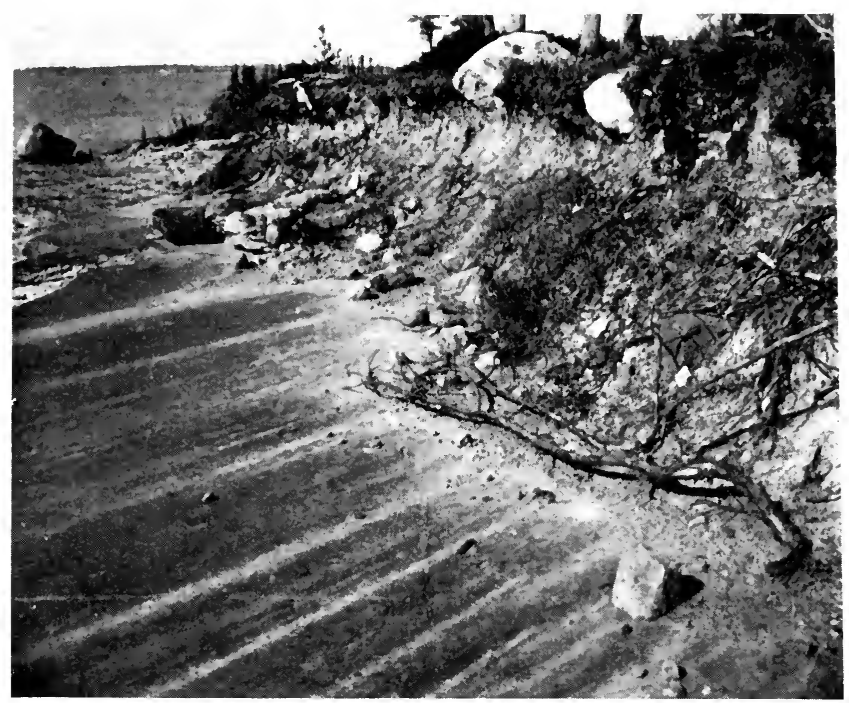

Fig. 100.-Shore of Lake Ontario at Pillar Point. Storm waves have washed away bouldery till, exposing bed-rock polished and scratched by the continental glacier.

The direction of the scratches corresponds to that in which the erratic boulders have been moved, and so, putting these and other facts together, we have full proof that glaciers have done the work.

\section{Surface Forms due to Glaciers}

134. Kames.-In New England, in central and western New York, in Ohio, Indiana, Wisconsin, and other Northern States are found clusters of sand- and gravel-hills (Fig. 101). Sometimes they are high and have steep sides. If we dig into them we find irregular layers, generally of sand, gravel, or coarse stones. Excavations for building 


\section{AN INTRODUCTION TO PIYSICAL GEOGRAPHY}

and road materials are common. Cemeteries are often placed upon such hills, because they are always perfectly

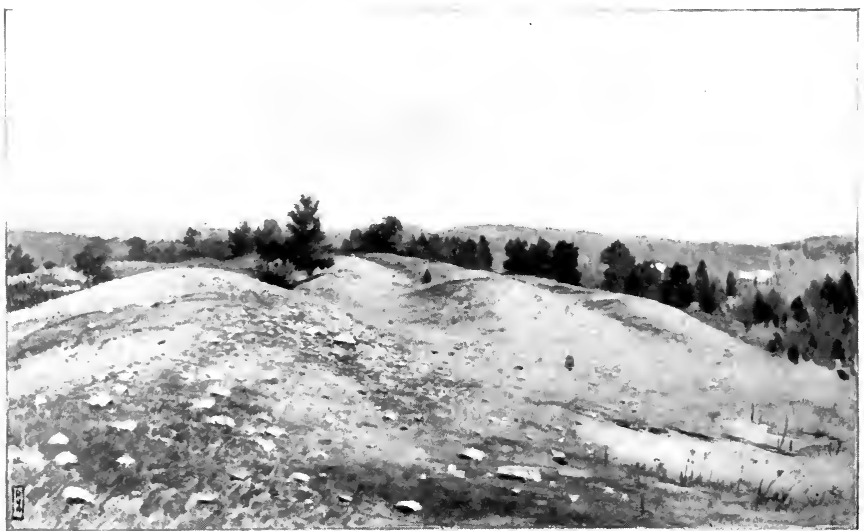

Fig. 101.-Kames, near North Acton, Me.

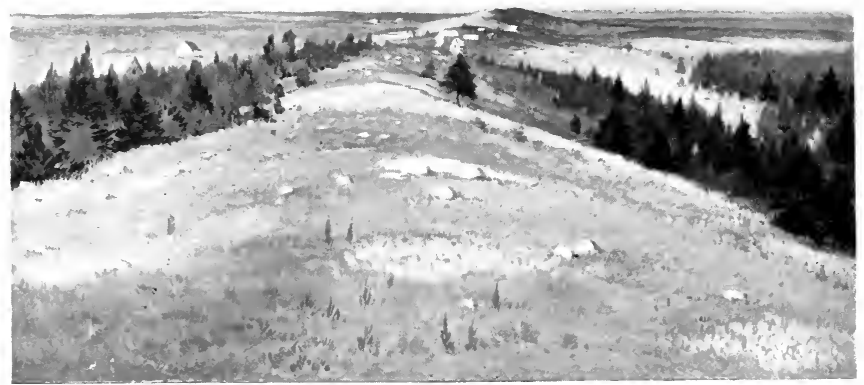

Fig. 102.-An esker; near Eufield, Me.

drained. Mount Hope Cemetery at Rochester, N. Y., is a case of this kind. Such hills are called Kames, a Scotch 
term. Similar hills are now being formed at the wasting edge of the Muir Glacier.

135. Eskers.-Long, narrow ridges of sand and gravel are sometimes found. Often they are winding, and the same ridge may be 20 feet high in one place and 50 feet in another. They have steep sides, and are often bordered by swampy grounds. Roads are sometimes carried along their crests. Such ridges, of remarkable length, are found in Maine. Others occur in southern New England and New York. They are called Eskers, an Irish term, and are believed to have been made by streams flowing in tunnels under the ice.

136. Drumlins.-In eastern Massachusetts, in western New York, and in Wisconsin are many hills, made, not of sand or gravel, but of boulder clay; in shape either round, oval, or elongated, and everywhere smooth and outlined by simple curves. Fig. 103 shows a characteristic form. They are called Drumlins, also an Irish term ; large numbers of such hills

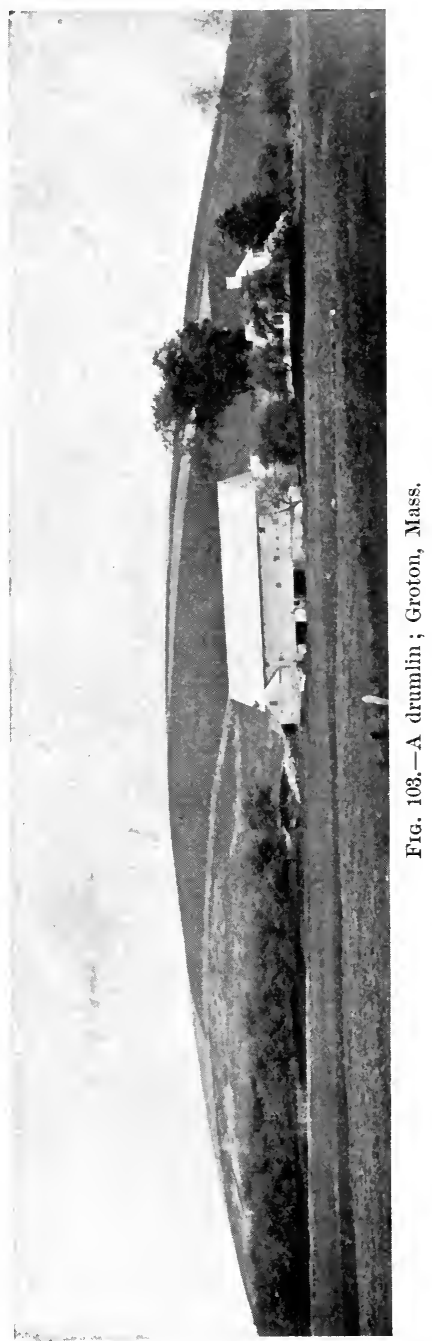




\section{AN INTRODUCTION TO PHYSICAL GEOGRAPHY}

are found in Ireland. They occur only in lands that have been modified by glaciers, and are believed to have been formed under the ice. Those of western New York are very long and have narrow crests; they may be seen from the railways between Syracuse and Rochester.

13\%. Wash plains. - The southern part of Marthas Vineyard is a low plain sloping southward to the sea. The north part of the island is hilly with moraine, and marks the position of the glacier front when the ice overspread New England. The plain was made by the streams that came from beneath the ice as they wandered this way

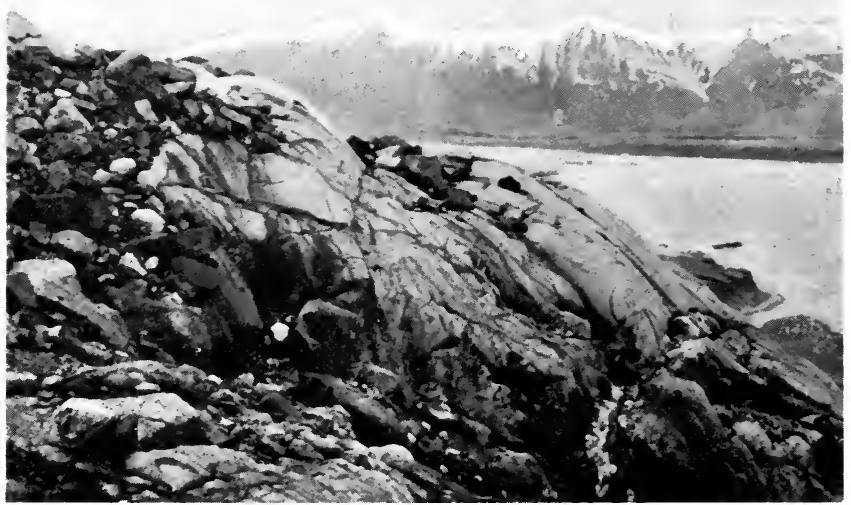

FIG. 104.-A mountain spur smoothed and rounded by a glacier; Glacier Bay, Alaska.

and that and dropped their load. Many such plains are found in the Northern States, and the process of their making may be witnessed at the margins of many glaciers of Alaska. 
138. Rounded and fluted rock hills.-If a region is marked by deep valleys and high hills, and a great glacier comes over it, the overriding and grinding of the ice will subdue

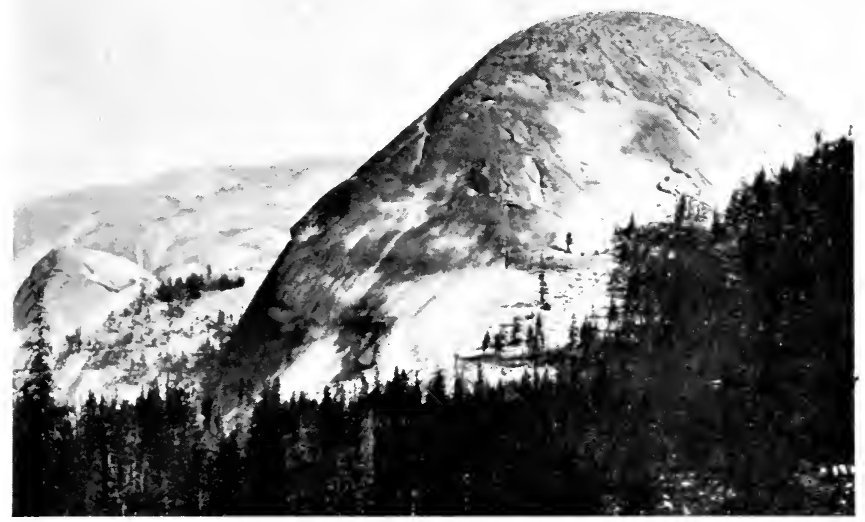

Frg. 105.-Tuolumne Monument, a peak of the Sierra Nevada, worn smooth by an overriding glacier.

the hilltops and hillsides, scour away frail ridges and sharp summits, and leave it a region of oval crests. Such hills are shaped like drumlins, but are often much higher and steeper, and, unlike the drumlins, consist of bed-rock, except the surface coating of boulder ciay. They often show a somewhat fluted surface, the fluting being parallel with the longer axis of the elevation. The Adirondack summits (Fig. 130) and the granite dome shown in Fig. 105 are examples of glacial rounding and smoothing.

A similar change is wrought in valleys which have such position that the moving ice follows them lengthwise. Projecting angles are pared away from their walls, and in time they become smooth-sided troughs with broad- 


\section{AN INTRODUCTION TO PHYSICAL GEOGRAPHY}

ly curved bottoms. The walls of Seneca Lake Valley (Fig. $42)$ were smoothed and straightened in this way, and the

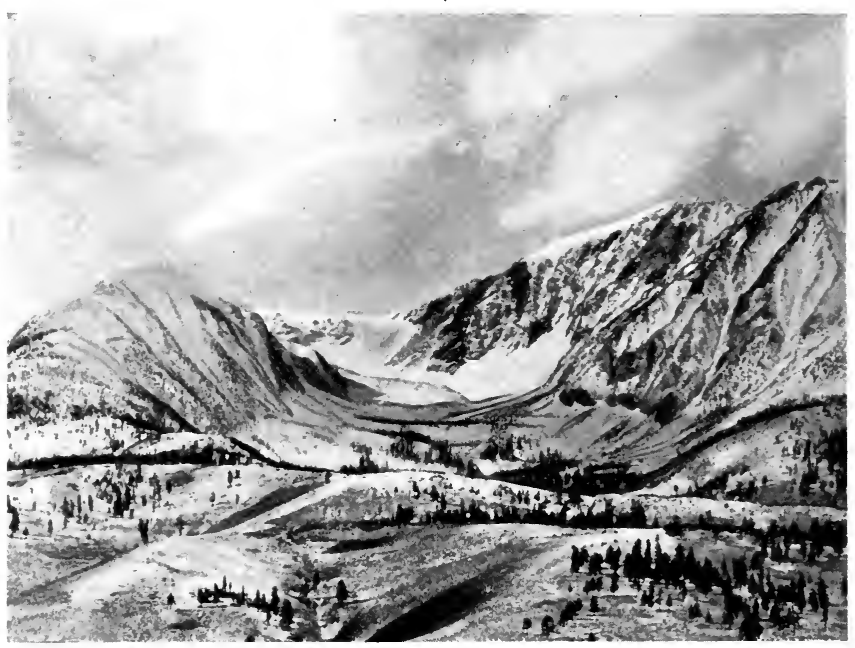

Fig. 106.-Gibbs Canyon, a U-trough of the Sierra Nevada. Compare with Fig. 107.

highland east of the valley illustrates the rounding of hilltops by an overriding ice-sheet.

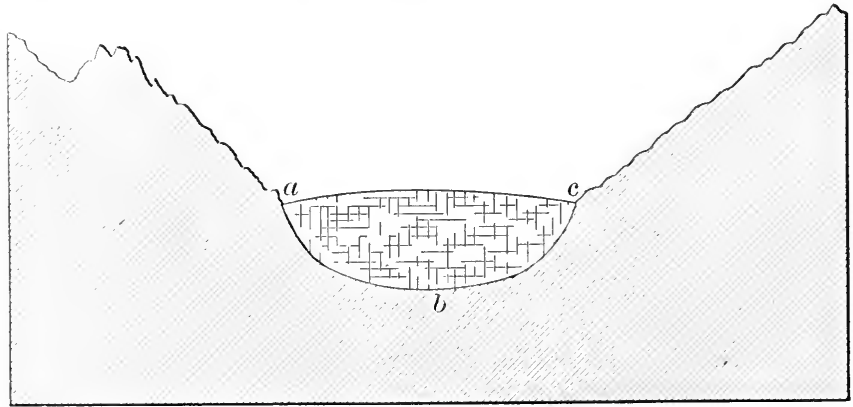

Fig. 107.-Cross-profile of Gibbs Canyon (Fig. 106), showing former glacier. $a b c$ is the channel worn out by the glacier. After the glacier disappeared the channel was partly filled by waste from the slopes above $a$ and $c$. Seale, 1 inch $=1,800$ fect. 
139. U-troughs. - Mountain glaciers also mold their valleys, giving them broad floors eurving upward at the sides so that the cross profile resembles a wide $U$. The Utrough is as characteristic of ice work as the V-gorge is of water work. See Figs. 106 and 10\%, and also the view of the Rhone Valley (Fig. 254), where the spoon-like trough once occupied and shaped by the glacier is beautifully shown.

140. Giant kettles.-We have seen how the plunging and swirling water of a river drills holes in the rock (Sec. 32). Pot-holes are also drilled by the streams which drop through wells from the top to the bottom of a glacier. Falling hundreds of feet, the streams acquire great force and are able to excavate pits of astonishing size. At Cohoes, N. Y., are several which measure from 10 to 30 feet in diameter, and these held ponds and swamps after the glacier which made them had disappeared. In clearing out the swamp muck from one of these, to find firm foundation for a mill, the skeleton of a fossil elephant was discovered.

141. Lake basins. - In the northeastern United States are

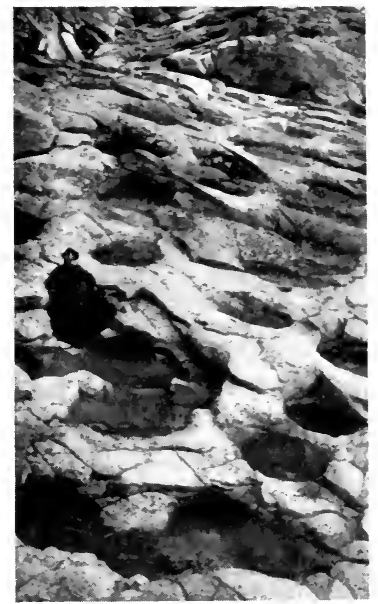

Fic. 108.-Pot-holes drilled in granite under an ancient glacier; $\mathrm{Si}$ erra Nevada. many thousand lakes. Ten thousand are found in the single State of Minnesota. Such regions as the Adirondacks and eastern Massachusetts are thickly set with them. Unnumbered thousands are found in the provinces of Canada. Almost without exception, these marked features of the landscape are due to glacial action in some form. Wherever, as on Cape Cod, great quantities of waste are left 


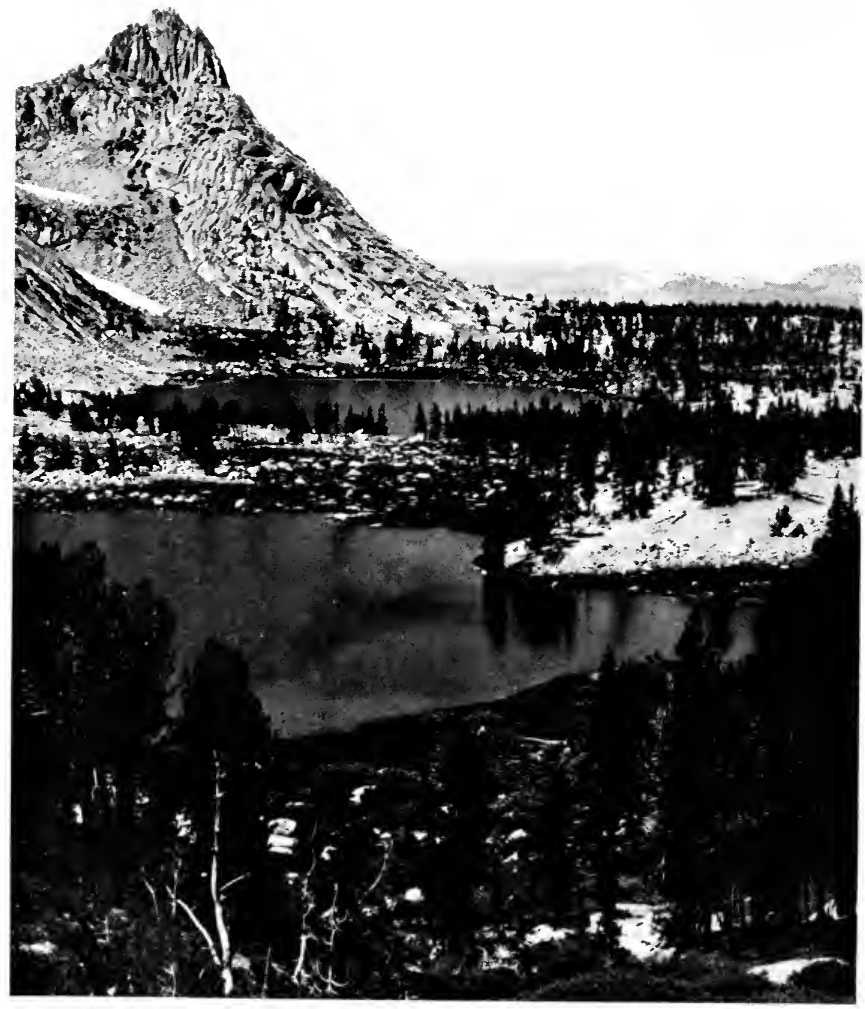

FIG. 109.-Shapes of valley and mountainside wrought by a glacier. Only the high crags were above the ice. Sierra Nevada. 
irregularly as moraines, many hollows occur which will hold water. Sometimes remnants of the wasting ice-sheet have been buried by the gravels of a wash-plain. This ice, melting out at last, has left a basin. Many lakes with steep rims, in the midst of much glacial waste, are known as Kettlehole Lakes.

In highland regions, plateau or mountain, the valleys were often clogged with drift, and parts of them thus turned into lake basins. Most of the Adirondack lakes can best be explained in this way.

Glaciers are so heavy and move with such power, that they will scoop out basins in the solid rock. The lakes shown in Figs. 109 and 110 lie in bowls thus

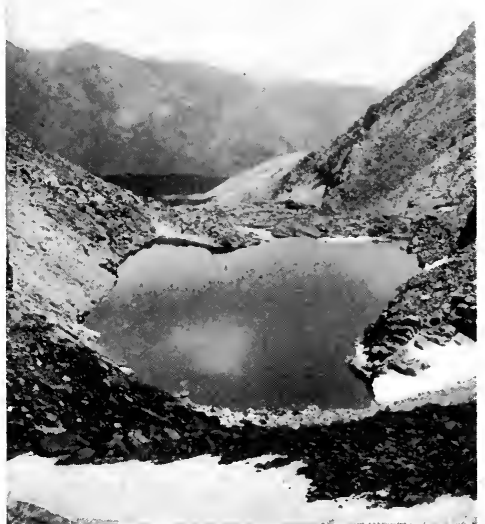

Fig. 110.-Lake basin hollowed from the rock by a glacier; Rocky Mountains. hollowed out by glaciers, as also do some of the Alpine lakes. The Finger Lakes of western New York are partly to be thus explained, and many lakes in the highlands of Canada lie in rock basins dug out by glaciers. Even the Great Lakes of the St. Lawrence system are believed to owe much of their depth to excavation by the great ice-sheet.

\section{History of the Glacial Period}

The full story of the ice invasions belongs to geology, but since it is a very late chapter in the history of the earth and tells much of the shaping of the present surface of 


\section{AN INTRODUCTION TO PHYSICAL GEOGRAPHY}

the lands, it is important for geography also. We have just studied some of the changes that glaciers cause, and we shall understand them better if we review, in a connected way, the story of the Glacial period in our own continent.

142. Gathering and advance of the ice-At the beginning of the period of cold, deep snows gathered and ice was formed on broad uplands of Canada. As the cold inereased, the areas of ice formation grew larger, and the ice also spread by flowing outward about its edges. The icecenters were not among high mountains, but the ice grew in thickness until, like a mass of pitch, it was forced to flow by its own weight. It spread in all directions, and the south edge crept out over what is now the boundary of Canada and invaded the region of the United States. How far it reached can best be understood by studying the map (Fig. 111). The line of its extreme limit, which geologists have traced with care, traverses the southern border of New England, crosses New Jersey, Pennsylvania, and southwestern New York, and then follows a crooked course north of the Ohio River. It nearly follows the Missouri River across Missouri, and then runs northwest through Nebraska, the Dakotas, and Montana. Much of our Western mountain region, where now a few remnant glaciers are found, was covered with ice, continuing into the greater ice-fields of British Columbia. North of this line are the till, the traveled boulders, plains and hills of washed drift, abundant lakes and waterfalls, glacial scratches, and many other signs of a glacier. South of the line these are absent, and both the soil and the land forms contrast with those on the north. The soils, for example, to the southward are made alone by the decay of the underlying rocks. There are no glacial scratches, no erratic boulders, and few lakes or waterfalls.

143. Glacial epochs. - As shown by the map, the ice outline had different forms at different times. The two forms 


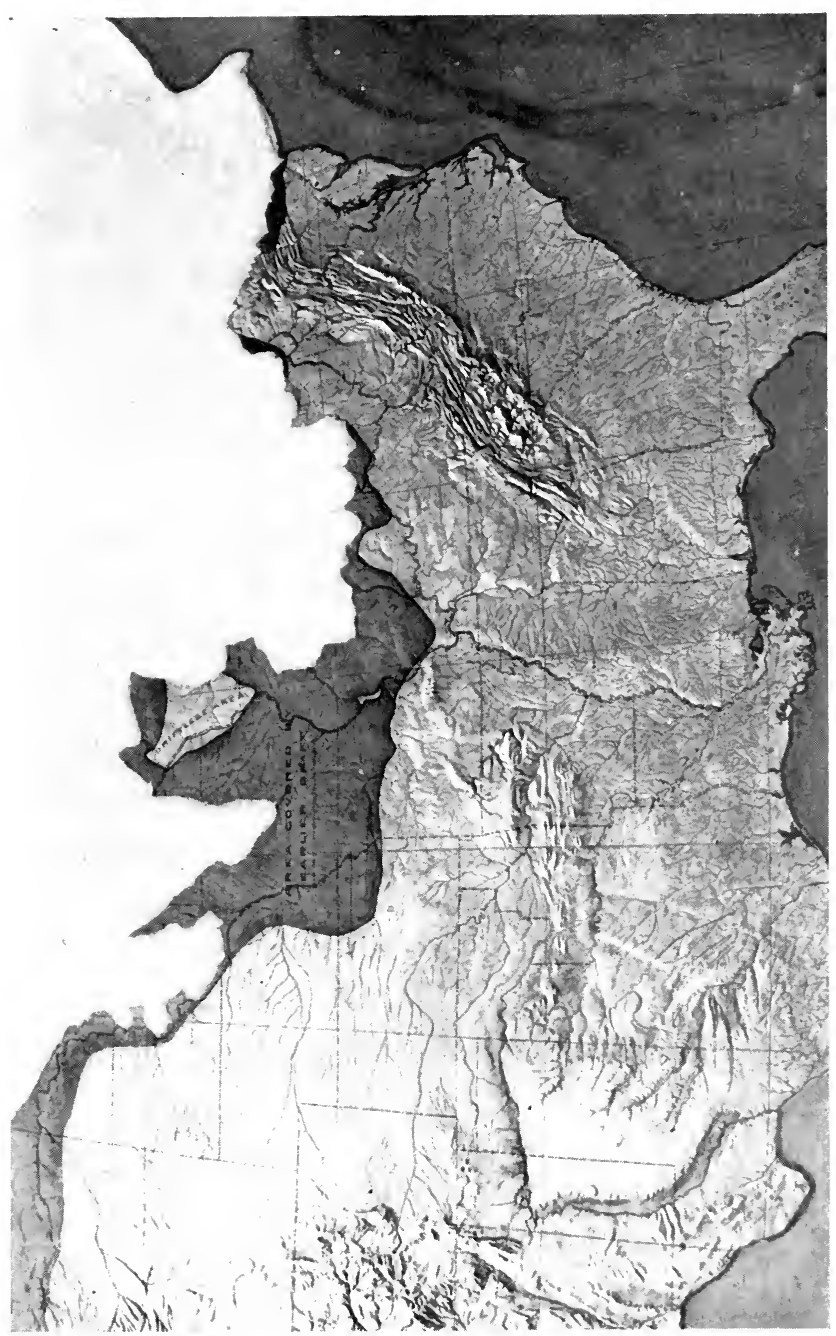

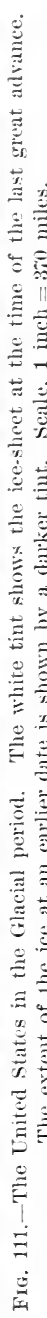




\section{AN INTRODUCTION TO PHYSICAL GEOGRAPHY}

there represented are the ones best known, but there were many changes. Sometimes the glacier melted off far to the north, and then more snows came for a long time, and the ice gathered and pushed on again. All this required a long period, as we count time; but the important point for us now to grasp is, that the ice served as a powerful plow or scraper to stir the rocks and soils, move materials from their sources, and make over the surface of the lands.

144. Glacial lakes.-Let the student trace on a map the line of water-parting, or the divide, that separates the Great Lake drainage from the Mississippi, Susquehanna, and Hudson River systems. Let him also remember that the ice in the time of its farthest flow to the south passed considerably beyond this divide. While it was first melting off, therefore, the waters flowed mainly into the Mississippi and Susquehanna basins. When the glacier had melted off in the vicinity of the present Chicago and Detroit to points north of the divide, the eastern region about the Mohawk and St. Lawrence valleys was still full of ice. It will readily be seen, therefore, that there were lakes gathered between the divide on the south and the wasting glacier on the north. As the ice melted farther back these lakes became greater in size and often changed much in form. But in time the ice melted out of the Mohawk Valley in New York, and the drainage of these glacial Great Lakes poured out between the Adirondacks and Catskills to the Hudson and the sea (see Fig. 112). Still later, the glacier melted out of the St. Lawrence Valley, and the Great Lakes came to their present levels and forms. This is a short review of the history, leaving out a multitude of the lesser changes. But even this short story helps us to understand two features of the Great Lake region. One is the old lake beaches which are found, sometimes several hundred feet above the present lakes, and at varying distances back from their shores. The other is the flat lands of silty or clayey soil found about the edges of the lakes, as in north- 


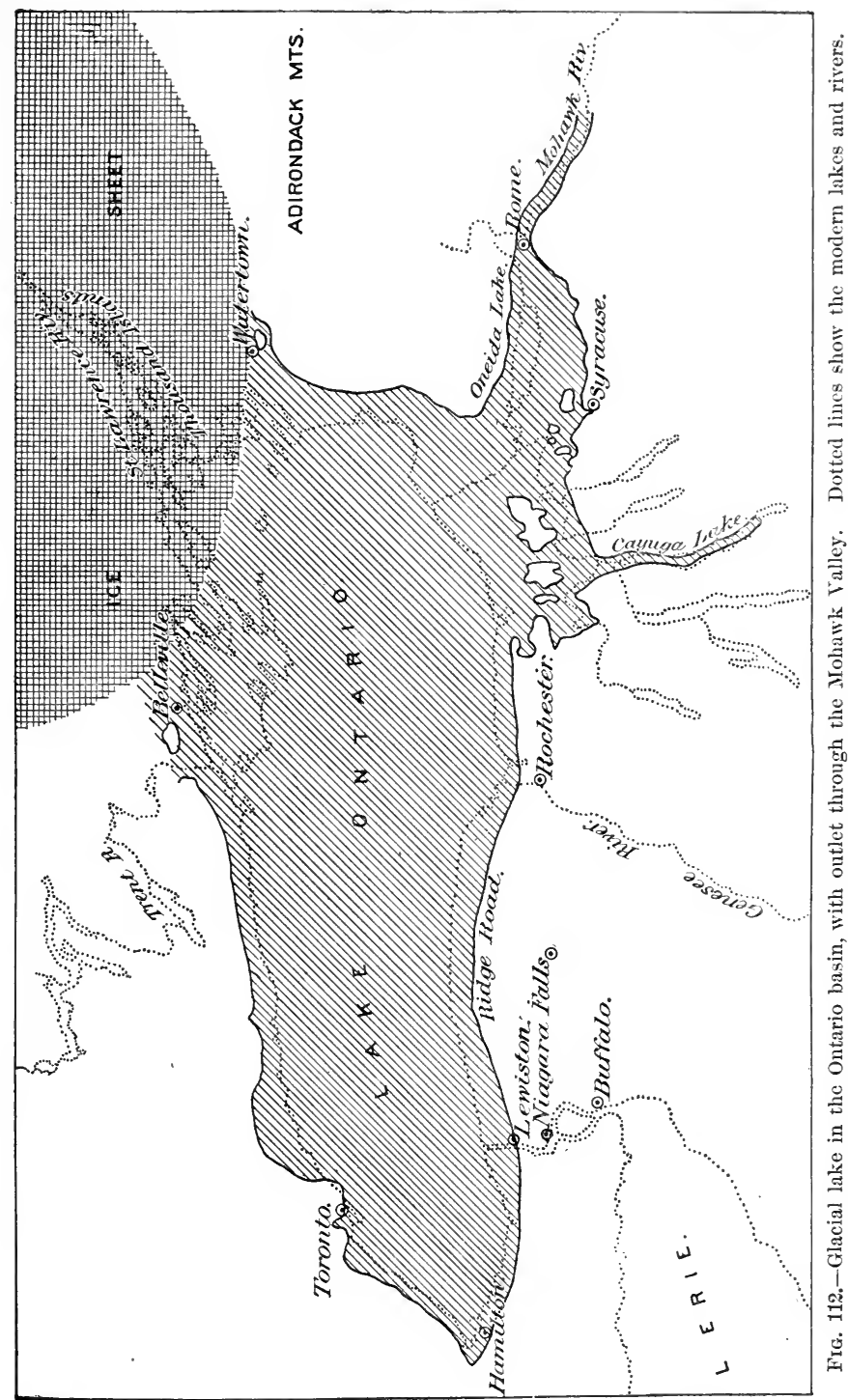


western Ohio and southern Ontario. They are lake bottoms turned into habitable and often most fertile lands by the drawing down of the lakes.

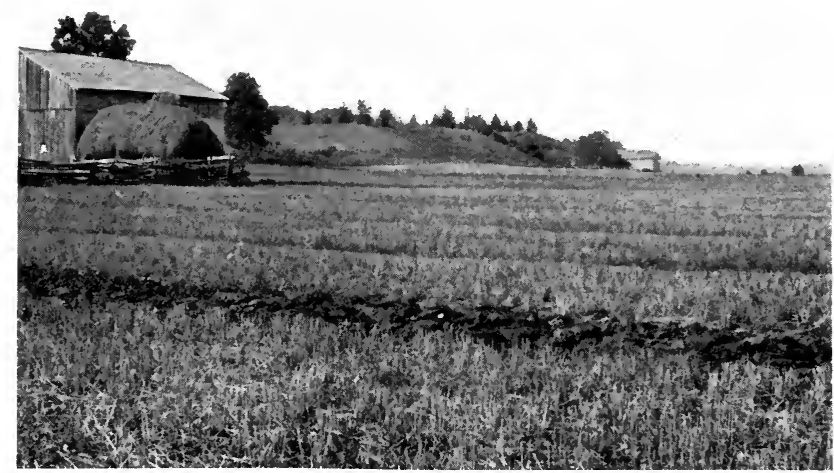

F1G. 113.--Smooth bed and bluff shore of ancient lake; near Lewiston, N. Y. See page 146 and Fig. 112.

145. Changes since the disappearance of the ice.-The rivers, the winds, and all the processes of decay have been at work breaking down the rocks, accumulating the soils, and changing the land forms. Valley bottoms covered with coarse waste by glacial streams have been mantled over with the fine muds of river flooding. In swampy districts plants, including their stems, leaves, and fruits, have lodged and decayed, making beds of black soil or of peat. Many shallow lakes formed during the glacial invasion have been filled by such vegetation, and by fine muds brought in by streams. 'The "vlies" or natural meadows of the Adirondacks mark such filled lake basins, and they can be found everywhere in the northeastern United States.

Many lakes which remain have their bounds narrowed by deltas built at their heads or along their shores where streams enter. A great number of deep gorges have been 
cut out by streams since the glacial time. Reference was made to many of these in Chapter III. Here belong Niagara, Trenton, Ausable, and a multitude of more local fame.

146. Changes in the course of rivers.-Much waste was lodged in valleys, either at certain points or for long distances. Hence rivers often could not resume their ancient paths and sought out new ones, following the lowest levels they could find. The Mississippi was thus, as we have seen, forced out of its old, open valley, at Minneapolis, and is gradually reducing the grade of its new course by cutting the gorge that runs down to St. Paul. Before the Glacial period much of western Pennsylvania drained to a valley where now is Lake Erie, and the upper valley of the Missouri found outlet to Hudson Bay or the Gulf of St. Lawrence instead of to the Mississippi and the Gulf of Mexico.

Much of the effective water power of the Northern States is due to such changes. The old valleys had low, graded bottoms, but blockades of drift made the water flow across at higher levels. In the making of new valleys rocks were encountered, and waterfalls and rapids result. Water power is most effective when, by diverting the water for a short distance through a raceway, it can be given a plunge of some height. Just such conditions were brought about by the glacier at Lowell, Fall River, Holyoke, Bellows Falls, Trenton Falls, Niagara, and in a multitude of lesser cases. Many features of natural scenery in which we most delight have thus come into existence by the direct influence of the ice invasion.

147. Effects on soils.-We have seen that soils will develop by rock weathering and the admixture of decaying plants over nearly all lands. The exceptions are slopes too steep to retain waste, and areas too dry to support plants. The glacier, however, affected soils in several ways. It added much to the amount of available rock waste by grinding material from the rock surfaces, and making it so 


\section{AN INTRODUCTION TO PHYSICAL GEOGRAPHY}

fine that it could readily be dissolved by water, and so taken up by the rootlets of plants. It also stirred the old soils and mixed them with foreign matter, often greatly enriching them. Limestone was often ground up and pushed on to mingle with the somewhat barren soils of a sandstone region.

We may refer here also to certain other useful materials of glacial origin. The most common source of building sands, of brick clays, and of road-making gravels is in the drift. Multitudes of glacial boulders, while a hindrance to tillage, have been gathered into fences and foundation walls, and the walls of the first granite building in the United States, Kings Chapel in Boston, are of dressed granite boulders.

148. Effects on animals and plants.-Botanists know that plants are grouped largely according to the nature of soils and their situation. Swamps have their plant societies, as also the sand-hills, and the clayey uplands. Thus, by determining land forms and soil, the glaciers have influenced the groupings of herbs and trees, and through these the settlements and industries of man. We must not forget that long before the ice invasion the land was mantled with plants, and was the home of a multitude of animals of lower order than man. All these had to change their home gradually as the icy winter spread over the lands. In such forced migration many kinds of living things would be overwhelmed, and, when the ice had gone and life resumed its sway over the lands, the kinds and groupings were different from those that had existed before.

149. The Glacial period in Europe.-All of northern Europe was shrouded in ice. Scandinavia, the British Islands as far south as the Thames Valley, the North and Baltic Sea basins, northern Germany and northern Russia, were occupied, and changes were wrought similar to those in North America. The glaciers of the Alps were much greater than now, flowing out upon the plains of northern Italy, northern Switzerland, and southern Bavaria. 


\section{CHAPTER VII}

\section{PLAINS}

ALL continents are composed in part of low and comparatively level ground, and in part of hills and mountains. No sharp lines of separation can be drawn, but this will be best understood as we study special cases.

\section{Marine Plains}

150. The Atlantic coastal plain.-Southern New Jersey is a low, flat country, and, excepting a narrow strip along the Delaware River, slopes gently southeastward to the sea. It is a sandy region, with sluggish rivers and many swamps, and is largely covered with scanty forest. If we dig below the surface we find beds of sand, gravel, and clay, not yet bound into firm rock, and, like the surface, sloping gently down to the ocean border, where they are continuous with beds of coarser and finer mud that descend beneath the salt waters. In these uncemented rocks are shells and other animal remains, which closely resemble those gathering on the bottom of the sea at the present time. Except that it is exposed to the air, has some coating of soil and plants, and has been slightly roughened by streams, southern New Jersey is like a sea bottom, and hence we conclude that not long ago in the history of the earth it was a sea bottom. Such a belt of new land we call a Coastal Plain.

All of Delaware belongs to the same plain, and also much of Maryland, east and west of Chesapeake Bay. The plain includes eastern, or "Tidewater" Virginia, as far west as Richmond. The same uncemented deposits, con- 


\section{AN INTRODUCTION TO PHYSICAL GEOGRAPHY}

taining ocean shells, are found, and they incline, or dip, gently toward the coast line. Many bluffs on the borders of Chesapeake Bay show these beds well. The chief streams run to the southeast in shallow valleys, and the low bordering bluffs are often notched by the valleys of tributary streams. Between the watercourses, however, are blocks of flat country, not traversed even by rivulets (see Fig. 44). The rain which falls on these surfaces drains away by underground movements. Roads and villages are more often laid out on the interstream areas than in the valleys.

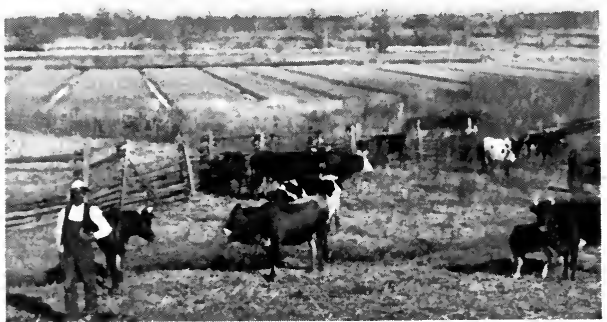

F1G. 114.-The Atlantic coastal plain. A rice and stock farm in South Carolina.

Similar is the Atlantic Coastal Plain in the Carolinas and Georgia. There it is about 100 miles wide, and extends as far as Raleigh and Columbia. Washington, Philadelphia, and Trenton also mark its western limit. The tide enters the rivers nearly or quite to these cities. Beyond them the country is higher and rougher and the streams flow more swiftly. On one side is the plain with its muds and half-cemented beds of sand, its navigable and sluggish streams and its flat uplands of small elevation. On the other side are hard rocks with worn and 
uneven surfaces, rising gradually to the base of the $A_{1}$ palachian Mountain ranges. This line, as already mentioned, is known to geographers as the Fall Line (see pages 65 and 70 ). There are rapids in some of the rivers, as they pass from hard to soft rocks, and the association of water-power with the up-stream limit of navigation has caused many cities and towns to grow up.

It will be remembered that the resemblance of Chesapeake Bay to a branching river was explained by saying that the Coastal Plain had sunk down so as to let the sea flow into the Susquehanna Valley. Because we now point out that the plain is an old sea-bed which has risen, it must not be thought that one fact contradicts the other. Both changes have taken place, but at different times. After the plain had been formed under the sea it was lifted so high that rivers dug deep valleys across it; then it was lowered part way, to the present height. Such risings and sinkings have much to do with the shapes of coasts and coastal lands.

Because America was discovered from the east, it was natural that settlements should be earliest made on the Atlantic border, and should thence extend across the easily traveled lowlands. The tidal rivers enabled boats to bring the manufactures of England direct to almost every plantation, and to receive in exchange the colonists' crop of tobacco. Various parts of the Atlantic plain differ much in soil and climate, and hence in occupations and in density of population. Such deposits as underlie this belt do not afford metals or coal, hence there is no mining industry; but in New Jersey and elsewhere they include clays which are much used for pottery and brickmaking. The country nearer the shore is usually sandy and little suited to agriculture, so that great tracts are still clotled with their original pine forests, as in southeastern New Jersey and eastern North Carolina and Georgia. At the south, lumber, tar, and turpentine are important products of 


\section{AN INTRODUCTION TO PHYSICAL GEOGRAPHY}

forest lands. Other parts of the plain, especially at some distance from the sea and along the Fall Line, have richer soils, and are farmed to great advantage. In them grow the fruits and vegetables which supply the early markets of the great Atlantic cities and inland towns. Such a rich district is found in New Jersey, in the narrow belt which drains toward the Delaware River near Philadelphia. Here the subsoils often hold deposits of marl, which is used as a fertilizer. Far to the south, cotton is an important crop, and rice is grown on coastal lands and sea islands of South Carolina.

The student should refer to Section 101 for definition of artesian wells. A coastal plain offers all the needed conditions-continuous, gently sloping beds, of which some are fine and close, not allowing the easy passage of water, and others are porous and open. Hence the wells are an important source of supply for the towns of eastern and southern New Jersey. In such a region pure surface-waters can not readily be obtained.

151. Siberian marine plain.-The largest plain in the world forms the north and west parts of Siberia. It is difficult to appreciate the size of Siberia as a whole. It has been said that if the United States were spread out upon it, enough land would be left to hold all Europe, save Russia, with a space larger than the German Empire yet to spare. Northwestern Siberia, to a width of 1,000 miles or more, is a smooth plain sloping imperceptibly northward to the borders of the Arctic Sea. As the rivers flow northward, their lower courses are often bound in ice while their upper parts are open, and this leads to ice-jams and great flooding of the plains. The divides between the streams (Sec. 31) are ill-defined and variable. Shallow lakes and quaking marshes are of large extent. The water from the marshes between the $\mathrm{Ob}$ and Yenisei flows sometimes to one river and sometimes to the other, according to the direction of the wind. From about the sixty-ninth parallel 
northward the plain is a Tundra, or frozen prairie. The cold of winter lasts longer there than the warmth of summer, and controls the condition of the ground. To a great and unknown depth the subsoil is forever frozen; but in the brief summer the snows melt away and a few inches or a few feet of the soils are unlocked by the sun. Grass, mosses, swamp plants, and stunted berry bushes grow rapidly, and this scanty vegetation, with fish from the rivers, supports the scattered and miserable population of this cheerless region. A few reindeer constitute riches, and these, for two-thirds of the year, live by pawing the snow cover from the mosses of the plain.

The tundra of Siberia has half the area of the United States. It gradually passes into a vast forest zone lying between the sixtieth and sixty-ninth parallels. Much of the timber is already exhausted, but the hunting of furbearing animals is an important industry. The forest belt is temperate in climate, as is a narrow but important zone of good agricultural land lying to the south of it. The latter is also rich in minerals. In western Siberia the plains cross all the zones now described, and embrace the hot, dry region about the Aral and Caspian seas.

This vast plain is marine, and young. Not long ago, as geologists count time, it was sea bottom, and by gentle elevation of northwestern Asia it has become land. Its surface parts indeed have been somewhat modified. Rivers wandering over its northern floors have spread land waste. The peaty accumulations of swamps have gathered upon it, and in the dry regions of the south the winds have worked over the surface materials. But below the thin sheets of later deposits the beds are marine, and the land has never been far above the sea-level.

\section{Lake Plains}

152. Red River valley.-The Red River forms the boundary of Minnesota and North Dakota, and flows 
thence through Manitoba to Lake Winnipeg. The stream meanders in strong curves, and has scarcely sunk its channel below the surface of the land, which is so flat that one may travel for miles without rising or descending through a vertical interval of 20 feet. Thus the valley, so called, is a smooth plain, sloping faintly toward the river, from the east in Minnesota and from the west in North Dakota. The soils are everywhere fine and rich, and bed-rock is nowhere to be found. The fields are readily tilled and produce enormous quantities of wheat, for which the region is famed.

The student should now recall the account of glacial lakes given in Section 144. As large lakes formerly covered lowlands of Ohio and New York, so a vast lake lay in the valley of the Red River. It had its outlet where now are Big Stone and Traverse lakes, at the head of the Red River, and drained down the valley of the Minnesota River. Its northern boundary was the southern front of the glacier. As the glacier melted off, the lake grew larger, until it was several hundred miles long. Over its bottom settled the muds that came from the glacier and the adjacent land. Lake Winnipeg is a remnant of this greater lake, which is called Lake Agassiz, in honor of Louis Agassiz, the first to recognize the traces of ancient glaciers in North America. When the lake was largely drained off, by the removal of the glacier, its bottom became the Lake Plain we have described.

153. Great lake plains.-The traveler on the New York Central Railroad crosses flat ground between Rome and Syracuse. To the south are the bounding hills. To the north stretches the plain (Fig. 115). It is the bottom of the older Lake Ontario and marks the time of its outflow through the Mohawk Valley. If we could drain Lake Ontario, its present bottom would form a similar but much larger plain. Along the Rome, Watertown and Ogdensburg Railroad, east of Niagara Falls, the Lehigh and other lines 


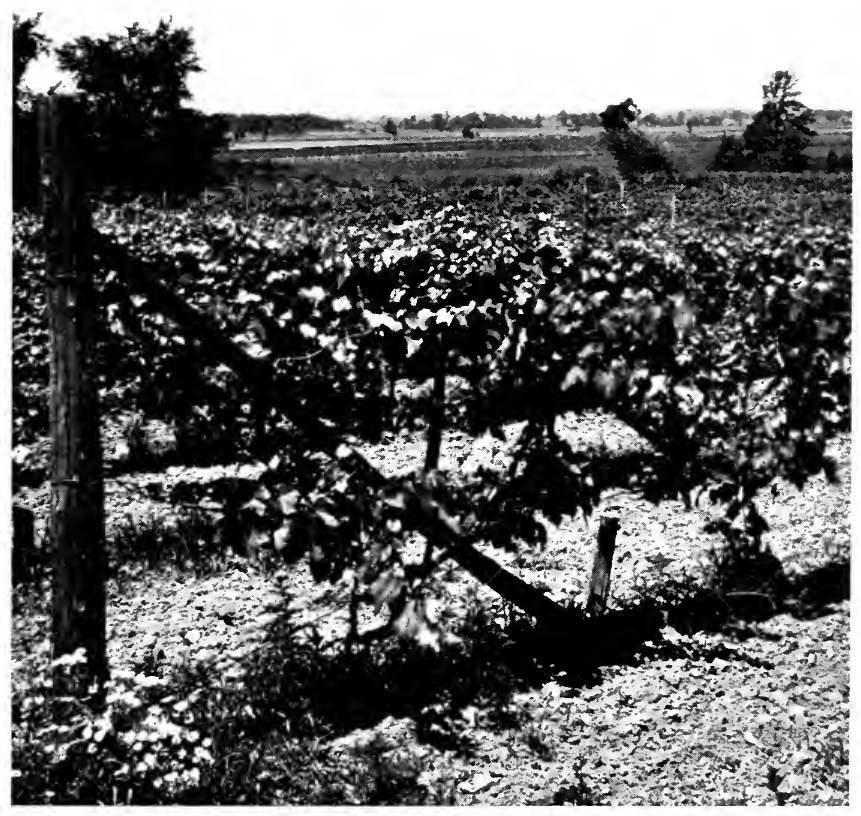

Fig. 115.-Plain of the old glacial lake of the Ontario basin; east of Niagara River. Fig. 112 gives a map of the lake, and Fig. 113 its shore. 


\section{AN INTRODUCTION TO PHYSICAL GEOGRAPHY}

east of Buffalo, the Grand Trunk in southern Ontario, and various roads crossing northern Ohio, the same flat grounds stretch out for long distances. Whatever may have been the inequalities of the earlier surfaces, they are subdued and hidden by the covering of lake muds gained at the close of the Glacial period.

154. Great Salt Lake plain.-Great Salt Lake has an area of about 1,700 square miles. It is very shallow, but

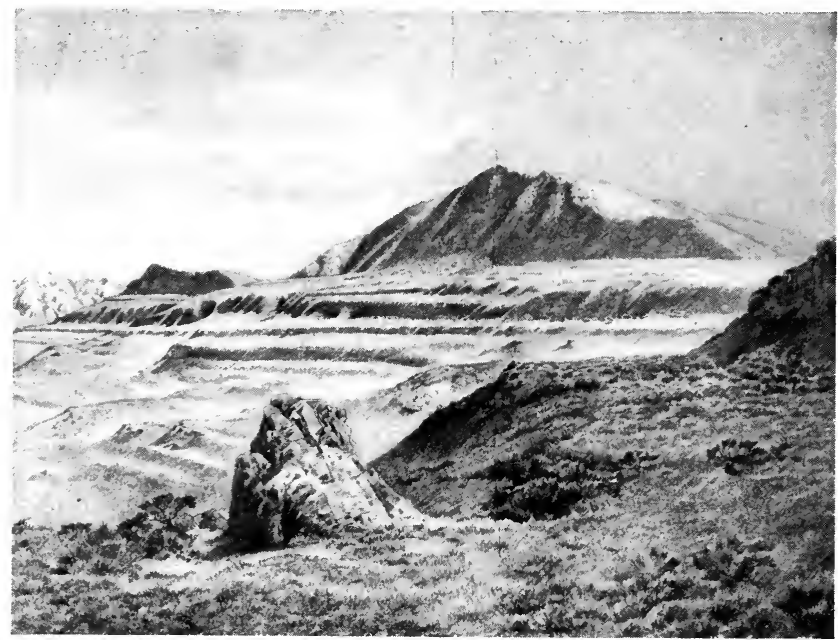

Fic. 116.-Shores of Lake Bonneville, near Garfield, Utah. The water stood at various levels, enabling the waves to wash out shore terraces at different heights. See sec. 154 and Chap. XlV.

40 feet deep in its deepest parts. If it were removed, the bottom would appear to the eye as a level plain. Such a plain extends out from the lake border for long distances, particularly on the west (Fig. 117). It is a great floor of fine sediment, interrupted by mountain ridges and peaks which here and there jut through it, like islands from a sea. This floor is the bottom of an older and greater lake, 


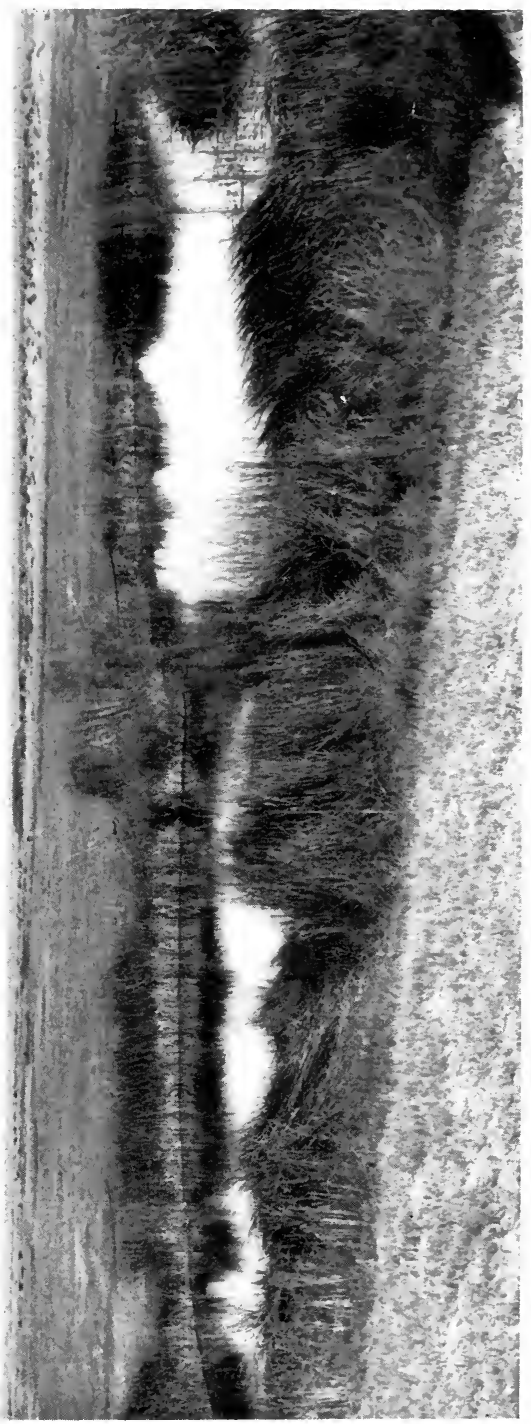

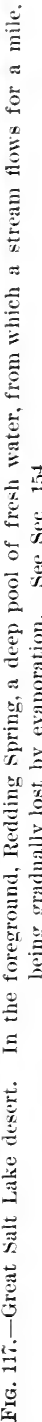


which was as large as Lake Huron, and was more than 1,000 feet deep. The principal proof of such a lake is in the presence of shore-lines on the lower mountain slopes (see Fig. 116). The reason that so large a lake existed is that the climate was formerly much more moist in that region; but with the change to the present climate the lake dried away, until only Great Salt Lake is left. As evaporation can remove only pure water, all the mineral substances which were dissolved in the greater lake remain in the smaller, and its water is a strong brine. The ancient body of water is known as Lake Bonneville, having been named in honor of Captain Bonneville, an early explorer whose journals were afterward edited by Washington Irving.

155. Other lake plains.-We have now studied three illustrations of level lands of this kind-one in the East, one in the Northwest, and one in the far West. In the first case large lakes still remain. In the second case, as also in the third, a lake of moderate size is left. Surface drainage has uncovered the Eastern and Northwestern plains, and evaporation has brought the Western to light. Wherever a swamp or meadow is found rimmed about with higher land, a lake has probably existed and has disappeared by the filling of the basin with mud or the draining off of its waters. Such small lake plains are numerous in all the region of the ancient ice-sheet, and they are often found in the high mountain valleys of the West.

\section{River Plains}

The alluvial plains of rivers, and their deltas, great and small, must be classed here. We readily see there is no sharp distinction between great river deltas and the adjacent coastal marine plains, as where the Mississippi delta merges into the other lowlands of our Gulf region. The rivers of Siberia, flooding wide districts of the marine plain which they cross, illustrate this cooperation of river and sea in shaping lowland surfaces. 
156. Central valley of California.-Reference has already been made (Sec. 61) to this region, but we return to it in this connection as a fine example of a river plain made not by one but by many streams. The numerous branches of the trunk rivers have shifted their courses again and again, and thus spread widely the waste from the mountains.

\section{Worn-down Plains}

We have already given an account (Sec. 45) of the gradual wearing down of a river basin by the meandering of the streams and the weathering of the lands between. If such wasting were continued long enough a perfect plain would be produced. But as the slopes become gentle the wasting becomes very slow, and it is not known that the work has ever been carried to completion. Because the worn-down plains are imperfect, they are sometimes called Pene-plains, a word meaning "almost plains." The part of the Hudson Valley shown in Fig. 9 is a good example.

15\%. Piedmont plain.-Bordering the Atlantic Coastal Plain is a belt of land originally high, which has been reduced to an uneven lowland by the slow wasting of its rocks. Lying at the eastern foot of the Appalachian Mountains, it is called the Piedmont plain. The material it has lost has helped to build up that part of the sea bottom which is now the coastal plain, and since the uplifting of that plain it has been trenched by the rivers from the mountains. It is further diversified by hills marking the position of rocks which have exceptional ability to resist the attacks of storm and frost.

\section{Plains of North America}

The principles which have been explained by reference to a number of scattered regions may now be profitably applied to a short study of the lowlands of the interior of our own continent. Let us remember that North America 


\section{AN INTRODUCTION TO PHYSICAL GEOGRAPHY}

is bordered on the west and east by great belts of mountain and plateau. Between these, from the Arctic Sea to the Gulf of Mexico, runs a broad belt of lowland, rising moderately on the borders of Canada and the United States, as in Minnesota, and sloping gently up to the highlands east and west. Te shall now analyze this area of plains.

158. Gulf plains. - The Atlantic Plain (Sec. 150) is continued beyond Georgia in a marine coastal plain, which forms the southern part of all the Gulf States, and passes through the Gulf lowlands of Texas and down the eastern side of Mexico, to the flat, hot plain between Vera Cruz and the mountains. Here is included western Florida, much of southern Alabama, nearly all of Mississippi, all of Louisiana, and a wide belt in Texas. Large parts of the Mississippi and Louisiana plain are directly shaped by the Mississippi River, and covered by its flood-plain and delta deposits.

159. Prairie plains.-The Mississippi basin is floored with old beds of marine rock, and most of it has never been mountainous or raised to a great height. In these respects it resembles a marine plain, but so much surface rock has been carried off by weathering and river action that no remnant of old sea bottom remains. It is also true that the uplifting of the sea bottom was unequal, and that the parts lifted highest have suffered most wasting, so that in its broader features the basin is a worn-down plain. In places also it is veneered and smoothed over with loose materials of various origin, some deposited by glaciers, some by lakes, and some in rivers. Prairie is a French term, chiefly applied to plains in Indiana, Illinois, Iowa, Missouri, and to some extent to bordering areas, including a strip that on the west extends southward into Texas. These lowlands are well enough watered to bear luxuriant native grasses and cultivated crops. They are trenched in a shallow way by many streams, and along these most of the native timber is found. The intervening lands may be rolling, but are never high, and are without forests. This 
is not because the soil will not produce them, for it is deep and fertile. The absence of forest has been ascribed to various causes, among others, to the fires kindled by Indians to maintain open pasturage for the herds of buffaloes. Temperate climate, rich soils, absence of forests which must be laboriously cleared, easy tillage, good grades for railways-such are some of the conditions which made the settlement of the middle West so rapid, and its growth in wealth and population so surprising. Nor should we forget that much of the prairie surface has beneath it one of the most important minerals, coal. It may be added that the prairies merge often into the lake plains about our Great Lakes, already described.

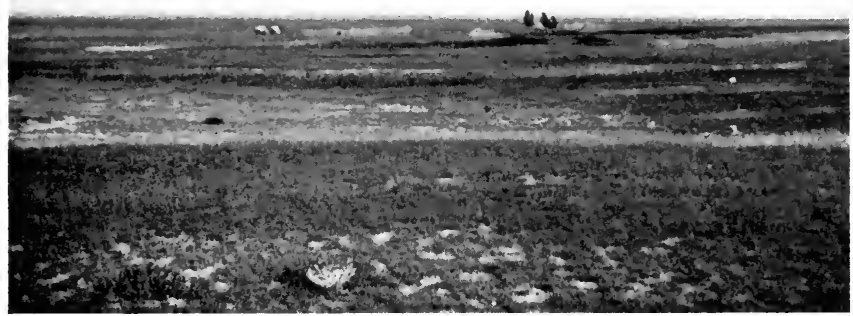

Fig. 118.--The Great Plains; eastern Colorado. Note the scant vegetation. The view includes a "ranch," with trees and fields of alfalfa, irrigated by a generous spring-a rare feature in that dry region.

160. Great plains.-This term includes a broad belt of country stretching from Canada to Texas. The western border is at the foot of the Rocky Mountains in Montana, Wyoming, Colorado, and southward. On the east it merges 


\section{$16 \pm$ AN INTRODUCTION TO PHYSICAL GEOGRAPHY}

into the prairies in Dakota, eastern Nebraska, eastern Kansas, Oklahoma, and Texas. The form of the land is not different as we pass from the prairies to the Great Plains, but as a whole the plains are drier and higher. The rise in height, from a few hundred feet on the east to 5,000 and 6,000 feet at the base of the mountains, is gradual. The general slope is so gentle that the eye does not detect the inclination. It must not be thought that this great surface is a smooth plain, though large districts are nearly such. Weathering, winds, and streams have made some

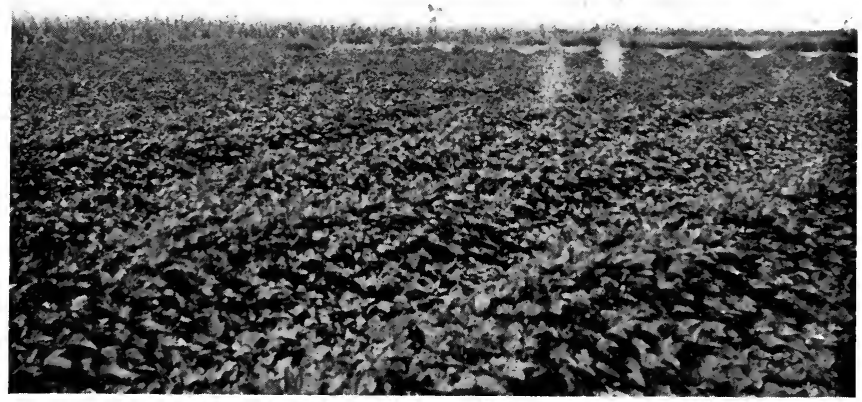

FIG. 119.-The Great Plains, Kansas. A sweet-potato field cultivated by irrigation.

parts very rough. It is a plain as compared with mountains, and its inequalities are trivial in relation to its great size.

Large portions are old river plains (Fig. 118) built like the plain of the central valley of California; they lie at the west, between the modern rivers, which have opened valleys at somewhat lower levels. Farther east are river plains built by the modern rivers (Fig. 119). But the greater part of 
the vast area is a worn-down plain; rocks which were formed by the sea or by lakes have been exposed for ages to the action of swinging rivers, and have been pared away unitil the grade is even from the mountains at the west to the central lowland.

The Great Plains are interrupted in South Dakota by the mountainous group of the Black Hills. In northwestern Nebraska and Texas soft rocks are sculptured into bad lands (Sec. 82). In Kansas, Colorado, and elsewhere, the winds have heaped the sands, and given diversity to the surface (see Sec. 112). In western Texas is the Llano Estaeado, a nearly quadrangular, treeless tableland, one-third larger than the State of New York, and surrounded by outward-faeing bluffs. It slopes eastward a little more than 8 feet per mile, and is exceedingly smooth.

161. Plains of Canada and Alaska. - The Great Plains of the United States are continued without interruption far into Canada. On the east are the hills and ancient worndown mountains of the St. Lawrence region. On the west rise the great mountains of the Cordilleran system. Here are the plains of Manitoba, Assiniboia, Saskatchewan, and other provinces. Wheat abounds in the southern provinces, and has been grown as high as latitude $58^{\circ}$, or opposite the middle portion of Hudson Bay. In the Arctic parts of the continent the plains resemble those of Siberia, though less extensive and more broken by waters. The Yukon Valley and other parts of Alaska form a tundra (Fig. 120).

162. Summary.-The student has read this chapter to little purpose if he has not seen that our object is not the mere description of certain important plain lands in different continents. They have been chosen in order to bring out the prineiples which explain them, and which will give us the key to other plains, like the vast, smooth lowlands of South America or Australia. The way in which a plain was made is one of the most instructive things that we can learn about it. We have seen that, with respect to 


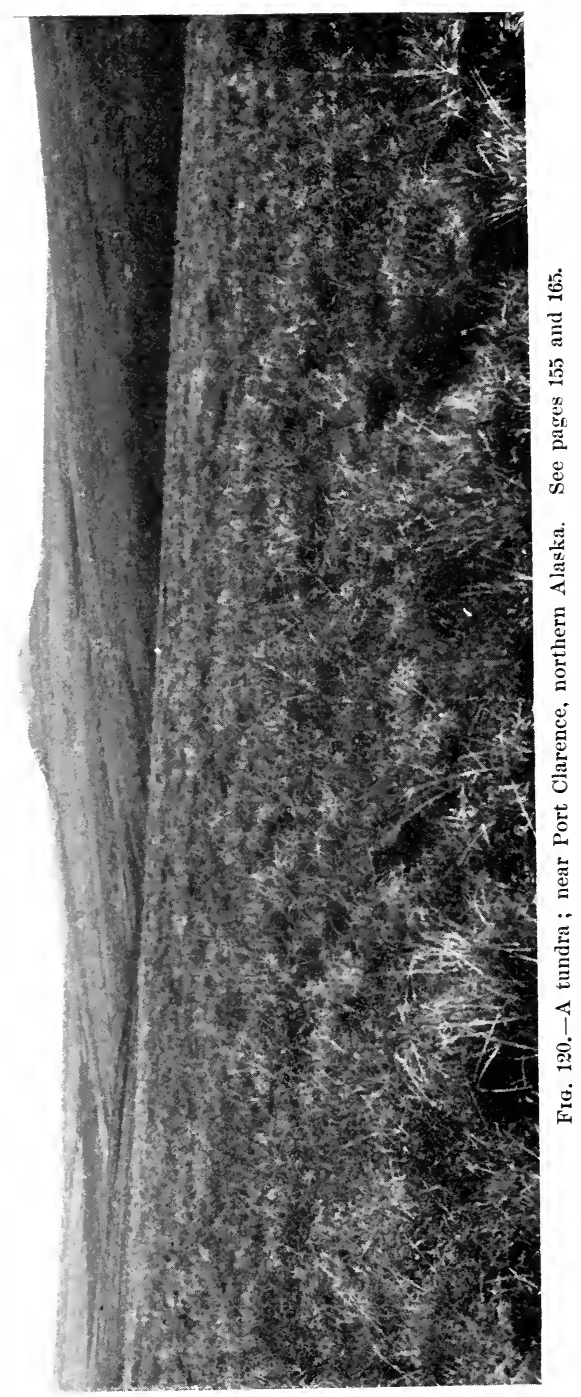


origin, plains are of several classes: (1) Marine plains, narrow or wide, which are sea bottoms made bare by uplift; (2) lake bottoms, uneovered by draining away or drying away of the water; (3) river lands, built of waste brought and spread by rivers; (4) worn-down plains, wrought out by the slow wasting of higher lands. We have also seen that a vast traet of plains, as in North Ameriea, can only be understood by using all of these principles.

Still further, it has appeared that plains having the same origin have different names (as tundra and prairie) because they hare different elimate. One region is temperate, another is frigid, and a third is hot; one is moist and another is dry, hence they differ in kind and abundanee of plants and animal life. So, too, man himself is restrieted, favored, and variously modified. The ways in which the surface of the earth affects the life of our race will be specially considered in Chapter XVI. 


\section{CHAPTER VIII}

\section{MOUNTAINS AND PLATEAUS}

Mountains are not an easy theme for elementary study; they are so great and so strange to many who have spent their lives on lowland plains. They are so varied, also, that no single definition can be a good one. We take up first the mountains of our own country, with the high plains, or plateaus, that are joined to them. Our purpose in this is to find the great principles concerning all mountains. We wish to be able to answer such questions as these: What is a mountain's form? How are mountains made? How are they related to the lower and smoother land? What is their history, and how do they pass from youth to age, or from high, sharp ridges and peaks to low, subdued hills? How do they affect the life of the earth?

163. The Rocky Mountains in Colorado.-As the traveler approaches Denver or Colorado Springs from the east, he sees, rising on the west, a lofty mountain front, stretching far away to north and south. This is the eastern face of the Rocky Mountains. The plains cease, and the mountains begin, at heights of 5,000 to 6,000 feet above the level of the sea. The highest peaks are above 14,000, but below 15,000 feet. Snow is always seen, even in summer, on some of the upper slopes and in the high gorges, but the mountains by no means appear to be snow-covered, like the Alps, whose heights are about the same. Part way up the Rocky Mountain slopes timber grows (Fig. 121). The upper limit is called the Timber Line. It is not a sharp boundary, but 


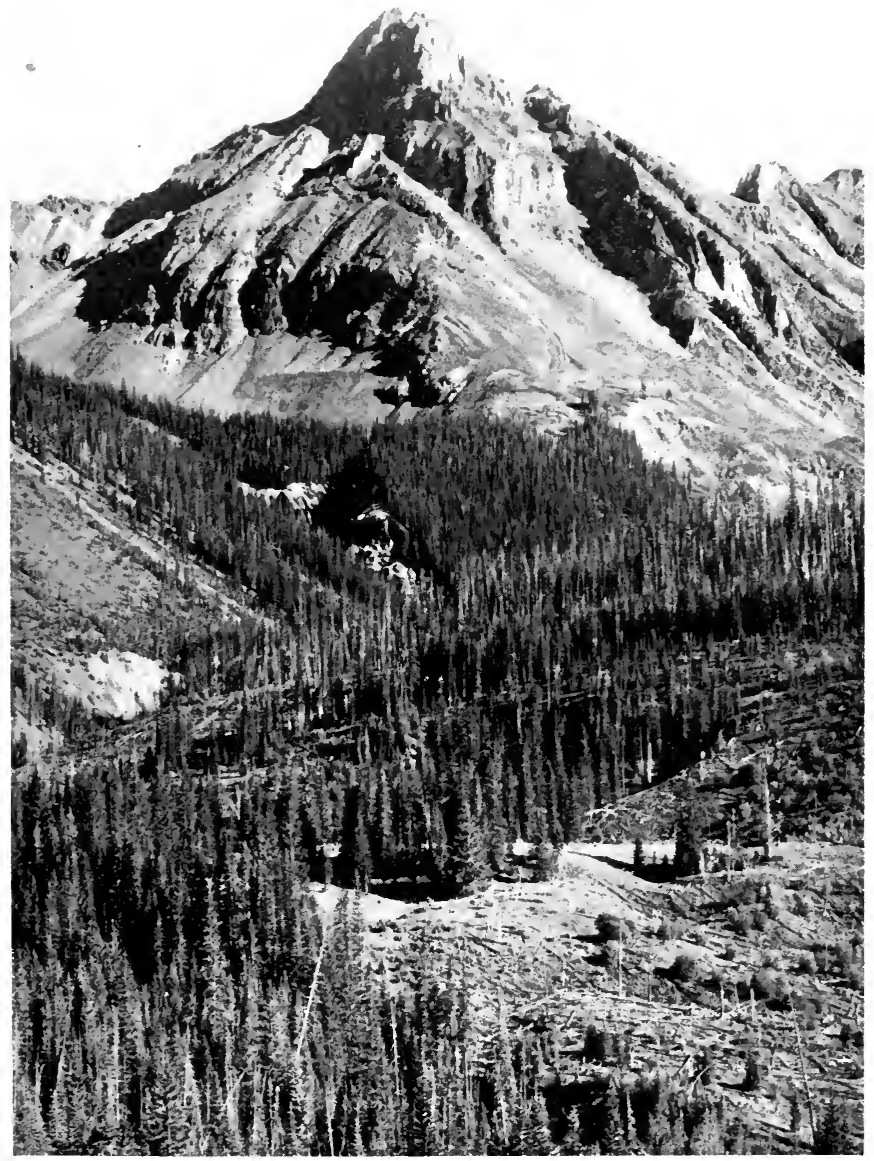

FIG. 121.-South Lookout Peak, 13,500 feet high, in the San Juan Monntains of Colorado. The scenery is of the "alpine" type. The fir timber extends to about 11,500 feet altitude. 
a belt along the slope, in which the trees become scattering and disappear. This may be taken as a definition of the timber-line for all mountains. Above this line for several thousand feet, to the top, are crags and ledges of rock,

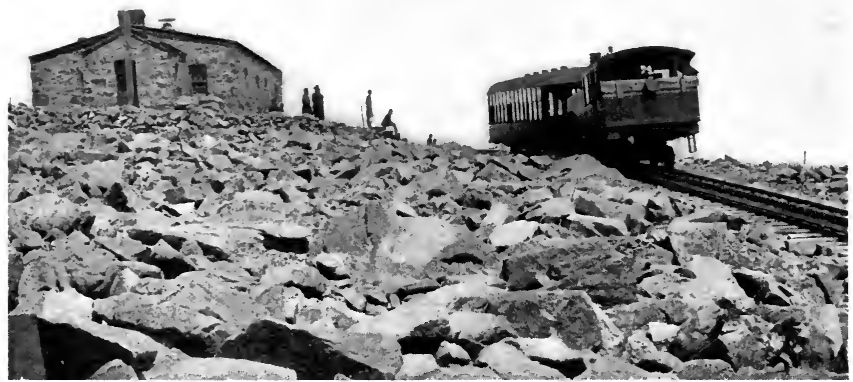

Fig. 122.-Summit of Pikes Peak, Colorado, 14,100 feet above sea-level. There is neither vegetation nor soil. The building is a station of the United States Weather Bureau.

mostly granite, and great slopes of angular, sharp-edged boulders riven from the mass of the mountain by frosts (see Fig. 122). The average slope is not great. The inclined railway ascends from Manitou to the top of Pikes Peak at the rate of about 1,000 feet per mile. The student should also remember that while this mountain is more than 14,000 feet above sea-level, it stands out but 8,000 feet above the plains at its foot.

The rains and melted snows from the well-watered mountain range drain down to the dry plains through deep canyons which they have worn out of the mountain's mass. Such are the valley of Clear Creek leading into the mountains west of Denver, and the Cheyenne and Fountain Creek canyons, about Pikes Peak. Stretching out from the foot of the range on the east, are sheets of coarse waste, 


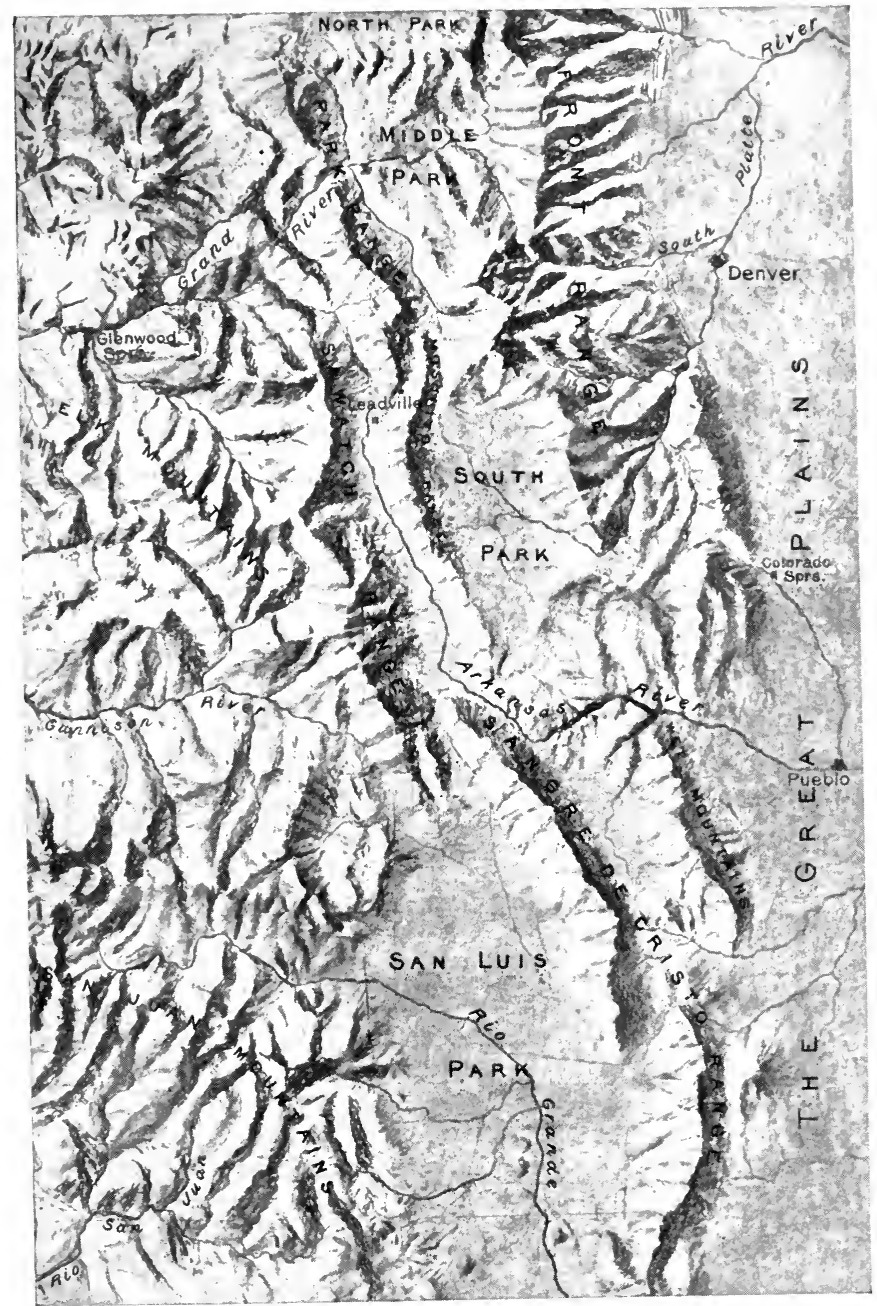

Fig. 123.-Map of the Rocky Mountains in Colorado. Scale, 1 inch $=52$ miles. 
sand, and gravel. These are deposits made by the mountain torrents of present and past times.

If we pass beyond this first, or Front Range, we shall enter a high, treeless plain, known as the South Park. Its floor lies 8,000 feet or more above the sea. It is not a valley worn out by streams and weathering, but a region left at a lower level, while high mountains were lifted upon

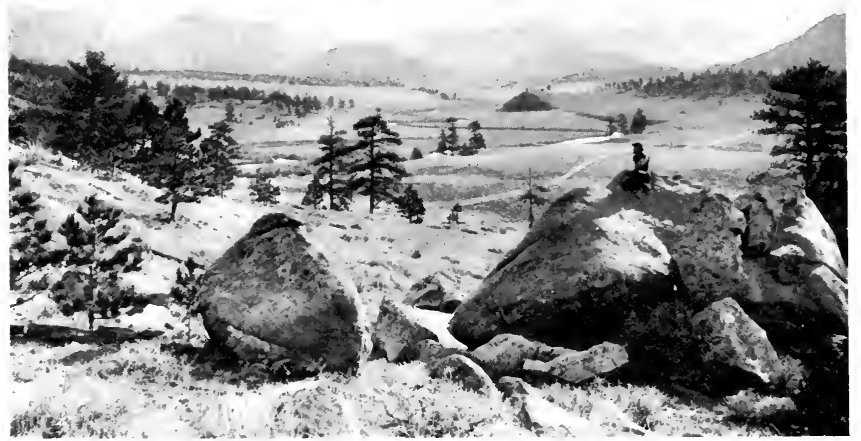

Fig. 124.-Estes Park, Colorado ; an open prairie valley, fringed with pines, and surromnded by ranges of the Rocky Mountains. Altitude, 7,000 feet.

the east and west. The climate is cool; the Park is good for grass and grazing, but not for grain or fruit. West of South Park is the Mosquito Range, a great mountain ridge parallel to the Front Range.

If we go north in Colorado, we shall see that between the Front Range on the east and the Park Range on the west lie the Middle and North Parks, which are broad, 
high valleys like South Park. The Mosquito Range may be considered as continuing north into the Park Range, and thus we have two lines of mountains enclosing between them the three parks. We should think of each range as a tangled belt of high land, whose ragged offshoots separate the parks from each other.

If we go west instead of north, we find the Sawatch Range beyond the Mosquito, with the upper valley of the Arkansas River between. The Sawatch here forms the divide between the Mississippi and Colorado river systems. Still west of the Sawatch Range are great knots of high peaks, the Elk and San Juan Mountains. In southern Colorado, the Front and other ranges break into different arrangements, and are called by other names.

The important fact is that we have here a chain of mountain ranges, running roughly north and south, with intervening plains and valleys. The system is complex, somewhat like the tangled and frayed strands of an untwisted rope.

The Rocky Mountains are lower and less important in central Wyoming, but rise to great heights and are strongly developed in northern Wyoming and Montana. Their southward continuation in New Mexico is somewhat lower, and bears various local names.

164. Structure of the Rocky Mountains. - In order to understand these and many other mountains the student should refer to the two great classes of rocks already described (page 5). The central and higher parts of each Rocky Mountain range consist of the crystalline, or older rocks. On the slopes-sometimes far up, but generally near the base-and among the foot-hills, the stratified rocks are found. This will be best understood by reference to Fig. 125. It will be seen that the Great Plains strata are nearly horizontal, and turn up at large angles against the foot of the range on the east. These upturned edges are often a few hundred feet in height above the plains. 


\section{AN INTRODUCTION TO PHYSICAL GEOGRAPHY}

In the same manner the beds on the west side of each range, in the Parks, or on the Pacific side, are bent up. All below and between is granite or some other crystalline rock. It is for the text-books of geology to seek to explain how the mountains are thus made. We can offer here only the gen-

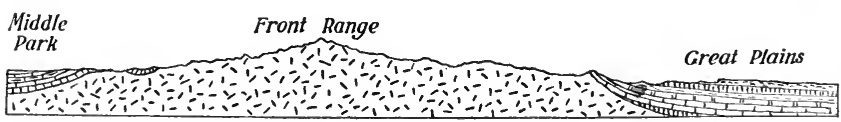

FIG. 125.-Section to show the arrangement given to the rocks by the uplifting of the Rocky Mountains. The base-line corresponds to sea-level. Altitndes: in Middle Park, 8,000 feet; crest of mountain, 13,500 feet; at the edge of the Plains, 5,500 feet.

eral explanation that great crushing has taken place, by which the once horizontal beds are bent up at various angles, and the older rocks were forced up between them. Each range is a part of the earth's crust that has been raised high up, and each great valley is a part that has been less lifted.

But crushing and uplifting tell only half the story. The lifting took place a long time ago, and a vast amount of rock has been worn away. Not only have the mountain ridges been reduced in height, they have been carved into new shapes. Their gorges and spurs, cliffs and peaks, all the details that give character to their scenery, are the work of storm, stream, and glacier.

\section{Plateaus and Mountains Between the Rocky Moun- TAINS AND THE PaCific OCEaN}

165. The Colorado plateaus. - The Colorado canyons have already been described (page 71 ). We now come to the plateaus beneath whose surfaces the gorges have been sunk. They are not all at one level, but differ much in height above the sea. Most of western Colorado and eastern Utah and much of New Mexico and Arizona are included. This great area is limited by the Rocky Mountains on the east, by the Wasatch Mountains on the west, and by the Uinta 
Mountains on the north. The various tables are divided from one another by deep gorges, or are arranged like steps, each overlooking its lower neighbor from the top of a cliff. The rocks are stratified and mostly horizontal; they constitute a system of great blocks, separated by fissures and dislocated so as to stand at different heights. Much of the region is a desert because it is so dry. Some of the higher platforms receive enough rain to create rich coverings of grass and forest.

\section{Wasatch Moun-} tains and the Great Basin. -The Wasatch Moun-

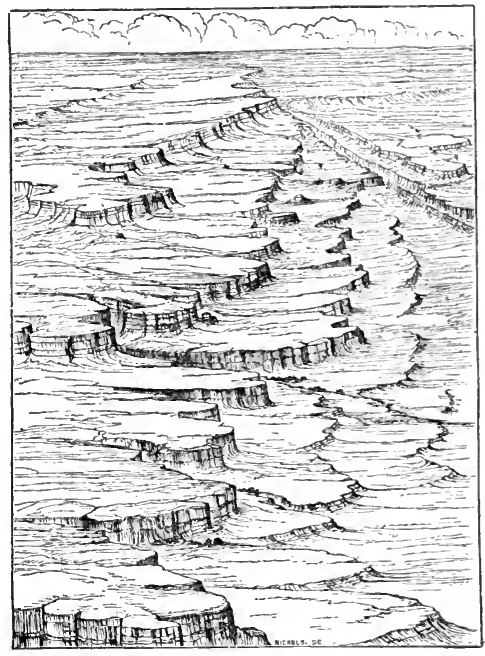

FIG. 126.-Bird's-eye view of plateaus in southern Utah.

tains form a short north and south range in central Utah. On the east are the Colorado plateaus. On the west is the Great Basin, so called because it has no outlet to the sea. It is very dry and its scanty waters enter lakes, of which Great Salt Lake is the principal one. Its floor in Utah and much of Nevada is 4,000 to 5,000 feet above the sea. It would therefore be proper to call it a plateau, at least its northern parts. To the south it descends, and in Death Valley, southern California, is even below the sea-level. Parts of the Great Basin are smooth as a floor, but this is not its general character. Many mountain ridges of moderate size run far to north and south within it. Each of these originated by the uplifting of a dislocated block or strip of the earth's crust, and usually 


\section{AN IN'TRODUCTION TO PHYSICAL GEOGRAPHY}

the mass was tipped toward one side, so as to give that side a comparatively gentle slope and make the opposite one a bold cliff (see Fig. 128). After uplift came weathering and the carving of gorges. The waste from the mountains has not been carried to the sea but has gathered in the valleys between the ranges, giving them smooth floors and hiding the rocks beneath. Along each mountainside are

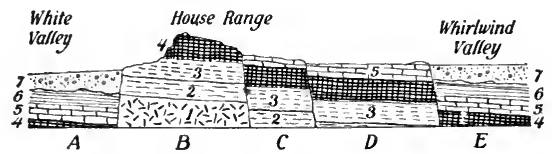

FIG. 127.-Section of the House Range (Fig. 128). Scale, 1 inch $=7$ miles. Each bed -for example, No. 1t-was once continuous from side to side; but the eountry is now divided into blocks which stand at different heights. Block $B$ is lifted higher than any other, and its top has been worn away, so that all of beds 6 and 5 , and parts of 4 and 3 , are gone. The waste is gathered in the valleys at the sides, where it,rests on and conceals blocks $A$ and $E$.

series of gorge-mouths, from which spread great fans of waste, and the fans usually merge together, giving to the mountain a sloping foot-plain. The Great Basin is limited, north and south, by regions drained by the Columbia and Colorado Rivers, but the district of block-like mountains and waste-filled valleys extends beyond its boundaries in both directions.

West of the Great Basin there rises in eastern California the lofty Sierra Nevada. Not only do its principal peaks surpass those of the Rocky Mountains by several hundred feet, but its flanks descend to low valleys instead of high plateaus. It is a superlative mountain range, at once broader, higher above its base, and longer, than any other single range of our domain. Like the ridges of the Great Basin, it has been uplifted bodily, the east side most, so that its broad back drains to the great California Valley.

16\%. General view of our Western highlands.-The Rocky Mountains, the Wasatch, the Basin Ranges, the Sierra and the Coast Range, form the mountain uplands. They all 


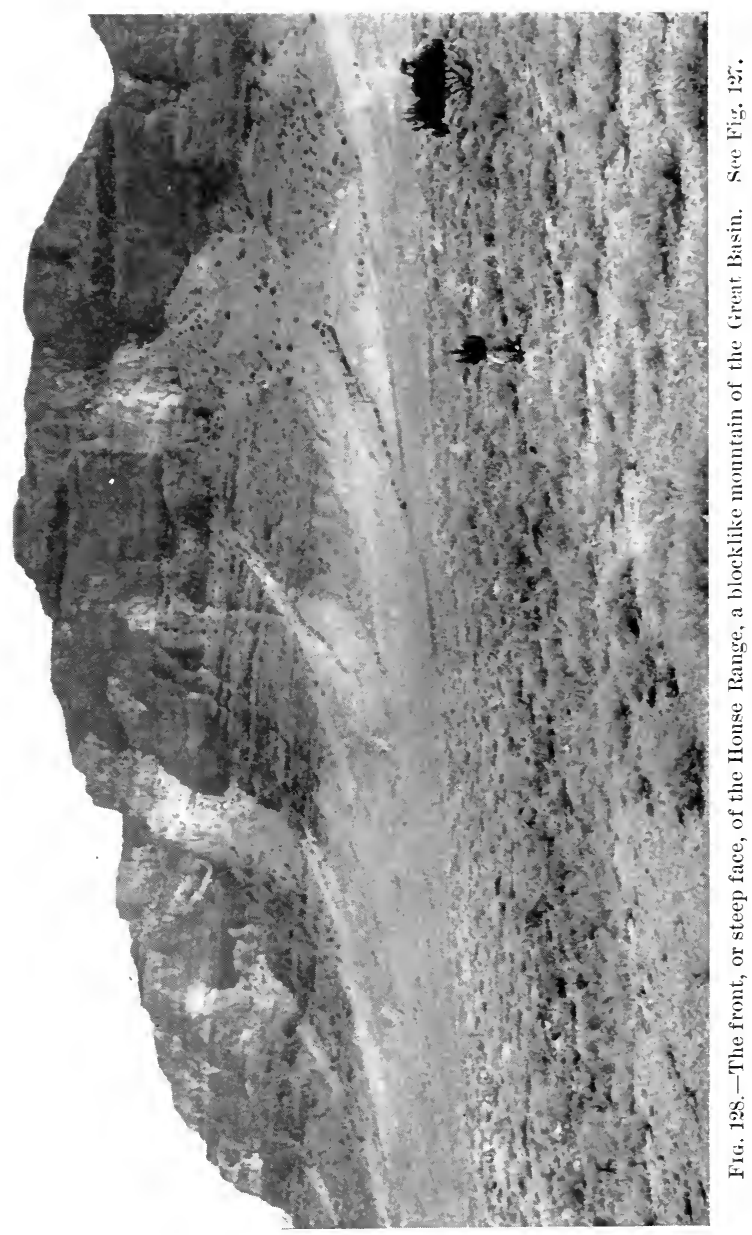


have a general north and south direction, but run out or change into other forms with different names as we go northward or southward to the borders of the United States. Beyond, to the north, they form the mountain system of British Columbia and Alaska. Southward they continue to the Isthmus of Panama, or, in a broader sense, to Cape Horn. As a whole they are the Cordillera of America. All western America is a region of mountainous foldings and uplifts of the earth's crust.

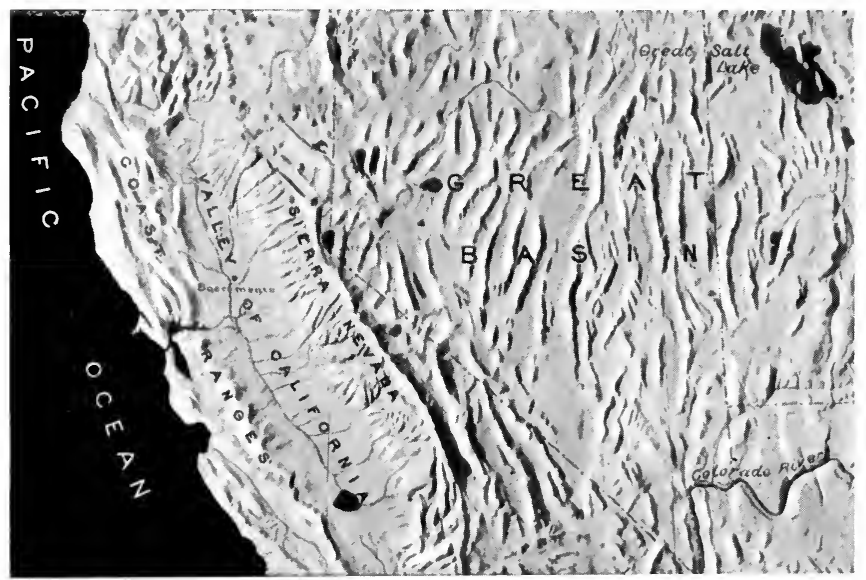

Fig. 129. - Map of parts of California, Nevada, and Utah, showing the Sierra Nevada and mountain ranges of the Great Basin. Scale, 1 inch $=2 \% 5$ miles.

Between and adjoining these ranges in the United States are great plateaus. The Great Plains are properly also a platean; then come those of the Colorado and Great Basin. As a whole, therefore, the western United States is a platform 2,000 to 8,000 feet high, carrying upon and above it lofty ranges of mountains. The plateaus are such by uplift from the sea-level, and the mountains are mountains by reason of breaking and folding as well as uplift. Some 
ranges are much older than others. A single range did not come up suddenly to its full height, but rose slowly and at different periods. Uplift, dislocation of the rocks, folding of the rocks, and the close association of plateaus and mountains-such are some of the principles we have gained from our study thus far. We have also learned that after their uplift, mountains are greatly changed by down-wear. Sharp peaks, rough crags, rugged slopes of waste, deep gorges, swift torrents, and broad foot-hills and waste plains-such are some of the characteristics of mountain lands.

168. Mountains of the eastern United States.-These are called the Appalachian Mountain System and extend from near the Gulf to New England and beyond. They are not all alike and they were not all made at one time. Let us study some of the groups or chains which make up the system.

169. Adirondacks. - These are a small group of ridges and peaks in northern New York. The ridges are irregular, but in general run from northeast to southwest. They are low mountains, the highest peak rising to little more than 5,000 feet. For the most part the slopes are not steep and are wooded. Here and there rocky heights rise above the forest, but most of the summits are smooth and tree-covered. They are much older than any of the mountains of western America. They may once have been just as high, but have wasted to their present form and height. Thus we have another illustration of the maturing and aging of the forms of the land.

1\%0. Folded Appalachian mountains.-The Adirondack Mountains are of crystalline rock. So are the highlands of the Hudson, and the Blue Ridge, overlooking the Piedmont plain. But the low mountain ridges northwest of the Blue Ridge and running through central Pennsylvania, Virginia, eastern Tennessee, and far into Alabama, consist of stratified rocks built into great folds. The rocks were 


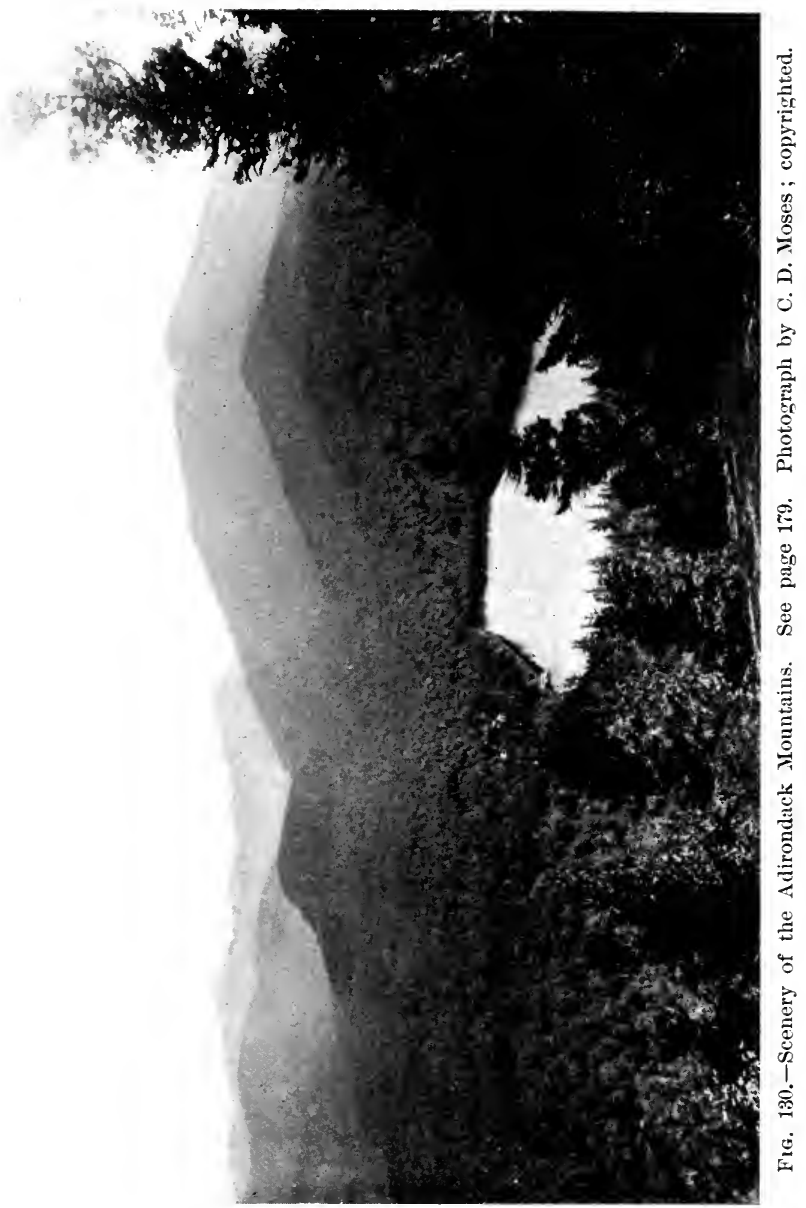


once horizontal, but have been pushed into a series of folds or arches (Fig. 131). It is such a series of folds as is made by the wrinkling of a coat-sleeve. Or, grasp a thin stack of writing paper on each edge and push the hands toward each other; the sheets of paper will represent the rock strata and the pushing shows how the force is applied in making many mountains. In the Appalachian belt the direction of the pushing was northwest and southeast, and the wrinkles run northeast and southwest. The wrinkling was very long ago, and there has since been an enormous wasting of the rocks. Some rocks have wasted more than others, and the ridges which are left are not the original wrinkles, but the projecting edges of such rock beds as were best able to resist wasting influences. These ridges have already been mentioned in Section 51, and some of them are shown in Fig. 46. In some of the down-folds, or

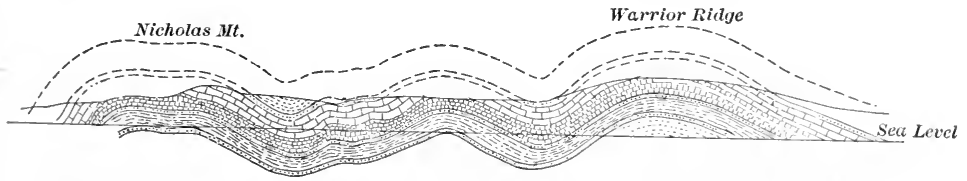

F16. 131.-Section across Appalachian ridges in Maryland, showing their relations to the up-folds and down-folds of the rocks. Parts indicated by the broken lines have been worn away. Scale, 1 inch $=\tau, 000$ feet.

inverted arches, of these bent strata lie the coal-beds of eastern Pennsylvania, as about Scranton, Wilkesbarre, and Pottsville.

171. Mountains of New England.-All the mountains of the New England States are old and subdued, only the Green and White Mountains retaining any ruggedness. In eastern Massachusetts, in Rhode Island, and Connectient, and on Manhattan Island, the rocks show all those wrinklings and complications which belong to mountains, but the land is a worn-down plain. The mountains which once were there have wasted away almost to the level of the sea. 
172. Young, mature, and old mountains.-This is the history of mountains: First, ridges are uplifted; they may be wrinkles (Fig. 131), or they may be blocks, broken loose and pushed upward (Fig. 12\%). In youth they are small, in maturity large, but the change is always slow. As they grow, storm, frost, and stream attack them; gorges furrow them from summit to base; spurs, sharp crests, and peaks are carved out. Uplift strives to make the summits higher, wasting to make them lower. The mountains are now mature. When uplift ceases, wasting continues alone. Slowly through the ages the tops are lowered, and the rugged angles of vigorous middle life are replaced by the smooth curves of old age. The old summit lines are now lost, and new summit lines follow the harder rocks. Still more slowly these too fade away, and all that remains is a worndown plain, with low, scattered hills-the second childhood of mountains.

173. The Alleghany plateau.-We have seen that our Western mountains either overlook or stand upon lofty plateaus. In the East, however, the plateau belt, which is associated with the Appalachian Mountains, is for the greater part as high as the mountains themselves. In the long wasting the steep-sided mountains have suffered more than the flat plateau. The plateau has its northeastern beginning on the west of the Hudson River, and is known there as the Catskill Mountains. The uplands are not mountains, in the sense of being due to folding and breaking, but are like the buttes and bad-land hills of the West, in having their strata horizontal. The worn edges of the roek beds form a wall, or high cliff, facing the Hudson Valley (Fig. 9). But the tops of the so-called Catskill Mountains are rolling and eovered with forests and meadows, and, while the surface descends somewhat to the west, it passes gently into the upland that occupies most of central New York and all of the southern part of the State. This upland is usually about 2,000 feet above the level of the sea, and 
below its surface are sunk the north and south valleys which furnish the natural highways of the region.

The same highland continues into Pennsylvania, and forms the northwestern half of the State. The so-called Alleghany Mountains are not true mountains, but are the eliff or escarpment by which the platean is bordered on the southeast, and are thus similar to the Catskills. Beyond this, the folded rocks begin, but the plateau is as high as the mountains. Some of the horizontal beds of this plateau consist of soft coal, and the edges of the coal-beds are exposed on the sides of the valleys, as the Monongahela, south of Pittsburg.

In other parts, especially in northwestern Pennsylvania, porous sandstone beds at some distance below the surface, contain mineral oil, or petroleum, and natural gas. 'These products are lighter than water, and would

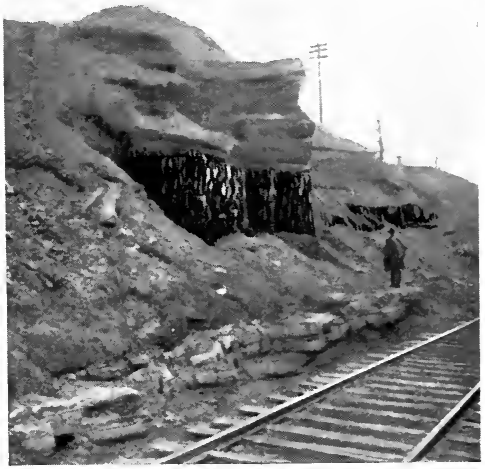

FIG. 132.-A bed of bituminous coal-" the Pittsburg coal "-with strata of shale and sandstone above and below. long ago have risen through the rocks and been lost, but for the fact that close, fine-grained beds overlie the porous beds or "oil sands," and keep the oil (or gas) down. It is reached by boring. Much of the petroleum is refined, producing illuminating oil and many other useful substances. The refineries are in the oil region, and also in the eities of the seaboard, to which the crude oil is pumped by means of pipe-lines hundreds of miles in length.

The platean, with its deposits of oil and coal, continues through Virginia, Kentucky, and Tennessee, where it is 


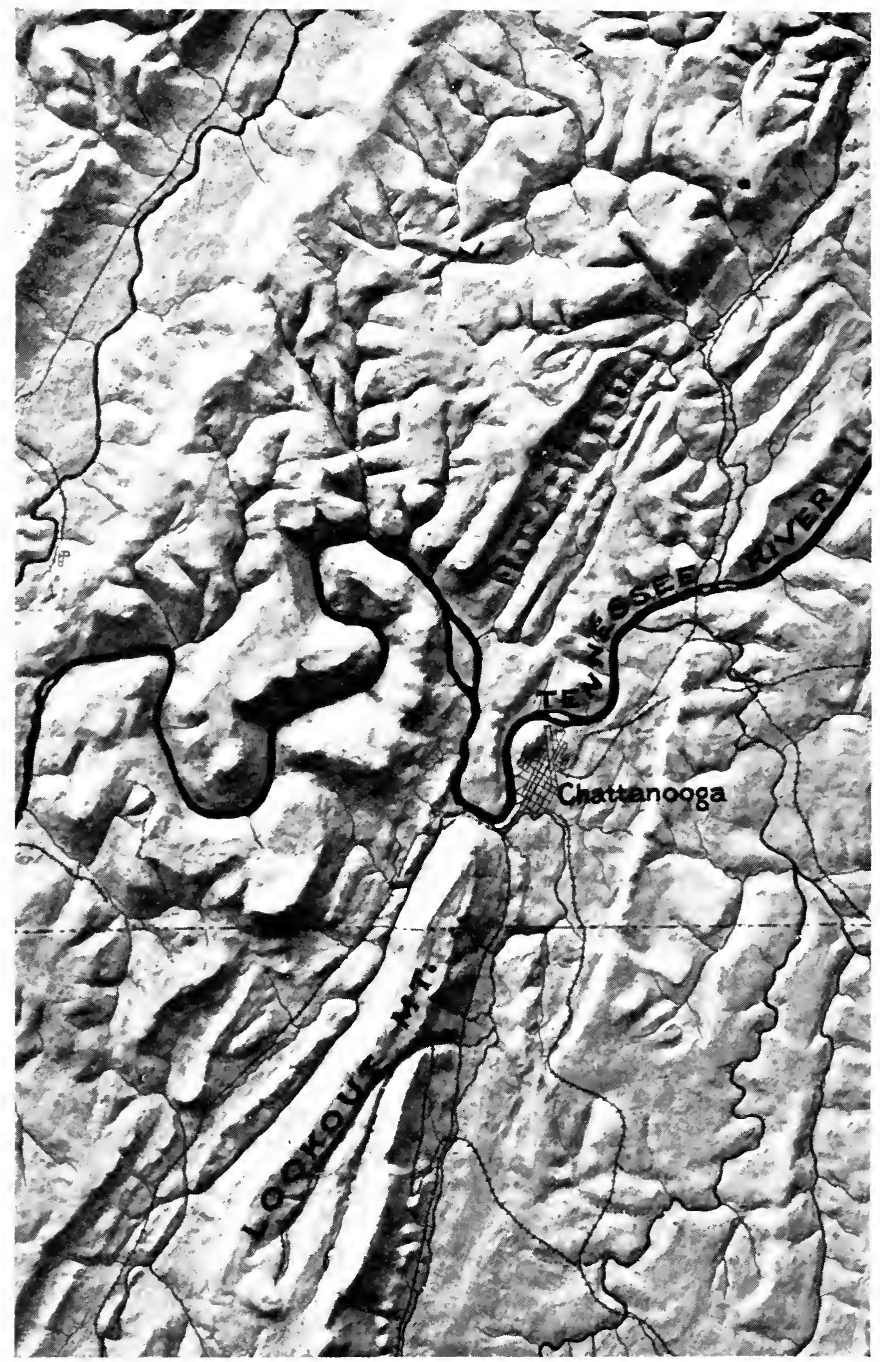

Fig. 133. - Plateaus and valleys about Chattanooga, Tenn. Scale, 1 inch $=7$ miles. The uplands are parts of the Cumberland plateau. The main platean is seen at the extreme northwest. A detached portion, the Walden platean, crosses the map from northeast to sonthwest, and the end of Lookout Mountain show's at the south. Gorges are carved in all these uplands. 
known as the Cumberland Plateau. There, as farther north, it is a flat, high country, with a cliff overlooking the mountain ridges and valleys on the east. On the west it slopes gradually down toward the prairies and low plains of the Mississippi Valley, resembling, in this respect, the Great Plains west of the river. Far to the south it is divided into belt-like parts by straight, open valleys (see Fig. 133).

174. Mountains of other lands. - We may describe the geography of mountains by comparing a few other examples with those of North America. The highlands of Scotland are like the Adirondacks and the uplands of New England in being very old mountains, much subdued and of small height. Similar are the mountains of the English Lake District in the north of England, whose chief summits are little more than 3,000 feet above sea-level. The mountains of the Scandinavian peninsula are also old and worn, though higher than those of Great Britain.

In the south of Europe, however, we find mature mountains, high and very rugged. In the Pyrenees and the Alps, both the unstratified and the stratified rocks have been squeezed, folded and broken, and foreed upward, so that the mountains rise from twelve to nearly sixteen thousand feet above the sea. As they were not overridden by the ice of the glacial period, their peaks are unworn; and the gnawing of the modern glaciers, which flourish in alcoves under their summits, keeps their crests blade-like. Below the glaciers, torrents are powerful and busy, and in all the uplifted country are gorges and deep valleys. Sharp peaks, lofty and often vertical cliffs, and valleys strewn with the waste of the heights, are the features of the land. Conspicuous in the scenery of the Alps are its separated peaks, springing from spurs between gorges and standing free from the main crest-line. These are often named needles or horns, as in the Matterhorn (stag-horn), shown in Fig. 134. A line of peaks marks a ridge, a strand of 


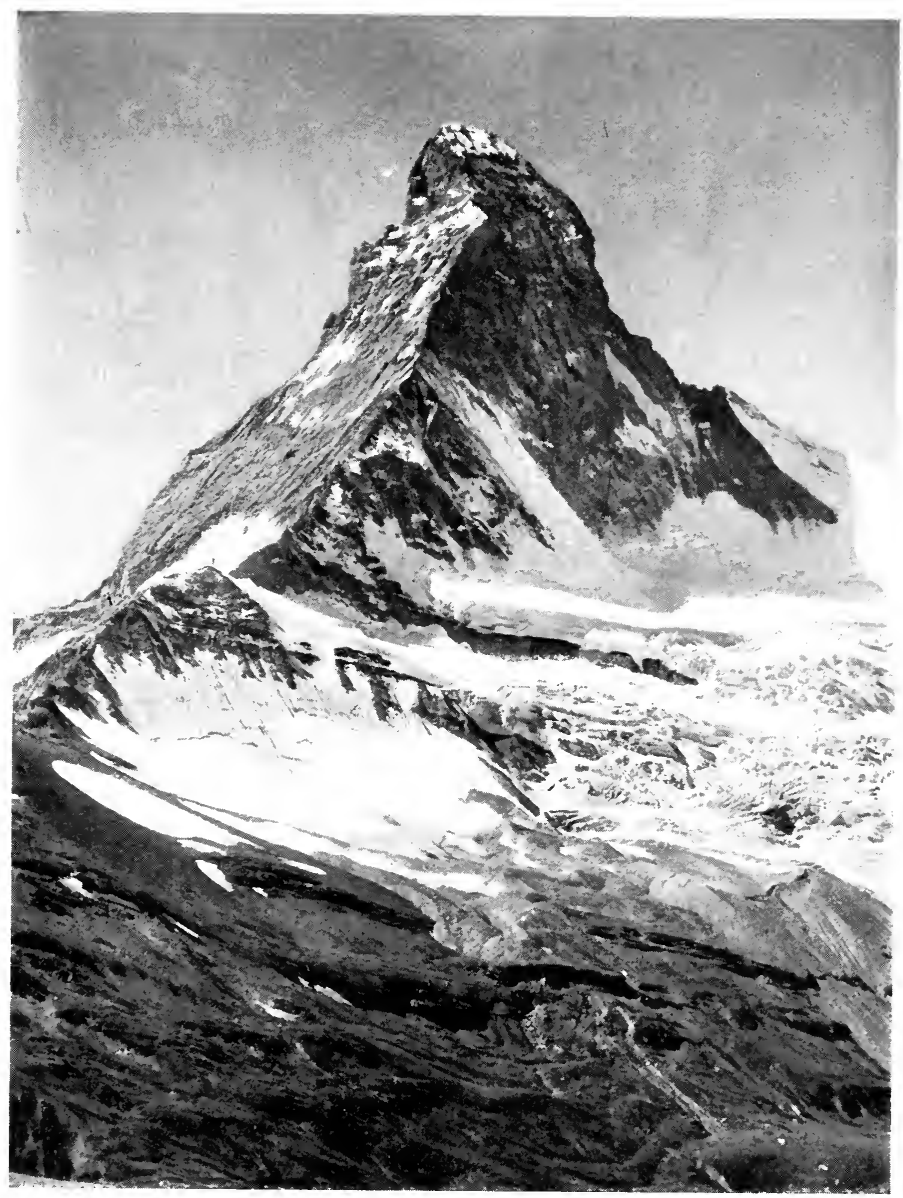

Fig. 134.--The Matterhorn. See page $1 \times 5$. 
ridges makes a chain, and several chains, as in western America, make up a mountain system. On the north of the eastern Alps is the Bavarian plateau, with a smooth surface about 2,000 feet above the sea. Munich stands on this plateau near the northern foot of the mountains, and the Danube flows eastward over it. It is related to the Alps as the Great Plains are to the Rocky Mountains.

In Asia, the highest mountains in the world, the Himalaya, are in middle life, like the Alps. Far up among their heights the rocks contain shells which originally grew in the sea. Along a belt running far east and west, the earth's crust was crumpled and broken and the mountains reared. Glaciers, deep valleys, and strong streams are common here as in the Alps. In both regions immense landslides occur, as ill-supported sides of the mountain fall off into the valleys. In both, also, snow comes down in the form of avalanches, overwhelming forests and destroying human life.

To the north is the plateau of central Asia. Its highest parts in Tibet are about 14,000 feet above the sea, or as high as our western mountain peaks. Hence the region is sometimes called the "Roof of the World." As our Great Basin plateau is broken by mountains, so is the platean of central Asia, and its mountains and plains are on a grander scale. Gradually on the north, plateau and mountains descend to the level of the Siberian plains. A vast continental rise of land, of which the rugged parts are mountains and the smoother, intervening parts are waste-floored plains - such is the character of the highlands of Asia, as of those of western America.

The Andes also are high and rugged mountains, and by that fact we are told that they are in the vigor of youth or middle life. South America has less of plateau and more of low plain than the other great continents.

1\%5. Earthquakes in mountain-making.-More will be said about earthquakes in the chapter on volcanoes. Any 
shock given to the firm rocks of the earth's crust causes vibration, and produces a shaking of objects at the earth's surface. In straining the crust enough to bend thick beds of rock many sudden breaks and slips take place, which send pulses, or shocks, for long distances through the rocks. Many earthquakes are due to this cause.

1\%6. Mineral products of mountain regions. - As we have seen, coal is found among the mountains of Pennsylvania.

So is it in Colorado, as

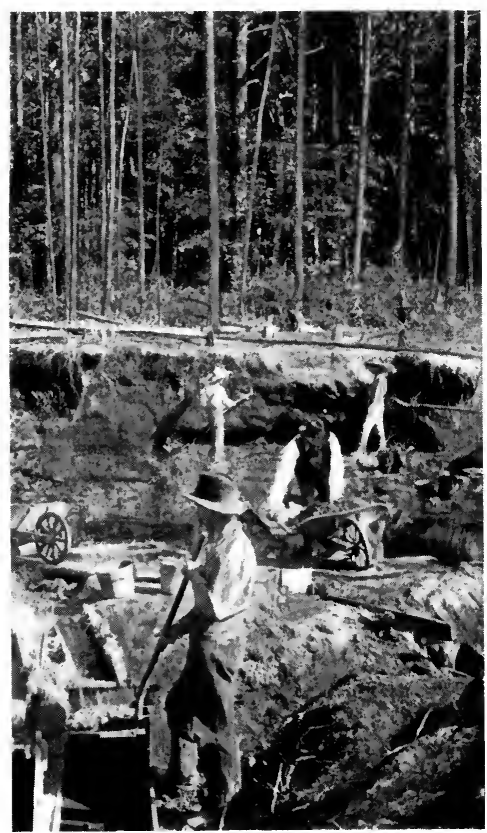

FIG. 135.-Placer mining in North Carolina. The gold is separated from the contained earth by means of a swift current of water. at New Castle. But both east and west, coal is also found where the rocks are undisturbed. Coal is not therefore a result of mountainbuilding, though soft coal may be changed to anthracite by the crushing that goes with the rearing of mountains.

But many of the metals are found chiefly in mountain lands. It is there that they have been dissolved out of the rocks, often by heated waters, and deposited in mineral veins (page 97). Hence it is that in the Cripple Creek region of Colorado are rich goldmines, and in the Leadville and San Juan regions valuable deposits of silver and lead. The metallic wealth of Wyoming, Idaho, Montana, California, Oregon, 
and Washington, and other Western States, is all in their mountain lands. In connection with the folding and crushing, the various ores have been formed by the slow deposition of dissolved matter in the crevices of the rocks. 'The iron and copper of Lake Superior are found in a region of ancient mountains now worn away.

When gold-bearing veins waste away, along with the general wasting of a mountainside, the gold is washed down stream, and comes to rest along with gravel and sand wherever the progress of the waste is cheeked. Such goldbearing gravels are known as placer beds, and the washing of the gravels to separate the gold is known as placer mining (see Fig. 135).

Not all mountains contain mineral wealth. Little gold and no silver is mined in the Appalachians. The Green Mountain group has no metals of importance, but is rich in slate and marble. The low mountains of Saxony have long been a mining center, while the lofty Alps are poor in valuable minerals.

17\%. Climate of mountains. - In ascending lofty mountains one finds the same changes of climate in a few hours or days that would be met in a journey from tropical or temperate to arctic latitudes. This will be well understood by reviewing the belts of temperature and regetation in the Alps. On the plains of northern Italy the olive flourishes, and in the deep valleys and along the lower slopes the vine abounds. As we ascend we find first the broad-leaved forest trees to heights of 5,000 to 5,500 feet on the south slope, and 4,000 feet on the north slopes. This brings ont the fact that elimate may differ much on two sides of a mountain range. The direct rays of the sun and the winds from the warm Mediterranean affect the south front of the Alps. Above the deciduous trees come the cone-bearing or evergreen forests. The coniferous trees are important in preventing floods and cheeking avalanches, as well as affording supplies of timber and fire-wood for the thrifty 
peasants. Above the trees are the upper pastures, brilliant with flowers of every hue, to which the flocks and herds are driven only in the summer. Still above is the zone of rock and perpetual snows. Snows may wrap the highest summits, as Mont Blanc; while often the upper mountains are so steep for thousands of feet

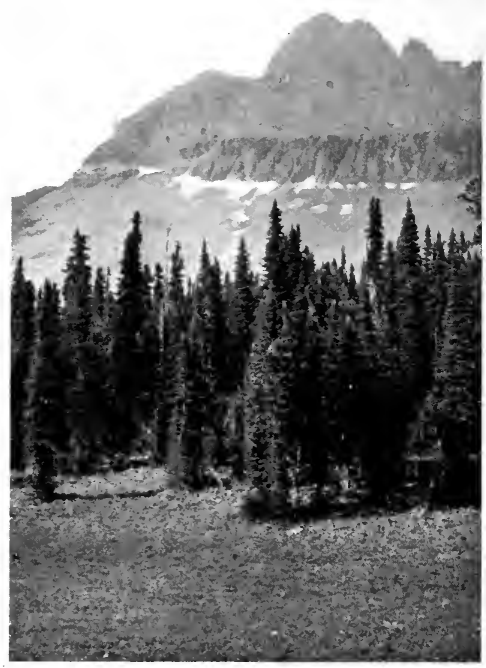

FIg. 136.- Vegetation at an altitude of $九, 500$ feet in the Rocky Mountains of Montana; a patch of prairie in a forest of fir. that the snows slide off and bare crags prevail. From base to summit of the Alps, one-fourth is tillable, one-half is forest and pasture, and the remaining fourth is utterly barren.

The climate of north. ern Italy is warm-temperate, and we thus range from this to polar climate as we ascend. If we rise, however, from the foot to the summit of the equatorial Andes, we there range from a tropical to a polar climate. In the far north and south there is less contrast, because ice and snow there prevail down to the level of the sea, as upon the slopes of Mount St. Elias. In the United States the Sierra and Cascade Mountains most nearly represent the conditions of the Alps; but the Wasatch, the Rockies, and all other high mountains are belted by zones of climate-cooler and moister above, and warmer and drier below.

In the Appalachians the range of temperature is small, 
because the mountains are low. Still, in the Adirondaeks the summits are always cold at night, the mean temperature for the day is never high, and the winters are long and marked by heavy snows. Even in the low Berkshires of Massachusetts the climate is much cooler than in the adjacent Hudson and Connecticut valleys. The southern $\mathrm{A}_{\mathrm{p}}$ palachians carry a wedge of cooler climate far down between the hot Carolina coasts on the east and the half-tropieal country along the lower Mississippi.

178. Life of mountain lands. - Some facts belonging to this subject have already been given. Thus we have seen how rapid is the change to colder climate and the corresponding plants as we rise toward the tops of high mountains; tillage of the soil is confined to the valleys and lower slopes, while grazing and timber industries run to the middle slopes or to the summits, according as the mountains are in higher or lower latitudes, or are themselves of great or small altitude.

In the mountainous parts of Switzerland the peasants till the narrow valley bottoms, reclaim the rough surfaces of the torrent fans, and raise patches of grain and hay on the talus and other waste slopes. The dairy is a chief means of support, and men, women, and children join in all the industries of the field, while wood-earving and other small manufacturing occupy the winter months. Houses are built of wood, with wide-spreading cornices, the thatch sometimes weighted down with large stones. The splendid scenery of the Alps, close to many populous lands, has made Switzerland the "playground of Europe," and the entertainment of tourists may be called the chicf industry of the mountain people.

In the Rocky Mountains the conditions of human life are entirely different. The chief attraction in these mountains is the mining of the precious metals. Instead of humble peasants, native to the soil for centuries, we find the most hardy and energetic types of American life in the 


\section{$192 \Lambda \mathrm{N}$ INTRODUCTION TO PHYSICAL GEOGRAPHY}

absorbing search for mineral wealth. Mining camps which are in truth cities, spring into being, and as swiftly decay when the mines cease to be productive. Agriculture is possible only in the lowest of the mountain valleys, and is carried on mainly in the adjacent plains. The roadways have been built not often for the tourist, but almost without exception for the shipping of mineral products and the introduction of supplies. The keen, vigorous, and often rough life of our western mountains is in strong contrast to the quiet and simplicity of Alpine regions. The causes are partly geographic and partly historical.

As New York and other cities have grown, the Adirondacks have become chiefly a playground. Lumbering, already far too destructive, has been somewhat restrained, and the summer camp, the gun, and the canoe are the true symbols of the region. The same is true of the uplands of New England, where, indeed, the valleys abound in farms and villages, but the mountains, too low for snow-field and glacier, are forever set apart to rocky ledge and forest.

Ancient and worn mountains make up much of the rugged surface of Wales. No precious metals occur, but the slate, found only in mountainous countries, furnishes, in its quarrying and shipping, an important industry, while in the south are deposits of coal, leading to mining and manufacture. Similar are the low mountains of the English Lake District. Here, however, there are no important minerals, but lakes, mountains, and beautiful valleys, made memorable as the homes of Wordsworth and other men of letters, the whole region being chiefly a summer refuge for toilers from the cities.

The Scottish Highlands, with their thin, cold soils and stretches of bare rock, their rough stone cabins and unchanging poverty, under the leaden skies of the north, show us still another type of the life of mountain lands. No great cities-diligent but small tillage of the soil, isolation and primitive ways-such is the life of mountains, save where 
the rocks yield coveted treasure. There modern life pours in like a tide, and the virtues and vices of the latest civilization are seen to the full.

179. Barriers and passes.-Because most mountains are in the form of long belts of folding and uplift, they serve to separate the lands on their opposite sides. Thus on the east of the Appalachians are the low plains of the Atlantic, while to the west are the plateaus that extend from north to south. The Mohawk Valley is a famous gap in this great system, offering a gateway from the Atlantic seaboard to the interior. More will be said about the Appalachian barrier in Chapter XVI. The Rocky Mountains form a strong and continuous wall between the Great Plains and the Colorado Basin. It is partially eut by the deep gorge of the Arkansas River, but beyond that one must surmount the Marshall Pass, over 10,000 feet in altitude, or other and higher passes, in order to reach the Pacific slope. In Wyoming, however, the Union Pacific Railway finds a low passage at about 8,000 feet. On the west of the Sierra Nevada is the rich and fertile valley of central California, while on the east are the arid slopes and salty basins of Nevada.

The Andes show marked contrasts on east and west. The Pacific slope is relatively dry, while the Atlantic moisture spreads far over the Amazon plains and enriches the head-waters of this master river on the east slopes of the mountains.

In the Old World the Pyrenees are an effective wall between France and Spain. But two railways join the countries; one of these follows the shore of the Bay of Biscay, and the other is close to the Mediterranean. Carriage roads cross the range at but two points. The Alps are higher and more rugged than the Pyrenees, and throughout historic time have stood as a barrier between the Iediterranean and central Europe. On the south is the subtropical and sunny Italy. On the north are the cool tem- 


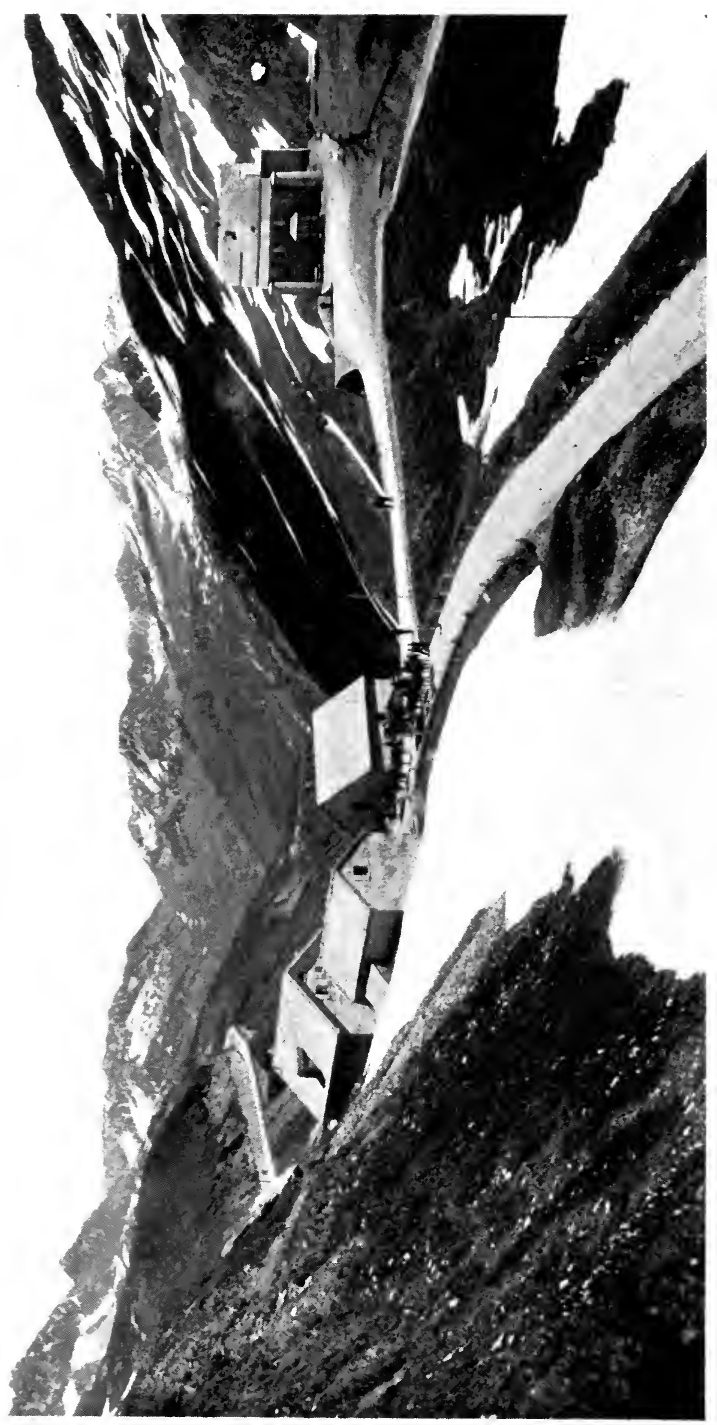

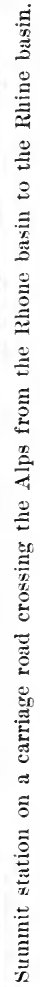

薄 
peratures and somber skies of Germany. But the passes, as compared with the Pyrenees, are low and numerous, and have been trodden by travelers, merehants, and invading armies since Roman days. Trails, beautiful carriage roads, and railways have in turn assumed the chief importance.

In Asia, the mild, fertile, and crowded districts of India are shut off from the high, cold, wild, and sparsely peopled lands of Tibet by the Himalaya Mountains, while the several mountain ranges of central Asia lie between the advancing Russians on the north, and the English, entrenched in India, on the south. 


\section{CHAP'TER IX}

\section{VOLCANOES}

WE shall begin our study by looking at several wellknown volcanic regions, the one about the Bay of Naples, the Hawaiian Islands, and Mount Shasta. We shall then compare these volcanoes, and see what great principles we can find to help us understand this part of the earth's machinery, which is so strange to most dwellers in the United States. The first examples are chosen outside our North American domain, because here the volcanoes have nearly ceased to be active. But it is well to mention at the outset that nowhere in the world have the fires of the earth had more effect on the surface, in past ages, than in some parts of our own land.

180. Figurative terms.-The word "fire" in the last sentence, and in other passages of this chapter, is not used in its ordinary sense, but somewhat figuratively. When fire burns, two substances combine-for example, coal and oxygen-and heat and light are caused. The substances are said to be consumed. In the volcano nothing is consumed; the lava as it comes from below is already in a hot and glowing condition. Before the real facts were known, people believed the heat was caused by burning, and the words expressing this belief are still used in speaking of volcanoes. Among these misleading terms are flame, ash, cinders, and igneous (fiery) rocks.

181. Vesuvius.-If one were to visit the west coast of Italy and ascend this mountain, he would find an observatory part way up the slope, where for many years Italian 196 
scholars have watched the behavior of the volcano. This small mountain, about 4,000 feet high, rising from the shore of the Bay of Naples, is a good sample volcano; the better because it has been studied so long, and its principal changes for nearly 2,000 years have been recorded. That small things may unfold principles is as true in geography as in all other fields of knowledge.

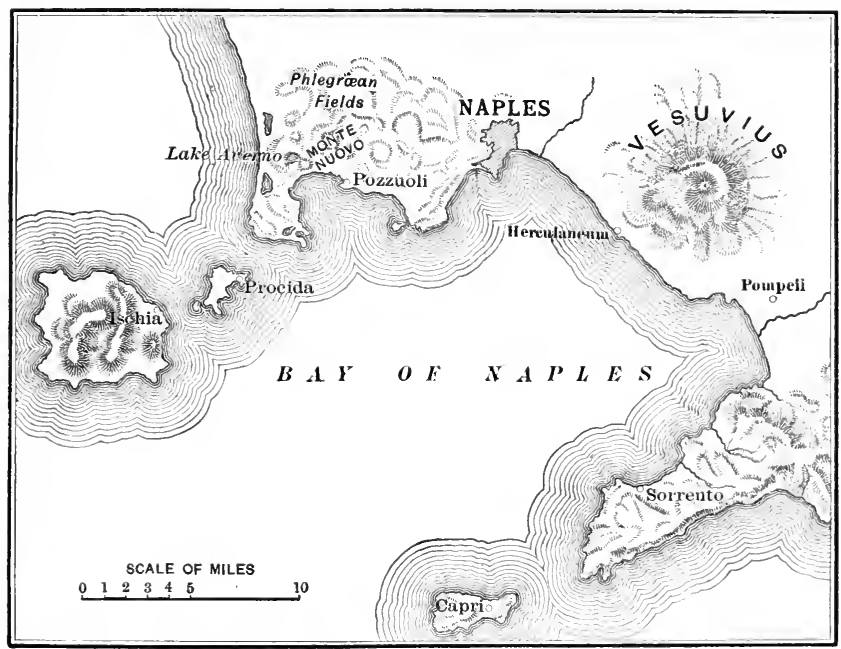

Frg. 138.-Map of Mount Vesuvins and vicinity.

The student should give careful attention to the map (Fig. 138). On the north of the bay are a number of localities well known in classic story-Misenum, Lake Averno, the Elysian Fields, and Puteoli (Pozzuoli), the port at which Saint Paul landed on his voyage to Rome. Near the shore west of Naples is Monte Nuovo, or new mountain, a hill 440 feet high, cast up by volcanic action during a few days in September, 1538. All about it are voleanic hills of earlier origin, and two islands bordering the bay are also voleanic. Thus we learn that Vesuvius is not alone, but is 
surrounded by a district under which the volcanic heat has been more or less active. The whole region is subject to earthquakes, due, it is belicved, to the pent-up fires below, and when the volcano gives vent to the confined lava the earthquakes subside.

Let us now look at the mountain itself. Sunk into its top is a bowl-shaped depression, the crater. In it is molten rock, and from it there come forth steam and other hot vapors. When the wind is right, the edge of the crater can be reached and a look had into its fiery depths. When a powerful eruption begins, immense clouds of steam rise and spread above the top of the mountain, taking a form that has often been likened to a pine-tree. It is not smoke, but vapor, that pours out; and the glow often seen, especially at night, is not flame, but the reflection from the vapor clouds of the light that flashes up from the melted rocks, either in the crater or overflowing in streams that roll down the sides of the mountain.

These streams sometimes flow so fast as to overtake a man running swiftly. At other times they creep. The differences depend on the slope and on the consistency of the lava. Some lavas are thick and viscous, like molasses, others are thin and watery. If the stream is shallow, it cools quickly and comes to rest. After lava has flowed for some distance the surface cools and is brittle, while the lower parts are soft and hot. As these lower parts push on they break up the surface into a rough, clinkery mass, which appears like a creeping heap of slaggy boulders. After the lapse of a human lifetime a lava stream may still send steam forth from its crevices, while the surface has long been cold, hard rock. Lavas are often frothy, with hot vapor in the form of bubbles, and after cooling to rock are full of rounded pores or cells. Certain lava-rocks are so porous and filmy that they will float on the sea. The pumice-stone used in the arts is a volcanic rock.

As the lava streams of Vesuvius have poured down its 


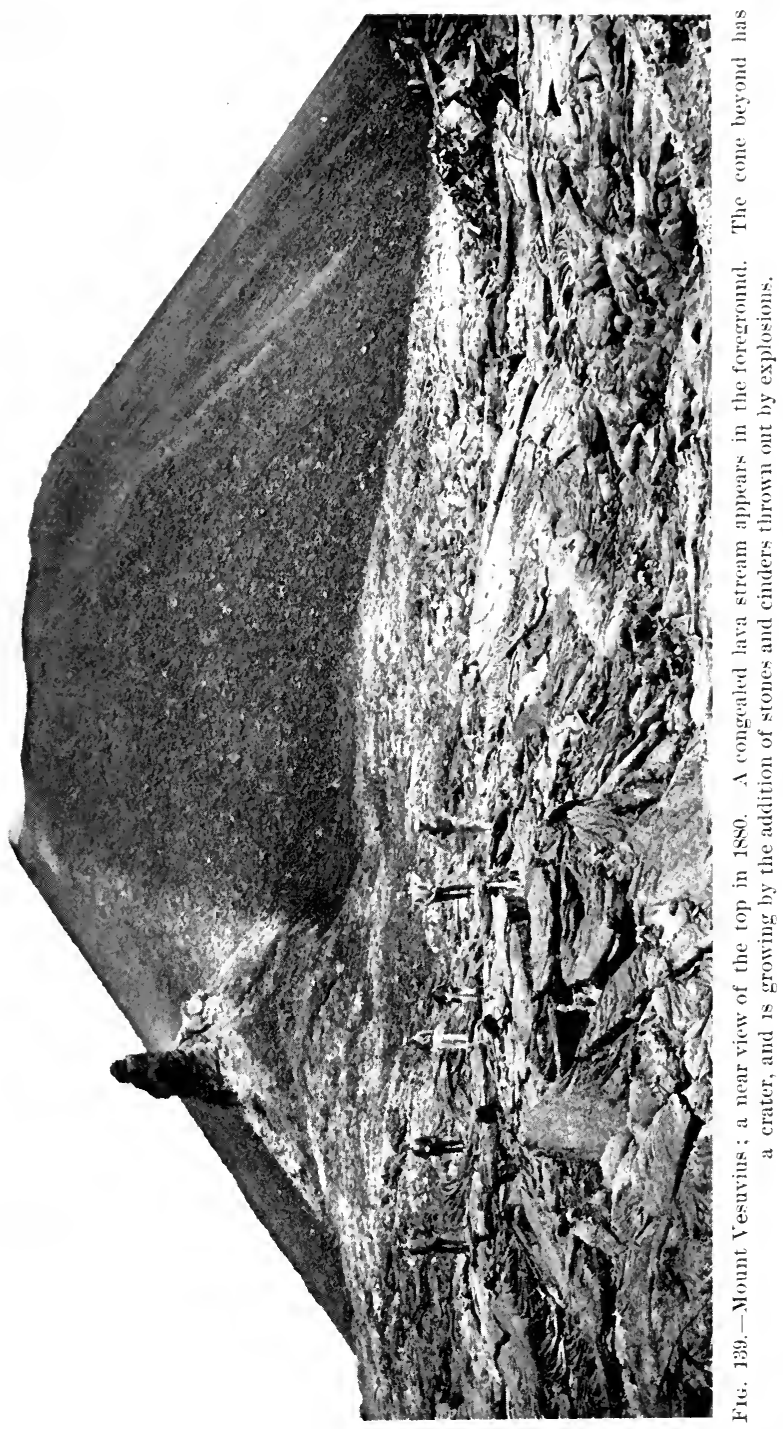


sides they have added successive coats to its slopes, thus increasing the size of the mountain. But not all the growth of the cone is thus explained. Some eruptions take place by means of powerful explosions, whose seat is somewhere below the outside opening. In this case the interior rock comes out, not as lava, but in the form of fine dust, or coarser pieces of rock, which fill the air, and fall or slowly sink to rest on the sides of the mountain or on neighboring plains and seas. Built up in these two ways, the mountain mass is a mixture of lava torrents and "ash" beds.

The student will observe that the height of Vesuvius was given as about 4,000 feet. It is not always the same, and has varied several hundred feet during the Christian era. In early Roman times the volcano had always been quiet, though previous to $\% 9 \mathrm{~A}$. D. the neighborhood was shaken by earthquakes. In this year there was a great eruption. It is vividly described in two letters written by the younger Pliny to Tacitus the Roman historian. These letter's referred to the uncle of the writer, Pliny the Elder, the great naturalist, who at that time commanded a fleet and was stationed at Misenum. He crossed the bay to see the eruption more closely and also to rescue a friend, and was suffocated in the fumes of the volcano. There was no lava, but immense quantities of ash were thrown out and rained on the neighboring land and sea. Two cities, Herculaneum at the west foot, and Pompeii at the south base of the mountain, were buried and lost for many centuries. Had they bcen deluged with lava, they could not now be uncovered and seen in such perfection-walls, pavements worn by wheels of carriages, rooms, wall-paintings, utensils, and all the signs of the luxury of the inhabitants. As the centuries have passed, other outbursts have sent forth streams of lava as well as clouds of ash. Sometimes the top of the cone has been cut off several hundred feet by a great explosion, only to be slowly built up again by the contributions of more quiet eruptions. 
182. Other Mediterranean volcanoes. - With what we have learned about Vesuvius, it will now be useful to associate some facts about other volcanoes in the middle Mediterranean region. South of Naples, near the Straits of Messina, are the Lipari Islands. They are composed of volcanic rocks. Of several volcanoes in this group, Stromboli is best known, because it is always active. Like Vesuvius, it is sometimes explosive and sometimes quiet, giving forth both molten and broken material. Its perpetual column of steam, illuminated at night with unfailing regularity by the fires of the crater, has caused it to be known as the "Lighthouse of the Mediterranean."

Still southward, close by the eastern shore of Sicily, rises another volcano, also famed in classic myth, and in comparison to which Vesuvius is but a mound. Etna is more than 10,000 feet in height, and has a circumference of 40 miles. Like Vesuvius, this vast cone is built chiefly of lavas and ash coming to rest about a central pipe or throat leading up from the depths, but there have also been many small eruptions on the flanks. From time to time cracks open on the sides of the great cone, allowing the escape of lava and cinders and causing small cones to be built. Fig. 140 shows some of these minor cones in process of formation. Like other great mountains, it has a rugged surface, and rises through several zones of climate, being almost tropical at its base, temperate and forested on its middle slopes, and arctic and snowy toward its summit. One German scholar has written two great volumes, wholly given to a description and history of this single volcano.

In 1831 the sea south of Sicily gave a fine illustration of the volcanic habit of that region. At a point where the water was 600 feet deep, volcanic materials were cast up until they stood 200 feet above the water. This new island, however, was soon cut away by the sea waves, leaving a shoal where the transient land had been. 


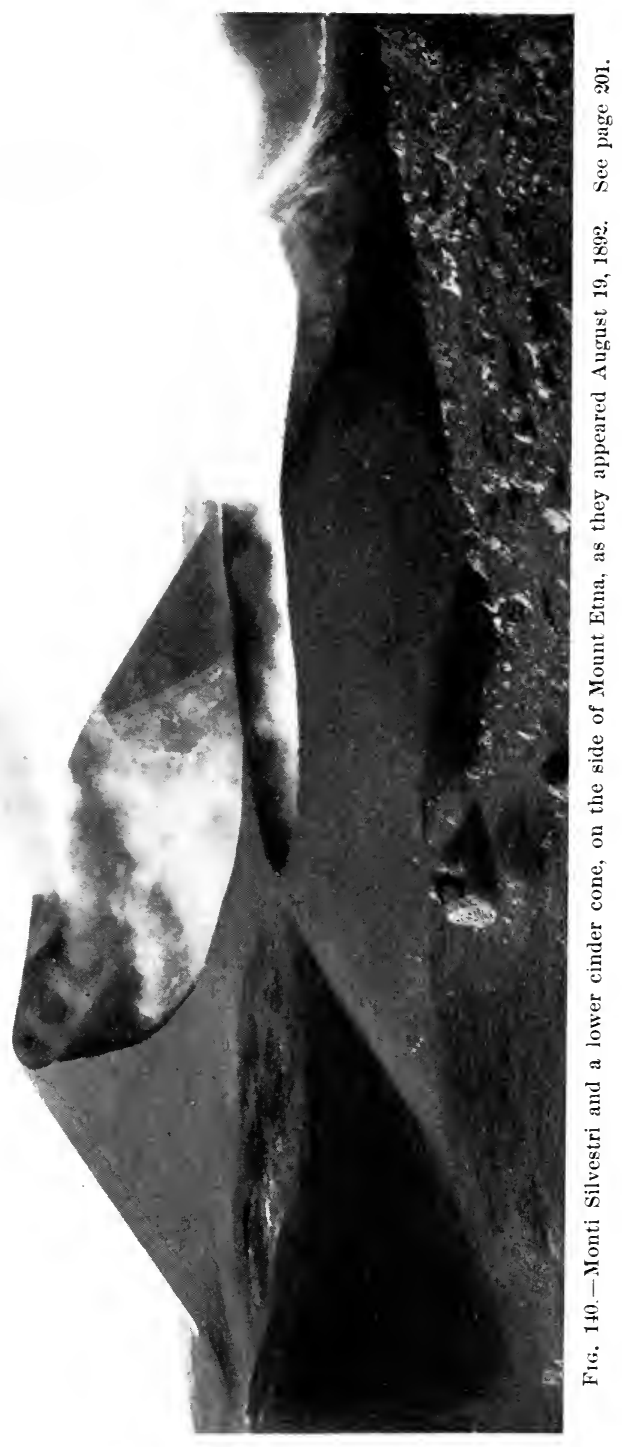


183. Hawaiian volcanoes. - The Hawaiian Islands form a northwest by southeast chain, about 400 miles long. All are volcanic piles built up from the floor of the leep seas. The only active volcanoes, however, are on Hawaii, the southeastern member of the series. This is a large island, about 80 miles across and having the form of a rude triangle. The two highest volcanoes are Mamna Loa and Mauna Kea, rising nearly 14,000 feet above the sea. 'The total height above the sea bottom is about 30,000 feet, or in the neighborhood of 6 miles. If the sea could be drained away, this whole island would be a broad-topped mountain, as high as the loftiest summits of the Himalayas. Successive outpourings of lava have reared the islands from the floor of the sea. The work of Vesuvius or even of Etna is insignificant as compared with this.

The slopes of the Hawaiian cones are very gentle (Fig. 142). This is due to the fact that the rocky matter sent forth is all in the form of lava, and the lava is in a very liquid condition. Hence when it flows out, it spreads widely. Thicker lavas and falling ash build steeper cones. There is great difference between the craters of Vesuvius and Hawaii. The one is a narrow, steep-sided bowl, the others are broad, sunken basins several miles across (Fig. 141). The walls of Hawaiian craters are cliffs several hundred feet high, but at some points descent can be made. During the time of quiet between eruptions, the traveler finds a floor of cooled lava covering over most of the erater basin. But at some points there are small ponds or lakes of molten lava, which bubbles and sputters with the escape of hot vapor.

The eruptions are vaster but more quiet than those of many small volcanoes. For a number of years the lava may rise, and spread in the crater, so that the basin can no longer be entered. But it has not been known to flow over the rim. Before this is reached it pushes through deepseated eracks and issues on the sides of the mountain, often 


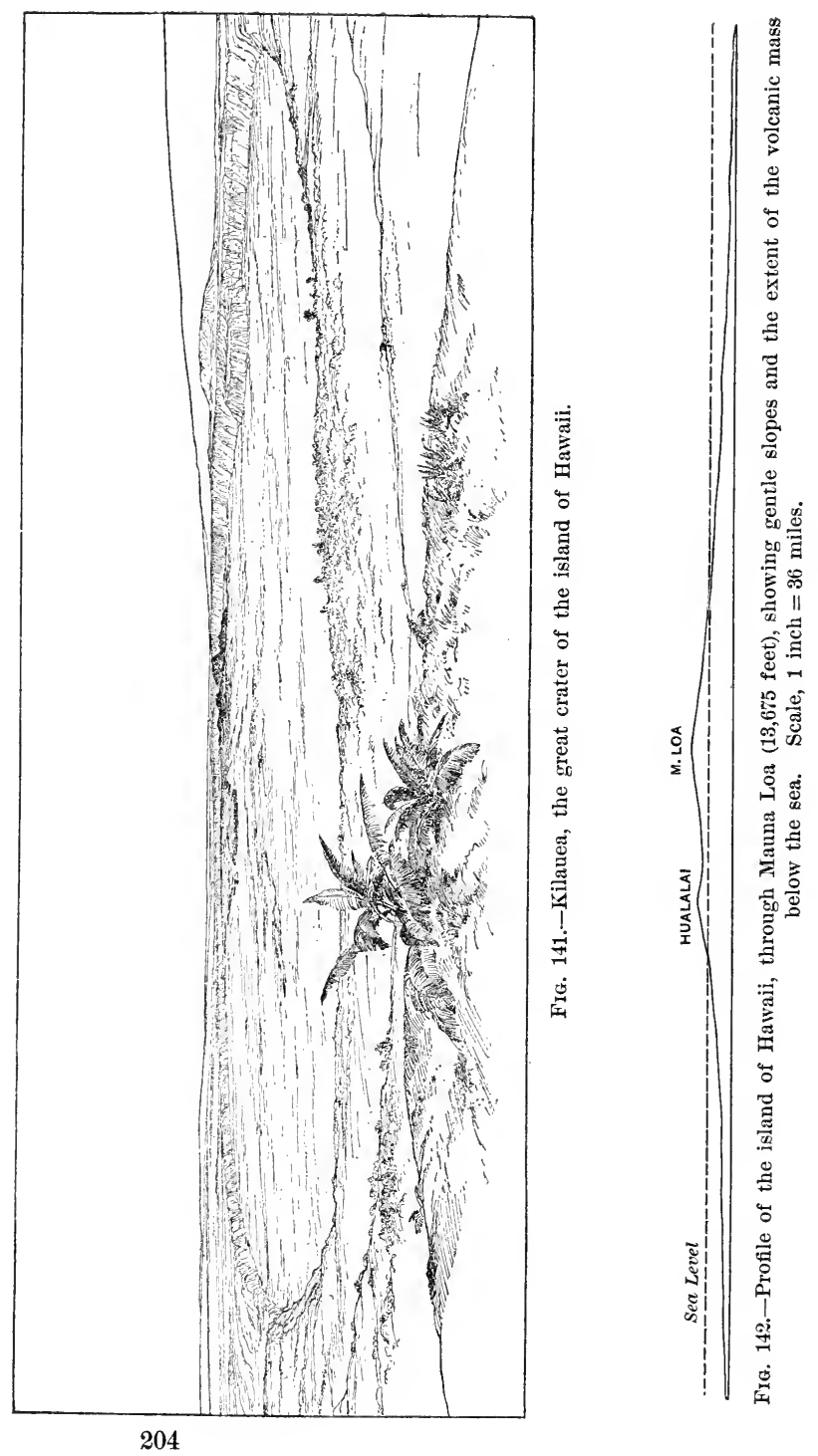


several miles away from the crater, and flows down the slope as a great hot river. Being very liquid at the start, it flows long distances, sometimes as far as 50 miles. Sometimes it has reached the seashore, and there, like a waterfall, has poured over the sea cliffs upon the beach below.

Much of the surface of the islands is mantled with soil and forest. But where the outflows have been recent, as over a large part of Hawaii, the lava surfaces are rugged and utterly barren. In the forested regions streams are abundant, and some of them have worn out deep gorges

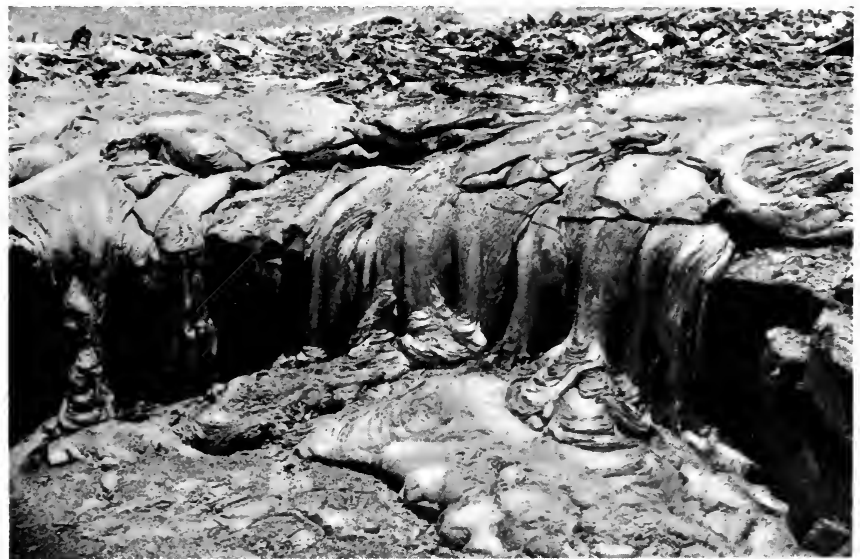

FIg. 143.-A congealed lava cascade; Hawaii.

which add variety to the surface. Thus volcanic action, weathering, and stream erosion combine to give the land its form and expression, and the climate, moist and tropical, clothes much of the surface with ferns, breadfruit-trees, screw-pines, and coconut palms.

184. Krakatoa.-Like the Hawaiian group, many islands of the Pacific Ocean are volcanic. They are the "high" islands, in distinction from those that are low, or of eoral origin. Krakatoa is an island volcano, lying in the strait 
that separates Sumatra and Java. It was not known as a great voleano until August, 1883, when for two days a succession of explosions blew away about half of the island mountain, brought the neighboring seas and lands to total darkness, impeled the sailing of ships by the ash that fell on the sea, and gave forth reports which were heard in Bangkok, in the Philippine Islands, in Australia, and more than 2,000 miles to westward in the Indian Ocean. Dust fell on ships 1,600 miles away, and is believed to have been carried in the upper air around the world (Sec. 205). The student will find it profitable to consider the strong contrasts between this and the Hawaiian Group.

185. Mount Shasta.-This voleano is no longer active, but is none the less useful for comparison with those already

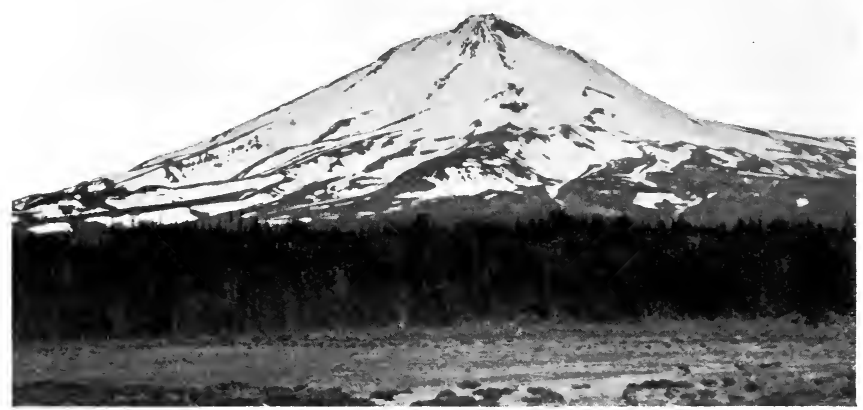

Fig. 144.-Mount Shasta.

studied. It is in northern California and rises to an altitude of 11,000 feet above neighboring lowlands. Its slopes are steep above, and become gradually gentler below, until they merge with the plain. The upper part of the moun- 
tain is double, its two summits marking two principal points of eruption. The higher is also the older; it had been completed and had begun to waste away before the building of the other. Fig. 144 shows only the older summit, the younger being hidden behind it.

If one were to dig deep into the mountain mass he would find various beds, some of ash, bound into firm rock, and some of cool lava, thus showing that, like Vesuvius, the rolcano was sometimes explosive and sometimes sent streams of molten rock welling forth from its crater. On the lower slopes of the mountain are smaller cones, as in the case of Etna, and some of these are much younger than either of the great peaks. From one of them a lava stream flowed to the Sacramento River and followed its valley for 50 miles. The river has since opened a canyon across it, and elsewhere sunk a deep channel at its side so as to leave the lava plain as a high terrace.

For a long period, as we reckon time, the fires below the mountain have gone out, or at least have been unable to send forth the signs of their presence. We call the volcano extinct. Instead of fire, glaciers cling to its upper slopes. There are five of them, two to five miles in length, each scooping a glacial alcove and trough out of the sides of the peak, and strewing the space below with moraine, or sending rock-flour and pebbles down the torrent courses of the monntain. 'The torrents have dng deep gorges. So the forces of waste are striving to tear down what the volcanic forces have built up.

186. Other volcanoes of the western United States.-If we go northward from Mount Shasta along the Cascade Range of Oregon and Washington, we find magnificent volcanic peaks, of which the highest is Mount Rainier, rising to 14,500 feet above the sea. Standing on a broad platean and apart from other high summits, it is an imposing landmark, seen afar from the cities and the sea. As measured by the amount of wear, it is older than Shasta. Its glaciers and 
torrents have deepened and enlarged their valleys until the intervening ridges are narrow and crusted. It may be said also to have renewed its youth, for after the work of de-

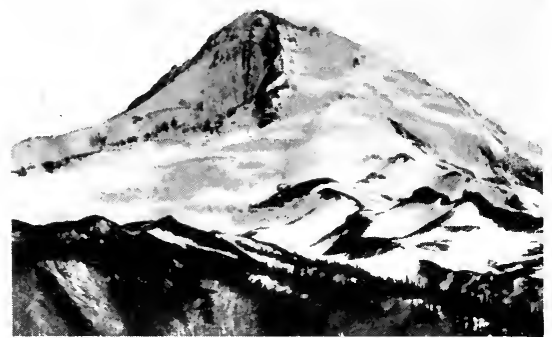

Fig. 145.-Upper part of Mount Hood, Oregon, shrouded by snow and ice.

struction had made great progress its fires broke forth once more and constructed a wellformed coneand crater at top. Mount Hood, Mount Jefferson, Mount St. Helens, and Mount Baker are among the other volcanoes of the region. All of these lofty peaks are white above and forested below. "Could an observer obtain a bird's-eye view of the Cascade Mountains, they would appear as a belt of emerald studded at irregular intervals with immense brilliants" (Russell).

Mount San Francisco in northern Arizona and Mount Taylor in northern New Mexico, each rising 5,000 feet above the plateau, are conspicnous landmarks, though less massive than the cones of the Pacific region. They are old and worn, but near their bases are ash-rimmed craters and black jagged lava fields so young that soil and plants have not yet begun to cover them. From the top of Mount San Francisco one may look down into nearly 200 craters. The number of small volcanoes scattered through the Cordilleras is great, and a few are found along the western border of the Great Plains. They are of all ages, and some have doubtless been active within a few centuries; but no eruptions have been witnessed by white men.

18\%. Regions of active volcanoes. - We have selected certain volcanoes because they are especially instructive, and 
we have seen some of the principles that arise from their study. Another general fact is that they are confined to no part of the world, but form one of the common features of the earth's surface.

The Atlantic Ocean contains many volcanic islands. Iceland is one of the most northerly and important. Its lava streams are of great size, while the ash from some of its volcanoes has fallen on ships in the northern seas, has descended on Scandinavia, and has even injured crops in the north of Scotland. Farther south, the Azores, Canary, Cape Verde, St. Helena, and other islands are volcanic.

In the West Indies is a line or narrow belt of volcanoes 500 miles long. They make the higher islands of the Lesser Antilles, including, among others, St. Kitts, Guadeloupe, Martinique, and St. Vincent. Because they are arranged in a line, it is thought that they are related to one another in origin, and make up a system. Their eruptions, though not frequent, have been energetic and destructive. Ifere, as about Vesuvius, the long periods of rest have given a false sense of security, and tempted to extensive settlement on the rich volcanic soils, to be followed by fearful disaster when activity was resumed. There were outbreaks on St. Vincent in $1 \% 18$ and 1812, on Guadeloupe in 1\%9\%, and on Martinique in 1851. The outbreak of 1812 was an explosion almost rivaling that of Krakatoa. A crater called Soufrière was either created or greatly enlarged, the fertile lands of the island were overwhelmed by ashes, and the town of Caracas, with 10,000 inhabitanis, suffered the fate of Pompeii.

In May, 1902, while the type for this book is being set, the attention and sympathy of the world are again drawn to these unhappy islands. The Soufrière, after a rest of ninety years, and the Pelée volcano on Martinique, which had slumbered for fifty-one years, have again wakened to activity. Explosions scatter stones and ashes widely over the lands. Streams of hot mud are flowing from the 


\section{AN INTRODUCTION TO PHYSICAL GEOGRAPHY}

craters to the sea. A new crater has opened on the slope of Mount Pelée. A sudden blast of hot gas and cinders

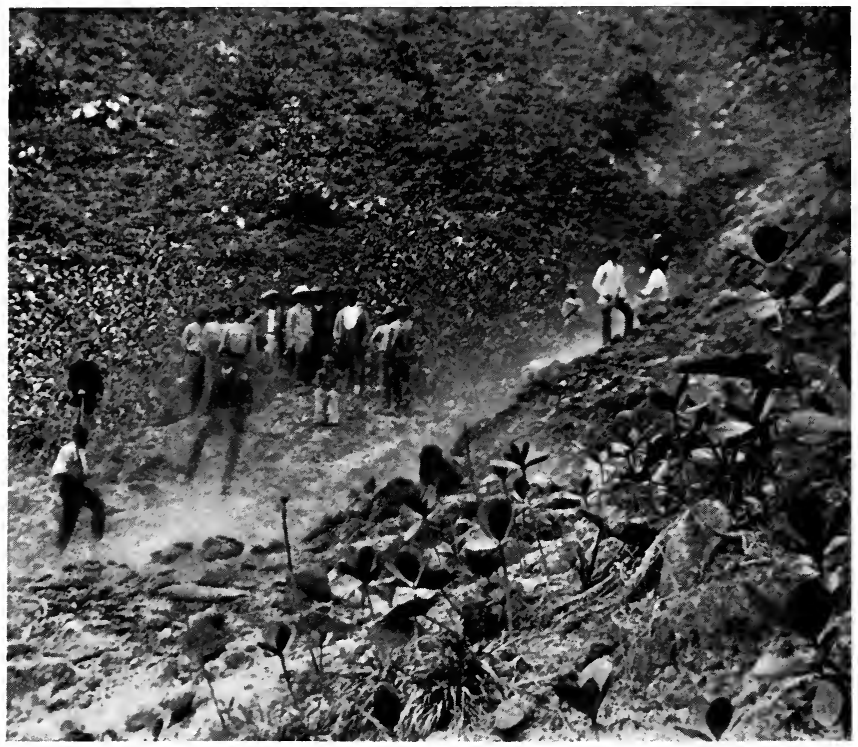

Fig. 146.-Interior of the crater of Mount Misery, on St. Kitts, West Indies. It is still steaming, though so old that its lavas are covered by soil and plants.

from this has destroyed the city of St. Pierre. More than 30,000 inhabitants of the islands have lost their lives, and great areas are laid waste.

We have already told of a few great cones of the Pacific coast region. Following the mountain belt through Mexico and Central America and far along the Andes, great volcanoes are abundant and active. Northward, a few volcanoes occur on the islands of southern Alaska, and a great volcanic belt, beginning on the south coast of western Alaska, may be followed almost around the Pacific Ocean. The Aleutian Islands, Kamchatka, the Kuril Islands, Japan, 
the Philippine Islands, and those of more southern seas, with the mountains of western America, almost girt this vast ocean with fire, while many a chimney, as we have seen, rises from its waters, and many submarine volcanoes

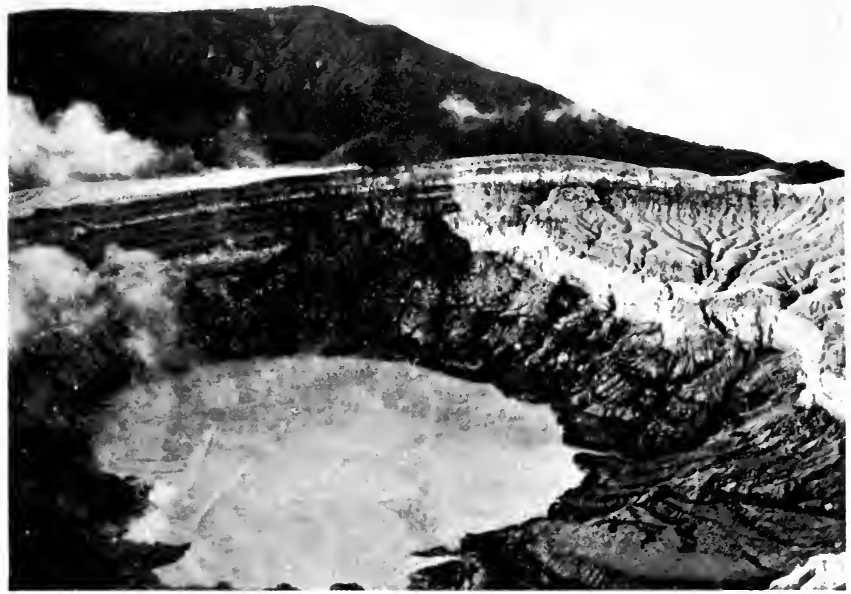

Fig. 147.-A volcanic crater, holding a lake; Costa Rica.

have not been able to pile their outpourings to the surface of the sea. Krakatoa belongs to a field of great volcanic activity, including Java, Sumatra, and almost all parts of the East Indies.

188. History of a volcanic cone-This is a story of growth and decay. Vesuvius, Etna, and the Hawaiian cones are still growing. The time was when their piles of volcanic matter were small like Monte Nuovo. Through progressive stages they have grown to be what they are. In time they will cease to send forth ash and lava, and destruction will begin. We see the first stages of it in Mount Shasta. Here the form is still well preserved, and 


\section{AN INTRODUCTION TO PHYSICAL GEOGRAPHY}

the mountain has lost little from its top and sides. But there has been some wasting. The glaciers are scooping out the higher slopes, and the torrents are furrowing the lower with ravines. In time the summits will yield, the ravines will become vast canyons, and the volcanic pile will be deeply cut and scarred. This stage is well illustrated by Tahiti, a high volcanic island in the Pacific Ocean. A series of radiating valleys, like the spokes of a wheel, head abruptly toward the center and summit, and extend out to the shores of the island. These valleys are sometimes 3,000 feet deep, and have so widened that a ridge like the edge of a knife is all that is left between them. Dana ascended to the top along one of these ridges, whose upper edge was in places but 1 to 3 feet wide, while the cliffs below were 1,000 to 2,000 feet high and stood at an angle of $60^{\circ}$ to $\% 0^{\circ}$.

We can readily see that in time these sharp ridges will break down, the gorges be extended at their heads, the summits decay and thus the height be lessened, the rough surface become subdued, and, if time enough be granted, the entire island will be worn down to the level of the sea.
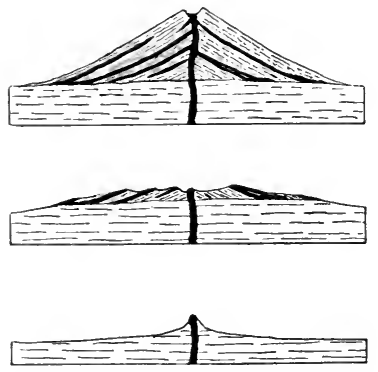

FIG. 148.-Ideal sections of a wasting volcanic cone at three stages of its history.

The student should imagine all this, and the picture thus formed will be true to nature. In many parts of the world are found volcanic mountains which have been worn away until the merest stumps and roots remain. This is best understood by reference to the diagram (Fig. 148). We see first the original profile of the cone; second, we have a low, subdued pile or hill, still rising above the general surface; third, all of the original cone is gone, and much of the surface rock in the surrounding region. 
But the lava that occupied the old throat, far below the crater, is harder than the surrounding rock, and in the great wasting, has survived and stands above the surface. It has been well likened to the cork in a bottle, and geologists call it a volcanic neck or plug. Many of them stand out on the surface of the plateau in parts of New Mexico (see Fig. 149).

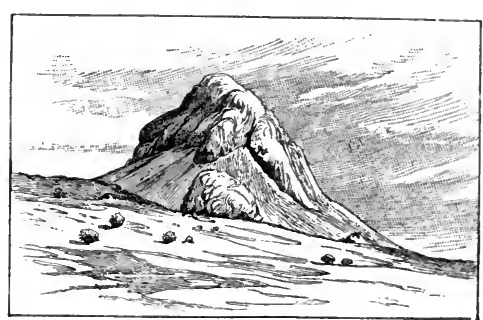

Fig. 149.-A volcanic neck; northern New Mexico.

189. Sheets of lava.-While no lavas are so fluid as water, they show great differences in this respect. Some are very stiff and can scarcely flow at all; others are thin and flow easily. When a lava stream starts from a crater it also begins to cool and it stops flowing when it gets so cool as to be stiff. If the amount which comes out is small it stops quickly. The piling up of such short streams makes volcanic mountains. But sometimes a very large quantity of very thin lava escapes all at once, and then it runs farther and spreads more widely. If it runs into a valley or over a plain it makes a lava lake. When it hardens it makes a broad, flat sheet of lava-rock. In the basin of the Columbia River there have been many such eruptions, with the result that broad plains are composed wholly of volcanic rocks, piled up in sheets. The Snake River, crossing such a plain, has made a long, deep canyon (Fig. 51), in the walls of which the sheets or beds of lavarock are arranged like the beds of sandstone and limestone in the canyons of the Colorado. Before the eruptions began, the region had for long periods been a district of mountains and valleys. Hence the outpourings flooded the valleys and low grounds, while the higher mountains still rise as islands 


\section{AN INTRODUCTION TO PHYSICAL GEOGRAPHY}

from the plateau, or send out ridges or spurs from its border. Thus the boundary of the lava sheets runs in and out, like the shore-line of a lake in a rough country.

There have been volcanic eruptions in all the past ages of the earth. Some of these spread under the ocean and were covered by sediments, and so there are lava-rocks buried among the stratified rocks. Lavas have also in-

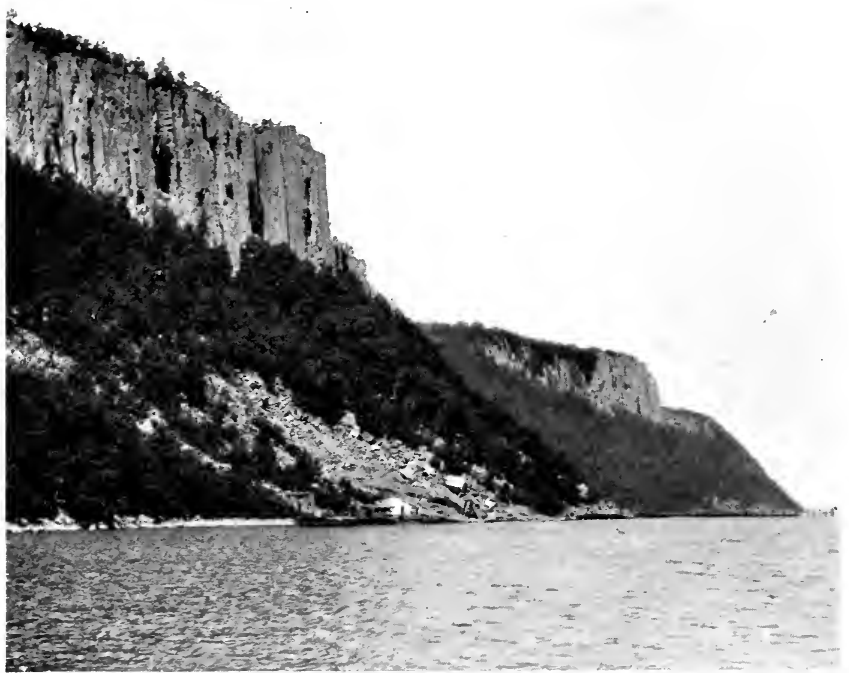

Fig. 150.-Palisades of the IIndson.

truded themselves in broad sheets between strata and there hardened to rock. Afterward, when great series of strata have been lifted into the air and gradually wasted away, the sheets of lava-rock have been exposed to view; and, being very durable, they often stand forth in the landscape as hills and ridges. The Watchung Mountains of New Jersey, the Palisades of the Hudson (Fig. 150), and Mount Holyoke in Massachusetts are of this character.

The cliffs at the edges of the sheets have a peculiar 


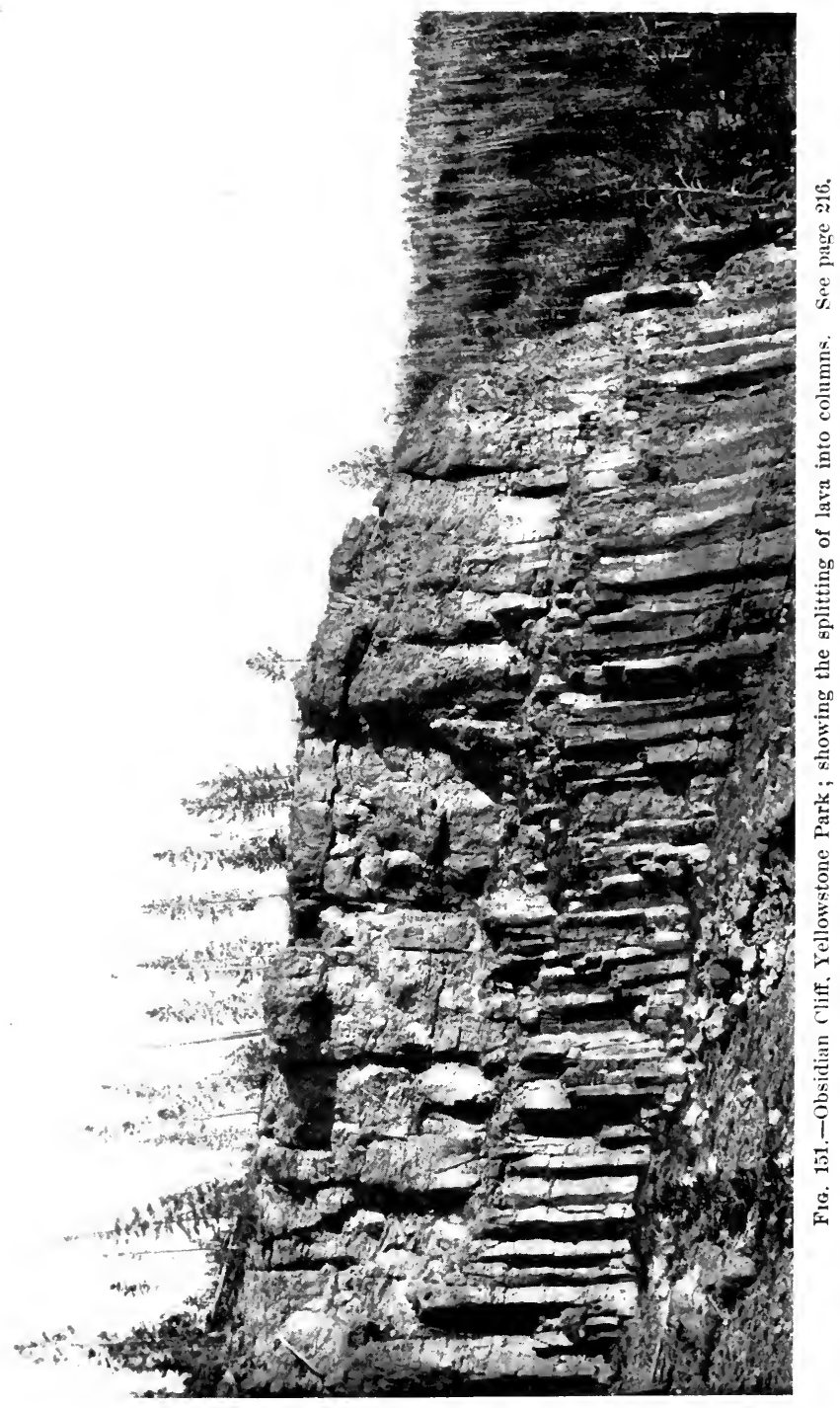




\section{AN INTRODUCTION TO PHYSICAL GEOGRAPHY}

character because of a tendency of lava-rock to break up into columns. It shrinks and cracks in cooling just as mud cracks in drying, and the cracks run far into it, dividing it into long blocks with five or six sides (Fig. 151).

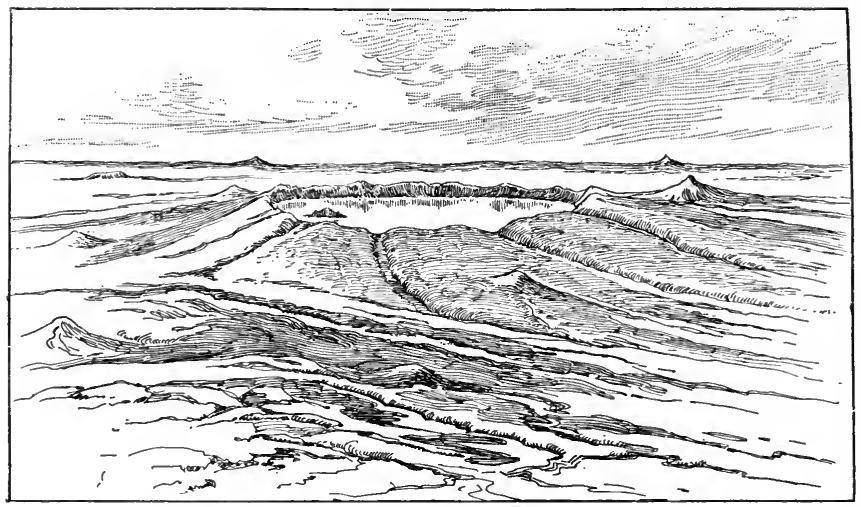

Fig. 152.-Bird's-eye view of Crater Lake, Oregon.

Extensive sheets of lava are found in Colorado, Utah, Arizona, New Mexico, and other western States. Sometimes they have been worn away to small remnants, as in the lava caps of North and South Table Mountain at Golden, Colorado, or Castle Rock, south of Denver. From the latter place is quarried a gray or pinkish lava which is used as a building stone in that region.

In western Scotland are important lava sheets also. Here belong the columnar rocks of Mull, Staffa, and other islands, which consist largely of remnant lava-beds. Into the southern cliffs of Staffa the sea has worn Fingal's Cave by removing the vertical columns of lava. Giant's Causeway, on the shore of Ireland, consists of similar volcanic rock. One of the largest outpourings in the world forms the plateau known as the Dekkan in India. The lavas are sometimes 6,000 feet thick. 
190. Volcanic lakes.-These may be formed in at least two ways: A flood of lava sometimes blockades a valley; behind such a dam a lake will form and remain until the basin is full of sediment, or the outlet stream saws through

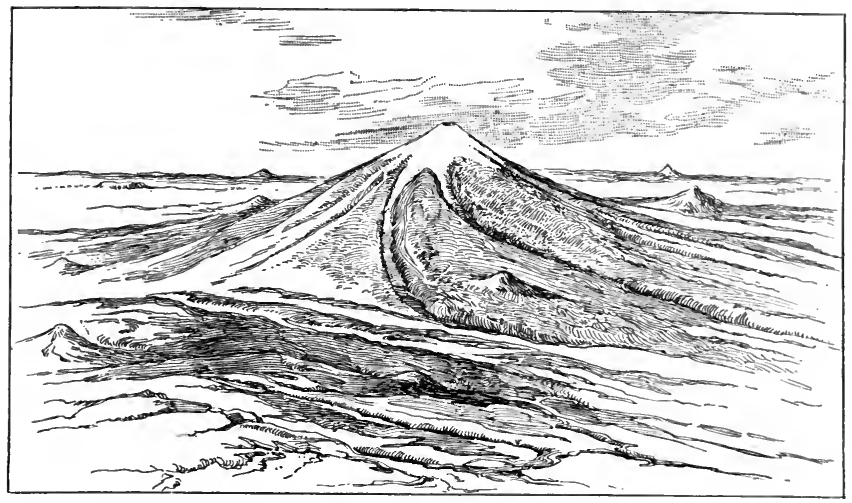

FiG. 153.- "Mount Mazama," an ideal restoration of the Crater Lake volcano. See Fig. 152 and Sec. 190.

the barrier. And when a volcano becomes extinct its crater may serve as a water-basin (Fig. 147). Crater Lake, in southern Oregon, lies in the heart of an old volcano, the higher and central parts of which have disappeared. Instead of an explosion, as in the case of Krakatoa, there was a withdrawal of the lava beneath, so that all the upper part of the cone, with its gorges and glaciers, fell in and disappeared, leaving a nearly circular pit 4,000 feet deep and 6 miles wide (Fig. 152). The water of the lake is 2,000 feet deep. Above it rises an island, which is a small volcanic cone, made after the disappearance of the greater cone.

191. Volcanic soils.-Lavas and ash are often so porous that they are easily entered by air and water, and weather rapidly into soils. Thus, after a few generations, the lava 


\section{AN INTRODUCTION TO PHYSICAL GEOGRAPHY}

fields about Vesuvius, and other volcanoes in genial climates, become densely populated, and all danger from eruptions seems forgotten. Parts of the Dekkan are important in wheat and cotton growing, and the black and fertile soil is due to the decay of the lavas. In the same way lavas furnish the soils for extensive wheat-fields in Oregon and Washington. This is perhaps the most important way in which volcanoes affect mankind, unless we except the catastrophes which have wrought destruction of life. The volcano does not compare with weathering or with streams; and it probably has not influenced the more progressive races so extensively as has the glacial invasion. Certainly glaciers, much more than volcanoes, have molded the conditions of life in the United States.

192. Causes of volcanic explosions.-The general causes of volcanoes are not well known, but the reason that lavas sometimes explode is better understood. There is water in all lavas, the quantity being large in some and small in others. Deep down in the earth's crust the pressure is so great that the water, though intensely hot, can not change to vapor; but as the lavas rise they experience less and less pressure until at last the water within them suddenly becomes steam and is instantaneously expanded. If there is little water, the lava quietly bubbles; if there is much, it is torn to fragments, and the fragments are hurled into the air. The principle of the explosive volcano is the same as the principle of the geyser.

193. Summary of principles.-The descriptions of particular volcanoes and districts have illustrated various general facts, and some of these have been pointed out. We now bring together the more important:

(1) Many volcanoes build around their vents a cone; it may be of mountainous height, and the term mountain, in a general sense, is commonly used. It is not at all due to uplift of the earth's crust, but to the bringing up of materials from below which are heaped up about an open- 
ing. In this respect, as well as in form, the volcano finds its miniature representative in the ant-hill (Fig. 58).

(2) Some cones are large both in height and base, like the Hawaiian, while others are small, like Vesuvius, Stromboli, or the diminutive Monte Nuovo. They also differ in form; some are very flat and others as steep as a talus of coarse waste, the difference being due to the character of the materials forming the pile.

(3) The materials sent forth are various. First, we have the lavas, and these differ much. Some are dark and very heavy, as basalt, and others are pale in color and lighter in weight. Second, we find the ash, with larger angular pieces of rock, as in some eruptions of Vesuvius and Shasta, or the great eruption of Krakatoa. Of importance also are the vapors, particularly the steam, which often condenses and causes heavy rains, or mixing with the ash gives rise to eruptions of mud, which flow from the volcano and harden into rock. Any volcanic ash which thus becomes bound into firm rock is called Volcanic 'Tuff.

(4) Volcanoes differ much in the manner of eruption. Stromboli is constant; Vesuvius and the Hawaiian volcanoes are intermittent or spasmodic. Some are quiet; others are violent and explosive. Some vents emit many small eruptions and build up mountains; others discharge great volumes of their lava and construct plains.

(5) Craters are formed in various ways. Fragments thrown out by explosive eruptions fall to the ground all about the opening, and thus build up a circuiar rim. Sometimes a great explosion blows off the upper part of a conical mountain, leaving a hollow in its place. And sometimes the interior of the mountain is melted out, letting the top fall in.

(6) A volcano, like a mountain range, is caused by forces belonging to the mysterious interior of the earth. As soon as made it is attacked by the destructive forces of air and water, which gradually wear it away. Growth and decay make up the history of its life. 


\section{EARTHQUAKES.}

194. In volcanic regions.-The earthquake and the volcano often go together. Thus, earthquakes are common about Naples and Mount Vesuvius. Before the great eruption of $79 \mathrm{~A}$. D., shakings of the earth had occurred for several years. When the energy that had been sealed below. the surface broke forth, the shaking ceased. Still farther south in Italy great earthquakes have shaken the Calabrian region repeatedly. For four years, beginning in 1783 , they were almost constant. Nine hundred and forty-nine shocks took place in the single year 1783 . Over a large district all the villages and towns were reduced to ruins. The surface often rolled like sea waves; trees rocked, and monuments were thrown down, or twisted about on their foundations. Deep fissures and ravines were opened in the soil and in the rocks. Animals, and even houses, were engulfed in some of these. In some places funnel-shaped basins were formed and occupied by water, thus creating ponds or small lakes. In the mountain regions, landslides occurred, and rivers were in some cases turned from their course. In certain places whole villages were swept away in these slips. On the shore, the inrushing of great waves destroyed much life and many homes. Such waves are due to the shaking of the earth's crust and should never be called tidal. About 40,000 people lost their lives directly through these earthquakes, while many others died of pestilence or neglect.

The Calabrian shocks must serve as an illustration of many. New Zealand, Chile, the East Indies, and Japan have all suffered from powerful disturbances. Nowhere has there been greater havoc than in closely peopled Japan. Deep fissures, houses and towns shaken down, and enormous waves rolling in from the Pacific and destroying thousands of lives-such are the features of Japanese earthquakes. 
195. Charleston earthquake. - The date of this great shock is 1886 . It took place at 9.50 P. M., August 31, and lasted for a little more than a minute. Every building in Charleston was more or less injured, thousands of chimneys were thrown down, and the ground rocked so as to give the impression of a heavy sea. Near the city, the railway tracks were severely twisted in a number of places, cracks

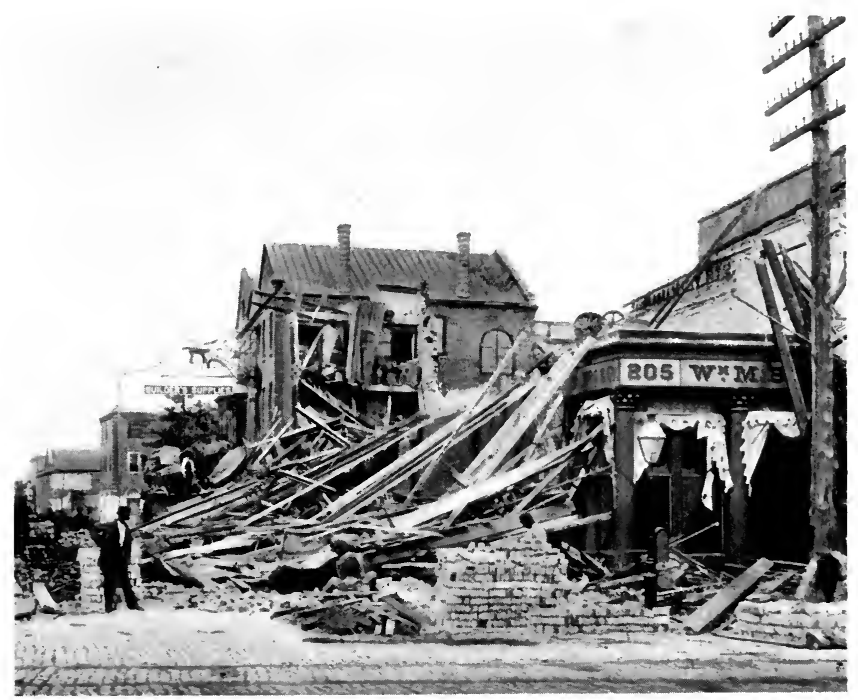

Fig. 154.-Street scene in Charleston after the earthquake.

opened in the ground, and water was cast up. The shock was felt in the Northern as well as the Southern States, and even in the Province of Ontario. At least 2,500,000 square miles were affected by it. By comparison of times in the different places, it was found that the earthquake wave traveled 150 miles per minute. This shock was not connected with an eruption, and Charleston is far from any active volcanoes. 
196. What is an earthquake?-It is not so easy to answer as to ask this question. It is quite clear that the rocks of the earth's crust receive an impulse, which spreads out in every direction, as a water-wave does when water is forcibly disturbed at any point. In the latter case it is not the water which moves, except slightly, but the force is passed from one part of the water to another, and thus the wave may cross an ocean. Just so the force or impulse travels in the rocks.

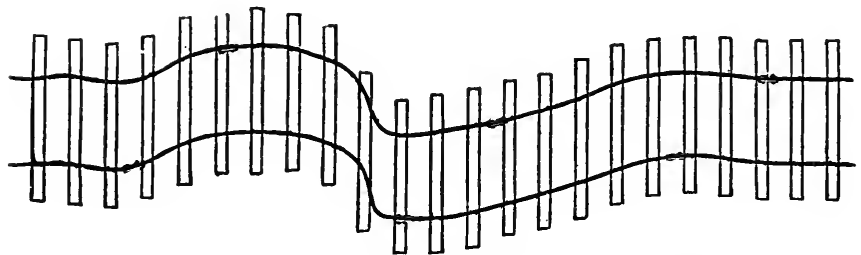

FIG. 155.-Bends in a railway track made by the Charleston earthquake.

We now see that the real question is, What is the force? When an earthquake accompanies a volcanic explosion the same force evidently causes both-the expansive force of steam. In other cases it is thought that the forces which lift mountains and those which push lavas through the crust are able to bend or strain the rocks, and the straining gradually increases for a long time, until at last there is a sudden breaking, which gives the earthquake impulse. 


\section{CHAP'TER X}

\section{THE ATMOSPHERE}

We now pass from the forms of the land to the study of the Atmosphere, which covers land and sea and has much to do with both. The word means vapor ball, and is thus a good name for the envelope of the globe. It lies outside the watery sheet which so nearly covers the planet, and the water in turn mantles the rocky crust. Thus the inner parts of the earth may be thought of as having three covers - of rock, water, and air. The atmosphere is a part of our globe, and not merely an outside blanket.

19\%. Composition of air-Air is the name of that mixture of gases which makes up the atmosphere. Before we give an account of these gases, we may notice certain facts about the air. As it has neither odor, taste, form, nor color, we can not smell, taste, or see it. We feel it when it is in motion or when we move through it, and we notice keenly whether it holds much or little heat. Our hearing depends entirely upon wave motions which spread through it. It is elastic, and expands and contracts by changes of temperature, and when pressure is withdrawn or applied. It can be turned into liquid, a property whose importance may prove to be very great. It is essential to combustion as well as to the slow processes of decay, and is required, in larger or smaller amounts, by all animals and plants (Sec. $2 \% 8)$.

Air is made up chiefly of the two gases, oxygen and nitrogen, in the proportion of one part of the former to four of the latter. The two are not chemically joined, as the 


\section{AN INTRODUCTION TO PHYSICAL GEOGRAPHY}

hydrogen and oxygen of water, but are mechanically mixed. To stir ashes with soil would roughly illustrate the mingling of the invisible molecules of oxygen and nitrogen. The oxygen is the active element in burning, in decay, and in living bodies. It unites with certain substances and heat is given off. If this process goes on rapidly, and much heat appears, we call it burning. In our bodies this action is constant but slower, and with less heat. In decay the process is very slow, and the heating is correspondingly little.

The nitrogen, while large in amount, is the inactive element in the air. It does not unite with other substances, but without it the activity of the oxygen would be destructive. Animals can not breathe pure oxygen. Nitrogen serves for the air the same purpose as the dilution of a strong liquid by water.

Carbon dioxid, often called carbonic acid gas, is a combination of carbon and oxygen. It is present in the air in very small amount-about 0.03 of one per cent-but is of very great importance. Plants take in this gas through the leaves, break it up, use the carbon and release the oxygen. Animals, on the other hand, breathe in oxygen, and give off carbon dioxid. It is the presence of this, and other harmful vapors from the body, that makes the ventilation of sleeping and living rooms important. This gas is given off in all ordinary burning, hence the use of gas and oil lamps without sufficient supplies of fresh air is harmful. We thus see that a gas which is a deadly poison to animals in any but minute quantities is necessary to the life of plants, and thus indirectly to all animal life. Certain other gases are in the air in very small amounts, but we need not concern ourselves with them.

The vapor of water is always present, but the quantity is very variable. It is gathered by evaporation, mainly from the ocean, is floated everywhere by the winds, as rain it waters the fields and forms the rivers. All the life of the land depends upon it, and the forms of the land also, as 
molded by solution, river, and glacier. In later sections we shall study Humidity, Dew, Frost, Clouds, and Rainfall. All these topics relate to moisture in the air.

Fine dust is everywhere present, especially in the lower levels of the atmosphere. It is not a part of the air, but floats within it. We can sometimes see its particles when a beam of sunlight enters a poorly lighted room. The haze following great forest fires, and the pall often hanging over manufacturing cities, are due to dust. All man's operations cast more or less dust into the air. The winds blow fine plant and mineral fragments up from the forests, roads, and fields (Chapter V), and explosive volcanic eruptions scatter dust widely. When heavy rains follow a period of drought, the dust is washed from the air, and we say that the air is cleared. When rain-water is gathered in tanks and cisterns, some of the dust appears as sediment. Not least important are the minute living things which are always found in the air, and may be blown to long distances. Such are seeds and the pollen of flowers, and especially the microscopic germs of many diseases.

198. Weight and height of the atmosphere.-Air, thongh a mixture of gases, is a material substance, as is well shown by forcing it into liquid form. It has weight, therefore, though much less than a liquid or solid. In the space of a cubic foot there is more than an ounce of air, and an ordinary school-room contains several hundred pounds. Because of its weight, air pushes downward, pressing on the ground and the ocean. The upper part of the atmosphere also presses on the lower part. Though the atmosphere is really not separated into parts, we can think of it as composed of horizontal layers, resting one on another, and thus compare it to a pile of boards. Just as each board bears the weight of all the boards above it, so each layer of air is pressed upon by the weight of all the air above it. The boards are unyielding, but the elastic air is crowded together by the pressure-like a dry sponge or a coiled spring. The 


\section{AN INTRODUCTION TO PHYSICAL GEOGRAPHY}

greater the pressure, the more the air is packed together. So low layers of air, sustaining great weight, are comparatively dense, and high layers, sustaining less weight, are comparatively thin or rare. There is a gradual thinning from the level of the sea upward; about the top of Mount St. Elias the air is only half as dense as about its base. Therefore, on a high mountain the lungs get less air at each breath, and one must breathe quickly to keep them supplied. A very little exertion makes one pant violently.

In the first few miles of ascent the air thins more rapidly than at greater heights, and the change finally becomes very gradual. Reasons have been found for feeling sure that very thin air exists at the height of a hundred miles. How much farther out into space the last scanty remnant of our atmosphere reaches may

Fia. 156.-Diagram of the atmosphere. Varying depth of shade indicates varying density. The highest peak corresponds to the Himalaya, the lower peaks to the Sierra Nevada and Rocky Mountains.

never be known. By far the greater part of it, as measured by weight, lies below the level of the highest mountain tops (see Fig. 156).

199. Humidity.-This is a scientific term which is also much used in common speech in referring to the moisture of the atmosphere. If there is much moisture we say that the humidity is great. In warm weather the air is heavy and lifeless, and we call the day or the night sultry. In addition to the depressing effect, we perspire freely. Mois- 
ture is always escaping from the pores of the skin, but in dry weather it evaporates. Warm and humid air about us is like a filled sponge, refusing to absorb more, hence the drops gather on the body. If the air is cold and humid, it brings chill and a cutting sensation upon exposure. In dry, hot days the air is like an empty sponge-it absorbs readily, plants lose their moisture through the leaves and wilt, washed clothes dry rapidly, and we say the humidity is low.

The warmer the air, the more water vapor it can hold. The sun's heat, falling on the sea, on rivers, and on moist earth, causes evaporation. If the air has thus taken in all the vapor it can hold at a particular temperature, and the temperature be lowered, some of the invisible particles will fly together-that is, condensation will take place-and there will be fog, clouds, dew, rain, or snow. Thus the atmosphere is always receiving water in some places and yielding it up in others.

If air at a temperature of $75^{\circ}$ (or any other degree) has all the vapor it can hold, it is said to be saturated. Its vapor contents exactly equal its capacity for vapor, and hence the relative humidity is said to be 100 per cent. If the same air were filled to only half its capacity, the relative humidity would be 50 per cent. If now we gradually lower the temperature, but keep the amount of water the same, we come at last to the point of saturation, and the relative humidity becomes 100 per cent, instead of 50 per cent. Relative humidity does not tell us how much water there is in the air, but it gives the ratio of the moisture present, to that which the air at that temperature is able to hold.

200. Dew and frost.-As night comes on the sun's heat is removed, the air grows cool, especially near the ground; its ability to hold moisture decreases, and it may become saturated-that is, the relative humidity may become 100 per cent. If now the temperature continues to go down, 


\section{AN INTRODUCTION TO PHYSICAL GEOGRAPHY}

the vapor will condense and be found on grass and leaves, and even sometimes on roofs and stones. This is Dew. The temperature at which it begins to form is known as the Dew-point.

Not all of the drops which in the morning sparkle on blades of grass and leaves of shrubs and trees have come from the air. Many of them have traveled up through roots and stems and been "transpired" by the leaves. This goes on by day also, but the water is at once evaporated, because then the air near the ground is warm. Thus plants as well as animals condense the vapor on their outside surfaces when the air is overcharged with water.

When the air is comparatively dry (relative humidity low), and the drop in temperature is slight, there will be no dew, the point of saturation not being reached. This is apt to be the case on cloudy nights, because the clouds prevent the rapid cooling of the ground. It will be understood that the dew does not really "fall," but gathers by direct contact with moist air.

If the surplus moisture from the air or from the ground condenses at temperatures below the freezing-point we have white frost, or "hoar" frost, instead of dew. It is most noticeable in autumn and spring upon roofs, fenees, and fields. Clouds often prevent frost by holding in the heat which has aceumulated during the day, and we sometimes imitate nature by covering plants on elear nights to protect them from frost.

201. Clouds and fog.-Fog is a cloud in the lower air. If the dew-point is reached at the earth's surface, moisture gathers there. If a few feet or a few hundred feet of the lower air cool to the dew-point, fog is formed. The particles of invisible vapor unite and become visible, but are still so small that the air supports them. Thus it is that a thin layer of mist may spread over a swamp or valley bottom, so that from a hilltop we can look out over a lake of fog. In the rays of the sun the air grows warmer, and 


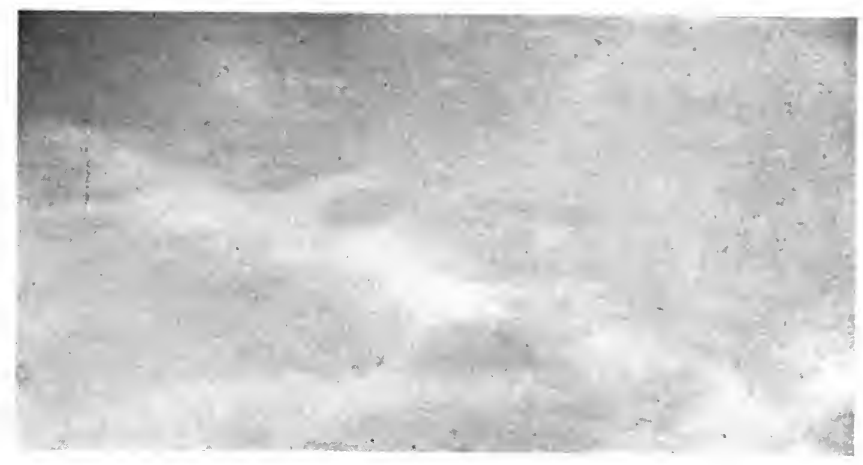

Fig, 15\%,-Cirrus clouds.

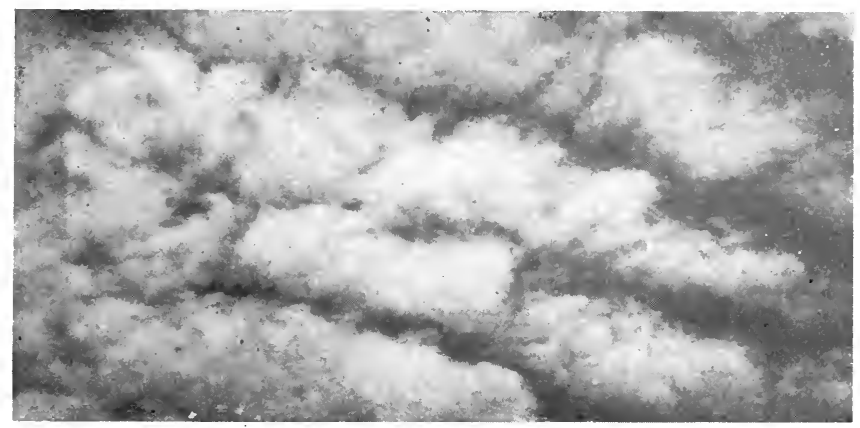

F1G. 158.-IIigh cumulus clouds.
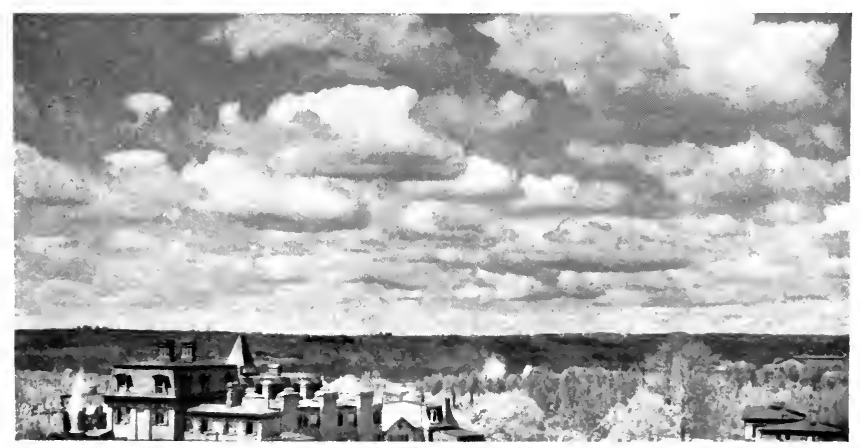

Fig. 159.-Low cumulus clouds. 
when the relative humidity falls below 100 per cent the fog evaporates.

Clouds are not different from fogs except that they are higher in the air. If we ascend a mountain which is wrapped in cloud, we find ourselves enveloped in fog. Clouds are caused by condensation resulting from the cooling of the air. The cooling may be brought about in various ways, but is usually occasioned by an upward movement of air. So also clouds are sometimes dissolved when air is warmed by downward movement. We shall see how the rising and sinking of bodies of air make them cooler and warmer when we study the sections (20\%-216) on heat and temperature.

A little watching of clouds will show us that we can divide them roughly into classes by their form. Ascending currents of moist air cool, condense, and roll up mountainous masses of cloud, having a height of thonsands of feet or sometimes of several miles. Whether large or small, they are known as Cumulus clouds. Their bases are horizontal, and mark the level at which the rising air is cooled to the dew-point so that condensation begins. Great cumulus clouds, growing rapidly in height, are often seen in summer in connection with thunder-storms. They are popularly spoken of as "thunder heads." Tangled and feathery, delicate and plume-like clouds are called Cirrus. They are the highest clouds, usually from 5 to 10 miles above the sea level, and they are thin, obstructing but slightly the passage of the sun's rays. Any widely spread cloud mass from which rain or snow is falling may be called Nimbus, and the name Stratus is sometimes applied to horizontal layers of cloud.

202. Rain and snow.-Everything that moves through the air rouses a resistance called friction. Heavy bodies are less checked by this friction than light bodies. The minute water particles forming clouds, like the particles of fine dust, have so little weight that their falling is exceed- 
(3)

(1)

s.

?

1

. 


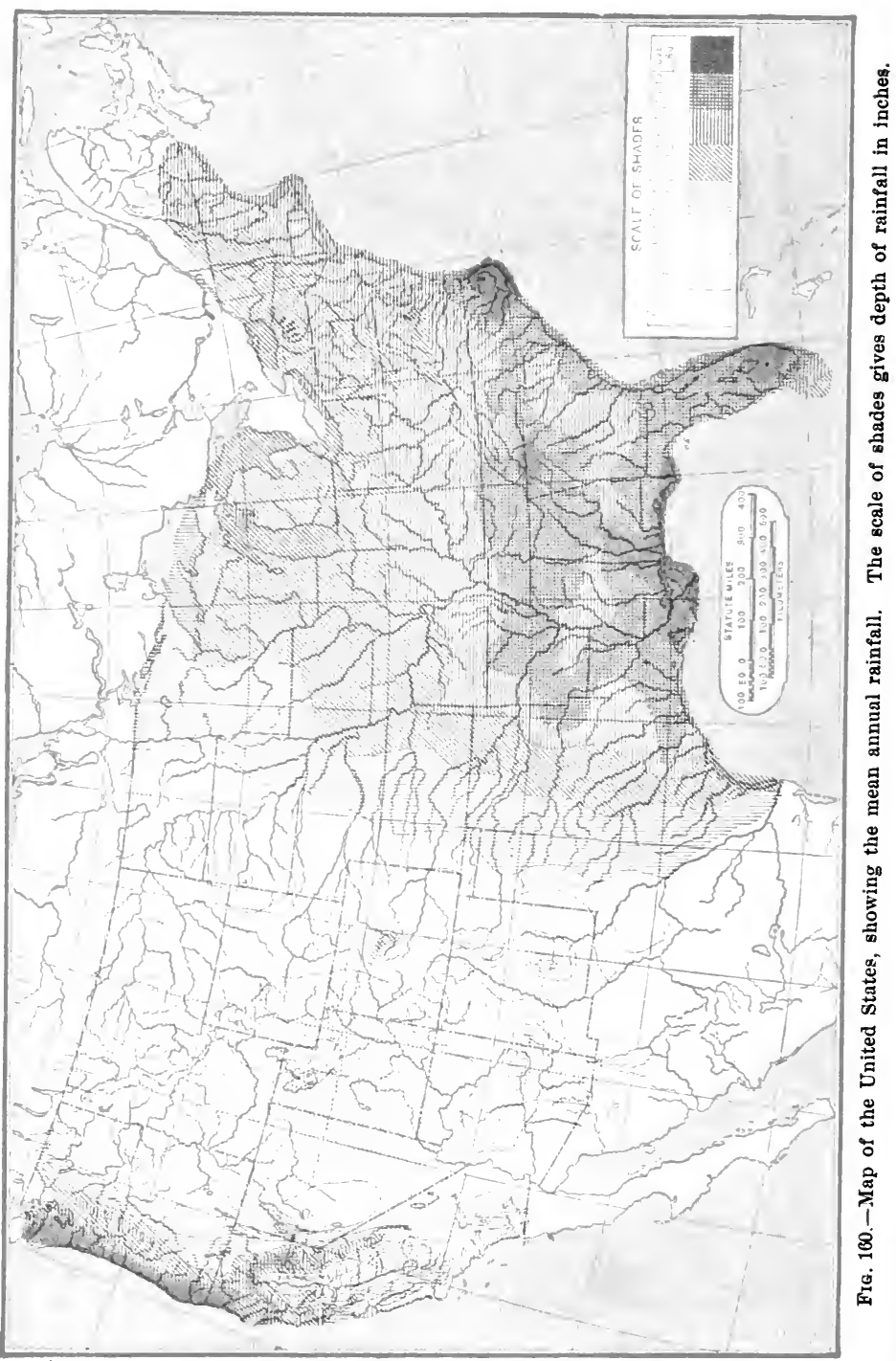


ingly slow, and we say they float in the air. If the condensation that made them is carried farther they grow larger, fall faster, gather still more moisture as they descend through moist air, and come down as Rain.

If condensation takes place in a region whose temperature is below the freezing-point, the moisture gathers into crystals of ice of various forms, and these fall as Snow. Flakes of snow are related to drops of rain as hoar frost is to dew. When a cloud in which rain-drops are forming is at the same time cooled below $32^{\circ}$, the drops are frozen to ice pellets. Sometimes these pellets, by falling through freezing rain, gather more ice and become hailstones, and these are often large enough to reach the earth without melting even in midsummer.

203. Rainfall.-This term is applied to all descent of water to the earth's surface, whether as rain, snow, or hail. It relates to the quantity of the downfall. The word Precipitation is also used in this sense. As we shall see in Chapter XI, the rainfall of a region is one of the most important elements of its climate. When snow falls in still weather it makes an even layer on the ground, and we can measure its depth in inches or feet. But as snow may be wet and heavy or dry and light, such measurement does not tell how much water the snow represents. Therefore, for exactness, the snow resting on a definite space-a square foot, for example-is melted, and the resulting water is measured. To learn the amount of rain which falls, a vessel like a bucket, with straight sides, is placed out of doors, and after each rain the depth of the water caught in it is measured. The quantity of rainfall at any place or in any time is expressed in inches of depth.

The map of the United States in Fig. 160 shows by shades of blue the amount of rainfall during a year in different parts. For example, a shade made by parallel, slanting lines covers all districts in which the rainfall is more than 30 inches and less than 40 inches. There is a "scale 
of shades" to show what each pattern stands for, and with its help any part of the map can be read. The map should be carefully studied not only beeause of the information it gives about rain, but because it is an example of an important mode of combining many facts into a sort of picture easily understood. Such a map is said to show the Geographic Distribution of rainfall. Instead of rainfall, eolors and shades may be made to stand for temperatures, or soils, or population, or anything else having a geographic arrangement.

A narrow belt along the sea in Oregon and Washington receives more than 60 inches of rainfall in a year. In places in the latter State the amount is a little more than 100 inches. The west winds from the warm Pacific, laden with vapor, are chilled to the dew-point as they begin their journey over the cooler land. Similar abundant rains occur in part of Florida, and the rainfall of all the States bordering the Gulf of Mexico and the Atlantic Ocean is in general more than 50 inches per year.

On the other hand, there are districts in Nevada, southern California, and Arizona where the rainfall is less than 5 inches a year; and over most of Nevada and Utah, with parts of Arizona, New Mexico, Colorado, and Wyoming, the amount is below 10 inehes a year. A still wider belt, reaching from middle Oregon far into Nebraska and southward, has less than 20 inches. Here is the great arid region of the United States. The moist air from the ocean loses much of its moisture in passing the mountains of the coastal belt, especially at the north, and has little rain to distribute in the interior. The Rocky Mountains receive much more of this remnant than the plateaus on either hand.

In southern California, Lower California, and northern Mexico the arid region extends to the very coast of the Pacifie Ocean, the explanation being found in the comparative warmth of the land as compared to the ocean. This 
leads to the prineiple that mere nearness to the ocean does not eause abundant rain unless the air from the ocean grows cooler in erossing the land. If the ocean is cooler than the adjacent land, then whatever winds blow from ocean to land have their eapacity for moisture inereased by warming, and instead of dropping rain, drink up any water they find.

The northern Mississippi region receives a medium amount of rain. It has enough to support abundant vegetation, but less than the regions adjoining the Gulf or either ocean. This brings out another great prineiple: that rainfall is less abundant in the interior of continents than it is upon their borders. Such lands are farther from the source of supply.

If we go south we shall find very great rainfall in some parts of Central Ameriea, and in the northern, central, and eastern parts of South Ameriea. Much of the Amazon country receives over 80 inehes. The prevailing winds from the warmest part of the Atlantic explain this eondition, which is the great exeeption to the rule of small rainfall in the eenters of continents. We may now say that, as a rule, rains are more abundant in the tropieal latitudes, but there are exeeptions to this prineiple, as some parts of South America, west of the Andes, are very dry. We may also observe that in polar latitudes the rainfall (mainly as snow) is less than in temperate and tropieal regions, beeause these regions are too cold for much water to be evaporated from the seas.

The rainfall of Great Britain and Ireland (Fig. 161) gives us an interesting parallel, on a small seale, with the western United States. The moisture-bearing winds eome from the Atlantie, and the western eoasts have 40 inehes of rainfall, with 60 to 80 inches on the highlands, but the central and eastern plains have only 25 to 30 inches. In a hot region 25 inches of rain would be a meager supply for farm or garden, but in the cool elimate of England it is ample. As 
we go eastward over the plains of Europe, we find the rainfall gradually less, and much of Russia is arid-further illustrating the principle that the interior of a continent is drier

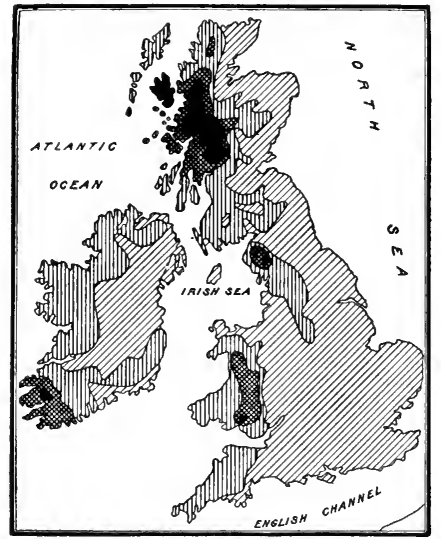

FIG. 161.-Rainfall map of the British islands. The country with more than 20 and less than 40 inches is shaded by oblique lines; that with between 40 and 60 inches, by vertical parallel lines; with between 60 and 80 inches by crossed lines; with more than 80 inches, by solid black. (See page 233 .) than its borders. In southern Europe the Alps receive abundant moisture, brought by warm winds from the evaporating surface of the Mediterranean.

The rainfall of Asia shows the usual contrasts between the sea border and interior, and between tropical and arctic latitudes. Thus, in India and Burma, the southwest monsoons (Sec. 224 and Fig. 182) from the Indian Ocean bring great rains, and southern Asia is well watered up to the Himalaya Mountains. Amid their cold heights the moisture which has been successfully carried over the plains of India is condensed, and the high plateaus of Tibet and of central Asia in general are a desert. Southern Siberia receives moderate rainfall, but the north is dry, even though bordering the Arctic Sea, for the reason already stated, that little evaporation can take place where winter continues for most of the year.

Eastern Asia has a plentiful supply of rain. Japan has a rainy season lasting most of the time from April until September. The average fall at Tokio is 58 inches. This resembles in abundance that of western Washington and the Florida coast in our own country. At the capital of Korea the rainfall averages 36 inches, but at Hongkong, 
much farther south and directly affected by the sea, the amount is 78 inches. Similarly heavy is the rainfall of the Philippine Islands and the Duteh East Indies. The most wonderful rainfall in the world is found where the monsoon winds from the Indian Ocean send down their moisture upon the delta region of the Ganges, resulting in an average fall of 500 inches a year, and amounting in one exceptional year to 800 inches, which, if it could have remained on the surface, would have formed a sea 67 feet deep.

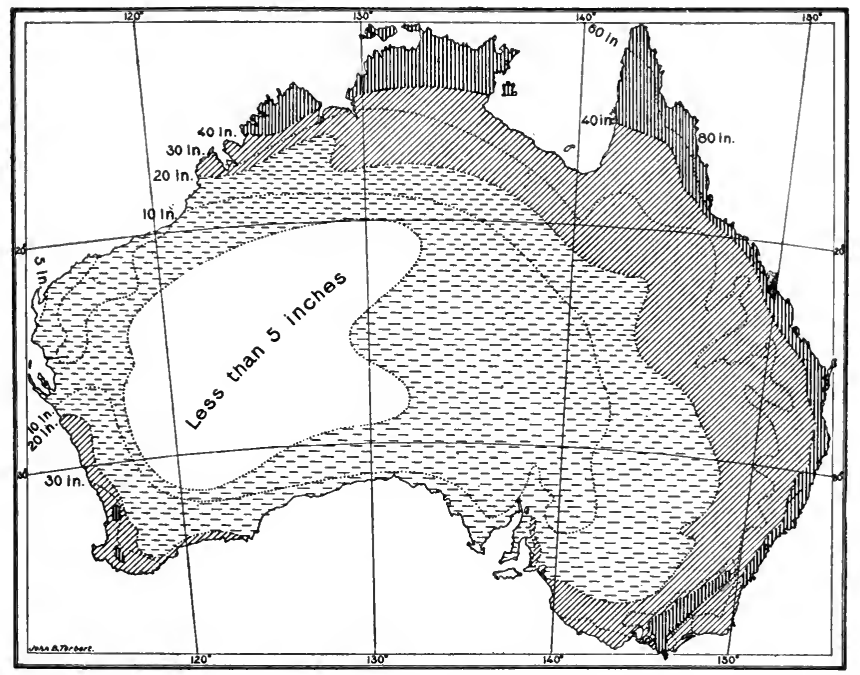

Fig. 162.-Rainfall map of Australia. Dotted lines run through points of equal rainfall. The country with more than 5 and less than 20 inches rainfall is shaded by broken horizontal lines; that with between 20 and 40 inches, by oblique lines; with more than 40 inches, by vertical lines.

Australia (Fig. 162) has an enormous interior area with rainfall of less than 10 inches. In a general way, this inereases toward the shore line, though parts of the south and west coast are dry. The north and east coast areas have from 30 up to 50 inches or more. We still find our 
principle of a dry interior and a wet border true for the great lands.

The largest dry area in the world is the Sahara of North Africa. The general movement of air across it is from the Mediterranean at the north, and this air, passing from a relatively cool ocean to a very warm land, refuses to give up its water. The same principle controls as in southern California.

\section{Light AND COLOR}

204. Light. - The light which comes to us from the sun travels in a straight line, and with such wonderful speed that it reaches the earth in about eight minutes. It is white, and we commonly say it is withont color, but the absence of color is really black, and white is the sum of all colors. A beam of white sunlight is made up of a great number of variously colored rays-red, orange, yellow, green, blue, violet. The full understanding of the nature of light belongs to the subject of physics, but we need to know a few of its properties, in order to study the sky intelligently.

There are three ways in which white light is divided into the colors which compose it: (1) When it falls on an object which is neither white nor black, some of the rays are absorbed and disappear while others are Reflected. Thus grass reflects the green rays and a lemon the yellow rays. (2) When sunlight passes from one transparent substance to another its rays are usually bent or Refracted, and some rays are bent more than others. Thus if a narrow beam of light is allowed to pass through a glass prism to a sheet of white paper, the red rays reach the paper in one place, the yellow in another, the blue in another, and we have a beautiful series of color-bands. (3) And when light is sifted through a thin cloud of very fine particles it is scattered by Diffraction, the several colors being differently affected and thus separated. Nearly all the beautiful 
and infinitely varied colors of nature are produced in some one of these ways.

205. Colors of the sky.-We have already learned that the atmosphere carries small particles picked up by the wind. The finest of these are so minute as to be invisible; they float so high as to be above all rain and are never washed out. Their existence is known only by their effect on sunlight, which they scatter enough to give color to the sky. Without the dust a cloudless sky would be black. With it all the upper part is blue, changing to pale gray near the sun and near the horizon, while at sunset and sunrise the blue grades downward into rich yellow and rose, orange and red. Little wonder is it that the sky is thought by savage peoples to be a solid dome of crystal.

When the lower air contains coarser dust, or haze, all the colors become duller, and grays predominate; but what may be called water-dust-the minute particles of vapor at the edges of clouds-give at sunset the most intense of all sky colors. The great explosion of Krakatoa in 1883 sent an immense cloud of fine dust into the upper air, which gradually drifted and spread, intensifying the sunset effects wherever it went. Within a year it had covered the whole globe, and it settled from the air so slowly that some of its effects were still visible three years later.

206. The rainbow.-This is an arch showing the eolors given by the prism. It is seen where the sun shines on drops of falling water. It most often appears after a thunder-shower has passed, but on a small scale may be seen in the spray of a waterfall or even an artificial spray. In each drop of water the sun's rays are bent (refracted), turned back (reflected), and bent again, and the white light is broken up into its constituent colors. The rainbow is not seen in widely extended rains, becanse the clonds then cut off the sunlight.

A halo is a ring of light about the sun or moon, and is believed to be due to similar action of the light rays upon 
very small ice crystals, forming thin clouds in the upper regions of the atmosphere.

\section{Temperature of the Atmosphere}

$20 \%$. Measurement of temperature. - This is done more or less carefully by almost every one in civilized lands. The

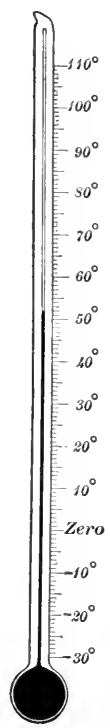

Fig. 163.-A thermometer with the Fahrenheit scale. instrument is the Thermometer (from two Greek words meaning warm and measure). A small glass tube, of uniform size, has a bulb at one end which is filled with some liquid, usually mercury, which extends part way up the tube. If the mercury is warmed it expands, some of it passes from the bulb to the tube, and the column of mercury in the tube grows longer. If the mercury is cooled the column becomes shorter. Thus the position of the top of the column depends on the degree of warmth, or the Temperature, of the mercury. To each thermometer a scale of parts is attached. English-speaking peoples use mainly what is known as the Fahrenheit scale, on which the temperature at which water freezes is marked as $32^{\circ}$, and the temperature at which water boils as $212^{\circ}$. In many other countries the Centigrade scale is used, in which $0^{\circ}$ marks the freezing-point and $100^{\circ}$ the boiling-point of water. As 180 degrees of one scale covers the same range as 100 degrees of the other, their degrees have not the same size. One degree of the centigrade scale equals 1.8 degree of the Fahrenheit. In this book the Fahrenheit scale is used.

To measure the temperature of the air the thermometer is hung where it will not be affected by heat radiated from other objects, especially the sun and the human body, and allowed to remain a few minutes until the air has had time 
to cool or warm the mercury to its own temperature. Then the top of the mercury column is compared with the scale, and the mark it stands nearest is noted. This is called " reading the thermometer" or "observing the temperature."

208. Source of heat in the atmosphere.-We may neglect the small amount that comes from the stars. So also we may leave out of account any heat from the earth's interior. The cold crust lets little heat come through, except locally in volcanic eruptions and hot springs. Practically all atmospheric warmth comes from the sun. As the earth is only a speck, far from the sun, and the sun blazes out in all directions, we receive only an inconceivably small fraction of the sun's total heat. But without it the earth would be a frozen, dark, and lifeless ball.

209. Modes of warming and cooling.-Place a brick on a hot stove. After it has been there a few minutes lift it for a moment and feel the under surface. It is warm. It has become warm by receiving heat from the iron of the stove. You know that it is warm because it communicates heat to your hand. Such transfers of heat are called Conduction. Conduction may also take place within a body; leave the brick on the stove for an hour, and the heat will be conducted through it so that the top as well as the bottom will be hot. Now set the hot brick away from the stove, and then bring your hand near it. Without touching it you feel its heat. This is because the brick is losing heat by Radiation; your hand receives some of its rays and is warmed. In time it will radiate away all the heat it gained from the stove and be as cool as the air about it. Try yet another experiment. Bring your hand near a block of ice. Your hand is cooled because it radiates heat to the ice. Take the ice in your hand and the hand soon becomes unpleasantly cold ; the heat is now passing from it by conduction. All bodies have some heat, but there are differences in quantity. The important principle is that heat 
constantly tends to pass, by conduction and radiation, from warmer to cooler bodies. We are now ready to understand-

210. How the sun warms the atmosphere.-The sun's rays, falling all day on the ground and the ocean, warm them. The ground and ocean, because they are warm, radiate heat outward. Both radiations pass through the air, and the air is warmed by them. The amount of heat received by the air directly is small, but the dust and clond particles absorb heat more freely than the gases, and much that they receive is given to the air about them. The air is also warmed by contact with the warm ground.

At night the outward radiation by ground and ocean, cloud and dust, is not balanced by the sun's radiation and there is a general cooling. The change in temperature from day to night and night to day is small in the upper air and greatest at the ground. So the ground at night usually cools the low-lying air instead of warming it.

Clouds intercept radiation whether from above or below. So when a dense canopy spans all the sky the ground is little warmed in the day and little cooled at night, and the lower air, with which we are most concerned, under-

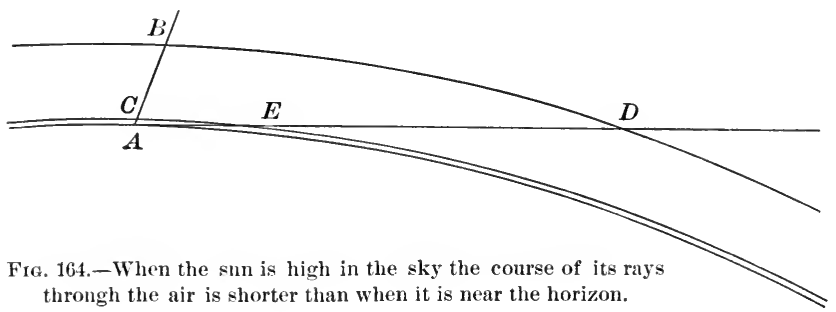

goes little change. So, too, haze protects the ground and the lowest air from extreme changes; but the hazy air itself is warmed and cooled more than clear air would be. It is when the sky is clearest that we feel the greatest changes in the warmth of the air. In clear weather come the hottest days of summer, the latest frosts of spring, and 
the earliest frosts of autumn. 'The sun's rays do not seem so warm in early morning and late afternoon as they do in the middle of the day; and, in fact, they carry less heat then, for they have lost more in passing through the air. Fig. 164 shows this. The curve through $A$ stands for the earth's surface, the curve close to it for the upper limit of clouds, and the upper curve for the outer limit of the atmosphere. Suppose we are at $A$. When the sun is low in the sky the rays that reach us pass through much more air $(D$ to $A)$ than when the sun is high $(B$ to $A)$; and the difference is still greater ( $E$ to $A$, compared with $C$ to $A$ ) in respect to the denser air which absorbs most heat. In the warming of the ground there is another difference also, for a slanting beam spreads its

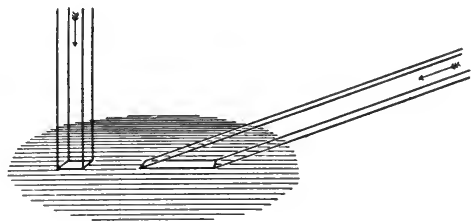

F1G. 165.- The influence of a slanting beam is spread over a larger area than that of a vertical beam.

larger surface than a vertical beam of the same size (Fig. $165)$, and even if it had the same total amount of heat to bestow, could give less to each square foot of surface.

211. Temperature of day and night.--We have just seen that the sun warms the air most when it is highest in the sky, and that is at noon; but the warmest part of the day is usually several hours later. This is because heat is accumulated. The air about us is all the time receiving heat in various ways and all the time parting with it. So long as it gains more than it loses the temperature rises; when it loses more than it gains the temperature falls. On ordinary days the temperature begins to rise just after sunrise, and rises most rapidly in the middle of the forenoon. It stands highest at about two or three o'clock, and then falls through the remainder of the day and all the night.

Hang a thermometer in some convenient place out of 16 
doors, where it will be in shadow all the time, and then take a reading every hour. Rule a sheet of paper, as in Fig. 166, with two sets of lines. Make each vertical line stand for a particular hour and each horizontal line for a particular degree of temperature, and mark them with figures at top and side. Suppose your first reading in the morning is at six o'clock and you find the temperature to be $24^{\circ}$. Make a dot on the paper where the line for 6 A. M. is crossed by the line for $24^{\circ}$. At seven o'clock you may find the temperature $23^{\circ}$, and at eight o'clock $26^{\circ}$. Make the dots at the proper places, and connect each dot with the next one by a line. At the end of the day you will have a record of the temperature. In the figure the record is complete for twenty-four hours. Such a record, by means

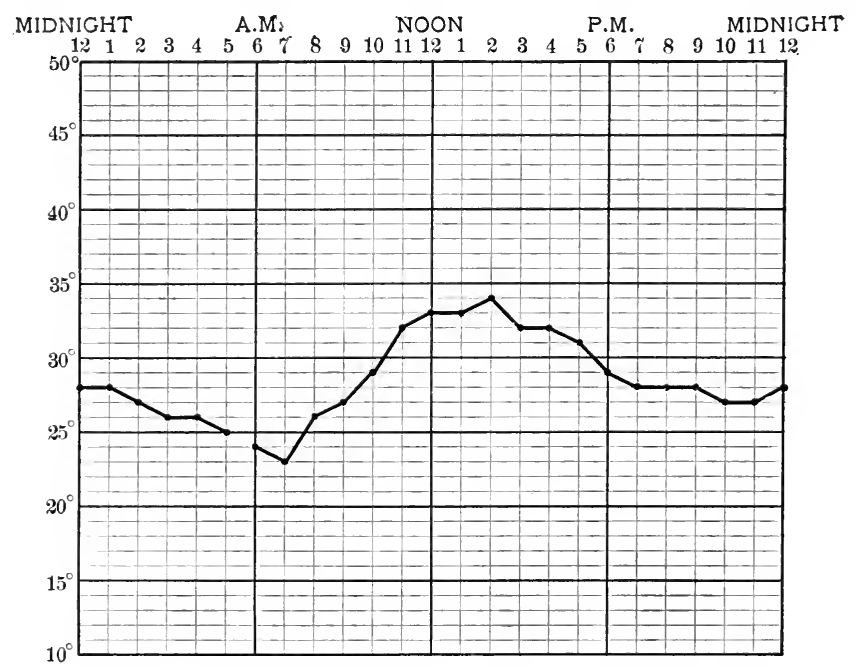

Fig. 166.-A thermometer record for a complete day, beginning at 6 A. M.

of a rising and falling line, is called a Curve of Temperature. The upward swing in the afternoon shows the warmest part of the day; the downward swing, near morning, 
shows the coldest part of the night. Not all days yield the same kind of record. Clouds may interfere with the warming of the air or with its cooling, or winds may bring warmer or cooler air from some other place.

212. Temperature and latitude.-Let us think of the earth at one of the equinoxes (page 25), when day and night are equal in all the zones, for these positions represent the average for the whole year. In tropical latitudes (Fig. 16\%) the midday rays come directly down through the air and have their greatest heating power; in temperate regions they come slanting to the ground and are less effective; and in polar regions their direction is still less favorable. So tropical lands and seas are very warm, polar regions are very cold, and there is a gradual transition from tropical warmth to polar cold.

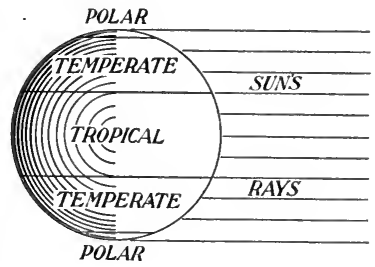

Fig. 167.-Relation of the great zones of the earth to the sun's rays in March and September.

It is true that in another part of the year the northern hemisphere, for example, is tipped toward the sun and gets more heat; but this advantage is exactly balanced by a disadvantage six months later. The tipping causes the yearly procession of the seasons, but does not affect the average or, as it is called, mean temperature.

The cause of the seasons has been so fully described in Sections 19 to 22 that only a reference is needed in this place, but mention may be made of an additional fact which Section 211 enables us to understand. Just as the day heat accumulates till the middle of the afternoon, so the summer heat accumulates until a month or more after the solstice. The longest days come in the second half of June, and the sun's rays are then most powerful, but our hottest month is usually July or August instead of June. 


\section{AN INTRODUCTION TO PHYSICAL GEOGRAPHY}

The normal or average curves of temperature for the year at three cities are given in Fig. 168. The curve showing the observations for a single year would not be smooth, but very irregular, going up and down steeply for each day and

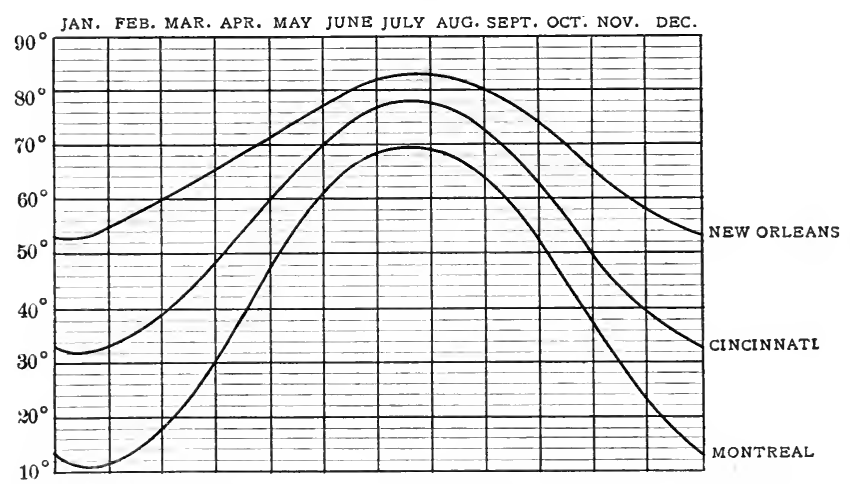

F1G. 168.-Annual curves of temperature for New Orleans (lat. $30^{\circ}$ ), Cincinnati (lat. $39^{\circ}$ ), and Montreal (lat. $\left.45^{\circ} 30^{\prime}\right)$.

night, and for all the warm and cold periods. Note the differences due to latitude, also that New Orleans shows least change from winter to summer. This is because it is nearest the equator, and because the neighboring waters of the Gulf temper the climate (Sec. 214).

213. Temperature affected by winds and currents. - We have seen that the day and night changes of temperature are not always the same. Nor does latitude tell us surely the amount of heat which the air will contain at a given place. Great winds, either steady or in transient storms, sweep volumes of warm air into cold regions, or masses of cold air into warmer places, and thus cause great and often sudden variations, as when a warm interval in winter or summer is followed by a sudden drop of $20^{\circ}, 30^{\circ}$, or $40^{\circ}$ in the temperature. Such changes will be explained in the following chapter. Ocean currents also, Iike the Gulf Stream, transfer great quantities of 
warm or cold water across thousands of miles of latitude, and change thus the amount of heat in the overlying air.

214. Temperature affected by land and water.-Earth and rock are not penetrated by the sun's rays. The daily warming and nightly cooling extend but a few inches into the ground. Even the accumulated heat of summer does not penetrate many feet. But water allows the rays to enter freely to some scores or hundreds of feet in depth, and through all this space receives heat. The sea warms less rapidly than the land, but when warmed retains heat longer. Hence the temperatures are less extreme and less exposed to sudden change on water than on land. The winter voyager on the ocean often encounters but a moderate degree of cold. Thus we can understand why the climate is more mild in the autumn in the presence of large lakes. Frosts hold off so long as the body of warm water is giving forth the heat accumulated in the summer. This is one of the reasons why the lake regions of western New York have proved favorable for the raising of fruits. But as the cold becomes intense, the surface waters are chilled, grow dense, and sink to the bottom, until at length the waters as a whole have lost much heat, and the smaller or more shallow lakes are frozen over.

215. Temperature affected by altitude.-Illustrations of increasing cold and changing plant growth have already been given in our study of mountains (Sec. 17\%). As a rule the temperature decreases about $1^{\circ}$ for every 300 feet of altitude. Two experiments will help to explain this. Fill a bicycle tire by means of an ordinary bicycle pump. Then feel the pump cylinder and tire. The cylinder is warm, especially at the end where the air has been compressed, and the tire is also warm. This means that the air has been warmed by compression. Wait until the tire has cooled to the temperature of the surrounding air; then open the valve and let the air in the tire escape. As it blows on your hand you feel that it is cold. It has been 
cooled by expansion. The general principle is that air and other gases grow warm when they are crowded into less space, and grow cool when they push apart so as to occupy more space.

As we shall presently see, the air has many motions. Some of them are horizontal, others up and down. When a body of air goes down, it is subject to more pressure (Sec. 198), and the compression warms it; when air goes up it is partly relieved of pressure, and its expansion cools it. 'Thus the changes, back and forth, between higher and lower parts of the atmosphere keep the lowlands warmer than the uplands and give to the loftiest peaks perpetual frost.

216. The mapping of temperature. Isotherms.-We shall see, as we go on, that it is important to record the temperature of many places on a map, so that the distribution of heat over large regions may be seen at a glance. This is accomplished by having reports of thermometer readings at a given time sent in by telegraph from hundreds of observers in different places. These temperature figures are written on the map in their proper places. Lines are now drawn through places having equal temperatures. This will be best understood by studying a temperature map of the United States (Fig. 169). The one chosen is for January $\%$, 1886, at $\%$ A. . . . A dotted line has been traced through all stations reporting a temperature of zero. We find the line running from Quebec past Buffalo. Then it swings far to the north and almost follows the curve of the north shore of Lake Superior. It then passes south and west through Minnesota, Iowa, eastern Nebraska, and Kansas, crosses southern Colorado, and runs up to northwestern Utah. The map does not mean that the belt of zero temperature stopped at Montreal and in Nevada, but only that observations were not reported beyond those two points. All areas north of this line have temperatures below zero, and the lines are drawn for each 10 degrees down to $-30^{\circ}$. This is in Montana. There were doubtless still 

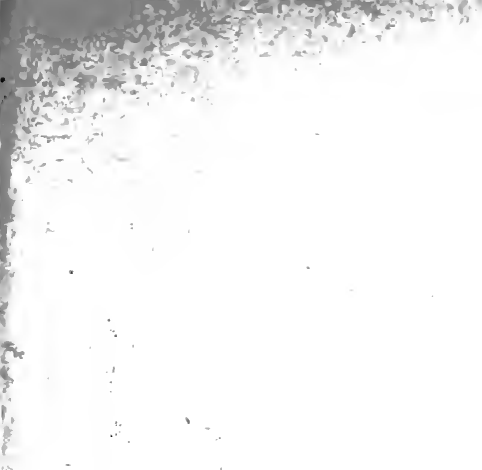

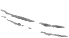




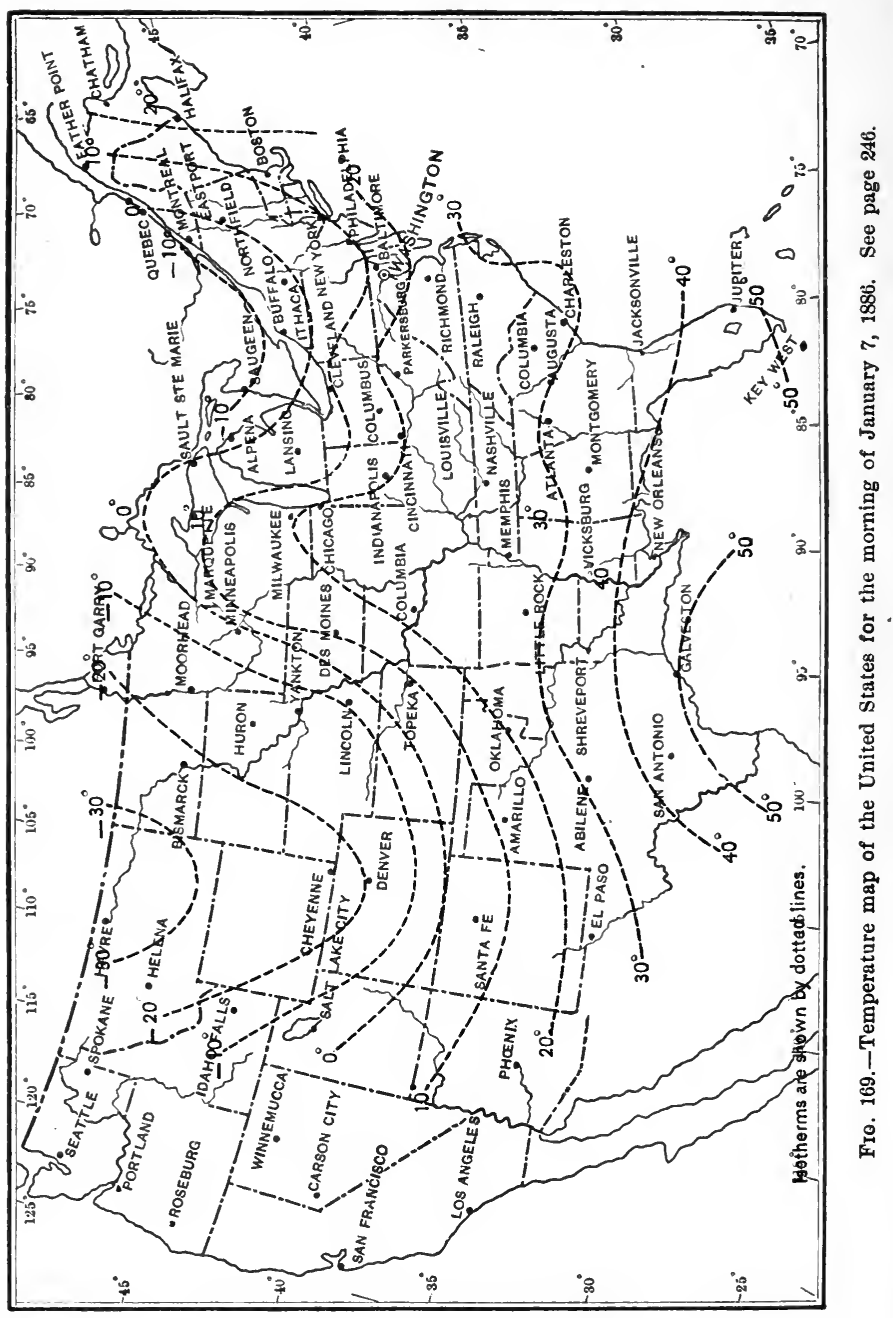


lower temperatures farther north, but the curves beyond the United States boundary are not given. In the east the line for $-10^{\circ}$ is a little north of Lake Ontario. Thus it appears that intense cold prevailed in Canada, extending down into New York at the east, and as far down as the southern border of Colorado in the west.

All the land south of the zero line was warmer. Thus we find $20^{\circ}$ at Cincinnati, $30^{\circ}$ near Little Rock, $40^{\circ}$ south of Vicksburg, and $50^{\circ}$ at Galveston. The line of $32^{\circ}$ - that is, of the freezing temperature-is not drawn, but would run a little south of the line for $30^{\circ}$. This suggests that a line might be drawn for every degree, if observations were numerous enough, but so many lines would make a confused map. Such lines are called Isotherms (meaning equal heat), and they are an essential part of all weather maps.

This map should be studied thoroughly, for it explains the principle of all temperature maps; but it shows the conditions for one morning only in one country. With observations enough, and if it were possible to have reported them from all lands and all parts of the sea, a temperature chart of the world for that morning could have been made. This can not be done, but records can be kept by thousands of observers in different countries and on board ship in all oceans, and a map of mean temperatures for a longer time can be made. For example, if the thermometer were read several times each day and night for a month in New York city, we could easily find the mean temperature for that month. Doing the same for all weather stations in the United States, and putting the means on the map, as we did the records of one cold morning, we could draw the isotherms for the month.

The student will now be ready to study three maps showing mean temperatures for the world. Fig. 170 shows the isotherms for January. This means that all possible observations on land and sea have been taken into account, 


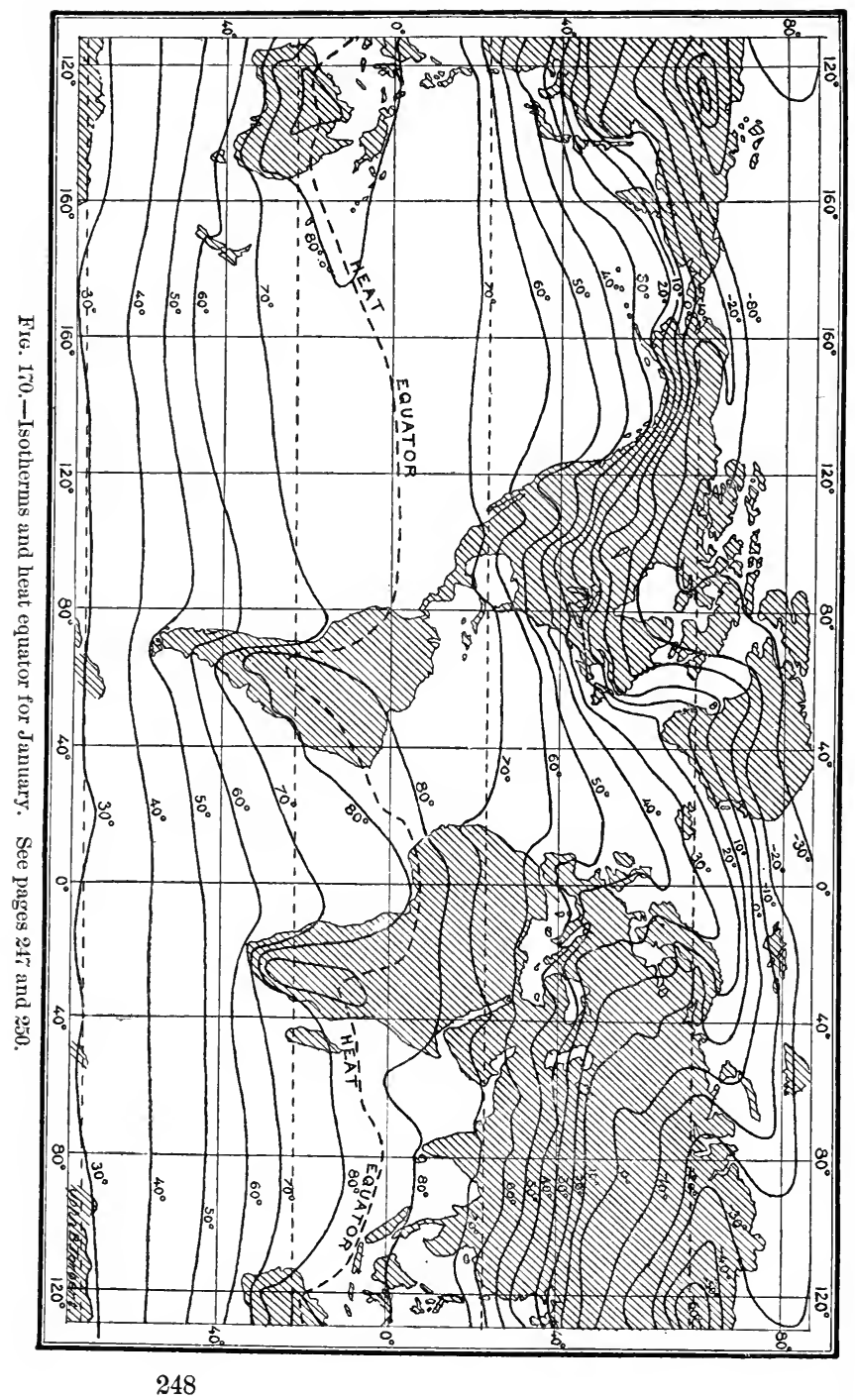




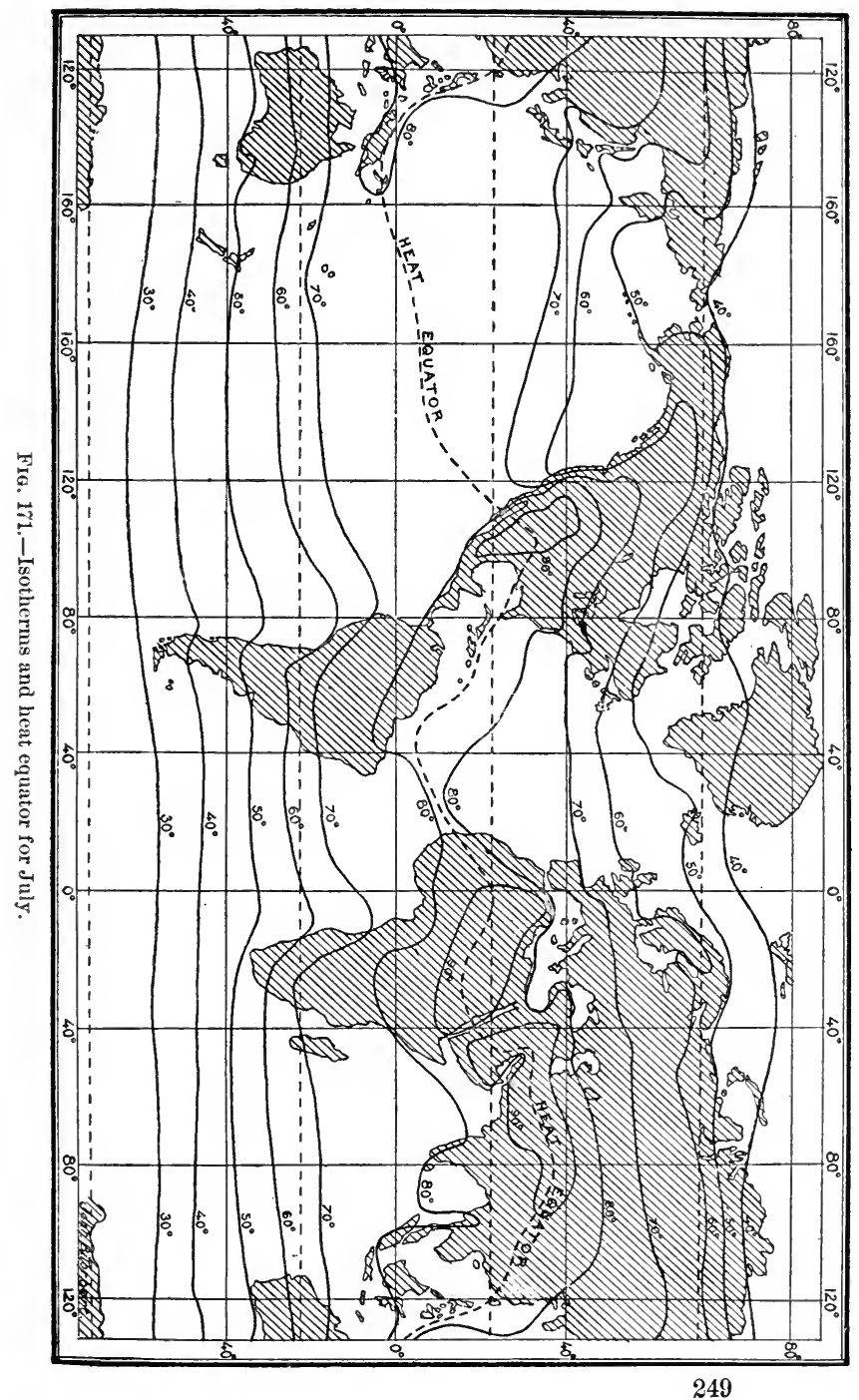


averaged for each locality, and the lines drawn through points of equal mean temperature. Fig. $1 \% 1$ shows the same for July, and Fig. 172 for the entire year. It will not be possible to point out all that may be learned from a study of these charts, but some of the more important facts are as follows :

(1) The isotherms run in general east and west directions around the globe, like parallels of latitude, but in curved instead of straight lines.

(2) Sometimes the curves are strong, showing that differences of land and water change the amount of heat that would otherwise be present. Thus the January isotherms run far north in the Atlantic.

(3) The isotherms are more regular in the southern hemisphere, because there the almost continuous water gives a more even temperature.

(4) In passing from north to south, in any longitude, the temperatures met are first higher and higher, and then lower and lower; at some point a highest temperature is passed. The line connecting all such points is called the Heat Equator. It is a curved line and does not closely follow the geographic equator.

(5) In January all the isotherms in both hemispheres, and the heat equator also, are farther south than in July. The lines sway to and fro with the sun.

One thing which the maps do not show is the variation of temperature according to height. Whenever the record gave the readings on a mountain or plateau, a certain amount was added so as to obtain the corresponding temperature at the level of the sea, and the sea-level temperature was used in making the map.

Further illustrations of the distribution of heat in various parts of the world will be given in the chapter that follows.

21\%. The Mercator projection.-Each of our maps of isotherms shows nearly the whole of the earth's surface, but 


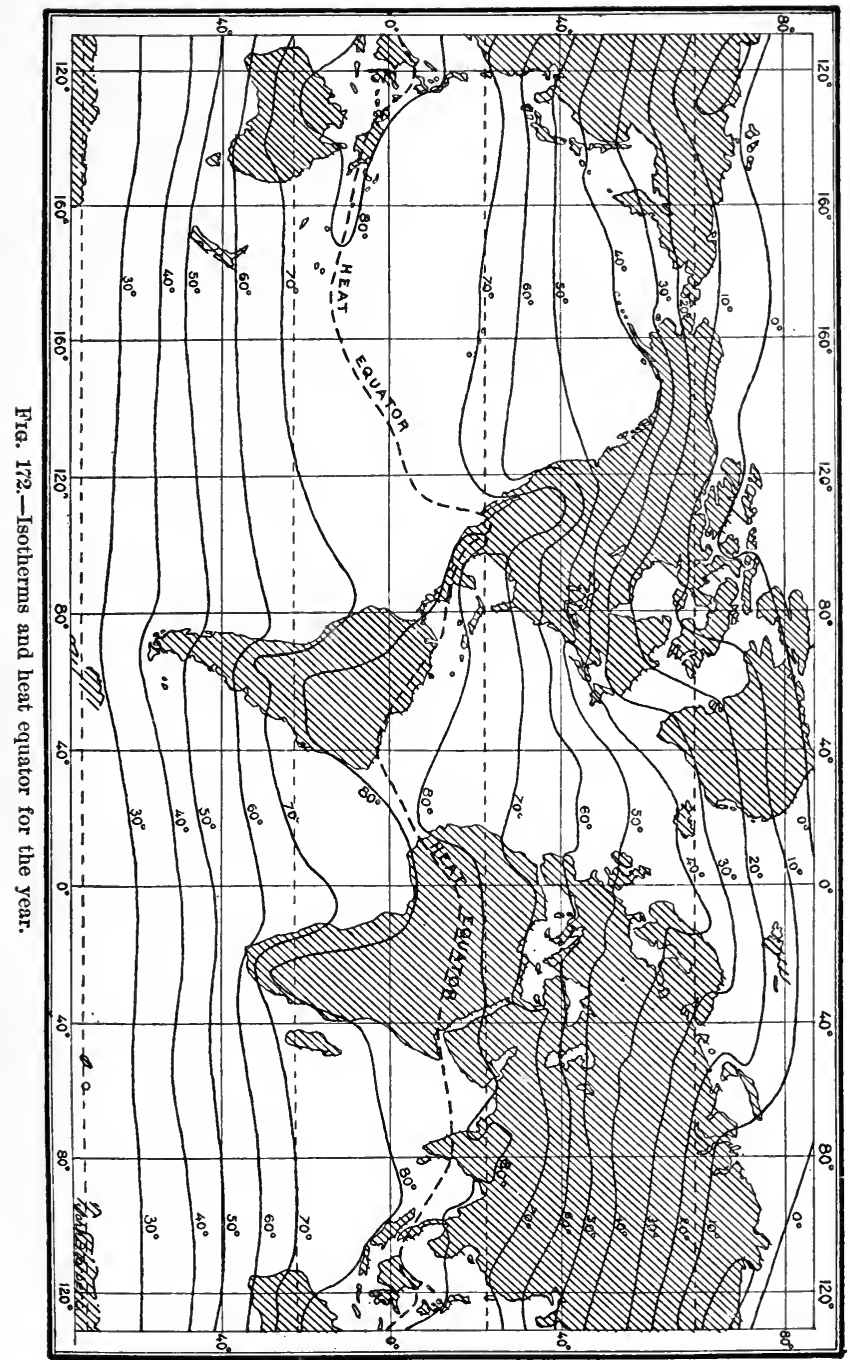


is square-cornered instead of being round like the maps in Fig. 6. Let us interrupt the study of the air for a moment to see if we can understand why maps of the same thing do not always have the same shape. 'The skin of an orange, or any large piece of it, can not be made to lie out flat without stretching some parts. For the same reason a map of the round earth can not be drawn on flat paper without giving some parts the wrong size or wrong shape. In trying to make this unavoidable error as small as possible, geographers have contrived several different ways of drawing maps, each one being best for some particular use. The arrangements are called Projections and have separate names. The maps in Figs. 1\%0, 1\%1, and $1 \% 2$ are drawn on the Mercator projection. Imagine the surface of the earth to be divided along a meridian and thus unrolled into a sheet, with the equator in the middle and the polar parts at the edges. All except a belt near the equator must of course be stretched, the amount of stretching being greater at a distance from the equator than near it. Thus, in Fig. 172 the parallel of $60^{\circ}$ is as long as the equator, although on a globe it is only half as long; and Greenland seems larger than Australia, though really much smaller. This projection is useful when we wish to bring all sides of the earth, except the poles, into one view. 


\section{CHAPTER XI \\ WINDS, STORMS, AND CLIMATE}

THIs chapter will deal especially with the movements of the atmosphere. We have seen how the air is made up, and have studied some of its relations to moisture, light, and heat, but before we can understand its movements we must know it in another way-as regards its pressure.

218. Pressure of the atmosphere.-We have already seen in Section 198, that the atmosphere presses downward, and that its pressure is greater at low levels than at high. This pressure depends on the weight of the air, and varies somewhat in amount at any place as the temperature or moisture of the air is changed. The ordinary or mean pressure is called the normal pressure. The normal pressure at the level of the sea is about 15 pounds on each square inch of surface.

We can tell in a rough way how warm or cold it is by our sensations, but we know nothing thus of the amount of pressure which the air exerts in its different conditions, except, as has been said, at great heights. We measure the pressure by means of instruments called Barometers (from words meaning weight and measure). One kind of barometer is made with mercury and a glass tube. The glass tube, which must be nearly a yard long and closed at one end ( $B$ in Fig. 173), is filled with mercury, and then inverted with the open end in a basin of mercury, care being taken to admit no air in the tube. The mercury does not all run down into the basin, but only part of it; 
the rest stands in the tube, with an empty space ( $n$ to $B$ ) above it. You will understand why this is so if you consider that the atmosphere presses on the mercury in the basin, but there is nothing to press on the mercury in the tube. The mercury stands just high enough in the tube

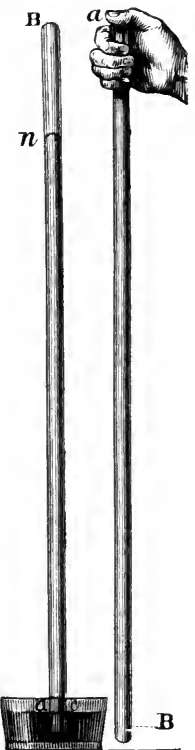

Fig. 173.-The barometer tube and mercury. In the complete instrnment a scale of inches stands beside the tube, the zero of the scale being at the level of the mercury surface outside the tube. for its weight to balance the pressure of the air on the outside mercury. If the air pressure increases or diminishes, the column of mercury grows longer or shorter, and its length therefore measures the pressure. At sea-level the normal height of the mercury column in the barometer is 30 inches. For brevity we commonly say that the pressure of the air at sea-level is 30 inches.

If we carry the instrument up a mountainside the top of the column will settle about one inch for each 900 feet of ascent. Hence it is that the barometer can be used for ascertaining altitude, when carried in a short time from one point to a higher position. As the mercurial barometer is heavy and inconveniently carried, another instrument, called the aneroid barometer, is more often used for this purpose.

\section{Maps showing atmospheric pres-} sures. Isobars. - As in the case of temperature, so with pressure, it is important to know the condition not only at one point but at many. It is convenient to record the figures for pressure at the respective points on a map, as of the United States. The same persons who observe temperatures read their barometers for pressure, and in the Weather Service transmit the reading to Washington. We shall best understand 
by taking a real case, and will choose, as before, January \%, 1886, at 7 A. M. The atmospheric pressures for all stations then reporting in the United States were first put down on a map. Then lines were drawn through all points having the same pressure. In the case of pressure, one-tenth of an inch is an important variation, and the map was arranged to show differences of this amount. These lines, called Isobars, are shown in Fig. 174, and the isotherms of Fig. 169 are also given. Let the student observe that there is a belt of normal pressure, marked by the isobar of 30 inches, running from New York southward to the Carolinas. Other isobars, for $29.9,29.8$, etc., appear to the eastward or to the northeast until in Nova Scotia we find 29.2, and the region is marked as having Low pressure.

To the west of the isobar of 30 inches we see that the lines swing around to the west and run across the continent, with higher and higher pressures in the northwest, until the last isobar curves around the south side of an area marked High, in Montana. The pressure there is 30.8 inches. Curving across the southern United States is another isobar for 30 inches, and south of that the pressure diminishes until, in southern Texas and Mexico, we find another area marked low, but still 0.6 of an inch higher than the low area of Nova Scotia.

Thus we find, on the morning of January \%, 1886, one area of high pressure and two of low pressure, all on the edge of the United States, or just beyond. In the intermediate regions the pressure is also intermediate. The most important contrast is between the northeast and the northwest, ranging from 29.2 up to 30.8 inches.

All these pressures are supposed to be measured at sealevel. In the interior of the continent the barometers used are actually several thousand feet above sea-level, but an allowance has been made in each case for the loss of pressure due to height, and the pressure marked on the map is that which would have been found if the barometer had 
been carried down a deep well to the level of the sea and there read.

The condition of the air continually changes, and the map we have just studied represents the temperatures and pressures only for a single part of one day. This will be plain if we now look at a map for twenty-four hours later, 7 A. M., January 8, 1886 (Fig. 175). The student must remember that continuous lines represent the belts of equal pressure, and for the present should neglect the other symbols of the map. The high-pressure area has moved eastward and is more in North Dakota than in Montana, and the figure is 30.9 instead of 30.8 . The isobars nearly enclose it instead of curving broadly south of it. Pressure is still low in Nova Scotia but has slightly increased, being 29.4 instead of 29.6. The greatest change is seen in the south, where a well-developed center of low pressure appears on the Gulf coast, the lowest isobar marking 29.5.

Again, let us study the pressures one day later, January 9 (Fig. 176). The high-pressure area has slowly moved eastward and is in central North Dakota. A subordinate center of high, but not very high, pressure (30.3) has developed in Utah, Nevada, and Idaho. The great Gulf center of low pressure has moved far up to the northeast, being central in New Jersey, with a pressure of only 28.\%. Varying pressure in any one place, and a moving to and fro of centers and belts of high and low pressure-these are the principles emphasized at this point. The student should ask himself whether he now clearly knows the meaning of isotherms and isobars, and thus can read a map showing atmospheric temperatures and pressures. If he can do this he is prepared for a further step.

220. Winds. - Let us turn again to our series of maps, taking first Fig. 174. The arrows show the direction toward which the wind blows, as reported by different observers on the morning of January 9. In the east they point toward the center of low pressure. In the west they are more 


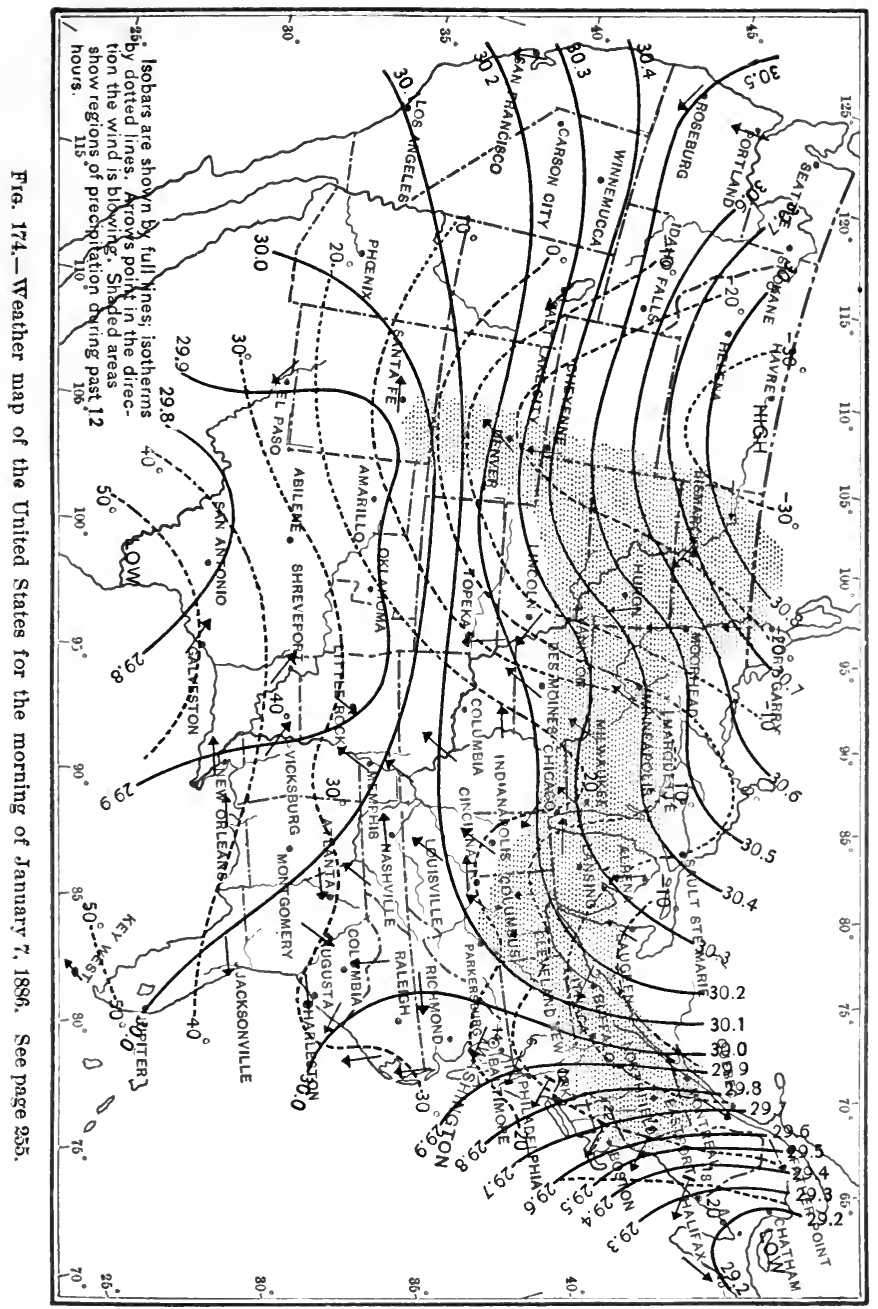




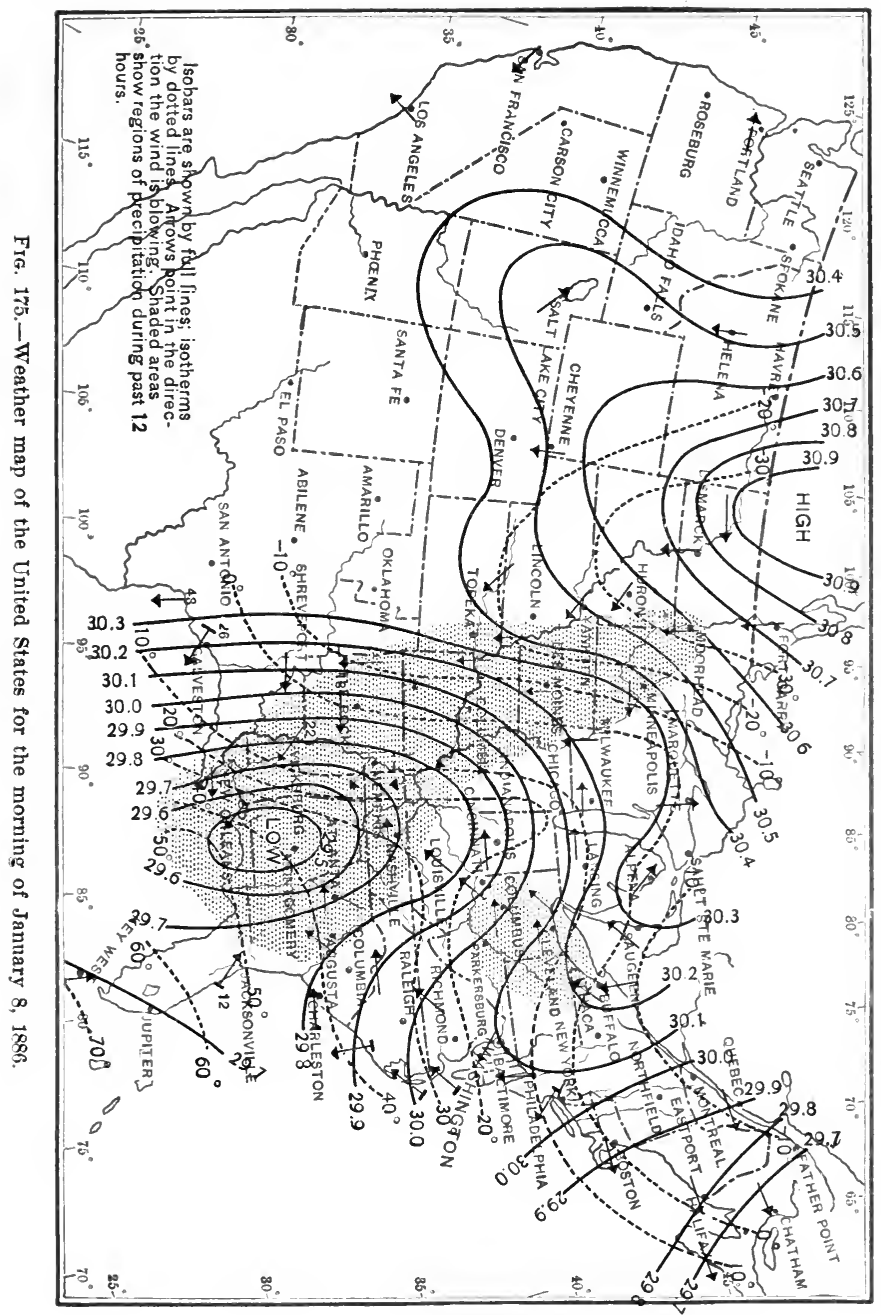




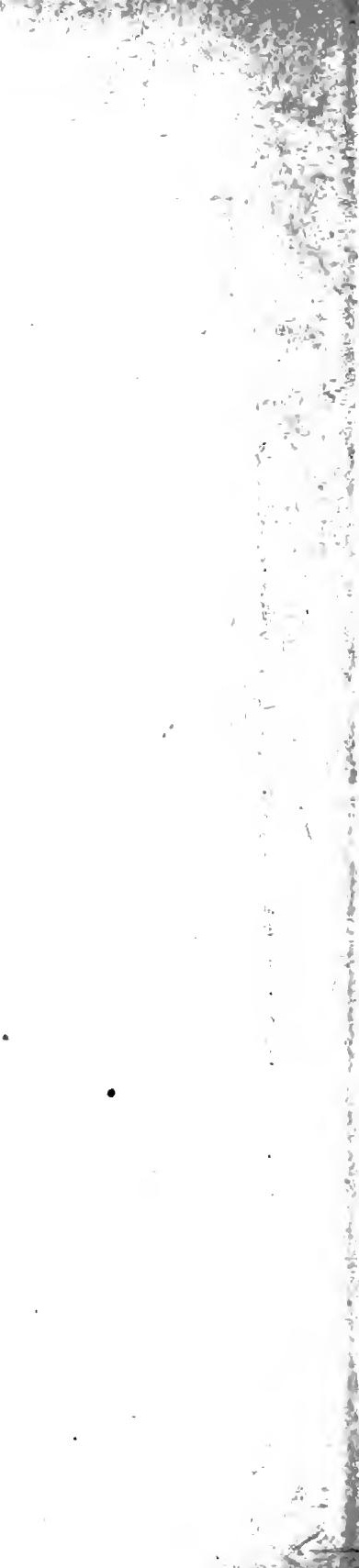




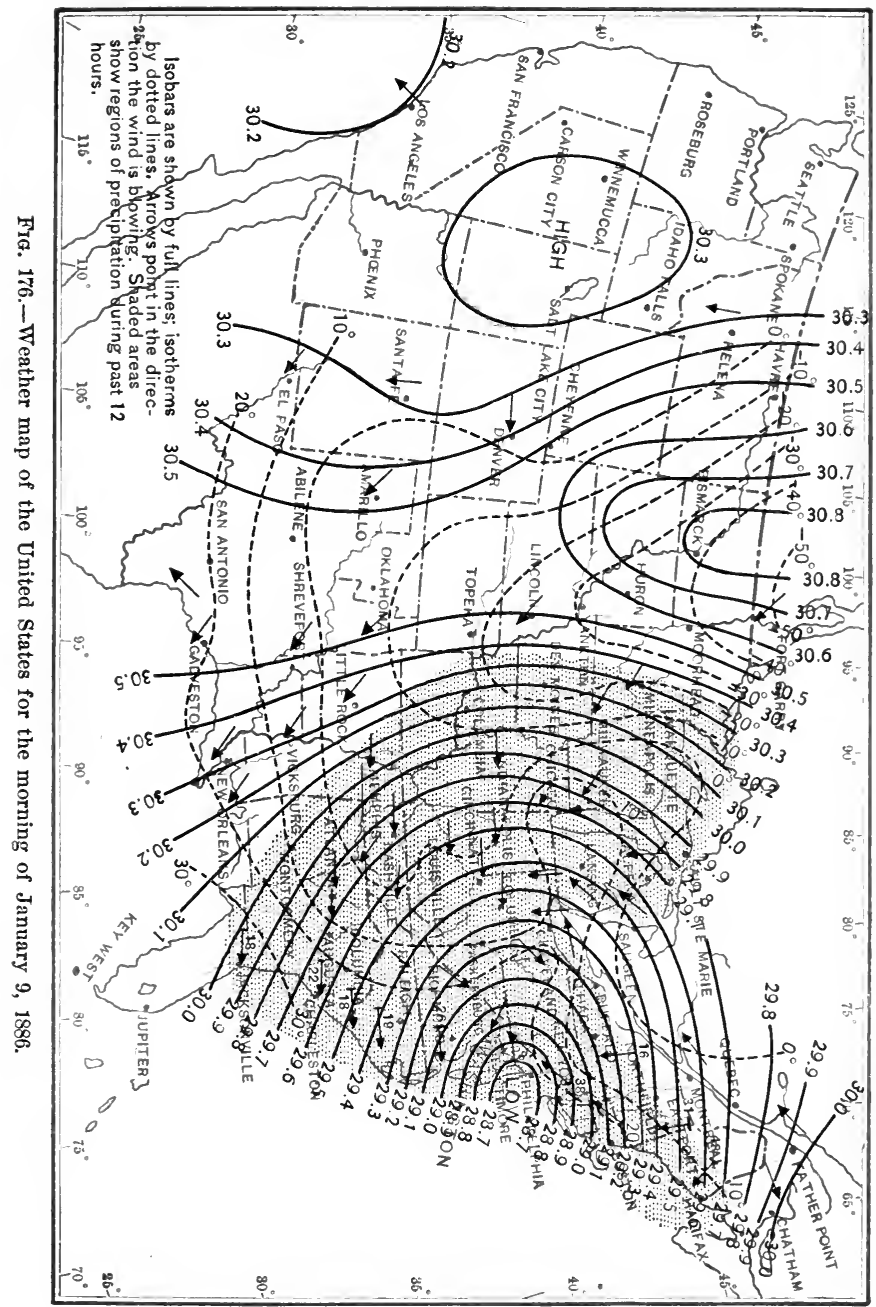



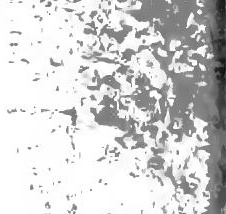

$\therefore$

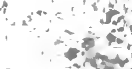

$\therefore$

th

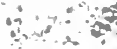

?

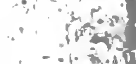

$\therefore-\cdots+4$

$\therefore \quad$

:.

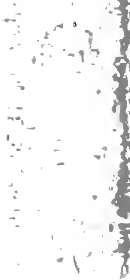

3

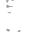


scattering because reports are fewer, but they are pointing away from the centers of high pressure. This is a general law, that winds blow from regions of greater pressure to those of less. If a fire be built in a stove which stands in a large cold room, the region around and above the stove is warmed, and its air becomes less dense; it therefore is a region of low pressure, and the colder, heavier air from the sides crowds in and displaces the warm air, which is thus forced upward. The draft toward the stove, whether strong enough to be felt or not, illustrates the origin of winds. They are sidewise movements by which the heavier air from centers or regions of high pressure is rushing toward the regions of low pressure. There are always winds blowing somewhere, and winds blow at frequent intervals everywhere, because something is always taking place to cause unequal pressure. Heat comes into and goes out from the air, through the succession of day and night, by the changes of seasons, and in regions of varying height and varying moisture. The atmosphere is a sea of gas, now at rest, now in gentle motion, and now tumultuous like the ocean in a storm.

One further statement should be made about this general principle of wind formation. If the centers of high and low pressure are comparatively close together,

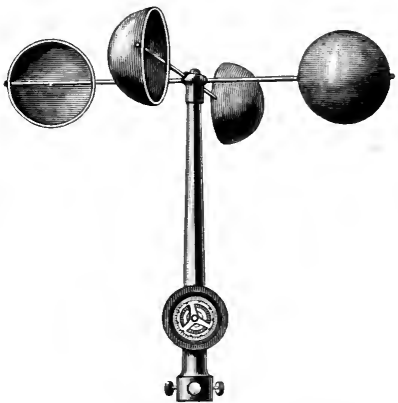

FIa. 1\%.-The anemometer. Inside the upright is a spindle to which the cross-bars are fastened. The wind pushes harder against the hollows of the cups than against the ontsides. and thus turns the spindle. The stronger the wind, the faster the spindle whirls. A counting machine below is worked by the spindle and makes a record.

the rush from one to the other is powerful and the wind has high velocity. In such case the isobars lie close together. The technical way of putting it is that the pres- 
sure slope or Gradient is steep. The velocity of winds is stated in miles per hour. Under 10 miles we may call a wind a breeze. A strong wind has a rate of 20 to 30 miles, 40 to 50 miles marks a gale, and a hurricane has still higher speed. The direction of the wind is determined, if accuracy is desired, by a Wind Vane, and the velocity is measured by an instrument known as an Anemometer (Fig. 17\%).

221. Prevailing westerly winds.-In the middle latitudes of both northern and southern hemispheres, the winds more often come from the west than from any other direction. This is true to some extent even farther north and south. These winds are often briefly mentioned as the Prevailing Westerlies. We do not now ask why more winds should come from the west, but observe that we have here one of the great parts of the atmospheric circulation of the planet. These winds blow more steadily in the southern hemisphere than in ours, because there is less interruption by lands. Sailing vessels readily go by the way of Cape of Good Hope, cross the South Pacific, and return by Cape Horn, while it is difficult, especially near Cape Horn, to make the voyage in the opposite direction.

222. Storms of the westerly winds, or cyclones.-These winds, especially in the northern middle zone, do not blow forever to the east without interruption. They break into vast whirls or spirals, something like a small whirlwind, excepting that the winds are not always swift, and the whirl may be several hundred or one thousand miles across. Fig. 178 shows such a whirl in the eastern United States. The winds are blowing toward the center, not directly, but in a spiral way, and swinging around from right to left. As we may know from the inflow of the winds, this is a low-pressure area. It is partly a region of rain, as indicated by the shading. Low pressure, relatively high temperature, rain, and shifting winds characterize the region. It is a Cyclone or Cyclonic Storm. This is the proper use 


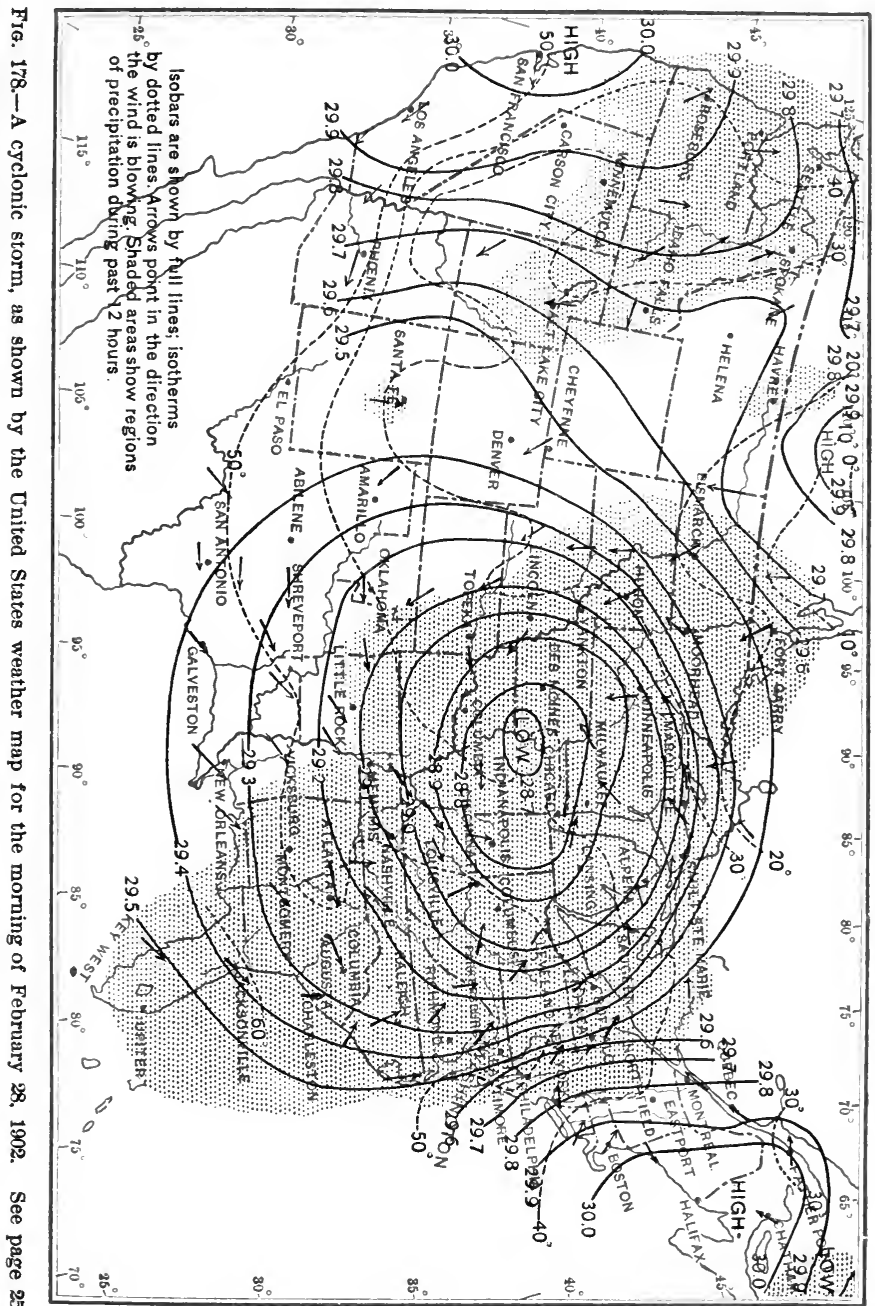


$\mathrm{r}_{-1} \mathrm{~B}_{\mathrm{s}}$

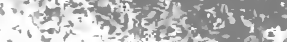

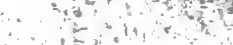

$\because$

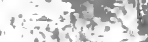

(a)

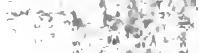

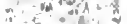

$\therefore$

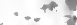

$=17=$

$2-2, \cdots$

$\min =1$ 
of the word cyclone, and we should not apply it to the tornado.

Now this cyclonic whirl is not stationary but moving, usually in an eastward or northeastward direction. It will be followed by a center or area of high pressure, also steadily moving eastward. In this case the winds flow spirally, but out from the center. Such a whirl is called an Anticyclone. It is associated with low temperature and clear skies. As the cyclone with its variable and warmer winds passes, the skies clear, the winds come from the northwest, the anticyclonic whirl takes possession, and we say that a cold wave has come. We may again refer to Fig. 176. Observe the center of low pressure on the Atlantic coast, the inflowing winds, the temperature of about $20^{\circ}$, and the great area of rain and snow stretching westward beyond the Mississippi. The chief high-pressure area is on the Canadian border, the sky is clear, the winds flow out, and the temperature is $-50^{\circ}$. Thus the low and high areas follow each other across our continent. We may now understand why the temperature sometimes falls suddenly, $30^{\circ}$ or $40^{\circ}$ or even $50^{\circ}$. It happens in the rear of a cyclonic storm. We shall have occasion to review these important facts in the section on weather prediction.

223. Trade-winds.-These are the most important movements of the atmosphere in the tropical and equatorial regions. They prevail in general to $28^{\circ}$ north and south latitude. They blow obliquely toward the equator from the northeast and sontheast. Thus there is a broad belt of northeast trades in the northern hemisphere and a similar belt of southeast trades sonth of the equator. Their velocity is 10 to 30 miles per hour. They have received their name from the steadiness with which they flow. The tradewind belt is usually clear, notwithstanding the winds blow over warm seas. The reason is that the air is moving from cooler to warmer regions and thus can hold more vapor without forming clouds. Between the northern and south- 
ern trades is a belt of calms. Here the moist, warm air of the trades rises to greater heights, is chilled and sends down, almost daily, abundant rains. This region is called the Doldrums. The Atlantic trades give up great quantities of moisture in equatorial South America, and up the eastern slope of the Andes. The west side of the range, however, as in Peru, is dry. Thus we see here the reverse of the conditions caused by the prevailing westerlies and the mountains of our Pacific coast.

Outside of the trade-wind belts in both hemispheres is a belt of calms and light winds, in which, however, the currents of air are descending. These regions are called the

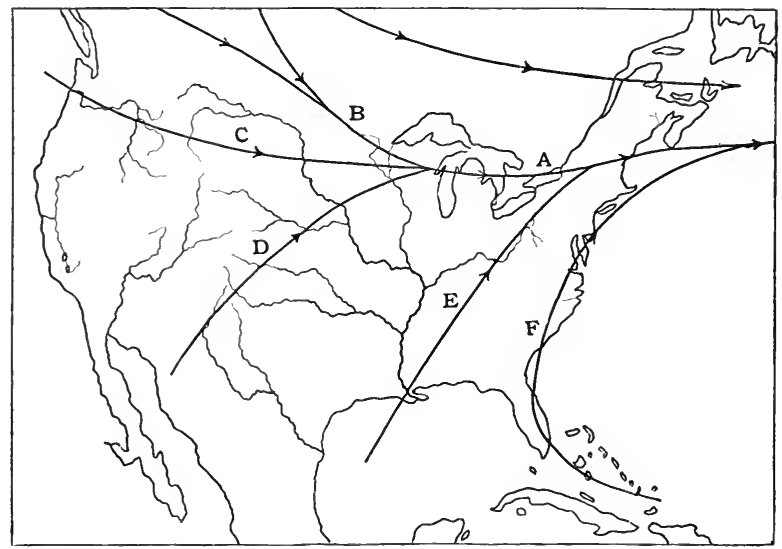

FIG. 179.-Paths usually followed by centers of cyclonic storms across the United States. Path $B$ brings more storms than any other to the main track, $A$. Storms from the southwest $(D, E)$ are comparatively mild. Tropical hurricanes follow path $F$.

Horse Latitudes. Thus we have a great series of parallel wind belts. It is important to observe that the entire system of tropical and equatorial belts shifts somewhat northward and southward with the sun in the annual change of of seasons. More will be said of them in Section 230 . 


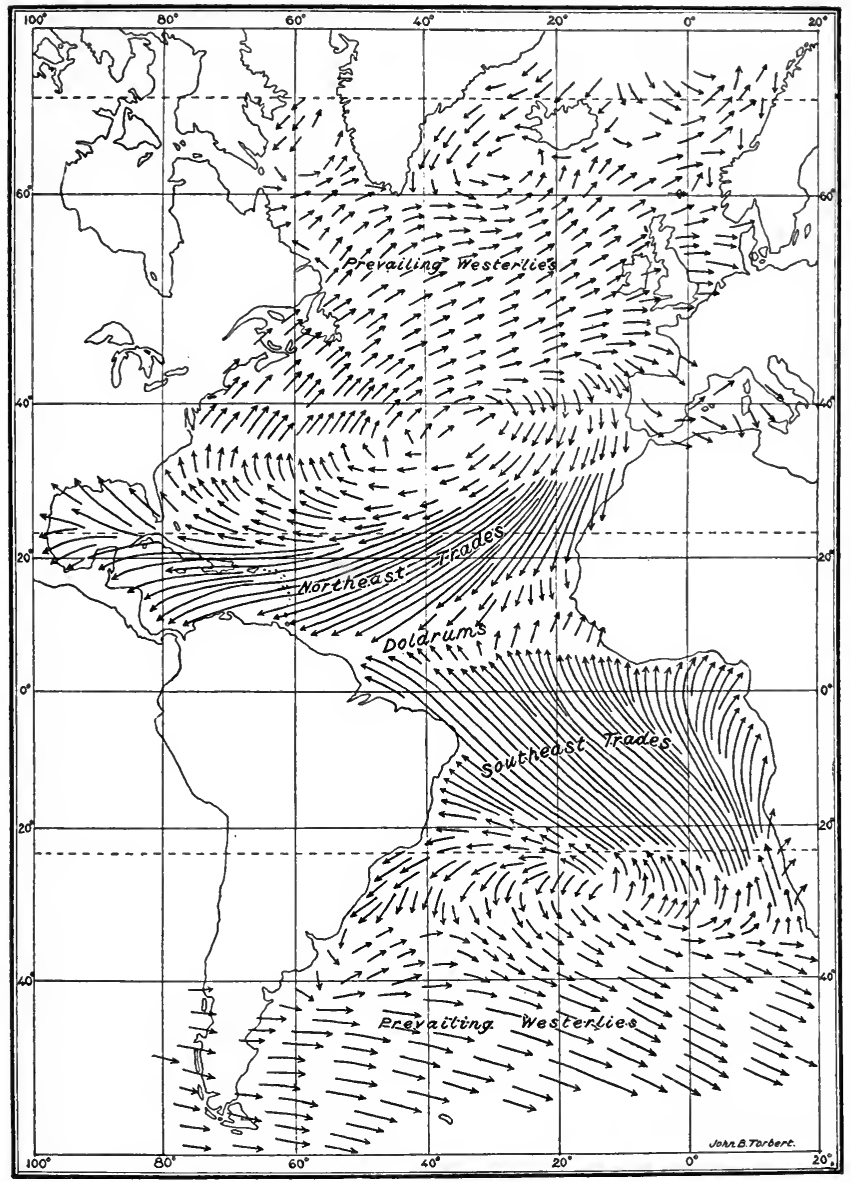

Fig. 180.-Winds of the Atlantic Ocean. The long arrows show directions of steady winds, the short arrows the prevailing directions of variable winds. 
224. Monsoons. - We shall define these winds by a description of the best illustration of them. They blow over southern Asia and the Indian Ocean. In the summer all the lands of India and central Asia become much heated. The expansion of the air makes its weight and pressure less than over the Indian Ocean. High pressure over the ocean and low pressure over the land cause winds toward the land, and they blow strongly and steadily all through the summer months (Fig. 182). The southeast trades swing around near the equator and blow from the southwest over southern Asia. To these winds are due the excessive rains and wet season of southern India. In the northern winter, on the other hand, the heat equator shifts southward, the Asiatic lands are chilled, the air is cold and heavy, and the pressure is greater than above the ocean. Hence there is a rush from the land to the sea. The northeast trades now swing across the equator into the southern hemisphere (Fig. 181), and India has its dry season. These great periodical or seasonal winds are the Monsoons. The arrangement of land and sea favors their development in this region. Similar winds occur in the Gulf and lower Mississippi Valley, but they are less developed, and are not commonly called monsoons, this being an Oriental word.

225. Land and sea breezes.-These are not to be confused with monsoons, though they are like them in flowing now from the land and now from the water. They are light winds which spring up by day and night. As the land heats and cools more quickly than the sea, it often becomes warmer than the adjacent water during the day and cooler at night, and it communicates its temperature to the lower part of the air. So by day the air above the sea is the heavier and flows toward the land, and at night the cool air above the land flows toward the sea. The same changes may take place on the borders of lakes. These are daily changing breezes, therefore, while monsoons are steady winds changing with the seasons. 


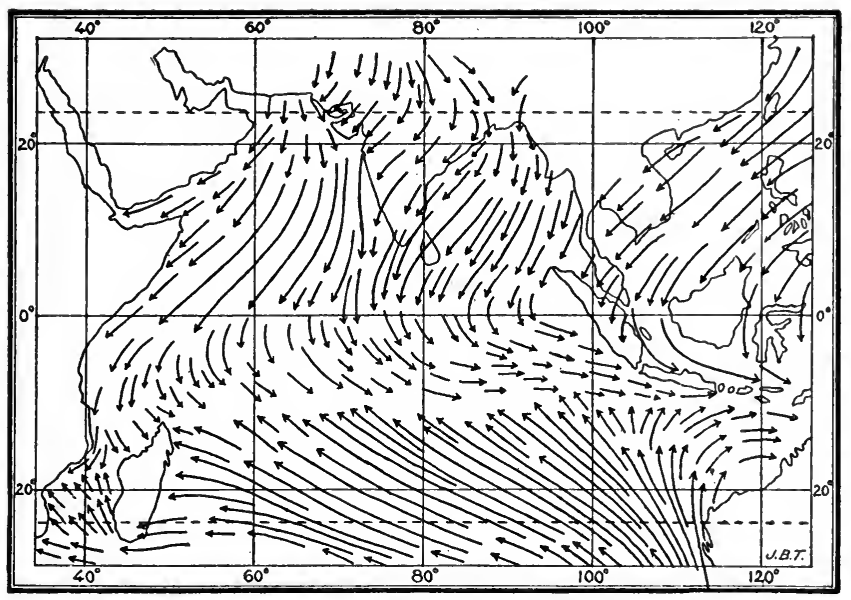

Fig. 181.-Winds of the Indian Ocean in January and February. The winds north of the equator are the Northeast Monsoon, or Dry Monsoon.

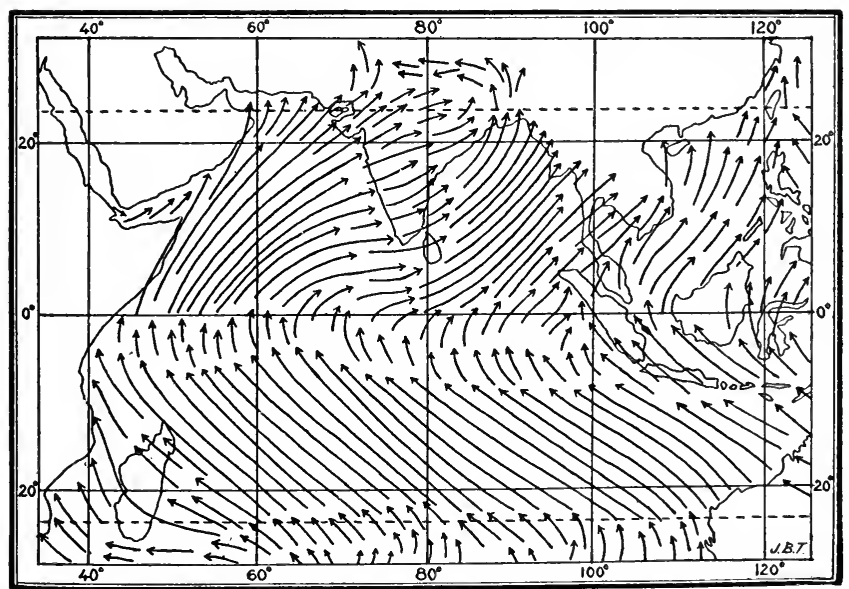

Fia. 182.-Winds of the Indian Ocean in July and August. The winds north of the equator are the Southwest Monsoon, or Wet Monsoon. See page 262. 


\section{AN INTRODUCTION TO PHYSICAL GEOGRAPHY}

226. Day breezes and night calms.-The student has often noticed that considerable breezes may rise during a warm summer day, but that they usually subside toward evening, leaving the air calm. During the day the air near the ground becomes much more heated than the upper air, owing to its receiving much heat by radiation from the earth. Hence the heavier air above sinks through the lighter air below and crowds it away here and there, causing sidewise movements or breezes. These movements cease when the sun's warmth is withdrawn.

22\%. Thunder-storms. - We have as yet studied but one kind of disturbance to which we give the name of stormnamely, the Cyclone or broad spiral whirl, developing in connection with the westerly winds in middle latitudes. We now take up special kinds of storms, which are alike in that most of them are somewhat local and all are more or less sudden and violent. We take first the Thunderstorm.

The student is familiar with the common character of such a storm. It usually occurs in warm latitudes or in the warm season of the temperate regions. It often follows a period of intense heat and usually occurs in the afternoon. It is heralded by the approach of large cumulus clouds from the west. A sharp breeze springs up, the sky is overspread, and rain pours down. After a short time, usually not above a half-hour, the rain ceases, the clouds move to the eastward, the sun shines, and a rainbow appears. The rapidly forming cumulus cloud marks a swift up-draft of heated air which expands because it rises, cools because it expands, and discharges rain because it cools. The lightning is due to the electricity generated in the clouds in their sudden formation. It is an electric spark, like other electric sparks except for its intensity and power. The thunder is caused by sharp vibrations set up in the atmosphere by the passage of electricity. It comes to us later because sound travels more slowly than light; it continues 
to roll because the sound from remote parts of the flash requires more time to reach us.

In the temperate latitudes the thunder-storm is usually associated with the cyclonic storm, and is most often reported as occurring some hundreds of miles south, southeast, or southwest of the cyclonic center, or area of low pressure. Many thunder-storms occur near the equator, in the belt of calms, where the warm air is chilled by rising (Sec. 215). These take a westerly direction. Thus tropical thunder-storms follow the trade-winds, and middlelatitude thunder-storms follow the eastward moving cyclones of the westerly winds.

228. Tornadoes.-These are violent, whirling disturbances, arising, like thunder-storms, in connection with cyclones. A dark funnel-shaped cloud extends down to the earth with a swift, whirling motion, at the same time rushing swiftly over the land. The wind has such force as to destroy houses, uproot trees, and hurl men and animals for considerabledistances through the air, but the path of destruction is narrowonly a few hundred yards wide. Such storms are often reported as

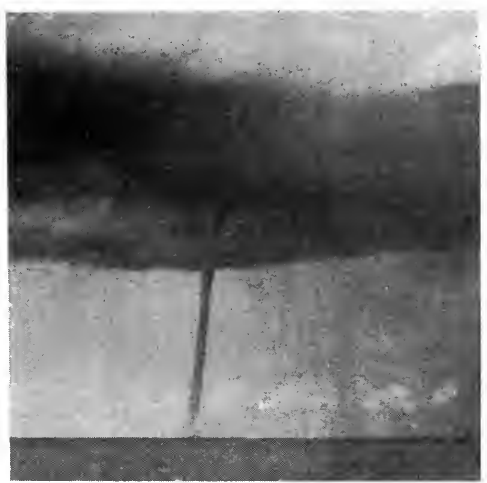

FIg. 183.-A waterspout; Vineyard Sound, Au. gust 19, 1896. From a photograph ; copyrighted by Baldwin Coolidge. cyclones, but this term should be reserved for the larger, less violent storms already described. A tornado at sea is called a Waterspout.

229. Tropical hurricanes.-These are also called tropical cyclones, because, like the cyclones already described, they 


\section{AN INTRODUCTION TO PHYSICAL GEOGRAPHY}

are whirling storms. The whirls are not so extensive as those of higher latitudes, but they may still have a diameter of 300 miles or more, and the spirally blowing winds are much more violent, reaching velocities of 60 to 70 miles per hour. They start in the equatorial belt of calms and travel westward. Those of the Atlantic often swing around and pass northward over the West Indies and Gulf region and then bear to the northeast off the eastern shores of the United States. These storms do not form on the land. Being always on the sea and of exceeding violence, they are most dangerous to ships, which have often been greatly injured or wrecked by them. The spiral movement does not extend to the center. There an area of calm is found 10 to 20 miles across, which is called the eye of the storm. Within it the sky is clear. Outside, but not far from this central area, the clouds are dense, often causing darkness, and heavy rains fall. The progress of such a storm occupies several days, and in some cases a number of weeks, traversing a very long track. Such storms in Oriental seas are known as Typhoons. Destruction is very great when one of them moves over an inhabited island or drives great sea waves upon the shores of a continent.

230. Origin of terrestrial winds.-The trade-winds and the prevailing westerlies, or broad currents from west to east in middle latitudes, belong to a great system of atmospheric movements, called Terrestrial, because they pertain to the earth as a whole. Thunder-storms, tornadoes, and cyclones are local disturbances which temporarily interrupt the uniformity of the greater movements.

Two facts are fundamental to the explanation of terrestrial winds. First, the regions about the equator are much warmer than those nearer the poles. Hence the air is light and the pressure low, and the colder air from the north and south pushes in and crowds it up. Thus great volumes of warm air rise in the doldrum belt. This can not go on without some equalizing of the air. Otherwise 
all the air of the globe would be piled up around the equator. Hence the movements toward the equator, or the trades, are compensated by upper-air currents moving toward the poles. These are the antitrade winds. 'The air composing them is working poleward, but in large part descends to low levels again in the horse latitudes. Then instead of pursuing its way northward and southward, it is deflected and forms the prevailing westerlies. Their deflection brings us to our second fact, the earth's rotation. But for this the trades Fig. 184.-The general circulation of the atmosphere. should blow directly

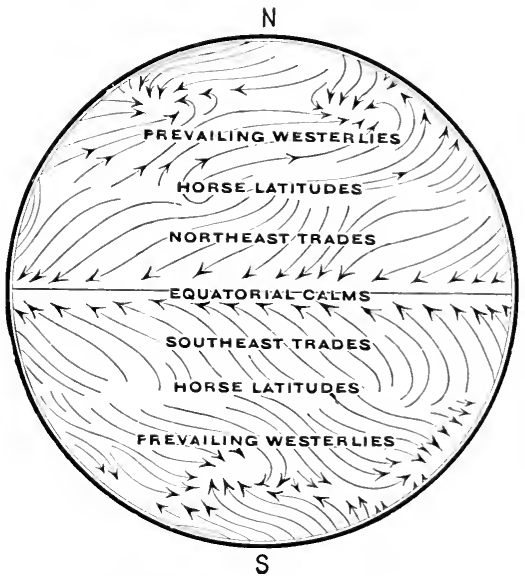
toward the doldrum belt, and the antitrades shonld blow directly away from it. As a matter of fact, the trades bear off to the west, and the antitrades turn away to the east. This is due to rotation. The result depends on the fact that near the pole any object on the earth's surface whirls with much less speed than an object at the equator. Hence the air of a wind, having a certain speed of movement with the earth to the east, and at the same time flowing toward the equator, will thus flow into a region where the earth's surface has greater velocity. The water or air will thus lag behind the earth in its easterly swing, and hence will turn partly toward the west. It is for this reason that the trades are diagonal to the equator.

On the other hand, a wind blowing from the equator toward either pole is passing from a region where it has 
acquired great easterly speed to a region where the earth's surface moves east more slowly. As the wind moves north it keeps some of this high easterly speed, hence it outruns the earth and forms an east-moving wind. As winds are named after the direction from which they blow, it is called a westerly wind. The "prevailing westerlies" are of this character.

\section{Weather and Climate}

231. Weather.--This word refers to the state of the atmosphere. The atmosphere may be warm or cold, wet or dry, still or moving, cloudy or clear, and we therefore speak of the weather as hot, or sultry, or cold, or cloudy, or stormy, as the case may be. If the condition is stable for days or weeks, we speak of settled weather, or if it is changeable, we characterize the weather accordingly.

We not only speak of the weather and describe it fully in language, but we record it upon maps. Temperature is a weather element, and we record this by means of isotherms (Sec. 216). Barometric pressure is another weather element, and.we express this by isobars. In like manner arrows represent the direction of winds. Shaded areas tell where there is rain or snow, at the time for which the map is made. Other features may be shown, but these are the chief things.

232. Weather service and prediction.-For about thirty years the United States Government has maintained a weather service. It is in charge of the Weather Bureau, a part of the Department of Agriculture. Each morning at the same hour (eight o'clock in the East and five o'clock on the Pacific coast) 150 or more observers record the various weather elements at their stations and send the results by telegraph to Washington. A force of clerks receive the facts and record them on weather maps. From these maps experienced forecasters determine as nearly as possible what the weather will be, and the forecasts are sent to all parts of 
the country. At some stations, a local forecaster receives such reports as he needs and makes up a bulletin for his region. The forecasts are widely published in newspapers, and are told to multitudes of people by the display of weather signals in the form of flags. Special warnings are sent to seaports, in order that shipmasters, knowing the coming of dangerous storms, may delay in putting to sea. The coastwise vessels of every kind greatly profit by the weather service. The coming of a tropical hurricane from the West Indies may be made known along our southern coast in time for protection of shipping and coastwise property. The advance of chilling frosts from the west and north into the fruit regions of the south may likewise be foretold in some cases. Many stations are maintained along rivers, from which the data as to rainfall, melting of snow, and other changes are reported, and on these are based forecasts of damaging floods, so that property on low grounds may be removed and life be less endangered.

The principal predictions of the weather service are possible because of what is known of the direction and progress of the great cyclones or low areas, and of the behavior of winds, of clouds, and rainfall in all parts of them. No two cyclones, indeed, are just alike, and some depart widely in rate or direction from the usual rate or course, so that mistakes may be made, but the service as a whole has demonstrated its value to the people of the country, and is sure to come to greater completeness and accuracy in the future.

Many supposed signs of the weather have no foundation in fact. Such are the aspects of the moon, and all sayings about the relations of certain days of the month or season to the weather that will follow. On the other hand, old observers of the weather know many true signs of wind, cloud, and sky, which give them shrewdness in prediction even when they are not able to explain or assign a cause. By long habit they recognize the usual order. But such 
foretelling could only serve for one locality, and could in no way take the place of the wide view provided by the Weather Bureau.

233. Climate.-The elimate of a region is the sum of its weather. It includes the weather of the succession of seasons for a succession of years. A year's weather follows the general course of all years for the special region, but may be quite peculiar in some respects. Thus in the northern United States we occasionally have an "open" winter, or an exceptionally hot summer, or abnormally heary snows. Hence a period of years is necessary for a full knowledge of climate. Like the weather, climate is described aecording to its most important or striking features. Thus climate may be dry, wet, cold, temperate or hot, uniform or subject to great extremes. Or we may describe climate by its relations to man, as heathful or the contrary, as bracing or enervating, as agreeable or unpleasant.

234. Climates of the United States.-We use the plural here, because our country covers so many degrees of latitude, ranges so far from coast to interior, and has such a variety of lowland and upland, that a variety of climates is the result. We are wholly in the North Temperate zone, and therefore a temperate climate is more common than any other. But along our South Atlantic and Gulf borders tropical conditions prevail. There is a wide difference, however, between the Carolina coasts and the cool uplands of the sonthern Appalachians. An isothermal line will sometimes run from Massachusetts southwest in the eastern border of the Appalachian highlands, into Georgia, and then double sharply back on the west of the uplands as far north as the Great Lakes, before turning to the west. Thus the wedge of mountains with cooler air is driven far down between the warm areas of the Atlantic on the one hand and the lower Mississippi on the other. Even a sharper contrast is seen if we compare the high Sierras of 
California, with their snows and glaciers, with the warm central valley and Pacific shore of the same State. Or we may compare the same mountains with the driest and hottest region of the United States, in southern California, Nevada, and Arizona.

A most important fact of climate in the United States is the prevalence of the great cyclonic and anticlyonic storms, and a strong swing between winter and summer conditions, especially in northern districts. Thus in the summer the areas of low and high pressure follow each other across the continent from the west to the northeast, giving an alternation of hot waves and cooler spells. In winter these alternations are still stronger, giving us violent

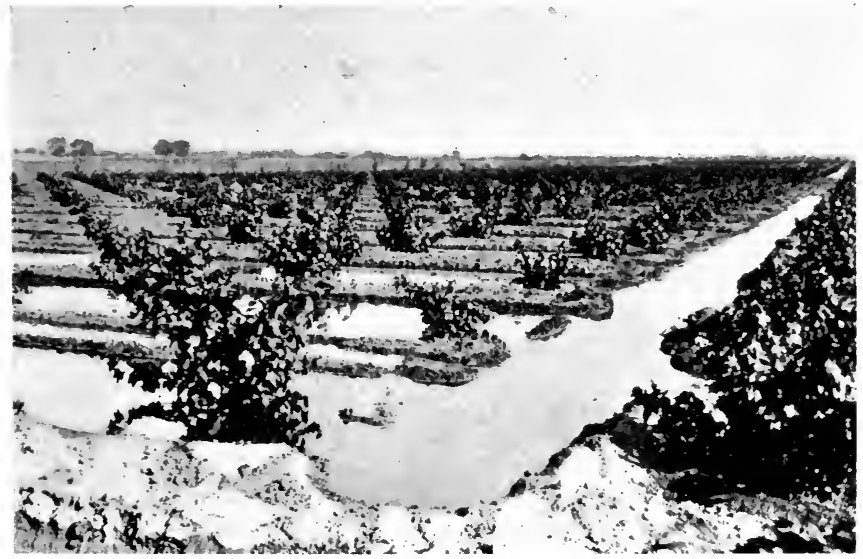

Fig. 185.-A vineyard in soutbern California, where rainfall is so small that crops must be irrigated. The field is traversed by a system of ditches into which water from a stream is run several times during the growing season.

winter storms, followed by cold waves, with clear skies and zero temperatures. Only in Florida and along the Gulf and California coasts are the contrasts subdued by the presence of the ocean. 
Almost as often as by heat and cold, we describe the climates of our country according to the amount of rainfall. Here we need do little more than refer the student to the section on that subject (203). Throughout the north, the winter precipitation is mainly in the form of snow. This being a poor conductor, keeps the ground from freezing as deeply as it otherwise would, serving as a blanket to retain the heat already received. On the other hand, the sun's heat is lost by reflection from its surface, and the winter cold is thus increased. All the eastern region is well watered. Over the prairies the rainfall diminishes, but is abundant for plants until we reach the semiarid belt in eastern Dakota, eastern Nebraska, and central Kansas. Beyond that region the arid belt begins, with less than 20 inches. There the most important problems are how to store up and save the waters of storms and streams, and how best to use them in irrigating the lands.

235. Climates of other lands. - Space will not permit of any complete account of the climates of the world. In describing the distribution of rainfall and the winds and storms of the globe, much information has been given concerning climate. It is more important that the student should grasp the principles which control climate, than that he should here find a systematic account of climates. A restatement of some of these principles follows.

Difference in latitude, and the resulting differences in the amount of heat received from the sun, give us the basis for climate. The inclination of the earth's axis, causing the succession of seasons and an alternation of seasons in the two hemispheres, is the next great principle. The distribution of land and water introduces other great changes into the climates which latitude would give. This is strikingly seen in the North Atlantic, with its currents carrying warm water against the Gulf shores, and drifting thence upon the shores of Europe, giving mild climates in Great Britain and Germany, which have the latitude of Labrador. 
As a further principle, the atmospheric circulation of the globe gives us the trade-wind climates of the tropics, with their occasional hurricanes, and the monsoons of the East, with strong periodic winds and rains. We refer again to the all-important fact of temperate latitudes, the prevailing westerlies, with their cyclones, anticyclones, occasional tornadoes, and frequent summer thunder-storms. We observe again the fact of "continental" or dry interior climates, with wet sea-borders, as shown in nearly all continents, and seen in a conspicuous way if we compare the Great Plains with the Pacific Coast, the Central Plateau of Asia with India, or Central Australia with the most of its shore regions. Finally, we observe the effect of altitude on climate when we see the cool summits of the Adirondacks rising from the warmer lands about Lake Ontario, observe the Rocky Mountain snow-fields from Colorado Springs, or see the wintry Alps towering above the warm lowlands of Italy. 


\section{CHAP'TER XII}

\section{THE EARTH'S MAGNETISM}

236. The compass-Consider for a moment how we find our way from place to place. Often we follow a road or path. To cross a field we select some object beyond, and walk toward it. The traveler on a prairie, or in a forest, may notice which way his shadow falls, and guide himself by that. But if clouds hide the sun, that aid fails him, and he takes the Compass. The compass needle points toward the north; and if he knows which way north lies he can easily lay out a course toward the east or west, or in whatever direction he desires. Such a guide is peculiarly useful on the sea, where neither pathway nor distant object can be

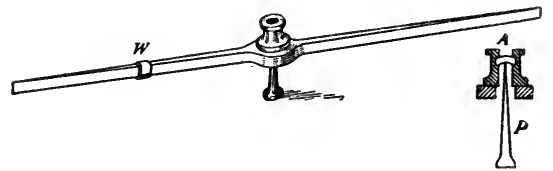

FIG. 186.-A magnetic needle, with a cross-section to show the mode of hanging. $P$, pivot ; $A$, cap of agate with hollow beneath to rest on the pivot; $W$, adjustable weight to counteract the dipping tendeney (page 277 ).

seen. Though sun and stars are hidden for many days, the mariner pushes boldly forward, steering always as the compass directs, and knowing it will not send him astray.

The compass is a rod or "needle" of magnetized steel, balanced on a pivot so as to be free to swing to the right or left. Like other magnets, it has two poles, named north and south. In the instrument made for the mariner several such needles are placed side by side, and all are fast274 
ened to the under side of a circular card, which may be either balanced on a pivot or floated on a liquid. On top of the card is a printed rosette or star with 32 rays, each indicating a direction, or "point of the compass" (Fig. 187).

23\%. Magnetic declination.-While Columbus was sailing westward in search of the Indies, and before he had found the New World, he made another discovery, and one equally unexpected. He found that the needle, instead of pointing steadfastly

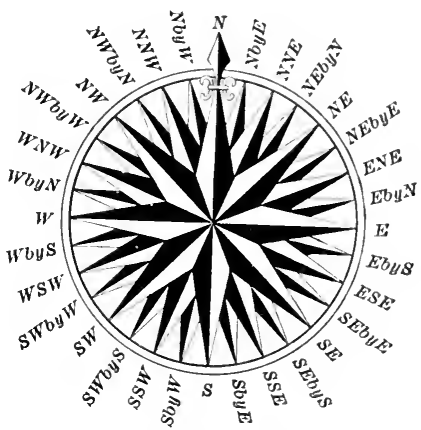

FIG. 187.-The compass card. Reciting the names of the 32 points is called by sailors "boxing the compass."

toward the north star, swung to one side, and the farther he went the greater its error. This was by no means a welcome discovery, for it weakened confidence in a faithful friend, and seemed an evil omen to his superstitious sailors. But it led to a better knowledge of the magnetic needle, and this has been of great value to mankind. The difference between the pointing of the compass and the direction of true north, or the Magnetic Declination, has now been measured at many places and at many times, and maps have been made to show its distribution. These maps are of two kinds, illustrated by Figs. 188 and 189. In Fig. 188 the lines show by their directions the positions taken by the needle at different places. Thus, where one of them crosses Massachusetts, near the meridian of $70^{\circ}$ west longitude, it is evident, by comparing its direction with the meridian, that the needle points west of north. Its direction is still more to the west in Labrador and Greenland. But along the Mississippi River it points a little east of north, while the declination to the east is large 
in California and Alaska. The lines of this system are known as Magnetic Meridians. If we should start with a compass in hand and travel steadily in the direction in which it pointed we should follow a magnetic meridian, and should eventually be brought to a place inside the arctic circle where all these meridians meet. This place is the North Magnetic Pole of the earth, and is nearly $20^{\circ}$ distant from the geographic pole. There is a similar point, the South Magnetic Pole, within the antarctic circle.

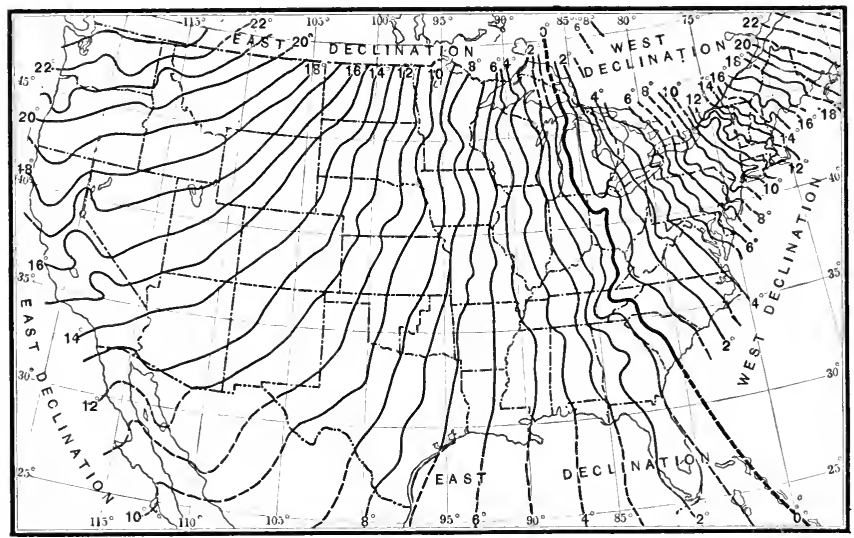

FIG. 189.-Isogonics, or lines of equal magnetic declination, for the United States in $190 \%$.

Fig. 189 shows the same facts, more in detail, for the United States, but shows them by a very different set of lines. It will be remembered that a map contour runs through all points having the same height above the sea, and that an isobar shows the line along which the air pressure is everywhere the same. In like manner the lines of this map pass through points at which the declination of the needle is the same. Thus, a line crossing Texas, Oklahoma, Kansas, Nebraska, South Dakota, and Minnesota includes all points at which the needle turns $10^{\circ}$ to the east 


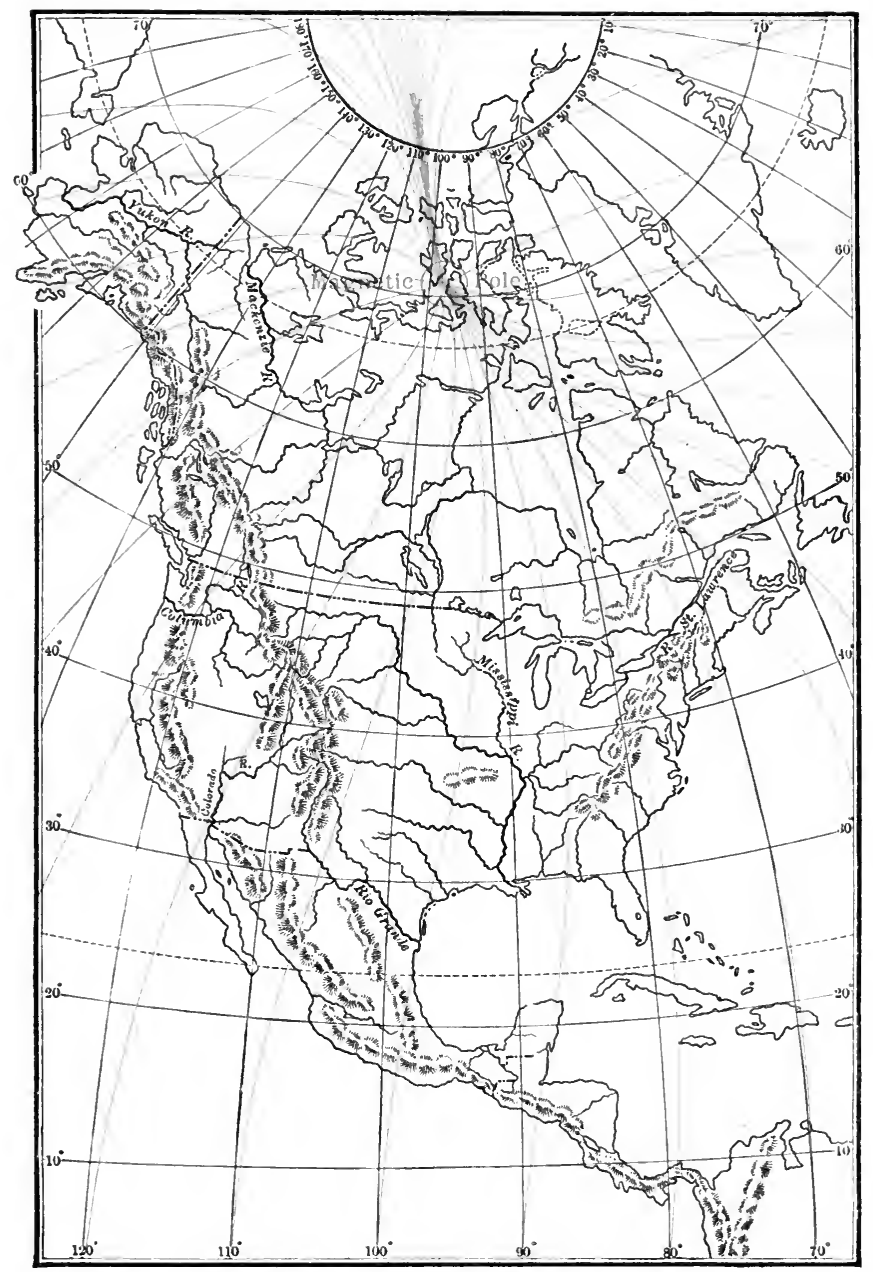

Fig. 188.-Magnetic meridians for North America in 1885. (See page 275.) 

of north. The line next east of it stands for an eastward turning of $9^{\circ}$, and at any locality in the belt between the two lines the declination of the needle is between $9^{\circ}$ and $10^{\circ}$. The "line of no declination" crosses a belt of States from Michigan to South Carolina, and east of it the needle turns toward the west. These lines are called "isogonics" (equal angles). From an isogonic map the mariner and surveyor learn how much allowance to make for the difference between "magnetic north" and true north.

The declination varies not only from place to place, but from time to time. Fortunately the change with time is slow, so that a good magnetic map is serviceable for many years. The magnetic meridians in Fig. 188, which were made for the year 1885 , are not strictly accurate now. The isogonics in Fig. 189 represent the latest work of the Coast Survey, the bureau charged by the Government with magnetic surveys.

238. The magnetism of the earth.-Every magnet has an influence on other magnets when they are brought near. It is very instructive to lay a strong magnet on a table and then move a compass about it. The needle changes its direction with every change of position, now pointing toward the magnet, now from it, and now lying parallel; or, in other words, it is controlled by the magnet. Now, as the compass shows similar changes of direction when it is moved from one position to another about the earth, the conclusion has been reached that the earth also is a magnet. In comparison with its size it is not a strong magnet, but its strength is sufficient for the guidance of those who must journey without beaten paths-the explorer and the navigator.

239. Dip.-The compass needle can swing to the right or left. If it were hung so that it could swing up or down it would usually not lie level, but slant, or "dip," in one direction or the other. A needle thus hung is called a dip needle, and is said to show the Magnetic Dip. At the 
magnetic equator it lies level. Carried northward, it turns its north end more and more downward, until at the magnetic pole it points toward the center of the earth. Carried southward, its south end is turned downward, and it becomes vertical with its north end upward at the south magnetic pole. Fig. 190 shows the dip all about the globe. Close to the magnetic poles the magnetic force is all vertical, and the compass will not act. It is therefore fortunate that these poles are in regions unsuited to man.

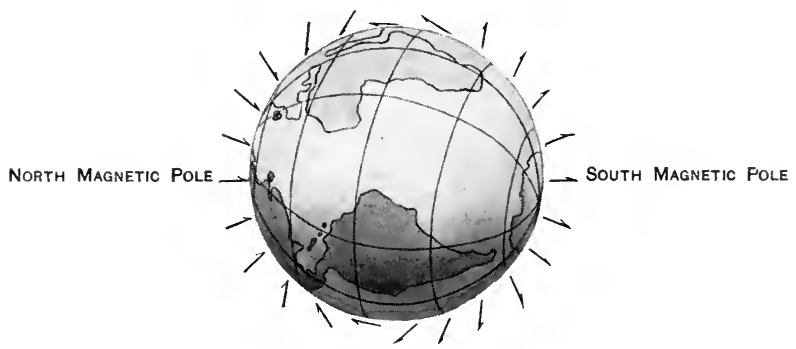

FrG. 190.-Positions of the dip needle at various points about the globe.

There is a kind of iron ore which is magnetic, and fragments of it, called lodestones, were the first compasses. Large masses of this ore are contained in the rocks about Lake Superior, and they are able to swing the compass and dip needle out of their regular positions. Those instruments have therefore been used in searching for this ore, and valuable mines have been located in this way. 


\section{CHAPTER XIII}

\section{THE OCEAN}

We now pass from the Lands and the Atmosphere to the study of the third great feature of the physical world, the Ocean. To mankind it is an essential feature, for land life could not exist without it. A " good round ball of meadow and plowland" would be impossible. We must see what the ocean is and what it does.

240. Ocean-basins. - We give this name to those low parts of the earth's surface which are covered by ocean waters, and we think of the lands as making rims about them. The student must not forget that an ocean-basin is vastly broad as compared with its depth, and that its bottom is not a plane but a part of the surface of a sphere. Either the top or the bottom of the sea may be thought of as a part of the surface of the round earth. The ocean may be likened to a film of liquid clinging to the outside of a spoon.

We have already seen (Sec. 5) that all the oceans may be truly regarded as one. In no strict sense can we speak of several basins. The American continents do indeed separate the Atlantic and Pacific, but there is no division between either and the so-called Antarctic Ocean. The same is true of the Indian Ocean and the Antarctic, and in some degree of the Arctic and Atlantic Oceans. It is better to think of the waters as forming a spherical sheet over nearly three-fourths of our planet, and broken by a few large and many small bodies of land.

The sea-floor, as it is often called, is in general quite 279 
smooth, as compared with the land. It has mountains, but they have still the simplicity of shape with which they were uplifted, and are not cut into a thousand crags and gorges, as on land. It has also many volcanoes, great and small, and these too are unworn. Between and about such mountains and hills is spread an ever-growing sheet of sediment

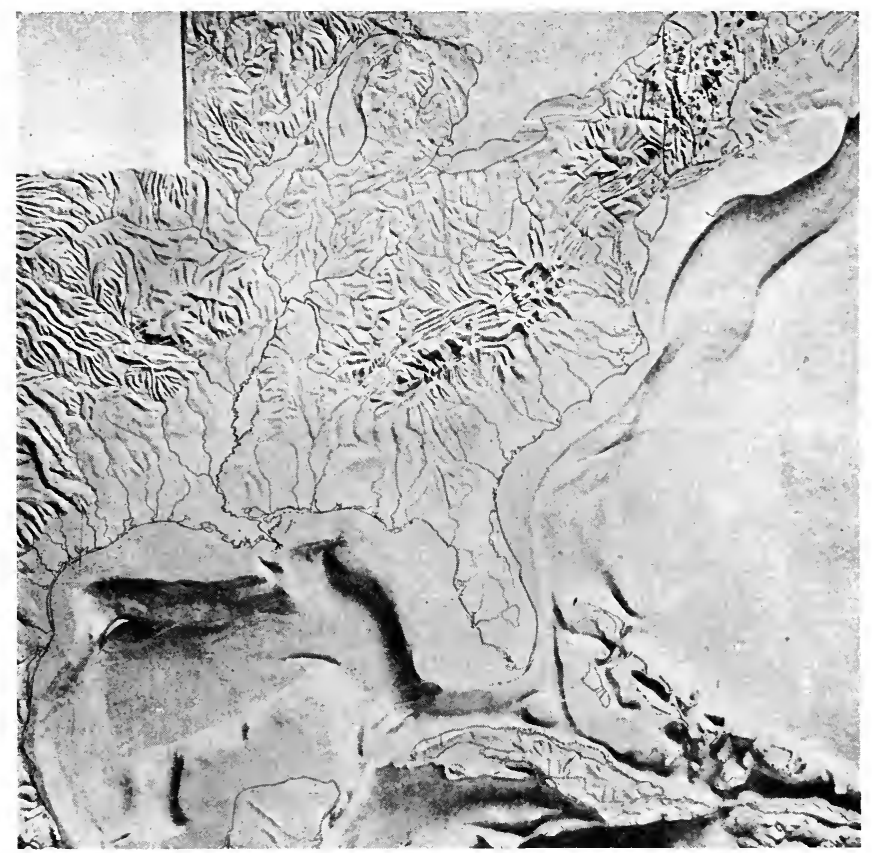

Fig. 191. - Western part of the Atlantic basin. This map was made by photographing a model, in which the scale of heights was many times greater than the scale of distances.

- partly the waste from the land, delivered at the sea-border by streams, partly the myriad shells of small ocean creatures (page 300). Of such fine deposits vast plains are made, smoother than the prairies of the Mississippi Valley. 
Much of the Atlantic Ocean is 15,000 to 20,000 feet deep. Running in a generally north and south direction through it is a gentle swell of the floor, over which the water is about 12,000 feet deep. The slope from deeper to shallower parts is so gentle that the eye could not detect any variation from a perfectly level plain. The deepest point thus far sounded marks $2 \%, 366$ feet and lies near Porto Rico.

The average depth of the Pacific Ocean is greater than that of the Atlantic, being 23 miles. At least two soundings of more than 30,000 feet have been made, one near the Ladrone Islands and the other not far from New Zealand. Thus the greatest known depth of the ocean about equals the greatest known height of land, that of Mount Everest, the measure in each case being nearly six miles. This total unevenness of about 12 miles nearly equals the amount of flattening of the earth at either pole. In this flattening, and in the difference between sea-bottoms and mountains, we have the chief departures of the earth's crust from the form of a sphere.

241. Continental shelves.--Thus far we have considered only the deeper parts of the ocean-basins. But the deep seas do not commonily come close to the shore-line. For many miles offshore, soundings often show but a few score or a few hundred feet. This is the case along our Atlantic coast. Shallow water surrounds Newfoundland, and a belt of shallow sea 50 to 100 miles wide runs past Nova Scotia, New England, and down to Florida. A very smooth bottom slants gently down to depths of about 100 fathoms. Then there is a rapid descent to the deep bottom of the Atlantic. The relief map (Fig. 191) and the cross profile (Fig. 192) show these features. This slightly submerged belt is called a Continental Shelf, because it seems a true part of the continental block, rising above the deep bottoms. The sea laps over upon the edges of the great land masses.

Our last statement implies that continental shelves are 
common. Our Atlantic shelf can be traced around southern Florida and all about the Gulf of Mexico, except where it is pierced by the Yucatan channel and by the deep passage which carries the Gulf Stream between Florida and

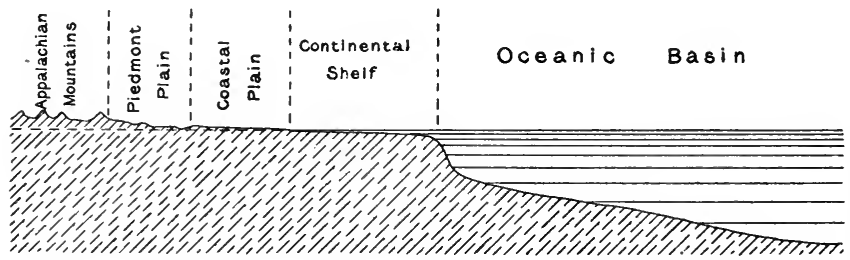

FIG. 192. - Profile of the bottom of the Atlantic Ocean and adjoining land in New Jersey and Pennsylvania, showing the continental shelf. Scale of distances, $1 \mathrm{inch}=140$ miles. Scale of heights, 1 inch $=\tau$ miles.

Cuba. Another continental shelf is found on the European side. It extends to the westward of the British Islands. Soundings show shallow waters in the North Sea, the English Channel, the Irish Sea, and west of Scotland and Ireland. In other words, these islands rise from a platform which is but slightly overflowed by the ocean waters.

242. Mediterranean seas. - The water of the Strait of Gibraltar is but 1,200 feet deep. But the sea within has depths of 13,000 feet. As it lies between two continents, the name Mediterranean (between lands) has been given to it. It does not lie in a basin cut out of the land, but in a basin made by the rising of the lands around it. The continents have grown up about a part of the ancient, open sea. On a smaller scale the same is true of the Black Sea, and even of the Caspian, though the latter has no connection with the ocean. The Caribbean Sea and the Gulf of Mexico are also mediterraneans.

243. Islands in the ocean. - We might call the greater lands islands, because they are washed on every hand by the seas; but we agree to call them continents. The origin of the continents and greater islands is too difficult 
a subject for elementary study, but the growth of many smaller islands can be better understood.

Hundreds of these small lands are due to volcanoes discharging at the bottom of the sea, gradually building their cones of lava and ash to the water-level, and even many thousands of feet above. These form the principal inequalities of the ocean-basins. Detailed soundings over all the seas would show their submerged erests at all depths. In the Atlantic, the Azores, the Canary, and St. Helena are among those that have grown above the sea surface. In the Pacific such shoals and islands are to be numbered by hundreds or thousands. The Hawaiian Islands (Sec. 183) are among the largest and loftiest.

Around the borders of many of these volcanic islands, fields of coral flourish in the shallow waters. The coral is an animal of low order, consisting of littie more than a sack or hollow body, with a mouth at the top, surrounded by a fringe of simple arms or feelers. It is attached to the mud or rocks of the bottom, and often great num- Fis. 193.-A coral from the Fiji Islands. The flowerbers of these sim-

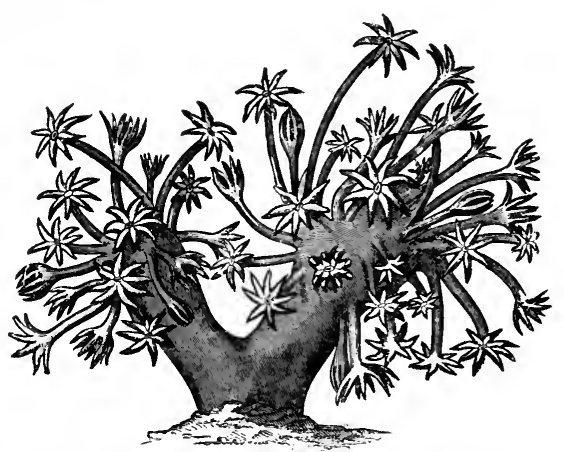
like parts are the living animals.

ple forms are crowded together on twig-like branches, formed of the calcium carbonate which they take from the sea-water. In eolor and form they look more like flowers than animals. The waves often break and grind to pieces the skeletons of these lowly forms and make coral-mud. In the shallow seas about the islands, therefore, are fields of living coral and floors of coral fragments and mud. 


\section{AN INTRODUCTION TO PHYSICAL GEOGRAPHY}

Such a field is a coral reef, and when it borders an island it is called a fringing reef.

Sometimes a belt of water lies between the high island and a low, long island which is of coral making. On the seaward side of this offshore island the corals are growing. Here we have a barrier reef, with a lagoon of protected water. In other cases, low coral islands and reefs form a

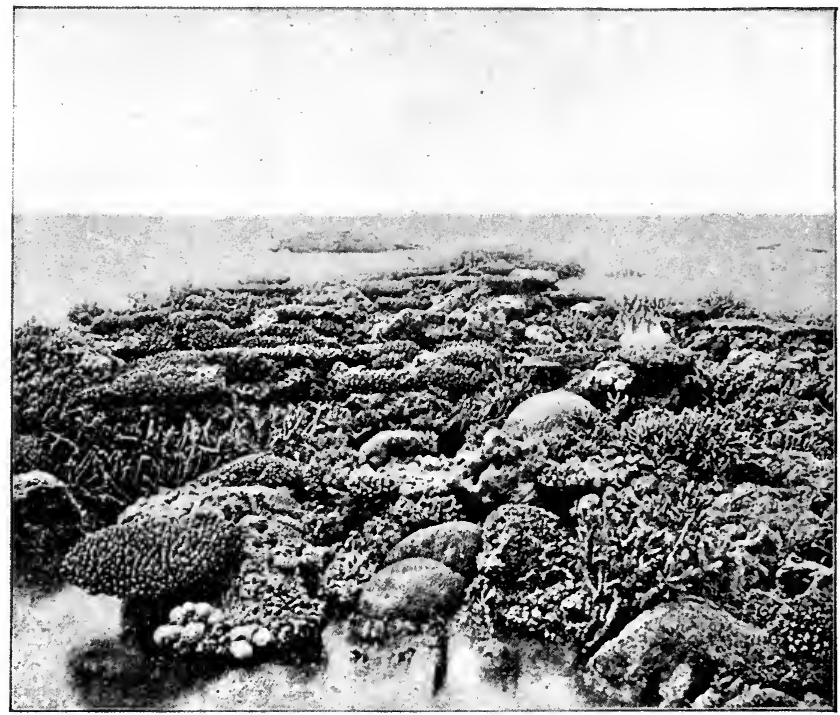

FIG. 194.-A coral reef at low tide; part of the Great Barrier Reef, off the coast of Australia.

rude circle or loop, with a shallow basin of quiet water within. Corals, as before, thrive all about the outside in the shallow water, while the coral sand, heaped by waves and winds, forms the low islands, clad with palms and other tropical plants. Such a bracelet of low islands is an Atoll.

The student should remember two or three important facts, about corals. They are not "insects," but are far 
below these creatures in their rank as animals. They have no instinct which prompts them to build islands. They do

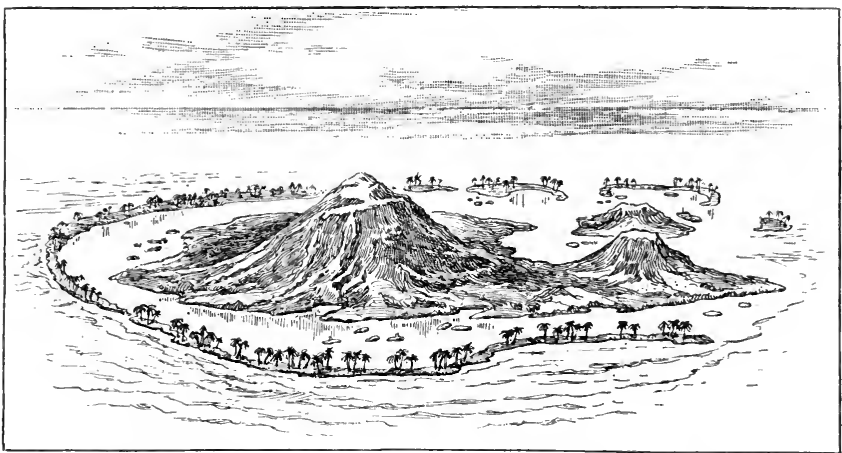

Fig. 195.-A volcanic island encircled by a barrier reef and lagoon.

not work from the bottom of the sea. Most of them can not live below a few hundred feet of depth. That they "build" anything is wholly due to the crushing and push-

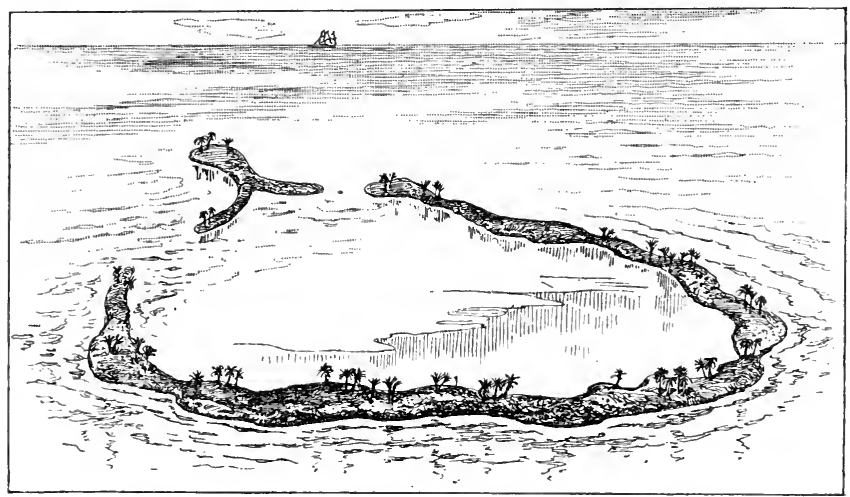

Fra. 196.-An atoll.

ing of their remains by waves and winds. And finally, they can only live in water having temperatures of $68^{\circ}$ or 
more. Hence they are never found far from the tropics. The Bermudas are the most northerly of coral islands. The Galapagos Islands, close to the equator in the Pacific Ocean, have no bordering reefs, because ocean currents bring cold water from the southern seas.

244. Composition of sea-water.-The waters of the ocean contain much material which is also found in a solid state in the rocks of the earth's crust. These solids in solution make about $3 \frac{1}{2}$ per cent. of the ocean waters. Much the greatest part of this is common salt. Far less in quantity is calcium carbonate. This is important, however, for many sea animals form shells of it. The gases which make up the atmosphere are minutely distributed through sea-water. The oxygen held in the sea makes life possible even at great depths, but deep-sea animals get very little of it, and their life is probably sluggish. Some forms, as the whales, must come up to the surface to breathe.

The ocean is more salty in some places than in others. In a nearly closed sea, like the Baltic, where much water comes in from the land, and does not freely spread to the open ocean, the water is partly fresh, and is called "brackish." This has the effect of diminishing the size of some shelled creatures whose tribes have lived in these waters a long time. Other enclosed seas, where evaporation is great and the influx of streams small, are much more salty than the open ocean. This is true of parts of the Mediterranean. And in tropical regions of the Atlantic there is more salt than in the arctic seas. Fresh water is lighter than salt; hence the waters of a great river like the Mississippi or Amazon will flow out over the salt water and freshen the surface parts of the sea for long distances from the shore.

The salt-beds found in the rocks are due to the evaporation of waters in shallow, land-locked basins of the ancient seas. They were natural evaporating-pans, heated by the sun. Common mud afterward drifted in over them, and so the layers of salt and rock were formed. The sea has 
always been salty, and it is constantly receiving through the rivers whatever the waters dissolve from the rocks of the lands.

245. Temperature of the ocean. - The surface waters are warm in the tropics, cooler in temperate latitudes, and cold in the polar regions. Thus, in a general way, they are like the lands. Near the equator about $80^{\circ}$ is the prevailing temperature. Some closed seas, like the Red and the Persian Gulf, attain almost to blood-heat. In the polar regions the temperatures go down to the freezing-point of $28^{\circ}$ or $29^{\circ}$, varying with the amount of salt in the water.

Comparatively warm waters push into northern and southern regions by means of ocean currents, and cold waters invade temperate latitudes in the same manner. Such cold drifts come from Greenland into the Atlantic, often floating chilling fleets of icebergs.

The student should notice that we have spoken only of the surface temperatures; we are now ready for the important statement that no such wide differences are found in the temperature of the deep waters in different latitudes. The sun's rays affect only the surface waters. Even in the torrid zone the bottom waters are always cold, having temperatures of $35^{\circ}$ to $40^{\circ}$. There is a considerable drift of surface waters from low to high latitudes. On the contrary, the water from north and south slowly creeps toward the equator in the depths. This accounts for the coldness of the deep waters everywhere.

246. Light and color.-The prevailing hue of the sea is blue. But those who have sojourned by it or sailed over it know how various are its colors. Offshore the waters are often tinged with the muds that have floated out from the land. The blue of the saltier parts is specially deep. The Gulf Stream is thus distinguished from the less salty Labrador current; and the Japan current is called Kuro Siwa (black water). In mid-ocean myriads of creatures may 
send forth a phosphorescent glow that seems to touch the sea with fire.

$24 \%$ Movements of the ocean waters.-Even in the deepest calm the ocean is never perfectly still. It is more fixed than the changeful sea of air above it, and less stable than the lands that border it. But even the lands are never twice quite the same, and so, from beginning to end, geography deals with an unfolding world. The movements of the sea fall into three classes, Waves, Tides, and Currents. We shall study them in this order.

248. Waves. - The winds ruffle the surface and make a series of ridges and furrows. The summit line of a single wave is its Crest and the furrow is the Trough. Under a moderate wind the crest will be a few feet higher than the trough. In storms the waves may be 20 or 30 feet high. In powerful storms the height may rise to 40 or 50 feet. Even great ships must be guided across the crests of such waves, or be overturned by the rolling motion. Wave motion ceases a few hundred feet below the surface, for the winds, like the sun, can not affect the deeper waters.

The student will remember that even a small steamer may raise waves astern, and that a gentle swell may afterward be felt at some distance, if we cross the track of the steamer in a small boat. On a larger scale the wave motion in a region of ocean storm is passed on and may create a swell in otherwise quiet seas, thousands of miles away.

Waves may be studied conveniently on a pond which is stirred by the wind. Drop a twig in the water, and observe its motions. It may drift slowly, but does not travel so fast as the waves. As each wave passes, it rises and falls; on the crest it moves a little forward, in the trough a little back. The motion of the twig is also the motion of the particles of water about it, and it shows their motion to the eye. The wave is not a body of water gliding forward, like a current, but a traveling shape of water. A field of grain 
swaying in the summer wind shows how the sea may keep its place while the wave moves on.

While urged by the wind, the larger waves sometimes break and whiten at the crest, even in the open sea, and nearly all waves break at the shore. As a wave moves through shallow water near the shore, the crest goes faster than the base, the front becomes steeper, and finally the crest falls forward in a cascade (Fig. 19\%). This tumbling crest is a breaker. As the advancing cascade looks like a turning cylinder, the term Rollers is sometimes used. If the bottom descends slowly,

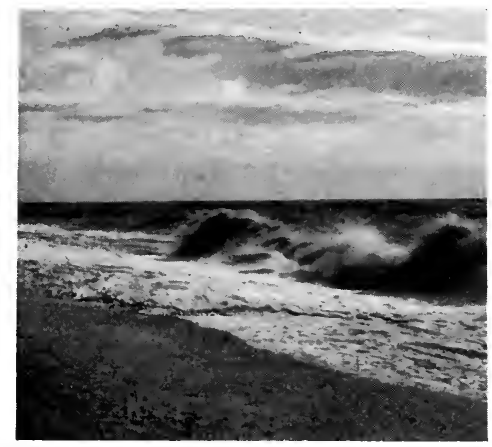

Fig. 197.-Surf, on a beach of sand and gravel.

a series of waves may be seen thus breaking, the water of the inshore breakers rushing up the slopes of the strand. This water pours back by a swift flow along the bottom, under the onrushing surface waters, and is known as the Undertow, so dangerous to bathers in the surf. The changes which waves cause along the shore will be described in the next chapter.

If a strong earthquake happens under the sea, a shock may be communicated to the waters, and great waves may be raised. The term tidal should not be applied to these waves. In some parts of the world, as Japan and Chile, such waves have rushed in over the coastal lands, overwhelmed cities, and stranded men-of-war and other vessels at some distance inland. Such a wave travels swiftly across the seas as a broad swell, and breaks with destructive force at the shore. The Lisbon shock in 1755 sent forth a wave that deranged shipping and flooded streets of an Irish port, 
while the shaking that accompanied the eruption of Krakatoa (Sec. 184) in 1883 caused half the waters of the earth to vibrate with wave motion. On neighboring shores these waves rolled to heights of 60 or 70 feet.

249. Tides.-If we stand on the shore of the open sea we shall observe a regular rise and fall of the waters, even in a time of calm. If the surface be at its highest level now, about six hours later it will be at its lowest. In case the shore is rocky, the boulders and cliffs up to a certain

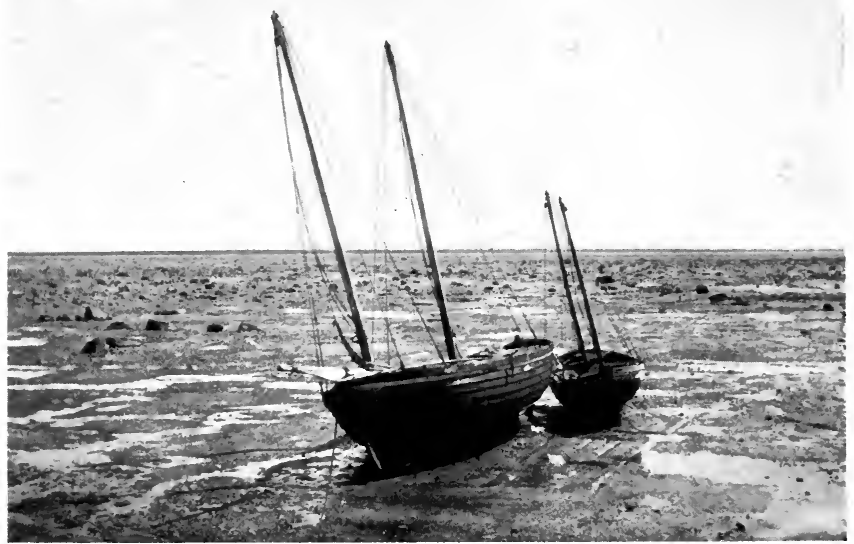

Fig. 198.-Low tide on a shelving coast. The edge of the water is now far away and the boats are stranded. When high tide returns they will again float.

height will then be seen covered with barnacles and dripping seaweeds. Pools left by the receding waters will be full of small, shelled creatures, and a strand several rods, or even miles, in width may be left bare. In another six hours the waters will have crept slowly in again until the upper line of seaweeds is reached. The average interval between two periods of High Tide is twelve hours and 
twenty-five minutes. The alternating extremes mark Low Tide.

About the shores of islands the rise and fall are small, often not more than 2 or 3 feet. On the borders of continents the change is greater. Toward the head of a long bay which has an open mouth and narrows gradually the rise and fall may be 50 feet, or even more. The Bay of Fundy and the estuary of the Severn fulfil these conditions, and are noted for their great tides. On open shores the water falls back, or creeps up, gently. But in and out of these landlocked arms it goes with a rush. An abrupt tidal wave with a steep and foaming front enters some rivers, as the Seine. Such a wave is called a Bore. High and low tides do not always occur at the same time on opposite sides of a strait, and the difference in level causes a swift current, known as a Tidal Race. Hell Gate, near New York, affords an illustration. In a landlocked sea which has a very narrow entrance from the ocean, the tides are unimportant. Those of the eastern shores of the Mediterranean Sea are scarcely perceptible.

The tides exist, but can not be seen, in the open ocean. They are broad, gentle swells, which, like wind waves, pile up and become visible at the shore. If the earth were covered by a universal ocean, the tidal waves would forever roll around it unseen. But the lands bring them to view.

250. What is the cause of the tides? - What can make a wave come to its height every twelve hours and twenty-five minutes? Twice this period, or twenty-four hours and fifty minutes, is the time from one setting of the moon to the next, and this fact long ago led people to connect the tides with the moon. But many centuries passed before the relation was wholly understood. The full explanation would take so much space that we must content ourselves with a simpler statement. Suppose a man and a boy to join hands and whirl about. Each will move in a circle, but the boy's 
circle will be larger than the man's because he is not so heavy. Each will feel a pull in his arms, and they must hold fast or they will break apart. The moon and earth whirl about in a similar way, making one turn a month, but as the earth is eighty times the heavier, the center about which they circle is close to the center of the earth. It is in fact inside the circumference of the earth. Instead of clasping hands they are held together by Gravitation, the same attractive force which keeps us from being whirled off by the daily rotation of the earth. The earth attracts the moon and the moon attracts the earth. Thus the earth feels two forces-an attraction or pulling toward the moon, and a pulling away from the moon in consequence of the circling. The pulling away is called the Centrifugal Force.

To make this quite clear let us look at Fig. 199. $C$ is the center of the earth, and the circle about it is the equator. $A$ is the point about which the moon and earth

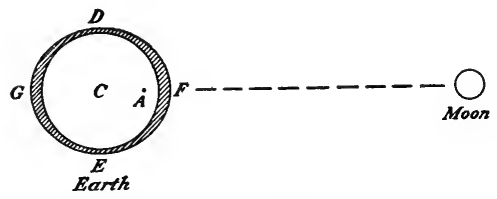

Fig. 199.-Diagram to illustrate the tides. The shaded belt represents the ocean, as though a complete envelope. circle. The centrifugal force is the same for all parts of the earth, but the attractive force is not. The principle is that attraction is stronger for small distances than for large, and under this principle the moon draws the nearer side of the earth more than it does the farther side. At $D$ and $E$ the moon's attraction is just as strong as the centrifugal force, but nowhere else about the equator. At $F$ the attractive force is greater than the centrifugal, and the difference is a pull toward the moon. At $G$ the centrifugal force is greater than the attractive, and the difference pulls away from the moon. So there is a tendency to stretch the earth out, making the diameter $G F$ greater than $D E$. The water of the ocean yields to these pulls and is drawn together 
and piled up a little about $F$ and $G$. These two swellings of the water (greatly exaggerated in the diagram) are tidal waves.

Up to this point we have paid no attention to the fact that the earth turns once in twenty-four hours about its own center, $C$. The effect of this turning is to carry the tidal waves all about the earth's circumference each day, and as there are two of the waves, each part of the ocean feels two high tides and two low tides. Thus the tides are caused by a combination of the moon's attraction with the motions of the earth.

The contiuents and islands and the shapes of coasts and shoals interfere with the free movements of the waters, but in each ocean the water is swayed twice a day, and from the oceans tidal waves

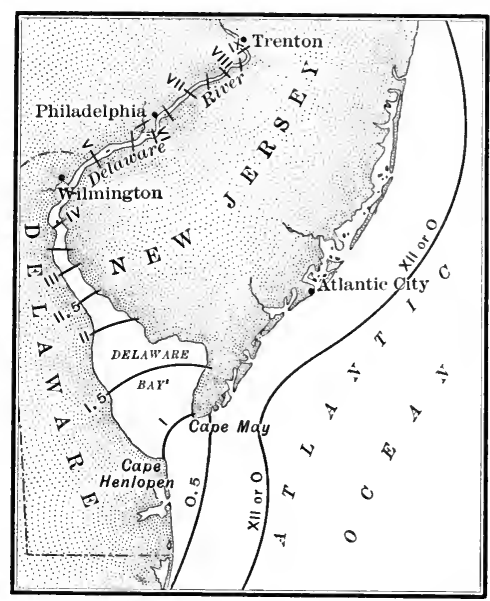

F1G. 200.-Cotidal lines in and near Delaware Bay. On the day of full moon or new moon high tide reaches Cape May at one o'clock, Wilmington at half-past four, and Philadelphia between six and seven. Scale of map, 1 inch $=55$ miles. adyance against the coasts, and enter all the bays. Their speed is checked as they enter shallow water, and their arrival at the heads of long bays may even be delayed many hours. For the guidance of shipmasters, maps are made showing by "cotidal" lines (Fig. 200) the places which are reached by the tides at the same time. There are also tide-tables for all ports, to tell the mariner when high and low tide occur, and the amount of rise and fall. Many channels can be used at high tide which can not be passed 


\section{AN INTRODUCTION TO PHYSICAL GEOGRAPHY}

at any other time, hence the knowledge of them is of much practical importance.

251. Ocean currents. - When waves started by winds, earthquakes, or tidal attraction traverse the ocean, the water itself moves little except in shallow or confined areas. We are now to study movements of the sea in which there is a continual transfer of water for long distances.

We take first the Gulf Stream and the North Atlantic Drift (Fig. 201). The term Gulf Stream is properly applied to a stream of salt water which pours eastward from the Gulf of Mexico, between Florida and Cuba, and then bears northeastward into the Atlantic. The width of this current in the Florida Straits is about 50 miles, its velocity is about 50 miles per day, and it is several hundred feet deep. It is very warm and it passes between "walls" of colder water. As the stream progresses, its waters scatter, their velocity drops to a few miles per day, and thus as a "Drift" they cross the middle Atlantic and wash the shores of western Europe. It is hardly correct to say, therefore, that the Gulf Stream touches Europe or gives it a mild climate. It is true, however, that the neighboring waters are warmed by the drift from the tropics, and the mild winds carry heat and moisture from the sea over the lands of western Europe.

But the currents of the North Atlantic have now been described only in part. Flowing westward along the equator is a strong current, some of which passes South America, enters the Caribbean Sea, and then the Gulf of Mexico, to pass out as the Gulf Stream. Other strands of the equatorial current turn north outside of the West Indies and join the Gulf Stream waters to form the drift above described. At the far northeast some of the waters push on into the arctic seas, and others return southward along the shores of southwestern Europe and western Africa, and pass again into the equatorial current moving west. There is thus a complete eddy in the North Atlan- 


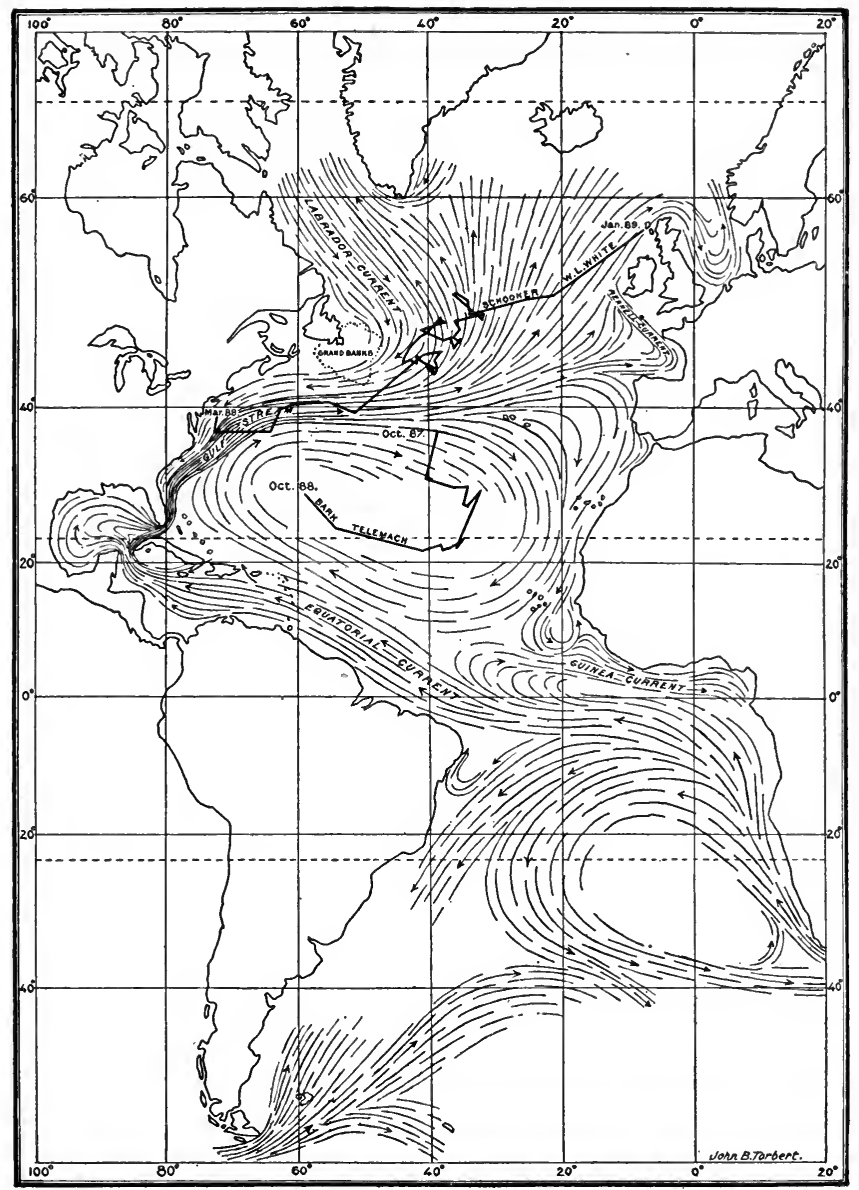

FIG. 201.-Currents of the Atlantic Ocean. The arrows show direction. The heavy lines are the courses of two derelicts, drifted by currents and winds. 
tic, the waters moving as the hands of a watch. In the center is a quiet region, where vast fields of seaweed float, known as the Sargasso Sea.

Beyond Florida the Gulf Stream soon bears away from the shores of the United States, which are washed by colder waters from the north. These come down from the neighborhood of Greenland and meet the Gulf Stream in what is known as the "cold wall." Along this belt are the Banks of Newfoundland, and here the contact of cooler with warm, moist air causes dangerous fogs.

There is a similar eddy in the South Atlantic. A division of the equatorial current turns southwestward down the coast of South America, and returns eastward to Africa, and northward, completing the circuit. At the south the easterly flowing current mingles with a great drift passing easterly around the world in the southern seas. This South Atlantic eddy whirls in a direction opposite to that of the hands of a watch.

It may now be asked: How are these currents known to exist? The answer is, by the course taken by drifting objects. Certain floating but abandoned ships, known as derelicts, are now and then sighted by vessels, and by comparing successive positions, their course can be plotted (see Fig. 201). Whenever a derelict is seen, its latitude and longitude are reported as soon as possible to the United States Hydrographic Office, for the better mapping and safer navigation of the sea. Thousands of sealed bottles are, from time to time, cast into the sea. They contain, often upon blanks furnished by the Hydrographic Office, record of the latitude and longitude at which they were committed to the waters, with a request that the finder transmit to Washington the point of their coming ashore. Less than in former days is the sea a trackless waste.

In the Pacific the swing is more vast, but the general arrangement of eddies is similar to that of the Atlantic, and the Japan Current resembles the Gulf Stream. The 
northern eddies of both oceans are more perfect, because formed in more fully enclosed waters.

The eurrents are formed by the winds. This is seen on a small scale by watching the floating twig in the pond, and is understood for the oceans by studying the winds and currents together. The student should compare the winds of the Atlantic (Fig. 180) with the currents of the Atlantic (Fig. 201). The great current-makers are the steady trade-winds, driving the waters westward in the tropics; the prevailing westerlies of middle latitudes drift them eastward, and thus the great eddies are maintained.

252. Ice in the sea.-Icebergs, singly or in fleets, leave the shores of Greenland in the spring and descend far enough into the Atlantic to endanger ships in the great path between America and Europe. The icebergs are the frontal parts of Greenland glaciers which have pushed into the sea far enough to float. All northern seas are more or less crowded with pack or floe ice, formed by the freezing of the surface waters, and moved about by winds and currents. Polar exploration abounds in experiences with such ice. Ships are caught and crushed in it. Long sledge-jour-

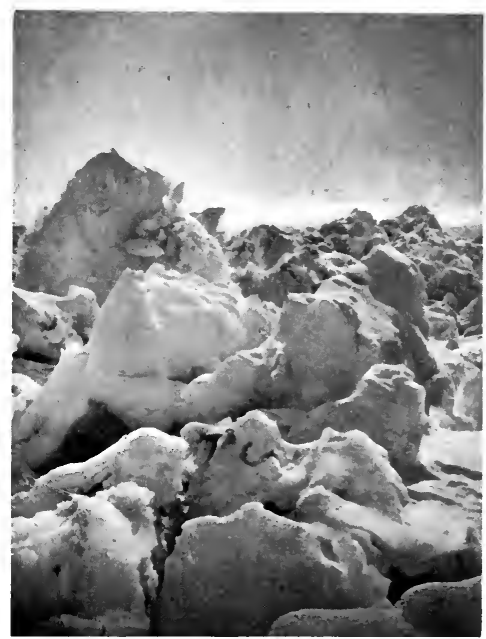

Fig. 202.-Floe ice. near the west coast of Greenland. Great cakes, crushing together, are made hummocky at their edges.

neys are made over it. Through it Nansen drove the Fram, and over it he made his final dash toward the pole. 


\section{AN INTRODUCTION TO PHYSICAL GEOGRAPHY}

On floe ice about twenty persons of the Polaris party drifted south for 2,000 miles in the winter of $18 \% 2-\% 3$, and were picked up, after a journey of six months, off southern Labrador. Large, flat-topped icebergs break from the antarctic ice-fields and invade the South Atlantic and South Pacific Oceans.

253. Exploration of the ocean.-This has been done in many ways. In ancient times daring mariners in small

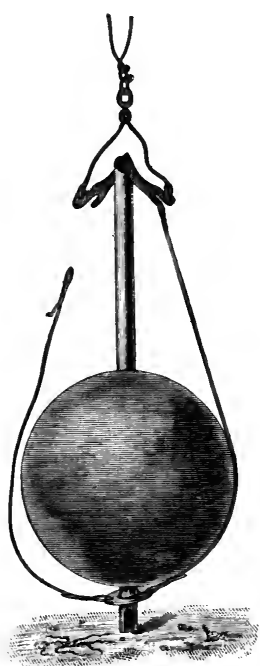

FIg. 203.-To carry the sounding wire to great depths a heavy weight is needed. It can not be drawn up again, and is therefore so arranged as to disconnect itself at the bottom.

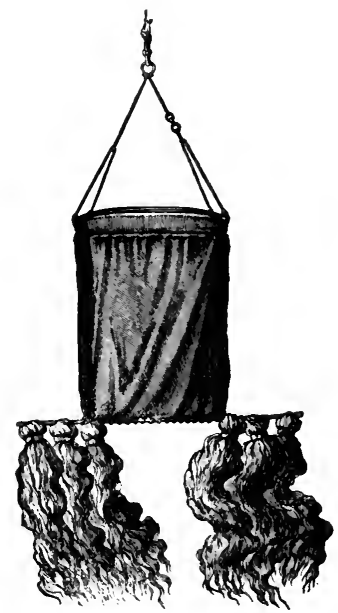

FIG. 204.-A deep-sea dredge. The iron lip of the sack scrapes shells, mud, etc., into it, and small animals are caught by the "tangles."

ships learned to track the wastes of the Mediterranean. Then they sailed by the Pillars of Hercules and began to creep up and down the Atlantic shores. Hardy vikings of the north found Iceland, settled in Greenland, and, as many believe, followed our shores as far as New England. Then came Columbus, Magellan, Drake, Hawkins, and 
Cook, crossing the great oceans and beginning to sail around the world. In our modern days commerce has threaded all waters, daring explorers have pushed far into the frozen north, and ships have gone forth, equipped with apparatus and directed by men of science, to seek the mysteries of the ocean. The forms of the shores, the currents, the temperature, composition, and depth of the water, the life of the upper and deep waters-all these are subjects of study. Sounding-lines, dredges for bringing muds from the bottom, and self-registering thermometers for testing temperatures at the bottom, are parts of the apparatus used. The United States Coast Survey has furnished us with much of our knowledge of the Atlantic Ocean.

254. Life of the ocean.-The highest forms of life are on the land. There they find abundant supplies of air, and are able to live an active life. Even the beasts have more elaborate bodies and far more intelligence than the highest creatures that live in the sea. But all land creatures are close to the surface, while the ocean is rich in living creatures not only near the shore and at the surface in midocean, but at the greatest depths. Vast numbers of sea animals have delicate, jelly-like bodies, made almost entirely of water, and able to exist only in water. Others, equally confined to a watery home, have hard skeletons, either internal, like the fishes, or on the outside, like the crab, the lobster, and the innumerable creatures which form shells as a cover for their bodies. More will be said of sea animals in the chapter on life.

255. Deposits in the ocean.-We have seen that rivers may enter the sea and build out the land, as their deltas grow. But not all the waste of the continents is dropped at the water's edge. The finer mud floats for a long time, and finally settles to the bottom far from the river mouth. Thus the continental shelves, and even deeper waters outside, receive a cover of muds derived from the land. The shallow waters teem with fishes and shell creatures, and at 


\section{AN INTRODUCTION TO PHYSICAL GEOGRAPHY}

death their remains mingle with the muds. Far out, however, the fine muds from the land do not go. But multi-

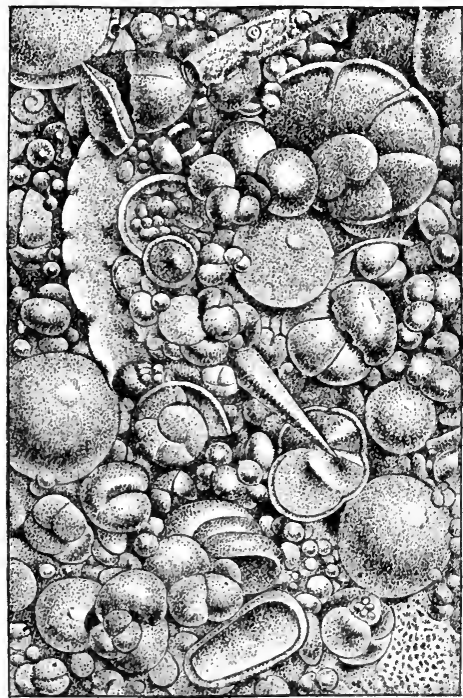

Fig. 205.-A deep-sea deposit composed of shells. Magnified 20 times. tudes of minute shells are formed by creatures in the surface waters. These shells, chiefly made of calcium carbonate, sink, when the animals die, to the deep sea-bottoms. They make a fine chalky ooze (Fig. 205), which has been brought up by the dredge and studied. In the very deepest seas a fine red clay is found. This comes, in part at least, from volcanic dust, which falls on all seas. The fine deposits of midocean accumulate very slowly, while the muds of offshore waters gather rapidly.

256. Navigation.-The ocean is the highway of nations. In primitive times the winds furnished power and the sun and stars guided the course. Now the mariner has a charted sea; with his compass on the deck and engines in the hold, he crosses the waters whither he will, and his speed is scarcely checked even by waves and winds. Storms bring little danger to the great steamship, and collision and fire are so well avoided that travel is nearly as safe on the ocean as on the land. Even the waves are robbed of their fierceness by allowing a little oil to drip from the prow, and a ship with its hundreds or thousands of temporary inhabitants, and with all provision for human comfort, seems 
less a vehicle than a floating town. The Pacific is coming to be a busy highway like the Atlantic, and the building of a ship canal in Central America will make possible in the tropical regions continuous voyaging around the world. Almost equally with the land, is the sea a field of discovery, of travel, of commerce, and, unhappily, also of war.

25\%. Submarine cables.-During the last half of the nineteenth century many lines of telegraphic communication have been stretched between Europe and America, and important foreign news passing between civilized lands is rarely one day old. The coming years will see an equal development of marine telegraphy in the regions of the Pacific, and messages without wires may yet place all ships in constant communication with the land.

258. Fishing.-The seas are an important source of supply for man. The shallow waters near the shore teem with fish and other marine animals fit for food. Hence fishing communities abound on the shore, like Gloucester in Massachusetts and the Marblehead of former days. From the beginnings of voyaging to America, fishing has been carried on over the Banks of Newfoundland, and the French, the English, and the American have regarded these ocean fields as of national importance. 


\section{CHAPTER XIV \\ THE MEETING OF THE LAND AND SEA}

Tre line along which the ocean waters wash the edge of the land is often called the Shore, or Shore-Line; or we may use the term Coast, or Coast-Line. The latter suggests more particularly the margin of the land, the former the border of the sea. We have deferred our study of this narrow belt, that the chapters on the ocean and the land might prepare us to understand it. We have already learned some facts about sea-borders, as in connection with deltas (Sec. 42), coastal plains (Sec. 150), and tidal bays (Secs. 249 and 250). We shall now look at the shore-lines of the United States, to see what general principles we can gather from them.

259. Shore-line of Maine.-This will be understood by reference to the map (Fig. 206). Many rocky ridges run in a southerly direction from the mainland into the sea. Between them deep bays penetrate the land. The headlands are exposed to the full force of the waves, hence no sands or gravels can lodge, or beaches form about them. At the head of the inlets, however, the sands and clays, whether brought down by streams or swept in by waves, may lodge and form floors of worn waste, to which the name Beach is given. The south parts of these ridges are often surrounded by water, forming hundreds of islands fringing the shore. The shore-line is vastly lengthened by its irregularity. Calais is about 200 miles from Portland, but the shore-lines between the two places are said to be more than 2,000 miles long. The Penobscot and Kennebec 302 
enter the sea through deep tidal channels. These furrows, cut in the edge of the land and entered by the sea, are known as Fiords, and have their best examples along the shores of Norway and Scotland. They were begun by rivers and finished by glaciers during the Glacial period.

260. Shore - line of Massachusetts. North of Cape Ann are thesmooth,sandy beaches known as Salisbury Beach and Plum Island, with swamps and sluggish tidal streams behind them on the west. Cape Ann is a rough, rocky headland, enclosing on the south the quiet waters of Gloucester Harbor. The waves beat upon the granite shore, the coast-line is jagged, and few sands can rest about its exposed border. To-

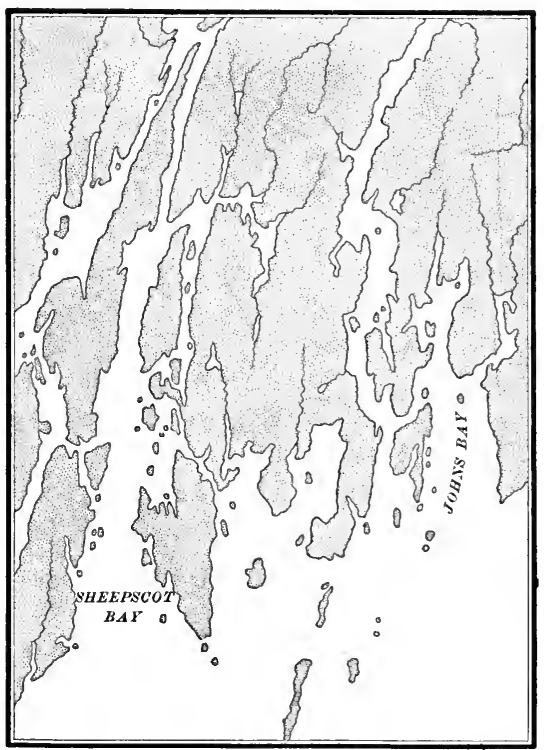

FIt. 206.-Outline of part of the coast of Maine. Scale, 1 inch $=5 \frac{1}{2}$ miles. The sea laps against a surface shaped by glaciers, converting ridges to promontories and islands, and making bays and straits in the hollows.

ward Boston the wash of shore currents has built a bar from the mainland to the rocks of Nahant, hence Nahant is an old island tied to the shore by a recently made beach. The same is true of Marblehead Neck; a rugged island is bound to the mainland by a narrow belt of sand cast up by the wares. The hills in Boston Harbor are drumlins (Sec. 136) and show many shore cliffs, due to their outer 
slopes being cut away by wave action. At Nantasket is a long, smooth beach of fine sand, a little concave toward the sea, protecting Hingham Bay to the westward. These are local cases, but instructive, and should be studied upon the atlas sheets of eastern Massachusetts. Nahant is shown in Fig. 20\%. Cape Cod has a very smooth eastern shore, facing the ocean. Low, sandy lands formerly extended farther east, but have been carved away by the unceasing attacks of the waves. Some of the material has been swept northward by currents, carried around the point, and built into the hook which encloses Provincetown Harbor. We should note the difference between the jagged shore maintained by the hard rocks of Maine and the smooth shore carved from the soft beds of Cape Cod. We should compare also the rough, irregular shore-line about the protected waters of Buzzards Bay. Nantucket and Marthas Vineyard consist wholly of soft, easily destroyed beds, and are much exposed to attacks of the sea. Hence the shores have smoothly curved forms. Bars have often been carried across the openings of bays, turning them into lakes. The shores of Rhode Island and Connecticut are like those of Maine. The rocks are ancient and hard, and the rivers enter great bays like the Narragansett, or pour through narrower, but deep, tidal channels, as the Thames from Norwich to the Sound.

261. New York and New Jersey.-The most important feature of the New York shore-line is the trough of the Hudson River, cut many feet below sea-level, and admitting the tides far within the land. Salt water reaches Poughkeepsie, and the rise of the tides is felt at Albany and Troy, 150 miles inland. Other submerged channels are occupied by East River, Raritan Bay, the Upper Bay, and the Narrows, affording the best harbor facilities in America. Outside of the Lower Bay are long stretches of flat, sandy beach, made by waves, and by currents moving along the shore. These are common on the south shore of Long 


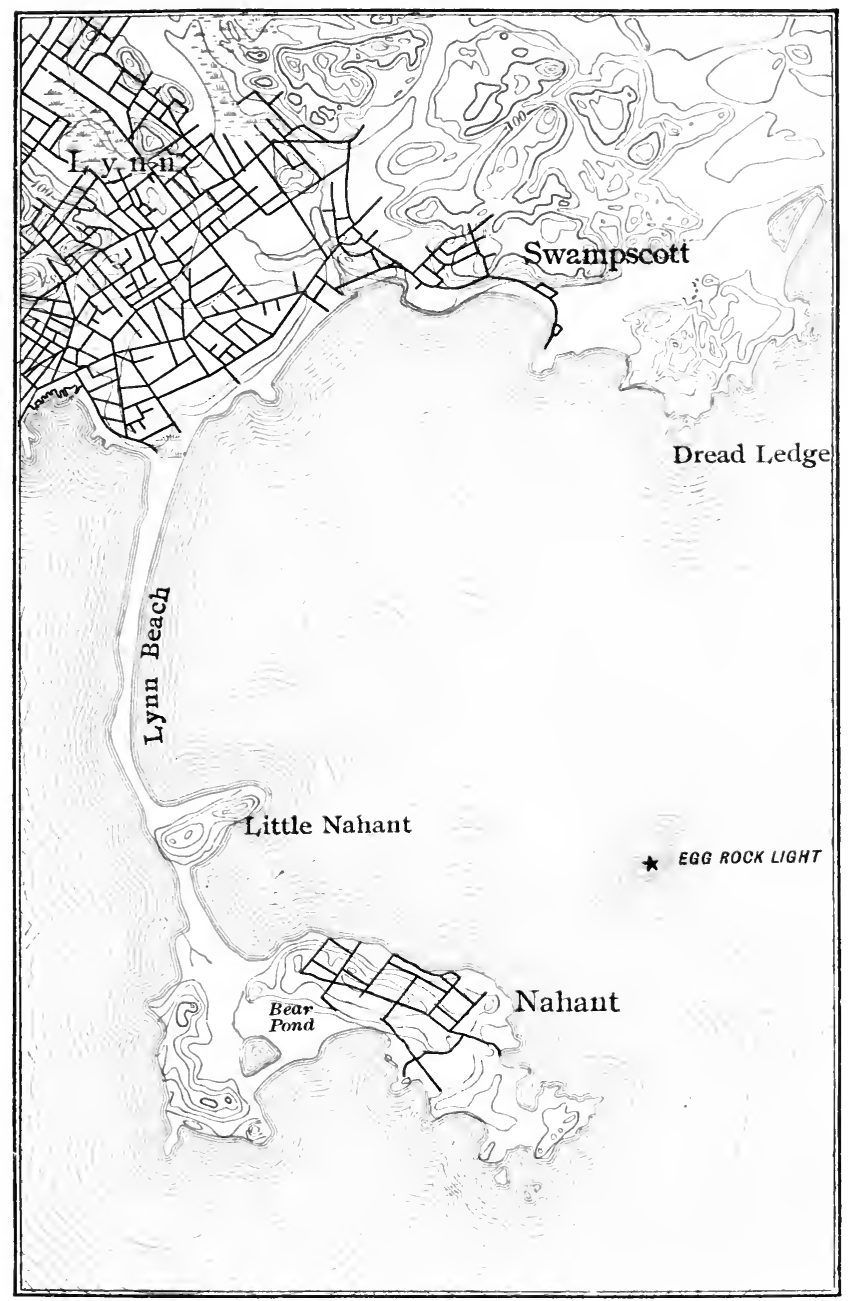

Fig. 207.-Part of the coast of Massachnsetts. Scale, 1 inch $=1$ mile. Contour interval, 20 feet. Nahant and Little Nahant, originally islands, have been joined together and to the mainland by spits. 


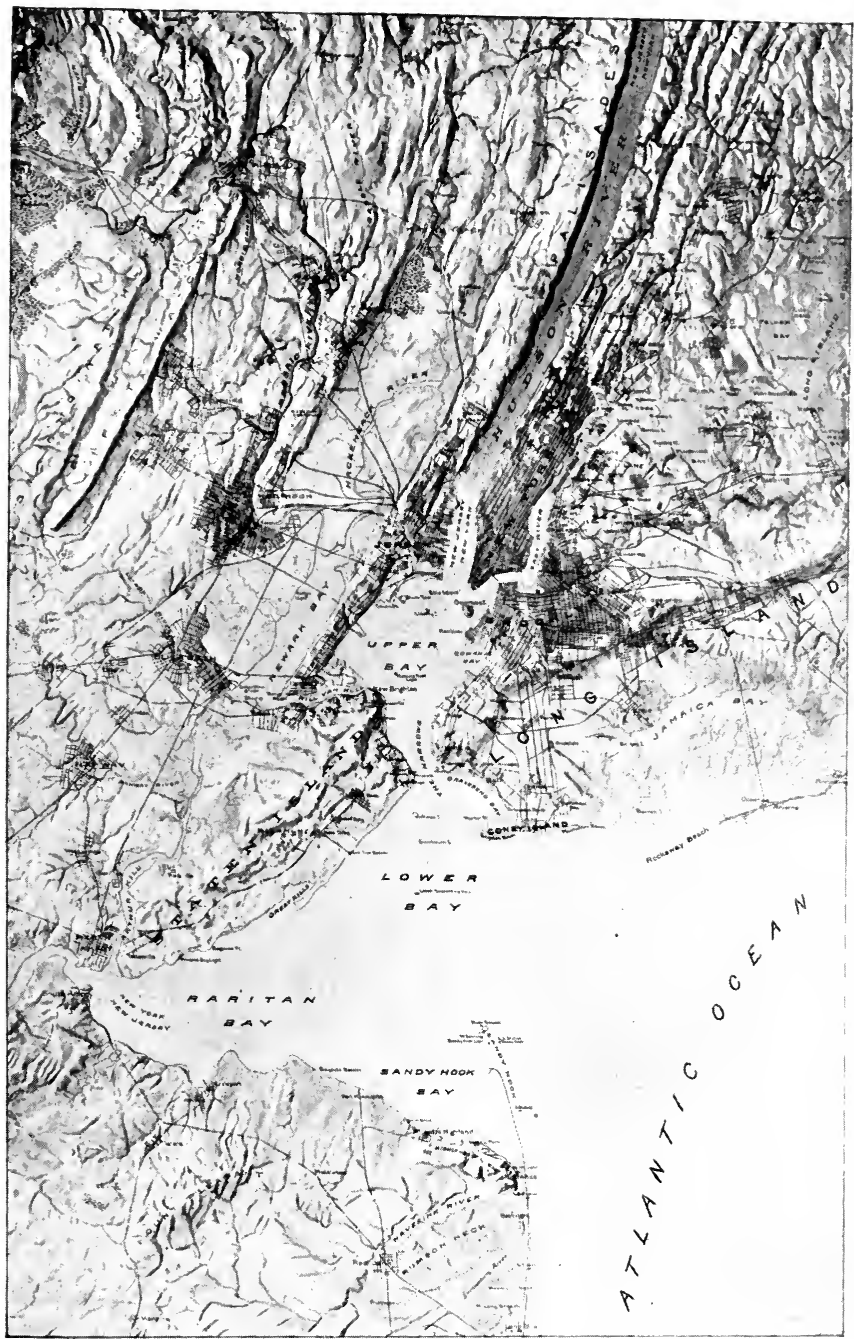

Fig. 208.-New York and vicinity, showing the harbor and its approaches. Scale, 1 inch $=9$ miles. (See pages 304 and 315.) 


\section{AN INTRODUCTION TO PHYSICAL GEOGRAPHY}

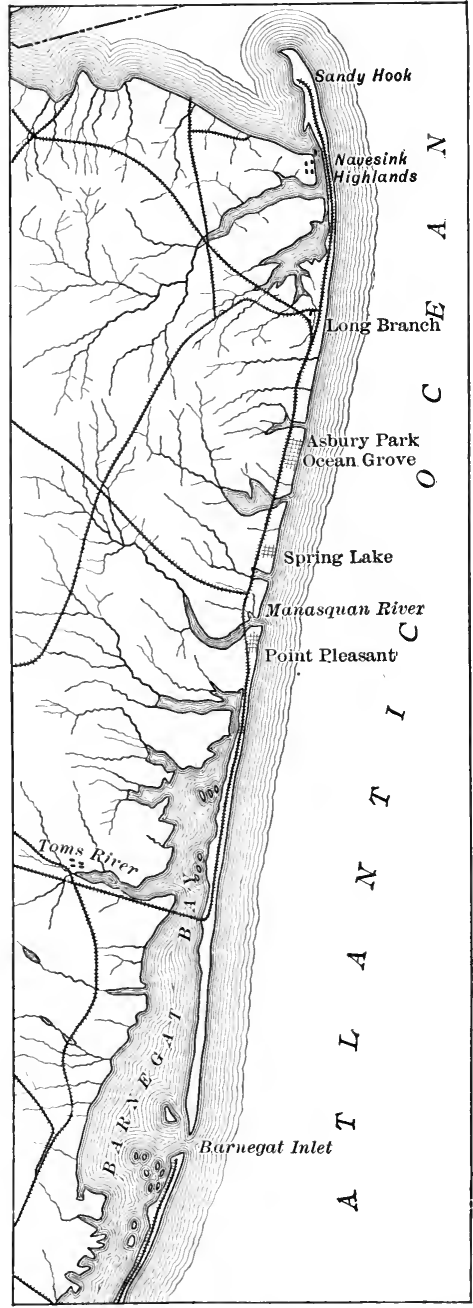

Fig. 209.-The coast of New Jersey, showing wave-made spits and barriers, and quiet waters behind. Scale, 1 inch $=11$ miles.
Island. Rockaway and Coney Island Beaches run out to points on the west (Fig. 210), and were made by shore currents driven by winds from the east. Behind them are Gravesend and Jamaica Bays and a network of swamps and channels.

If we turn to the New Jersey shore we find Sandy Hook stretching up into the Lower Bay (Fig. 209), built by currents moving north along the Jersey shore. Farther south are low bluffs, due to cutting back by the waves. This is the quarry to supply the sea with sand for the building of Sandy Hook. From Asbury Park to Cape May is a nearly unbroken beach, long, narrow, low, and sandy, with a belt of quiet water separating it from the mainland. The waves there break in shallow water, drop the load of waste they have pushed in from the sea-bottom just outside, and form thus an offshore beach. 
Here, as along other parts of the Atlantic coast, a canoe could sail in quiet waters for long distances.

262. The South Atlantic and Gulf coasts.-Here we have long lines of straight or gently curved shore, with shallow sea-bottoms and low, flat lands. Great bays or smaller inlets often break this smooth line. Such are the Delaware and Chesapeake Bays, Albemarle and Pamlico Sounds, Pensacola and Mobile Bays. All the larger rivers of Virginia and Maryland discharge into the Chesapeake Bay, and from the bay the tide flows far up the streams. Hence we have the expressive name "Tide-water Virginia," because all the low plains of the State are threaded by tidal rivers. As we go southward, long offshore beaches and fringes of islands border the Carolinas and much of Florida. Texas shows a wonderful extent of these low, long, and sandy offshore beaches. Nearly the entire Texas coast for 300 miles has such a shore-line, running in a smooth, gentle curve, with lagoons and bays behind. Galveston is on such a beach, with Galveston Bay behind it, and was thus exposed to fearful destruction by storm waves when, in 1901, a West India hurricane abandoned the ordinary course and turned westward across the Gulf.

263. The Pacific coast-line.-This is less winding, along the western border of the United States, than much of our eastern shore-line. Instead of low, coastal plains, we find cliffs and mountainous elevations rising from the water. Barrier beaches are few, because the water deepens rapidly and waves break at the very edge of the water, instead of offshore. There are three principal breaks, by which ocean waters flow within the land. The Golden Gate is a narrow channel leading into a system of bays lying behind low mountains, the Columbia River is open to the tides for some distance, and Puget Sound offers an extensive system of protected sea-waters. The last named are fiords and are the beginning of a great system extending northward along the shores of British Columbia and Alaska. The waters 


\section{AN INTRODUCTION TO PHYSICAL GEOGRAPHY}

are deep, and the coast is fringed, not by barrier beaches, but by a continuous chain of mountainous islands, behind which protected channels of coastwise navigation may be found. On the west as on the east, the North American shore-line

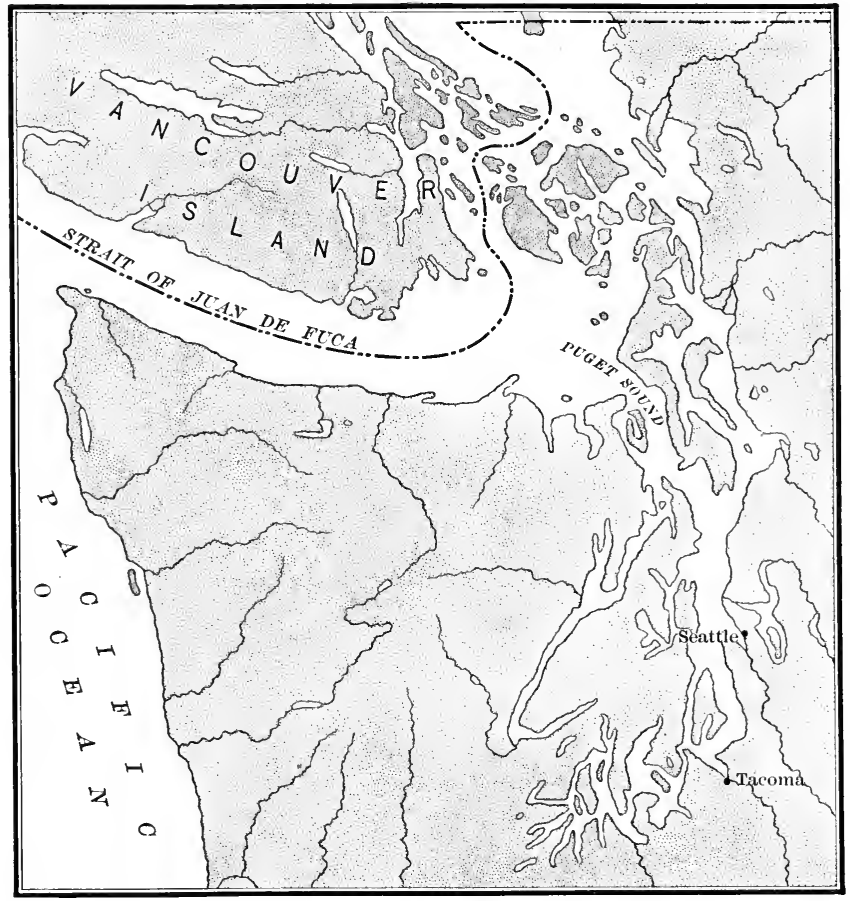

FIG. 210.-The fiords of northwestern Washington. Scale, 1 inch $=38$ miles. The sea invades hollows shaped by ancient glaciers.

is broken and rough at the north, for the irregular shorelines of New England pass into yet more broken lines about the Canadian provinces and the Gulf of St. Lawrence.

264. Summary of principles.-Having learned the chief facts about the coast-line of our continent, we shall now 
classify and more fully explain them, and compare with them some of the features of other parts of the world. The behavior of the water where it washes the land, is much the same everywhere, giving us the same kinds of coast forms. Even on the borders of pools and small lakes the student may find in miniature what the ocean displays on a scale of magnificence.

265. Wave work.-We have already learned that winds raise waves, that waves move over the sea, that they break against the edge of the land, and send the water rushing upon it. These waves attack the rocks of an uneven land border. They pick up pebbles and stones and hurl them against the ledges of the shore. Grinding away the lower ledges, they undermine the ledges higher up, and thus form cliffs. In front of the cliffs nearly flat platforms are made, and strewn with the coarser waste. The finer mud, easily washed away, is floated out, to settle at a greater or less distance from the land. Waves do the most of their work at the level of the sea. Storm-waves may dash a hundred feet or more above it, and may grind strongly over shallow bottoms, but they have no effect on the deeper bottoms. The waves act as a saw, cutting horizontally against the edge of the lands.

266. Beach platforms.-Let us look more closely at the stretch of sand, pebbles, or boulders that so often borders the sea. The wave-saw has cut a notch into the sloping land, and the continual moving in and out of wares and tides strews the floor with the waste of the land. This platform slopes gently toward and under the water. It may be covered entirely at high tide, but a strip, perhaps many rods wide, is bare at low tide. Sometimes the beach platform is a floor of solid rock. This means that waves, or currents moving along the shore, sweep all the waste off to some other point.

$26 \%$. Sea-cliffs.-Overlooking the beach, if the sea beats upon the edge of high land, is a cliff. It may be vertical 


\section{AN INTRODUCTION TO PHYSICAL GEOGRAPHY}

and rise for hundreds of feet, as at some points on the shores of Scotland and California. It may even overhang in places, if the rock is strong enough to hold, and sea caverns may have been formed underneath by the dash of the surf. Fingal's Cave is cut 200 feet into the south side of the island of Staffa, off the Scottish coast. The floor of the cave is below the sea surface, and the roof is 50 or more feet above it. The waves rush in and are still quarrying out

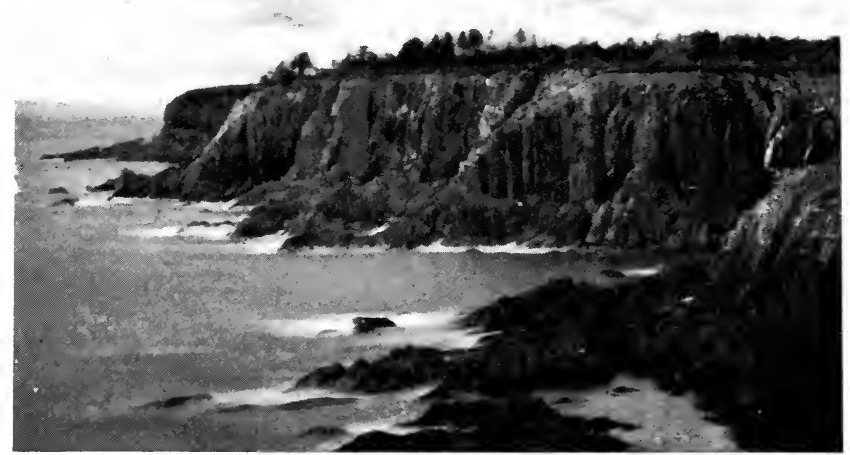

Fig. 211.-Cliffs and irregular platform wrought from hard rock by sea-waves; Nova Scotia.

the great columns of ancient lava that compose the island. Where the border-land is not solid rock, but clay or sand, the cliff slopes down to the beach more gently, as seen in Fig. $7 \%$ At Sankaty Head, Nantucket, is such a sloping cliff cut in land about 100 feet high. Such are the Gay Head cliffs of Marthas Vineyard, and many cliffs in the soft beds of Norfolk and other parts of the east English shore, where farms and village sites have in times past been cut away and absorbed by the North Sea.

268. Lagoons and barrier beaches.-We have seen that these are common on our Atlantic and Gulf coasts. They 
belong to shore-lines along which the water is shallow for some distance from shore. This means that incoming storm-waves break at some distance from the land, and spend their force there. The rush of the surf stirs the waste on the bottom, carries it forward a little way, and then drops it. By this process a low ridge is raised from the bottom, is built at length above the water, and may be broadened by the addition of waste against its outer slope. The quiet water on the land side is known as a Lagoon. It re-

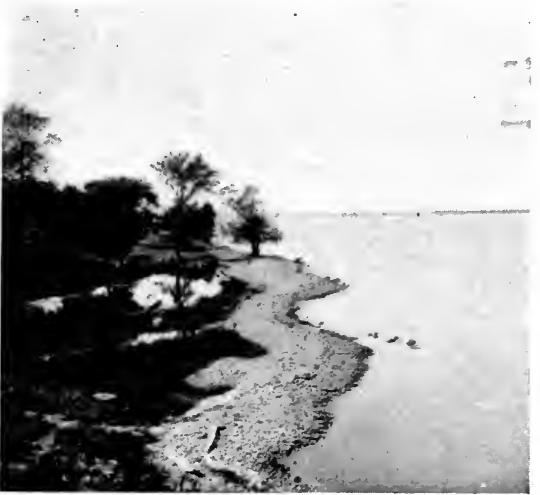

Frg. 212.-Barrier and lagoon on the shore of Lake Ontario.

ceives fresh water from the land, and tends to become brackish. Muds from the land gather in lagoons, and plants grow in them, and they are gradually filled.

269. Traveling beaches and spits.-Often the same wind which makes large waves will cause a current to flow along the shore. The waste lifted by each wave is then carried forward a little by the current before it drops again to the bottom. In this way the waste slowly travels in the direction of the current. If the shore is straight the waste follows it, but if the shore-line bends back the waste keeps straight on, and is built into a low cape or spit (Fig. 214). Sandy Hook is a spit curved at the end. Sometimes a spit grows all the way across a bay so as to close it, and sometimes it joins an island to the mainland (Fig. 20\%). A barrier usually becomes a traveling beach also, and its sand is shifted to and fro as the shore current changes. 


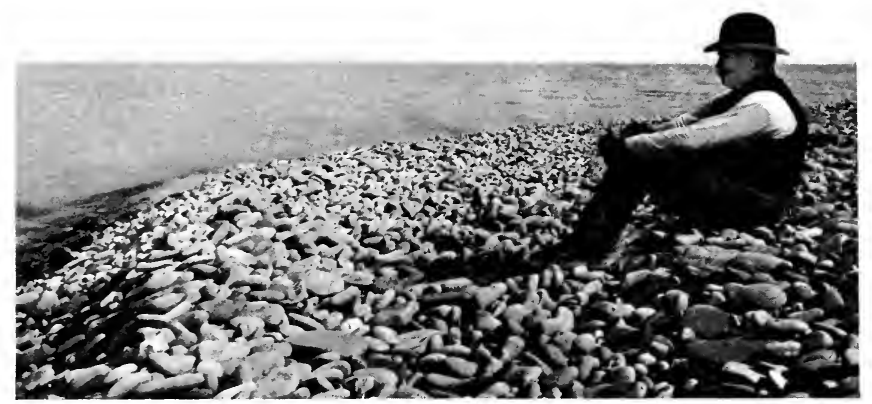

Fig. 213.-A traveling beach on the shore of Lake Ontario. The stones, originally angular, become rounded as the waves roll them along.

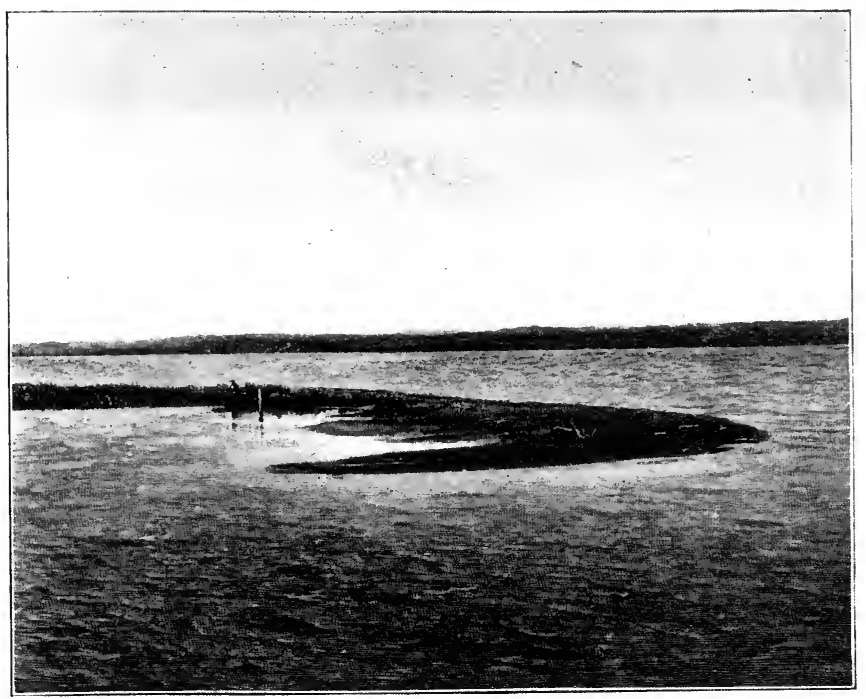

Fig. 214.-A curved spit, made by waves, on the shore of Lake Michigan. 312 
$2 \%$. Irregular shore-lines tend to become smooth.-Let us take the Maine shore as an illustration. Wherever a stream enters the head of a bay it makes a delta and shallows the water, or even pushes the shore-line forward. At the same time the waves cut away the exposed headlands, and while some of the waste from this cutting goes out to sea, some of the sands and gravels are often swept into the bay, and form within it a curved, smooth beach. 'This curve may straighten out as it receives more material, and so by this double or triple process the entire shoreline will grow in time to be smooth and uniform. Where the headlands are of soft materials, as on the south shore of Marthas Vine-

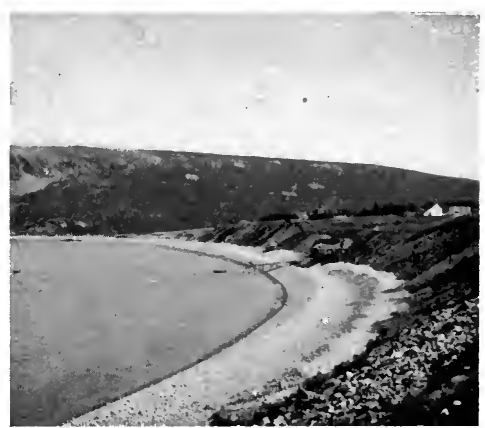

Fig. 215.-Beach at the head of Conception Bay, Newfoundland. The waves have here made the shore-line smooth.

yard, the work goes on rapidly, the spits soon become barriers, and the bays are shut off from the sea and become lakes.

2\%1. Coast-lines of rising lands. - Consider a land standing at a given height in relation to the bordering sea. The waste of the land is spread smoothly in the shallow waters. If the land rises, these plains of waste become flat grounds on the edge of a continent. We have followed such changes in our study of marine plains (Sec. 150). Such a coast-line is smooth, and the waters deepen very gradually from their edge. Hence offshore beaches will form. These are the conditions of southern New Jersey and our south Atlantic coast.

If coasts are steep and the seas deepen rapidly, no marine plain is uncovered by the rising of the land, but a 
beach platform and cliff is carried above the sea surface and left as an ancient sea-margin on the slopes that rise from the water (Fig. 8). Such old beaches, or marine terraces, are found on the coast of Maine and along the ocean borders of Alaska, Cuba, Norway, and Scotland.

272. Coast-line of sinking lands.-This subject is not altogether new to us (see pages 64-65). The edge of any land is creased by streams, and thus divided into a series of higher grounds, separated by valleys. On the down-sinking of the land the sea flows into these valleys and "drowns" the lower part of the rivers. The coast-line thus produced is very crooked, and there are often many islands. The waves and currents busy themselves with the work of straightening, and the water-front soon shows a rapid succession of cliffs, traveling beaches, and spits.

273. Coast swamps. - When a lagoon forms behind a barrier beach, and its quiet waters become so shallow that plants grow, we have a coast swamp. Or if the land is sinking, and low, flat areas are flooded, swamps develop. In either case the tide flows in and out, and with its incoming brings mud, which settles among the stems of the plants and raises the surface. This is the origin of the salt meadows whose grasses are harvested on many shores. Among the meadows channels form, by which the tidal waters first roll in and last drain out. By building dikes, hundreds of thousands of acres yet below high tide are reclaimed for agriculture and for homes. This saving of rich coastal swamps has gone on most extensively in Holland and in the low Fen country of eastern England. The saving of these lands has been the work of centuries, and further extensive operations are now in hand for reclaiming the Zuyder Zee in Holland. The abundance of land in America has thus far made it unnecessary to reclaim much of the swamp area of our coasts.

274. Lake shores.-In Section 153 an account was given of a large lake of which Great Salt Lake is the remnant. 
Deeply eut shore-lines are found at various levels on the surrounding slopes, up to 1,000 feet above the present lake. These shores are like abandoned beaches of the ocean, except that they have been left high and dry by the gradual drying away of the lake, instead of by the rising of the land. In lakes the tides are unimportant. Wind waves do their work on ocean and lake border alike, except that most lakes are so small that the waves have little space in which to develop, and are therefore small and weak. Still, upon lakes less than a half-mile wide, well-developed beaches are often found, and a succession of little horizontal platforms or beaches may often be found running about a pond or reservoir whose waters have been from time to time drawn down. At each stand of the surface, a new shore-line is made. Even where a pool has dried away by the roadside, beaches, deltas, bars, and spits may often be seen (Fig. 40).

275. Harbors and cities. - The waters of the lower Hudson are protected from the ocean waves by surrounding lands (Fig. 208). They are not so broad that the winds can stir up great waves upon them. They are deep enough for sea-going vessels, and are connected by a deep channel with the ocean. Hence they form a harbor. Boston Harbor is in a recess of the shore-line and protected by many islands. Philadelphia lies on the great estuary of the Delaware River, and Baltimore at the head of the land-locked Chesapeake Bay. Sinking or sunken coasts have many harbors, and rising coasts have few. The point where ships can come safely to the land is the natural home of commerce. There men gather, there manufactured products are made and can at will be sent seaward or landward. The relation of a harbor to the land is also important. The supremacy of New York is due in part to the easy passage from its harbor to the heart of the continent. The navigable Hudson and the low pass by the Mohawk Valley through the Appalachian uplands have combined with its good harbor 


\section{AN INTRODUCTION TO PHYSICAL GEOGRAPHY}

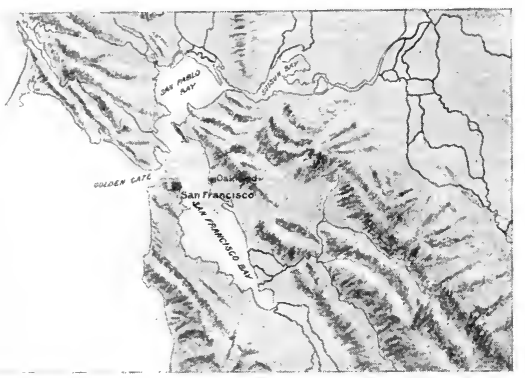

FIG. 216. - The Golden Gate. Scale, 1 inch $=40$ miles.

Except at this point the Great Valley of California is separated from the sea by a mountain barrier (see Fig. 129). Here an outlet for commerce is combined with a good harbor. to make it the leading port of the Atlantic seaboard.

Splendid harbors, too, about the Golden Gate (Fig. 216) and Puget Sound (Fig. 210) have fixed the centers of life on the Pacific coast, because thence lead the steamship highways to Hawaii, Japan, China, the Philippines, and the Indies. Great Britain's commercial greatness has grown in part from her drowned rivers and resulting harbors. She has no river that would be important if not tidal. London, Bristol, Liverpool, Southampton, and Glasgow are great cities because of the sinking of the land. But not all harbors are in fiords and drowned valleys. In the lower or delta channels of great rivers, as at New Orleans, or behind barriers, or hooked spits, as at Provincetown, Mass., shipping may find a haven.

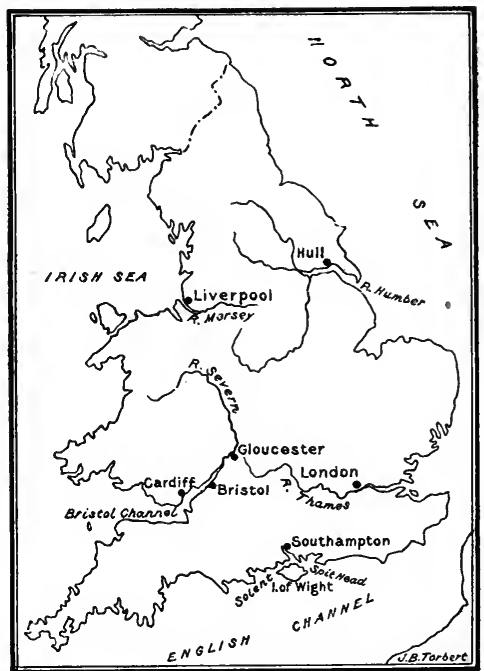

Fig. 217.--Outline of England, showing the relation of its great commercial cities to drowned rivers and the drowned valley north of the Isle of Wight. Scale, 1 inch $=250$ miles. 
2\%6. The United States Coast Survey.-Through this organization our Government provides minute knowledge of our entire shore-line. Soundings off all shores, in full detail in all harbors and harbor entrances, and with frequent revision, to keep pace with the shifting bottoms of the border seas-such is the work of this bureau, that charts may be issued for the use of mariners and coast dwellers. A similar survey under a separate bureau is carried on for the Great Lakes, for the benefit of the rast shipping interests of these inland waters.

2\%\%. Lighthouses and life-saving stations.--The lighthouse tells the sailor both where to go and where not to go.

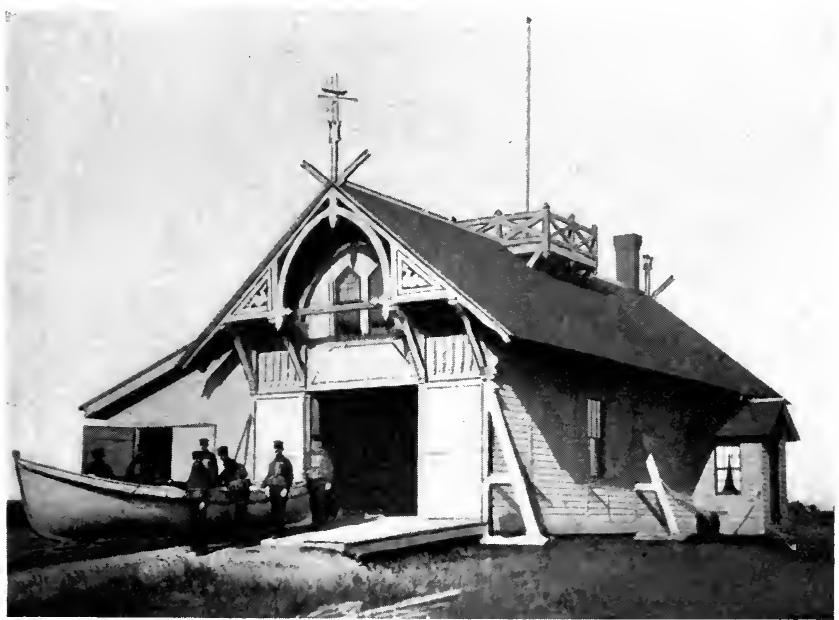

Fra. 218.-A life-saving station on the coast of Maine.

On the Navesink Highlands of eastern New Jersey it directs the mariner toward the harbor of New York. In the English Channel beacon lights warn the sailor off the Eddystone rocks. Such lights are guides to all vessels, even those that cross the wide seas. Especially needful are all 


\section{AN INTRODUCTION TO PHYSICAL GEOGRAPHY}

possible marks, such as buoys and lights, for the smaller vessels engaged in coastwise trade, or in fishing. Such craft are always near the point of danger and in risk of running upon shoals in the darkness or in storms.

Life-saving stations are established along frequented shores, with every appliance for aiding distressed mariners, and maintaining in times of special danger a watchful patrol of the shore. 


\section{CHAPTER XV}

\section{LIFE}

We have looked upon the Earth as a whole. We have studied its lands, its atmosphere, and its mantle of waters. We come now to the living things which throng our planet. They are animals and plants. The botanist studies the plants, tells us their structure, their habits, how they are related to one another, and how they divide into small and great groups. Zoology is devoted to the animal kingdom and gives to those who seek it the same full knowledge of these forms. But geography seeks only to know the greater truths about living things. Plants make a carpet over the lands - a carpet varying according to climate and soil. Animals too are found in groups over the world, devouring plants and other animals for food. Living things covering the land and swarming in the seas, and seen in their grouping and general relations, belong to geography.

\section{Plants of North America}

278. Forests. - The eastern United States abounds in forests, while the West is forested only in the high mountains and along part of the Pacific coast. Trees grow in the regions best supplied with water. The western boundary of the eastern forest area is a line running irregularly north and south from the eastern Dakotas through central Texas. But this region includes the prairies of Iowa, Illinois, and other States, where forests are almost confined to the water-courses. The great forests are in the Great Lakes region, the Appalachian Mountains, and on the Gulf Plains. 
Chestnut, oak, maple, beech, walnut, and cherry are among the hardwoods of the East. The broad-leaved trees chiefly compose these Appalachian forests (Fig. 219), often numbering 50 kinds or more, while the narrow-leaved or coniferous

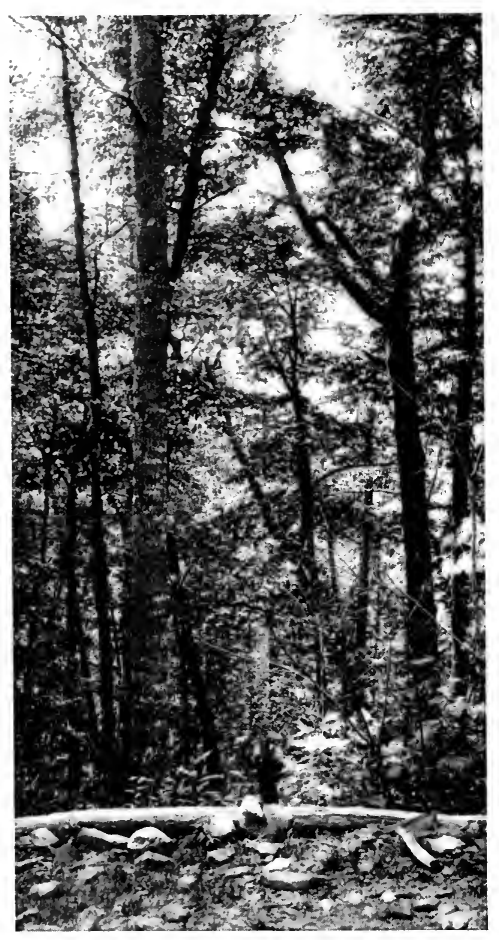

Fig. 219. - An Appalachian forest of broadleaved (or deciduons, or hardwood) trees. trees show a half-dozen sorts. White pine, hemlock, and spruce are common in New England, in Michigan, and farther west along the lakes. Along the South Atlantic and Gulf plains the hard pines flourish, with magnolias, tulip, gums, and cypress.

The Great Plains are too dry for trees except here and there along the rivers. Even the lower valleys among the Rocky Mountains (Sec. 163) are without trees. The high mountain valleys and slopes are forested up to the so-called timber-line, the trees belting the slopes in successive zones controlled by temperature and moisture. Next the bushy lowlands are low junipers and nut-pines; then, in order, yellow pines, Douglas firs and silver firs, with occasional groves of aspen. In the arid belt between the Rocky Mountains and the Sierra Nevada most mountains do not reach up- 
ward to timber-line, but end in the zones of juniper or yellow pine. On the Sierra and along the moist North Pacific region all cone-bearing trees-pines, firs, hemlock, cedars, and sequoias-have a wonderful development, towering to great heights, and constituting the most magnificent forests of our continent (Fig. 220).

In Canada are great forests. Only two regions are treeless. One of these is the great interior plain continuing from Dakota and Montana northward. The other is the far northern area, called "barren grounds," which is too cold for forest growth. Much land in the southeastern provinces has been cleared, but enormous forests stretch from the Laurentian uplands to Hudson Bay, and others from the basin of Mackenzie River southward along the slopes and valleys of the western mountains. The latter extend over Alaska to

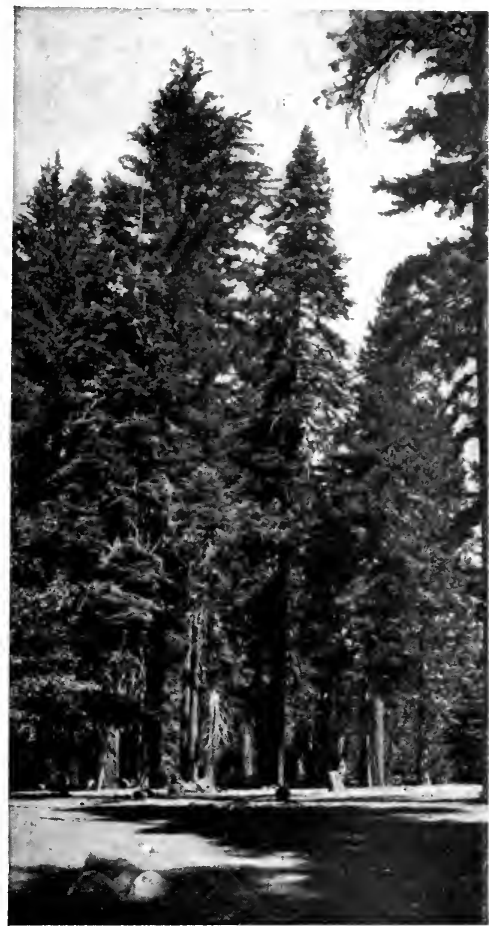

Fig. 220.-A pine forest of the Sierra Nevada. Pines are narrow-leaved (or evergreen, or cone-bearing) trees.

the Pacific coast. At the east are scrub pine, white and black spruce, larch, aspen, and birch. At the west are spruces, firs, hemlocks, and cedars. The softer woods, like spruce, poplar, and basswood, are much used for making wood pulp. 
Southern Mexico and Central Ameriea show forests of the tropical sort. Palms, rosewood, mahogany, logwood,

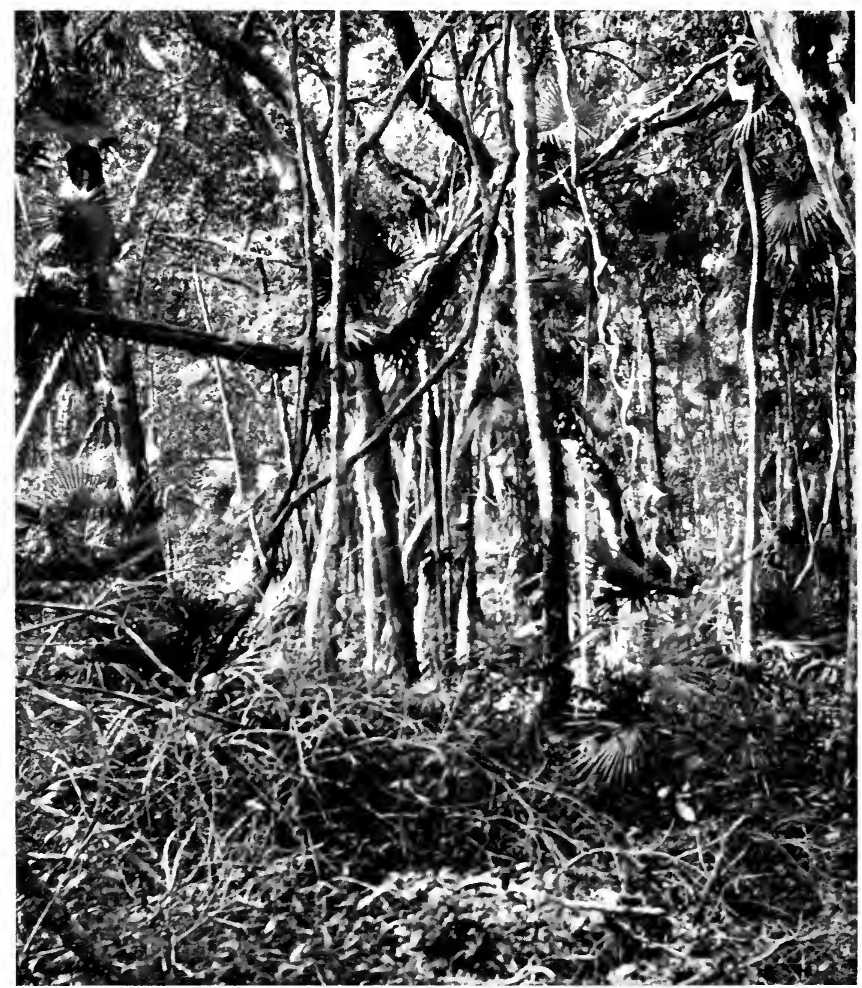

Fig. 221.-A tropical forest, Yucatan.

and rubber trees are common, while upon the mountains more northern types, such as oaks and pines, are found.

2\%9. Forestry.-This is the name given to a scientific system of managing woodlands. The United States Department of Agriculture maintains a Bureau of Forestry, to study forest problems and give skilled assistance to forest 
planters and owners. In the early days the settlers cut off forests wastefully, to clear the land. Now it has become a matter of public interest to regulate tree-cutting and to plant forests. This is done in part to keep a supply of timber, and in part to regulate floods and prevent the wasteful washing of the soil. The cutting of the Adirondack woods exposes the spongy cover of mosses and leaves to destruction, and lets the storm- and snow-water run swiftly off, flooding the Hudson, while at other times the water is low and scanty. In other words, the soil mantle and its nap of vegetation serve as a reservoir to hold the water and dole it out throughout the year. This storage service and the preservation of the Adirondacks as a playground are regarded as so important that the State is purchasing and reserving much forest land in these mountains. Similarly, the National Government is reserving forest parks, as in the Yellowstone region and among the mountains of California. The care of existing forests consists mainly in proper thinning, and cutting only the mature timber, instead of reaping a wasteful harvest at the expense of the future.

Some land in New England, no longer regarded as profitable under the plow, is relapsing into forest. Schools of forestry are being established, as at Cornell and Yale Universities, and on the Biltmore estate in North Carolina.

280. Small plants in forests.-In the moist and shaded places beneath forest trees, low growths flourish. If enough light streams in, flowering herbs will thrive, as in our northern woods, and in any case mosses and other lowly plants will establish themselves. Hence we may think of these wild grounds as having several layers of vegetation, from the modest mosses up to the iorest monarchs.

281. Natural meadows.-This is another name for Prairies. The student should review Section 159. There the origin of the plains was the special theme. Here we refer to the vegetation. Trees are absent except along the streams. Coarse grasses and large flowering herbs cover the ground 
in its natural state. The glowing colors of the aster, goldenrod, and other tall plants are common. The great prairie region separates the region of the eastern forest from the Great Plains, on which forests do not grow because the climate is too dry. But the elimate of the prairies is not unfavorable to tree growth. The tree limit has been crowded eastward beyond its natural position by fires. Two centuries ago there were prairies of some extent in central Virginia and western New York, but their boundaries have disappeared with the clearing of the trees from the surrounding lands.

282. Alpine plants. - The term Alpine is derived from the lofty mountains of southern Europe, but applied to similar characters and conditions wherever found-to scenery, climate, plants, animals, and even the customs of men. In eastern North America most of the mountains are too low to reproduce Alpine conditions of plant life, and forests usually rise to the top. But in the western mountains are high fields and slopes, above the timber-line, where the ground is often closely covered by a mat of low plants, with flowers of many and brilliant hues, resembling the flora of the Alps. The term Flora means the total plant life of a region. The flora of Rhode Island, for example, is the entire assemblage of plants, large and small, living within the State.

283. Water-loving plants.-All plants require water, but some have become fitted to live with very little, while others require much. In the latter class we find many kinds. In the waters off the seashore are many humble, flowerless plants known as seaweeds. If we row our boat over the shallow waters of any pond or lake, we look down upon plants that are perfectly submerged, even though they stand upright and are of considerable height. If we pull one of these stems, we find it limp. It is supported by the water, and does not need a strong, woody stalk, like an open-air plant. It may have poor roots also, since it takes 


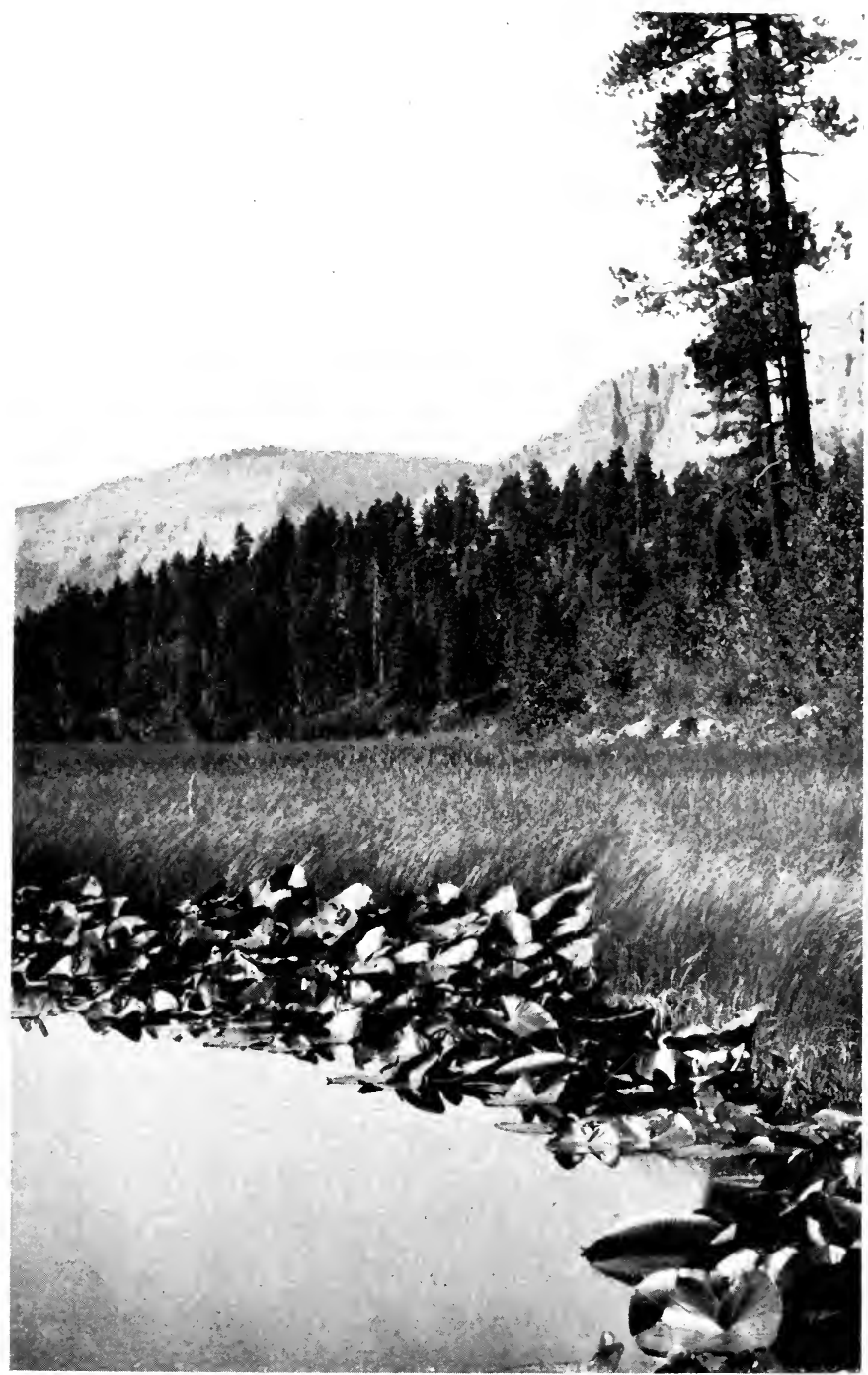

F1G. 222.-A mountain view in Colorado, showing the grouping of plants with reference to water. In the lakelet are yellow pond-lilies, thell a belt of swamplatas, a belt of shore bushes, and finally a pine forest on firm, dry land. 


\section{AN INTRODUCTION TO PHYSICAL GEOGRAPHY}

its food less from the soil than from the water. Other plants, like the water-lily, are well rooted, and the stems submerged, but their leaves rest on the water, and their blossoms rise a little above it. Multitudes of lowly plants are not attached, but move or float free in the water.

Swamp plants root in water or very wet earth and rise. more or less above the water surface. Reeds, rushes, and cat-

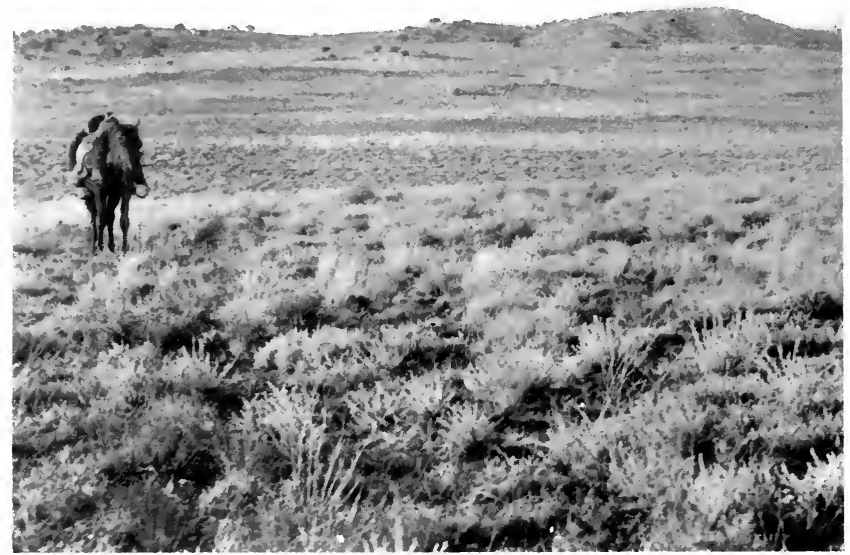

Fig. 223,-An arid plain in northern Arizona, seantily clothed with low bushes. On the distant hills is the beginning of the juniper zone.

tail flags are good examples of these, and may be seen on the borders of any pond. There the conditions of plant life are 
about half-way between those of water and those of land. In swamps are found the cup-like leaves of the pitcherplant, the spongy mat of the sphagnum moss, and the fruitful cranberry. Upland trees assume special characters when growing on swampy ground, and the great swamp-cypress of the Southern States is never found on drier land.

284. Dry plains and deserts.-As we pass from the prairies, or natural meadows, westward, we find the plants be-

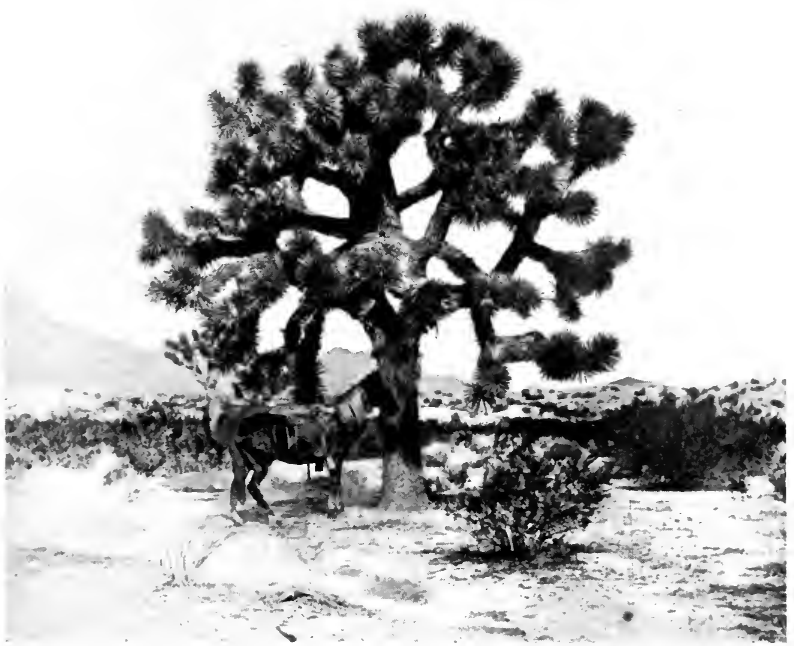

Fig. 224.-A tree-yucca on a desert of sonthern California.

coming more scattered and of fewer kinds, consisting mainly of bunch-grasses and low bushes. The region is not a desert, but affords a certain amount of pasturage. Wide ranges, however, are needed for herds, in comparison with wellgrassed regions. 
Farther south and west, areas of true desert begin. Parts of western Texas, New Mexico, Arizona, Nevada, Utah, southern California, and Mexico, fall in this class. Ordinary plants could not live in such heat and drought. Some desert plants, as the cactuses, have no leaves to exhale the moisture. Others have only a few small leaves and shed them in early summer. Yet others, like the larrea, Spanish bayonet and agave, have varnished leaves, from which there is little evaporation. All stand wide apart, so that each plant may have a large patch of soil to store for it the scanty rain, and some send their roots to great depths.

\section{Animals of North America}

We have grouped the plants mainly according to the conditions in which they thrive. It is not so easy to do this in the case of animals, for while plants are generally attached to the soil, animals often range freely over long distances. But animals, too, are dependent on climate. Some dwell on the ground, others in the soil, and yet others move freely in the air. Many can live only in the water, and some, like the frog, or the beaver, are at home in the water

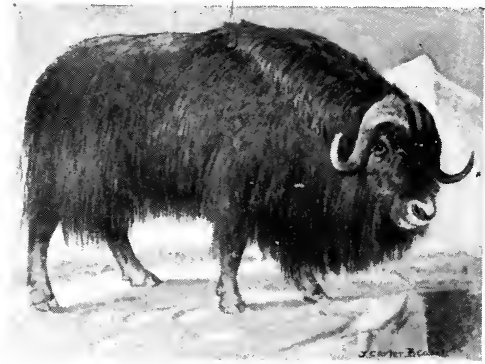

FIG. 225.-The musk-oxen inhabit tundras and barren grounds of the far North. See Fig. 226. or on the land, dividing their lives between the two.

285. Animals of the North.-On the tundras of Alaska and northern Canada are polar bears, arctic wolves, foxes and hares, lemmings, and, at the east, herds of muskoxen. Most of these have whitish fur, so that they are not easily seen against a background of snow. The barren-ground caribou, closely resembling the Lapland reindeer, roams the 


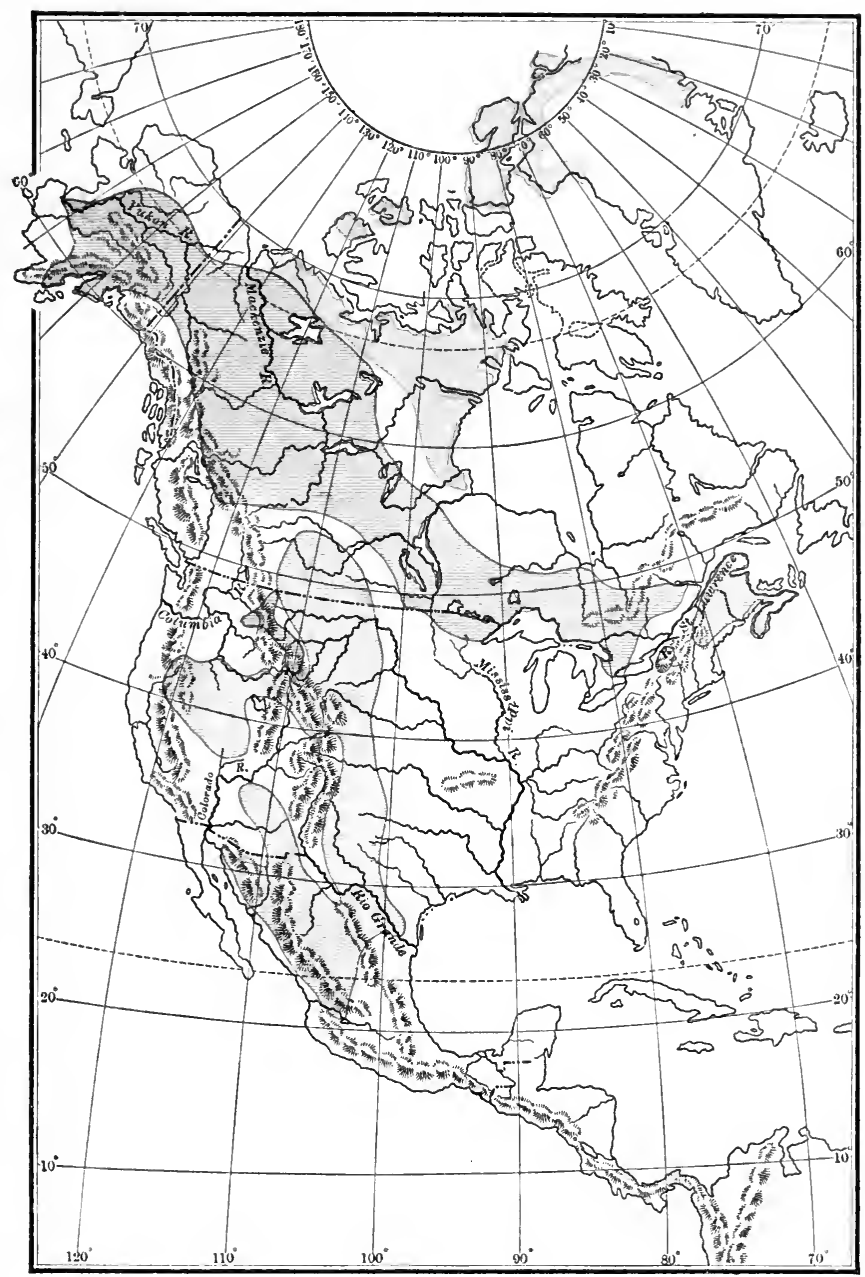

Fig. 226.-Distribution of the musk-ox, moose, and antelope. The country of the musk-ox is shown by orange; that of the moose by green; that of the antelope, in the year 1900 , by purple. 
- *1, 
country in vast herds. In neighboring forests, brown and black bears abound, with the moose, woodland caribou, and lynx. The fisher, otter, marten, and mink are still numerous, though reduced bylong hunting for their furs. The beaver is still common in Canada and in some parts of the United States. "This very intelligent animal is the chosen emblem of Canada, for it is at home in the woods and water." (Dawson.)

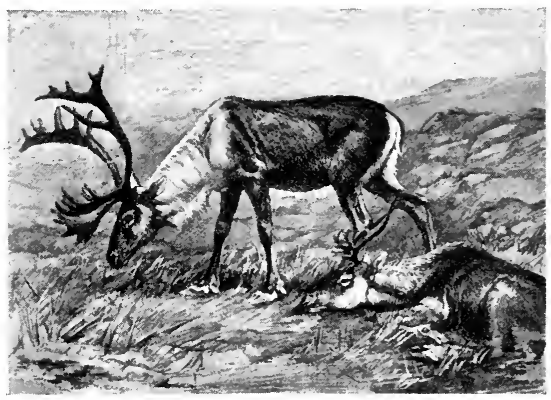

F1G. 22\%.-The woodland caribou inhabits the forests of Canada and Alaska. See Fig. 231. (Copyrighted by Forest and Stream.)

At least 600 kinds of birds live in Canada, most of which spend the summers and breed there, but escape the ice and snow of winter by flying southward. As we might expect

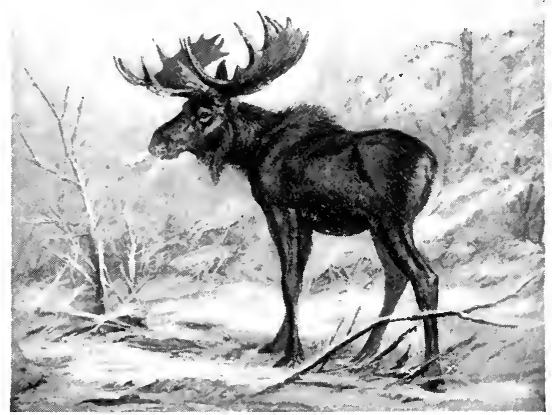

Frg. 228. - The moose lives in northern forests. See

Fig. 2:6. (Copyrighted by Forest and Stream.) from the wide forests and thousands of lakes, ducks, geese, and other water - fowl are found in countless numbers.

286. Animals of the temperate regions. - These regions include much of southern Canada and nearly the whole of the United States. They include also great differences of animal life, if the mountains and the plains, the North and the 


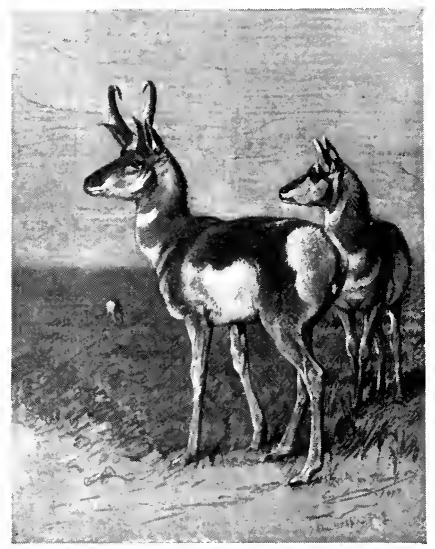

Fig. 229.-The antelope, or pronghorn, occupies open comntry on the Great Plains and westward. See Fig. 226. (Copyrighted by Forest and Stream.)

South, are compared. In the forests of the West live elks, and bears, black, brown, and grizzly; about crags and peaks climb mountain sheep and mountain goats; and antelopes roam the open lowland. All these large animals are numerous, though less abundant than formerly. Buffaloes once ranged the Great Plains of the United. States and Canada in millions, so that the land was sometimes black with them. It is believed that not more than 50 now survive in a

wild state. With ruthless hand man has destroyed them, for sport or for the sale of their hides, and so we have a striking example of how man is changing the animal population of the world. The destructive jack - rabbits and prairic-dogs of the plains are less worthy to survive, but better able to hold out against the attack of man. Bears and wildcats are found in all the forests of the East, and deer, under the protection of the game laws, are

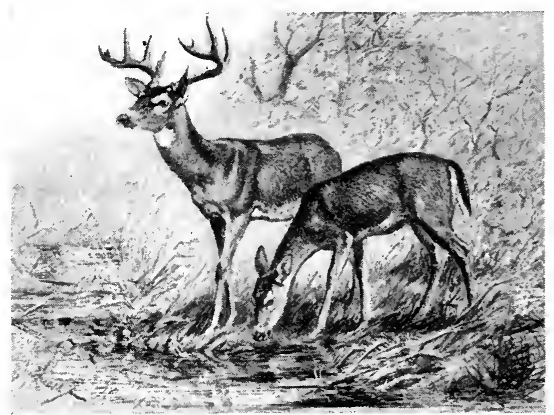

FIG. 230.- The white-tail or Virginia deer lives in temperate forests from the Atlantic coast to the Rocky Mountains. Its range grows smaller as the lands are cleared. See Fig. 231. (Copyrighted by Forest and Stream.) 


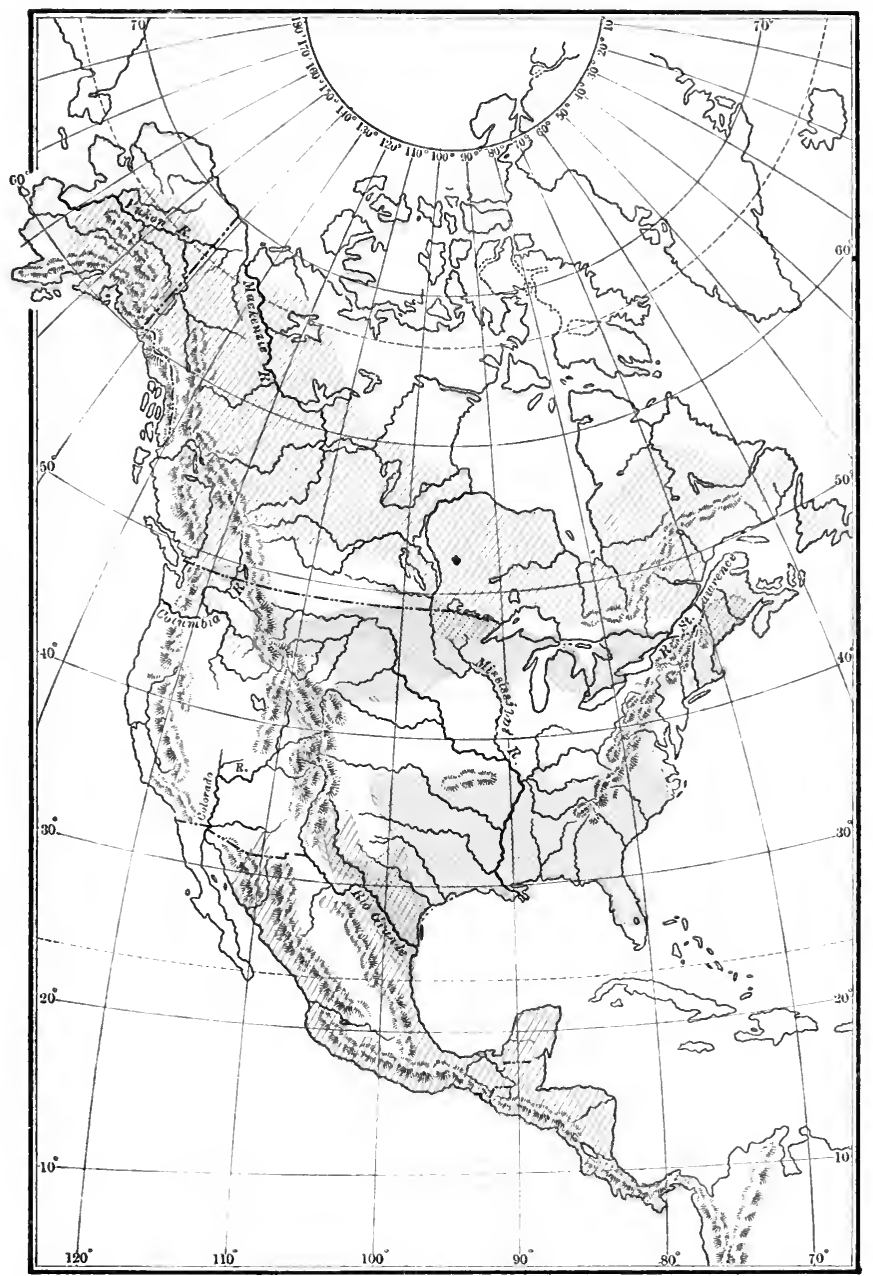

Fig. 231.-Distribution of the caribous, 'white-tail deer, and peccaries. The summer range of the barren-ground caribou is shown by blue; the range of the woodland caribou by bars of darker blue; the country of the deer by yellow; the country of the peccaries by red. 
abundant. In the Adirondack woods and the woods of Maine more than 10,000 deer are annually killed.

28\%. The southern lands--Here the animals, like the plants, change to tropical kinds. The tapir, jaguar, and many monkeys inhabit Central America and parts of Mexico. Armadillos and peccaries flourish as far northward as Texas, and opossums northeastward to New York. Brilliantly plumed birds and venomous serpents tell of more southern latitudes. Serpents of all kinds diminish toward the north, and are unknown in Alaska and northern Canada.

We must not omit the most abundant of all animals, the countless insect hosts that swarm from farthest north to farthest south. So, too, all fresh waters are full of life. Lakes and rivers teem with fish, and even the soil is honeycombed with the paths of earthworms or burrowing

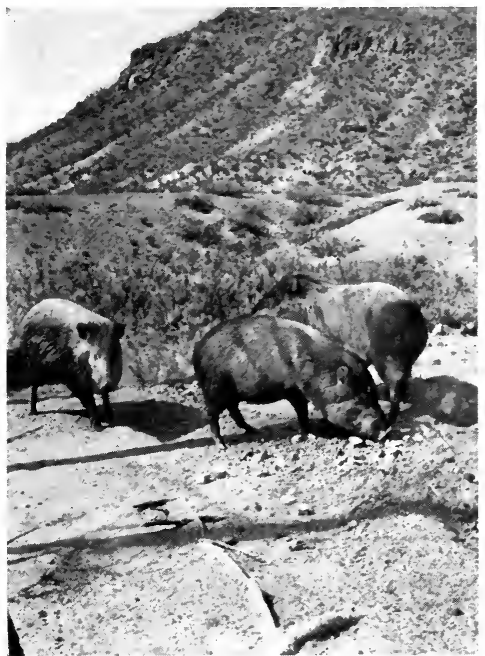

Fig. 232.- The home of the peccaries is in the thickets and forests of tropical lands. See Fig. 231. moles, gophers, woodchucks, and prairie-dogs. The continent is filled with animals and plants on its lands, in its soil, in its waters, and in the atmospheric sea that rests upon it. Each condition of temperature and each sort of abode has its own groups of living things.

We shall now study the principles that are illustrated by the plants and animals of our own or of any other continent. 


\section{Geographic Conditions of Life}

288. Temperature.-Neither plants nor animals can ordinarily live and be active in temperatures below $30^{\circ}$ or above $120^{\circ} \mathrm{F}$. They may for a time endure greater extremes, as when plants survive the low temperatures of winter or a man toils in a drying-room of some factory. Certain arctic animals are protected against great cold by coverings of fat and fur, and certain lowly plants live at higher temperatures in the waters of hot springs, but the range of $90^{\circ}$ above given is all that life can usually endure for a long time. As we have seen in studying the life of our own continent, the range is not the same for all forms; serpents and monkeys can not live in the arctic zone, nor polar bears and reindeer in the far South. Cotton belongs in the Gulf region, corn in the prairie and Middle Atlantic States, and wheat, overlapping the corn, will thrive far north in Canada, in regions too cold for the taller cereal. The life depends on the latitude, because the latitude determines the amount of heat. At the foot of the Rocky Mountains in Colorado is a mild climate, with bushes and cactus on the plains, with cottonwood along the streams, and with grain, alfalfa, and abundant fruits wherever the land is cultivated with aid of irrigation. Up the mountainsides are evergreen trees. Beyond the trees are alpine flowers, and above the flowers, rock, snow, and chilling winds. The same story is told if we ascend Mount Etna, the Alps, or any other lofty mountains rising out of a warm country. All grades of temperature, to those of arctic climes, characterize the different parts of a great mountain. Thus altitude vies with latitude in deciding how much heat a place shall have, and what plants and animals shall live and thrive. By shedding their leaves, or by the annual death of the open-air stem, plants may endure great cold in winter. By natural or artificial covering, animals, including man, provide for extremes of temperature; but 


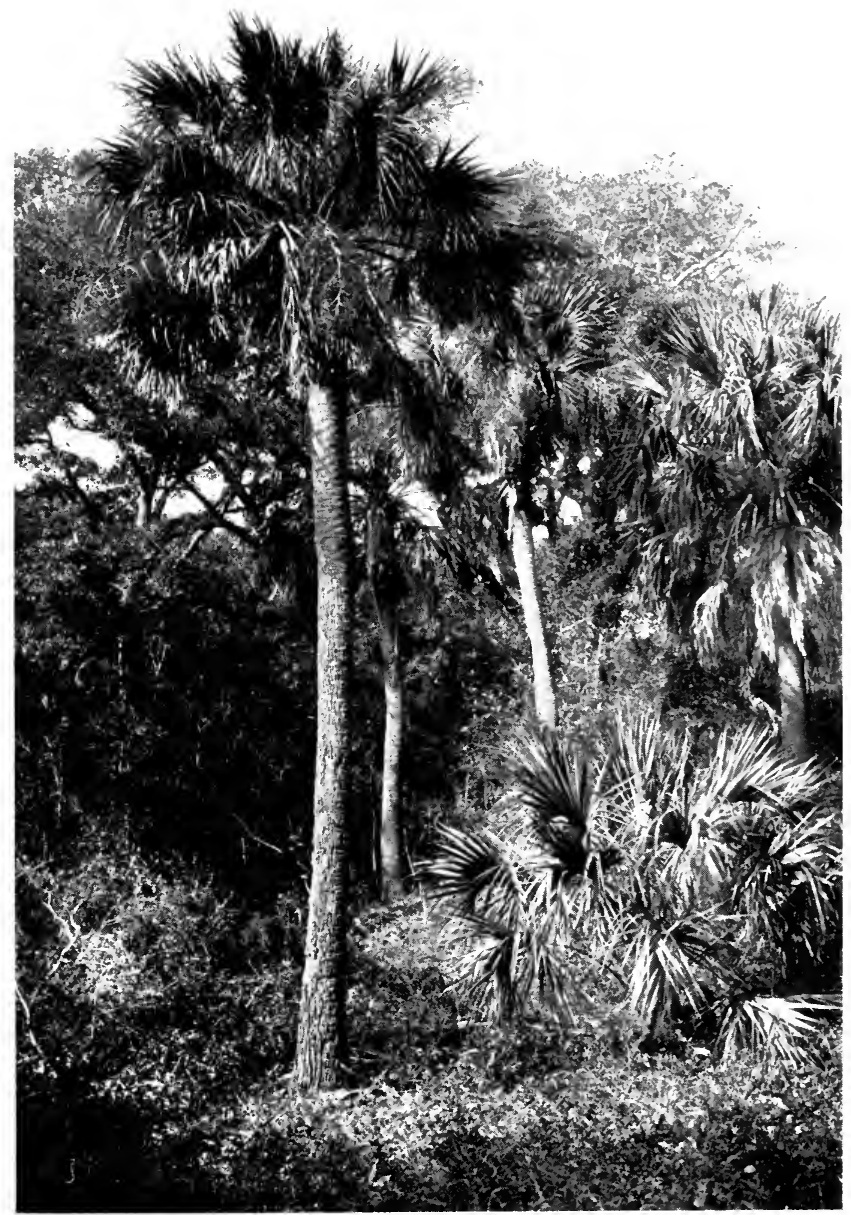

Fig. 233.-A palmetto grove. Most of the palms are tropical plants; but the palmetto follows the Atlantic coast northward to North Carolina. It is the chosen emblem of South Carolina. 


\section{AN INTRODUCTION TO PHYSICAL GEOGRAPHY}

heat and cold decide largely what creatures shall fill a region.

289. Water.-No life can be carried on without water. The greater part of all animal bodies, and of many plants, is water. It supplies food, or it serves as a moving fluid to carry food to all parts of the body-as the blood of higher animals and the sap of trees. We have seen that plants in particular show the greatest differences in respect

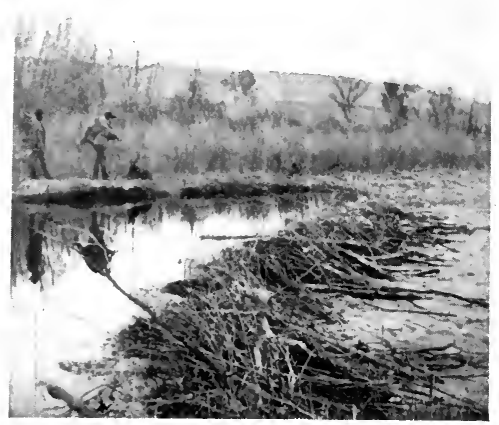

Fig. 234. - Dam and pond made by beavers; Wyoming. The beaver makes his home in streams and uses great skill in controlling the water to suit his needs. to water. Some live in the desert, others in places of alternate moisture and drought, others root in moist soil, and yet others are partly or wholly covered by water. The cactus sends out spines instead of leaves, and grows a stocky trunk, to avoid breathing all its water into the dry air. The tree braces itself with many roots, rises high and strong into the air, and requires a moderate supply of water. The water-lily has a limber stalk and a limber leaf, because the water bears both up, and the water and wet soil below it nourish the plant. With the most heat and the most water we find the most luxuriant plant growth of the world-the tropical forest. With the most heat and the least water we find the opposite conditionthe desert.

290. The atmosphere.-This is essential to all life. In a general sense all creatures "breathe" the air. The higher 


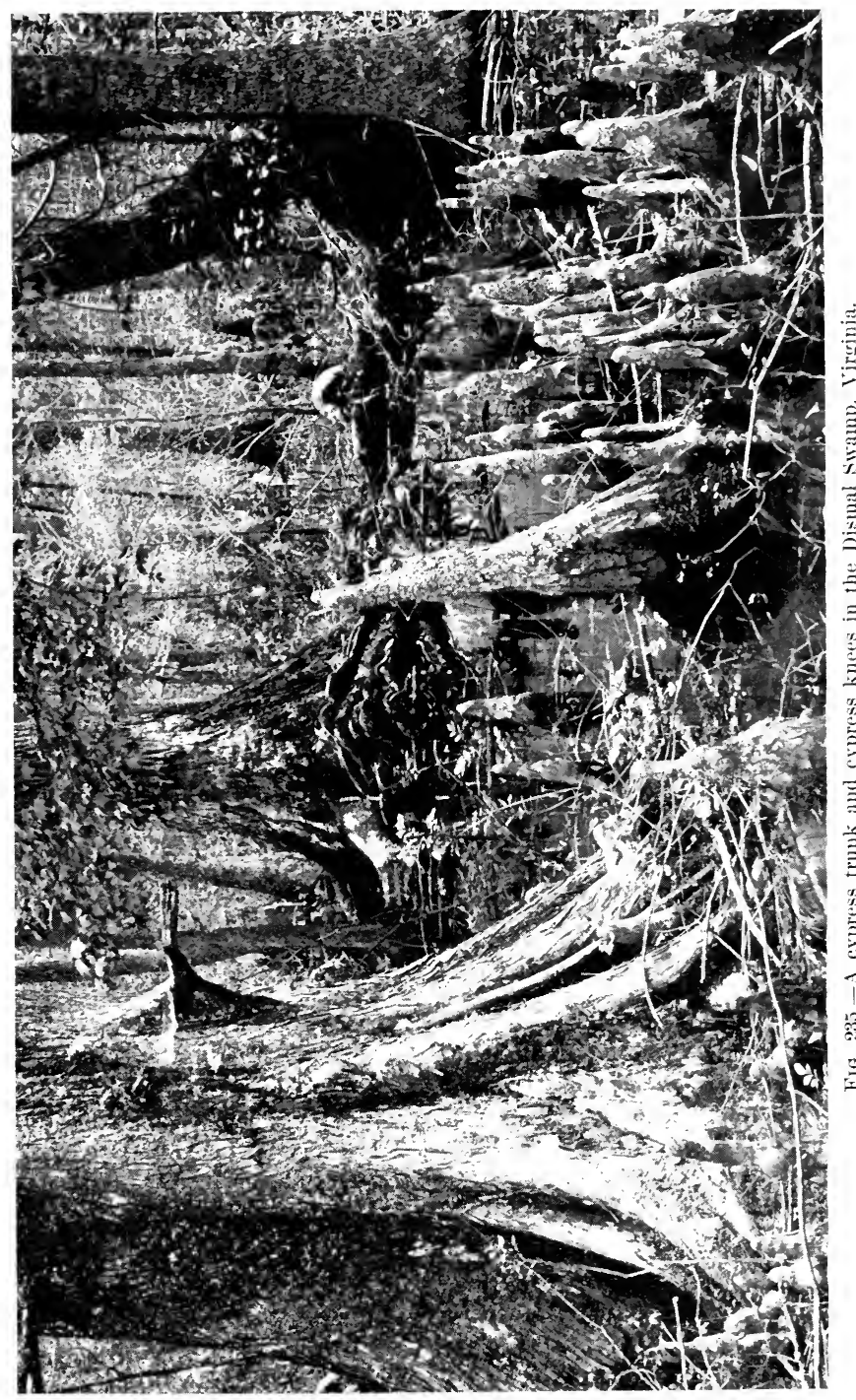




\section{AN INTRODUCTION TO PHYSICAL GEOGRAPHY}

animals have various devices, such as lungs and gills, by which they take in large amounts. Man and the other warm-blooded animals use by far the most, but all lowly animals and all plants must have air, and have some means of absorbing it. This is true even of those that are covered by water, and at great depths. At the bottom of the sea, for example, air is present, though in minute quantities. The roots of the swamp-cypress illustrate a special device. They are in submerged soil, and send up short, blunt extensions known as "knees," above the water surface. If the water is raised to cover the knees, the tree dies, for it is the work of these parts to receive air, which otherwise can not reach the roots.

291. Light.-This is required by nearly all life and by all high forms. The higher plants can not live without it; submerged, plants survive with a partial supply. The dependence of plants on light is illustrated by the pale and feeble growth of vegetables in a cellar, even thongh moisture and heat be fully supplied. Thus we may explain the appearance of close forests, in which each tall, bare trunk bears a canopy of limbs and leaves like an umbrella. As the tree grows, the lower branches, condemned to the shade, die and fall off, while the top branches thrive in the sunlight. The arrangement of branches on a trunk and of leaves on a branch is such as to expose the most leaf surface to the sun. Exceptions to the general rule are found in burrowing creatures, like moles and earthworms; in cavern fishes and cavern insects, surviving for generations in the darkness, and partly or wholly losing their eyes for lack of use; and in creatures in the depths of the sea, where sunlight does not penetrate, and darkness is only relieved by such phosphorescent glow as their own bodies can furnish.

292. Soils. - The plant groups on land depend directly on the soil, in connection, of course, with the supply of heat and water. Some soils contain calcium carbonate, others are of clay, and some are almost wholly made up of 
sand. Sand supports but a partial covering of plants, as the scant grasses and scrubby pines of dunes. The nature of the soil also controls the water supply. Sand parts with water too easily, while a clay soil holds it so tenaciously that artificial drainage by ditches and tile is often needed.

293. Climate.-This, as we have seen, is determined by many conditions of heat, moisture, and seasonal change, and plants and animals in any region must adapt themselves to these conditions, or migrate, or perish. Some plants, as certain mosses or lichens, may dry up entirely in a period of drought, and revive when moisture comes again. Many survive the winter by maturing in the autumn seeds which lie in the ground and sprout in the spring. Others, as many bulbous plants, die down to the surface of the ground, and the underground stem lives, to start the growth of the next season. Broad-leaved trees drop their leaves in winter, and quickly put them on again with the renewal of warmth. Evergreen trees have small, tough, enduring leaves, which are proof against the frosts of winter. Some animals lie dormant through the winter, neither eating food nor wasting the tissues of their bodies by aetivity. Birds, whose swift flight gives them independence, adapt themselves to the changes of season by migration to remote regions, all save those which have accustomed themselves to the pinch of winter and to living upon buds, and other supplies that do not fail.

294. Other animals and plants.-Heat, light, and air are hardly more important to a living form than the animals and plants by which it is surrounded. Animals find in other animals their friends and foes, and of plants we may truly say the same. Not less is it true that animals and plants influence each other, helping or destroying. Some illustrations of these relations will be given as we proceed.

295. Environment. - All surrounding nature is important to the plant. The earth, the sum and sky, and all living things about it, make up what we call the Environment, 
which is only a scientific word for the total surroundings of an animal or plant. We have just been studying the elements or parts of environment-namely, temperature, water, atmosphere, light, soil, and other living things. The environment largely but not wholly decides what a plant or animal shall be.

296. The tendency to spread.-Single plants usually ripen many seeds, and some plants mature them by hundreds or

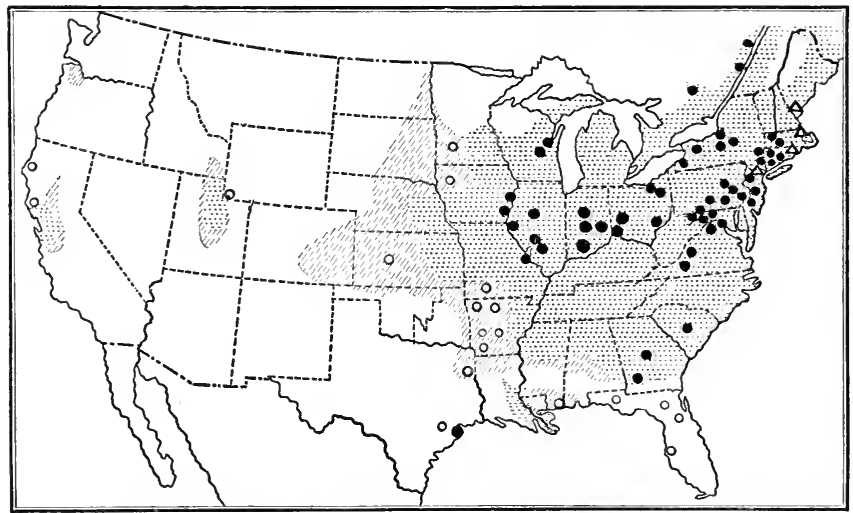

Frg. 236.-The spreading of the English sparrow. The large dots show places where the sparrow was introduced by man from 1852 to 1870 , and the small dots the country over which it had spread by 1886 . The circles show additional introductions to 1886, and the broken lines the extent of spreading from 1886 to 1898 .

thousands. We may say in a figurative way that every plant tries to occupy as much ground as possible, taking possession wherever there is an opening and pushing ont into wider fields, so far as soil, moisture, and other conditions are favorable. The same is true of animals. Thus the buffaloes multiplied until they virtually possessed the Great Plains. If a single pair of birds should be placed in a favorable region and no accident should happen to them or to their offspring, their descendants would in a few years be numbered by thousands and spread over a wide 
field. A heavy fine is said to be the penalty for bringing a white daisy into Minnesota. It might diffuse itself over the entire State, bringing untold harm to the farmer. A few years ago a foreign insect known as the gipsy-moth was brought into eastern Massachusetts. In the caterpillar stage it preys upon the foliage, and it has filled New England with alarm lest the trees be destroyed. Large sums have been expended by the State of Massachusetts to check its spread.

$29 \%$ The struggle for existence.-Thus we see how, if left to itself, any animal or plant would take possession of all the land or water where it could live, if it met no impassable barrier. But the space is limited, and so each group of plants as well as each individual has to contend with every other. The oaks can not fill the forest because the chestnut, ash, and maple are there. In a thicket of young maples, not all can grow up to be large trees. Those will win which have the best roots, the deepest soil, the best exposure to the sun, or suffer no injury from beast or man. Thus we explain what is meant by the now common phrase, Struggle for Existence. It is not usually a conscious strife, but it is the silent contest going on among competing plants and animals. Fishes produce vast numbers of eggs, part of which are devoured or otherwise perish, while the remainder hatch. But of the multitudinous "fry" only a small part arrive at maturity. Many die of accident, or from failure to get food, or fall a prey to other fishes, and out of such a "struggle" only the strong or the fortunate reach full size and live to their natural limit. In some regions the white oaks are said to be falling behind in the struggle with other oaks, because their acorns are more prized by squirrels and diligently sought by them. Thus by an innocent preference of the squirrel, one kind suffers and the others win in the struggle. Let us take again the case of the tree. A beech may produce thousands of nuts in a single season. These seeds are eagerly gathered by 
forest animals. If they escape this fate, they may germinate and drive a root into the soil. But even then, in the thick of the forest the chances are vastly against the sapling. Taking the seeds of plants and the eggs and infant offspring of animals, especially of lowly sorts, only one in many thousands is likely to produce a mature life.

298. Migration.-Animals and plants often succeed in the struggle for existence by migrating. All plants scatter their seeds somewhat, and some strew them broadly. The dandelion provides them with plumes that the wind may carry them, the burdock hooks them to the hair of animals, and there are many other devices. So each plant tends to increase its range and spread as widely as it can find suitable environment. When the cold of the Glacial period came on, each kind of plant found life harder at the North and easier at the South, and so, in the course of generations, its range was reduced on one side and extended on the other. Individuals were killed, but the race gradually migrated toward the south. The plant species which could easily send seeds southward survived, and any which could not migrate perished. This is the sense in which fixed plants can migrate-that is, from generation to generation. Land animals and free-swimming oceanic animals can migrate as individuals, and the birds, as we have seen, for the greater part, are in the habit of periodic migration.

299. Helps and hindrances to migration.-Some of the devices that favor the spread or migration of plants have been noticed. Such are the hooks of the burdock and the plumes of the dandelion. Other seeds have a hard covering which protects them against destruction in the crops of birds, and they may thus be dropped after being carried long distances. Seeds embedded in soil or mud are carried on the hoofs of beasts or the claws of birds. Since man has come upon the earth, multitudes of seeds-some good, some bad-have been diffused over the earth by him. Such 
is the so-called Russian thistle, whose roundish tuft of branches breaks off at the ground and is rolled and driven widely by the winds over the Great Plains. The restrictions upon the importation of fruit, meat, and other articles, by various nations, illustrate the human agency in distributing the germs of life.

Floating timber and roots may transport seeds, plants, and even small animals, for long distances down rivers, and even across seas. It has been shown that some seeds may live after long journeys in sea-water. This helps to explain how new islands in the ocean obtain a covering of plants. As we have seen, swimming and flying animals have an advantage. The beasts of continents can not reach remote islands unless carried there by man. But the birds are there, because they have the means of traveling over the waters, being often blown out by storms, and alighting there for refuge.

We have now begun to see that migration is hindered or prevented by Barriers. The sea is an absolute barrier to most land plants and animals. The wider the sea the completer the barrier. Hence lands with the same climates may have very different groups of animals. Thus in Australia, South Africa, and South America are found very similar conditions, but the animals and plants are different because there has been no chance for them to mingle, and each continent has developed its own kinds of life. Islands have a life of their own, except as migration is possible, or has been at some time possible, or the hand of man has interfered. So far as islands resemble continents in their animals and plants, they are like the nearest continents. The Galapagos Islands, for example, resemble South America, and the Cape Verde Islands, western Africa, in their life. Hawaii is far from large lands and has no large mammals or snakes.

Lands serve as barriers between seas, and hence the ocean forms differ on opposite sides of the Isthmus of Pan- 
ama. There is some likeness, however, and this shows that the waters have some time crossed where the isthmus now lies. So too the life of the Red Sea is not like that of the Mediterranean. The English Channel is a narrow water barrier between England and the Continent. It has not always been there, and in the days of land connection wild animals went freely to and fro, which explains the close resemblance of the native animals of Great Britain to those of the rest of Europe.

300. Dependence of animals and plants. - The animal and plant kingdoms belong to each other in many ways. First, we have the familiar fact that most of the higher land animals depend on plants for food. And beasts of prey, in devouring other animals, depend indirectly on plants for life. Vegetation is the only means by which the minerals of the soil can be changed into food for land animals-insect, beast, or man.

We have seen that by direct carriage of seeds or roots, animals foster the wider distribution of plants. But the botanist and zoologist know of many more intimate and curious ties that bind plants and animals together. Insects are protected by taking on certain colors, as the green of forest or meadow. Worms may mimic the color and even the forms of branching twigs, and thus escape enemies. The tiger is not easy to see in the jungle because its stripes confuse it with the upright lines of light and shadow of luxuriant plants.

We find also that insects and flowering plants have much to do with each other. Many plants would never be fruitful if insects did not drop the pollen of one flower upon the pistils of another. And insects and plants have become adapted to each other by this means. Some insects seek the pollen itself, and others seek the nectar of the flower for food, but in any case the result is the transfer of the pollen. Darwin describes a red clover which could not live without the visits of bumblebees; the honey- 
bees can not reach deep enough into the flower tubes to get the nectar. Hence any enemy that should destroy the bumblebees wonld make it impossible to raise this kind of clover.

301. Life of the ocean.- Some facts have been learned in previous chapters. The ocean has its regions and groups of forms as well as the land. Deep water is a perfect barrier

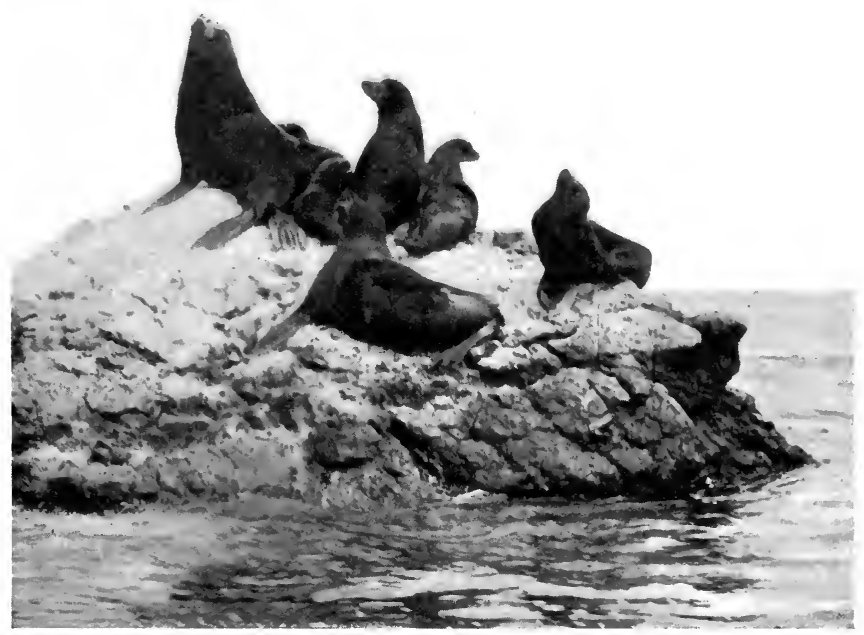

Frg. 23\%.-Sea-lions, Santa Catalina Islands, California. Thongh these animals are thoroughly fitted for the sea, and subsist on cuttle-fishes, it is thought that their remote ancestors lived on the land and resembled bears.

to shallow-water forms, and if they should migrate along the shores they might find warmer or colder water that would be fatal to them. Corals belong in warm seas, walruses thrive in northern waters, and each is as characteristic of its zone as palms and polar bears are of the land zones. The whale is a great specialized mammal, whose ancestors are believed to have lived on the land. It has developed its 


\section{AN INTRODUC'IION TO PHYSICAL GEOGRAPHY}

fore limbs into paddles and its tail into a powerful rudder, but has only partly become fitted for life in the water, for it must come to the surface to breathe. It has a wide range in the sea, but its numbers have been reduced by man. A whale was, in the autumn of 1901, reported as having strayed up the St. Lawrence as far as Montreal.

Oysters, clams, scallops, and other so-called shell-fish inhabit the shallow waters near the shore. These shelled creatures (mollusks) exist in enormous numbers and have

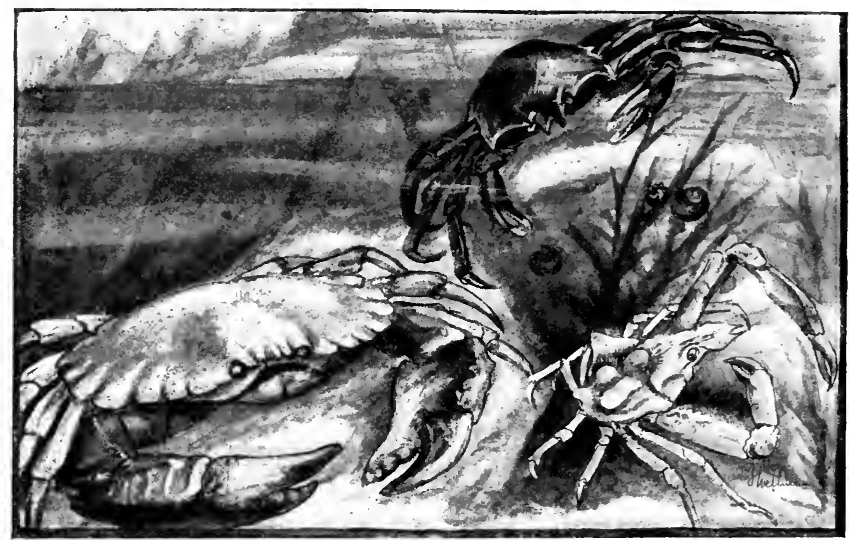

Fig. 238.-Crabs living in shallow water of the ocean; the kelp erab, in upper part of figure; to the left the edible erab ; and to the right the shore crab.

shells of great variety of form, especially in tropical waters, where ornamentation of form and color has its highest development. With them are starfishes, thorny sea-urchins, and the more active lobsters and crabs. The product of the seas most important to man is the fish. The shoal-water fishes and the deep-sea fishes furnish the study of a lifetime to any one who would know them well.

Let any one go into what we call the silence of forest or open field and watch and listen. It is a world of sights and sounds, of living things. Or let him wander by the 
seashore, and look into the pools that the ebbing tide leaves, or see what the waves cast up. The sea is full of life also.

If we would know something of the living world, and would understand what it means, we must also learn that all creatures have come down from a remote past, and that the ancestors of herb and tree, of mollusk, serpent, bird, and horse, are buried in the rocks. This opens the realm of geology, which ever forms the background of geography. 


\section{CHAPTER XVI}

\section{THE EARTH AND MAN}

MaN is more widely scattered over the lands than any other animal. He is not confined to single continents or to separate zones, although some races or tribes have become specially adapted to hot climates and others to cold regions. The man of temperate latitudes, by his greater intelligence, is able to live and work for years in the arctic or in the tropical regions. Man may not live among the rocks and snows of the highest mountains, in the driest and hottest deserts, or on ground covered by a great glacier, as central Greenland. He may, however, visit all these places. The only regions where, so far as we know, man has never lived. or journeyed, are those nearest the poles. He has so accustomed himself to safe and prolonged travel upon the ocean that he may almost be said to occupy the great waters as his home. Like the plants and the other animals, he depends on a variety of conditions which make up his environment.

302. Food.-Here we have the most important relation which our kind holds to the earth. There was a rude, primitive man, living in ages now long past, who, in simple ways, got his food from the life that was about him. There were herbs, shrubs, and trees, producing nuts and other seeds, wild berries and other fruits, and affording, beneath the surface of the soil, juicy stems and roots which could be dug by fingers or sticks; and various small animals could be caught for flesh. At length rude implements of chase were invented, such as flint arrows and fish-hooks of bone, 
and the flesh of larger animals was added to the food supply. Flint knives, ehipped and rough, served to skin the animals, and as the arts of fire were learned cooked food began to be used.

In a gradual way, through the ages, foods multiplied, until now the world is ransacked to provide for the table of a civilized household. Wild plants were eultivated and were improved, until, in many cases, all traces of their original condition were lost. By constantly seleeting the best,

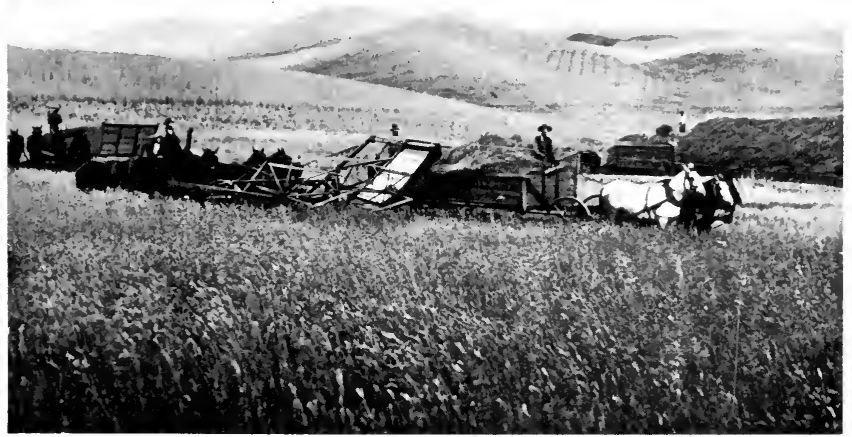

FIG. 239.-A wheat-field in Washington. Reaping and loading by machinery.

and by tilling and enriching the soil and removing other plants, the various grains, fruits, and vegetables familiar to us have been developed. Rocks weather into soil, water moistens it, the sun heats it, a seed is provided, a plant spreads its leaves in the air, and by its roots, stems, or fruit man lives. The great foods of temperate regions are the cereals or common grains. Wheat is one of the most widespread. Its origin is unknown, but it is now grown on the plains of Russia, the prairies and plains of the United 


\section{AN INTRODUCTION TO PHYSICAL GEOGRAPHY}

States and Canada, in South Ameriea, Australia, and other parts of the world. Maize, or Indian corn, is a native of America, requires a warmer elimate than wheat, does not thrive so far north, and is one of the most important grains of America and of other

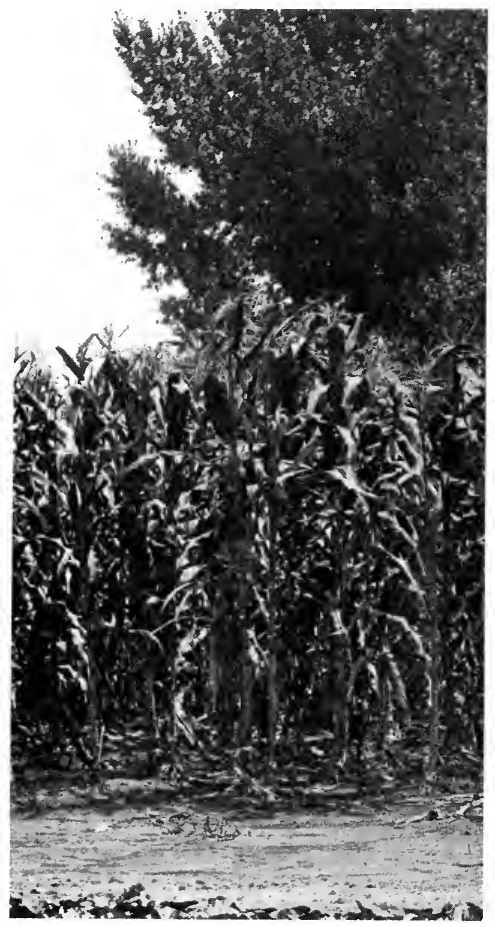

FIg. 240,-Maize. lands as well. Barley, rye, and oats agree in their adaptation to the cooler temperate climates of the world, as in Canada, northern Europe, and Siberia, and each in certain regions is the most important food plant raised by the people.

Rice, grown in many lands where heat and moisture abound, is the chief food in vast regions. In China, Japan, India, and the East Indian islands $500,000,000$ people live mainly upon it. Other plants which thrive in warm lands offer an abundant food supply obtained with little labor. Here belong the fig, the various palms, and the breadfruit. The temperate regions also have their improved fruits, such as the apple, pear, peach, and many berries, all derived from wild ancestors. The potato is the most important example of a tuber or underground stem used for food. It is a native of South America, has spread to other 
continents by the hand of man, and sometimes, as in parts of Ireland, forms the principal article of food. A great variety of plants could be named from which stimulating drinks are brewed or distilled. Such are tea, coffee, the saps of various plants, many grains, and many fruits. Here also reference may be made to the wonderful diffusion of the growth and use of tobacco in modern times.

303. Animal food. -We have seen that the early man sought to take fish and to pursue wild animals as his prey. With increasing skill he secured much game, as did the American Indian, with his use of bow and arrow. In course of time fishing became an art pursued by thousands of men

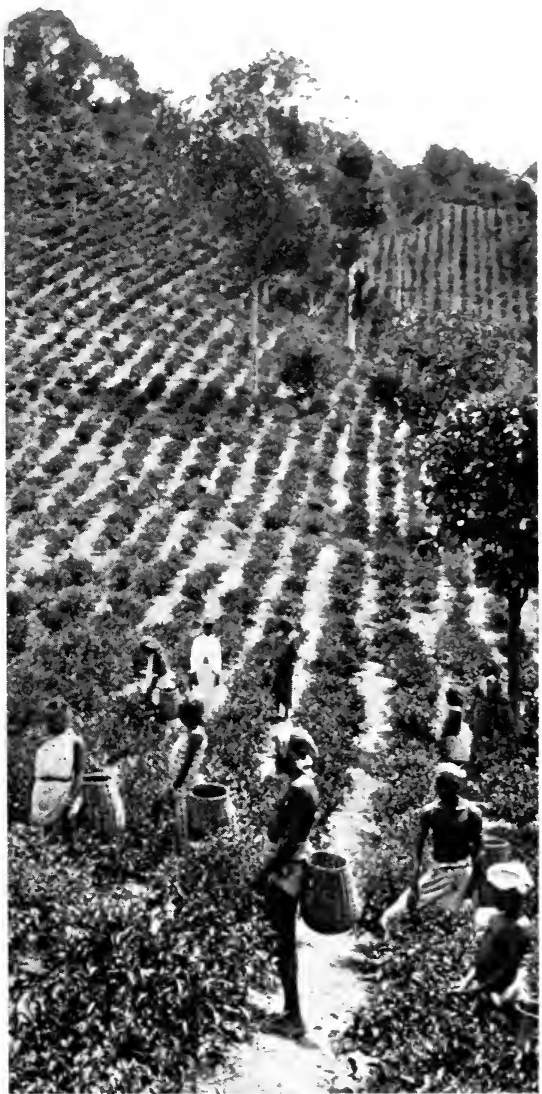

FIG. 241.-A tea-plantation in India. The gathering of the leaves. on lake, river, and sea, and the coastal tribes and peoples have always thus obtained much of their food. Other 


\section{AN INTRODUCTION TO PHYSICAL GEOGRAPHY}

marine animals, like the oyster and lobster, add their part to man's support. But most important of all have been the domesticated animals, from the time when Oriental tribes had their chief wealth in flocks and herds, down to the present day of great stock-ranches, stock-yards, and refrigerator-cars. Scarcely second to the flesh food are eggs and dairy-products of every kind. It is convenient here to observe that water and common salt are the only mineral or inorganic substances habitually taken into the body by man.
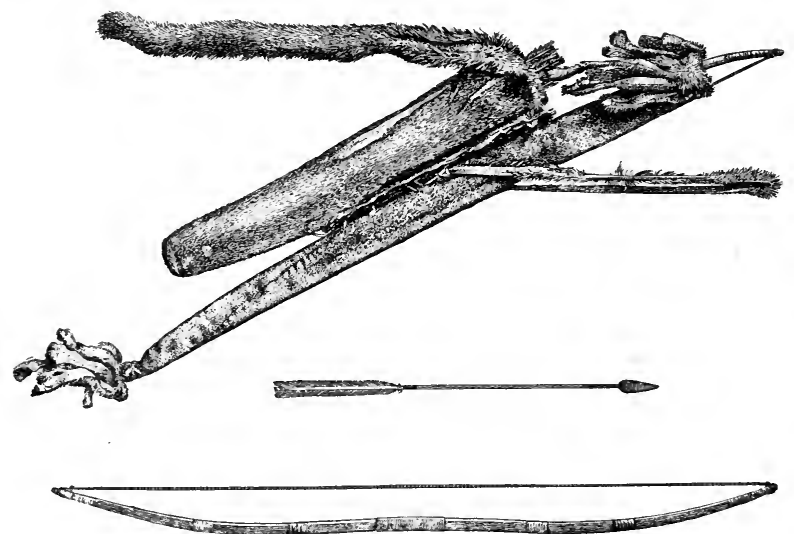

Fig. 242.-Bow, arrow, and deerskin quiver of a Navajo Indian.

304. Clothing.-In covering and protecting his body man is brought into another set of relations to the earth. The earliest men were probably unclad, and to the present time little clothing is worn by savages living in warm climates. The earliest garments were rude mantles of skin taken from animals, or fringes or plaitings of reeds and grasses. Then came primitive weaving, practised somewhat even among wild tribes like the American Indians. Instead of wrapping skins about the body men began, like the Eskimos of to-day, to cut and sew them. The last stages in the growth 
of dress bring us to the highest arts of the loom at the present time. Here the animals and the plants contribute almost equally the fibers for cloths of every sort. Chief among plant fibers is cotton-that is, the silky hairs which clothe the cotton-seeds. It is cultivated in the warm belt extending around the globe. It was known in ancient times, but does not go back to the earliest days in Egypt or China. It is one of the few commercial products of supreme importance. Flax furnishes another vegetable fiber, well known in linen and laces, and often used for sails and twine. It thrives in a wide range of temperature, north and south, and was used in remote times. The coarser fibers of hemp, jute, and manila, which we know chiefly in cordage, still serve primitive peoples for clothing. The wool of sheep is the most widely used of all animal materials, especially in

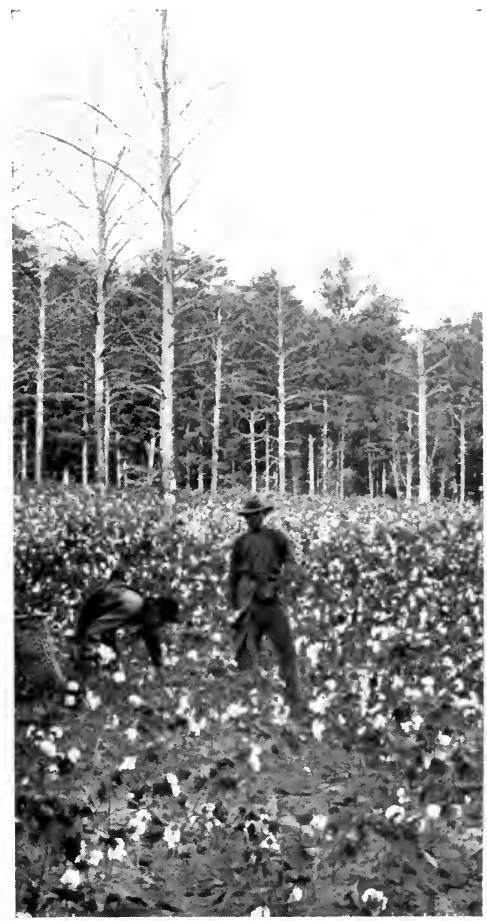

FIG. 243,--Cotton-picking in Georgia. temperate and cold latitudes, and the fibers of the silkworm furnish the most delicate fabrics that the art of man has produced. Gradually perfection has been reached in the tanning of skins, particularly for foot coverings; and furs are the necessity of arctic peoples and the luxury of 
dwellers in lower latitudes. The feathers of birds have long furnished favorite ornaments, and man also draws directly from the earth the lustrous and rare minerals that he calls gems and the variety of objects for personal adornment that he makes from the precious metals.

305. Tools and utensils.-Man is the only animal that contrives tools. First he chipped stones into arrow-heads, spear-heads, and knives. Then he ground and smoothed them, and tied stones to sticks for axes. He cut bone into scrapers, awls, and needles, and beat masses of native copper into useful shapes. His great progress came when he learned to extract metals from ores and could fashion hard and sharp instruments of iron. Thence the unfold-

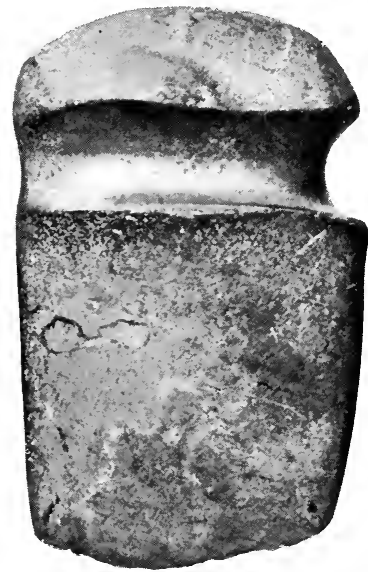

Fig. 241.-A stone ax made by North American Indians; one-half actual size. The groove is for tying on the handle. ing never stopped until the intricate machinery of to-day was contrived. In early days men wove twigs, roots, and leaves into baskets and other receptacles (Fig. 258). They found also that they could mold clay into useful vessels and bake it, so that it would resist the influence of air and moisture (Fig. 259), and this has led on to the making of plastic objects as delicate and beautiful as jewels. Another mineral, the quartz of every bed of sand, provides many of the most ornamental as well as useful receptacles, those made of glass.

306. Shelter.-Here our dependence upon the earth is as close as it is in the supply of other needs. Caverns were perhaps the first shelters, requiring no invention. The forests served as a roof, relieving the sun's heat and the 
force of winds, but offering little barrier to rains and chilling snows. Huts of boughs, thatched with leaves, perhaps came next, and in colder lands dugouts in the earth or walls of turf and rough stones, with roofs of skin. Very early stones were dressed, and the temples of Assyria, Egypt, Mexico, and Peru prove that skill to quarry and build is of no modern growth. Iron tools made it possible to use the wood of the forests, to hew, saw and mortise it, and thus to provide cottages for the poor and palaces for the rich. The molding of bricks and the arts of carving, plastering, and painting made more complete man's mastery of the earth for shelter and a home.

30\%. Fuel and light.The farther north or south from the equator man lived, the more he found fire a necessity, if he was to lead better than an

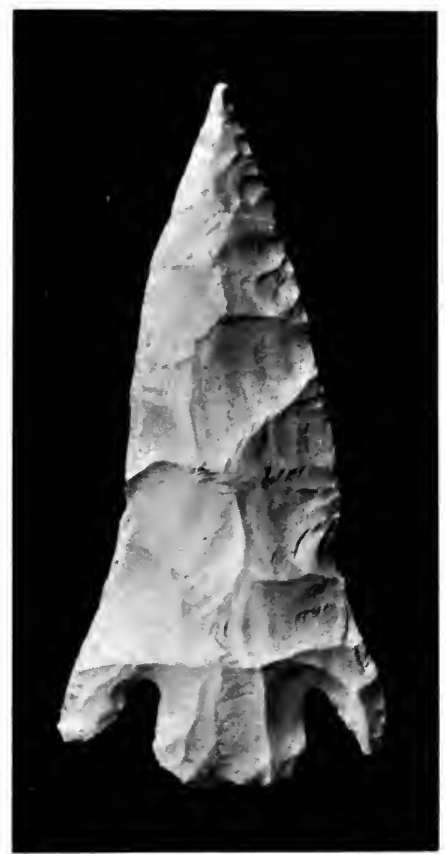

Fig. 245.-A spear-head of flint; actual size. Made by Osage Indians, Indian Territory.

animal life; so the supply of fuel became an important problem. For a long time the forests were ample, until increasing population and foolish destruction of trees had partly exhausted this supply. Fat and animal oils took the place of wood in cold latitudes. Then coal was found, which is a supply of woody matter and of mosses, leaves, and seeds stored away in ancient forest beds and 
gradually changed to black mineral. In a few regions natural gas can be obtained for heating by boring down into the rocky layers.

Light, too, was needful to prolong the day, especially in temperate and arctic regions, where the winter nights are so long. Fats and animal oils, as of the whale, were first used, then gas distilled from coal, and oil from the

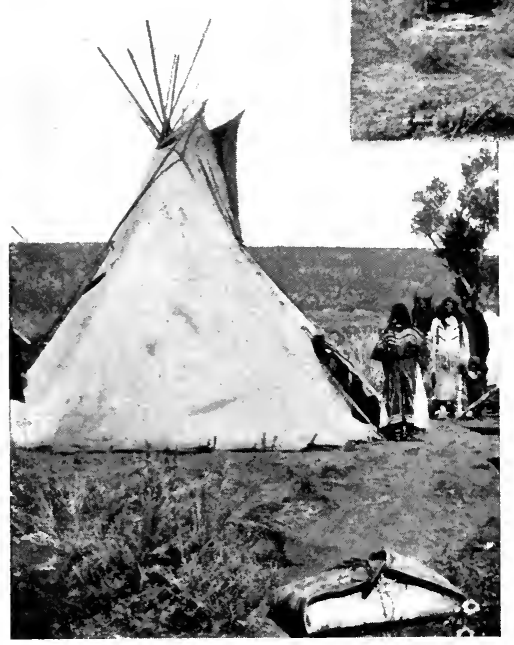

Fig. 24\%-A tepee, or Indian skin tent; Wyoming.

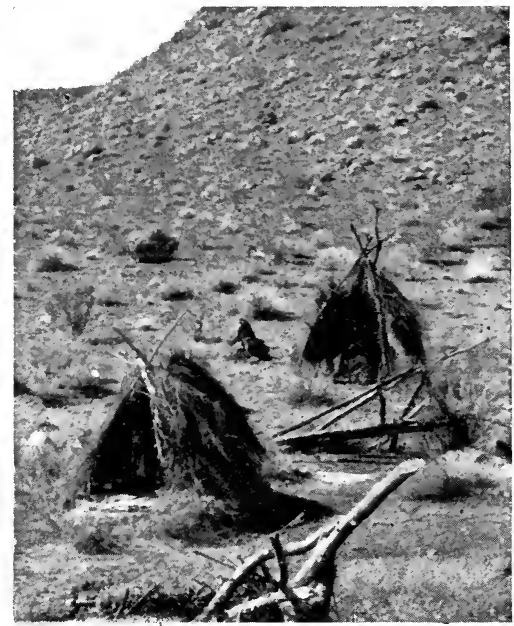

Fig. 246.-Brush shelters used by Indians of southern Utah.

refining of petroleum, and now has come the cleaner, safer, and more brilliant lighting by electricity. First man lived by light of sun, moon, and stars alone; then he used the oil of creatures now living, until he found the oil of creatures and plants buried for ages in the rocks; and finally he turus to one of the great forms of physical force for his illumination. 


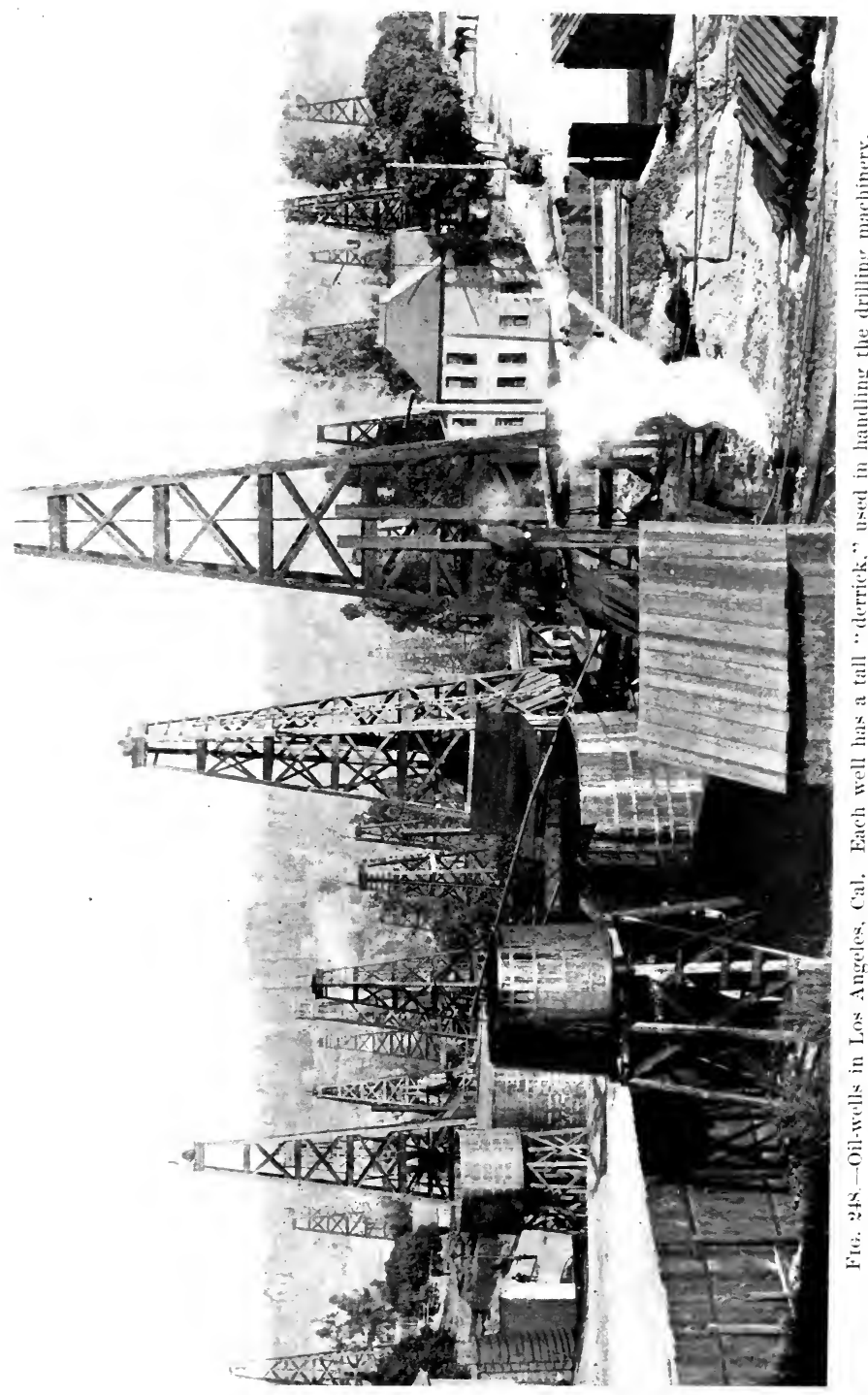


308. Travel-Let us now see how man has used the earth in moving about upon it. First he traveled by his legs and feet, needing no invention. Across rivers he might swim, but over lakes and arms of the sea he must be floated

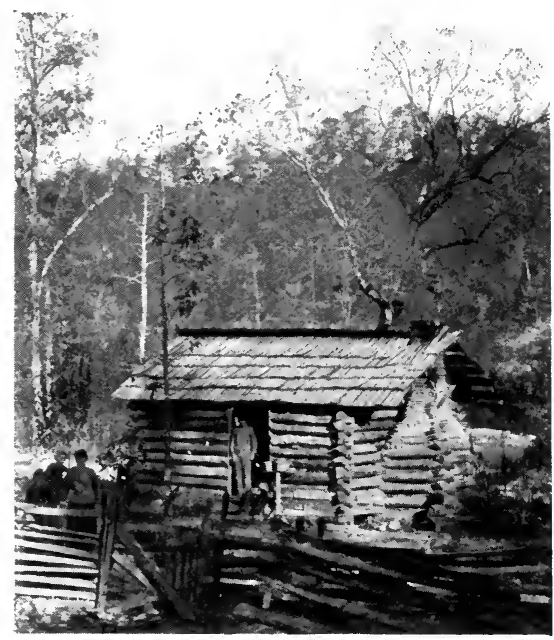

Fig. 219.-A $\log$ cabin and rail fence; Cumberland Platean.

if he went at all, and for this the dugout and bark canoe were devised. With the domestication of horse or ass, he mounted and rode, and by and by a rude harness and sledge or simple wheeled vehicle advanced him farther in the arts of travel. Then progress was steady, from the paddle to the sail, and at length to the propeller screw; and on land, from the

sled and wagon to the steam-car and the electric carriage. Navigation of the air must be counted as yet in its beginnings.

With the invention of vehicles has gone the making of roads and the opening of routes once thought impracticable. Fifty years ago the United States Govermment carried several lines of survey across our western mountain ranges, to see where railways could be built to the Pacific coast. The Colorado route, where now several railways cross, was pronounced impracticable. Northern Asia, once a region of a few wandering tribes and of convicts, is now opened to the world by the Siberian Railway, linking St. Petersburg 


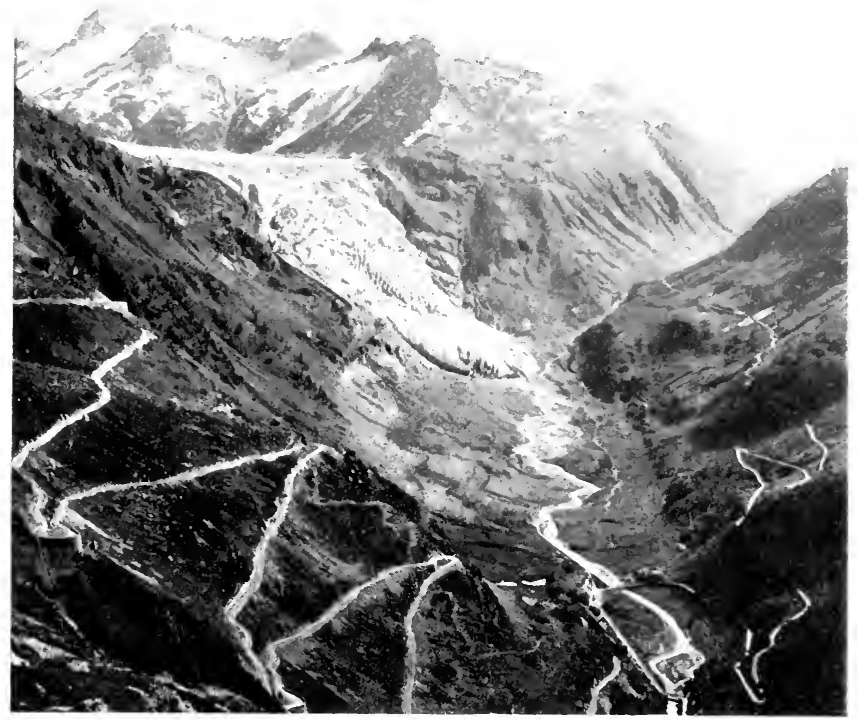

Fig. 250.-A carefully graded carriage road. winding up from the Rhone valley to an Alpine pass. The view shows also the work of glaciers. (See pages 124 and 141.)

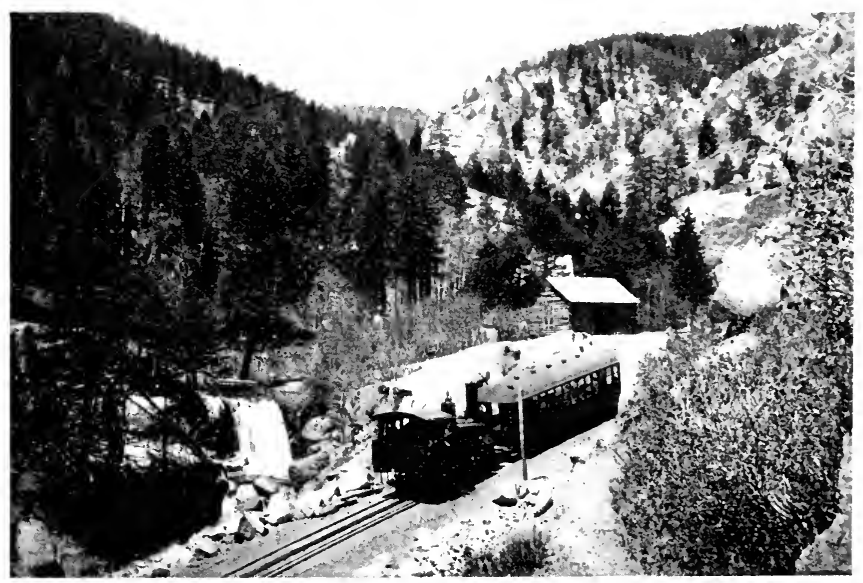

Fig. 251.-The cog railway from Maniton to Pikes Peak, Colo. Even for climbing mountains machinery is taking the place of muscles. 


\section{AN INTRODUCTION TO PHYSICAL GEOGRAPHY}

and the Pacific Ocean. Another railway is projected, from Cairo to Cape Town, to make a highway throughout the length of the African continent. Rivers and lakes have made a great network of inland navigation. Man covers the gaps between these natural waterways by making canals, storing water at the summits, and letting it down by locks through a succession of levels. All valleys invite men to easy routes of travel. The trails which lead among hills and mountains are followed by graded roads for the removal of ores or timber, and often by rails of steel over which roll trains of laden cars. In his travel, as in providing shelter, raiment, and food, man is closely linked to the earth, but more and more uses it with triumphant skill and power.

309. Communication and record.-If the early man sent a message, he told it to his fellow, who carried it to its destination. Or, if he desired to record some story of his experience, he made a rude picture by bruising or scratch-

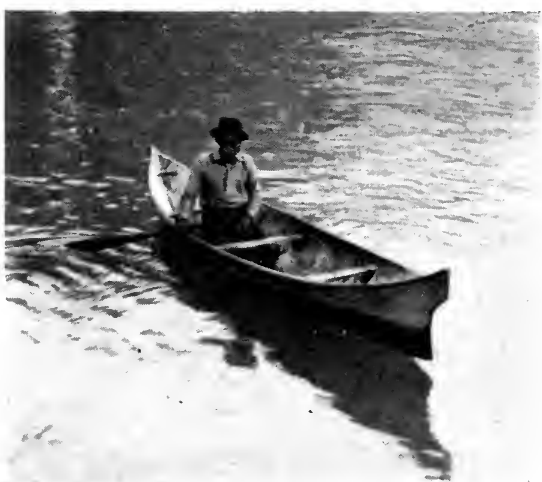

Fig. 252.-A dng-ont, a boat carved from a $\log$ and propelled by a paddle; Alaska. ing the face of a cliff. Picture language in time became elaborate and was written on rude paper called papyrus, or carved on stone. Such records are now eagerly sought by students of ancient history in Oriental lands. Out of picture signs grew letters, and picture-writing was followed by alphabetic writing. Manuscript letters and manuscript books were succeeded by printed books, by newspapers, and 
in these later days by the electric telegraph and the telephone for swift communication. As wonderful, if less swift in its operations, is the modern postal system, covering all civilized lands and bringing messages of friendship and of business to the door of many millions of people.

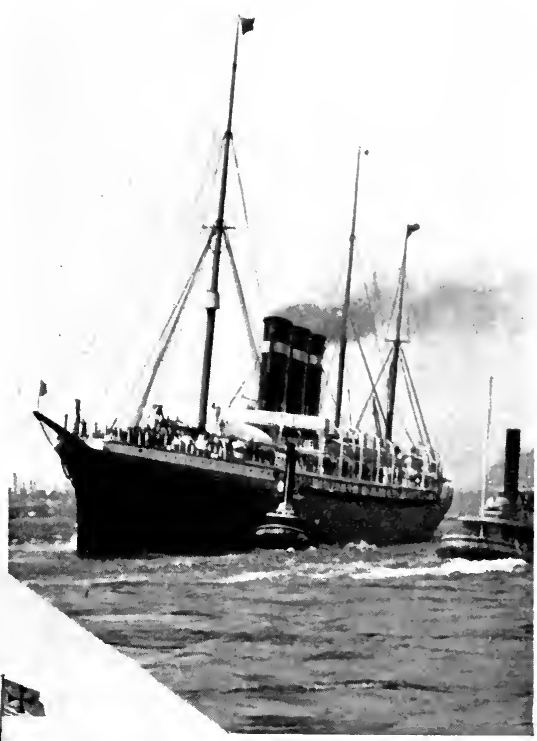

F19. 253.-The modern steamship - the City of New York.

INFLLEXCE OF ENvironment'

We have seen how man satisfies his wants by using the minerals, plants, and animals of the earth. It is also easy to see that he meets these wants in different ways, ac- 


\section{AN INTRODUCTION TO PHYSICAL GEOGRAPHY}

cording to the kind of country in which he lives. Warm and cold climates, deserts and forests, coast lands and

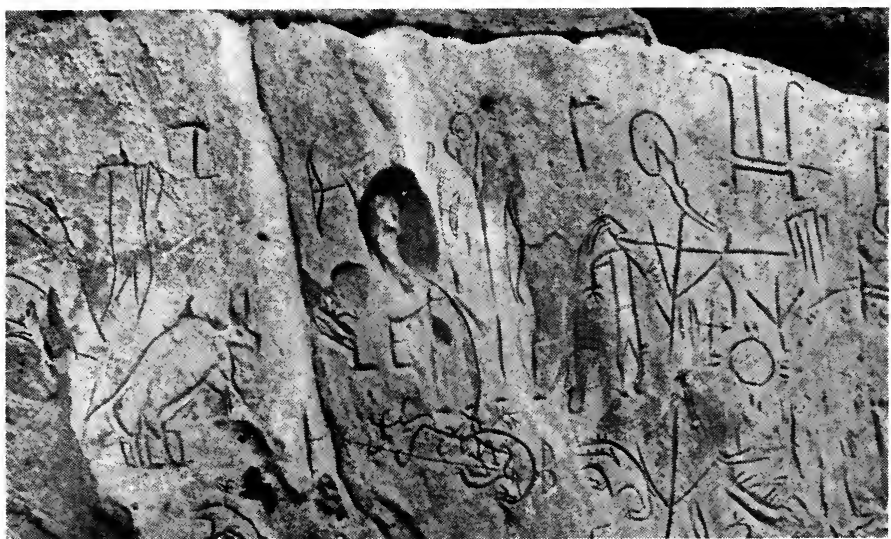

FIG, 255.-Rock-carvings by Indians of Nebraska; a pictorial record of events.

interior lands, all influence him and change him. This is the work of environment, and we shall now select

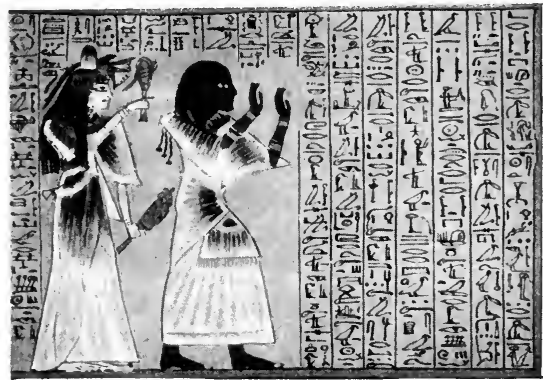

FIG. 256.-Picture-writing; a stage in the development of letters. The Book of the Dead, of which a page is here copied, was written by ancient Egyptians on papyrus.

several sorts of environment, and see how man thrives in each. 
310. Life along arctic shore-lines.-Here the sea is of first importance. 'The fishing and hunting of walruses and seals are the main occupations, and almost the only means of maintaining life. Houses are built of earth or snow. Skins are the only clothing, implements are fashioned from bones, fat must serve for light and heat. A bare struggle for animal existence makes up nearly all of life, and the higher cravings of human nature are unknown. Only a single race, the Eskimo, has become fitted to this severe environment.

311. People of the northern deserts.-These lands stretch south from the polar seas, and are covered with snow most of the year. The soil is always deeply frozen except a few inches at the surface in the short summer. Such regions are found in Alaska, British America, and Siberia. In the summer many herbs and a few stunted wooded plants put forth leaves and blossoms.

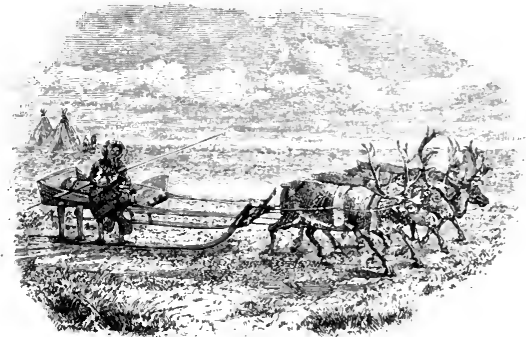

Fig. 257.-Life on the Siberian plain. A Samoyed sled drawn by reindeer.

Mosses abound, on which the reindeer feed. The people can not live in villages or settled homes, for they must move to get food. They can not till the soil, for crops will not ripen. A few leaves and berries are the only plant food. Fish and the milk and flesh of reindeer are their chief dependence, and the fish must be diligently sought and dried during the short summer. Life is in tents, often moved, and is nearly as barren as that of the Eskimo.

312. Temperate forests of North America-Here lived Indians. They were hunters and fishers, but depended 
largely on seeds and fruits of wild plants, and many tribes had the beginnings of agriculture. Some, as the Pueblos of the southwest, lived in permanent villages, with well-

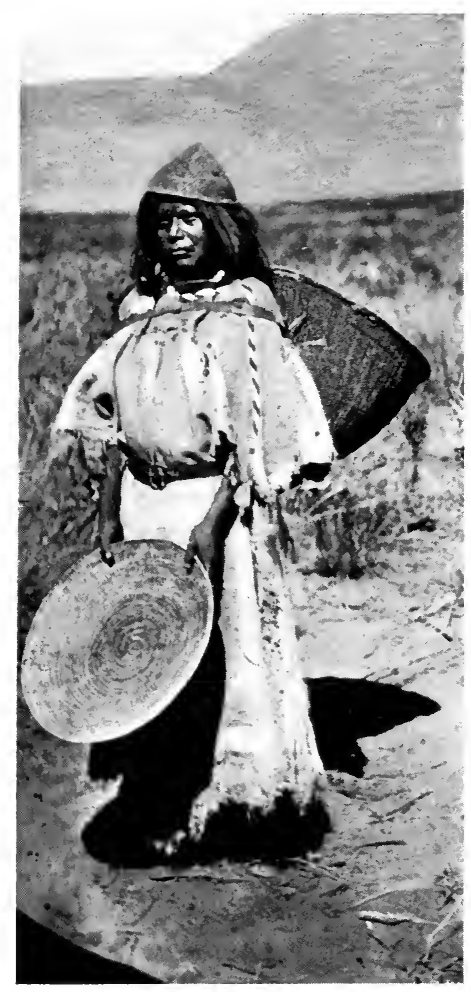

FtG, 258.-Indian basketry. This Indian woman of Utah. clad in buckskin, has a carrying basket, a basket for wimnowing seeds, and a basketry cap. built houses of stone; others were more or less migratory, making temporary shelters of boughs and bark, or portable tents of skins. They were expert in basketry and pottery, but knew nothing of iron, and had trained no animal to their service. They dwelt in a land which was able to nourish a far higher society, and upon which, during a short occupation by a more advanced race, the highest type of human life has established itself. Such a forest region gives us at first the savage, next the trapper, then the pioneer farmer, laboriously elearing the trees from a few acres to make space for field and orchard. Gradually the forests melt away, roads are built, cities grow, and all the signs of eomplex civilization appear.

313. Tropical lands.-No single deseription will suffice for man's use of the earth in warm countries. In general 
we may say that continued heat makes man less active and keen than in the temperate lands, and more disposed to a sluggish reliance on the gifts of nature. These in turn are often abundant, nuts and fruits growing freely, and nourishing man without effort on his part. At the same time the warmth enables life to go on without much shelter or clothing. Hence there is little incentive to endeavor, and the tropical races, as a rule, do not use the earth wisely, or make progress in the higher arts and occupations.

In hot deserts, as the Sahara, conditions are quite different. Life there requires activity and struggle. Oases - rare spots where abundant water makes the soil fertile-

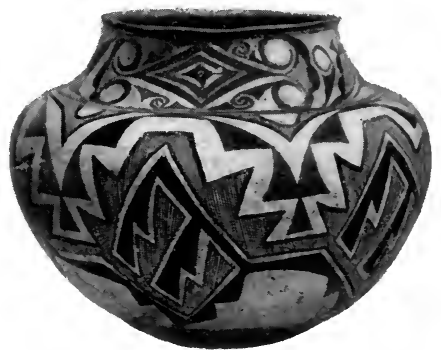

Fig. 259.-Indian pottery. A water jar made in the Pueblo of Zuñi, New Mexico. are planted with datepalms, and yield much food. But the broad face of the land bears so scanty a growth of grasses and herbs that it can give support only to herds which continually move from place to place. So life is chiefly pastoral and migratory. It is also in part commercial, because the desert, like the ocean, is a barrier which must be crossed to exchange the products of richer lands on either side.

314. Man in temperate climates.-Let us think of such a region as the United States or central Europe. By reasonable toil abundant food can be drawt from the soil, hence the wandering life of the hot and cold deserts is unnecessary. Man has time to make a home and to gather about him its conveniences and refinements. The struggle to live is not so severe as to make his life barren, but enough effort is needed to keep him in the ways of strength and growth. If he till the soil, he must be diligent in summer, 


\section{AN INTRODUCTION TO PHYSICAL GEOGRAPHY}

to provide food and other supplies for winter. If he do not cultivate the earth, he must busy himself with products which he can exchange for food and his other necessities. In temperate latitudes more than elsewhere, civilization has developed division of labor. Primitive or savage men have few needs, and each one must meet them all. Civilized men have many needs, and they satisfy them by working for one another, and exchanging the work of their hands.

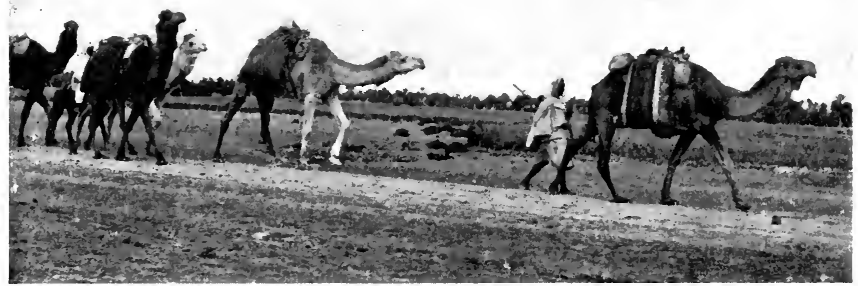

Fig. 260.-The commerce of Sahara is by means of caravans-long lines of laden camels.

The cold and poverty of the north, the heat and plenty of the tropics, do not blight human life in the countries that lie between. Temperate climates have produced the inquiring, daring men, who have sought out the unknown parts of the earth, and set going the machinery of commerce everywhere.

We learn in our study of history of great migrations of tribes from Asia westward into Europe, and sonthward and westward in Europe to the Mediterranean and the Atlantic. Early English history is the story of the Roman, the German, the Dane, and the Norman pushing into the British Islands. The settlement of America is the further morement of these great human waves to the westward. Thus man illustrates the law described in Section 296 as the tend- 
ency to spread. He, of course, moves with more or less conscious purpose. The love of adventure and desire to know new lands make a part of his reason for moving, but in general man migrates to find fertile lands or to escape oppression.

315. The influence of the sea.-The oceans are the highway of nations. The classic peoples navigated the Mediterranean. Gradually they crept beyond the Pillars of Hercules (Straits of Gibraltar), and coasted along the shores of Africa and Europe. 'Then the Norse mariners threaded the northern seas, and finally the great modern voyages began, which ended in the knowledge of all waters. 'To meet the dangers of the ocean, ehallenge its mystery, and compel it to give up its secrets, has educated and splendidly developed civilized man. The great nations of the world have usually been found on the sea-border. Roman, Greek, Northman, Englishman, Dutchman, and Spaniard-all have illustrated this principle. 'The Roman Empire was gathered around the Mediterranean. Britain is a great empire because her sons have crossed the seas. Cities grow up along shore-lines and become centers of commerce and travel. Their life is broader and more various in its occupations and interests than the life of inland places. Fishing determines the life of many coastwise towns, and in these modern days the ocean-border becomes a summer camp, where crowded dwellers of the city and inland people may seek rest, and enjoy in body and mind the peculiar influences of the sea.

316. Life among mountains.-It is not easy to describe all the effects of mountain life, or to tell how momntain people differ from those of the sea. But one fact is plain, and is perhaps the chief one. Mountain people live, as a rule, in narrow valleys, and are much secluded from one another and from dwellers on the plains. This, of course, does not apply to the mountains of western North America, where metallic deposits have attracted the most active men, 
and where roads and telegraphs foster travel and constant interchange of thoughts and things.

But we can find shut-off people among the southern Appalachians, in western North Carolina, eastern Kentucky, and Tennessee. There the forests remain. Until lately, no railways had entered the region. Visitors from the outside world were few. Ancient ways are the rule, and there has hardly been progress since white people first settled in those regions. Indeed, instead of progress there has been a falling back into coarse and ignorant ways. The peasant life of Switzerland-that is, of the Alpine part of that country-shows what we mean. These people are thrifty, simple-hearted, and know little of the ontside world. Their solitary life, however, is more and more invaded and changed as multitudes of people seek the mountains as a playground.

31\%. Geography and history of North America.-The discoverers of our continent came over the sea from the East. Hence they landed on eastern shores, and sailed into the bays and rivers that there join the ocean. The Spanish discoverers occupied the West Indies and the shores of the Gulf, and carried exploration, conquest, and settlement across the plateaus and mountains of present Mexico, New Mexico, Arizona, and California, to the shores of the Paeific. 'The French devoted themselves to the gulfs, islands, peninsulas, and rivers of the St. Lawrence region, made long voyages on the Great Lakes, and toiled along the streams and across the prairies of the Mississippi Valley. The English sought all shores, but settled by the harbors of the Atlantic from the Carolinas to New England. Winning New York from the Dutch, and at length wresting the St. Lawrence, Canada, and the West from the French, they made the Anglo-Saxon people the future masters of North America. The destinies of the continent were decided in the temperate region.

The early English settlements formed a chain along 
the Atlantic coast. New England had abundant harbors, about which grew Salem, Plymouth and Boston in Massachusetts; and Providence and Newport in Rhode Island. Then the open, fertile Connecticut Valley invited settlement.

New York is the natural gate of the eastern United States. Its harbor, the tidal Hudson, provides for the ships of all seas, and the low pass of the Mohawk Valley makes easy the transfer of men and products between the ocean and the great inland States of the Mississippi and Lake regions. But for Niagara Falls and the rapids of the St. Lawrence, the metropolis of America might have been on the Gulf of St. Lawrence. Philadelphia developed in colonial times upon the estuary of the Delaware. Another group of the earliest settlements was made along the shores and rivers

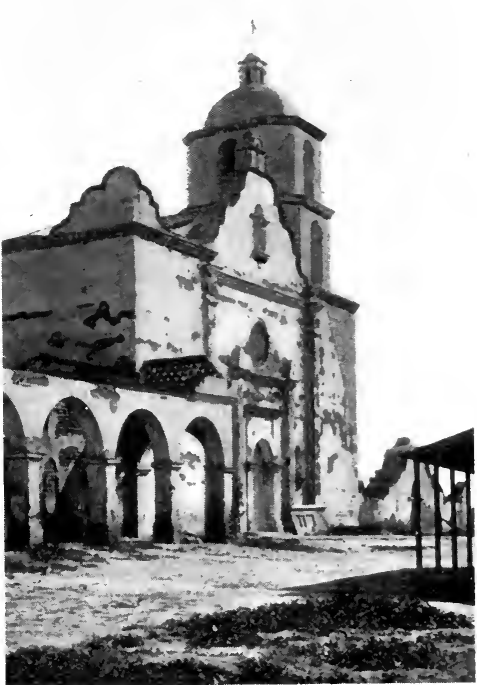

Fig. 261.-The mission church at San Luis Rey, Cal, a record of early spanish settlement. of the Chesapeake, in Virginia, and later in Maryland. The country is flat, and divided by tidal rivers. "Into the depths of the shaggy woodland, for many miles on either side of the great bay, the salt tide ebbs and flows. One can go surprisingly far inland on seagoing eraft. while with a boat there are but few plantations on the old York penin- 


\section{AN INTRODUCTION TO PHYSICAL GEOGRAPHY}

sula to which one can not approach very near" (John Fiske). 'Thus plantations were much by themselves, roads were few, and there was little life in towns.

As the narrow belt along the sea became occupied, frontiersmen pushed their way through the forests, along the

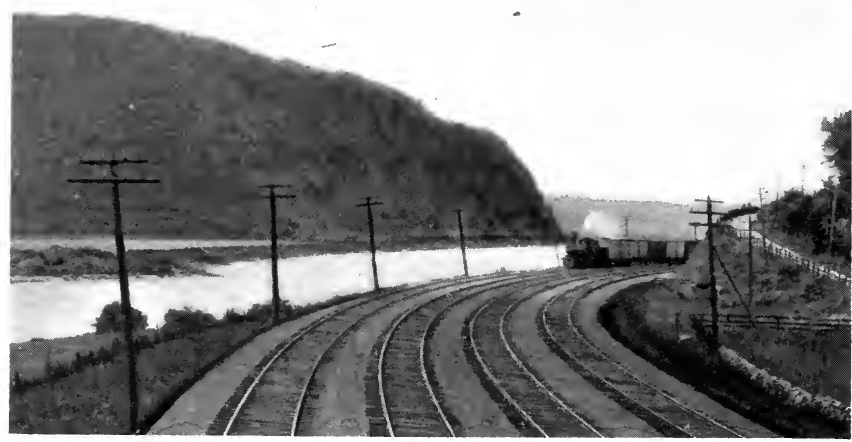

Fig. 262.-The pass of the Mohawk, used by exploration, carly migration, canal traftic, and now by still greater rail traftic.

valleys and over the ridges of the Appalachian Mountains into the fertile plains of Kentucky, Ohio, and the West. For a long time this mountain wall held the colonies together, until they became strong, separated themselves from the mother country, pushed orer the low, wooded mountains, and covered, within two or three short generations, the smooth and open grounds of the Mississippi basin. The tide of Anglo-Saxon settlement was for two centuries held in by mountains near the shore-line, and then swept to the base of the Rocky Mountains in much less than half that period. This, in part at least, is due to the smoothness of the interior country, the richness of its soil, and its comparative freedom from forests. The two 
natural features which have shaped the modern life and industries of the western mountains and plateaus are the dryness of the climate and the wealth of precious metals. The Pacific coast region is feeling new conditions in its growing relations to the lands across the Pacific, and the ports of the West may, in years to come, vie with those of the Atlantic seaboard. Meantime the traffic of the Great Lakes resembles in importance that of an ocean, and the tonnage of Chicago, Cleveland, or Buffalo compares with that of Liverpool or Hamburg.

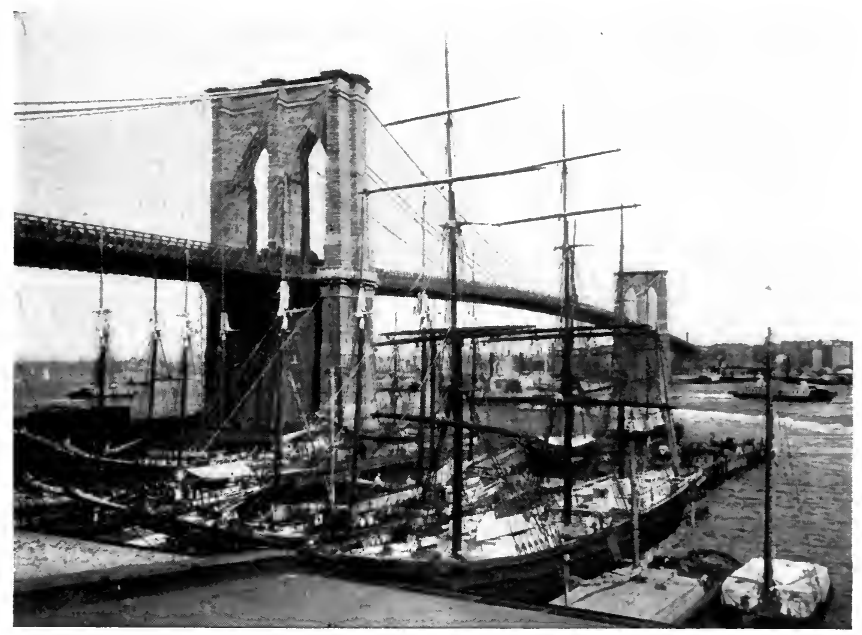

FrG. 263.-Shipping in the harbor of New York. A iridge, above mast-tops, joining Manhattan and Brooklyn.

318. Summary.-In different parts of the world the several races of men have in ages past developed. The white man, the yellow, red, and black man are what they are, largely through the influence of their surroundings, gaining their appearance and habits through generations. As mankind in past times has thus split into branches, using 


\section{AN INTRODUCTION TO PHYSICAL GEOGRAPHY}

many languages, so now modern commerce and knowledge tend to bind the world together. In ancient and in modern days, from motives of war, religion, science, and trade, man has sought a knowledge of the world, and helped to build up the science which we now study-Geography. As the earth has had its influence on man, so man has stamped the earth everywhere with his presence. He has fast driven out the wild animals, or trained them to his use. He has swept the native plants from the fields and filled them with improved fruits and grains. He has sailed upon the waters and made a network of roads upon the land. He is constantly learning new uses for mineral substances, and is pouring out water on the deserts to make them fruitful. He predicts storms and floods. He uses the forces of nature to turn the wheels of factories, to bring what he wishes from all lands, and to flash his thoughts around the world. Dependent on the earth, he subdues the earth to his use. 


\section{N D E X}

Adirondaeks, forms, 139, 179, 180 ; climate, 191 ; uses, 192 ; forestry, 323 ; deer, 331.

Af'riea, railway, 359. (See also Egypt, Sahara.)

Agassiz, Lake, 156.

Air and life, 334.

Air, composition of, 223.

Alabana, waterfall, 39 ; mountains, 179.

Alaska, Yukon River, 72 ; glaeiers, 126, 131, 133, 137, 138 ; plains, 165, 166 ; voleanoes, 210 ; eoast, 307 ; marine terraces, 314 ; forests, 321 .

Alleghany plateau, 182 .

Alluvial cone, lakes, 60 .

Alluvial eones, 42.

Alpine plants, 324 .

Alps, glaciers of, 119-124; inhabitants, 191 ; structure and scenery, 185 ; elimate, 190 ; as a barrier, 193.

Altitude and temperature, 245; and life, 332 .

Andes, 193.

Anemometer, 257, 258.

Animals, wasting of rocks by, 83 ; in caverns, 100; of North America, 328-331; as food, 349 .

Antaretic, ice-sheet, 131.

Antelope, 330.

Ant-hill, 83.

Antieyclones, 259, 271.

Antitrades, 267.

Appalachian forests, 320 .
Appalachian Mountains, rounded summits, 92: structure, 179; elinate, 190 ; inhabitants, 366 ; as a barrier, 368.

Appalaehian valleys, 64 .

Aretic aninals, 328; conditions of human life, 361 .

Arid region, 232 ; vegetation, 326,327 .

Arizona plateau, 164; Mount San Francisco, 208; arid vegetation, 326.

Arkansas River, 49, 67.

Artesian wells, 103 .

Ashes, voleanie, 200, 219.

Asia, drifting sands, 112; glaeiers, 124 ; mountains, 187; rainfall, 234.

Atlantie eoast, 302-307; fall line and drowned valleys, 65 ; dunes, 114.

Atlantic Coastal Plain, 151.

Atlantic Ocean, winds, 261; depths, 280 ; currents, 294.

Atmosphere, 12, 223-273; an agent of roek-wasting, 78 ; weight and height, 225 ; temperature, $238-252$; pressure, 253-256; general circulation, 266.

Atoll, 284, 285.

Australia, rainfall of, 235 .

Avalanehes, 85, 86 .

Axis, inclination of, 20.

Bad lands, 91, 92, 93.

Barometer, 253.

Barrier beaehes, 306, 310 .

Barrier reefs, 284. 
Barriers and passes, 193.

Barriers to migration, 341.

Basketry, 362.

Bayous, 55.

Beaches, 303, 305, 306, 309, 310.

Beaver, 329.

Beaver dams, 83, 334 .

Bonneville, Lake, 158, 159, 314.

Bore, tidal, 291.

Boulder clay, 133.

Bow and arrow, 350 .

Brook, a carrier, 8.

Buffaloes, 330 .

Butte, 91, 93.

Cables, telegraphic, 301.

Calabrian earthquakes, 220.

Calcium carbonate, 76, 99.

California, drainage system, 71 ; soils, 87; gold, 97; dust storms, 111 ; glaciers, 126 ; U-trough, 140 ; potholes, 141 ; glacial lakes, 142 ; central valley, 161, 178; Great Basin, 175 ; Sierra Nevada, 176 ; mountain barrier, 193 ; voleanoes, 206 ; rainfall, 232; climates, 270 ; coast, 307 ; Golden Gate, 316 ; plant zones, 320 ; forestry, 323 ; yucca, 327 ; sea-lions, 343 ; oil wells, 355 ; mission church, 367.

Canada, glaciers, 126 ; glacial lakes, 141, 143 ; ice-sheet, 144 ; lake plains, 155 ; plains, 165 ; temperature at Montreal, 244; forests, 321 ; animals, 328.

Canyon, 28.

Cape Cod, map, 15; dunes, 114, 116 ; coast features, 304 ; harbor, 316.

Caribou, 329.

Cascade Mountains, 207 ; glacier, 125.

Cascades, 37, 38.

Cascades of the Columbia, 108.

Catskill plateau, 182 ; map, 14 ; shifting of divide, 66 ; due to wasting, 87 .

Caverns, 98.

Central American volcanoes; 202.
Charleston earthquake, 221.

Chattanooga, 184.

Chelan River delta, 54 .

Chesapeake Bay, a drowned river valley, 64, 153; map, 65; shores, 152; tidal rivers, 307 .

China, loess of, 113.

Cincinnati, tempcrature curve, 244.

Cirrus clouds, 229, 230.

Cities and harbors, 315 .

Cleopatra's Needle, 79, 81.

Cleopatra Spring, 101.

Climate, 270-273; of mountains, 189 ; and life, 337 ; in relation to man, 363,364 .

Clothing, 350 .

Clouds, 228; in relation to radiation, 240.

Coal, under prairies, 163 ; of Alleghany Plateau, 183; of Colorado, 188 ; as fuel, 354 .

Coasts, 302-318.

Colorado, Arkansas Valley, 67 ; gold, 97 ; Hogback, 89 ; Glenwood Springs, 101 ; landslides, 197 ; glaciers, 124 ; Rocky Mountains, 168 ; parks, 172 ; plateaus, 174 ; mineral deposits, 188 ; passes, 193 ; lava sheets, 216 ; plant groups, 325 ; cog railway, 357.

Colorado canyons, 71, 90.

Colorado plateaus, 174.

Colorado River, 70 ; rapids, 38; delta, 56.

Colors of the ocean, 287; of the sky, 237.

Columbia River, 72; landslides, 108 ; dunes, 112.

Columnar structure, 215, 216.

Commerce of the Great Lakes, 69.

Communication and record, 358 .

Compass, 274.

Conduction, 239.

Connecticut, soils, 87 : mountains, 181.

Connecticut Valley, 68, 70.

Continental glacier, southern boundary, 145 .

Continental glaciers, 128, 132. 
Continental shelves, 280, 281.

Contour maps, 15.

Coral reefs, 283.

Cordillera, 177.

Corn, 348.

Cotidal lines, 293.

Cotton, 351 .

Crabs, 344.

Crater, of Vesuvius, 198; Costa-Rican, 211.

Crater Lake, 216, 217.

Craters of Hawaii, 203 ; of West Indies, 209.

Creep of soils, 84,85 .

Crevasses, 120, 122.

Crystalline rocks, 6,76 .

Cumberland plateau, 183.

Cumulus clouds, 229, 230.

Currents, ocean, 294.

Cut-off, 51.

Cyclones, paths of, 260 ; tropical, 265 ; of the westerly winds, 268 ; prediction of, 269 ; of the United States, 271.

Cypress knees, 335, 336.

Dana, J. D., 212.

Darwin, Charles, on work of eartliworms, 84 ; on bumblebecs and clover, 342 .

Dawson, George M., 329.

Day and night, 20.

Death Valley, 175.

Declination, magnetic, 275 .

Deep-sea deposit, 300 .

Deer, 330.

Dekkan Plateau, 216, 218.

Delaware Bay, tides in, 293 ; early settlement, 370 .

Delaware coastal plain, 151.

Delaware Water-Gap, 63.

Deltas, 54, 61 .

Derelicts, 296.

Desert plants, 327.

Deserts, wind work on, 111; Sahara, 112, 236: Western United States, 232.
Dew and frost, 227.

Dew-point, 228.

Dip, magnetic, 277.

Distributaries, 55 .

Divides, 36 ; shifting of, 65 .

Doldrums, 260, 267.

Drainage, development of, 59 ; imperfect, 60 ; controlled by rocks, 62 ; of rising and sinking lands, 63 ; modified by ice-sheet, 149 .

Drift, 87, 132.

Drowned river valleys, 64,153 .

Drumlins, 137, 303.

Dug-out, 358.

Dunes, 110 ; restraint of, 116.

Dust, transported by wind, 109 ; in the air, 225 ; volcanic, $206,237$.

Earth, general characters, 1-16 ; crust, 4 ; in relation to sun, $17-27$; motions, 18; magnetism, 274-278; in relation to animals and plants, 319 ; in relation to man, 346 .

Earthquake waves, 289.

Earthquakes, 187, 198, 220-222.

Egypt, picture writing, 360 .

England, dunes, 115; rainfall, 233, 234 ; coast, 310 ; estuaries, 316.

English exploration, 366.

English sparrow, 338 .

Environment, influence on plants and animals, 337-343 : influence on man, 359.

Erratics, 133.

Eskers, 136, 137.

Eskimos, 361 .

Estes Park, 172.

Etna, Mount, 201.

Europe, dunes, 115, 117 ; glacial period, 150 ; mountains, 185,192 ; rainfall, 233.

Explosions, volcanic, 218.

Eye of the storm, 266.

Fall Line, 65, 70, 153.

Fingal's Cave, 216, 310.

Finger Lakes, 143. 


\section{AN INTRODUCTION TO PHYSICAL GEOGRAPHY}

Fiords, 303, 307.

Fishing, 301.

Fiske, John, 368.

Flax, 351 .

Flint implements, 352, 353.

Floe-ice, 131, 297.

Flood-plains, 45.

Floods, 47.

Flora, 324.

Florida, springs, 100 ; coastal plain, 162.

Fog, 228.

Food, animal, 349.

Food, plant, 346 .

Forestry, 322 .

Forests, 319.

Forests, temperate, in relation to man, $361,362$.

Forms of land, due to surface wasting, 87-94.

France, dunes, 115, 116.

French exploration, 366.

Front Range, 172.

Frost, 227 ; wasting of rocks by, 81 .

Fuels, 353.

Galveston, 307.

Gas, natural, 183, 350 .

Geikie, A., 116.

Geography and history of North America, 366 .

Georgia, coastal plain, 152.

Geysers, 101, 103.

Giant kettles, 141.

Giant's Causeway, 216.

Gibbs Canyon, 140.

Gipsy moth, 339.

Glacial lakes, 146, 156.

Glacial period, 10, 132-135, 143-150; in relation to soils, 95 ; cause of migration, 340 .

Glacial rounding, 138, 139.

Glacial scratches, 134.

Glaciers, 119-150 ; mountain, 119-128; continental, 128-135; cause of, 131 ; forms of land made by, 135-143; of North America, 124-130. (See nlso Glacial period.)
Golden Gate, 307, 316.

Gold-mines, 97, 188.

Gorge, character and origin, 28.

Gorner Glacier, 119.

Gradient, atmospherie, 257.

Grand Canyon of the Colorado, 38, 71, 90.

Granite, 6, 76, 88.

Gravitation, 292.

Great Basin, 175, 178.

Great Britain, rainfall, 233, 234. (See also England and Scotland.)

Great Lakes, commeree, 372 ; exploration, 369 .

Great Lakes, in relation to rivers, 69 ; dunes, 113 ; origin of basins, 143 ; preceded by glacial lakes, 146 ; bordering plains, 156 .

Great Plains, 163; treeless, 320, 324 .

Great Salt Lake, 60.

Great Salt Lake Desert, 158.

Greenland ice-sheet, 128.

Green Mountains, 189.

Ground-water, 103.

Gulf plains, 162,320 .

Gulf Stream, 294.

Hachures, 15.

Harbors and cities, 315 .

Hawaiian voleanoes, 203.

Heat, 239.

Heat equator, 250 .

Hemp, 351.

Herculaneum, 200.

Highlands of the Hudson, 58 .

Highlands, Scottish, 59, 185, 192.

Hinalaya Mountains, 124, 187.

History and geography of North America, 366.

Hog-back, 89.

Holland, dunes, 115, 116 ; dikes, 314.

Hood, Mount, 208.

Horse latitudes, 260.

Hot springs, 101.

Ilouse Range, 176, 177.

Hudson River, route of exploration 
and commeree, $70,315,367$; tidal estuary, 304 ; head waters, 323.

IIudson Valley, worn-down plain, 14, 161 ; stage of development, 58 .

Humidity, 226.

Iurrieanes, 265, 307.

Icebergs, 126, 130, 297.

lce-jam, 34 .

leeland, 209.

lee-sheets, 128.

Idaho, Snake River Canyon, 72 ; lava sheets, 213.

Igneous rocks, 6, 76, 196.

Illinois, river valley, 67 ; artesian wells, 104 ; prairie, 162.

Illinois River, 16, 67.

India, lava sheets, 216 ; soils, 218 ; rainfall, 235 ; monsoons, 262, 263.

Indiana, dunes, 113 ; prairie, 162.

Indian Ocean, winds, 262, 263 . .

Indians, bow and arrow, 349, 350; stone implements, 352, 353; habitations, 354-356; dug-out, 358 ; rock earving, 362 ; basketry, 362 ; pottery, 363 .

Iowa, drift, 133 ; prairie, 162.

Irrigation, 163, 164, 271, 272 .

Island life, 341 .

Islands, coral, 283.

Islands, volcanic, 201, 203, 184, 209, 283.

Isobars, 254.

Isogonies, 276.

Isotherms, 246, 270; for January, 248 ; for July, 249 ; for the year, 251.

Italy, climate, 189; voleanoes, 196 ; earthquakes, 220 .

Japan, earthquakes, 220; rainfall, 234.

Joints, 28, 37, 38.

Kames, 135.

Kansas, sink hole, 98; Great Plains, 164.
Kentueky, sink holes, 60,99 ; soils, 87 , 96 ; Mammoth Cave, 98; Cumberland Plateau, 183; mountain life, 366.

Kilauea, 204.

Kings Chapel, 150.

Krakatoa, 205, 211, 237, 290.

Lagoons, 284, 285, 310.

Lake basins, glacial, 141.

Lake deltas, 56 .

Lake shores, 314; dunes on, 110-113.

Lakes, of various origins, 60 ; glaeial, 146 ; volcanic, $211,216,217$.

Land and sea breezes, 262 .

Land and water, 7 .

land forms due to surfaee wasting, $87-94$.

Landslides, 105-108.

Land, up and down movements, 10.

Latitude and life, 332.

Latitude and longitude, 2.

Latitude and temperature, 243.

Lava easeade, 205.

Lava sheets, 213.

Lava streams, 198, 203, 207.

Life, animal, in caverns, 100.

Life (plant and animal), 12, 319-345; in relation to glacial epoch, 150 ; of mountain lands, 365 ; of the ocean, 299, 333 ; geographic eonditions of, $332-345$.

Life-saving stations, 317 .

Light and color, 236-238.

Light, in relation to life, 336 ; source of artificial, 354.

Lighti.ouses, 317.

Limestone, 76 ; weathered, $79,82$.

Llano Estacado, 165.

Loess, 113.

Longitude, 2.

Lookout Mountain, 184.

Los Angeles, oil wells, 355 .

Louisiana, soils, 87 ; plain, 162 ; temperature at New Orleans, 244 ; harbor, 316 .

Luray Cavern, 99. 
Magellan, 1, 298.

Magnetism of earth, 274-278.

Maine, drift, 136, 137 ; coast, 302, 313 ; marine terraces, 314 ; life-saving station, 317 .

Maize, 348.

Malaspina Glacier, 128, 133.

Mammoth Cave, 98.

Man, relations to the earth, 346 .

Map projection, 250.

Maps, kinds of, 14.

Mark Twain, 52.

Marthas Vineyard, moraine and wash plain, 138 ; shores, 304, 310, 313.

Martinique, eruptions on, 209.

Maryland, coastal plain, 151; early settlement, 367 .

Massachusetts, water power, 42, 149 ; Connecticut Valley, 58, 70; dunes, 114,116 ; drumlins, 137 ; wash plains, 138 ; glacial lakes, 141 ; climate, 191; watcrspout, 265 ; fisheries, 301 ; coast, $303,310,313$; harbors, 315, 316; gipsy moth, 339 .

Matterhorn, 185, 186.

Meanders, 48, 49.

Mediterranean Sea, volcanoes, 201.

Mediterranean seas, 280, 282.

Meeting of the land and sea, 302-318.

Mereator projection, 250 .

Meridians, 3.

Meridians, magnetic, 275 .

Mesa, 91.

Mexico, forests, 322 ; animals, 331.

Michigan, dunes, 113.

Michigan, Lake, 312.

Migration of animals and plants, 150, 340.

Migrations of men, 366-368.

Mineral springs, 100.

Mineral veins, 97, 188.

Minnesota, valleys, 67 ; glacial lakes, 142; new river course, 149; Red River Valley, 156.

Misery, Mount, 210.

Mississippi, 162.

Mississippi Delta, 54.
Mississippi River, in flood, 46, 48; meanders, 49, 51, 52 .

Mississippi River system, 66 .

Mississippi Valley, 162; settlement, 368.

Missouri, 162.

Missouri River, 67.

Models, topographic, 16.

Mohawk Valley, stage of development, 58 ; as a gateway, $193,315,367$.

Monadnock, Mount, 87.

Monsoons, 262, 263.

Montana, avalanehe tracks, 85, 86; glaeiers, 126 ; vegetation, 190.

Monte Nuovo, 197.

Montreal, temperature-curve, 244.

Moon and tides, 291.

Moose, 329.

Moraines, 120, 123.

Mosquito Range, 173.

Mountains, and plateaus, $168-195$; due to wasting, 87 ; history, 182 ; climate, 189, 245 ; influence on men, 191, 365.

Muir Glacier, 126, 127.

Musk-ox, 328.

Nahant, 303, 304.

Nansen, 130.

Natural gas, 183,354 .

Navigation, 300 .

Nebraska, Platte Valley, 67; Indian rock-carving, 362 .

Neck, voleanic, 213.

Needle, magnetic, 274 ; dip, 277.

Nevada, Great Basin, 175; rainfall, 232.

New England, drainage system, 70; drift, 133,135 ; mountains, 181 ; forests, 323 .

New foundland, 313.

Newfoundland, Banks of, 281, 296, 301.

New Jersey, sinking land, 63 ; artesian wells, 104; coastal plain, 151, 153; lava sheets, 214; continental shelf, 282 ; coast, $304,313$.

New Mexico, plateaus, 164 ; voleanoes, 208 ; Indian pottery, 365.

New Orleans, temperature-curve, 244. 
New York, water power, 42, 149 ; valleys, 58 ; lakes, 61 ; Saratoga Springs, 101 ; drift, 133, 136, 137 ; glacial seratehes, 135 ; pot-holes, 141 ; glacial lakes, 141, 143, 156; lake plains, 156, 157 ; elimate, 191 ; coast, 304 ; lake shore, 311, 312 ; forestry, 323 ; prairies, 324 ; early history, 367 . (See also Adirondacks, Catskill, and $\mathbf{M o -}$ hawk Valley.)

New York Harbor, 315, 369.

Niagara Falls, 38-40,61.

Nile, floods, 47,48 ; delta, 55 .

North America, rivers, $66-73$; glaciers, 124; plains, 161-167; mountains and plateaus, 168-185; coasts of, 302-308 ; plants of, 319-328; animals of, 328331 ; relation of geography to history, 366 .

North Carolina, dunes, 114 ; coastal plain, 152; placer mining, 188; mountain life, 366 .

North Dakota, Red River Valley, 156.

Obsidian Cliff, 215.

Ocean, 279-301 ; water, 286 ; temperatures, 287 ; waves, 288 ; currents, 294 ; exploration, 298; deposits in, 299 ; life, 299,343 ; influence on mankind, 367 : ocean basins, 279 .

Ohio, temperatures at Cineinnati, 244. Oils for light, 354 .

Oil wells, 355.

Ontario basin and Glacial epoch, 147.

Ontario, Lake, 311, 312.

Orbit of the earth, 19.

Oregon, dunes, 112, 113; voleanoes, $207,217$.

Ox-bow lakes, 49-51.

Pacific coast, 307 ; commerce, 369.

Pacific Ocean, 281 ; currents, 296.

Palisades of the Hudson, 214.

Palmetto, 333.

Parallels of latitude, 3.

Park Range, 172.

Parks of the Rocky Mountains, 172.
Passes, 193.

Pass of the Mohawk, 368.

Peary, R. E., 130.

Peccaries, 331.

Pelée volcano, 209.

Pene-plains, 161.

Pennsylvania, valleys, 58; drainage system, 62 ; large spring, 100 ; till, 134 ; ehanges of drainage, 149 ; mountains, 179, 183.

Petroleum, 183, 354, 355.

Physieal geography defined, 13.

Pieture language, 360 .

Piednont Plain, 161.

Pikes Peak, 170.

Placer mining, 188.

Plains, 151-167 ; marine, 151-155; lake, 155-160 ; river, 160-161 ; worndown, 161 ; of North America, 161167.

Plants, wasting of roeks by, 82 ; of North Ameriea, 319-328; zones of, 320,332 ; as food, 347 .

Plateau, Alleghany, 182.

Plateaus and nountains, 168-195.

Plateaus, Colorado, 174.

Pliny, 200.

Pompeii, 200.

Potato, 348.

Pot-holes, 37, 141.

Pottery, 363.

Prairies, 162, 323.

Precipitation, 231. (Sce also Rainfall.)

Pressure of the atmosphere, 253-256.

Prevailing westerly winds, 258, 267.

Pueblos, 362.

Puget Sound, 307, 316.

Pyrenees, 185, 193.

Radiation, 239.

Railways, 356-358.

Rain and snow, 230.

Rainbow, 237.

Rainfall, 231; of Great Britain, 233, 234 ; of Australia, 235.

Rainier, Mount, 207. 


\section{AN INTRODUCTION TO PHYSICAL GEOGRAPHY}

Rain wash, 80 .

Rapids, 38, 44.

Redding Spring, 159.

Red River Valley, 155.

Relative humidity, 227 .

Revolution of the earth, 19.

Rhode Island, soils, 87.

Rhone Glacier, 124.

Rhone Valley, 141.

Rice, 348 .

River basins, 36 .

River plains, 160.

Rivers, 28-73; of North America, 6673 ; changed by ice-sheet, 149. (See also Streams.)

River terraces, 52 .

Rock-carvings, 360 .

Rock ledges and waste slopes, 89 .

Rocks, 5, 74; kinds, 74; wasting, 78 ; hardening of, 97 .

Rocky Mountains, sharp peaks, 93; lake basin, 143; in Colorado, 168; climate, 190 ; occupations, 191, 368 ; passes, 193 ; plant zones, 320.

Rotation of the earth, 18 ; influence on winds, 266.

Run-off, 36.

Russell, I. C., 208.

Russian thistle, 341 .

Sahara, drifting sands, 112 ; dryness, 236 ; occupations, 363.

St. Clair River delta, 61.

St. Elias, Mount, 128.

St. Lawrence River, 49, 69.

St. Pierre, destruction of, 210.

St. Vincent Island, eruptions on, 209.

Sand blast, 117.

Sand, carried by wind, 110 .

Sandstone, 74 ; weathered, 78.

Sandy Hook, 305, 306, 311 .

San Francisco, Mount, 208.

San Juan Mountains, 169.

Santa Maria (caravel), 359.

Sawatch Range, 173.

Scotland, Highlands, $59,185,192$; industries, 192 ; lava sheets, 216 ; rain- fall, 233, 234; sea cave, 310 ; marine terraces, 314 .

Sea, 279-301. (See also Ocean.)

Sea-cliffs, 309.

Sea-lions, 343.

Seasons, cause of, 21.

Seneca Lake Valley, 58, 61, 140.

Shale, 76 ; broken by down-hill ereep, 84.

Shasta, Mount, 206, 211.

Sheets of lava, 213.

Shelter, 352.

Shelves, continental, $280,281$.

Shore-lines, uplifted, 10 ; of glacial lakes, 146; of Lake Bonneville, 158, 160.

Shore of Lake Michigan, 106.

Shores, 302-318; wave action on, 289, 309.

Siberia, 154; railway, 356 ; native life, 361.

Sierra Nevada, glacial seenery, 142 ; uplift, 176 ; map, 178 ; forests, 321.

Sink holes, 60,98 .

Sky, colors of, 237.

Snake River Canyon, 72, 213.

Sneffels, Mount, 93.

Snow, 231.

Soils, 94-96; local and transported, 87 ; glacial, 149 ; in relation to plants, 336.

Solution of rocks, 79,81 .

Soufric̀re, crater, 209.

South America, mountains, 187 ; rainfall, 233.

South Carolina, coastal plain, 152; earthquake, 221.

South Dakota, bad lands, 92 ; artesian wells, 104; Great Plains, 165.

South Lookout Peak, 169.

South Park, 172.

Spanish exploration, 366 .

Spits, 311, 312.

Springs, 100.

Stalactites and stalagmites, 99 .

Standard time, 26.

Stanley, Dean, 112. 
Steamship, 356.

Stone implements, 352, 353.

Storms, 258, 259, 264-266 ; eyclonic, 258 ; thunder, 264 ; tropical, 265.

Stratified rocks, 5 .

Streams, 28-73; work of, 8 ; relation to gorge, 31 ; source of water, 35 ; development of valley, 43 ; relation to rocks, 62 .

Stromboli, 201.

Struggle for existence, 339 .

Sun and earth, 17-27.

Surf, 289, 309.

Susquehanna River, 64 .

Swamps, 62, 314.

Switzerland, alluvial cones, 43 ; deltas, 62 ; avalanches, 85 ; landslides, 107 ; glaciers, 119, 124, 131, 150 ; glacial sculpture, 141 ; glacial lakes, 143 ; climate, 190 ; industries, 191 ; carriage road, 356 ; mountain life, 366 .

Silvestri, Monti, 202.

Tahiti, 212.

Talus, 29.

Taylor, Mount, 208.

Tea, 349.

Temperate climates in relation to man, 363.

Temperature of the atmosphere, 238252 ; measurement of, 238 ; of night and day, 241; curves, 242, 244; in relation to latitude, 243 ; in relation to altitude, 245 ; mapping, 246 ; in relation to life, 332 .

Temperature of the ocean, 287.

Temple Creek Canyon, 29.

Tennessee, river bends, 51 ; mountains, 179, 183; mountain life, 365 .

Tepee, 354.

Terraces, 52.

Texas, bad lands, 91 ; coastal plain, 162 ; Llano Estacado, 165 ; coast, 307 : animals, 331.

Thermometer, 238.

Thermometer record, 242.

Thunder-storms, 264.
Tibet, 187.

Tides, 290.

Tidewater, Virginia, 151, 307.

Till, 133.

'Timber-line, 168, 320.

Time, standard, 26.

Tobacco, 349.

Tools, 352, 353.

Tornadoes, 265.

Trade-winds, 259.

Travel, modes of, 356 .

Trellised drainage, 63-65.

Trinity College, 82.

Tropical animals, 331 .

Tropical lands in relation to man, 362 , 363.

Tundras, of Siberia, 155; of Alaska, 165,167 ; animals, 328 ; peoples, 364 . Tuolumne Monument, 139.

Typhoons, 265.

Underground changes, 96-105.

United States, drifting sands, 111; in the Glacial period, 132,145 ; weather maps, $247,256,258$; weather predictions, 268 ; climates, 270 ; coasts, 302 ; Coast Survey, 277, 299, 317 ; Department of Agriculture, 116; Hydrographic Otfice, 296; Weather $\mathrm{Bu}$ reau, 48, 254, 268.

Utah, lake plains, 158; plateaus, 174 ; Great Basin, 175; old shore-lines, 314 ; Indian basketry, 362 .

U-troughs, 140, 141.

Valley, development of, 43,57 .

Veins, $97,188$.

Vesuvius, Mount, 196, 220.

V-gorge, 31.

Virginia, Shenandoah Valıey, 58; uplands, 59 ; soils, 96 : Luray Cavern, 99, 100 ; Natural Bridge, 99 ; coastal plain, 151; mountains, 179,183 ; tidal rivers, 307 ; prairies, 324 ; early settlement, 367 .

Vlies, 61, 148.

Volcanic cone, history of, 211. 


\section{AN INTRODUCTION TO PHYSICAL GEOGRAPHY}

Voleanie explosions, 218.

Voleanic lakes, 217.

Voleanic neck, 213.

Volcanic soil, 217.

Voleanie tuff, 219.

Voleanoes, 196-222.

Wasateh Mountains, 175.

Washington, landslides, 108; glaciers, 125,126 ; voleanoes, 207 ; lava sheets, 213 ; rainfall, 232 ; coast, 307 ; harbors, 316 ; forests, 321 .

Wash plain, 138.

Waste, in stream bed, 32 ; loeal and transported, 87.

Waste mantle, 4 ; thiekness, 86.

Waste slopes, 89.

Water and land, 7.

Water and life, 334 .

Waterfalls, 38.

Water-gap, 63.

Water-plants, 324.

Water-power, 42, 149, 153.

Waterspout, 265.

Water supply, 100-104.

Water, underground, 96.

Water-vapor, 224, 227.

Watkins Glen, 58, 75 .
Waves, 288.

Wave work, 309.

Weather and elimate, 268-273.

Weather Bureau, 48, 254, 268.

Weathering and soils, 74-108.

Weather-maps, 247, 256, 258.

Weather-signs, 269.

Wells, 103.

West Indies, voleanoes, 209 ; hurricanes, 266.

Wheat, 347.

Winds, storms, and climate, 253-273.

Winds, cause of, 256 ; prevailing westerly, 258; eyclonic, 258 ; trade, 259 , 266 ; of the Atlantie, 261 ; terrestrial, $26 f$.

Wind work, 109-118.

Winnipeg Lake, 156.

Wisconsin drumlins, 137.

Wyoming, hot springs, 101; geysers, 101, 103 ; pass, 193 . (See also Yellowstone Park.)

Yellowstone Canyon, 30.

Yellowstone Park, 101-103, 215.

Yukon River, 72 ; delta, 56.

Zones explained, 21. 



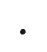
-

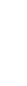
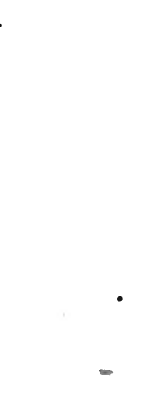


